\title{
Criticality Experiments with Low Enriched UO2 Fuel Rods in Water Containing Dissolved Gadolinium
}
S. R. Bierman
E. S. Murphy
E. D. Clayton
R. T. Keay

February 1984

Prepared for

British Nuclear Fuels, Ltd.

under contract with

the U.S. Department of Energy

Pacific Northwest Laboratory

Operated for the U.S. Department of Energy

by Battelle Memorial Institute 


\section{DISCLAIMER}

This report was prepared as an account of work sponscred by an agency of the United States Government. Neither the United States Government nor any agency thereof, nor any of their employees, makes any warranty, express or implied, or assumes any legal liability or responsibility for the accuracy, completeness, or usefulness of any information, apparattls, product, or process disclosed, or represents that its use would not infringe privately owned rights. Reference herein to any specific commercial product process, or service by trade name, trademark, manufacturer, or otherwise does not necessarily constitute or imply its endorsement, recommendation, or favoring by the United States Government or any agency thereof. The views and opinions of authors expressed herein do not necessarily state or reflect those of the United States Government or any agency thereof.

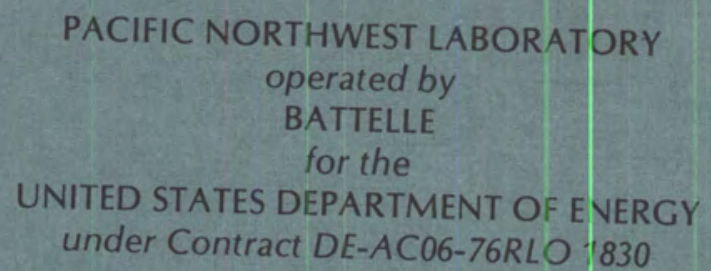

Printed in the United States of America Available from

National Technical Information Service United States Department of Commerce 5285 Port Royal Road

Springfield, Virginia 22161

NTIS Price Codes

Microfiche A01

Printed Copy

Pages

Price

001-025

026-050

051-075

076-100

101-125

126-150

151-175

176-200

201-225

226-250

251-275

276-300 
CRITICALITY EXPERIMENTS WITH LOW ENRICHED UO2 FUEL RODS IN WATER CONTAINING DISSOLVED GADOL INIUM
S. R. Bierman
E. S. Murphy
E. D. Clayton
R. T. Keay (a)

February 1984

Prepared for British Nuclear Fuels, Ltd. Risley, Warrington, Chesire United Kingdom Under Contract DE-SC06-82RL 10371 Through the U.S. Department of Energy (BNFL Contract Number L88502)

Pacific Northwest Laboratory Richland, Washington 99352

(a) British Nuclear Fuels, Ltd. 


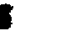




\section{PREFACE}

Early in 1981, the Technical Services staff of British Nuclear Fuels, Ltd. (BNFL) contacted personnel of the United States Department of Energy (USDOE) Pacific Northwest Laboratory (PNL) concerning the possibility of PNL performing some criticality experiments for BNFL. BNFL was interested in obtaining basic experimental data on light water reactor type fuel rods in water and uranyl nitrate solution poisoned with a soluble compound of gadolinium. They wished to obtain this data over a very wide range of gadolinium concentrations and moderator-to-fuel ratios. The data would be used primarily for validating calculational techniques that are used in criticality safety evaluations.

With considerable assistance from Alan C. Rither (PNL-Contract Services), M. J. Plahuta (USDOE - Richland Operations) and Clint Bastin (USDOE - Office of Nuclear Fuel (ycle), a contractural agreement between BNFL and the United States Department of Energy, Richland Operations Office, was reached in February 1982 for a series of criticality and related experiments involving low enriched $\mathrm{UO}_{2}$ fuel rods in water and in water containing dissolved gadolinium. Since these types of fuels are less reactive in nitrate solutions than in water and since measurements in uranyl nitrate solutions would have involved a much greater effort, a decision was reached to limit the program to experiments with fuel rods in gadolinium - water solutions only.

A major aspect of these measurements was that some of the experiments involved the simultaneous irradiation of reaction rate foils in the experimental assembly and in the well defined thermal neutron flux of the United Kingdom Atomic Energy Authority Nestor Reactor followed by transport of the irradiated foils to the U. K. Atomic Energy Establishment Winfrith for analyses within twenty-four hours. The authors would like to especially acknowledge the co-operation and diligence of the following people in successively carrying out the considerable logistics associated with these reaction rate measurements: 
Dale Hansen

A. S. Gregory

John M. Taylor

Patrick H. Burke

C. Andrews
Rockwe11 Hanford Operations

Rockwe11 Internationa 1

Atomic Energy Establishment

Winfrith

Pacific Northwest Laboratory

Pacific Northwest Laboratory

Lep Air Ltd., Heathrow Airport

Also the co-operation and patience of the Nestor Reactor Operations staff is appreciated as well as that of J. H. Smith, Senior Reactor Operator at the USDOE Critical Mass Laboratory, in the performance of the simultaneous irradiations. The very professional and thorough preparation and analyses of the foil packs by M. F. Murphy of the Reactor Physics Division, AEEW, is also acknowledged.

The authors would also like to acknowledge the assistance and typing of $L$. N. Terry in the preparation of this report. 


\section{SUMMARY}

The results obtained in a criticality experiments program performed for British Nuclear Fuels, Ltd. (BNFL) under contract with the United States Department of Energy (USDOE) are presented in this report along with a complete description of the experiments. The experiments involved low enriched $\mathrm{UO}_{2}$ and $\mathrm{PuO}_{2}-\mathrm{UO}_{2}$ fuel rods in water containing dissolved gadolinium, and are in direct support of BNFL plans to use soluble compounds of the neutron poison gadolinium as a primary criticality safeguard in the reprocessing of low enriched nuclear fuels.

The experiments were designed primarily to provide data for validatina a calculation method being developed for BNFL design and safety assessments, and to obtain data for the use of gadolinium as a neutron poison in nuclear chemical plant operations - particularly fuel dissolution. However, there are significant cost incentives to optimize the amount of gadolinium used per ton of fuel reprocessed, and thus to reduce the uncertainties present in the calculations upon which plant design and operations are based. Therefore, to the extent compatable with the primary objectives, the experiments were also designed to provide more general type information for use in improving neutronic calculations on $10{ }^{235} \mathrm{U}$ enriched uranium sys tems.

Very little operating experience or experimental data exists upon which to base the use of gadolinium as a soluble neutron poison for criticality control in plant operations. Consequently the experiments program covers a wide range of neutron moderation (near optimum to very undermoderated) and a wide range of gadolinium concentration (zero to about $2.5 \mathrm{~g} \mathrm{Gd} / \ell)$. Aslo the measurements presented herein provide critical and subcritcal $k_{\text {eff }}$ data $\left(1 \geq k_{\text {eff }} \geq 0.87\right)$ on fuel-water assemblies of $\mathrm{UO}_{2}$ rods at two enrichments $\left(2.35 \mathrm{wt} \%\right.$ and $\left.4.31 \mathrm{wt} \%{ }^{235} \mathrm{U}\right)$ and on mixed fuel-water assemblies of $\mathrm{UO}_{2}$ and $\mathrm{PuO}_{2}-\mathrm{UO}_{2}$ rods containing $4.31 \mathrm{wt} \%{ }^{235} \mathrm{U}$ and $2 \mathrm{wt} \% \mathrm{PuO}_{2}$ in natural $\mathrm{UO}_{2}$ respectively. Fission rate and fission-to-capture ratio measurement data were obtained on some of the experimental assemblies and are also presented herein. Specifically, the experiments involved the following: 
- $4.31 \mathrm{wt} \%{ }^{235} \mathrm{U}$ enriched $\mathrm{UO}_{2}$ aluminum clad rods in water at three uniform center-to-center rod spacings

- $2.35 \mathrm{wt} \%{ }^{235} \mathrm{U}$ enriched $\mathrm{UO}_{2}$ aluminum clad rods in water at two uniform center-to-center rod spacings

- 4.31 wt $\%{ }^{235} \mathrm{U}$ enriched $\mathrm{UO}_{2}$ aluminum clad rods mixed with $\mathrm{PuO}_{2}-\mathrm{UO}_{2}$ zirconium clad rods to achieve fuel-water lattices, at one uniform center-to-center rod spacing, characteristic of irradiated fuel compositions specified by BNFL.

The critical size of these lattices were determined with water containing no gadolinium and with water containing dissolved gadolinium nitrate. Pulsed neutron source measurements were performed to determine subcritical $k_{\text {eff }}$ values as additional amounts of gadolinium were successively dissolved in the water of each critical assembiy.

Fission rate measurements in ${ }^{235} \mathrm{U}$ using solid state track recorders were made in each of the three unpoisoned critical assemblies of $4.31 \mathrm{wt} \%$ $235 \mathrm{U}$ enriched $\mathrm{UO}_{2}$ fuel rods and in the near-optimum moderated and the close-packed poisoned assemblies of this fuel. Foils of $4.31 \mathrm{wt} \%{ }^{235} \mathrm{U}$ enriched $\mathrm{UO}_{2}$ and depleted $U$ metal $\left(0.04 \mathrm{wt} \%{ }^{235} \mathrm{U}\right)$ were also irradiated in these same five critical assemblies simultaneously with irradiations in the NESTOR reactor at the Atomic Energy Establishment-Winfrith to obtain data on neutron capture and fission in ${ }^{238} U$ relative to fission in ${ }^{235} U$. 


\section{CONTENTS}

PREFACE ............................ $i$

SUMMARY .............................. $i$...

FIGURES .............................. vii

TABLES ..........................

1.0 INTRODUCTION $\ldots \ldots \ldots \ldots \ldots \ldots \ldots$

2.0 EXPERIMENTS $\ldots \ldots \ldots \ldots \ldots$

2.1 TYPE OF EXPERIMENTAL MEASUREMENTS . . . . . . 2.1

2.2 DESCRIPTION OF EXPERIMENTAL ASSEMBLIES . . . . . . 2.3

3.0 EXPERIMENTAL RESULTS . . . . . . . . . . . . 3.1

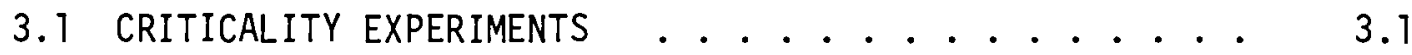

3.1.1 Measurement Technique . . . . . . . . 3.2

3.1.2 Criticality Experiments and Data ..... 3.4

3.2 SUBCRITICALITY EXPERIMENTS . . . . . . . . 3.17

3.2.1 Measurement Technique . . . . . . . 3.17

3.2.2 Description of Pulse Neutron System . . . . 3.21

3.2.3 Pulse Neutron Experiments and Data ..... 3.21

3.3 REACTION RATE MEASUREMENTS ............ 3.36

3.3.1 Measurement Techniques ........ 3.36

3.3.2 Reaction Rate Measurements and Data .... 3.37

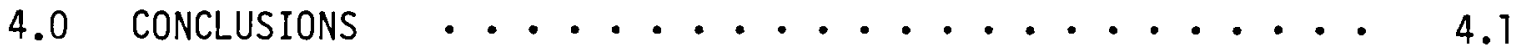

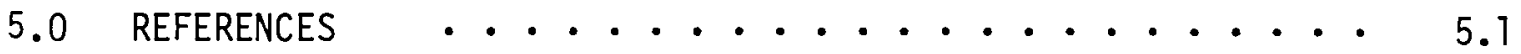




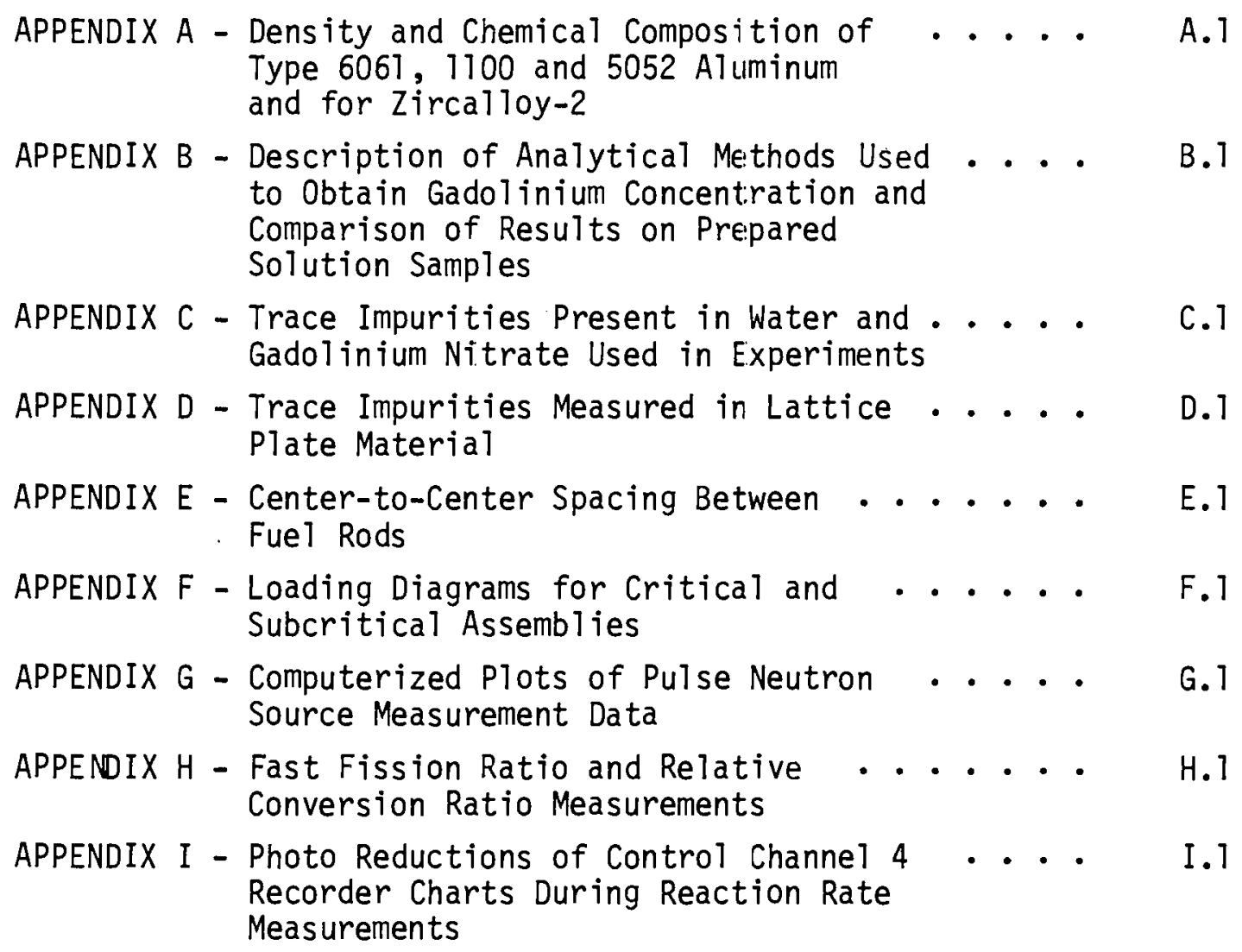




\section{FIGURES}

1.1 USDOE Critical Mass Laboratory Near

Richland, Washington ................ 1.3

1.2 Critical Mass Laboratory Floor Plan . . . . . . . . . . . 1.4

2.1 Experimental System Modified for Use in Experiments . . . . . . . . . . . . . . . 2.4

2.2 Flow Diagram of Experimental System . . . . . . . . . 2.5

2.3 Annotated Photograph of Experimental Vessel and Fuel Assembly . . . . . . . . . . . 2.6

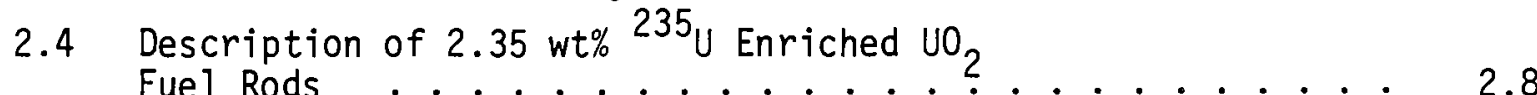

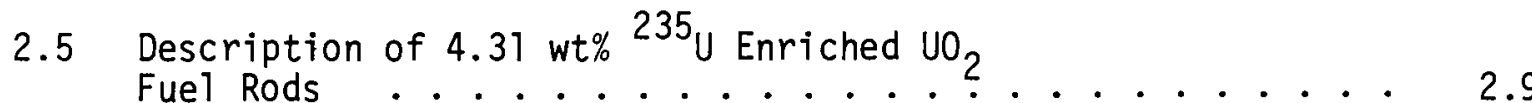

2.6 Description of Mixed 0xide Fuel Rods . . . . . . . . . 2.10

2.7 Experimental Assembly Elevations . . . . . . . . . 2.14

2.8 An Assembled Set of Lattice Plates
Outside the Experimental Tank . . . . . . . . . . . 2.16

3.1 Typical Approach-to-Critical Plot . . . . . . . . . 3.3

3.2 Measurement Data Showing Linearity and Effect of Aluminum Clad Water Columns in the Experimental Assembly . . . . . . . . . . . 3.8

3.3 Typical Measurement Data Obtained in Evaluating the Reactivity Effect of Aluminum Clad Water Columns Created by Withdrawal of the Safety and Control Rods . . . . . . . . 3.9

Critical Size as a Function of
Gadolinium Concentration . . . . . . . . . . . . 3.12

3.5 Effect of Gadol inium Concentrations on the Reactivity Worth of Aluminum Clad Water Columns Created by Withdrawal of the Safety and Control Rods . . . . . . . . . . . . 3.13

3.6 Pulse Neutron Source and Data Acquisition System . . . . . 3.22

3.7 Pulse Neutron Source Control Units and Data Acquisition Equipment .............. 3.23

3.8 Measured Variations in keff, $\ell$ and $\alpha$ with Concentration of Dissolved Gadol jnium in Fuel-Water Lattices of 4.31 wt\% $235 \mathrm{U}$ Enriched $\mathrm{U}_{2}$ Fuel Rods in a Triangular Pattern on $2.398 \mathrm{~cm}$ Center-to-Center Spacing . . . . . . . . . . . 
3.9 Measured Variations in keff, $\ell$ and a with Concentration of Dissolved Gadol inium in Fue 1-Water Lattices of 4.31 wt\% 235U Enriched

$\mathrm{U}_{2}$ Fuel Rods in a Triangular Pattern on $1.801 \mathrm{~cm}$ Center-to-Center Spacing

3.10 Measured Variations in keff, $\ell$ and a with Concentration of Dissolved Gadolinjum in

Fuel-Water Lattices of $4.31 \mathrm{wt} \% 235 \mathrm{U}$ Enriched

U02 Fue 1 Rods in a Triangular Pattern on

$1.598 \mathrm{~cm}$ Center-to-Center Spacing . . . . . . . . . .

3.11 Measured Variations in $k_{\text {eff, }} \ell$ and $\alpha$ with Concentration of Dissolved Gadolinium in Fuel-Water Lattices of 2.35 wt\% $235 \mathrm{U}$ Enriched

$\mathrm{UO}_{2}$ Fuel Rods in a Triangular Pattern on a

$1.895 \mathrm{~cm}$ Center-to-Center Spacing . . . . . . . . . . . . .

3.12 Measured Variations in keff, $\ell$ and $\alpha$ with Concentration of Dissolved Gadol inium in

Fue 1-Water Lattices of $2.35 \mathrm{wt} \% 235 \mathrm{U}$ Enriched

U02 Fuel Rods in a Triangular Pattern on a

$1.598 \mathrm{~cm}$ Center-to-Center Spacing

3.13 Measured Variations in $k_{e f f}, \ell$ and $\alpha$ with Concentration of Dissolved Gadolinium in

Fuel-Water Lattices of 4.31 wt\% $235 \mathrm{U}$ Enriched

$\mathrm{UO}_{2}$ Fuel Rods mixed with $\mathrm{PuO}_{2}-\mathrm{UO}_{2}$ Fuel Rods

in a Triangular Pattern on a $1.598 \mathrm{~cm}$

Center-to-Center Spacing

3.14 Measured Variations in keff, $\ell$ and $\alpha$ with Concentration of Dissolved Gadol inium in

Fuel-Water Lattices of 4.31 wt\% 235U Enriched

$\mathrm{UO}_{2}$ Fuel Rods mixed with $\mathrm{PuO}_{2}-\mathrm{UO}_{2}$ Fuel Rods in

a Triangular Pattern on a $1.598 \mathrm{~cm}$ Center-to-

Center Spacing

3.15 Illustration of Technique Used to Determine that

a Fundamental Mode of Prompt Neutron Decay was

Present in the Observed Measurement Data

3.16 Typical SSTR Geometrical Configuration . . . . . . . . . 3.39

3.17 Description and Arrangement of Reaction Rate Packets ............ . . . . . . . 3.40

3.18 Photograph of Fuel Rod Assembly and Reaction Rate Devices Used in Experiments . . . . . . . . . . . . .

3.19 Layout of Reaction Rate Fuel Clusters for Number 11 Lattices . . . . . . . . . . . . . . . . .

3.20 Layout of Reaction Rate Fuel Clusters for Number 12 Lattices . . . . . . . . . . . . . . . .

3.21 Layout of Reaction Rate Fuel Clusters for Number 13 Lattices 


\section{TABLES}

2.1 Experimental Program - Identification and Summary Listing of Measurements Performed with Lattices of

Fuel Rods in Water Containing Dissolver Gadolinium . . . . . 2.2

2.2 Results of Gadolinium-Water Sample Analyses . . . . . . . . 2.13

3.1 Experimental Results - Critical Lattices of Fuel Rods in a Uniform Pattern . . . . . . . . . . . . . 3.6

3.2 Experimental Results - Critical Lattices of Fuel Rods with Irregular Features . . . . . . . . . . . . . 3.10

3.3 Experimental Results - Effect of Gadolinium Concentration on keff, Neutron Lifetime and Prompt Neutron Decay Rate .. . . . . . . . . . . . 3.24

3.4 Experimental Results - Summary Table of Reaction Rate Measurements . . . . . . . . . . 3.38 
.

.

$\bullet$

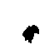


CRITICALITY EXPERIMENTS WITH LOW ENRICHED UO 2 FUEL RODS IN WATER CONTAINING DISSOLVED GADOLINIUM

\subsection{INTRODUCTION}

British Nuclear Fuels Limited (BNFL) is planning to use soluble compounds of the neutron poison gadolinium as a primary criticality safeguard in the reprocessing of nuclear fuels. Although effective in terms of plant capacity, such practices result in a cost penalty, both in the cost of the gadolinium itself and in the increased aqueous raffinate waste from solvent extraction. Consequently a cost incentive exists to control the gadolinum concentrations to a minimum conducive to criticality safety. Achieving this minimum concentration in actual plant operations is dependent on the uncertainties in calculations used to assess the criticality safety of the process in question. To reduce these uncertainties in the area of low enriched oxide fuel reprocessing, BNFL entered in a Contract (DE-SC06-82RL10371) with the United States Department of Energy for a series of criticality, and related, experiments. Primarily the experiments were to provide data for use in validating a calculation method being developed for BNFL design and safety assessments, and to derive data for the use of gadolinium as a neutron poison in nuclear chemical plant operations. To the extent compatable with this objective, however, the experiments were also to be designed to provide more general type information for use in improving neutronic calculations on $10 \mathrm{~W}{ }^{235} \mathrm{U}$ enriched uranium systems.

To provide data in support of plant design and operations, criticality data were needed, over a wide range of neutron moderation, on the poisoning effectiveness of gadolinium dissolved in aqueous solutions containing low enriched $\mathrm{UO}_{2}$ fuel rods. Specifically data were needed on the variation in critical mass (critical size) with gadolinium concentration for neutron moderation ranging from near optimum down to that of tight packed fuel rods in solution. Such data were needed to firmly establish and to reduce costly uncertainties existing in computational methods used in criticality assessments. 
Further, data were needed to establish uncertainties in the calculations as the gadolinium concentration was increased from the delayed criticality condition.

The experiments to provide the above data were performed at the USDOE Critical Mass Laboratory operated by Battelle Memorial Institute near Richland, Washington. A photograph of this facility is shown in Figure 1.1. A floor plan of the facility is shown in Figure 1.2. The experiments were performed in the large shielded area identified in Figure 1.2 as the critical assembly room. Existing experimental facilities within the critical assembly room were modified slightly for the experiments as described in the section entitled Experiments. The experiments performed and the results obtained are covered in detail in the sections of this report that follow.

Briefly, however, the experiments involved measurements with lattices of $2.35 \mathrm{wt} \%$ and $4.31 \mathrm{wt} \%{ }^{235} \mathrm{U}$ enriched $\mathrm{UO}_{2}$ fuel rods and $\mathrm{PuO}_{2}-\mathrm{UO}_{2}$ fuel rods in water containing up to about $2.5 \mathrm{~g} \mathrm{Gd} / l$. The $\mathrm{PuO}_{2}-\mathrm{UO}_{2}$ fuel rods consisted of $2 \mathrm{wt} \% \mathrm{PuO}_{2}$ in natural $\mathrm{UO}_{2}$ and were used with the $4.31 \mathrm{wt} \%{ }^{235} \mathrm{U}$ enriched $\mathrm{UO}_{2}$ rods to construct simulated "burn-up" fueled assemblies. Critical sizes were determined as a function of gadolinium concentration and neutron moderation. Reaction rate measurements were made on selected assemblies to determine fission rates in ${ }^{235} U$, and to determine the Relative Conversion Ratio (RCR) and the Fast Fission Ratio (FFR) of ${ }^{238} U$ and ${ }^{235} U$ for use in improving neutronic data. Also measurements were made, using the pulse neutron source technique, to determine the effect of gadolinium concentration on the effective neutron multiplication constant $\left(k_{e f f}\right)$ of assemblies simulating dissoilver conditions. 


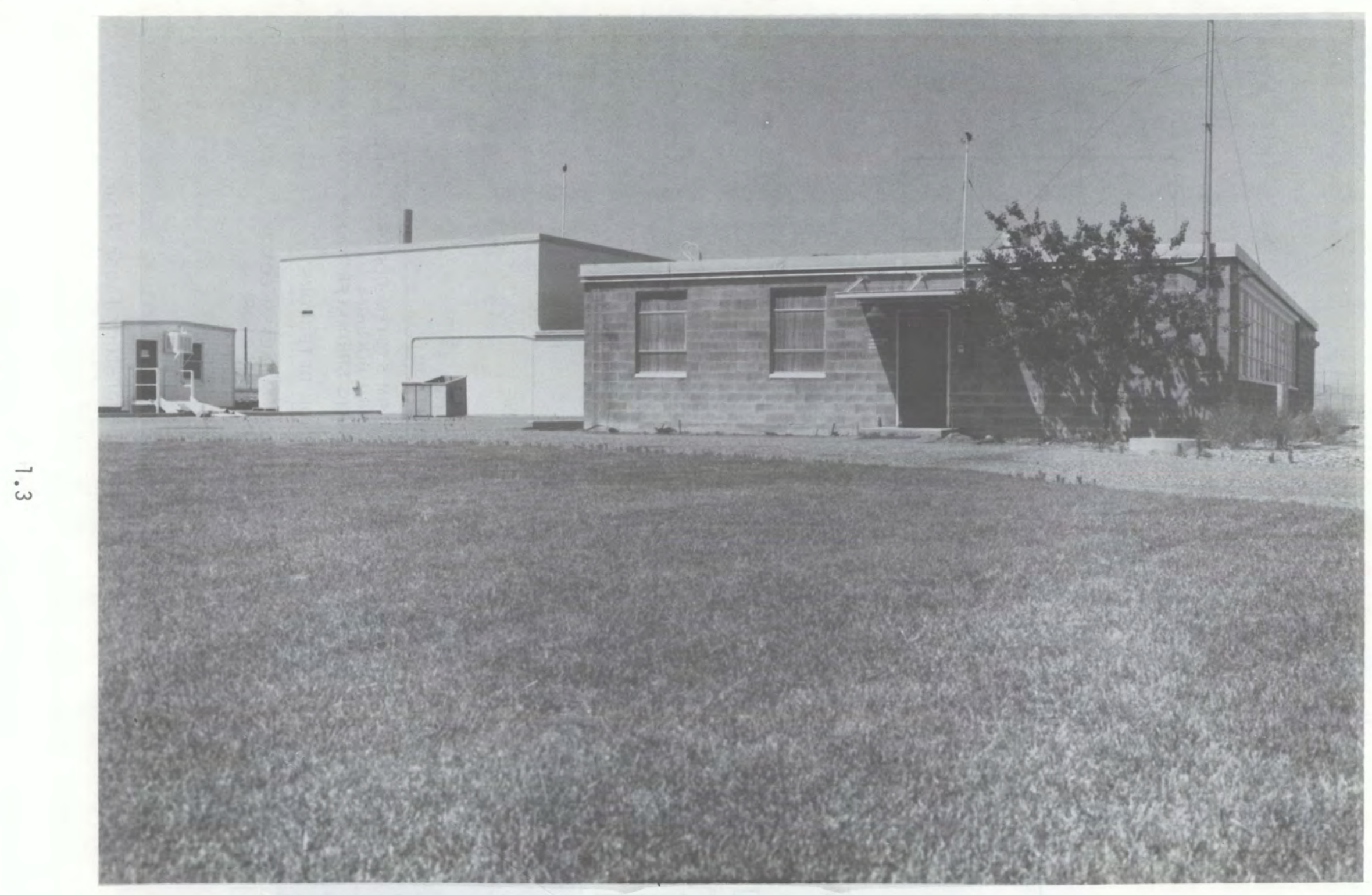

Figure 1.1 USDOE Critical Mass Laboratory near Richland, Washington 


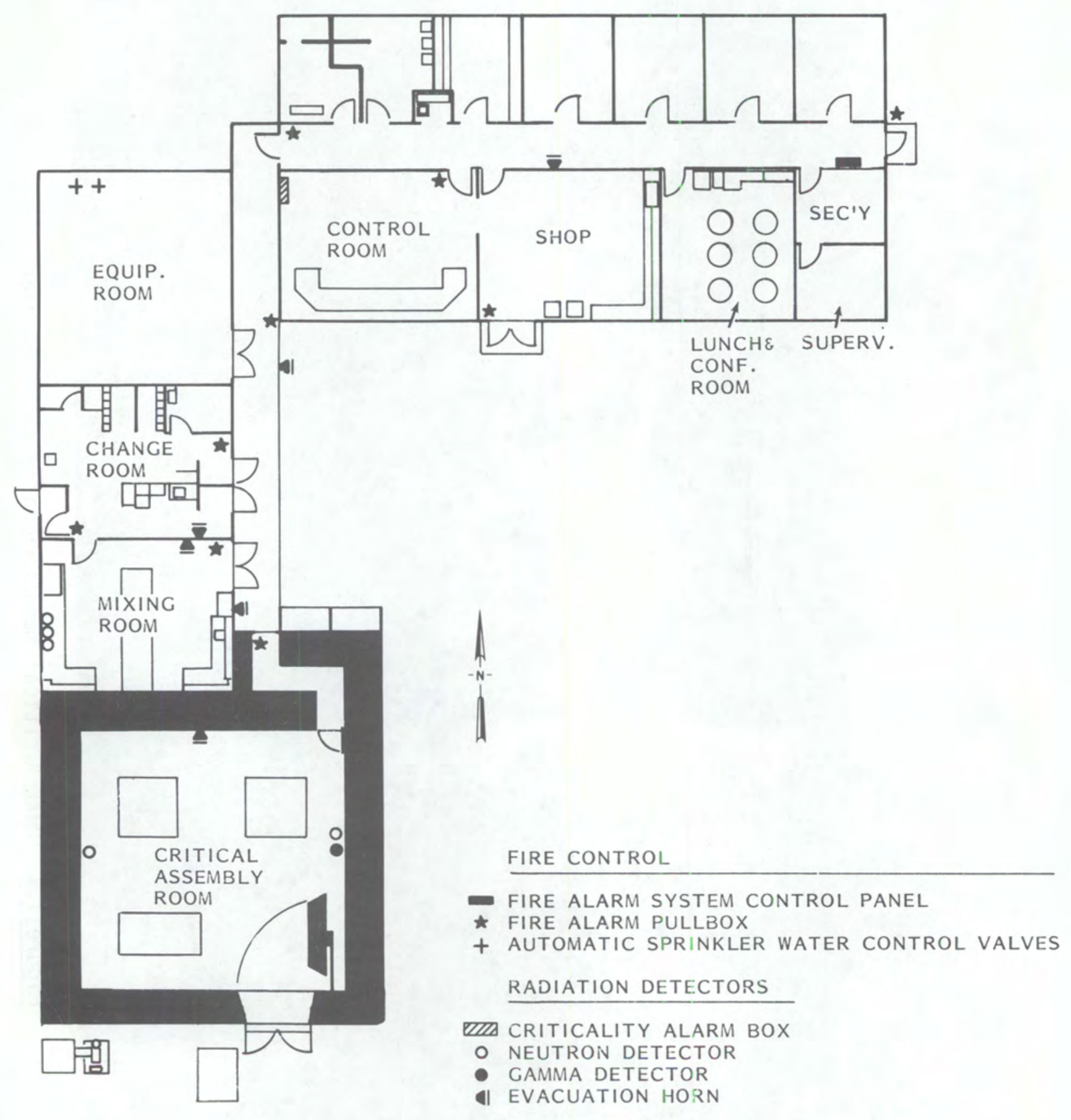




\subsection{EXPERIMENTS}

The types of measurements performed under this program are identified in this section. Also, the experimental system used in making these measurements is described in this section.

\subsection{TYPE OF EXPERIMENTAL MEASUREMENTS}

Measurements were performed on three types of uniform lattices of oxide fuel rods in water. These three fuel-water lattices were:

- $4.31 \mathrm{wt} \%{ }^{235} \mathrm{U}$ enriched $\mathrm{UO}_{2}$ aluminum clad rods in water at three uniform center-to-center rod spacings

- 2.35 wt\% ${ }^{235} \mathrm{U}$ enriched $\mathrm{UO}_{2}$ aluminum clad rods in water at two uniform center-to-center rod spacings

- $4.31 \mathrm{wt} \%{ }^{235} \mathrm{U}$ enriched $\mathrm{UO}_{2}$ aluminum clad rods mixed with $\mathrm{PuO}_{2}-\mathrm{UO}_{2}$ zirconium clad rods to achieve fuel-water lattices, at one uniform center-to-center rod spacing, characteristic of irradiated fuel compositions as specified by BNFL.

The critical size of these lattices were determined, as indicated in Table 2.1, with water containing no gadolinium and with water containing dissolved gadolinium nitrate. Also as indicated in Table 2.1, pulsed neutron source measurements were performed to determine subcritical $k_{\text {eff }}$ values as additional amounts of gadolinium were successively dissolved in the water of each critical assembly.

Fission rate measurements in ${ }^{235} \mathrm{U}$ using solid state track recorders were made in each of the three unpoisoned critical assemblies of $4.31 \mathrm{wt} \%$ ${ }^{235} \mathrm{U}$ enriched $\mathrm{UO}_{2}$ fuel rods and in the near-optimum and close-packed poisoned assemblies of this fuel. Foils of $4.31 \mathrm{wt} \%{ }^{235} \mathrm{U}$ enriched $\mathrm{UO}_{2}$ and depleted $U$ metal $\left(0.04\right.$ wt\% $\left.{ }^{235} \mathrm{U}\right)$ were also irradiated in these same five critical assemblies simultaneously with irraditions in the NESTOR reactor at the Atomic Energy Establishment-Winfrith (AEEW) to obtain data on neutron capture and fission in ${ }^{238} \mathrm{U}$ relative to fission in ${ }^{235} \mathrm{U}$. 
TABLE 2.1 Experimental Program - Identification and Summary Listing of Measurements Performed with Lattices of Fuel Rods in Water Containing Dissolved Gadolinium (a)

\begin{tabular}{|c|c|c|c|c|c|c|c|c|c|}
\hline \multirow{3}{*}{$\begin{array}{l}\text { NOMINAL } \\
\text { TTICE SPACING }\end{array}$} & \multicolumn{3}{|c|}{$\begin{array}{c}\mathrm{UO}_{2} \text { FUEL RODS } \\
4.31 \mathrm{wt} \%{ }^{235} \mathrm{U} \text { ENRICHED }\end{array}$} & \multicolumn{3}{|c|}{$\begin{array}{c}\text { UO }_{2} \text { FUEL RODS } \\
2.35 w t \% 235 \text { U ENRICHED }\end{array}$} & \multicolumn{3}{|c|}{$\begin{array}{c}\mathrm{PuO}_{2}-\mathrm{UO}_{2} \text { FUEL RODS } \\
2.00 w \mathrm{wt} \% \mathrm{PuO}_{2} \text { IN NATURAL UO }\end{array}$} \\
\hline & $\begin{array}{l}\text { CRITICAL } \\
\text { APPROACH }\end{array}$ & $\begin{array}{l}\text { PULSE } \\
\text { NEUTRON }\end{array}$ & REACTION RATES & $\begin{array}{l}\text { CRITICAL } \\
\text { APPROACH }\end{array}$ & $\begin{array}{l}\text { PULSE } \\
\text { NEUTRON }\end{array}$ & REACTION RATES & $\begin{array}{l}\text { CRITICAL } \\
\text { APPROACH }\end{array}$ & $\begin{array}{c}\text { PULSE } \\
\text { NEUTRON }\end{array}$ & REACTION RATES \\
\hline & $\left(k_{\text {eff }}=1\right)$ & $\left(1>k_{\text {eff }} \geq 0.87\right)$ & (SSTR) $^{(b)}$ (FOILS) $^{(c)}$ & $\left(k_{\text {eff }}=1\right)$ & $\left(1>k_{\text {eff }} \geq 0.87\right)$ & (SSTR) $^{(\mathrm{b})}$ (FOILS) $^{(\mathrm{c})}$ & $\left(k_{\text {eff }}=1\right)$ & $\left(1>k_{\text {eff }} \geq 0.87\right)$ & (SSTR) $^{(b)}$ (FOILS) $^{(c)}$ \\
\hline
\end{tabular}

\section{NEAR-OPTIMUM}

WITH NO GADOLINIUM

WITH GADOLINIUM

\section{INTERMEDIATE}

WITH NO GADOLINIUM

WITH GADOLINIUM

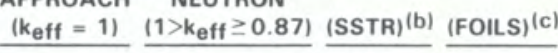

\section{CLOSE-PACK}

WITH NO GADOLINIUM

WITH GADOLINIUM

$\begin{array}{ll}1 & - \\ 3 & 9 \\ & \\ 1 & - \\ 6 & 8\end{array}$

(a) NUMBERS SHOWN FOR EACH FUEL LATTICE INDICATE THE NUMBER AND TYPE OF MEASUREMENT PERFORMED ON THAT LATTICE

(b) EACH MEASUREMENT WITH SOLID STATE TRACK RECORDERS INVOLVES A SINGLE BARE 235 U SSTR LOCATED IN ONE OF THE FOIL POSITIONS IN THE LATTICE

(c) EACH MEASUREMENT WITH FOILS INVOLVES $4.31 \%{ }^{235}$ U ENRICHED UO ${ }_{2}$ AND DEPLETED $\left(0.04 \mathrm{wt} \%{ }^{235} \mathrm{U}\right)$ U FOILS LOCATED IN THREE IDENTICAL POSITIONS IN THE LATTICE 
Specific details of all the measurements identified in Table 2.1 are provided in the section that follows on experimental results.

\subsection{DESCRIPTION OF EXPERIMENTAL ASSEMBLIES}

An existing experimental system used previously in fuel element array studies at the Critical Mass Laboratory was used in carrying out the experiments summarized in Table 2.1. The system, consisting of a $1.8 \mathrm{~m} \times 3 \mathrm{~m} \times 2.1 \mathrm{~m}$ deep carbon steel tank provided with a water dump valve, a water deionizer system, a control blade drive, a safety blade drive and associated electronic detection and interlock devices, was modified by positioning a $152 \mathrm{~cm}$ diameter open top fiberglass tank beneath the control and safety blade drives to reduce the volume of water and quantity of gadolinium used in the experiments. This open top tank was connected to the water dump valve and deionizing system in addition to two 2600 \& covered polyethylene tanks for mixing and storing gadolinium solution. Also the control and safety blade drive systems were modified to permit replacing the blades with rod type devices. An overall photograph of the modified system, not including the mix-storage tanks is shown in Figure 2.1. A flow diagram of the system including the mix-storage tanks is shown in Figure 2.2.

Each experimental assembly consisted of a single array of fuel rods fully submerged in, and reflected by, either water or water containing dissolved gadolinium nitrate. A photograph of an experimental assembly in place is shown in Figure 2.3. The photograph has been annotated to identify the location of the neutron detectors used in determining neutron multiplication (data channels), the neutron detectors associated with the safety shutdown system (control channels), the pulse neutron source, the safety and control rods, the location of the temperature probe, and the fuel-lattice. A11 instrumentation inside the experimental vessel is shown in Figure 2.3. In all of the experimental measurements, the instrument thimbles were at least $15 \mathrm{~cm}$ from the fuel region (data channel 3 was moved radially on occasion to achieve this $15 \mathrm{~cm}$ minimum separation). Not discernible, and therefore not identified, in Figure 2.3 is a small ( 0.6 microgram) ${ }^{252} \mathrm{Cf}$ source which was located in the center region of each experimental assembly. 


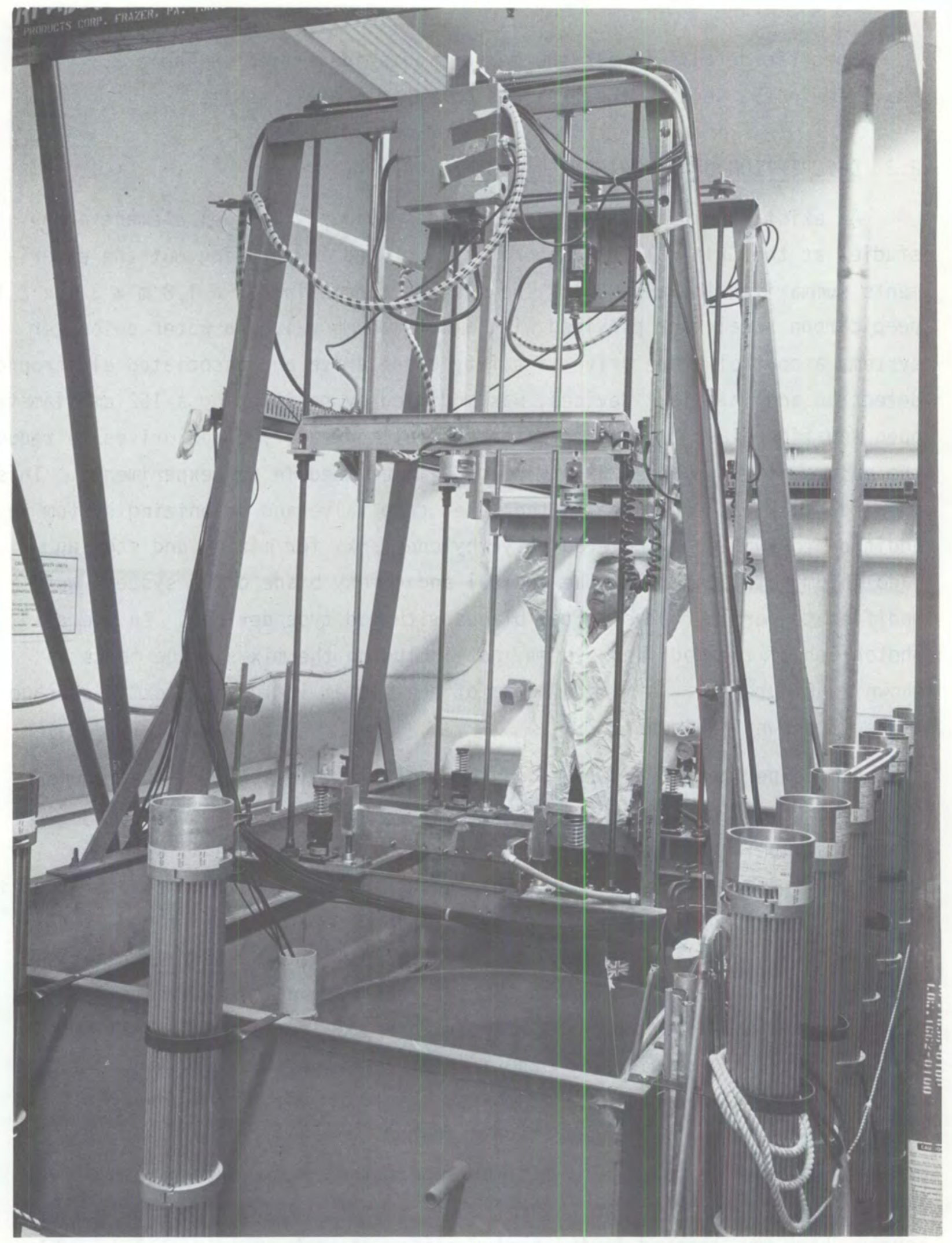

Figure 2.1 Experimental System Modified for Use in Experiments 


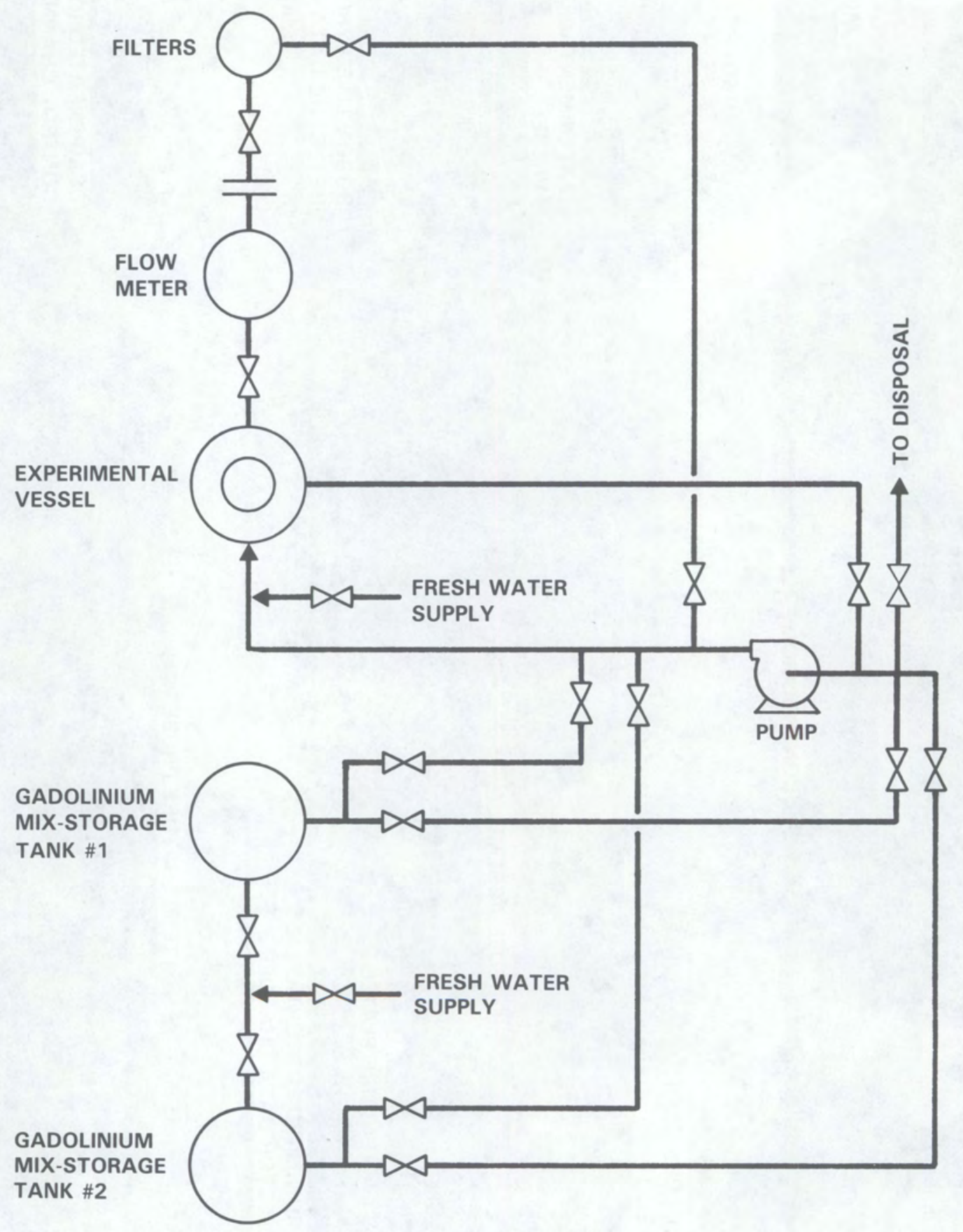

Figure 2.2 Flow Diagram of Experimental System 


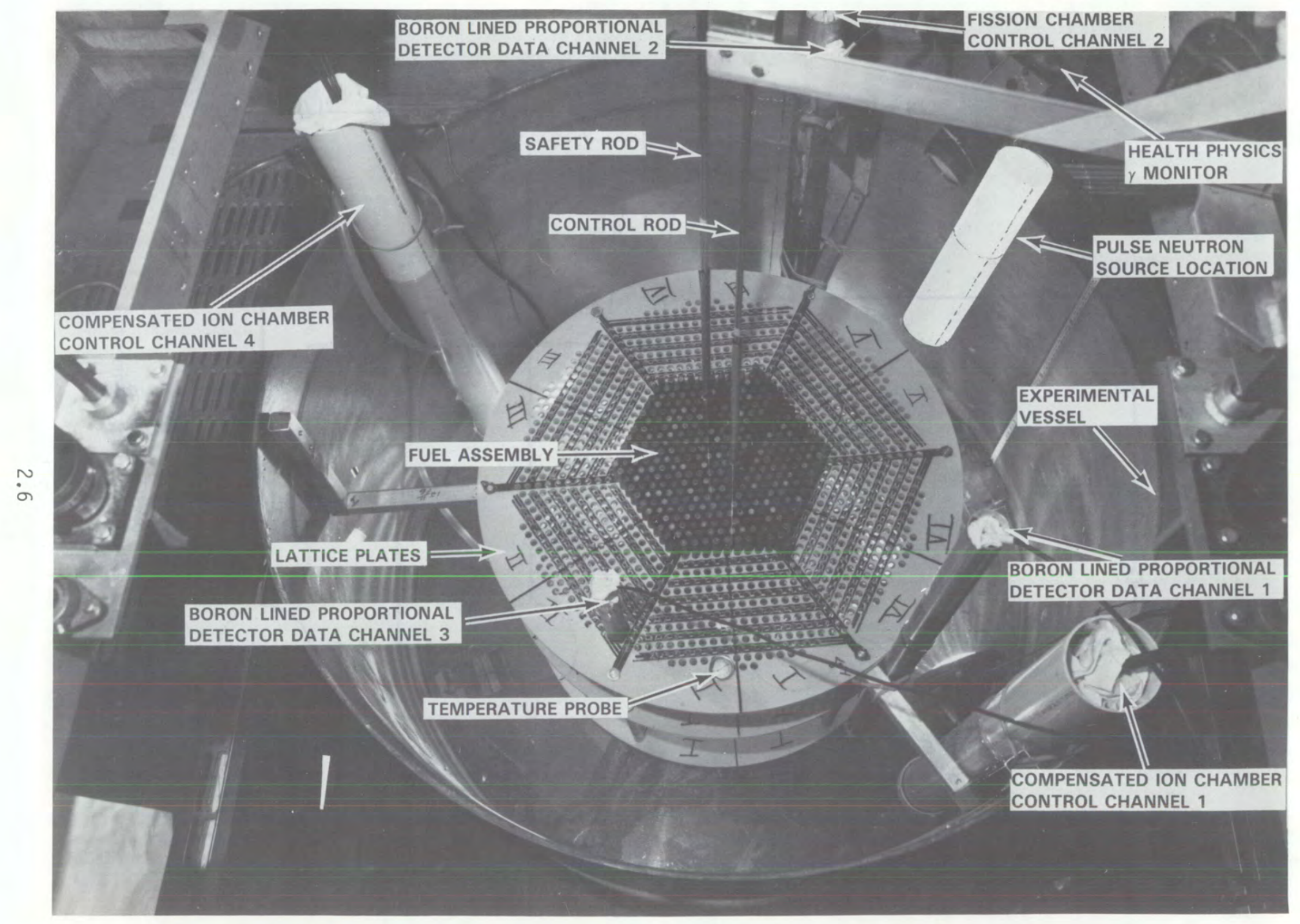

Figure 2.3 Annotated Photograph of Experimental Vessel and Fuel Assembly 
The source was mounted in an open $0.6 \mathrm{~cm}$ diameter acrylic tube to minimize voiding effects in the gadolinium-water assemblies.

As indicated earlier, the fuel rods used in the experiments consisted of $4.31 \mathrm{wt} \%{ }^{235} \mathrm{U}$ enriched $\mathrm{UO}_{2}$ rods, $2.35 \mathrm{wt} \%{ }^{235} \mathrm{U}$ enriched $\mathrm{UO}_{2}$ rods and $\mathrm{PuO}_{2}-\mathrm{UO}_{2}$ rods containing $2.0 \mathrm{wt} \% \mathrm{PuO}_{2}$ in natural $\mathrm{UO}_{2}$. A complete description of these rods is given in Figures 2.4, 2.5 and 2.6. The $4.31 \mathrm{wt} \%{ }^{235} U$ enriched $\mathrm{UO}_{2}$ fuel rods, described in Figure 2.5, were obtained by downloading stainless steel clad rods, originally fabricated for Core II of the N.S. Savannah (Kaiz 1969), and reloading the pellets into Type 6061 aluminum tubes (see Appendix A for American Society for Testing Materials, ASTM, Specifications). The uranium assay $(1059.64 \pm 4.80 \mathrm{~g} / \mathrm{rod})$ and the ${ }^{235} \mathrm{U}$ enrichment $(4.306 \pm 0.013 \%)$ shown in Figure 2.5 for these rods are the average of six assay and six spectrographic analyses made on fuel pellets chosen at random during this reloading. The oxide density $(10.40 \pm 0.006 \mathrm{~g}$ $\mathrm{UO}_{2} / \mathrm{cm}^{3}$ ) given in Figure 2.5 is based on individual volume displacement measurements with 20 pellets selected at random during the reloading operations. The mass of $\mathrm{UO}_{2}$ per rod $(1203.38 \pm 4.13 \mathrm{~g})$ is the average mass of the 1865 rods of this type available for use in the experiments. The fuel diameter $(1.265 \pm 0.003 \mathrm{~cm})$ given in Figure 2.5 was checked repeatable during the reloading operation and found to agree with that quoted in the document characterizing Core II of the N. S. Savannah (Kaiz 1969). The rubber end cap density $\left(1.321 \mathrm{~g} / \mathrm{cm}^{3}\right)$ quoted in Figure 2.5 for the $4.35 \mathrm{wt} \%{ }^{235} \mathrm{U}$ enriched fuel is the result of a single mass-volume measurement with six end caps selected at random. The composition of the end caps is the result of four analyses on randomly selected end caps.

The $2.35 \mathrm{wt} \%{ }^{235} U$ enriched $\mathrm{UO}_{2}$ fuel rods, described in Figure 2.4 , are vibrationally compacted oxide rods that have been used in low power and subcritical measurements repeatable in previous years. The physical description and chemical composition given in Figure 2.4 are those defined during some of these previous measurements (Smith and Konzek 1976) and verified in latter measurements (Smith and Konzek 1978). Additional reanalyses of the fue 1 rods were not considered warranted since such analyses would require destroying several rods. ASTM chemical specifications for the cladding materials are given in Appendix $A$. 
CLAD:

$1.270 \pm 0.002 \mathrm{~cm}$ OD

FUEL: $1.118 \pm 0.003 \mathrm{~cm}$ DIA. $\quad \times 0.076 \mathrm{~cm}$ WALL

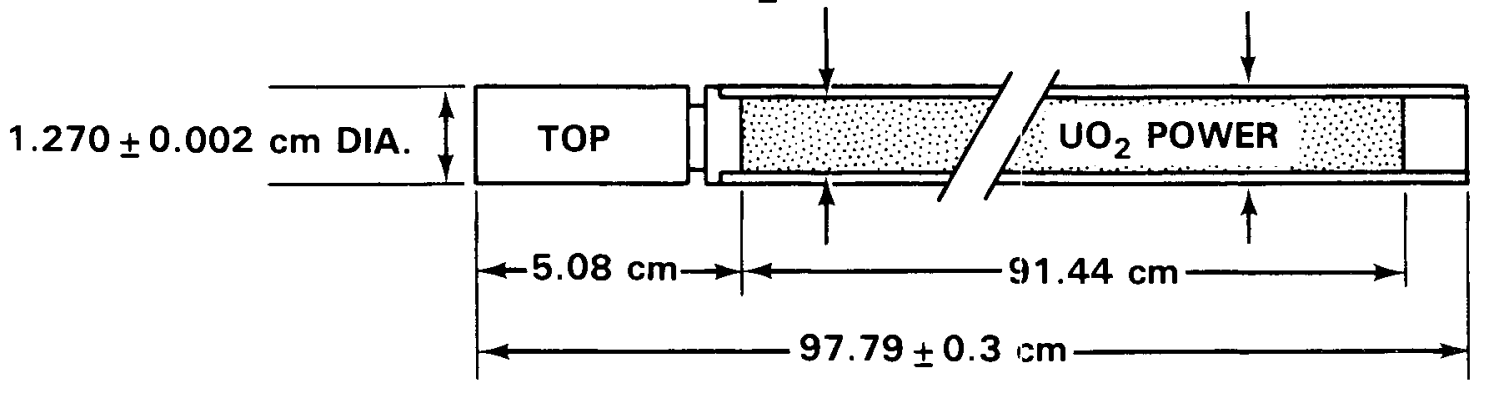

CLADDING: 6061 ALUMINUM TUBING SEAL WELDED WITH A LOWER END PLUG OF 5052-H32 ALUMINUM AND A TOP PLUG DF 1100 ALUMINUM

\section{LOADING:}

ENRICHMENT - $2.350 \pm 0.003$ WT\% $235 U$

OXIDE DENSITY $-9.20 \mathrm{~g} / \mathrm{cm}^{3}$

$\mathrm{UO}_{2}-825 \mathrm{~g} / \mathrm{ROD}$

$\mathrm{U}-726 \mathrm{~g} / \mathrm{ROD}$

URANIUM COMPOSITION:

$$
\begin{aligned}
& { }^{234} U-0.0137 \pm 0.0003 \text { WT\% } \\
& 235 U-2.350 \pm 0.003 \text { WT } \% \\
& 236 U-0.0171 \pm 0.0003 \text { WT\% } \\
& 238 U-97.62 \pm 0.003 \text { WT } \%
\end{aligned}
$$

NOTES:

1. ERROR LIMITS ARE ONE STANDARD DEVIATION

Figure 2.4. Description of $2.35 \mathrm{Wt} \%{ }^{235} \mathrm{U}$ Enriched $\mathrm{UO}_{2}$ Fuel Rods 


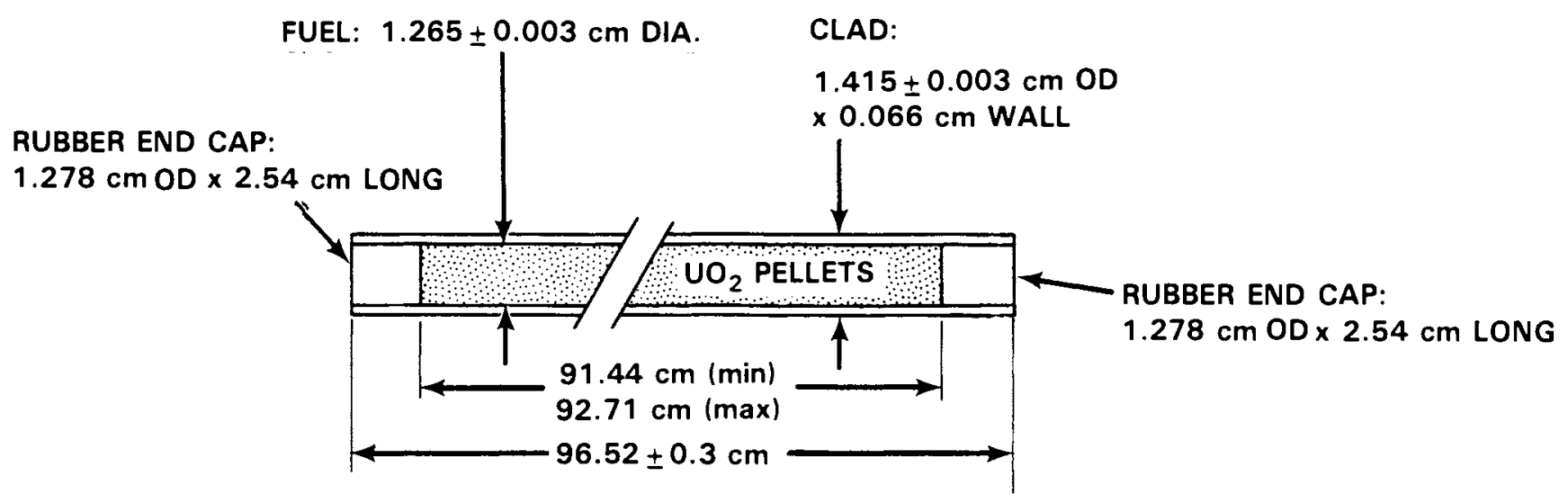

CLADDING: 6061 ALUMINUM TUBING

LOADING

ENRICHMENT $-4.306 \pm 0.013 \% 235 \mathrm{U}$

OXIDE DENSITY $-10.40 \pm 0.06 \mathrm{~g} / \mathrm{cm}^{3}$

$\mathrm{UO}_{2} \cdot 1203.38 \pm 4.12 \mathrm{~g} / \mathrm{ROD}$

$\mathrm{U} \cdot 1059.64 \pm 4.80 \mathrm{~g} / \mathrm{ROD}$

URANIUM COMPOSITION:

$234 U-0.022 \pm 0.002$
$235 U-4.306 \pm 0.013$
$236 U-0.022 \pm 0.002$
$238 U-95.650 \pm 0.017$

END CAP:

C. $58 \pm 1$ WT\% H-6.5 \pm 0.3 WT\% S-1.7 $\pm 0.2 W T \%$ Ca-11.4 \pm 1.8 WT\% 0-22.1 WT\% (BALANCE) Si-0.3 \pm 0.1 WT\%

NOTES:

1. ERROR LIMITS ARE ONE STANDARD DEVIATION

2. END CAP DENSITY IS $1.321 \mathrm{~g} / \mathrm{cm}^{3}$

Figure 2.5 Description of $4.31 \mathrm{wt} \%{ }^{235} \mathrm{U}$ Enriched $\mathrm{vO}_{2}$ Fuel Rods 
CLAD: $1.435 \pm 0.003 \mathrm{~cm}$ OD

$\times 0.076 \mathrm{crn}$ WALL

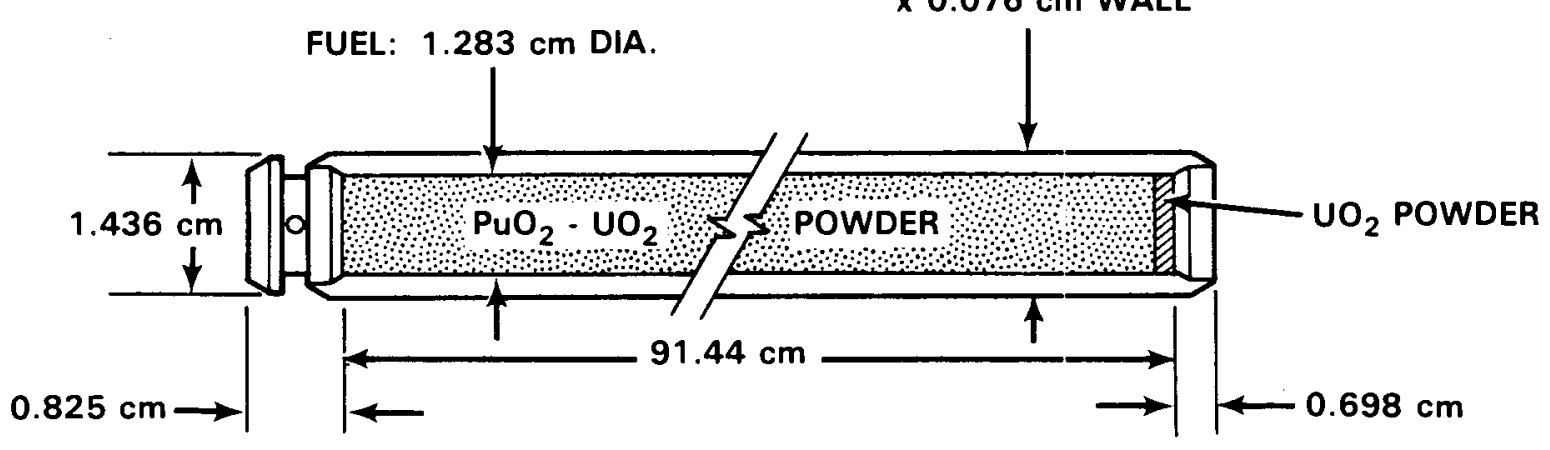

CLADDING: ZIRCALOY-2 TUBING WITH PLUGS SEAL WELDED AT BOTH ENDS

LOADING:

ENRICHMENT - $2.00 \mathrm{WT} \% \mathrm{PuO}_{2}$ IN NATURAL $\mathrm{UO}_{2}$

OXIDE DENSITY $-9.54 \mathrm{~g} / \mathrm{cm}^{3}$

$\mathrm{PuO}_{2}+\mathrm{UO}_{2}-1128 \mathrm{~g} / \mathrm{ROD}$

$\mathrm{Pu}-20.169 \pm 0.004 \mathrm{~g} / \mathrm{ROD}$

$U-970.306 \pm 0.225 \mathrm{~g} /$ ROD

$\mathrm{UO}_{2}$ POWDER - NATURAL URANIUM (SEE NOTE 4)

PLUTONIUM COMPOSITION:

$$
\begin{aligned}
& 238 \mathrm{Pu}-0.009 \pm 0.001 \\
& 239 \mathrm{Pu}-91.836 \pm 0.006 \\
& 240 \mathrm{Pu}-7.760 \pm 0.006 \\
& 241 \mathrm{Pu}-0.367 \pm 0.001 \\
& 242 \mathrm{Pu}-0.028 \pm 0.001
\end{aligned}
$$

AMERICIUM: $64.6 \pm 0.1$ PARTS ${ }^{241}$ Am PER MILLION PARTS PuO $_{2}+\mathrm{UO}_{2}$ MIXTURE BY WEIGHT NOTES:

1. EFFECTIVE AVERAGe CHEMICAL SEPARATION DATE FOR FLUTONIUM IS APRIL 1962

2. PLUTONIUM COMPOSITION AND AMERICIUM FROM ANALYSES MADE IN AUGUST 1976. SEE TEXT FOR JANUARY 1983 ANALYSIS BY GAMMA SPECTRUM ANALYSES.

3. DECEMBER 1965 CALCULATED ${ }^{241} \mathrm{Pu} /{ }^{241}$ Am ATOM RATIO IS 5.22 (STINSON, 1971)

4. $\mathrm{UO}_{2}$ POWDER IS AN END FILLER AND BARRIER ABOUT $0.2 \mathrm{~cm}$ THICK

5. ERROR LIMITS ARE ONE STANDARD DEVIATION

Figure 2.6 Description of Mixed 0xide Fuel Rods 
The mixed oxide rods, described in Figure 2.6, are also vibrationally compacted oxide rods that have been used in previous experiments. The ASTM specifications for the zircalloy cladding is given in Appendix $A$. The physical description and oxide chemical composition given in Figure 2.6 are those defined (Uotinen 1967) and later verified (Smith and Konzek 1978) during these earlier measurements. The plutonium composition and americium concentration given in Figure 2.6 were determined from the analyses of samples taken from five randomly selected rods (Smith and Konzek 1978). The isotopic weight percent given in Figure 2.6 for the ${ }^{241} \mathrm{Pu}$ is in very good agreement with that obtained $(0.366 \mathrm{wt} \%)$ by assuming a 14.5 year half life and calculating the decay of the ${ }^{241} \mathrm{Pu}$ concentration $(0.726 \mathrm{wt} \%$ ) used in the fabrication of these rods (March 1962).

Non-destructive gamma spectrum analyses were performed in January, 1983 using six randomly selected mixed oxide rods to obtain additional verification of the plutonium isotopic distribution in these rods. The results of this latest analyses is given below:

$$
\begin{aligned}
& { }^{238} \mathrm{Pu}-0.010 \pm 0.001 w t \% \\
& 239 \mathrm{Pu}-91.806 \pm 0.551 w t \% \\
& 240 \mathrm{Pu}-7.876 \pm 0.394 w t \% \\
& { }^{241} \mathrm{Pu}-0.277 \pm 0.008 w t \% \\
& 242 \mathrm{Pu}-0.031 \pm \ldots---w t \%
\end{aligned}
$$

The amount of ${ }^{241} \mathrm{Am}$ in the fuel was determined from the gamma spectrum measurements to be $0.0043 \mathrm{~g}^{241} \mathrm{Am} / \mathrm{g}$ Pu which agrees well with a value of 0.004 obtained by calculating the decay of the $1965{ }^{241} \mathrm{Pu}$, given in Figure 2.6, to January 1983.

It was anticipated that the experimental results would be very sensitive to the amount of gadolinium dissolved in the water. Consequently several techniques, involving four laboratories, were investigated for analyzing the gadolinium-water samples taken from the experimental assemblies. The various analytical techniques were:

- flame emission spectroscopy

- DC argon plasma emission spectrocopy

- inductively coupled plasma emission spectroscopy

- mass spectrometry. 
Each of these techniques, as performed by the various laboratories, are briefiy described in Appendix $B$. The analytical results obtained by the respective laboratories are given in Table 2.2. As will be discussed in greater detail in the sections concerned with experimental results, a conclusion was reached that mass spectrometry provided results as good as could be reasonably achieved. Consequently the gadolinium concentrations referred to throughout this report are the average of the mass spectrometry result:s given in Table 2.2 for the respective experiments. In addition to analyzing the gadolinium water samples for gadolinium concentration, analyses were performed to determine the trace impurities present in the water and in the gadolinium nitrate dissolved in the water. The results of these analyses are given in Appendix $C$. Also densities were determined for each sample using a PAAR digital density meter in which the natural vibrational frequency of a hollow oscillator filled with sample is measured. The meter was calibrated using deaerated demineralized water and dry air. Each density result given in Table 2.? is the average of two sample analyses, each by a different laboratory.

The analytical results in Table 2.2 and Appendix $C$ were obtained on samples taken from larger one liter samples to which about one milliliter of 13 molar nitric acid had been added to improve gadolinium solubility. The large one liter samples were obtained immediately following each measurement by vertically traversing each experimental assembly at the edge of the lattice plates. One liter archival samples were identically obtained and treated following each measurement.

Three $91.44 \mathrm{~cm}$ diameter, $1.35 \mathrm{~cm}$ thick polypropylene lattice plates, positioned in the center of the open top fiberglass tank as indicated in Figure 2.3, were used in each experiment to obtain assemblies of equally spaced fuel rods at the desired neutron moderation. In all of the experimental assemblies, the lattice plates were positioned at the elevations indicated in Figure 2.7 to maintain a uniform spacing between fuel rods over the length of each assembly with minimum ferturbation to the neutron flux. Polypropylene is a hydrocarbon having a $\mathrm{C}_{3} \mathrm{H}_{6}$ molecular structure with 


\section{TABLE 2.2 Results of Gadolinium-Water Samples Analyses}

\begin{tabular}{|c|c|c|c|c|c|c|c|}
\hline \multirow[b]{2}{*}{$\begin{array}{c}\text { EXPERIMENT } \\
\text { REFERENCE } \\
\text { NUMBER } \\
\end{array}$} & \multirow[b]{2}{*}{$\begin{array}{l}\text { SAMPLE } \\
\text { IDENTIFICATION } \\
\text { NUMBER }\end{array}$} & \multicolumn{5}{|c|}{ GADOLINIUM CONCENTRATION(a) } & \multirow[b]{2}{*}{$\begin{array}{l}\text { SOLUTION } \\
\text { DENSITY (a) }(g) \\
\left(\mathrm{g} / \mathrm{cm}^{3}\right)\end{array}$} \\
\hline & & $\begin{array}{c}\text { HEHF(b) } \\
\text { (g Gd/liter) }\end{array}$ & $\begin{array}{c}\text { PNL (c) } \\
\text { (g Gd/iter) }\end{array}$ & $\begin{array}{c}\text { AEEW(d) } \\
(\mathrm{g} \text { Gd/liter) }\end{array}$ & $\begin{array}{c}\text { AEEW(e) } \\
(\mathrm{g} \text { Gd/lites })\end{array}$ & $\begin{array}{c}\text { BNFL }(f) \\
(\mathrm{g} \mathrm{Gd} / \text { liter })\end{array}$ & \\
\hline $4.3 \cdot 000 \cdot 182 \& 185$ & $1 \cdot 1-2$ & $0.094 \pm 0.001$ & $0.06 B \pm 0.007$ & 0.069 & 0.069 & $0.06 \mathrm{~B}$ & $0.9986 \pm 0.0005$ \\
\hline 4.3-000-186 & $1-1.3$ & $0.508 \pm 0.011$ & $0.427 \pm 0.004$ & 0.434 & 0.441 & 0.436 & $1.0062 \pm 0.0011$ \\
\hline 4.3-000-188 & 1.1 .4 & $0.575 \pm 0.001$ & $0.450 \pm 0.005$ & 0.479 & 0.482 & 0.483 & $1.0033 \pm 0.0009$ \\
\hline 4.3-000-188 & $1-1.5$ & $0.645 \pm 0.021$ & $0.522 \pm 0.008$ & 0.543 & 0.555 & 0.543 & $1.0025 \pm 0.0006$ \\
\hline 4.3-000-188 & 1.1 .6 & $0.755 \pm 0.007$ & $0.586 \pm 0.006$ & 0.617 & 0.627 & 0.651 & $1.0012 \pm 0.0011$ \\
\hline $4.3 \cdot 000-188$ & 1.1 .7 & $0.940 \pm 0.001$ & $0.753 \pm 0.008$ & 0.777 & 0.781 & 0.796 & $1.0032 \pm 0.0011$ \\
\hline $4.3-000-192 \& 201$ & 1.2 .5 & - & $0.110 \pm 0.002$ & 0.120 & 0.122 & 0.123 & $0.9983 \pm 0.0009$ \\
\hline 4.3.000-202 & $1-2-6$ & - & $0.355 \pm 0.005$ & 0.373 & 0.414 & 0.385 & $0.9985 \pm 0.0007$ \\
\hline 4.3-000-203 & 1.2 .7 & - & $0.880 \pm 0.014$ & 0.903 & 0.903 & 0.912 & $1.0000 \pm 0.0013$ \\
\hline $4.3 \cdot 000 \cdot 204$ & $1.2-8$ & - & $1.275 \pm 0.034$ & 1.24 & 1.220 & 1.273 & $1.0008 \pm 0.0016$ \\
\hline 4.3-000-204 & $1.2-9$ & - & $1.354 \pm 0.025$ & 1.35 & 1.360 & 1.382 & $1.0010 \pm 0.0013$ \\
\hline 4.3-000-204 & $1 \cdot 2 \cdot 10$ & - & $1.434 \pm 0.035$ & 1.42 & 1.420 & 1.492 & $1.0013 \pm 0.0010$ \\
\hline $4.3-000-204$ & $1-2 \cdot 11$ & - & $1.752 \pm 0.013$ & 1.62 & 1.610 & 1.717 & $1.0022 \pm 0.0011$ \\
\hline 4.3-000-204 & $1.2-12$ & - & $2.343 \pm 0.043$ & 2.16 & 2.170 & 2.220 & $1.0040 \pm 0.0014$ \\
\hline 4.3-000.205 & 1.2 .13 & - & $1.457 \pm 0.018$ & 1.43 & 1.430 & 1.465 & $1.0014 \pm 0.0008$ \\
\hline $4.3-000-206$ & $1-2 \cdot 14$ & - & $1.527 \pm 0.026$ & 1.45 & 1.450 & 1.512 & $1.0015 \pm 0.0006$ \\
\hline 4.3-000-194 & 1.3 .3 & - & $0.763 \pm 0.008$ & 0.759 & 0.745 & 0.754 & $1.0025 \pm 0.0006$ \\
\hline $4.3 \cdot 000 \cdot 194$ & $1.3-4$ & - & $0.633 \pm 0.006$ & 0.636 & 0.644 & 0.633 & $1.0026 \pm 0.0005$ \\
\hline 4.3-000-194 & 1.3 .6 & - & $0.442 \pm 0.004$ & 0.449 & 0.455 & 0.456 & $1.0030 \pm 0.0056$ \\
\hline 4.3-000-194 & 1.3 .5 & - & $0.124 \pm 0.001$ & 0.129 & 0.129 & 0.130 & $1.0003 \pm 0.0024$ \\
\hline 4.3-000-198 & $1-3-7$ & - & $0.118 \pm 0.001$ & 0.121 & 0.123 & 0.120 & $0.9996 \pm 0.0006$ \\
\hline $2.35-000-160 \& 165$ & $2-9-2$ & $0.146 \pm 0.003$ & $0.116 \pm 0.001$ & 0.120 & 0.120 & 0.121 & $0.9986 \pm 0.0006$ \\
\hline $2.35-000-165$ & 2-1-5 & $0.247 \pm 0.004$ & $0.207 \pm 0.002$ & 0.210 & 0.217 & 0.218 & $0.9992 \pm 0.0011$ \\
\hline $2.35-000-165$ & $2 \cdot 1 \cdot 3$ & $0.306 \pm 0.002$ & $0.254 \pm 0.003$ & 0.258 & 0.260 & 0.264 & $0.9986 \pm 0.0005$ \\
\hline $2.35-000-165$ & $2 \cdot 1.4$ & $0.363 \pm 0.003$ & $0.302 \pm 0.003$ & 0.309 & 0.316 & 0.318 & $0.9986 \pm 0.0006$ \\
\hline $2.35-000-170 \& 172$ & $2-2 \cdot 2$ & - & $0.044 \pm 0.001$ & 0.051 & 0.056 & 0054 & $09988=00005$ \\
\hline $2.35-000-170$ & $2 \cdot 2 \cdot 1$ & - & $0.071 \pm 0.001$ & 0.078 & 0.078 & 0078 & $10004 \pm 00005$ \\
\hline $2.35-000-170$ & $2 \cdot 2-3$ & - & $0.236 \pm 0.003$ & 0.254 & 0.256 & 0258 & $0.9990 \pm 0.0005$ \\
\hline $4.3-002 \cdot 196$ & 3.2 .5 & 0.275 & $0.191 \pm 0.002$ & 0.196 & 0.194 & 0.194 & $1.0014 \pm 0.0023$ \\
\hline 4.3-002-196 & 3.2 .4 & - & $0371 \pm 0005$ & 0408 & 0404 & 0413 & $10014 \pm 00008$ \\
\hline 4.3-002-196 & 3-2-2 & 0.685 & $0.606 \pm 0.006$ & 0.611 & 0.620 & 0.632 & $0.9986 \pm 0.0006$ \\
\hline $4.3-002 \cdot 196$ & 3-2.3 & 1.060 & $0.910 \pm 0.009$ & 0.906 & 0.929 & 0.907 & $1.0054 \pm 0.0009$ \\
\hline 4.3-002-207 & $3 \cdot 2 M-1$ & - & $0.441 \pm 0.008$ & 0.467 & 0.465 & 0.467 & $09999 \pm 00005$ \\
\hline $4.3-000-208$ & $3-2 M-2$ & - & $0.556 \pm 0.005$ & 0.588 & 0.559 & 0.573 & $10004 \pm 0.0005$ \\
\hline 4.3-000-209 & $3 \cdot 2 \mathrm{M} \cdot 3$ & - & $0.646 \pm 0.006$ & 0.670 & 0.673 & 0.673 & $1.0003 \pm 0.0005$ \\
\hline 4.3-000-209 & $3 \cdot 2 M-4$ & - & $0.740 \pm 0.009$ & 0.744 & 0.760 & 0.759 & $10022=00005$ \\
\hline $4.3-000-209$ & $3-2 M-5$ & - & $1.389 \pm 0.029$ & 1.39 & 1.370 & 1.372 & $10008=00005$ \\
\hline 4.3-000-209 & $3.2 M-6$ & - & $2.374 \pm 0.040$ & 2.34 & 2.360 & 2.363 & $10013 \div 00005$ \\
\hline
\end{tabular}

(a) ERROR UMITS GIVEN ARE ONE STANDARD DEVIATIONS

(b)FLAME EMISSION SPECTROSCOPY BY HANFORD ENVIRONMENTAL HEALTH FOUNDATION

(c) DC ARGON PLASMA EMISSION SPECTROSCOPY ANALYSIS BY PACIFIC NORTHWEST LABORATORY

(d) INDUCTIVELY COUPLED PLASMA EMISSION SPECTROSCOPY ANALYSIS BY ATOMIC ENERGY ESTABLISHMENT WINFRITH. ESTIMATED UNCERTAINTIES OF $0.75 \%$ AT THE ONE STANDARD DEVIATION LEVEL

(6) ISOTOPE DILUTION MASS SPECTROMETRY ANALYSIS BY ATOMIC ENERGY ESTABLISHMENT WINFRITH. ESTIMATED UNCERTAINTIES OF $0.5 \%$ AT THE ONE STANDARD DEVIATION LEVEL

(f) THERMAL IONIZATION MASS SPECTROMETAY ANALYSIS BY BRITISH NUCLEAR FUELS LTD - SELLAFIELD. ESTIMATED UNCERTAINTIES OF 0.5\% AT THE ONE STANDARD DEVIATION LEVEL

(g) AVERAGE OF DENSITY MEASUREMENTS BY AEEW AND BNFL LABORATORIES 


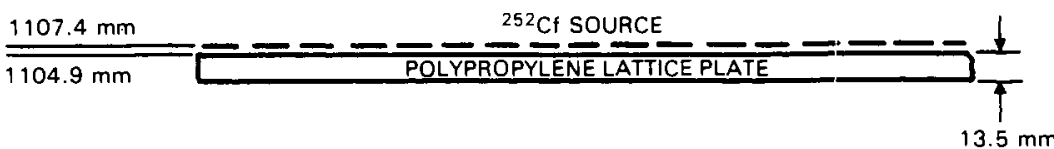

$84 \mathrm{~B} .49 \mathrm{~mm}$ - - BOTTOM OF $6.35 \mathrm{~mm}$ THICK TYPE 6061 Al SPACERS

$701.68 \mathrm{~mm}$ BOTTOM OF REACTION RATE PACKETS
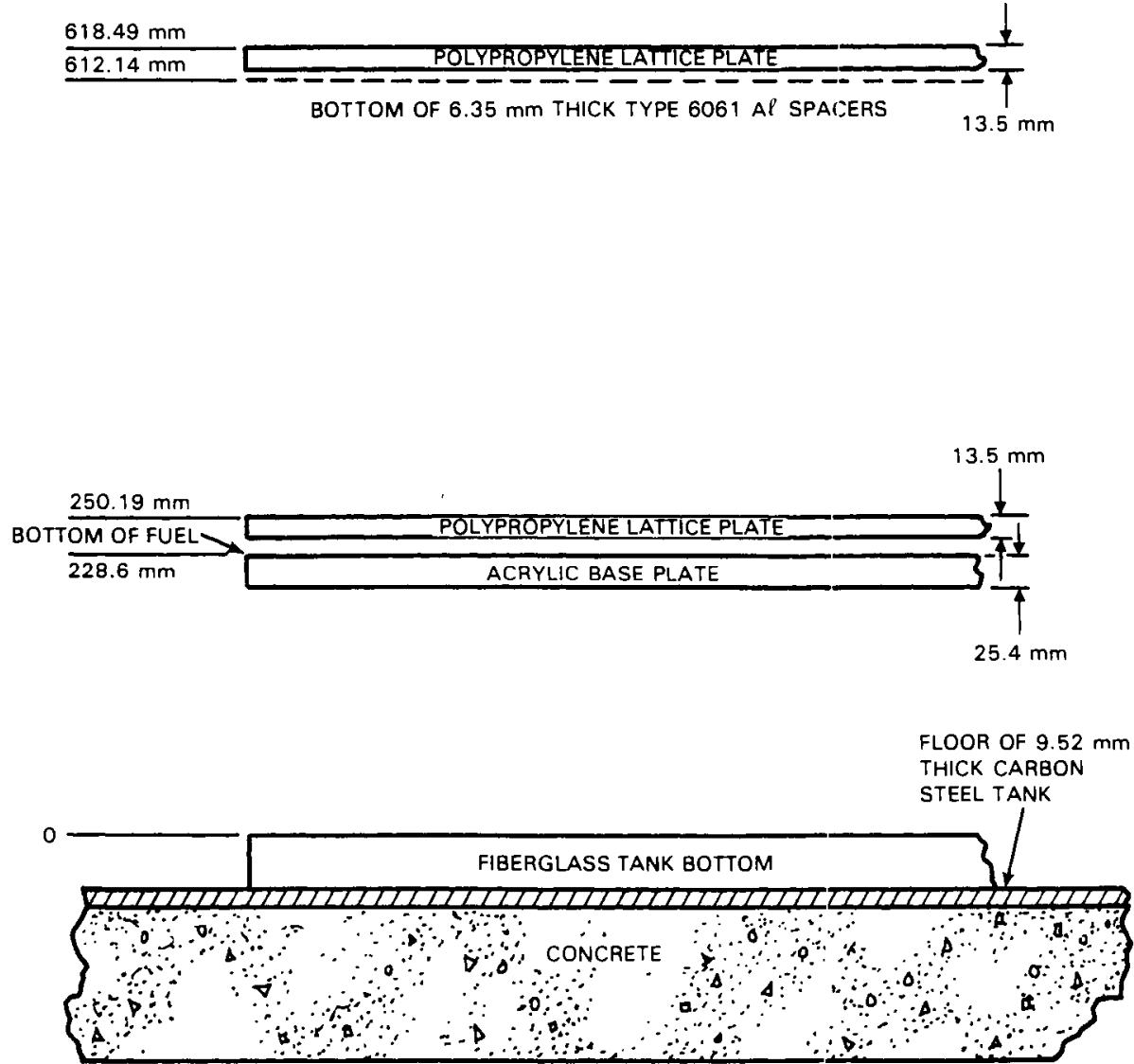

Figure 2.7 Experimental Assembly Elevations 
neutron moderating properties similar to water and a density range of 0.902 $\mathrm{g} / \mathrm{cm}^{3}$ to $0.906 \mathrm{~g} / \mathrm{cm}^{3}$. The density of a sample taken at random from the polypropylene during fabrication of the lattice plates was determined, by volume displacement, to be $0.905 \mathrm{~g} / \mathrm{cm}^{3}$. Trace impurities present in the polypropylene are given in Appendix D. All of the experiments were performed with the fuel rods in a uniform triangular pattern and supported on a $2.54 \mathrm{~cm}$ thick acrylic plate $\left(1.185 \mathrm{~g} / \mathrm{cm}^{3}\right.$ containing $8 \mathrm{wt} \% \mathrm{H}, 60 \mathrm{wt} \% \mathrm{C}$ and $32 \mathrm{wt} \% 0$ ) mounted off the sides of the figerglass tank.

As stated previously, each experimental assembly was provided with a control rod and a safety rod. The rods were identical. Each rod consisted of three $0.48 \mathrm{~cm}$ diameter gadolinium metal rods banded together and mounted on the respective drive systems to move vertically into and out of the fuel region of the experimental assemblies. These rods and their associated Type 6061 aluminum sleeves were located near the center of each assembly as shown in the respective loading diagrams (see Appendix F). The control and safety rods are not defined since all of the criticality and subcriticality data reported herein are with these rods fully withdrawn from the experimental assemblies. ASTM specifications for the aluminum sleeves are given in Appendix A. The aluminum sleeves extended from the arcylic base plate shown in Figure 2.7 to above the top reflector level. The sleeves had a $1.283 \pm$ $0.003 \mathrm{~cm}$ inside diameter and a wall thickness of $0.066 \mathrm{~cm}$. A typical positioning of the control and safety rods is shown in Figure 2.3. A photograph showing the rod guide sleeves and a set of lattice plates assembled outside the experimental assembly is shown in Figure 2.8. Relative elevations present in each experimental assembly are given in Figure 2.7. 


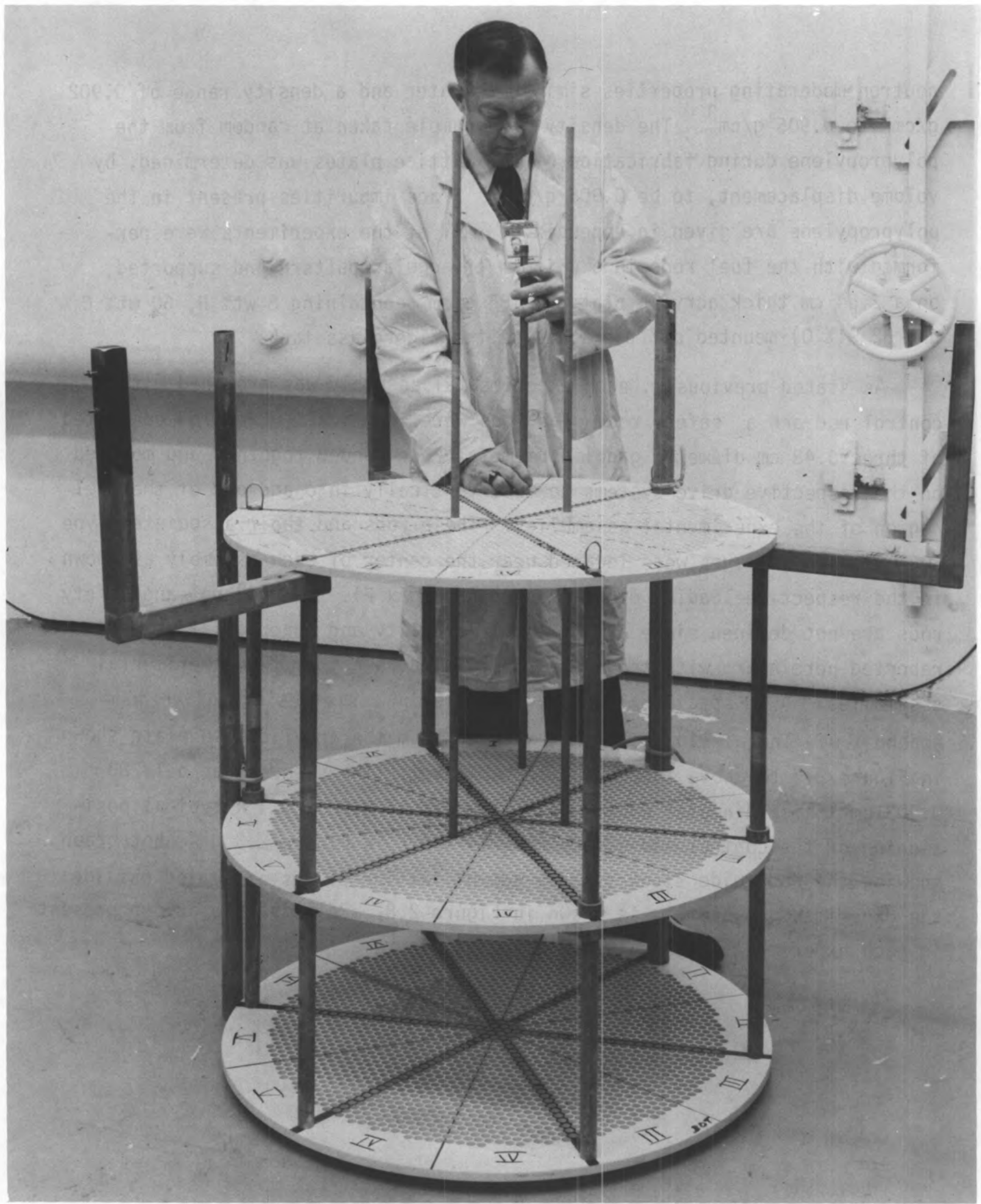

Figure 2.8. An Assembled Set of Lattice Plates Outside the Experimental Tank 


\subsection{EXPERIMENTAL RESULTS}

The measurement techniques used to obtain the data discussed previously in the section on experiments are presented and discussed in this section along with the measurement results. The factors affecting the accuracy of the measurement results and sources of error are also covered in this section.

\subsection{CRITICALITY EXPERIMENTS}

To measure the effect of gadolinium concentration on the critical size of an assembly of fuel rods in water, the critical size was first determined for the condition of no gadolinium in the water. Gadolinium in the form of gadolinium nitrate was then dissolved into the water to achieve a critical assembly having a fuel region radius approximating that of the THORP fuel dissolver basket (about $30-33 \mathrm{~cm}$ ). These two measurement determinations were made for each of the three fuel-water lattices as indicated in Table 2.1.

The objective of these measurements was to obtain data on fuel rods fully submerged in and reflected on all sides by water or water containing dissolved gadolinium. Direct experimental data was desired on fuel-water assemblies containing only perturbations that could be precisely and easily defined, or experimentally evaluated in terms of their effect on the critical size of the assembly. Consequently the experiments were performed with the assembl ies constructed such that only the perturbation caused by the polypropylene lattice plates exist in the final experimental data. Although experimental assemblies were taken critical by partially withdrawing the control rod, the critical size of all the experimental assemblies covered herein were obtained by extrapolation of subcritical data with the rod fully withdrawn, as discussed in the section that follows. 


\subsubsection{Measurement Technique}

In an approach-to.critical measurement to determine the critical conditions for a system, neutron multiplication measurements are made as the parameter of interest is varied such that the system "approaches" criticality. By extrapolating subcritical data very near critical, a precise definition of the critical conditions for that system can be obtained with the parameter of interest being the only perturbing variable. In each of the experiments covered by this report fuel was loaded into the lattice plates in increments that were neutronically symmetrical to each other. At each incremental loading, neutron count rates were obtained using the three boron 1 ined proportional detectors identified as data channels in Figure 2.3.

Although these data channel detectors shown in Figure 2.3 are located to minimize spatial effects in the count rate data, far subcritical loadings will exhibit spatial dependencies between detector-fuel loading locations and result in different critical sizes being predicted by the count rate data from the three data channels. As the delayed critical condition is approached, however, the neutron flux becomes relatively large and the fuel loading increments, for safety reasons become smaller. Under these conditons spatial effects become negligible and the count rates from all three data channels tend to predict the same number of fuel rods for delayed critical. Near this delayed critical conditon the neutron count rate data will begin to vary linearly and a linear least squares fit of count rate data as a function of subcritical fuel loading can be made to obtain a very accurate determination of the delayed critical condition.

A plot of the approach-to-critical data for experiment 4.3-000-182 is shown in Figure 3.1 as an illustration of the measurements typically performed to determine the critical size for each of the experimental assemblies. A plot of the relative inverse neutron count rate observed by the three data channels for each of the assembly subcritical loadings is shown in Figure 3.1 (for clarity the initial data point at a fuel loading of 59 rods is not shown and some of data. points for channel 3 have been deleted). At the delayed critical condition the neutron count rate approaches infinity. 


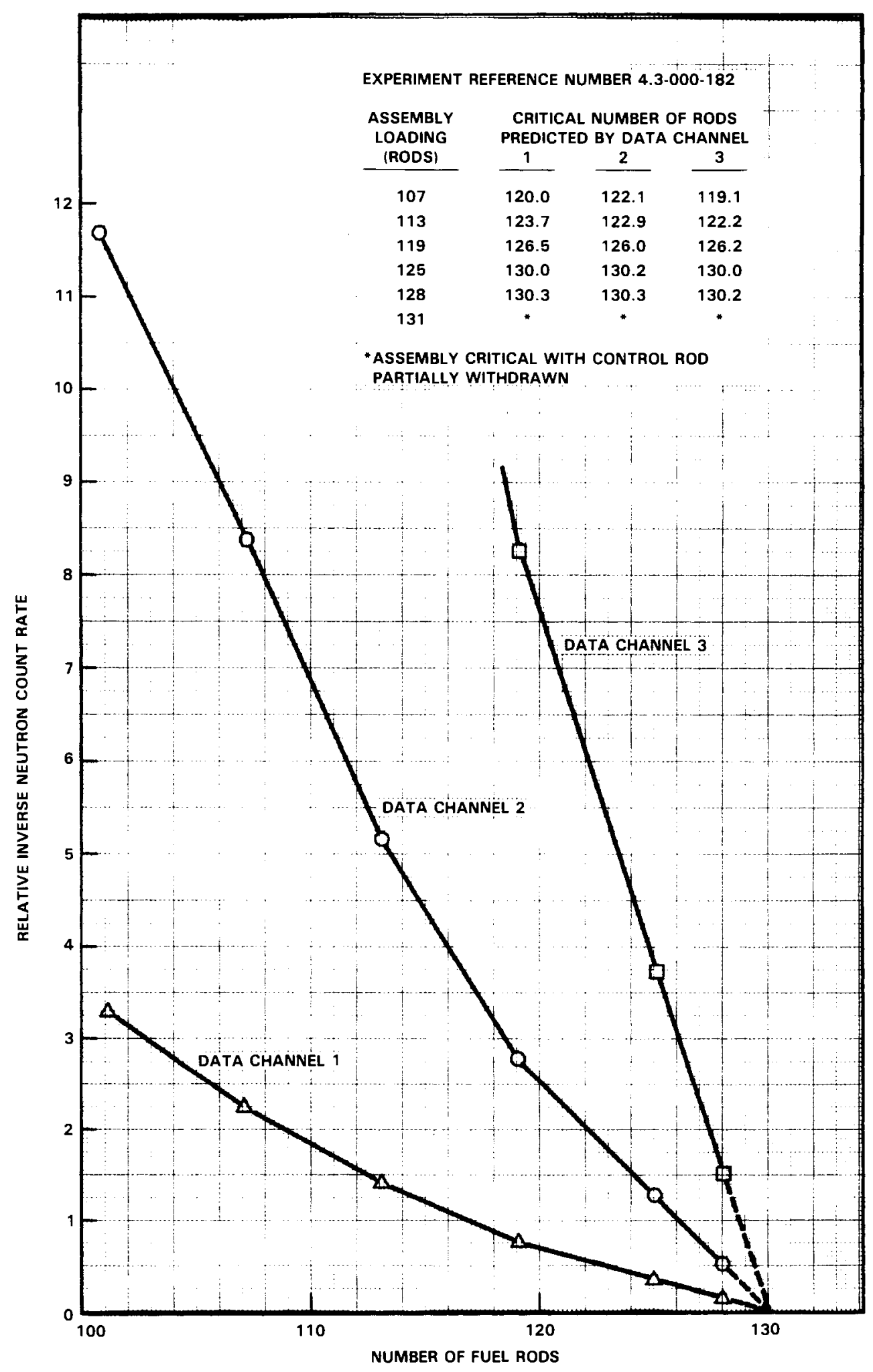

Figure 3.1 Typical Approach-to-Critical Plot 
Consequently the number of fuel rods required for criticality can be predicted by extrapolating to an inverse count rate of zero. The critical number of fuel rods predicted by the data channels at each fuel loading is tabulated in Figure 3.1 for assembly 4.3-000-182 with the control and safety rods fully withdrawn. Note that in these triangular pitched assemblies the minimum number of rods that can be added symmetrically is three and that such an addition to 131 fuel rods in assembly 4.3-000-182 results, as would be expected from the subcritical predictions, in criticality with the control rod only partially withdrawn.

\subsubsection{Criticality Experiments and Data}

As indicated in Table 2.1, criticality experiments were performed with basically three types of fuel-water lattices. One of these consisted of $4.31 \mathrm{wt} \%{ }^{235} \mathrm{U}$ enriched $\mathrm{UO}_{2}$ fuel rods (see Figure 2.5 for rod description) arranged in a triangular pattern, in water, on center-to-center spacings of $2.398 \pm 0.005 \mathrm{~cm}, 1.801 \pm 0.005$ and $1.598 \pm 0.005$. (See Appendix $E$ for measurement of lattice spacings). These spacings (lattice pitches) result in water-to-fuel volume ratios of $2.726 \pm 0.028,0.973 \pm 0.026$ and $0.509 \pm 0.019$ respectively.

The experiments were performed at the $2.398 \mathrm{~cm}$ spacing to obtain data with the $4.31 \mathrm{wt} \%{ }^{235} \mathrm{U}$ enriched fuel near optinum neutron moderation with no dissolved gadolinium in the water, and to determine the amount of dissolved gadolinium required to prevent criticality in such a fuel-water assembly approximately $30 \mathrm{~cm}$ in radius. Experiments were performed with fuel at the $1.801 \mathrm{~cm}$ spacing to obtain similar data in the intermediate region of neutron moderation (undermoderated) with no dissolved gadolinium in the water and at near optimum neutron moderation with sufficient gadolinium dissolved in the water to achieve criticality with an assembly approximately $30 \mathrm{~cm}$ in radius. The $1.598 \mathrm{~cm}$ lattice spacing was chosen to obtain data on this fuel at a neutron moderation as near as feasible to that of a tight packed assembly ( 0.91 fuel volume to total volume), fully sumberged and reflected on all sides with water. Although not originally planned, a sufficient amount of the $4.31 \mathrm{wt} \%{ }^{235} \mathrm{U}$ enriched fuel was available to construct an over-sized assembly (over $30 \mathrm{~cm}$ in radius) 
of this fuel in water containing dissolved gadolinium.

The second series of fuel-water lattices consisted of $2.35 \mathrm{wt} \%{ }^{235} \mathrm{U}$ enriched $\mathrm{UO}_{2}$ fuel rods (see Figure 2.4 for rod description) similarly arranged in a triangular pattern on center-to-center spacings of $1.895 \pm$ $0.005 \mathrm{~cm}$ and $1.598 \pm 0.005 \mathrm{~cm}$ resulting in water-to-fuel volume ratios of $1.853 \pm 0.038$ and $0.954 \pm 0.025$ respectively. Several experiments covering a wide range of neutron moderation had been previously performed (Smith and Konzek 1976, Bierman and Clayton 1981, Bierman, Durst and Clayton 1979) with this fuel in water only. Consequently the two lattice spacings of about $1.9 \mathrm{~cm}$ and $1.6 \mathrm{~cm}$ were chosen primarily to obtain data of interest on fuel-water assemblies containing dissolved gadolinium. As with the $4.31 \mathrm{wt} \%$ fuel, the $1.598 \mathrm{~cm}$ lattice spacing results in a neutron moderation as near to that of that packed fuel as is feasible in the experimental assembly. The $1.895 \mathrm{~cm}$ lattice spacing was chosen to obtain an approximately $30 \mathrm{~cm}$ radius critical assembly in water containing dissolved gadolinium. Also this spacing provides near optimum neutron moderation.

The third series of fuel-water lattices consisted of a mixture of the $4.31 \mathrm{wt} \%{ }^{235} \mathrm{U}$ enriched $\mathrm{UO}_{2}$ rods and $\mathrm{PuO}_{2}-\mathrm{UO}_{2}$ fuel rods containing $2.0 \mathrm{wt} \% \mathrm{PuO}_{2}$ and $98.0 \mathrm{wt} \%$ natural $\mathrm{UO}_{2}$. These lattices of mixed fuel were performed at the close-pack triangular center-to-center spacing of $1.598 \pm 0.005 \mathrm{~cm}$ with the $\mathrm{PuO}_{2}-\mathrm{UO}_{2}$ fuel rods uniformly distributed throughout the assembly to obtain a $\mathrm{Pu} /{ }^{235} \mathrm{U}$ ratio approximating that characteristic of 20,000 MWD/Te fuel burn-up. Two region assemblies of the $\mathrm{UO}_{2}$ and $\mathrm{PuO}_{2}-\mathrm{UO}_{2}$ fuel rods were also constructed at this lattice spacing to obtain data on large assemblies (35-40 cm radius) with high gadol inium concentrations ( $\sim 2.5 \mathrm{~g} \mathrm{Gd} / 2)$.

The experimental criticality data obtained on the three fuel-water lattice types are presented in Table 3.1, except for the easily defined lattice plates and base support plate, experimentally determined corrections were applied to the actual experimental data to obtain the critical sizes reported in Table 3.1 (except for the 2.35-000-172 data which was obtained in connection with the subcritical measurements). Replacement type experimental measurements were performed to determine in terms of fuel rods, the reactivity worth of: 


\section{TABLE 3.1 Experimental Resuits - Critical Lattices of Fuel Rods in a Uniform Pattern}

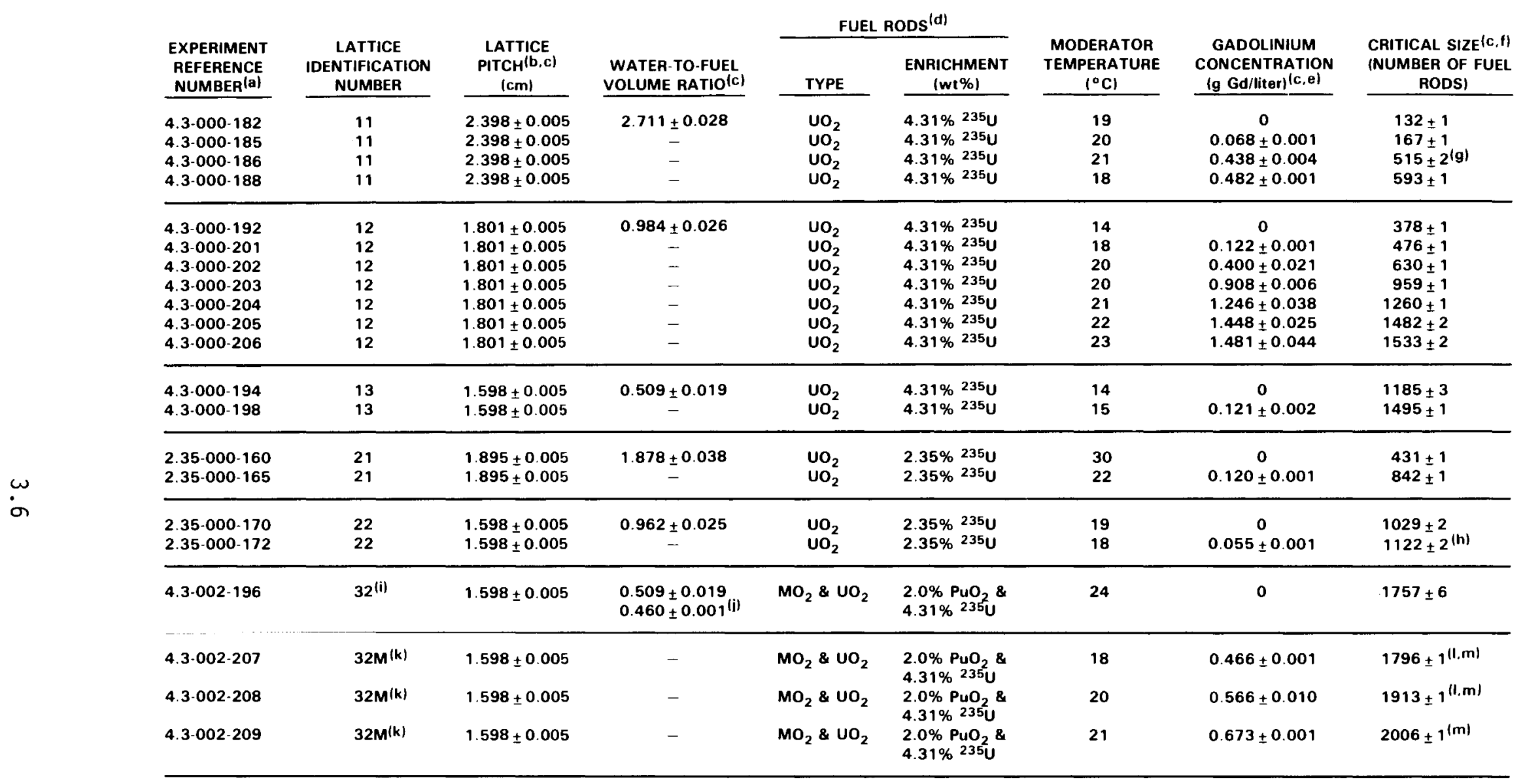

(a) SUPPORTING AND RELATED SETS OF MEASUREMENT DATA SIMILARLY IDENTIFIED ALPHA-NUMERICALLY

(b) CENTER-TO-CENTER SPACING BETWEEN FUEL RODS IN A TRIANGULAR PATTERN

(c) FRROR LIMITS ARE ONE STANDARD DEVIATION ESTIMATES. EPROR LIMITS ON CRITICAL SIZE ARE INTENDED TO INCLUDE THOSE ASSOCIATED WITH REPRODUCIBILITY

(d) FUEL RODS ARE FULLY DESCRIBED ELSEWHERE

(e) AVERAGE OF MASS SPECTROMETRY ANALYSES

(f) MEASURED CORRECTIONS APPLIED TO EXPERIMENTAL ASSEMBLIES TO OBTAIN LATTICES OF RODS IN WATER ONLY

(g) CORRECTED CRITICAL SIZE USING CORRECTIONS OBTAINED IN EXPERIMENT 4.3-000-188

(h) UNCORRECTED EXPERIMENTAL RESULTS. SEE TABLE IV.

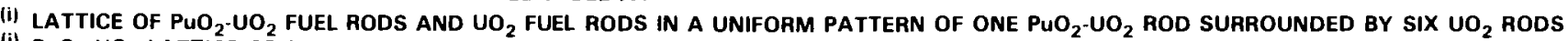

(j) $\mathrm{PuO}_{2}-\mathrm{UO}_{2}$ LATTICE CELL WATER-TO-FUEL VOLUME RATIO

(k) LATTICE OF $1657 \mathrm{UO}_{2}$ RODS SURROUNDED BY PuO $\mathrm{PO}_{2}-\mathrm{OO}_{2}$ RODS

(i) CORAECTED CRITICAL SIZE USING CORRECTIONS OBTAINED IN EXPERIMENT 4.3-002-209

(m) ERROR LIMITS APPLY TO $\mathrm{PUO}_{2}-\mathrm{UO}_{2}$ FUEL RODS ONLY (SEE NOTE j) 
- The aluminum clad water columns created in each assembly by the full withdrawal of the safety and control rods,

- the neutron source and source holder,

- the aluminum spacers used to achieve a higher degree of accuracy in positioning the reaction rate devices.

Of the above identified perturbations, only the water columns created by the withdrawal of the control and safety rod had a measurable effect on the critical size of the experimental assemblies. The reactivity worth of these water columns was determined to vary linearly over the range of interest (zero to three water columns) by varying the number of water columns present in an assembly and observing the changes in critical size as indicated in Figure 3.2.

As can be seen in Figure 3.2, the reactivity worth of the water columns is a linear function of the number of columns present over a sufficient range to permit linearly extrapolating to the critical assembly size with no water columns present. Also note in Figure 3.2 that to demonstrate this linearity between the critical size and number of water columns present, the assembly's safety rod was replaced in one measurement with a fuel rod leaving only the water column created by withdrawal of the control rod. Once linearity was demonstrated, however, the reactivity worth of the water col ums caused by the control and safety rods being fully withdrawn was determined by increasing the number of colums from two to three and linearly extrapolating to zero as indicated in Figure 3.3. The experimental data for these extrapolations are presented in Table 3.2 for each experiment identified in Table 3.1. Fuel loading diagrams are presented in Appendix $F$ for each experimental assembly identified in Tables 3.1 and 3.2 .

As indicated in Table 3.1, each of the experimental measurements have been identified by an "experiment reference number" and a "lattice identification number." Measurements performed in support of, or in conjunction with, other experiments are identified by the same number with an alpha 


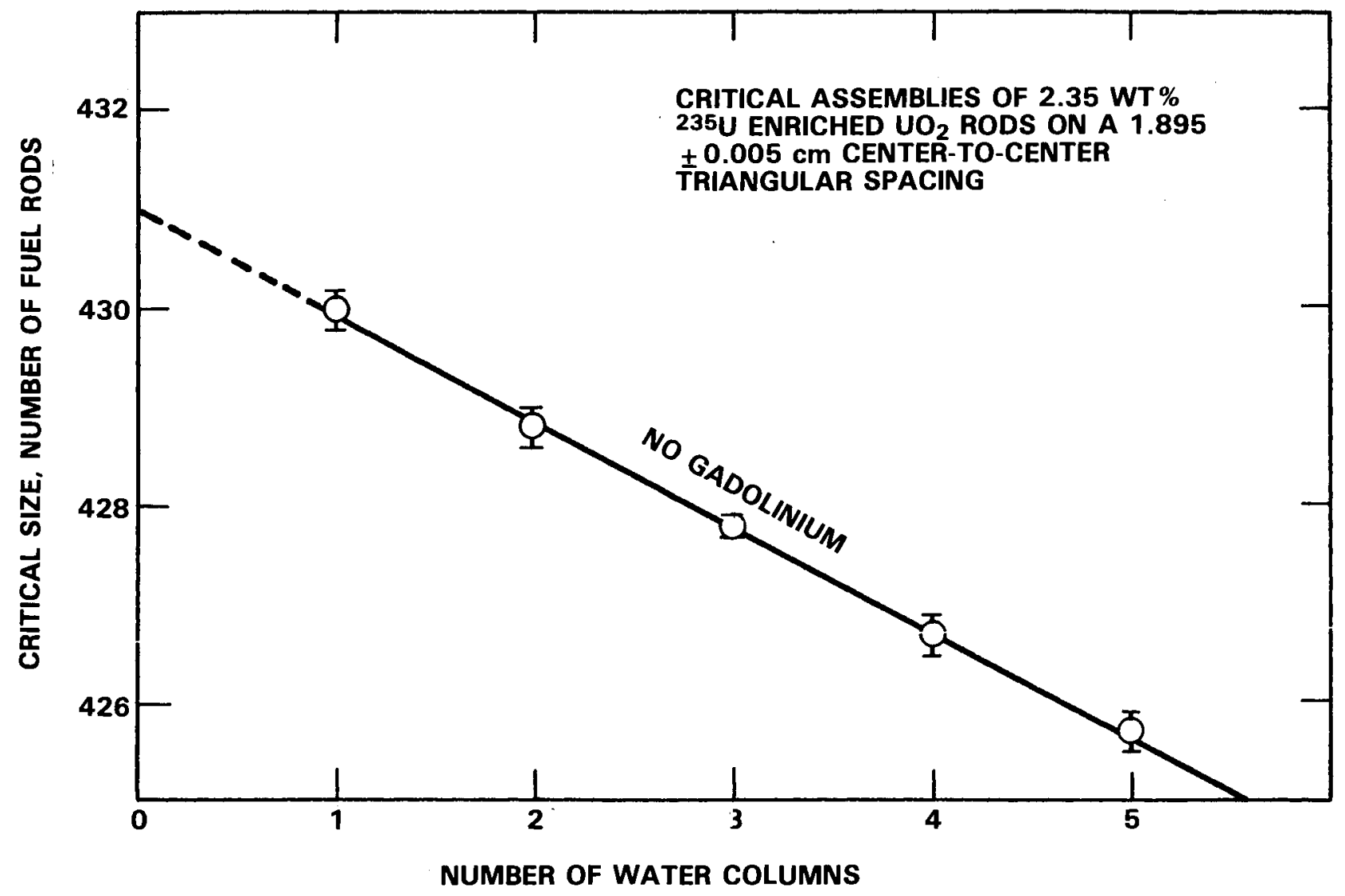

Figure 3.2 Measurement Data Showing Linearity and Effect of Aluminum Clad Water Columns in the Experimental Assembly 


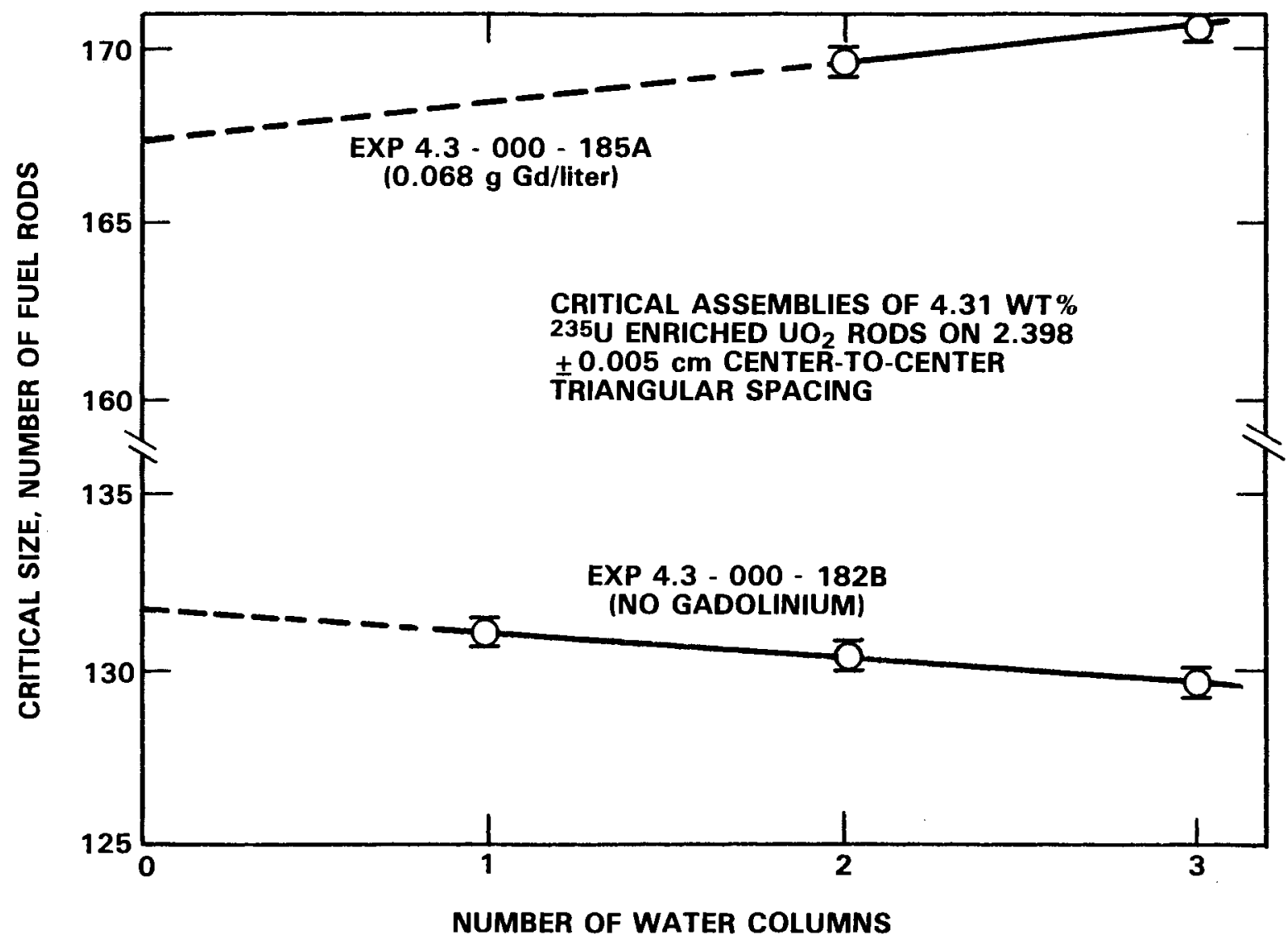

Figure 3.3 Typical Measurement Data Obtained in Evaluating the Reactivity of Aluminum clad Water Columns Created by Withdrawal of the Safety and Control Rods 


\section{TABLE 3.2 Experimental Results - Critical Lattices of Fuel Rods with Irregular Features}

\begin{tabular}{|c|c|c|c|c|c|c|c|c|}
\hline \multirow[b]{2}{*}{$\begin{array}{l}\text { EXPERIMENT } \\
\text { REFERENCE } \\
\text { NUMBER(a) } \\
\end{array}$} & \multirow[b]{2}{*}{$\begin{array}{l}\text { LATIICE } \\
\text { IDENTIFICATION } \\
\text { NUMBER } \\
\end{array}$} & \multirow[b]{2}{*}{$\begin{array}{c}\text { LATTICE } \\
\text { PITCH(b,c) } \\
\text { (cm) } \\
\end{array}$} & \multirow[b]{2}{*}{$\begin{array}{l}\text { WATER-TO.FUEL } \\
\text { VOLUME RATIO(C) } \\
\end{array}$} & \multicolumn{2}{|c|}{ FUEL RODS $(\theta)$} & \multirow[b]{2}{*}{$\begin{array}{l}\text { GADOLINIUM } \\
\text { CONCENTRATION } \\
\text { (g Gd/liter) } \mid \mathrm{c}, \mathrm{d}) \\
\end{array}$} & \multirow[b]{2}{*}{$\begin{array}{l}\text { CAITICAL SIZE[(f) } \\
\text { (NUMBER OF } \\
\text { FUEL RODS) } \\
\end{array}$} & \multirow[b]{2}{*}{ IRREGULARITY } \\
\hline & & & & TYPE & $\begin{array}{l}\text { ENRICHMENT } \\
\text { (wt\%) } \\
\end{array}$ & & & \\
\hline 4.3.000-182A & 11 & $2.398 \pm 0.005$ & $2.711 \pm 0.028$ & $\mathrm{NO}_{2}$ & $4.31 \% 235 \mathrm{U}$ & 0 & $130.3 \pm 0.9$ & TWO WATER FILLED AI SLEEVES \\
\hline $4.3 \cdot 000 \cdot 1828$ & 11 & $2.398 \pm 0.005$ & $2.711 \pm 0.028$ & $\mathrm{UO}_{2}$ & $4.31 \% 235 \mathrm{U}$ & 0 & $129.8 \pm 0.1$ & THREE WATER FILLED AI SLEEVES \\
\hline $4.3-000 \cdot 182 \mathrm{C}$ & 11 & $2.398 \pm 0.005$ & $2.711 \pm 0.028$ & $\mathrm{uO}_{2}$ & $4.31 \%{ }^{235 u}$ & 0 & $131.1 \pm 0.1$ & ONE WATER FILLED AI SLEEVE \\
\hline $4.3 \cdot 000 \cdot 185 A$ & 11 & $2.398 \pm 0.005$ & - & $\mathrm{UO}_{2}^{2}$ & $4.31 \% 235 \mathrm{U}$ & $0.068 \pm 0.001$ & $169.6 \pm 0.1$ & TWO WATER FILLED AI SLEEVES \\
\hline $4.3 \cdot 000-185 B$ & 11 & $2.398 \pm 0.005$ & - & $\mathrm{UO}_{2}^{*}$ & $4.31 \% 235 \mathrm{U}$ & $0.068 \pm 0.001$ & $170.7 \pm 0.1$ & THREE WATER FILLED AI SLEEVES \\
\hline 4.3.000.186A & 11 & $2.398 \pm 0.005$ & - & $\mathrm{UO}_{2}$ & $4.31 \% 235 \mathrm{U}$ & $0.438 \pm 0.004$ & $536.4 \pm 0.2$ & TWO WATER FILLED AI SLEEVES \\
\hline $4.3-000 \cdot 188 A$ & 11 & $2.398 \pm 0.005$ & - & $\mathrm{UO}_{2}^{2}$ & $4.31 \% 235 u$ & $0.482 \pm 0.001$ & $614.6 \pm 0.1$ & TWO WATER FILLED AI SLEEVES \\
\hline $4.3 \cdot 000-1888$ & 11 & $2.398 \pm 0.005$ & - & $\mathrm{NO}_{2}$ & $4.31 \%{ }^{235} \mathrm{U}$ & $0.482 \pm 0.001$ & $625.4 \pm 0.1$ & THREE WATER FILLED AI SLEEVES \\
\hline $4.3-000 \cdot 192 A$ & 12 & $1.801 \pm 0.005$ & $0.984 \pm 0.026$ & $\mathrm{uO}_{2}$ & $4.31 \% 235 \mathrm{U}$ & 0 & $369.9 \pm 0.1$ & TWO WATER FILLED AI SLEEVES \\
\hline $4.3-000 \cdot 1928$ & 12 & $1.801 \pm 0.005$ & $0.984 \pm 0.026$ & $\mathrm{UO}_{2}$ & $4.31 \% 235 \mathrm{U}$ & 0 & $365.8 \pm 0.2$ & THREE WATER FILLED AI SLEEVES \\
\hline 4.3-000-192C & 12 & $1.801 \pm 0.005$ & $0.984 \pm 0.026$ & $\mathrm{UO}_{2}$ & $4.31 \% 235 \mathrm{U}$ & 0 & $344.7 \pm 0.4$ & $\begin{array}{l}\text { TWO WATER FILLED AI SLEEVES } \\
\text { PLUS A SEVEN ROD WATER HOLE }\end{array}$ \\
\hline 4.3-000-201A & 12 & $1.801 \pm 0.005$ & - & $\mathrm{UO}_{2}$ & $4.31 \% 235 \mathrm{U}$ & $0.122 \pm 0.00$ & $468.4 \pm 0.1$ & TWO WATER FILLED AI SLEEVES \\
\hline $4.3-000-2018$ & 12 & $1.801 \pm 0.005$ & - & $\mathrm{UO}_{2}$ & $4.31 \% 235 \mathrm{U}$ & $0.122 \pm 0.00$ & $464.5 \pm 0.1$ & THREE WATER FILLED AI SLEEVES \\
\hline 4.3.000-202A & 12 & $1.801 \pm 0.005$ & - & $\mathrm{NO}_{2}^{2}$ & $4.31 \% 235 \mathrm{U}$ & $0.400 \pm 0.02$ & $625.3 \pm 0.2$ & TWO WATER FILLED AI SLEEVES \\
\hline $4.3-000 \cdot 202 B$ & 12 & $1.801 \pm 0.005$ & - & $\mathrm{UO}_{2}$ & $4.31 \% 235 \mathrm{U}$ & $0.400 \pm 0.02$ & $622.9 \pm 0.1$ & THREE WATER FILLED AI SLEEVES \\
\hline 4.3.000.203A & 12 & $1.801 \pm 0.005$ & .- & $\mathrm{UO}_{2}$ & $4.31 \% 235 \mathrm{U}$ & $0.908 \pm 0.006$ & $965.4 \pm 0.2$ & TWO WATER FILLED AI SLEEVES \\
\hline $4.3-000-2038$ & 12 & $1.801 \div 0.005$ & - & $\mathrm{UO}_{2}$ & $4.31 \% 235 \mathrm{U}$ & $0.908 \pm 0.006$ & $968.4 \pm 0.4$ & THREE WATER FILLED AI SLEEVES \\
\hline 4.3.000.204A & 12 & $1.801 \pm 0.005$ & - & $\mathrm{UO}_{2}^{2}$ & $4.31 \% 235 \mathrm{U}$ & $9.246 \pm 0.038$ & $1269.9 \pm 0.2$ & TWO WATER FILLED AI SLEEVES \\
\hline 4.3.000-2048 & 12 & $1.801 \pm 0.005$ & - & $\mathrm{UO}_{2}$ & $4.37 \% 235 \mathrm{U}$ & $1.246 \pm 0.038$ & $1274.9 \pm 0.4$ & THREE WATER FILLED AI SLEEVES \\
\hline $4.3 \cdot 000 \cdot 205 A$ & 12 & $1.801 \pm 0.005$ & - & $\mathrm{UO}_{2}$ & $4.31 \% 235 \mathrm{U}$ & $1.448 \pm 0.025$ & $1493.9 \pm 0.7$ & TWO WATER FILLED AI SLEEVES \\
\hline $4.3 \cdot 000 \cdot 205 B$ & 12 & $1.801 \pm 0.005$ & - & $\mathrm{UO}_{2}^{2}$ & $4.37 \% 235 \mathrm{U}$ & $1.448 \pm 0.02 !$ & $1500.0 \pm 0.8$ & THREE WATER FILLED AI SLEEVES \\
\hline 4.3-000-206A & 12 & $1.801 \pm 0.005$ & - & $\mathrm{UO}_{2}$ & $4.37 \% 235 \mathrm{U}$ & $1.481 \pm 0.04 .4$ & $1548.5 \pm 0.9$ & TWO WATER FILLED AI SLEEVES \\
\hline $4.3-000.2068$ & 12 & $1.801 \pm 0.005$ & - & $\mathrm{UO}_{2}$ & $4.31 \% 235 \mathrm{U}$ & $1.481 \pm 0.044$ & $1555.4 \pm 0.9$ & THREE WATER FILLED AI SLEEVES \\
\hline 4.3-000-194A & 13 & $1.598 \pm 0.005$ & $0.509 \pm 0.019$ & $\mathrm{UO}_{2}$ & $4.31 \%{ }^{235} \mathrm{U}$ & 0 & $1147.3 \pm 0.3$ & TWO WATER FILLED AI SLEEVES \\
\hline $4.3-000 \cdot 1948$ & 13 & $1.598 \pm 0.005$ & $0.509 \pm 0.019$ & $\mathrm{NO}_{2}$ & $4.31 \% 235 \mathrm{U}$ & 0 & $1134.7 \pm 2.5$ & THREE WATER FHLLED AI SLEEVES \\
\hline $4.3-000-194 \mathrm{C}$ & 13 & $1.598 \pm 0.005$ & $0.509 \pm 0.019$ & $\mathrm{UO}_{2}^{2}$ & $4.31 \% 235 \mathrm{U}$ & 0 & $11160 \pm 1.2$ & FOUR WATER FILLED AI SLEEVES \\
\hline 4.3.000.198A & 13 & $1.598 \pm 0.005$ & - & $\mathrm{UO}_{2}^{2}$ & $4.37 \% 235 U$ & $0.121 \pm 0.002$ & $14658 \pm 0.3$ & TWO WATER FILLED AI SLEEVES \\
\hline 4.3-000-1988 & 13 & $1.598 \pm 0.005$ & - & $\mathrm{UO}_{2}$ & $4.31 \% 235 \mathrm{U}$ & $0.121 \pm 0.002$ & $1451.1 \pm 0.1$ & THAEE WATER FILLED AI SLEEVES \\
\hline $2.35-000 \cdot 159 A$ & 21 & $1.895 \pm 0.005$ & $1.878 \pm 0.038$ & $\mathrm{UO}_{2}$ & $2.35 \% 235 \mathrm{U}$ & 0 & $427.8 \pm 0.1$ & THREE WATER FILLED AI SLEEVES \\
\hline $2.35-000-159 B$ & 21 & $1.895 \pm 0.005$ & $1.878 \pm 0.038$ & $\mathrm{UO}_{2}^{2}$ & $2.35 \% 235 \mathrm{U}$ & 0 & $426.7 \pm 0.2$ & FOUR WATER FILLED AI SLEEVES \\
\hline $2.35-000-159 \mathrm{C}$ & 21 & $1.895 \pm 0.005$ & $1.878 \pm 0.038$ & $\mathrm{NO}_{2}$ & $2.35 \% 235 \mathrm{U}$ & 0 & $425.7 \pm 0.2$ & FIVE WATER FILLED Al SLEEVES \\
\hline $2.35 \cdot 000 \cdot 160 \mathrm{~A}$ & 21 & $1.895 \pm 0.005$ & $1.878 \pm 0.038$ & $\mathrm{UO}_{2}$ & $2.35 \%{ }^{235} U$ & 0 & $428.8 \pm 0.2$ & TWO WATER FILLED AI SLEEVES \\
\hline $2.35-000-1608$ & 21 & $1.895 \pm 0.005$ & $1.878 \pm 0.038$ & $\mathrm{UO}_{2}^{2}$ & $2.35 \% 235 \mathrm{U}$ & 0 & $430.0 \pm 0.2$ & ONE WATER FILLED AI SLEEVES \\
\hline $2.35 \cdot 000 \cdot 165 A$ & 21 & $1.895 \pm 0.005$ & - & $\mathrm{UO}_{2}^{2}$ & $2.35 \%{ }^{235} \mathrm{U}$ & $0.120 \pm 0.001$ & $841.5 \pm 0.3^{(9)}$ & TWO WATER FILLED AI SLEEVES \\
\hline $2.35-000-165 B$ & 21 & $1.895 \pm 0.005$ & - & $\mathrm{NO}_{2}$ & $2.35 \% 235 \mathrm{U}$ & $0.120 \pm 0.001$ & $840.6 \pm 0.2$ & THREE WATER FILLED AI SLEEVES \\
\hline $2.35-000 \cdot 165 \mathrm{C}$ & 21 & $1.895 \pm 0.005$ & - & $\mathrm{UO}_{2}$ & $2.35 \% 235 \mathrm{U}$ & $0.120 \pm 0.001$ & $842.7 \pm 0.2$ & FOUR WATER FILLED AI SLEEVES \\
\hline $2.35-000-170 A$ & 22 & $1.598 \pm 0.005$ & $0.962 \pm 0.025$ & $\mathrm{UO}_{2}$ & $2.35 \% 235 \mathrm{U}$ & 0 & $1024.7 \pm 0.9$ & TWO WATER FILLED AI SLEEVES \\
\hline $2.35-000-1708$ & 22 & $1.598 \pm 0.005$ & $0.962 \pm 0.025$ & $\mathrm{UO}_{2}^{2}$ & $2.35 \% 235 \mathrm{U}$ & 0 & $1022.7 \pm 0.9$ & THREE WATER FILLED AI SLEEVES \\
\hline $2.35 \cdot 000 \cdot 172$ & 22 & $1.598 \pm 0.005$ & 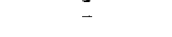 & $\mathrm{UO}_{2}$ & $2.35 \%{ }^{235} \mathrm{U}$ & $0.055 \pm 0.0019$ & $1122.2 \pm 1.0$ & TWO WATER FILLED AI SLEEVES \\
\hline 4. 3-002-196A & $32^{(h)}$ & $1.598 \pm 0.005$ & $\begin{array}{l}0.509 \pm 0.019 \\
0.460 \pm 0.001^{(i)}\end{array}$ & $\mathrm{MO}_{2} \& \mathrm{UO}_{2}$ & $\begin{array}{l}2.0 \% \mathrm{PuO}_{2} 8 \\
4.31 \% 235 \mathrm{U}\end{array}$ & o & $1700.8 \pm 1.2$ & $\begin{array}{l}\text { TWO WATER FHLLED AI SLEEVES AND } \\
\text { FOUR FOIL CLUSTERS IN ASSEMBLYY }\end{array}$ \\
\hline 4. 3-002-1968 & $32^{(h)}$ & $1.598 \pm 0.005$ & $\begin{array}{l}0.509 \pm 0.019 \\
0.460 \pm 0.001^{(i)}\end{array}$ & $\mathrm{MO}_{2} \& \mathrm{UO}_{2}$ & $\begin{array}{l}2.0 \% \mathrm{PuO}_{2} 8 \\
4.31 \% 235 \mathrm{U}\end{array}$ & 0 & $17076 \pm 18$ & $\begin{array}{l}\text { TWO WATER FILLED AI SLEEVES AND } \\
\text { THREE FOIL CLUSTERS IN ASSEMBLY }\end{array}$ \\
\hline 4.3-002-196C & $32^{(h)}$ & $1.598 \pm 0.005$ & $\begin{array}{l}0.509 \pm 0.019 \\
0.460 \pm 0.001^{(i)}\end{array}$ & $\mathrm{MO}_{2} \& \mathrm{UO}_{2}$ & $\begin{array}{l}2.0 \% \mathrm{PuO}_{2} \mathrm{\&} \\
4.31 \% 235 \mathrm{U}\end{array}$ & 0 & $1693.0 \pm 1.8$ & $\begin{array}{l}\text { THREE WATER FILLED AI SLEEVES AND } \\
\text { THREE FOIL CLUSTERS IN ASSEMBLY }\end{array}$ \\
\hline 4.3-002-207A & $32 M^{(j)}$ & $1.598 \pm 0.005$ & & $\mathrm{MO}_{2} \& \mathrm{UO}_{2}$ & $\begin{array}{l}2.0 \% \mathrm{PuO}_{2} 8 \\
4.31 \% 23 \mathrm{~V}^{2}\end{array}$ & $0.466 \pm 0.0<1$ & $1775.2 \pm 0.5$ & TWO WATER FILLED AI SLEEVES \\
\hline 4.3-002-208A & $32 M^{(j)}$ & $1.598 \pm 0.005$ & & $\mathrm{MO}_{2} \& \mathrm{UO}_{2}$ & $\begin{array}{l}2.0 \% \mathrm{PuO}_{2} 8 \\
4.31 \% 235 \mathrm{U}\end{array}$ & $0566 \pm 0.010$ & $1891.8 \pm 0.6$ & TWO WATER FILLED AI SLEEVES \\
\hline 4.3-002-209A & $32 M^{(j)}$ & $1.598 \pm 0.005$ & & $\mathrm{MO}_{2} \& \mathrm{UO}_{2}$ & $\begin{array}{l}2.0 \% \mathrm{PuO}_{2} \& \\
4.31 \% 235 \mathrm{U}\end{array}$ & $0.673 \div 0.001$ & $1985.1 \pm 0.6$ & TWO WATER FILLED AI SLEEVES \\
\hline 4.3-002-2098 & $32 M^{\{k\}}$ & $1.598 \pm 0.005$ & & $\mathrm{MO}_{2} \& \mathrm{UO}_{2}$ & $\begin{array}{l}2.0 \% \mathrm{PuO}_{2} \& \\
4.31 \% 235 \mathrm{U}\end{array}$ & $0.673=0.001$ & $1974.7 \pm 0.6$ & THREE WATER FILLED AI SLEEVES \\
\hline
\end{tabular}

(a) RELATED SETS OF MEASUREMENT DATA SIMILARLY IDENTIFIED

(b) CENTER-TO-CENTER SPACING BETWEEN FUEL RODS IN A TRIANGULAR PATTERN

(c) ERROR LIMITS ARE ONE STANDARD DEVIATION ESTIMATES

(d) AVERAGE OF MASS SPECTROMETRY ANALYSES

(8) FUEL RODS ARE FULLY DESCRIBED ELSEWHERE

(f) ERROR LIMITS ARE ONE STANDARD DEVIATION ON THE LEAST SQUARES FIT OF THE APPROACH TO CRITICAL DATA: HOWEVER. THE INDICATED ACCURACIES ARE RELATIVE ONLY BETWEEN THE PERTURBATIONS BEING EVALUATED

(9) BACK OFF WITH SOURCE REMOVED PREDICTS CRITICAL SIZE OF $841.8+0.5$ FUEL RODS

(h) LATTICE OF PUO $\mathrm{OO}_{2}$ FUEL RODS AND UO $\mathrm{FUEL}_{2}$ RODS IN A UNIFORM PATTERN OF ONE $\mathrm{PUO}_{2} \mathrm{UO}_{2}$ ROD SURROUNDED BY SIX UO 2 RODS

(i) PUO, UO ${ }_{2}$ LATTICE CELL WATER-TO.FUEL VOLUME RATIO

(i) LATTICE OF 1655 UO 2 RODS SURROUNDED $8 Y \mathrm{PUO}_{2} \cup \mathrm{O}_{2}$ RODS

(K) LATTICE OF $1654 \mathrm{UO}_{2}$ RODS SURROUNDED BY $\mathrm{PuO}_{2} \cdot \mathrm{UO}_{2}$ RODS 
notation. The experiment reference number refers to the experiment identification number assigned to the set of measurements and is tracable through the Critical Mass Laboratory operating records. The lattice identification number refers to the lattice type and degree of neutron moderation as described in Table 2.1. (For example, lattice 11 refers to the near-optimum moderated 1 attices of $4.31 \mathrm{wt} \%{ }^{235} \mathrm{U}$ enriched fuel and lattice 12 refers to the intermediate moderated lattices of this same fuel).

As stated previously, the objective of the criticality experiments was, in general, to determine the critical size of each assembly with no gadolinium dissolved in the water and the amount of dissolved gadolinium required to achieve a critical assembly of fuel having a radius of about $30 \mathrm{~cm}$ or larger. However, the performance of some experiments resulted in additional data that may be useful in validating or developing calculational models. These additional data are included in Table 3.1 and 3.2 and primarily involve:

- Critical sizes for some experimental assemblies over a range of gadol inium concentrations,

- critical sizes for experimental assemblies containing irregular fuel loadings and multiple sized "water holes" at various locations in the as semblies,

- variation in the reactivity worth of aluminum clad water columns in an assembly as a function of gadolinium concentration.

The additional data available on variation in critical size with gadolinium is graphically presented in Figure 3.4 to permit making visual comparisons more easily.

Although each set of exprimental data presented in Table 3.2 provides information for at least two gadolinium concentrations on the reactivity worth of water columns created in each assembly by the withdrawal of the safety and controls rods, the 200 series provide a set of data over a wide range of gadolinium concentrations for a single lattice spacing. The variation observed in the reactivity worth of a water column with gadolinium concentration in this series of experiments is plotted in Figure 3.5. As can be seen in Figure 3.5, the water column with no gadolinium dissolved in 


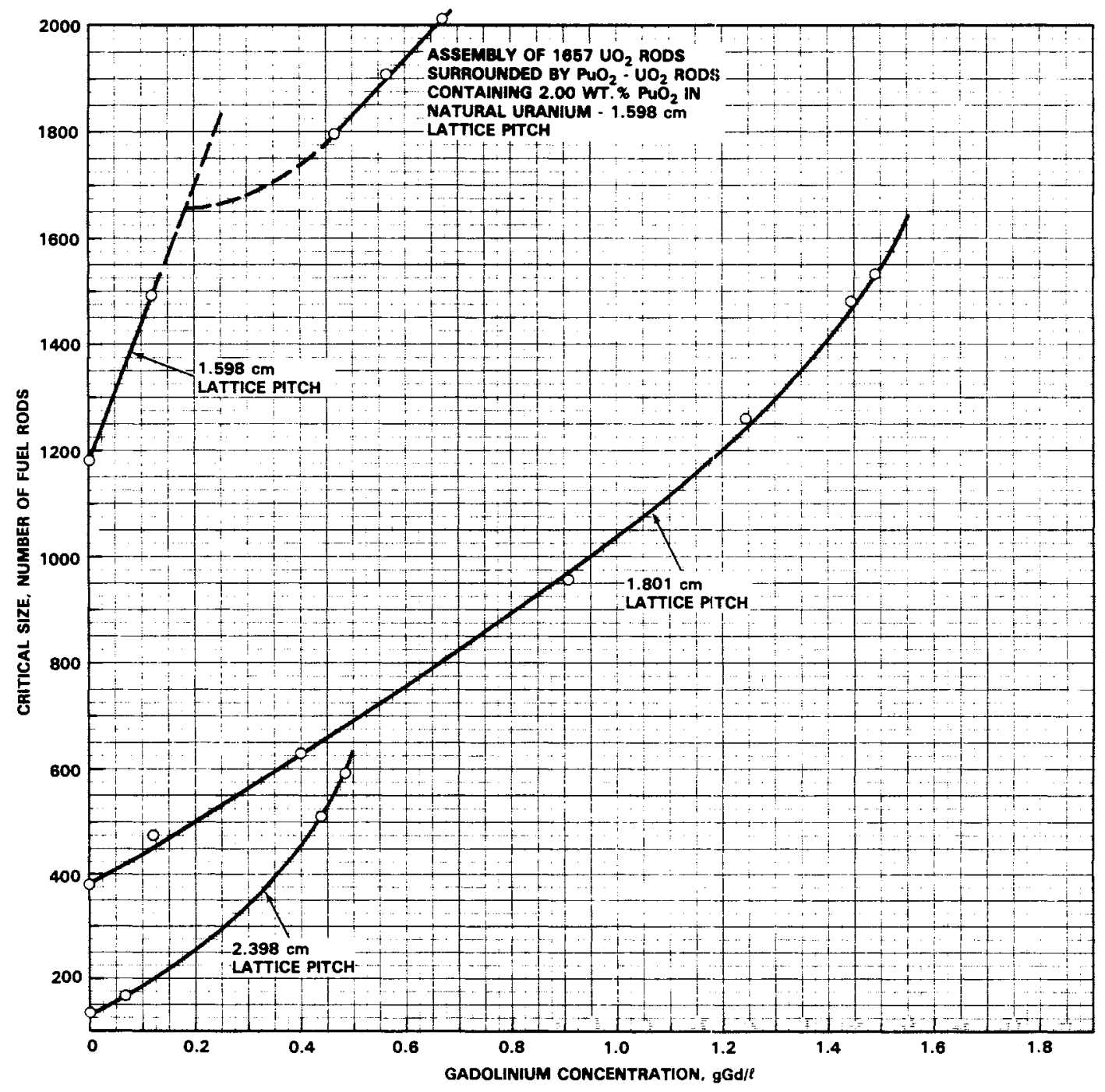

Figure 3.4 Critical Size of Lattices Using 4.31 wt\% $23.5 \mathrm{U}$ Enriched $\mathrm{UO}_{2}$ Fuel as a Function of Gadolinium Concentration 


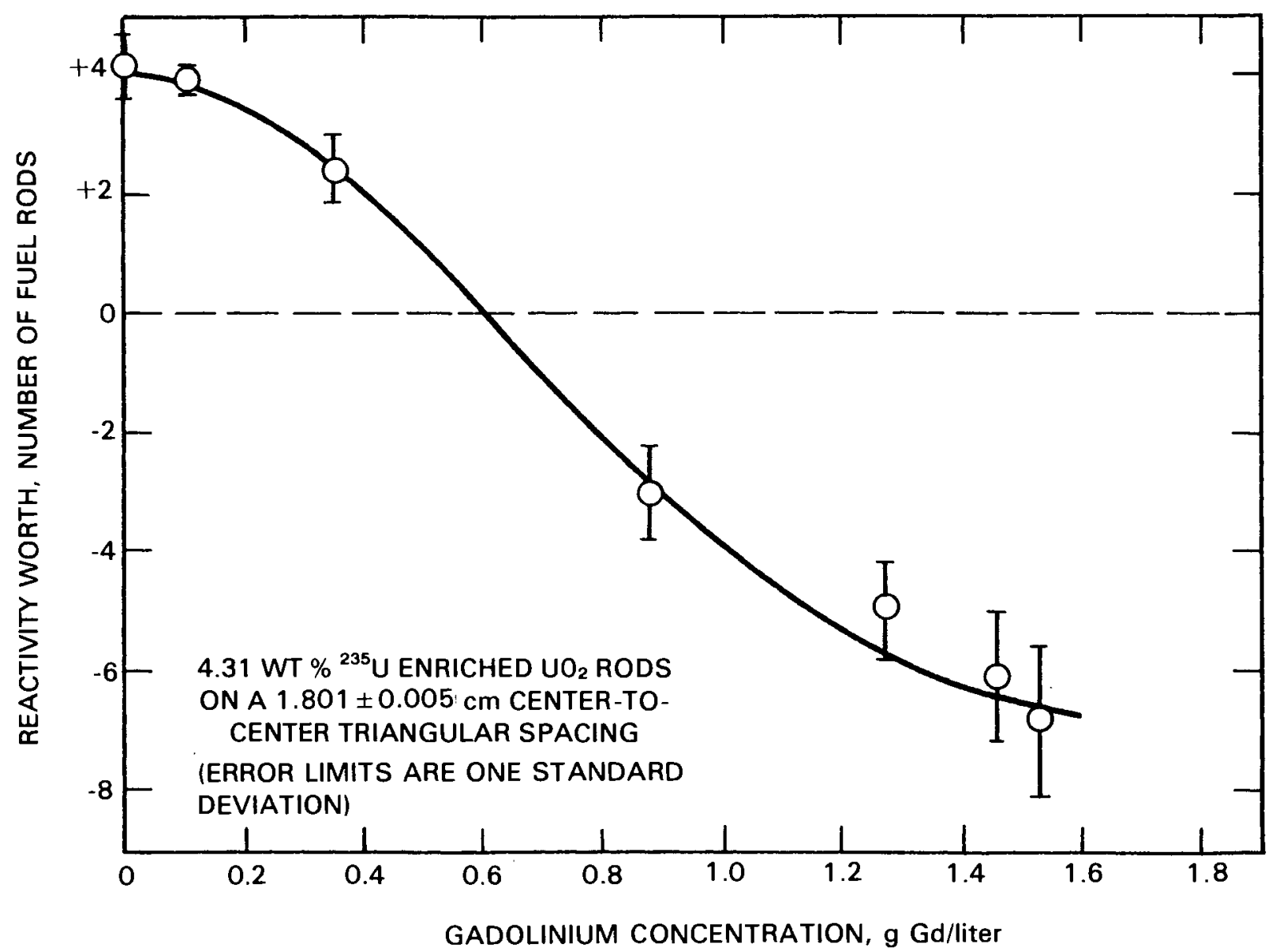

Figure 3.5 Effect of Gadol inium Concentrations on the Reactivity Worth of Aluminum Clad Water Columns Created by Withdrawal of the Safety and Control Rods 
the water has a reactivity worth equivalent to four fuel rods in terms of critical size (that is, the assembly with no water column would require an additional four rods to achieve criticality). As the amount of gadolinium dissolved in the water increases at this lattice spacing $(1.801 \mathrm{~cm}$ centerto-center triangular spacing), the worth of the water column decreases to a negative value approaching a limit of about seven rods. From the data plotted in Figure 3.5 it can be estimated that optimum neutron moderation for the $4.31 \mathrm{wt} \%{ }^{235} \mathrm{U}$ enriched $\mathrm{vO}_{2}$ fuel rods on a $1.801 \mathrm{~cm}$ triangular pitch occurs with about $0.6 \mathrm{~g} \mathrm{Gd} / \mathrm{l}$ dissolved in the water. At gadolinium concentrations below this value the experimental assembly is undermoderated.

Of primary concern in performing the experiments summarized in Tables 3.1 and 3.2 was the sensitivity of the measurement data to errors or variations in the two primary parameters - lattice spacing and gadolinium concentration. The center-to-center spacing between fuel rods was measured along two diameters of each lattice plate to obtain an average lattice spacing for each experimental assembly and to verify uniformity of spacing across each assembly. These measurements are presented in Appendix $E$ and resulted in lattice spacings quoted throughout this report with one standard deviation error limit. To assure that these stated spacings were not compromised by voiding due to air entrapped in the water and occluded in the fuel cladding, the final critical approach measurements on each assembly were not made until all voids had been removed and evidence obtained that gas evolution had ceased.

As discussed in Description of Experimental Assemblies, several analytical laboratories and methods were used to obtain values as good as could be reasonably achieved for the amount of gadolinium dissolved in the water of each experimental assembly. A discussion on the analytical methods and comparisons with prepared samples containing $0.25,0.5$ and $1.0 \mathrm{~g} \mathrm{Gd} / l$ is presented in Appendix $B$. The analytical results obtained by each method on samples taken from the experimental assemblies are given in Table 2.2. Although a great amount of effort was expended to obtain an adequate analyses of the amount of dissolved gadol inium in each gadolinium-water sample, a greater effort was made to assure the samples were representative of the respective experimental assembly. 
Precautions were taken to assure:

- uniform distribution of gadolinium throughout the experimental assembly,

- no gadol inium carry-over contamination between experimental assemblies,

- samples were representative.

The gadolinium concentration in an experimental assembly was adjusted by adding either water or a gadolinium-water solution. To dilute the gadolinium concentration, a predetermined amount of experimental solution was either transferred to one of the mix-storage tanks shown in Figure 2.2 or discharged to ground and fresh water was added to the experimental vessel as the experimental solution was being recirculated. To increase the gadolinium concentration in the experimental solution, a predetermined amount of concentrated solution of gadolinium-water was added to the experimental solution instead of fresh water. This concentrated solution was either pumped from one of the mix-storage tanks (solution used in previous experiments) or obtained by dissolving a predetermined amount of gadolinium nitrate in a 20 to 30 liter quantity of water taken from the experimental vessel.

To assure that a gadolinium concentration adjustment was uniformly distributed throughout the experimental assembly, the experimental solution was recirculated at least twice through the pump if there were no fuel in the system. If the experimental assembly was partial loaded with fuel rods following a concentration change, the experimental solution was transferred to an empty, previously cleaned, mix-storage tank and then recirculated back into the experimental vessel. This routine was required to assure that the solution in the fuel region of the assembly was of the same gadolinium concentration as that in the reflector region - particularly for the closer spaced lattices.

To prevent gadolinium carry-over contamination between experimental assemblies each fuel rod was individually subjected to a hot soapy water wash followed by two cold water wash-rinses and a drying cycle. Initially 
the lattice plates (lattice 21) and experimental vessel were subjected to a water wash and rinse only. However, reproducability measurements following the intial series of experiments involving gadolinium dissolved in the water (lattice 21) indicated a gadolinium retention in the experimental system of about 5 parts per million by weight. This carry-over was attributed to gadolinium retained on the lattice plates, support structures, detector thimbles, and the walls of the experimental vessel. Consequently, following a set of measurements involving gadolinium, the lattice plate assemby (typically shown in Figure 2.8) was removed from the experimental vessel, dismantled and subjected to the same wash, rinse and drying cycles as the fuel rods. The interior of the experimental vessel was also hand washed and rinsed following each series of measurements involving gadolinium.

Since it was necessary to completely remove and dismantle the experimental assemblies each time for hand washing to prevent gadolinium carry-over between experiments, the measurements were sequenced following those with lattices 11 and 21 such that a11 experiments without gadolinium were performed before those involving gadolinium. This procedure, al though time consuming, eliminated any concern associated with the possible carry-over of slight amounts of gadolinium between experiments.

To assure samples were representative of the experimental solution, vertical traverse samples were taken on either side of the experimental assemblies with one liter bottles. Approximately one milliliter of $13 \underline{M}$ nitric acid was added to each sample to minimize the possibilities of any gadolinium precipitation occurring during shipment to the various laboratories for analyses. The laboratory samples were taken from these one liter samples. An archival sample was retained. Except for the AEEW samples, all laboratory samples were shipped in polyethylene bottles. At the request of the AEEW laboratory, glass bottles were used for the samples analyzed by them.

It should be noted that about half way through the experimental program a white deposit was observed to be forming on top of some of the aluminum supports for the lattice plates. A DC Argon Plasma Emission Spectroscopy analyses of a deposit sample revealed the deposit to be about 
$60 \%$ gadolinium. To prevent this deposit formation, approximately $30 \mathrm{ml}$ of 13 M nitric acid was added to the gadolinium-water solutions. (This is probably the cause of the step increase reported in Appendix $C$ for the aluminum content of the water samples).

\subsection{SUBCRITICALITY EXPERIMENTS}

To measure the effect of gadolinium concentration on the reactivity of a critical assembly, incremental amounts of dissolved gadolinium nitrate were homogeneously added to the water, or water-gadolinium solution, of each critical assembly, as described in the previous section on Criticality Experiments. At each gadolinium concentration, pulse neutron source measurements were made to obtain $k_{\text {eff }}$ values ranging down to about 0.87 as a function of gadolinium concentration.

\subsubsection{Measurement Technique}

In the pulse neutron source measurements, a burst of neutrons is injected into a system in a fraction of a microscecond and its effect on the neutron population at some point in the system is observed as a function of time following the burst. In actual practice, the measurements are made by repetively injecting bursts of neutrons into the system and accumulating the observed time behavior following each burst. The repetition rate and number of neutron bursts required depends on the statistics of the accumulated data, which, in turn, is dependent on the particular system. A proportional counter or a $\mathrm{BF}_{3}$ tube is generally used for the detection of the neutrons, and a multi-channel analyzer is used as a series of sequentially gated scalers for the storage of the neutron counts as a function of time following each burst.

Since the pulse neutron source characteristically produces epi-thermal neutrons and since the neutron detector generally used is primarily sensitive to thermal neutrons, the count rate will reach a maximum and then begin to decrease exponentially as the epi-thermal neutrons slow down immediately following a neutron burst and become thermalized. Once an asymptotic distribution of neutrons is reached in the system, the count rate, as a function of time following the 
neutron burst, can be described as the sum of two exponential terms:

$$
n(t)=A_{1} e^{-\alpha_{1} t}+A_{2} e^{-\alpha_{2} t}
$$

One term describes the time behavior of the prompt neutrons and the other describes the time behavior of the delayed neutrons. Since the decay of the delayed neutrons is very slow compared to that of the prompt neutrons, Equation 1 is generally written as:

$$
n(t)=A_{1} e^{-\alpha} t+N_{D}
$$

where $N_{D}$ is a constant equal to the averaged delayed neutron contribution and

$$
A_{1} e^{-\alpha} t
$$

is the prompt neutron contribution decreasing exponentially with time at a rate $\alpha_{1}$.

After a period of time, the prompt neutron portion of the total population, that is due to the neutron burst, will approach the background level preceding the burst and only the delayed neutrons will remain. Since the prompt neutrons must al1 decay away before the delayed neutron contribution can be determined, the prompt neutron decay rate is a limiting factor in determining the pulse repetition rates and counting time intervals to be used. This rate of decay is dependent upon the system on which the measurements are being made. However, the faster the neutron spectrum is, the faster the decay rate will be. Also, the further subcritical a system is, the faster the decay rate will be. Therefore it is possible to obtain the same decay rate for two different degrees of subcriticality. It is this ambiguous feature of the prompt neutron decay which prevents it being used as a direct measurement of reactivity, although it is directly related to the reactivity of the given system. The rate of decay of the prompt neutrons can, however, be used to obtain an effective multiplication constant, keff, for the system by the following relationship: 


$$
\alpha_{1}=\frac{1-k_{e f f}\left(1-\beta_{e f f}\right)}{\ell},
$$

where $\alpha_{1}$ is the decay rate, $\beta_{\text {eff }}$ the effective delayed neutron fraction, and $\ell$ the neutron lifetime in the system. However, this requires a knowledge of $\ell$ and $\beta_{\text {eff }}$ and $\ell$ is as difficult to calculate as $k_{\text {eff }}$. However, Equation 3 and the definition for reactivity,

$$
\rho \equiv \frac{k-1}{k}
$$

can be combined to obtain an expression for the reactivity of a system in units of $\beta$ - i.e. dollars.

$$
\frac{\rho}{\beta}=-\frac{\alpha_{1}-k B / l}{k \beta / \ell},
$$

If the neutron generation time is assumed to be constant, Equation 5 can be reduced to:

$$
\frac{\rho}{\beta}=-\frac{\alpha_{1}{ }^{-\alpha}{ }_{c}}{\alpha_{c}}
$$

where $\alpha_{c}$ is the prompt neutron decay rate at delayed critical $(k=1)$. However, the generation time does vary significantly with the degree of subcriticality. Also, $\alpha_{c}$ is a parameter not generally available for plant systems.

Three methods have been developed whereby the reactivity of a system can be determined directly from the raw data. The earlist technique was suggested by Sjostrand (Sjostrand 1956) who simply separated the data into a prompt neutron component and a delayed neutron component, as implied by Equations 1 and 2, and then approximated the reactivity by taking the ratio of the area under the prompt neutron curve to the area under the delayed neutron curve,

$$
\left(\frac{\rho}{\beta}\right)_{S J}=-\frac{\text { Prompt Neutron Area }}{\text { Delayed Neutron Area }}
$$


Gozani (Gozani, et. al., 1965) improved on this by extrapolating the prompt neutron fundamental mode of decay back to time zero following the burst of neutrons, and taking the reactivity as:

$$
\left(\frac{\rho}{B}\right)_{G O}=-\frac{\text { Prompt Neutron Fundamenta }}{\text { Delayed Neutron Area Area }}
$$

Garel is and Russell (Garel is and Russell 1963) developed a more rigorous theoretical model and showed that the prompt neutron count rates multiplied by a factor involving the reactivity of the system must equal the total area under the pulsed neutron source curve between time zero and $1 / R$ following the burst of neutrons.

$$
\int_{0}^{l / R} A_{1} e^{-\alpha} t^{\frac{k B}{l} t} e^{l / R} d t=\int_{0}^{l / A_{1} e^{-\alpha} t} d t+\frac{N_{D}}{R}
$$

Where $A_{7} e^{-\alpha} t$ is the prompt neutron count rate at time $t$ following the burst, $N_{D}$ is the averaged delayed neutron count rate, and $R$ is the pulse repetition rate. All the information needed to solve Equation 9 for $k B / l$ is available in the data obtained from the pulse neutron source measurement. Consequently, all the data needed to solve Equation 5 for the reactivity of the system is provided by the pulse neutron source data in the Garel is -Russe11 model. No other information is needed about the system.

Both the Gozani and Garelis - Russell methods were used in analyzing each of the pulse neutron source measurements covered by this report. The two analytical techniques respond differently to spatial harmonic effects (Gozani, et. al., 1965) such that the true value of subcriticality is bracketed by these two methods. The average of the value determined by these two methods should be closer to the true value of the measurement data than either one. However, neither method rigorously eliminates all spatial dependence. Calculational corrections (see Becker and Quisewberry 1966) should be made to the data to account for, or evaluate, modal shape differences not considered by the Gozani or Garelis - Russell analyses. 


\subsubsection{Description of Pulse Neutron System}

The pulse neutron source measurements were made with a Kaman A808 pulsed neutron source capable of being repetitively pulsed up to 50 pulses per second and having a neutron yield of about $10^{9} \mathrm{n} / \mathrm{sec}$. The source is encased in a six-inch diameter oil filled cylinder, 36 inches long, and can be moved about. In all of the measurements the source was located outside the lattice plates, as indicated in Figure 2.3 , at least $15 \mathrm{~cm}$ from the fuel rods and at an elevation such that its tritium target was located approximately at the horizontal mid plane of the assembly fuel region. The pulse neutron source measurement data were accumulated with a boron line proportional detector using a Canberra 8100 channel analyzer operating in the time mode with 1.3 microsecond dead time between the counting channels. The neutron detector (Data channel 3, Figure 2.3) was centered at mid plane, in the reflector region, directly across the fuel region from the pulse neutron source. A diagram of the pulsed neutron source control and data acquisition system is shown in Figure 3.6. A photograph of the system, including the neutron generator, is shown in Figure 3.7.

\subsubsection{Pulse Neutron Experiments and Data}

Pulse neutron source measurements were performed on each experimental assembly to determine subcritical $k_{\text {eff }}$ values as incremental amounts of dissolved gadolinium nitrate were added to the originally critical assembly. The results of these measurements are presented in Table 3.3 for each experimental assembly; however, each set of measurements can be associated with the related criticality measurement data given in Tables 3.1 and 3.2 and elsewhere by means of the experiment reference number. As with the criticality measurement, a fuel loading diagram for each subcritical measurement is given in Appendix F. Computerized plots of the measurement data are presented in Appendix G. These plots are traceable to the results presented in Table 3.3 through the measurement identification number (for example BNFL 11-2, which is the second pulse measurement performed on the experimental assembly having a lattice identification of 11). 


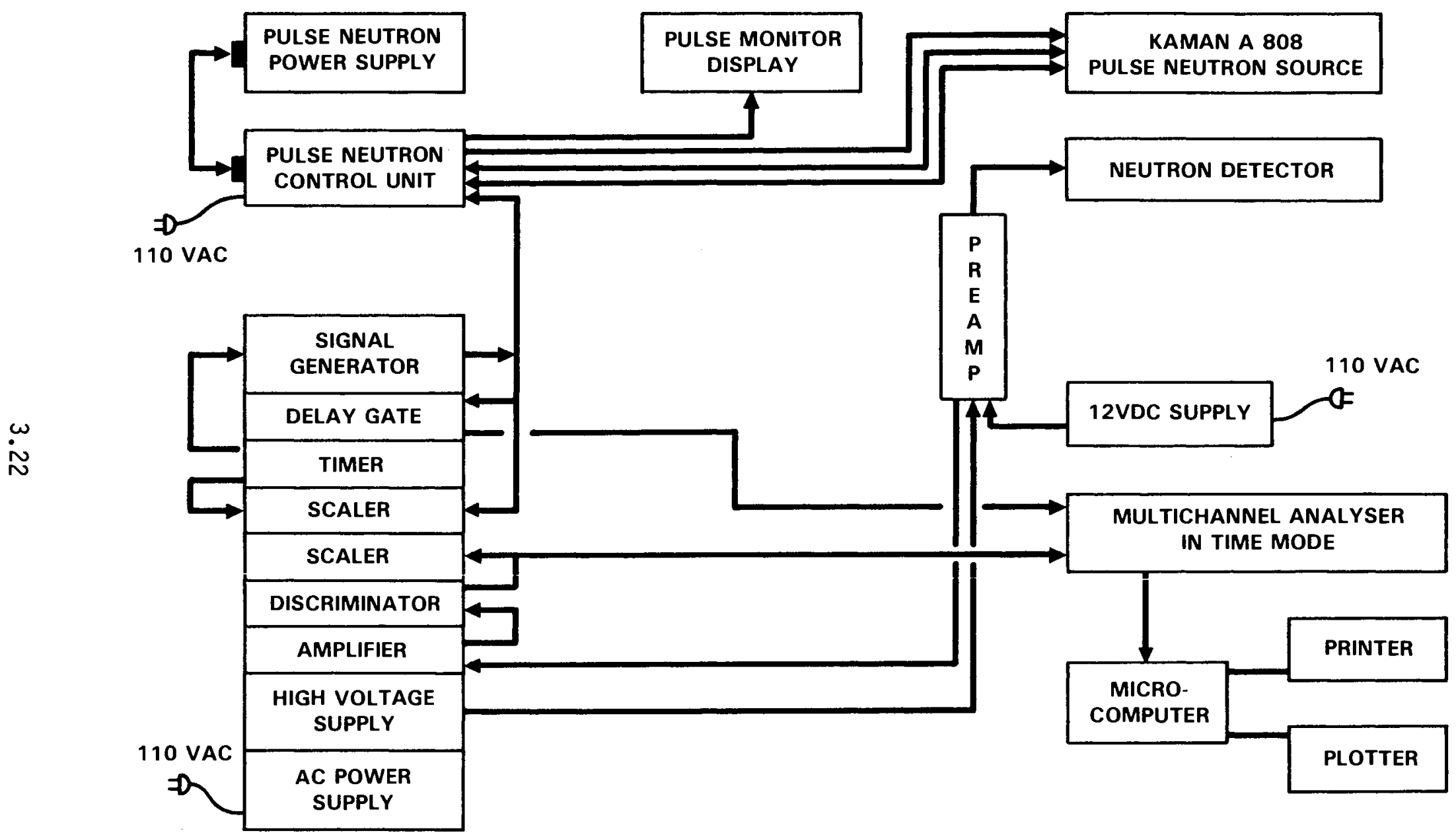

Figure 3.6 Pulse Neutron Source and Data Acquisition System 


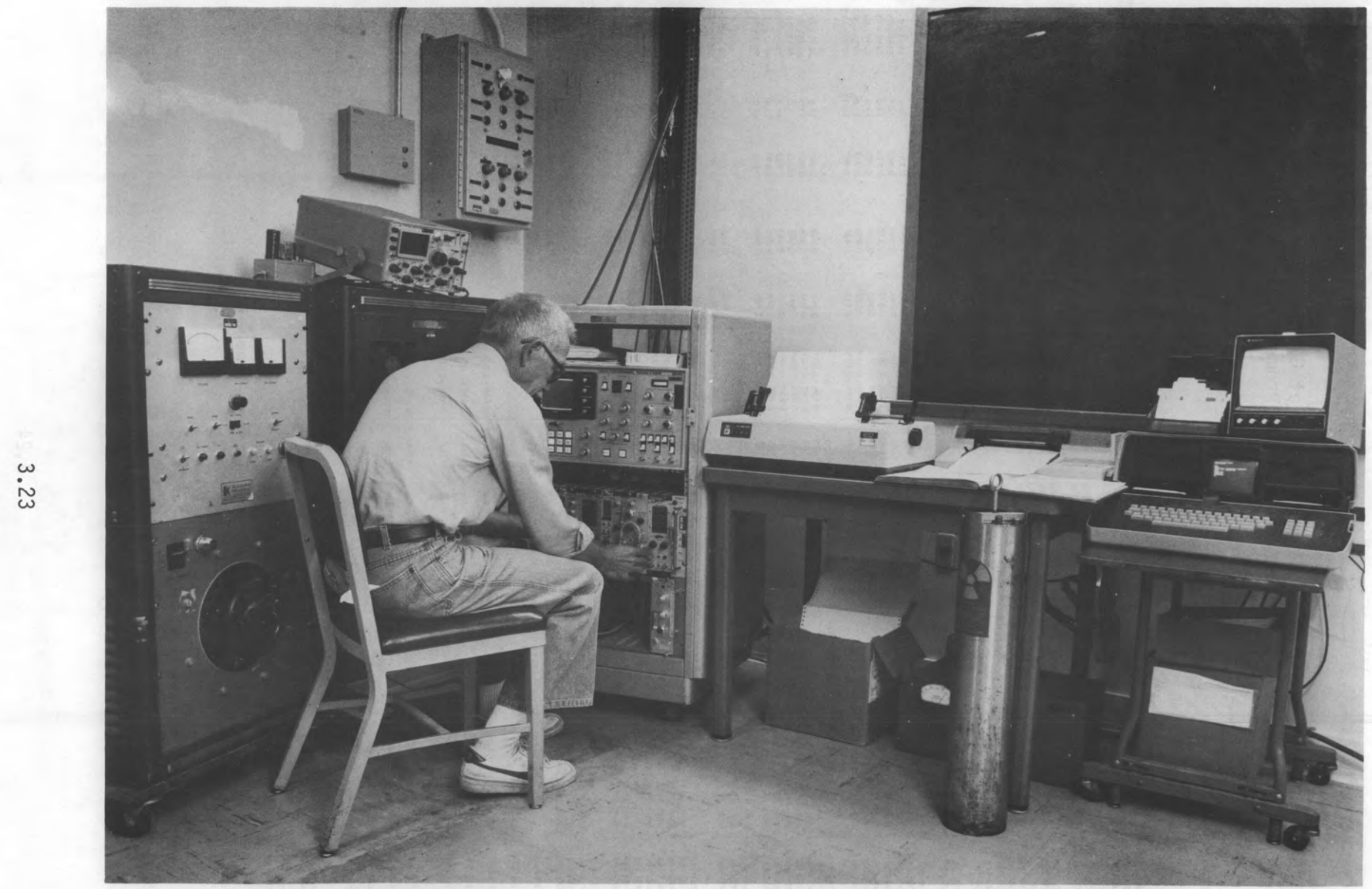

Figure 3.7 Pulse Neutron Source Control Units and Data Acquisition Equipment 


\section{TABLE 3.3 Experimental Results - Effect of Gadolinium Concentration on $\mathrm{K}_{\mathrm{eff}}$, Neutron Lifetime and Prompt Neutron Decay Rate}

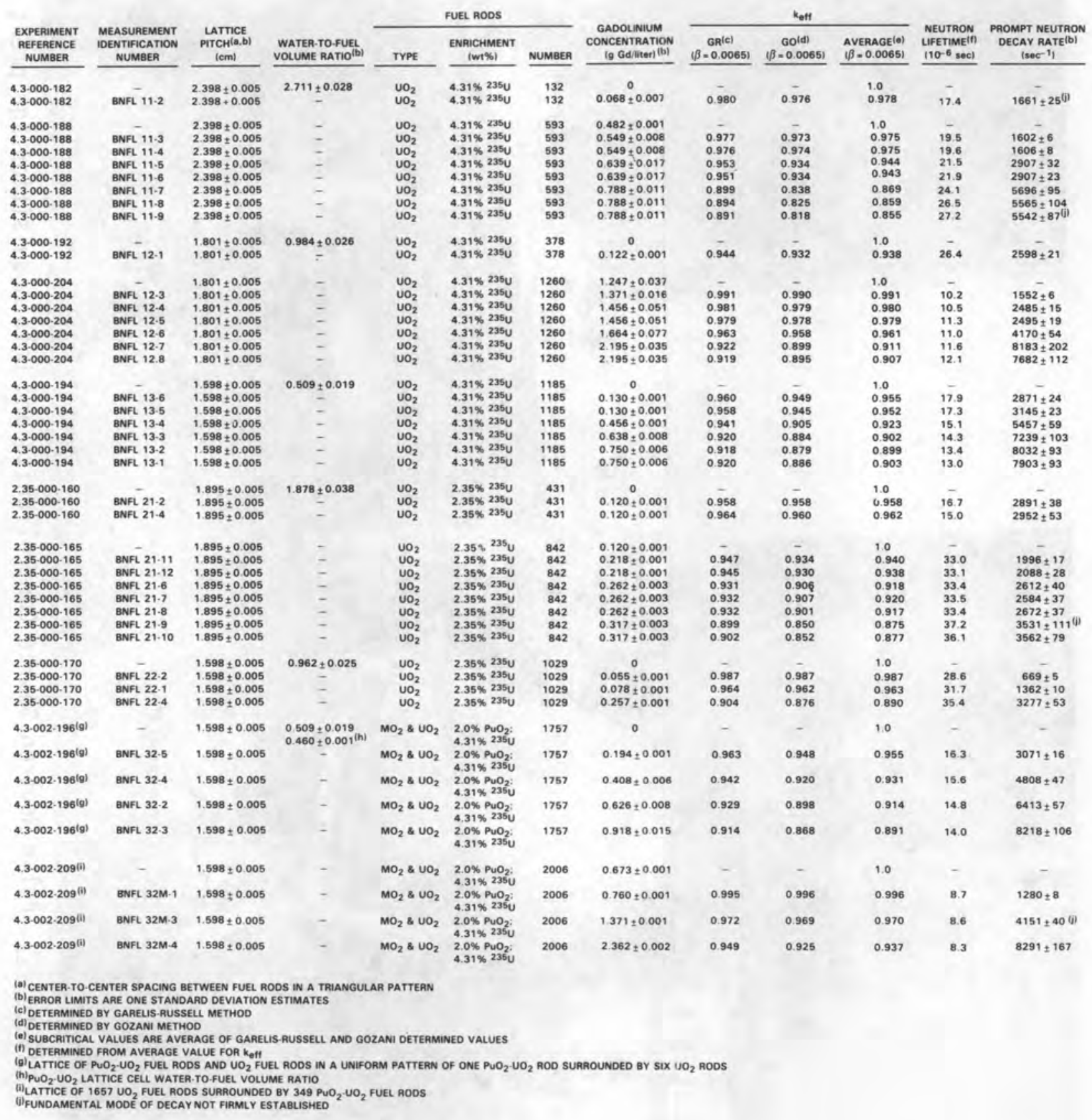


Effective neutron multiplication constants, as determined by both the Garel is - Russell 1963 method and by the Gozani method are given in Table 3.3 for each subcritical assembly. As stated in the section describing the pulse neutron source technique, the true $k_{\text {eff }}$ value for each assembly should lie somewhere between these two values due to spatial harmonics in the measurement data. If positive harmonics predominate in the data:

$$
\left|P_{G O}\right|<|\rho|<\left|P_{G R}\right|
$$

If negative harmonics predominate:

$$
\left|P_{\mathrm{GO}}\right|>|P|>\left|P_{\mathrm{GR}}\right|
$$

In general, an average of the $k_{\text {eff }}$ values determined by the Garelis-Russell and Gozani methods is probably closer to the true value than either. Consequently an average of the Garelis-Russell and Gozani values is also given in Table 3.3 for each subcritical assembly. As indicated previously however, calculational corrections (see Becker and Quisenberry 1966) should be made to these values to evaluate and account for any "kinetic distortation" that may be present in the measured data.

Although the data shown in Table 3.3 indicate that negative harmonics predominate in each of the subcritical measurements, they become relatively negilible as the critical condition is approached. For $k_{\text {eff }}$ values above about 0.95 the average value for $k_{\text {eff }}$ is within $1 \%$ of the Garelis-Russell and Gozani values. As the assemblies become further subcritical the spread in $k_{\text {eff }}$ values increase to about $2 \%$ at a $k_{\text {eff }}$ level near 0.87 .

In addition to subcritical $k_{\text {eff }}$ values, values for the neutron lifetime and the rate of decay for prompt neutrons in each of the assemblies can be obtained from the pulse neutron source measurement data. These parameters may be of future use in developing calculational techniques, particularly 
those involving neutron kinetics. These parameters, as will be discussed later, are also useful in indicating the consistancy and validity of the subcritical measurements. Consequentiy, neutron lifetimes and prompt neutron decay rates, obtained from the measurement data, are given in Table 3.3 for each subcritical assembly. These values, along with the $k_{\text {eff }}$ values, are plotted in Figures $3.8,3.9,3.10,3.11,3.12,3.13$ and 3.14 as a function of the gadolinium concentration for each set of experimental assemblies (lattices) involving a series of measurements.

The neutron 1 ifetime reported in Table 3.3 and Figures $3.8,3.9,3.10$, $3.11,3.12,3.13$ and 3.14 for each subcritical assembly is the average of that determined from the Garelis-Russell and the Gozani analyses of the measurement data. The prompt neutron decay rate reported in Table 3.3 and Figures $3.8,3.9,3.10,3.11,3.12,3.13$ and 3.14 for each subcritical assembly is the time rate of decay for the fundamental mode observed in the measurement data by least-squares fitting the data to a constant plus a single exponential term.

As indicated previous1y, and as can be seen in the computer plots of the measurement data presented in Appendix $G$, harmonics exist in the measurement data. To determine if a single mode of neutron decay eventually existed in each set of measurement data, a technique developed by Pfeiffer, Brown and Marshall (Pfeiffer, 1974) in a Fort St. Vrain startup test was used. The technique makes use of the standard deviation obtained on the fitted value for the prompt neutron decay rate, $\alpha$, and the random fluctuation of the fitted value for $\alpha$ within the standard deviation as measurement data immediately following the neutron burst is successively ignored in the fitting process. If it can be demonstrated that a decay rate, and the associated standard deviation, fluctuates within the standard deviation as data are deleted, it can be concluded that a single time rate of decay predominates and is the fundamental mode of neutron decay for that experimental assembly. Examples of the variation observed in the prompt neutron decay rate as a function of time are shown in Figure 3.15 as typical. Except as noted in Table 3.3, a single mode of neutron decay eventually predominated in each of the subcritical measurements. 


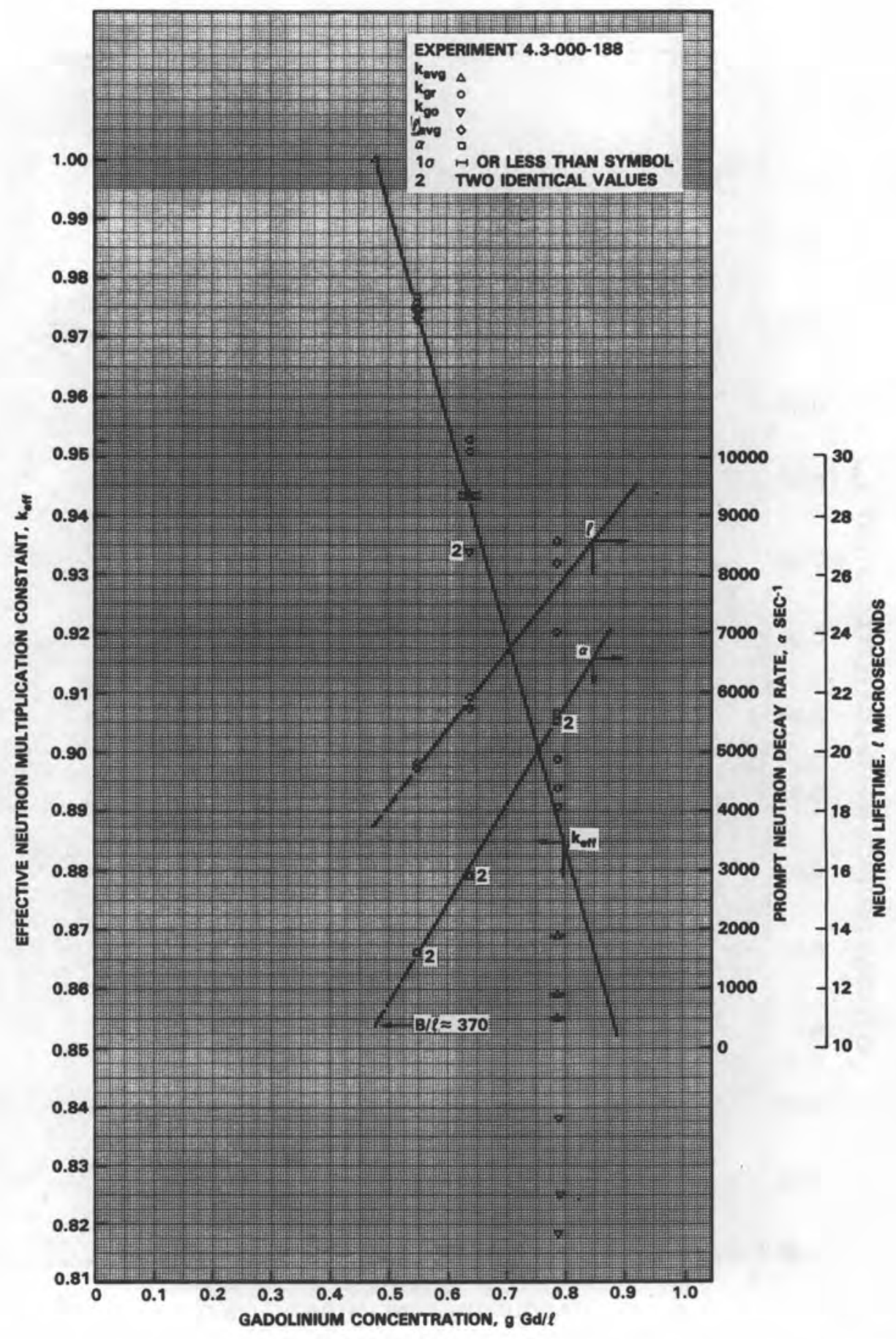

Figure 3.8. Measured Variations in keff, $\ell$ and $\alpha$ with Concentration of Dissolved Gadolinium in Fuel-Water Lattices of 4.31 wt\% $235 \mathrm{U}$ Enriched $\mathrm{UO}_{2}$ Fuel Rods in a Triangular Pattern on $2.398 \mathrm{~cm}$ Center-to-Center Spacing 


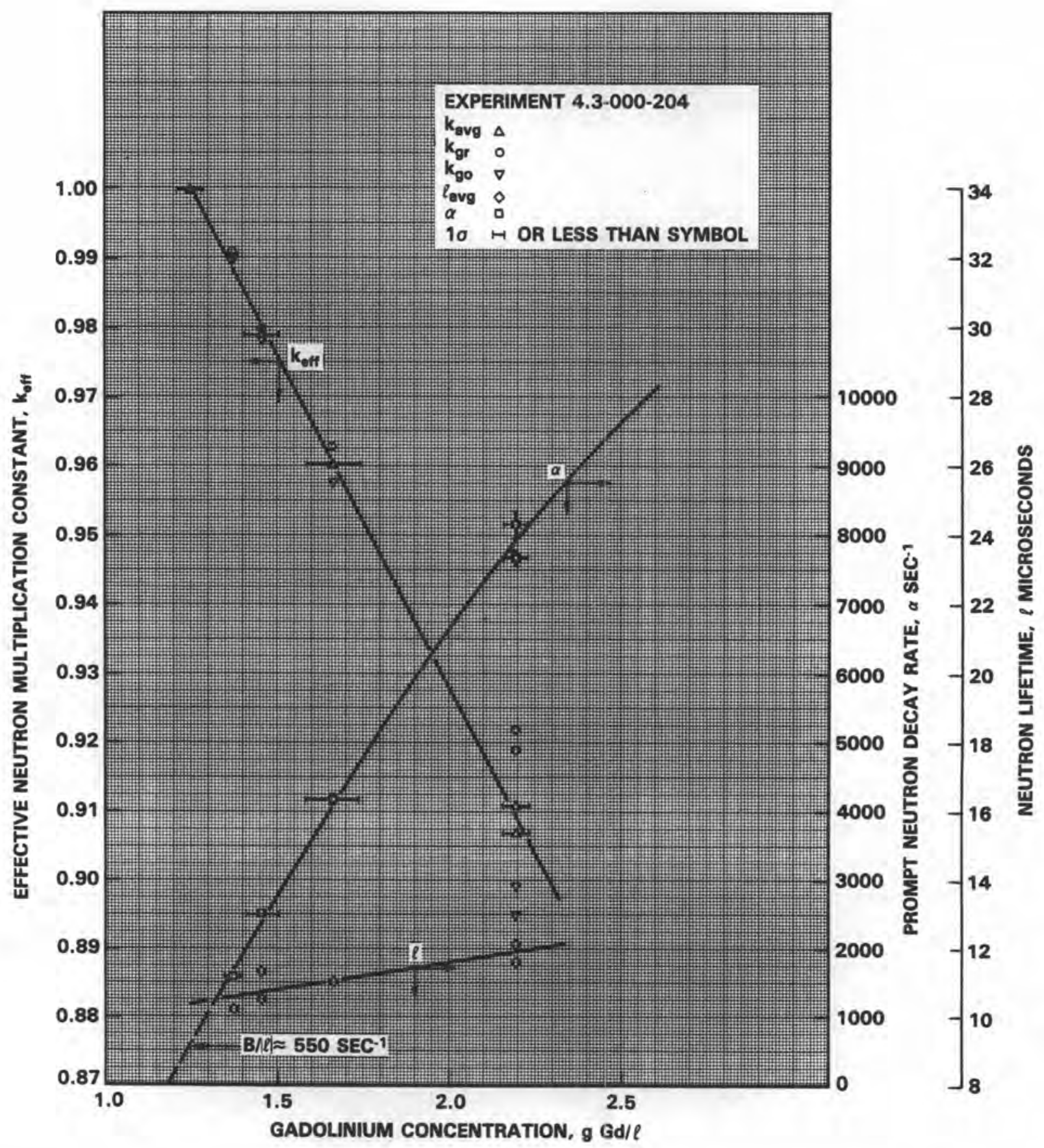

Figure 3.9 Measured Variations in keff, $l$ and $\alpha$ with Concentration of Dissolved Gadolinium in Fuel-Water Lattices of $4.31 \mathrm{wt} \% 235 \mathrm{U}$ Enriched $\mathrm{UO}_{2}$ Fuel Rods in a Triangular Pattern on $1.801 \mathrm{~cm}$ Center-to-Center Spacing 


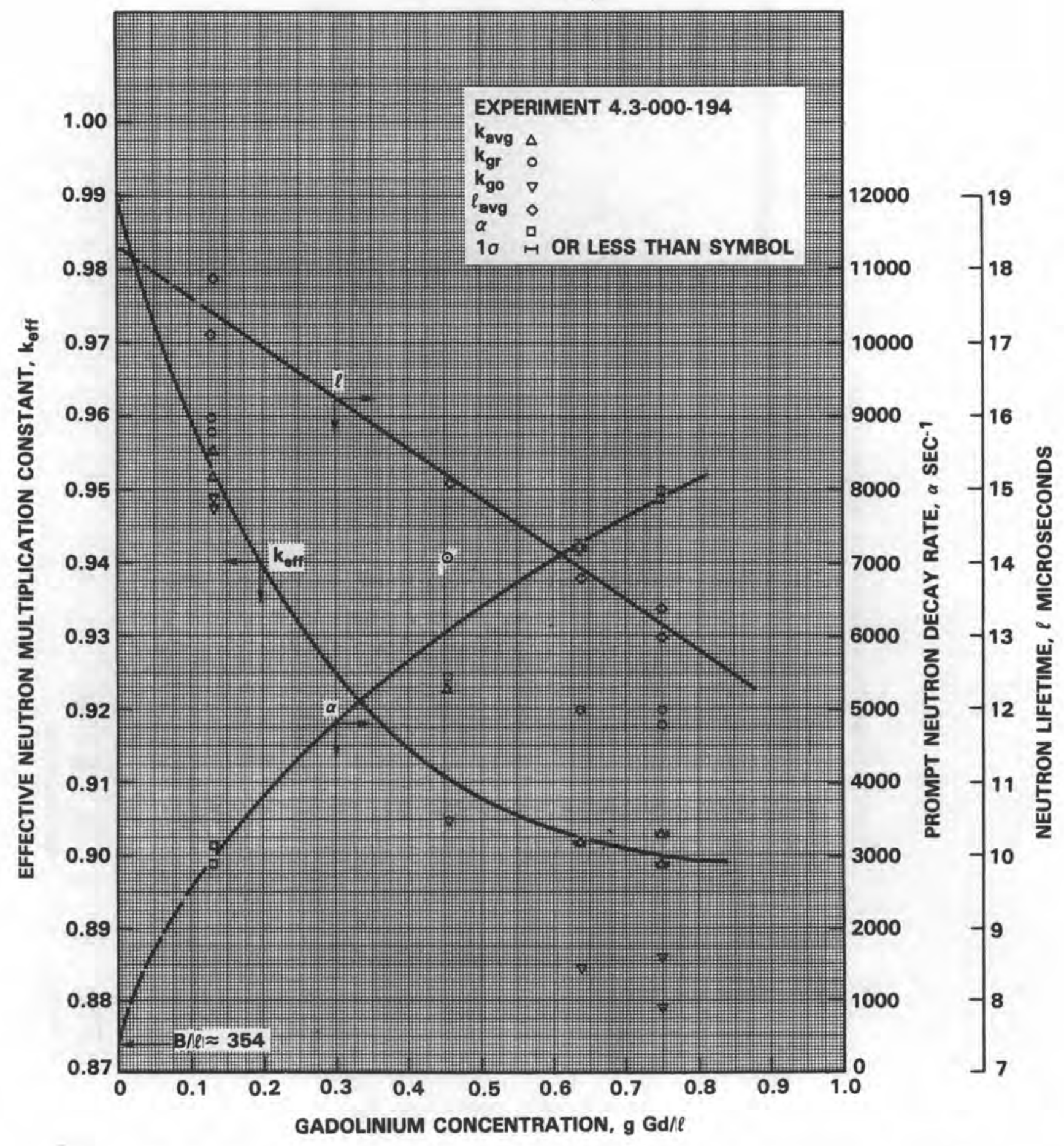

Figure 3.10 Measured Variations in keff, $\ell$ and $\alpha$ with Concentration of Dissolved Gadol inium in Fuel-Water Lattices of $4.31 \mathrm{wt} \% 235 \mathrm{U}$ Enriched $\mathrm{UO}_{2}$ Fuel Rods in a Triangular Pattern on $1.598 \mathrm{~cm}$ Center-to-Center Spacing 


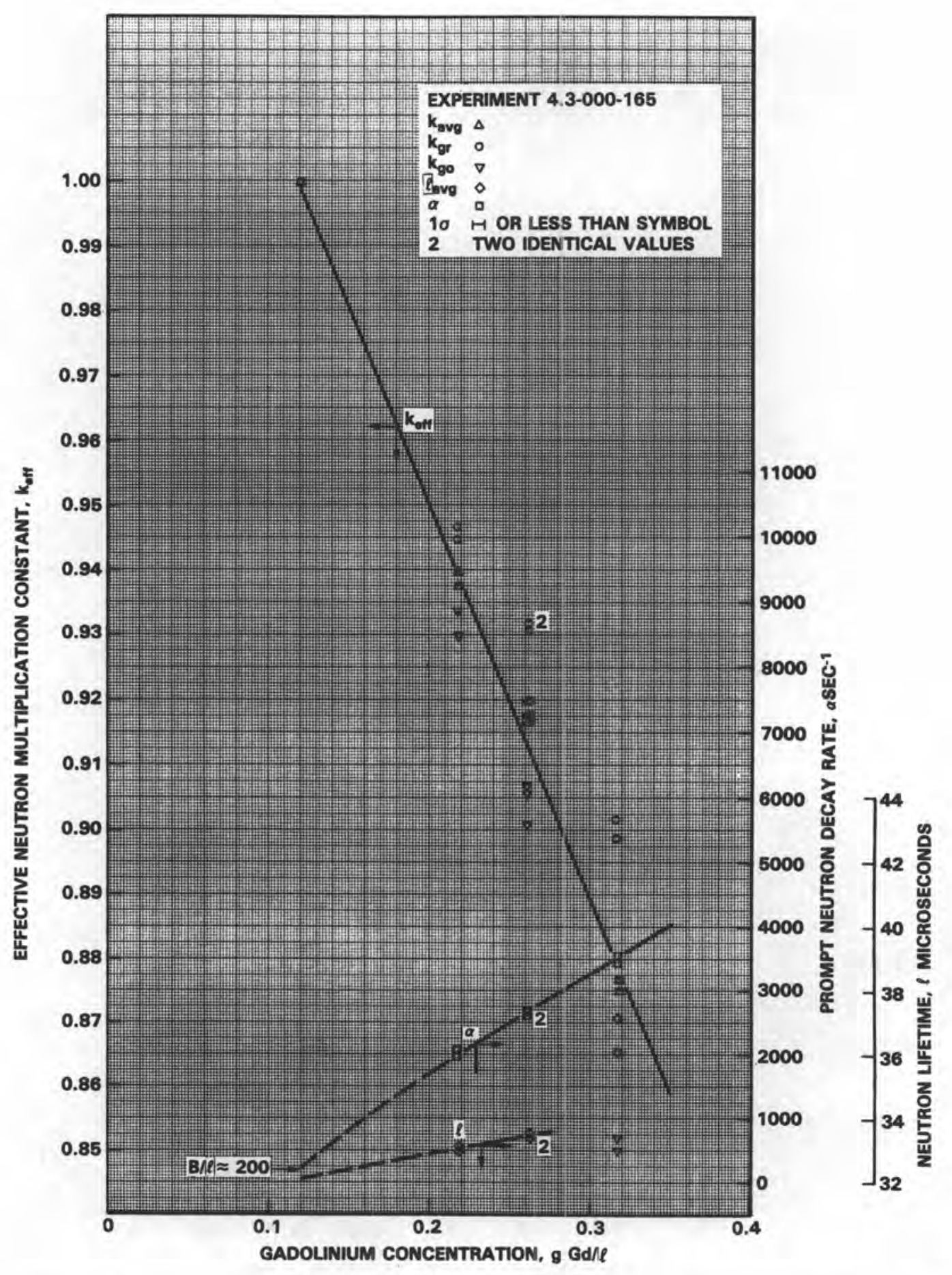

Figure 3.11 Measured Variations in $\mathrm{k}_{\mathrm{eff}}, \ell$ and $\alpha$ with Concentration of Dissolved Gadol inium in Fuel-Water Lattices of $2.35 \mathrm{wt} \% 235 \mathrm{U}$ Enriched $\mathrm{UO}_{2}$ Fuel Rods in a Triangular Pattern on a $1.895 \mathrm{~cm}$ Center-to-Center Spacing 


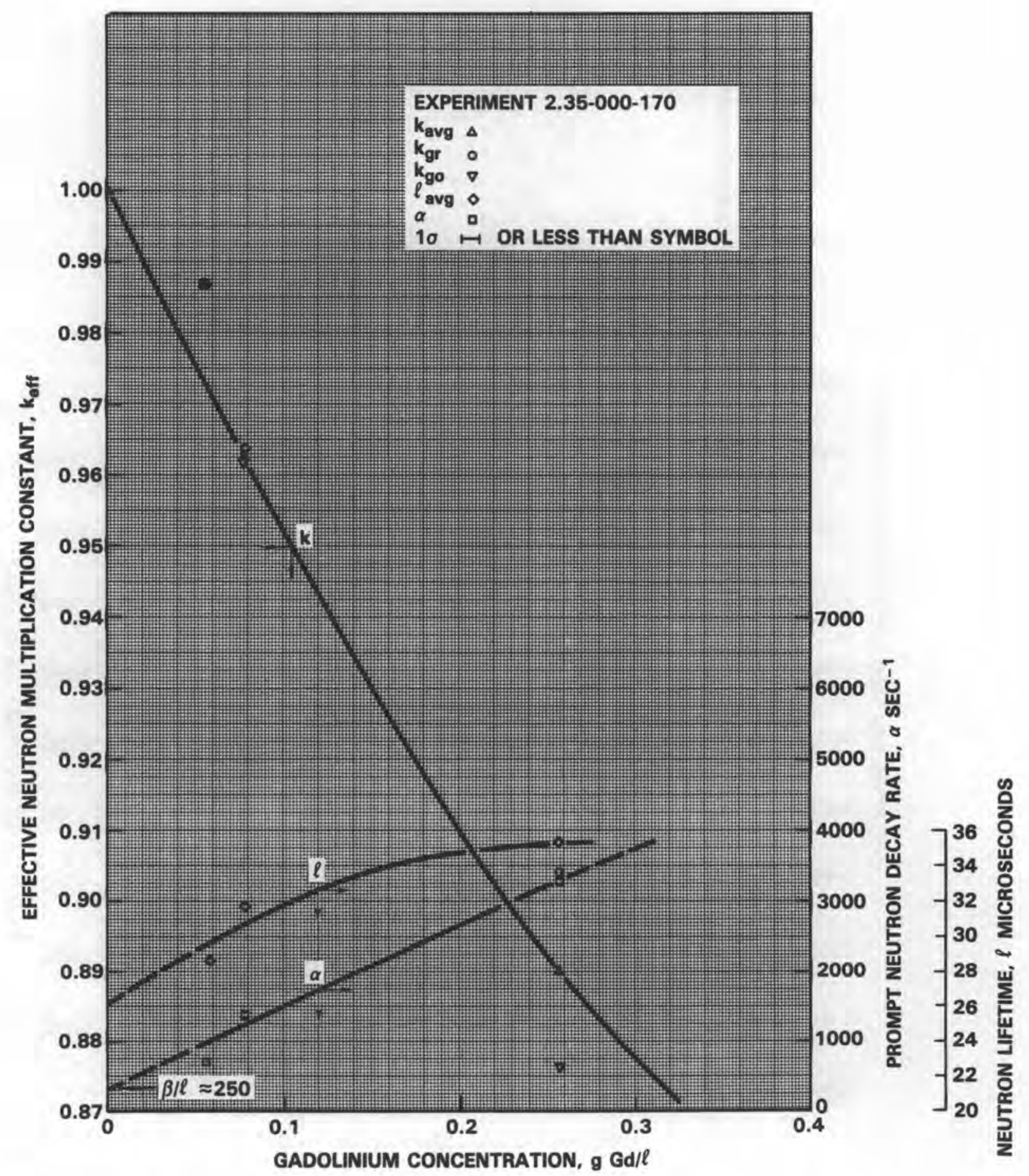

Figure 3.12 Measured Variations in keff, $\ell$ and $\alpha$ with Concentration of Dissolved Gadolinium in Fuel-Water Lattices of 2.35 wt\% $235 \mathrm{U}$ Enriched $\mathrm{UO}_{2}$ Fuel Rods in a Triangular Pattern on a $1.598 \mathrm{~cm}$ Center-to-Center Spacing 


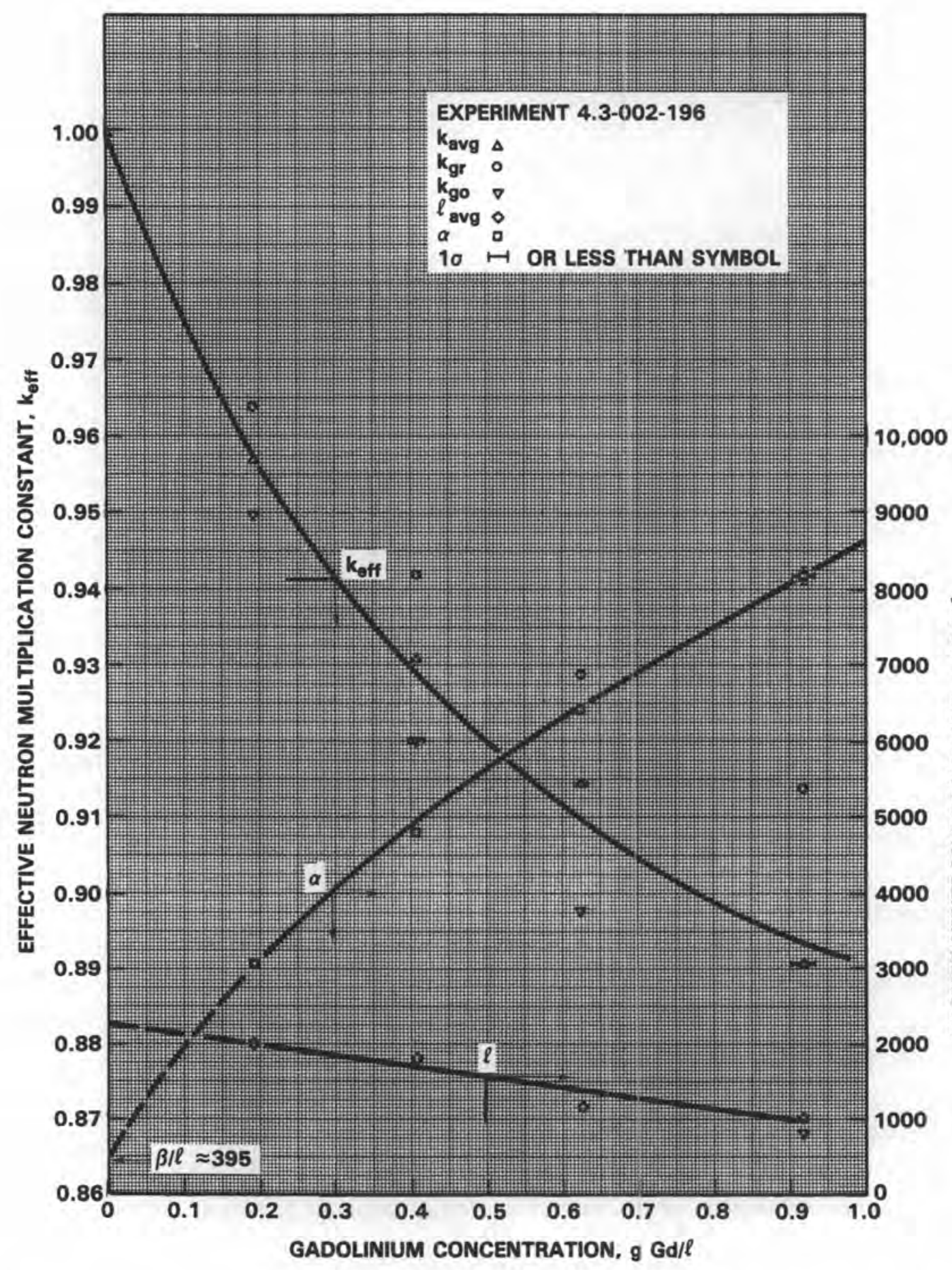

Figure 3.13 Measured Variations in keff, $\ell$ and $\alpha$ with Concentration of Dissolved Gadol inium in Fuel-Water Lattices of $4.31 \mathrm{wt} \% 235 \mathrm{U}$ Enriched $\mathrm{UO}_{2}$ Fuel Rods mixed with $\mathrm{PuO}_{2}-\mathrm{UO}_{2}$ Fuel Rods in a Triangular Pattern on a $1.598 \mathrm{~cm}$ Center-to-Center Spacing 


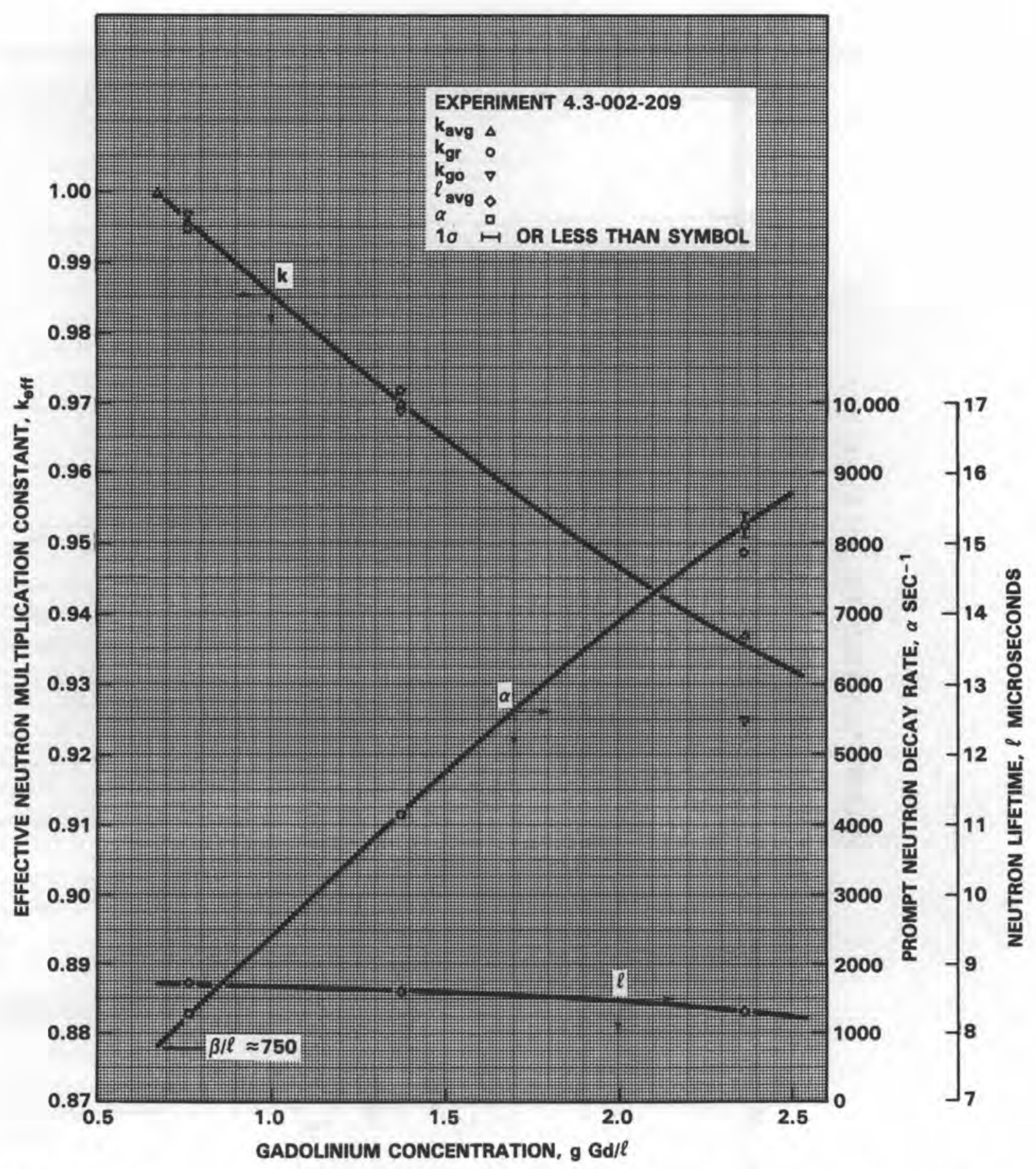

Figure 3.14 Measured Variations in $k_{e f f}, \ell$ and $\alpha$ with Concentration of Dissolved Gadolinium in Fuel-Water Lattices of $4.31 \mathrm{wt} \% 235 \mathrm{U}$ Enriched $\mathrm{UO}_{2}$ Fuel Rods mixed with $\mathrm{PuO}_{2}-\mathrm{UO}_{2}$ Fuel Rods in a Triangular Pattern on a $1.598 \mathrm{~cm}$ Center-to-Center Spacing 


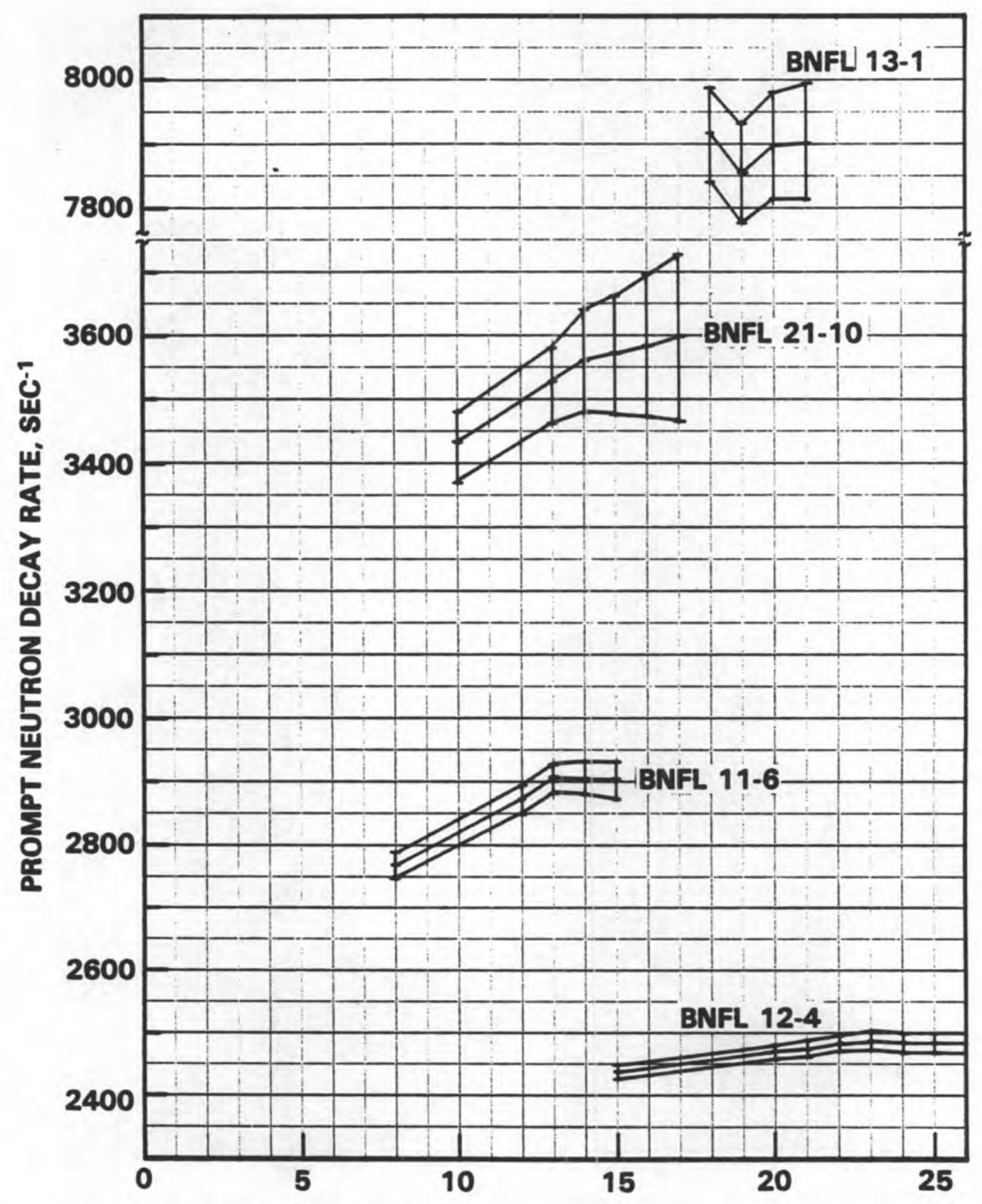

INITIAL DATA CHANNEL USED IN LEAST SQUARES FITTING PROCESS

Figure 3.15 Illustration of Technique Used to Determine that a Fundamental Mode of Prompt Neutron Decay was Present in the Observed Measurement Data 
Although the accuracy of the subcritical measurements cannot currently be verified by an independent method, the data reported in Table 3.3 indicate that multiple measurements reproduce $k_{\text {eff }}$ to within about 0.005 or less. Also, except for measurement BNFL 11-2, the measurement data presented in Appendix $g$ appear to be well behaved. Some perturbations appear in the measurement data for BNFL 11-2 (see computer plot in Appendix G). However, least-squares fitting and analyses of the data were performed to minimize the effect of those perturbations on the results given in Table 3.3.

An indication of the validity of the results can be obtained also by observing:

- The variation in $\mathrm{k}_{\text {eff }}$ as the critical condition is approached,

- the consistancy between the neutron lifetimes and the prompt neutron decay rates determined for a set of measurements.

As the delayed critical condition of an assembly is approached, the decay rate of the prompt neutrons in that assembly approaches $\beta / 2$, where $\beta$ is the effective delayed neutron fraction and $\ell$ is the neutron 1 ifetime (see section on Measurement Technique). Since $\beta$ is essentially constant the neutron lifetimes in an assembly should approach a value at decayed critical that is consistant with the prompt neutron decay rate at delayed critical. Very near the delayed critical conditions, variations in both the neutron lifetimes and the decay rates can be approximated as a linear function of the gadolinium concentration. However, as neutron absorption or leakage begins to increase, the variation in both parameters, as well

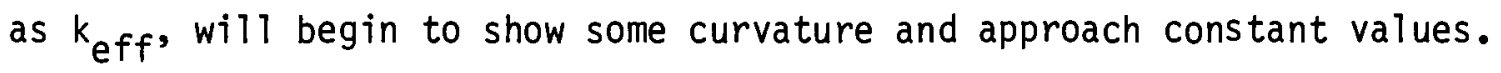

By reviewing the data as presented in Figures 3.8 through 3.14 conclusions can be made on the validity of individual data points within a series of measurements. For example, although a linear extrapolation of the subcritical data presented in Figure 3.8 predicts the delayed critical conditions, the value for $k_{\text {eff }}$ at the highest gadolinium concentrations of $0.788 \mathrm{~g} \mathrm{Gd} / \ell$ appears low and indicates some curvature should exist in the prompt neutron decay rate and/or the neutron lifetime data. For consistancy the $k_{\text {eff }}$ value at the $0.788 \mathrm{~g} \mathrm{Gd} / \mathrm{l}$ concentration should be at least 0.889 
and the decay rate-neutron lifetime correspondingly smaller. However, considering the complex neutron spectral shifts that occur in a system as gadolinium is varied, calculations beyond the scope of work covered here in may demonstrate the validity of the measurement data at $0.788 \mathrm{~g} \mathrm{Gd} / \ell$. Until this is demonstrated such data should be considered suspect. The data presented in Figure 3.9 for the 4.3-000-204 series of measurements are a more typical example of a complete set of consistant data having a high degree of reliability.

\subsection{REACTION RATE MEASUREMENTS}

Al though reaction rate measurements were not a primary objective of the program, measurements were made in selected experimental assemblies, as indicated in Table 2.1, to obtain data for improving neutronic calculations. These measurements were performed in the critical assemblies of the 4.31 wt\% ${ }^{235} \mathrm{U}$ enriched $\mathrm{UO}_{2}$ fuel rods. Absolute ${ }^{235} \mathrm{U}$ fission rates, using solid state track recorders (SSTR), were measured in this fuel at all three degrees of neutron moderation (1attices 11, 12 and 13) with no gadolinium dissolved in the water, and at near optimum neutron moderation (lattice 11) with gadolinium in the water. Relative Conversion Ratio (RCR)

and Fast Fission Ratio (FFR) measurements, using $4.31 \mathrm{wt} \%{ }^{235} \mathrm{U}$ enriched $\mathrm{UO}_{2}$ and depleted $U$ foils, were made in the near optimum neutron moderated lattice 11 and in the undermoderated lattice 13 with and without gadolinium dissolved in the water. RCR and FFR measurements were also made in the slightly undermoderated lattice 12 with no gadolinium in the water.

\subsubsection{Measurement Techniques}

The use of solid state track recorder type devices to measure absolute fission rates is extensivley discussed in readily available publications (Gold 1968) and (Roberts 1968). Briefly, however, SSTR measurements are carried out using thin deposits of material in contact with a material such as mica. Fissions in the deposit create damage tracks in the mica that can be optically counted to obtain the number of fissions per atom of deposit. 
Measurements to determine the Fast Fission Ratio $\left({ }^{238} \mathrm{U} /{ }^{235} \mathrm{U}\right)$ involve the simultaneous irradition of two uranium samples of different enrichments as discussed in detail in Appendix $\mathrm{H}$. Measurements to determine the ${ }^{238} \mathrm{U}$ capture to ${ }^{235} \mathrm{U}$ fission ratio relative to that in a known thermal flux are also described in detail in Appendix $H$.

\subsubsection{Reaction Rate Mea surements and Data}

The experimental assemblies in which reaction rate measurements were made are briefly described in Table 3.4. A fuel loading diagram (identified through the Experiment Reference Number) for each of these assemblies is presented in Appendix F. The measurement results obtained for each of the assemblies are summarized in Table 3.4 also. The results shown in Table 3.4 for the fission rates are based on the irradiation of a single SSTR in each assembly whereas each RCR and FFR result is the mean value obtained from three AEEW foil packs positioned in neutronically identical locations in the assemblies. The foil pack locations and the SSTR location in each assembly are identified in the loading diagrams of Appendix $F$.

For the ${ }^{235} U$ fission rate measurements, a thin layer of ${ }^{235} U$, with an active diameter of $0.635 \mathrm{~cm}(0.25 \mathrm{in.})$, was electroplated onto a $1.11 \mathrm{~cm}$ (0.437 in.) diameter, $0.013 \mathrm{~cm}(0.005 \mathrm{in.})$ thick nickle plate. This was placed in close contact with a thin $(\sim 0.01 \mathrm{~cm})$ disk of mica, and encapsulated in an aluminum holder by the Hanford Engineering Development Laboratory (HEDL) of Westinghouse Hanford Company (Ruddy 1983). A typical SSTR geometrical configuration is shown in Figure 3.16. The SSTR in each fission rate measurement was positioned between the first and second pellets of a three pellet column as indicated in Figure 3.17.

In each absolute fission rate measurement the SSTR was irradiated for a predetermined time at an integrated power level, $P$, given by

$$
P=P_{0}\left[\tau\left(1-e^{-\Delta t / \tau}\right)+t\right] \text {, }
$$

where $t$ is the irradiation time at a constant power level, $P_{0}$, and $\tau$ is the period at which this power level was approached. Following each irradiation, the SSTR was given a 45 minute etch in $49 \% \mathrm{HF}$ at $22^{\circ} \mathrm{C}$ and the fission fragment tracks counted by HEDL to obtain ${ }^{235} \mathrm{U}$ fission rates (Ruddy 1983). 
TABLE 3.4 Experimental Results - Summary Table of Reaction Rates

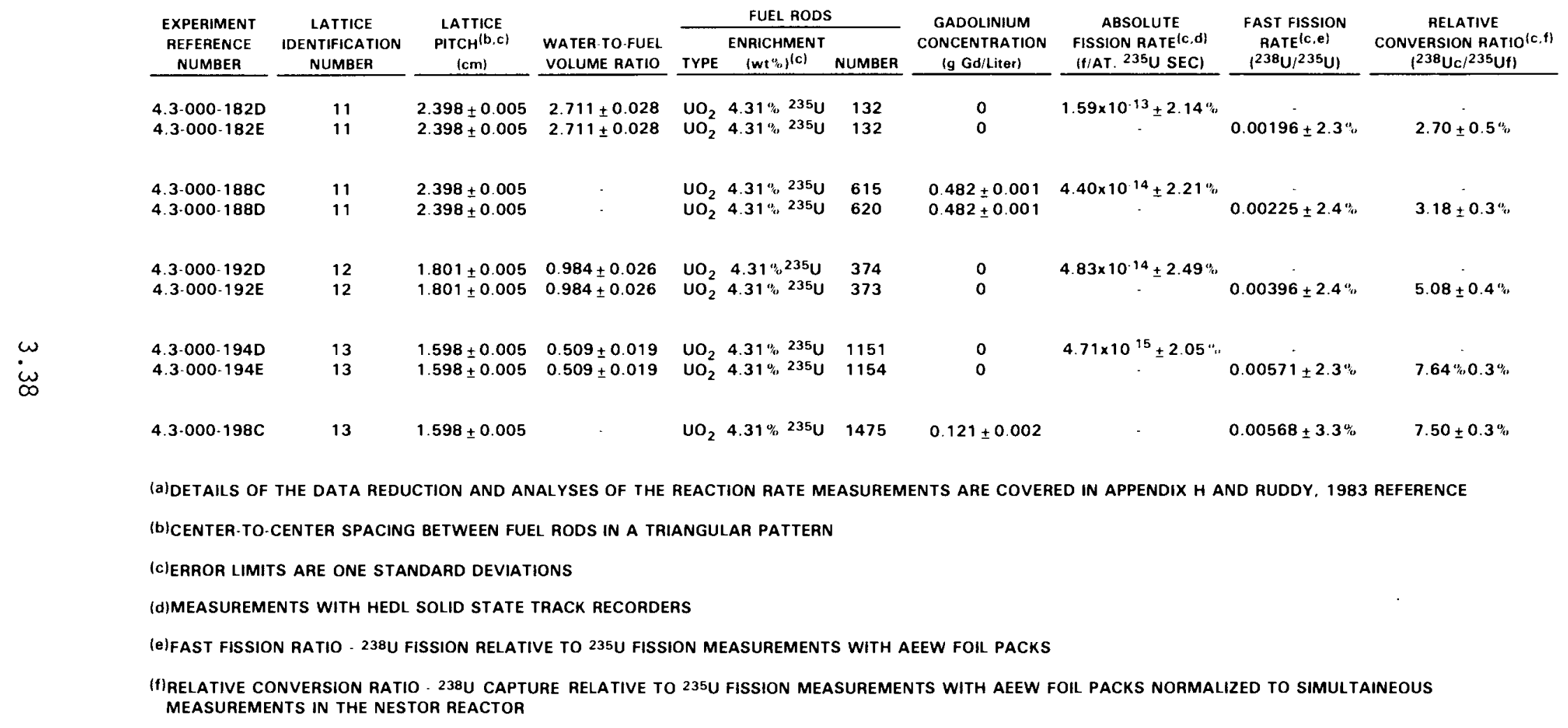




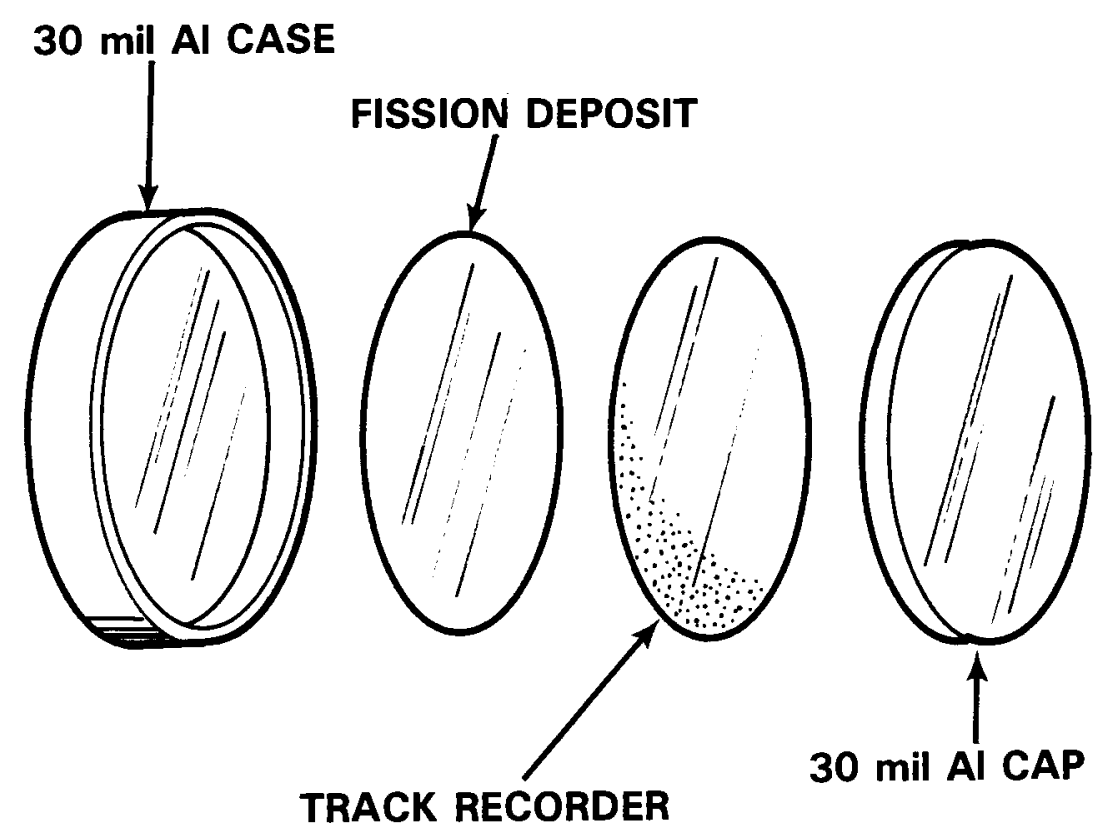

Figure 3.16 Typical SSTR Geometrical Configuration 


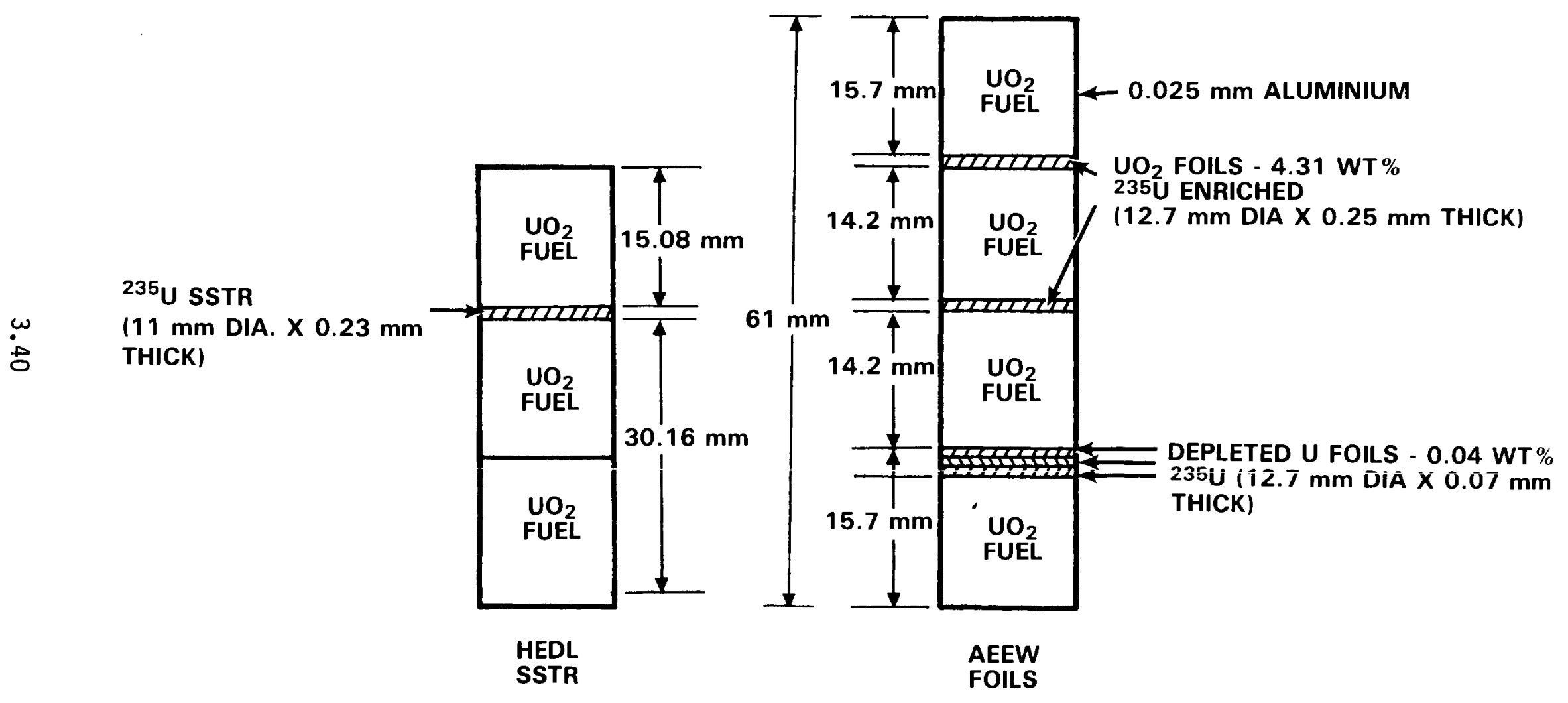

Figure 3.17 Description and Arrangement of Reaction Rate Packets 
Preparation and assembly of the AEEW foil packs is covered in detail in Appendix H. A sketch of an assembled foil pack is shown in Figure 3.17. The Fast Fission Ratios reported in Table 3.4 were obtained by simultaneously irradiating $4.31 \mathrm{wt} \%{ }^{235_{U}}$ enriched $\mathrm{UO}_{2}$ foils and depleted $U$ metal foils in the indicated experimental assemblies. To determine the Relative Conversion Ratios shown in Table 3.4, simultaneous irradiations were performed in the AEEW Nestor Reactor to obtain $238 U$ capture to $235 U$ fission ratios in a known thermal neutron flux. These irradiations were for exactly two hours at a constant thermal neutron flux of about $2 \times 10^{8} \mathrm{n} \mathrm{cm}^{-2} \mathrm{~s}^{-1}\left(\sim 5 \times 10^{-14} \mathrm{fat}^{-1} \mathrm{~s}^{-1}\right)$.

Due to the presence of the thermal neutron absorber, gadolinium, and the water-to-fuel ratios covered by the experiments, the neutron spectra varied considerably between experiments. To obtain thermal neutron fluxes of about $2 \times 10^{8} \mathrm{n} \mathrm{cm}^{-2} \mathrm{~s}^{-1}$ in each assembly, the power levels were ajusted based upon the absolute fission rates determined from the SSTR measurements. Photo reductions of the neutron flux recorder chart are presented in Appendix $I$.

Synchronization of the irradiations was achieved by maintaining a telephone connection between the control rooms of the Critical Mass Laboratory and the Nestor Reactor during the initial phase of each irradiation. To approximate the effects caused by the experimental assemblies approaching the power level on periods of about 60 seconds, the neutron shutter to the thermal column of the Nestor Reactor was opened each time when the experimental assembly reached $37 \%$ of full power. Therefore the total exposure time was slightly longer than two hours for each of the irradiations.

Following each irradiation the foil packs were removed from the experimental assembly, packaged and shipped to the AEEW for analyses as covered in Appendix $H$. Each set of foils were removed from the reaction rate fuel rods and packaged in a 6M shipping container approved by both the United States and the United Kingdom (USA/0002/X8) for this purpose. Shipment by road and air was coordinated to meet counting statistic requirements that each set of foils reach the AEEW within 30 hours following irradiation. 
Three of the 4.31 wt\% ${ }^{235} \mathrm{U}$ enriched $\mathrm{UO}_{2}$ fuel rods were modified such that fuel pellets could be replaced with either an AEEW foil packet or a SSTR packet. Either a single SSTR was loaded into a reaction rate rod for irradiation or an AEEW foil pack was loaded into each of the three reaction rate rods for irradiation. A photograph of a modified fuel rod, disassembled and assembled, is shown in Figure 3.18. THe reaction rate packs were loaded in approximately the center of these fuel rods such that the bottom of each pack was at the same elevation when phaced in an experimental assembly (see Figure 2.7, Experimental Assembly Elevations).

Since the reaction rate measurements are very sensitive to neutron moderation, special precautions were taken to assure that the neutron flux was uniformly characteristic of the region containing the reaction rate packet. As indicated previously, the reference elevation for the reaction rate packs was identical as defined in Figure 2.7 for all the experimental assemblies. The radial location of the reaction rate rods is given in the loading diagrams of Appendix $F$ for each experimental assembly of interest. These locations are very accurately defined with respect to the center of each of the three lattice types in Figures $3.19,3.20$ and 3.21. In addition, the distance between each reaction rate fuel rod and the surrounding adjacent six fuel rods is given in Figures $3.19,3.20$ and 3.21 for the respective lattices. The distances reported in Figures $3.19,3.20$ and 3.21 are the result of multiple micrometer measurements over the length of the reaction rate packs. Machined Type 6061 aluminum spacers, shown in Figure 3.18, positioned above and below the reaction rate packs were used to maintain these uniform spacings over an elevation distance of about $24 \mathrm{~cm}$ as indicated in Figure 2.7.

To verify that the neutron flux was uniformly characteristic of the region containing the reaction rate packet, multiple FFR - RCR measurements were simultaneously performed in each of the five experimental assemblies. In each assembly AEEW foil packs were located in three neutronically identical positions as indicated in the loading diagrams of Appendix $F$ and Figures $3.19,3.20$ and 3.21. As covered in Appendix $H$, the variations 


\section{FUEL ROD ASSEMBLY FOR BNFL REACTION RATE MEASUREMENTS}

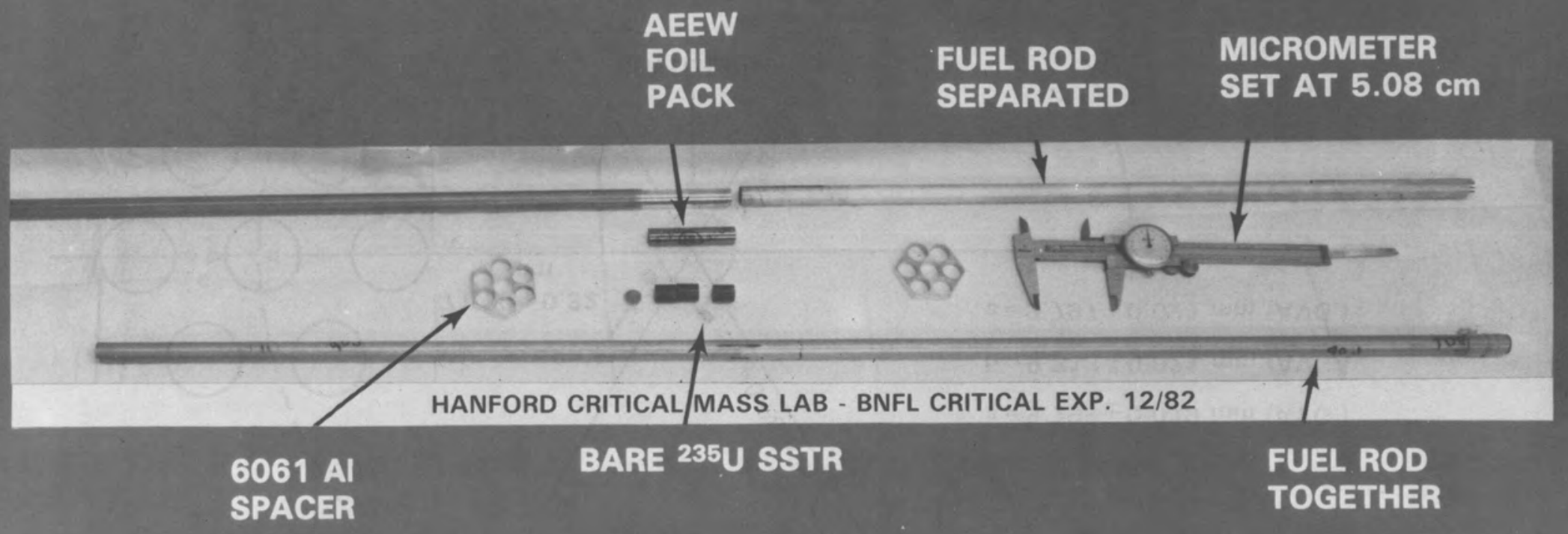

Figure 3.18 Photograph of Fuel Rod Assembly and Reaction Rate Devices Used in Experiments 


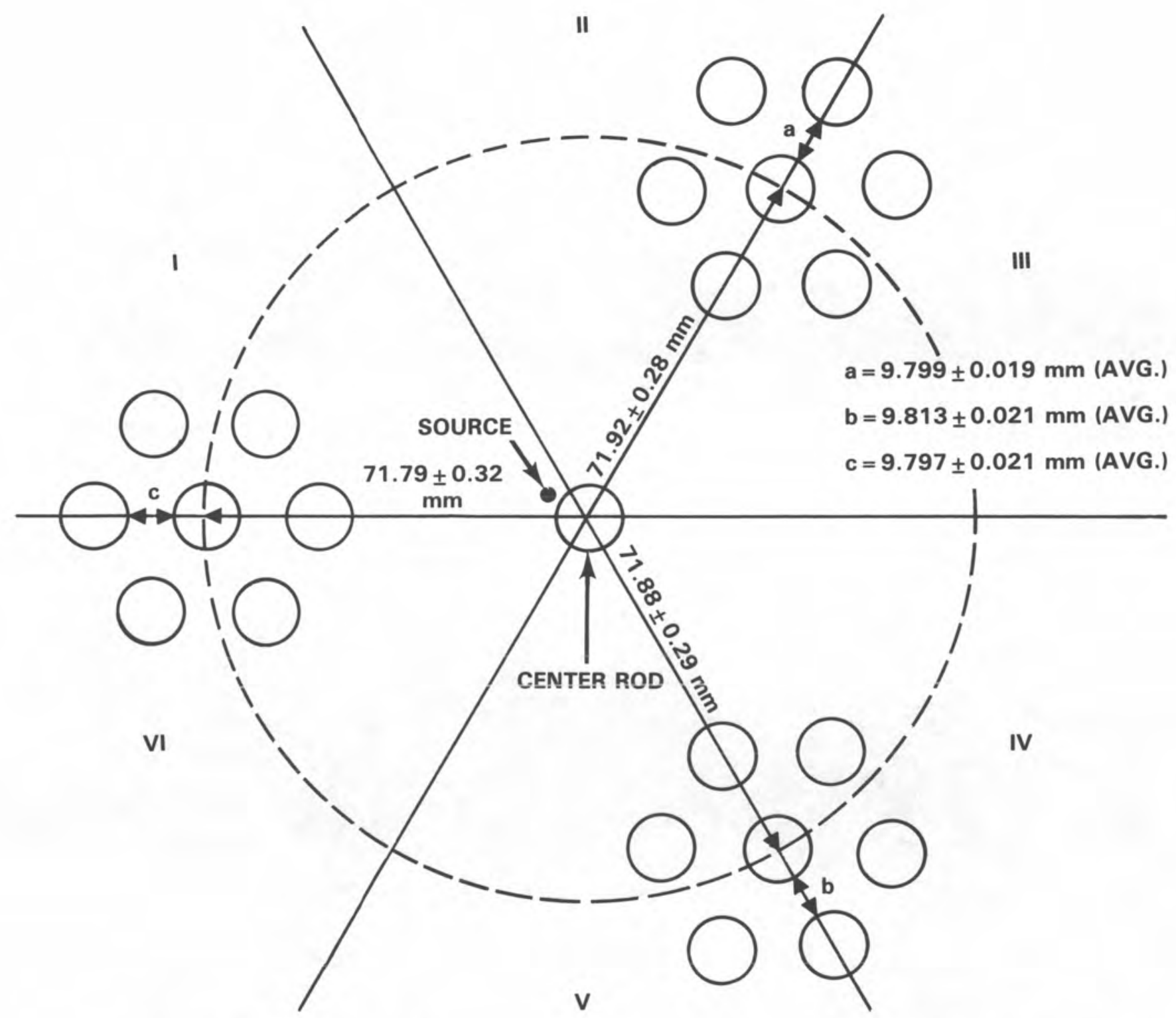

Figure 3.19 Layout of Reaction Rate Fuel Clusters for Number 11 Lattices 


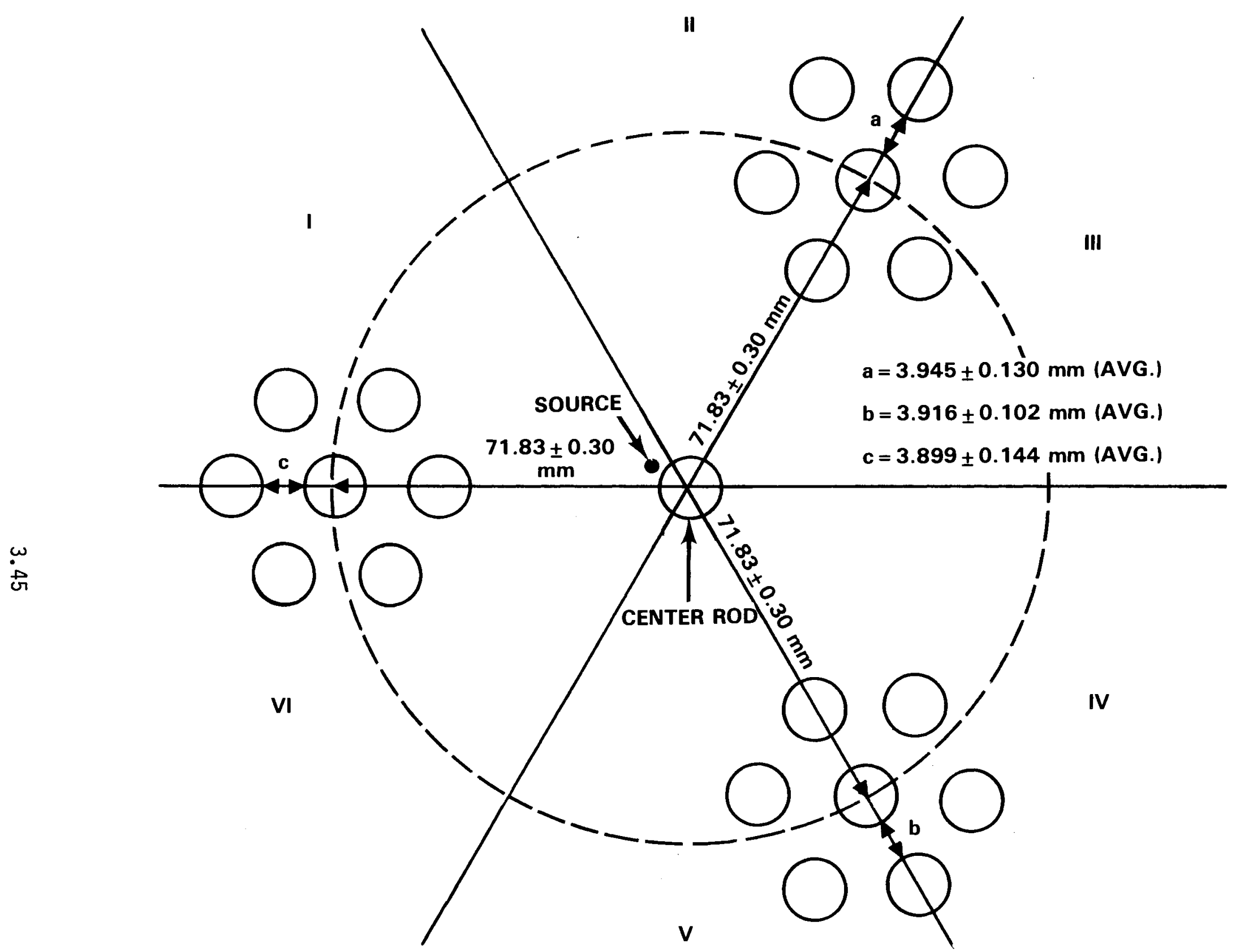

Figure 3.20 Layout of Reaction Rate Fuel Clusters for Number 12 Lattices 


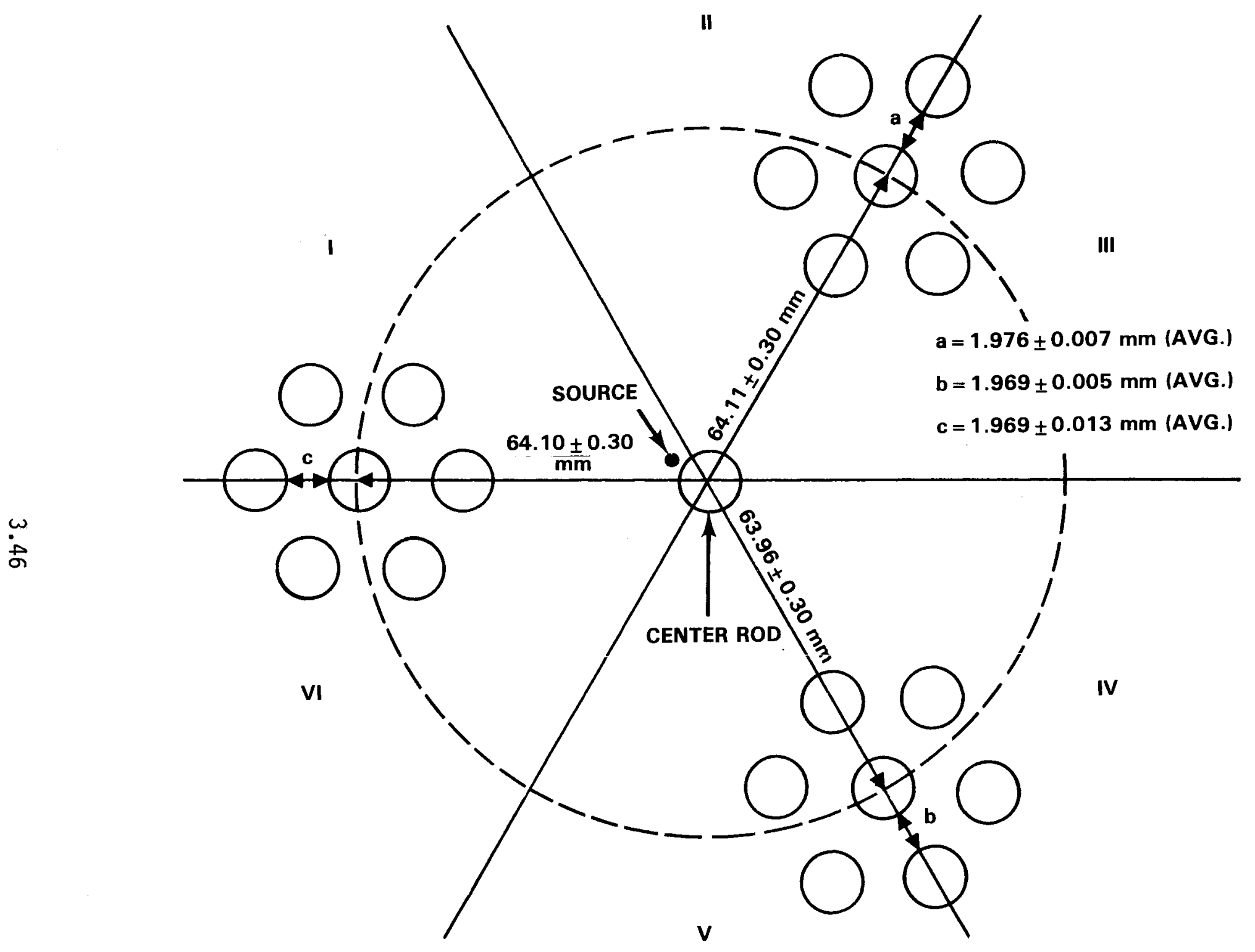

Figure 3.21 Layout of Reaction Rate Fuel Clusters for Number 13 Lattices 
observed in these measurements indicate that the FFR and RCR measurements were relatively insensitive to the dimensional variations reported in Figures $3.19,3.20$ and 3.21 . 



\subsection{CONCLUSIONS}

The number of fuel rods required for delayed critical ity have been experimentally determined for the following:

- Fuel-water lattices of $4.31 \mathrm{wt} \%{ }^{235} \mathrm{U}$ enriched $\mathrm{Un}_{2}$ fuel rods on center-to-center triangular spacings of 2,398 cm, $1.801 \mathrm{~cm}$ and $1.598 \mathrm{~cm}$ in water containing up to $1.481 \mathrm{~g} \mathrm{Gd} / \ell$.

- Fuel-water lattices of $2.35 \mathrm{wt}^{2}{ }^{235} \mathrm{~J}$ enriched $\mathrm{UO}_{2}$ fuel rods on centerto-center triangular spacings of $1.895 \mathrm{~cm}$ and $1.598 \mathrm{~cm}$ in water containing up to $0.12 \mathrm{~g} \mathrm{Gd} / \ell$.

- Fuel-water lattices of $4.31 \mathrm{wt} \%{ }^{235} \mathrm{U}$ enriched $\mathrm{UO}_{2}$ fuel rods mixed with fuel rods of $2 \mathrm{wt} \% \mathrm{PuO}_{2}$ in natural $\mathrm{UO}_{2}$ to obtain simulated irradiated fuel Pu/U compositions in lattices having a triangular center-to-center spacial of $1.598 \mathrm{~cm}$ between rods and up to $0.673 \mathrm{~g} / \mathrm{l}$ of gaddolinium dissolved in the water.

The critical size has also been experimentally determined for each of the above systems with fuel voided (i.e. water holes or columns) regions in the lattice assembly.

Using the pulse neutron source technique, subcritical $k_{\text {eff }}$ valves, prompt neutron decay constants and neutron lifetimes have been experimentally measured for each of the above described systems as a function of gadolinium concentration in the water. The data obtained covers $k_{\text {eff }}$ values down to about 0.85 and gadolinium concentrations up ot $2.362 \mathrm{~g} \mathrm{Gd} / \%$.

Absolute ${ }^{235} \mathrm{U}$ fission rates, fast fission ratios $\left({ }^{238} \mathrm{U} /{ }^{235} \mathrm{U}\right)$ and relative conversion ratios $\left({ }^{238} U_{c}{ }^{235} U_{f}\right)$ have been measured in the experimental assembilies of $4.31 \mathrm{wt} \%{ }^{235} \mathrm{U}$ enriched $\mathrm{UO}_{2}$ fuel. The absolute ${ }^{235} U$ fission rates varied from $1.59 \times 10^{-13} \mathrm{fat}^{-1} \mathrm{sec}^{-1}$ for the near optimum (with no dissolved gadolinium in the water) neutron moderated $2.398 \mathrm{~cm}$ lattice spacing to $4.71 \times 10^{-15}$ for the undermoderated $1.598 \mathrm{~cm}$ lattice spacing. Correspondingly, fast fission ratios of 0.00196 to 0.00571 , and relative conversion ratios of 2.70 to 7.64 were observed in these same fuel-water lattices. 
With respect to interpretation or use of the data presented herein, the following should be noted:

- Clean, easily defined critical assemblies to which experimentally determined corrections have been applied are provided (Table 3.1) for comparison with calculations. However, the experimental data from which these corrected data were derived are also provided (Table 3.2) for comparison purposes if desired.

- All of the subcritical keff values were obtained from data accumulated with the neutron detector located in the reflector region of each assembly. Consequently any calculational comparisons with the measured values of $k_{\text {eff }}$ should include a coresponding calculationed spatial correction using the same nuclear data.

- The relative conversion ratios are relative to the thermal neutron flux in the AEEW Nestor reactor.

- The average gadolinium concentrations used herein to correlate the measurement data with the amount of dissolved gadolinium present may be about $2 \%$ high based on the analysis results obtained with the prepared control samples. 


\subsection{REFERENCES}

Becker, M., and K. S. Quisenberry. 1966. "The Spatial Dependence of Pulsed Neutron Reactivity Measurements." In Proceedings of the Symposium on Neutron Dynamics and Control, Ser. 7, pp. 235-276, USAEC Symposium held at Tuscon, Arizona, May ${ }^{` 1966 . ~ N a t i o n a l ~ T e c h n i c a l ~ I n f o r m a t i o n ~ S e r v i c e, ~ S p r i n g f i e l d, ~}$ Virgina.

Bierman, S. R., and E. D. Clayton. 1981. "Criticality Experiments with Subcritical Clusters of 2.35 and $4.31 \mathrm{wt} \%{ }^{235} \mathrm{U}$-Enriched $\mathrm{UO}_{2}$ Rods in water with Steel Reflecting Walls." Nuclear Technology. 54: 131-144.

Bierman, S. R., B. M. Durst and E. D. Clayton. 1979. "Critical Separation Between Subcritical Clusters of Low Enriched $\mathrm{UO}_{2}$ Rods in Water with Fixed Neutron Poisons." Nuclear Technology. 42: 237-249.

Broome, P. 1983. Minutes of a Meeting to Discuss the Chemical Analyses Performed in Connection with the Hanford Dissolver Experiment. TSCG/PEB/ 783/3. British Nuclear Fuels, Ltd., Risley, England.

Garelis, E., and J. L. Russel1. 1963. "Theory of Pulsed Neutron Source Measurements." Nuclear Science and Engineering. 16: 263.

Gold, Raymond and Ronald J. Armani. 1968. "Absolute Fission Rate Measurements with Solid-State Track Recorders." Nuclear Science and Engineering. 34: 13-32.

Gozani, T., P. DeMarmels, T. Hurliman and H. Winkler. 1965. "On the Modified Pulse Source Techniques." In Proceedings of Symposium on Pulsed Neutron Research, Vol. II, pp. 49-62. Held by the International Atomic Energy Agency at Karlsruhe. International Atomic Energy Agency, Vienna, Austria.

Kaiz, G. H. 1969. N. S. Savannah Core II Nuclear Characteristics. NUS-597, prepared for Todd Shipyards, Corp. by NUS Corporation, Rockville, Maryland. 
Pfeiffer, W., J. R. Brown and A. C. Marsha11. 1974. "Fort St. Vrain Startup Test A-3: Pulsed Neutron Experiments." GA-A13079. Prepared for the United States Atomic Energy Commission, San Francisco Operations Office by General Atomic Company, San Diego, Ca.lifornia, 92138.

Roberts, J. H., and Song-Teh Huang. 1968. "Fission Rate Measurements in Low-Power Fast Critical Assemblies with Solid-State Track Recorders." Nuclear Applications. 5: 247-252.

Ruddy, R. H. 1983. "SSTR Fission Rates Measured in British Nuclear Fuels, Limited Critical Cores." 8352257 (JuTy 26, 1983). Pacific Northwest Laboratory, Richland, Washington.

Sjostrand, N. G. 1956. "Measurements on a Subcritical Reactor Using a Pulsed Neutron Source." In Proceedings of United Nations International Conference on Peaceful Uses of Atomic Energy. 5: 52. Geneva, Switzerland.

Smith, R. I. and G. A. Konzek. 1978. Clean Critical Experiment Benchmarks for Plutonium Recycle in LWR's (Foil Activation Studies). NP-196. Vol. 2. Prepared for Electric Power Research Institute by Pacific Northwest Laboratory, Richland, Washington.

Smith, R. I. and G. J. Konzek. 1976. Clean Critical Experiment Benchmarks for Plutonium Recycle in LWR's. NP-196. Vol. 1. Prepared for Electric Power Research Institute by Pacific Northwest Laboratory, Richland, Washington.

Uotinen, V. 0. and L. D. Williams. 1967. Experiments and Calculations for $\mathrm{H}_{2} \mathrm{O}$-Moderated Assemblies Containing $\mathrm{UO}_{2}-2$ Wt\% Pu0 ${ }_{2}$ Fuel Rods. PNL-SA-1107. Pacific Northwest Laboratory, Richland, Washington. 


\section{APPENDIX A}

Density and Chemical Composition of Type 6061, 1100 and 5052 Aluminum and for Zircalloy-2 


\section{APPENDIX A}

\section{Density and Chemical Composition of Type 6061,}

1100 and 5052 Aluminum and Zircalloy-2

Density and American Society for Testing Materials (ASTM) chemical specifications for the aluminum and zircalloy-2 presented in the experimental assemblies are presented in this Appendix.

A. 1 


\section{Chemical Composition}

\begin{tabular}{|c|c|}
\hline Element & $\mathrm{Wt} \%$ \\
\hline $\mathrm{Si}$ & $0.40-0.80$ \\
\hline $\mathrm{Fe}$ & 0.7 (Maximum) \\
\hline $\mathrm{Cu}$ & $0.15-0.40$ \\
\hline $\mathrm{Mn}$ & 0.15 (Maximum) \\
\hline $\mathrm{Mg}$ & $0.8-1.2$ \\
\hline $\mathrm{Cr}$ & $0.04-0.35$ \\
\hline $\mathrm{Zn}$ & 0.25 (Maximum) \\
\hline $\begin{array}{l}\mathrm{Ti} \\
\mathrm{Al}\end{array}$ & $\begin{array}{l}0.15 \text { (Maximum) } \\
\text { Remainder }\end{array}$ \\
\hline
\end{tabular}

Maximum Impurities

$\begin{array}{lc}\text { Element } & W t \% \\ \text { Each } & 0.05 \\ \text { Total } & 0.15 \\ \text { sity: } & 2.69 \mathrm{~g} / \mathrm{cm}^{3} \text { (Not part: of standard - measured } \\ & \text { by volume displacement) }\end{array}$


ASTM STANDARD B210-78 SPECIFICATIONS FOR TYPE 1100 ALUMINUM

\section{Chemical Composition}

\begin{tabular}{|c|c|}
\hline Element & Wt\% \\
\hline $\begin{array}{l}\mathrm{Si} \\
\mathrm{Fe}\end{array}$ & 1.0 (Combined Maximum) \\
\hline $\begin{array}{l}\mathrm{Cr} \\
\mathrm{Mn} \\
\mathrm{Zn} \\
\mathrm{Al}\end{array}$ & $\begin{array}{l}0.05-0.20 \\
0.05 \text { (Maximum) } \\
0.10 \text { (Maximum) } \\
99.00 \text { (Minimum) }\end{array}$ \\
\hline
\end{tabular}

Maximum Impurities

$\begin{array}{ll}\text { Element } & \text { Wt\% } \\ \text { Each } & 0.05 \\ \text { Total } & 0.15\end{array}$

Density: $2.70 \mathrm{~g} / \mathrm{cm}^{3}$ (Not part of standard - measured by volume displacement) 
ASTM STANDARD B210-78 SPECIFICATIONS FOR TYPE 5052 ALUMINUM

\section{Chemical Composition}

\begin{tabular}{|c|c|}
\hline Element & $w t \%$ \\
\hline $\begin{array}{l}\mathrm{Si} \\
\mathrm{Fe}\end{array}$ & 0.45 (Combined Maximum) \\
\hline $\begin{array}{l}\mathrm{Cu} \\
\mathrm{Mn} \\
\mathrm{Mg} \\
\mathrm{Cr} \\
\mathrm{Zn} \\
\mathrm{Al}\end{array}$ & $\begin{array}{l}0.10 \text { (Maximum) } \\
0.10 \text { (Maximum) } \\
2.2-2.8 \\
0.15-0.35 \\
0.10 \text { (Maximum) } \\
\text { Rema inder }\end{array}$ \\
\hline
\end{tabular}

Maximum Impurities

$\begin{array}{ll}\text { Element } & W T \% \\ \text { Each } & 0.05 \\ \text { Total } & 0.15\end{array}$

Density: $2.69 \mathrm{~g} / \mathrm{cm}^{3}$ (Not Part of Standard) 
ASTM STANDARD B 353-71 CHEMICAL SPECIFICATIONS FOR ZIRCALLOY-2

Chemical Composition

\begin{tabular}{|c|c|}
\hline Element & Wt\% \\
\hline $\begin{array}{c}\mathrm{Sr} \\
\mathrm{Fe} \\
\mathrm{Cr} \\
\mathrm{Ni} \\
\mathrm{Fe}+\mathrm{Cr}+\mathrm{Ni} \\
\mathrm{Zr}\end{array}$ & $\begin{array}{l}1.20-1.70 \\
0.07-0.20 \\
0.05-0.15 \\
0.03-0.08 \\
0.18-0.38 \\
\text { Remainder }\end{array}$ \\
\hline
\end{tabular}

Maximum Impurities

\begin{tabular}{cl} 
Element & \multicolumn{1}{c}{$W t \%$} \\
\cline { 1 - 1 } $\mathrm{Al}$ & 0.0075 \\
$\mathrm{~B}$ & 0.00005 \\
$\mathrm{Cd}$ & 0.00005 \\
$\mathrm{C}$ & 0.027 \\
$\mathrm{Cr}$ & - \\
$\mathrm{Co}$ & 0.0020 \\
$\mathrm{Cu}$ & 0.0050 \\
$\mathrm{Hf}$ & 0.020 \\
$\mathrm{Fe}$ & - \\
$\mathrm{H}$ & 0.0025 \\
$\mathrm{O}$ & 0.0025 \\
$\mathrm{Mg}$ & 0.0050 \\
$\mathrm{Ni}$ & - \\
$\mathrm{N}$ & 0.0080 \\
$\mathrm{Si}$ & 0.020 \\
$\mathrm{Ti}$ & 0.0050 \\
$\mathrm{~W}$ & 0.010 \\
U (Tota1) & 0.00035
\end{tabular}

Density: $6.55 \mathrm{~g} / \mathrm{cm}^{3}$ (Not Part of Standard) 
APPENDIX B

Description of Analytical Methods Used to Obtain

Gadol inium Concentration and Comparison

of Results on Prepared Solution Samples 
APPENDIX B

Description of Analytical Methods Use to Obtain Gadolinium Concentration and Comparison of Results on Prepared Solution Samples

Water samples taken from the experimental assemblies were analyzed for gadolinium by four different laboratories. These laboratiries were:

- Hanford Environmental Health Foundation - Richland, Washington, U.S.A.

- Pacific Northwest Laboratories - Richland, Washington, U.S.A.

- Atomic Energy Establishment Winfrith, Dorechester, Dorset, U.K.

- British Nuclear Fuels, Ltd., Sellafield, Cumbria, U.K.

The analytical methods as used by these laboratories are described briefly in this Appendix. The results obtained by these analytical methods on prepared solution samples are also covered in this Appenix. 
The Determination of Natural Gadolinium in Water Samples by Isotope Dilution Mass Spectrometry - Atomic Energy Establishment Winfrith

In Isotope Dilution Mass Spectrometry (IDMS), a known amount of an isotope, normally present as a minor constituent: of the el ement being analysed, is added as a tracer to a sample aliquot. After adequate mixing of the spiked solution a portion is loaded onto a mass spectrometer (MS) filament and isotope ratios determined in the MS. Ion beam intensities of the added isotope and a reference isotope are measured and the ratio calculated. The difference between this ratio and the isotopic ratio in an unspiked sample is used to calculate the concentration of the element in the original solution.

Gadolinium has a natural isotopic composition as shown below. Although Gadol inium-154 would have been the preferred tracer because of its low natural abundance, Gadolinium-157 was chosen as the isotope dilution tracer, because of its ready availability from the stable isotope production unit at Harwell.

\section{NATURAL ISOTOPIC COMPOSITION OF GADOLINIUM}

$\begin{array}{llllllll}\text { Isotope } & 152 & 154 & 155 & 156 & 157 & 158 & 160 \\ \text { Atom \% } & 0.20 & 2.15 & 14.73 & 20.47 & 15.68 & 24.87 & 21.90\end{array}$

Gadol inium- 157 tracer in the form of $\mathrm{Gd}_{2} \mathrm{O}_{3}$ was dissolved in $50 \%$ nitric acid and diluted to an acid strength of $5 \%$ nitric acid at a nominal concentration of $100 \mu \mathrm{g} \mathrm{Gd}-157 / \mathrm{ml}$. A second batch of tracer solution was prepared at $50 \mu \mathrm{g}$ Gd-157/ml. Accurate concentration of each tracer solution was measured by IDMS using gadol inium standards prepared for ICP analyses. Results are listed below.

CALIBRATION RESULTS OF GADOLINIUM-157 TRACER SOLUTIONS

\begin{tabular}{|c|c|c|c|}
\hline Tracer Solution No & $157 \mathrm{Gd}, \mu \mathrm{g} / \mathrm{g}$ & S.D. & RSD \\
\hline 1 & 96.72 & 0.57 & $0.59 \%$ \\
\hline 2 & 45.95 & 0.23 & $0.51 \%$ \\
\hline
\end{tabular}

Initially tracer solution 1 was used and, when exhausted, solution 2 was used. 
The RSD values of $0.59 \%$ and $0.51 \%$ were calculated from actual determinations and include all errors associated with the method, i.e., balance weighings, mixing of tracer and aliquots, and mass spectrometry isotope ratio measurements. This can be compared with RSD values of $0.48 \%$ and $0.43 \%$ from Table 1 (ICP standards) which are calculated only on the instrument response for standards. For actual analys is of samples the errors for the responses of the samples will have to be combined giving RSD values of approximately $0.75 \%$ for analytical results on the ICP.

To analyze the experiment samples, aliquots of tracer solution containing 50-100 $\mu \mathrm{g} \mathrm{Gd}-157$ were weighed into clean tared $5 \mathrm{ml}$ beakers and weight aliquts of sample containing 50-200 $\mathrm{gg}$ Gd added. Each spiked al iquot was mixed by swirling, slowly evaporated to dryness and the residue taken into solution with 3-4 drops of 4M nitric acid. Approximately 1-2 $\mu \mathrm{g}$ Gd from this solution was dried onto the side filaments of a triple rhenium filament mass spectrometer bead, loaded into the VG54E thermal ionisation mass spectrometer, and the Gd $157 / \mathrm{Gd} 156$ isotope ratio measured. From this ratio the Gd content of the sample was calculated. 


\section{The Determination of Natural Gadolinium in Water Samples by}

Argon Plasma Emission Spectroscopy - Pacific Northwest Laboratory

Samples were analyzed for gadolinium using direct current argon plasma emission spectroscopy. The instrument used was a Spectrametrics Spectraspan IIIB Echelle spectrometer operated in sequential mode at the $4401.86 \mathrm{~A}$ line. Samples were aspirated directly into the $D C$ source with a peristaltic pump. A SPEX Industries $995 \mathrm{ppm}$ gadolinium solution was used as the primary reference standard. Samples were run undiluted and compared directly against the standard. A series of sequential dilutions of the standard were prepared to verify that the analytical 1 ine chosen was 1 inear over the full range of interest. Distilled water was used as the low level reference blank. Accuracy and precision of the method is estimated to be $1-2 \%$. 
The Determination of Natural Gadol inium in Water Samples by Flame Emission Spectroscopy - Hanford Environmental Health Foundation

Flame emission is an analytical technique which is related to and complementary to atomic absorption. There are several basic differences between atomic absorption and flame emission spectroscopy. In atomic absorption, the only function of the flame is to convert the incoming aerosol into atomic vapor which can then absorb light from the primary light source, the hollow cathode $1 \mathrm{amp}$. The flame emission technique requires the flame to do two jobs: convert the aerosol into an atomic vapor and then thermally elevate the atoms to an excited electronic state. When these atoms return to the ground state, they emit light. The intensity of light emitted is related to the concentration of the element of interest in solution. 
The Determination of Natural Gadol inium in Water Samples by Thermal Ionization Mass Spectrometry - British Nuclear Fuels, Ltd.

The method is based upon the principle of adding a known amount of gadolinium enriched with gadolinium 160 to a suitable portion of the sample. By measuring the isotopic ratio of the other isotopes of gadolinium to the 160 isotope it is possible to calculate the gadolinium content of the sample.

The tracer, an isotopically enriched standard of gadolinium consisting of $98 \%$ gadolinium 160, was first calibrated against three natural gadolinium standards. One made from "specification pure" gadolinium oxide and two from high purity gadolinium metal. In order to prevent any surface oxidation, the gadolinium metal was received in, and at all times handled in, an argon atmosphere. Each calibration was performed eight times.

Using pre-etched glassware to minimize the possibility of rare earth contamination of the samples from the glass surface, weighed portions of the tracer and sample were mixed together and taken to dryness to ensure isotopic equilibration.

To maintain the optimum sample to tracer ratio each analysis was performed using 20 micrograms of tracer and 100 micrograms of gadolinium from the sample.

A small portion of this mixture ( 1 microgram of gadolinium) was mounted upon a triple filament mass spectrometer bead ard analyzed using a VG 54/38 double focussing thermal ionization mass spectrometer. Ratio measurements were made on 156, 157 and 158 to 160 for gadolinium and checks were made to assess whether any isobaric interference was caused by other rare earth elements. The total precision at the one standard deviation uncertainty level is estimated to be greater than $0.5 \%$. 
The Determination of Natural Gadolinium in Water Samples by

Inductively Coupled Plasma Spectroscopy - Atomic Energy Establishment Winfrith

In inductively coupled plasma (ICP) spectroscopy an efficient radio frequency generator directs high frequency energy to an induction coil where an intense magnetic field is created. A stream of argon gas directed through the magnetic field by a quartz torch, is ionized to form a plasma, and a fine aerosol of the sample is injected into the core of the plasma. There the elements are thermally excited at temperatures near $11,000^{\circ} \mathrm{C}$. These high temperatures insure the complete breakdown of chemical compounds and impedes the formation of other interfering compounds. The result is light energy emitted at identifiable wavelengths for each element (spectra). Precision entrance optics gather the light and directs it through a primary slit to a precision concave diffraction grating. The grating diffracts, resolves, and focuses the spectral light on exit slits at the spectrometer's focal curve. Exit slits are positioned to pass only specific wavelenghts for the elements of interest. Mirrors positioned behind the exit slits gather diverging light and focus it on the cathode of photomultiplier tubes, where light energy is converted to electrical signals proportional to individual elemental emission intensities.

Electrical signals from the photomultipliers are processed by the measuring electronics and are read direct from the operator's terminal in concentration units (e.g. ppm. ppb.\%). 


\section{Analysis Results on Samples Containing Known \\ Quantities of Gadolinium Dissolved in Water}

Standard solutions containing $0.25 \mathrm{~g} \mathrm{Gd} / \ell 0.50 \mathrm{~g} \mathrm{Gd} / \ell$ and $1.0 \mathrm{~g} \mathrm{Gd} / \ell$ were prepared by the Springfields Works of BNFL for use in comparing results obtained by the analytical techniques described in this Appendix. Gadol inium nitrate (a solid) was used in the experiments. However the nitrate form is deliquescent and can possess up to six waters of hydration. Therefore, to assure good controlled standards, the standard solutions were prepared by two methods.

Pure gadolinium oxide ( 99.999 wt\% $\mathrm{Gd}_{2} \mathrm{O}_{3}$ ) was heated at. $800^{\circ}$ for one hour. Weighed amounts $(0.288 \mathrm{~g}, 0.5763 \mathrm{~g}$, and $1.152 \mathrm{~g})$ of this $\mathrm{Gd}_{2} \mathrm{O}_{3}$ were dissolved in a minimum quantity of nitric acid, an excess of nitric acid equivalent to $20 \mathrm{~g} / \ell$ added, and then diluted with distilled water to $1 \mathrm{l}$, producing $0.25 \mathrm{~g}, 0.5 \mathrm{~g}$ and $1.0 \mathrm{~g} \mathrm{Gd} / \mathrm{l}$. The solution was then bottled to obtain $100 \mathrm{ml}$ samples. Samples were also prepared by dissolving weighed amounts $(0.7176 \mathrm{~g}, 1.4352 \mathrm{~g}$, and $2.8703 \mathrm{~g})$ of the gadolinium nitrate powder used in the experiments in a minimum quanity of nitric acid, an excess of nitric acid equivalent to $20 \mathrm{~g} / \mathrm{l}$ added, and then diluted with distilled water to $1 \mathrm{l}$, producing nominal $0.25,0.5$ and $1 \mathrm{~g} \mathrm{Gd} / \ell$ solutions. The solution was then bottled, $100 \mathrm{ml}$ per bottle.

The results obtained with the various analytical methods are summarized in the following table. 
Analytical Results

Sample Description

\begin{tabular}{ll}
\multicolumn{1}{c}{ Compound } & $\frac{g \mathrm{Gd} / \ell}{}$ \\
$\mathrm{Gd}_{2} \mathrm{O}_{3}$ & 0.25 \\
$\mathrm{Gd}_{2} \mathrm{O}_{3}$ & 0.50 \\
$\mathrm{Gd}_{2} \mathrm{O}_{3}$ & 1.00 \\
$\mathrm{Gd}\left(\mathrm{NO}_{3}\right)_{3} \cdot 6 \mathrm{H}_{2} \mathrm{O}$ & 0.25 \\
$\mathrm{Gd}\left(\mathrm{NO}_{3}\right)_{3} \cdot 6 \mathrm{H}_{2} \mathrm{O}$ & 0.50 \\
$\operatorname{Gd}\left(\mathrm{NO}_{3}\right)_{3} \cdot 6 \mathrm{H}_{2} \mathrm{O}$ & 1.00
\end{tabular}

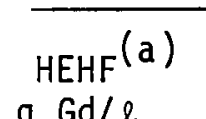

$\mathrm{g} \mathrm{Gd} / \mathrm{e}$

0.340

0.575

1.200

0.285

0.590

1.300
PNL (b)

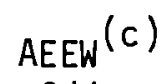

g Gd/l

0.260

$\mathrm{g} \mathrm{Gd} / \ell$

0.498 .

0.249

0.506

0.986

1.019

0.263

0.270

0.525

0.526

1.070

1.050

0.264

0.534

1.058
$\operatorname{AEEW}^{(d)}$

$B N F L(e)$

$\mathrm{g} \mathrm{Gd} / \ell$

$\mathrm{g} \mathrm{Gd} / \ell$

0.257

0.261

0.256

0.503

0.516

0.507

1.034

1.020

0.268

0.266

0.544

0.528

1.081

1.074
1.020

0.268

0.541

1.051

(a) Flame emission spectroscopy by Hanford Environmental Health Foundation.

(b) DC argon plasma emission spectroscopy analys is by Battelle-Northwest.

(c) Inductively coupled plasma emission spectroscopy analys is by Atomic Energy Es tabl ishment Winfrith.

(d) Isotope dilution mass spectrometry analys is by Atomic Energy Establishment Winfrith.

(e) Thermal ionization mass spectrometry analys is by British Nuclear Fuels, Ltd. Windscale.

To obtain exact agreement with the solution samples containing dissolved $\mathrm{Gd}_{2} \mathrm{O}_{3}$ the analytically determined concentrations, given above, require the factors indicated below:

Sample Description

Compound g gd/l

$\mathrm{Gd}_{2} \mathrm{O}_{3}$

$\mathrm{Gd}_{2} \mathrm{O}_{3}$

$\mathrm{Gd}_{2} \mathrm{O}_{3}$
0.25

0.50

1.00

\begin{tabular}{ll}
\hline HEHF & PNL \\
(FES) & (DAP) \\
\hline
\end{tabular}

0.7353

0.8696

0.8333
0.9615

1.0040

1.0142
Analytical Method

\begin{tabular}{lll} 
AEEW & AEEW & AEEW \\
(ICP) & (MS) & (MS) \\
\hline
\end{tabular}

$\begin{array}{lll}1.0040 & 0.9699 & 0.9728\end{array}$

0.9881

0.9901

0.9690

0.9814

0.9737

0.9804

Based on the above results and consultations with BNFL and AEEW staff, it was concluded that the average of the concentrations determined by mass spectrometry would provide consistent analytical values for the experimental solution samples as good as could be obtained. (Broome 1983). 
In addition to the Springfield's solutions, samples were periodically prepared at the Critical Mass Laboratory by dissolving into distilled water containing $1 \mathrm{~g}$ nitric acid, weiahed amounts of the gadolinium nitrate powder used in the experiments. The analys is results obtained for these samples are summarized below:

Sample Description g Compound/g Water

\section{(a)}

$7.190 \times 10^{-4}$

$7.190 \times 10^{-4}$

$7.190 \times 10^{-4}$

$7.190 \times 10^{-4}$

$7.185 \times 10^{-4}$

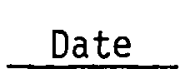

$08 / 11 / 82$

$08 / 11 / 82$

$11 / 16 / 82$

$11 / 16 / 82$

$01 / 22 / 83$
Analytical Results

\begin{tabular}{|c|c|c|}
\hline $\begin{array}{l}\mathrm{HEHF} \text { (b) } \\
\mathrm{gGd/ \ell}\end{array}$ & $\begin{array}{l}\mathrm{PNL}(c) \\
\mathrm{gGd} / \ell\end{array}$ & $\begin{array}{l}\mathrm{BNFL}(\mathrm{d} \\
\mathrm{gGd} / \ell \\
\end{array}$ \\
\hline 0.306 & -...- & ----- \\
\hline 0.307 & ----- & ---- \\
\hline 0.310 & 0.259 & ----- \\
\hline ----- & 0.260 & ----- \\
\hline 0.330 & 0.260 & 0.269 \\
\hline
\end{tabular}

(a) Equivalent to $0.25 \mathrm{~g} \mathrm{Gd} / \ell$ if compound is the hexahydrate.

(b) Flame emission spectroscopy by Hanford Environmental Health Foundation.

(c) DC argon plasma emission spectroscopy analysis by Battelle-Northwest.

(d) Thermal ionization mass spectrometry analys is by British Nuclear Fuels, Ltd - Windscale.

Based on the concentrations determined for the gadolinium nitrate samples by mass spectrometry, an average of $4.91 \pm 0.18$ waters of hydration was calculated for the gadolinium powder used in the experiments. 


\section{APPENDIX C}

Trace Impurities Present in Water

and Gadolinium Nitrate Used in Experiments 

APPENDIX C

Trace Impurities Present in Water and Gadol inium Nitrate Used in Experiments

Trace impurity levels are presented in this Appendix for the gadolinium nitrate powder and the gadolinium-water solutions. The gadolinium-water solutions are identified by sample numbers and experiment reference numbers which are tracable to the experimental assemblies described in the various sections of the report.

Impurities in the solutions were determined on a direct reading ICP which is capable of simultaneous analys is for 48 elements. A qualitative assessment of impurities was made by introducing a few millilitres of each sample solution into the argon plasma, and, while monitoring light emissions from the plasma on all the detectors, scanning across the detectors by moving the primary slit. The primary slit is the entrance slit to the spectrometer and small sideways movements have the same effect as moving the diffraction grating. Using this method, approximate concentrations of each element are obtained and interfering lines from other elements are highlighted. Those elements which gave a positive response were considered for quantitative analysis.

Standard solutions were prepared of those elements qualitatively identified. Following ICP calibration with these standards the samples were analysed.

Analysis of aluminum in the presence of gadolinium is a problem on the Winfrith ICP as the $308.20 \mathrm{~nm}$ Gd line overlaps the $308.2 \mathrm{~nm}$ Al line selected for aluminum analysis on the Winfrith ICP. (ICP direct readers have fixed slits so alternative lines cannot be used). To overcome this problem aluminum was determined by flame atomic absorption.

In the gadolinium-water impurity analyses the neodymium results tend to vary in direct relationship with the gadolinium concentration. Since 
the gadolinium nitrate used in the experiments originated from the same batch, the neodymium impurities are probably due to gadolinium interference in the analyses. Also, it should be noted that the step-wise increase in aluminum inpurity in the gadolinium-water samples corresponds to the practice of adding a small amount of nitric acid to the experimental solution to assure precipitation of gadolinium compounds did not occur. Therefore, the increase in aluminum impurity is probably due to corrosion products resulting from this practice. 
TRACE IMPURITIES PRESENT IN GADOLINIUM

NITRATE POWDER USED IN EXPERIMENTS

Spectrographic Analys is by Supplier, Research Chemical, Phoenix, Arizona 85063

\begin{tabular}{cr} 
Element & $W t \%$ \\
\cline { 1 - 2 } Eu & .03 \\
Tb & .05 \\
Dy & $<.01$ \\
$\mathrm{Y}$ & .01 \\
$\mathrm{Sm}$ & $<.01$ \\
$\mathrm{Si}$ & $<.01$ \\
$\mathrm{Fe}$ & $<.01$ \\
$\mathrm{Mg}$ & $<.01$ \\
$\mathrm{Ca}$ & $<.01$ \\
$\mathrm{Al}$ & $<.01$
\end{tabular}

Impurity Analyses by Atomic Energy Establishment Winfrith, United Kingdom

\begin{tabular}{|c|c|c|c|}
\hline Element & $w t \%$ & Element & $w t \%$ \\
\hline Y & 0.01 & $\mathrm{Ce}$ & $<0.005$ \\
\hline Eu & 0.005 & $\mathrm{Mg}$ & $<0.005$ \\
\hline $\mathrm{Cu}$ & 0.003 & $\mathrm{Rh}$ & $<0.005$ \\
\hline $\mathrm{Al}$ & $<0.1$ & W & $<0.005$ \\
\hline $\mathrm{Be}$ & $<0.1$ & $\mathrm{Zn}$ & $<0.003$ \\
\hline $\mathrm{Nd}$ & $<0.1$ & $\mathrm{Aq}$ & $<0.002$ \\
\hline$S i$ & $<0.1$ & $\mathrm{Au}$ & $<0.002$ \\
\hline$T i$ & $<0.1$ & $\mathrm{Ba}$ & $<0.002$ \\
\hline B & $<0.05$ & $\mathrm{Cd}$ & $<0.002$ \\
\hline $\mathrm{Ca}$ & $<0.05$ & Co & $<0.002$ \\
\hline $\mathrm{Na}$ & $<0.05$ & $\mathrm{Cr}$ & $<0.002$ \\
\hline $\mathrm{Pb}$ & $<0.05$ & $\mathrm{Fe}$ & $<0.002$ \\
\hline Ru & $<0.05$ & $\mathrm{Hf}$ & $<0.002$ \\
\hline Sn & $<0.05$ & $\mathrm{Li}$ & $<0.002$ \\
\hline $\operatorname{Ln}$ & $<0.01$ & $\mathrm{Mn}$ & $<0.002$ \\
\hline K & $<0.01$ & Mo & $<0.002$ \\
\hline $\mathrm{Ni}$ & $<0.01$ & sr & $<0.002$ \\
\hline Pt & $<0.01$ & V & $<0.002$ \\
\hline Sm & $<0.01$ & $\mathrm{Zr}$ & $<0.002$ \\
\hline U & $<0.01$ & & \\
\hline
\end{tabular}


TRACE IMPURITIES PRESENT IN GADOLINIUM-WATER SOLUTIONS

ICP Analysis by Atomic Energy Establishment Winfrith

Microgram of Element per Gram of Sample

\begin{tabular}{|c|c|c|c|c|c|c|c|c|c|c|c|c|c|c|c|}
\hline & $\begin{array}{l}\text { Experiment } \\
\text { Refference } \\
\text { Number } \\
\end{array}$ & $\begin{array}{c}\text { Samijle } \\
\text { Identification } \\
\text { Number } \\
\end{array}$ & Al & $B$ & Ca & Cu_..: & $\ldots$ & - $\mathrm{Pb}$ & My & $\mathrm{Nd}$ & $\mathrm{Ni}$ & $S i$ & $\mathrm{Ni}$ & $Y$ & $z_{n}$ \\
\hline & $\begin{array}{l}4.3-000-182 \\
4.3-000-185 \\
4.3-000-186 \\
4.3-000-188 \\
4.3-000-188 \\
4.000-183 \\
4.3-000-188\end{array}$ & $\begin{array}{l}1-1-1 \\
1-1-2 \\
1-1-3 \\
1-1-4 \\
1-1-5 \\
1-1-6 \\
1-1-7\end{array}$ & $\begin{aligned}< & 0.25 \\
< & 0.25 \\
< & 0.25 \\
< & 0.25 \\
< & 0.25 \\
< & 0.25 \\
& 0.3\end{aligned}$ & $\begin{array}{l}<0.05 \\
<0.05 \\
<0.05 \\
<0.05 \\
<0.05 \\
<0.05 \\
<0.05\end{array}$ & $\begin{array}{l}0.9 \\
1.5 \\
1.6 \\
2.9 \\
2.7 \\
2.9 \\
1.8\end{array}$ & $\begin{array}{l}0.03 \\
5.6 \\
0.15 \\
0.15 \\
0.15 \\
0.15 \\
0.16\end{array}$ & $\begin{array}{r}0.03 \\
<0.03 \\
0.04 \\
0.04 \\
0.05 \\
0.06 \\
0.06\end{array}$ & $\begin{array}{l}0.2 b \\
1.0 \\
0.37 \\
0.42 \\
0.44 \\
0.52 \\
0.57\end{array}$ & $\begin{array}{l}0.04 \\
1.3 \\
1.3 \\
2.4 \\
2.9 \\
3.1 \\
3.3\end{array}$ & $\begin{array}{r}0.5 \\
1.1 \\
4.0 \\
4.4 \\
4.9 \\
5.7 \\
7.2\end{array}$ & $\therefore \begin{array}{rl} & 0.1 \\
< & 0.1 \\
< & 0.1 \\
0.1 & 0.1 \\
0.1 \\
0.2 \\
0.2\end{array}$ & $\begin{aligned} & 2.6 \\
< & 0.2 \\
< & 0.2 \\
< & 0.2 \\
< & 0.2 \\
< & 0.2 \\
< & 0.2\end{aligned}$ & $\begin{array}{l}6.6 \\
0.6 \\
0.6 \\
6.8 \\
7.3 \\
8.9 \\
0.5\end{array}$ & $\begin{aligned}< & 0.01 \\
< & 0.01 \\
< & 0.01 \\
< & 0.01 \\
& 0.01 \\
& 0.02 \\
& 0.04\end{aligned}$ & $\begin{array}{ll}- & 0.03 \\
3.7 \\
0.19 \\
0.22 \\
0.22 \\
0.22 \\
0.23\end{array}$ \\
\hline & $\begin{array}{l}4.3-000-194 \\
4.3-000-194 \\
4.3-000-194 \\
4.3-000-194 \\
4.3-000-198\end{array}$ & $\begin{array}{l}1-3-3 \\
1-3-4 \\
1-3-5 \\
1-3-6 \\
1.3-7\end{array}$ & $\begin{array}{l}<0.25 \\
<0.25 \\
<0.25 \\
<0.25 \\
<0.25\end{array}$ & $\begin{array}{l}<0.05 \\
<0.05 \\
<0.05 \\
<0.05 \\
<0.05\end{array}$ & $\begin{array}{r}4.0 \\
7.0 \\
15.4 \\
5.0 \\
15.7\end{array}$ & $\begin{array}{l}0.15 \\
0.13 \\
0.03 \\
0.12 \\
0.03\end{array}$ & $\begin{array}{l}0.07 \\
0.07 \\
0.06 \\
0.05 \\
0.07\end{array}$ & $\begin{array}{r}0.52 \\
0.44 \\
<0.25 \\
0.30 \\
<0.25\end{array}$ & $\begin{array}{l}3.6 \\
3.9 \\
4.7 \\
2.7 \\
4.9\end{array}$ & $\begin{array}{l}7.1 \\
5.9 \\
1.1 \\
4.0 \\
1.1\end{array}$ & $\begin{aligned} & 0.2 \\
& 0.1 \\
&< 0.1 \\
& 0.1 \\
&< \\
& 0.1\end{aligned}$ & $\begin{aligned}< & 0.2 \\
< & 0.2 \\
& 1.2 \\
= & 0.2 \\
& 1.2\end{aligned}$ & $\begin{array}{l}4.0 \\
4.4 \\
3.0 \\
3.4 \\
3.1\end{array}$ & $\begin{aligned} & 0.04 \\
& 0.0 \hat{1} \\
&< 0.01 \\
&< 0.01 \\
& 0.02\end{aligned}$ & $\begin{array}{l}0.23 \\
0.23 \\
0.12 \\
0.18 \\
0.15\end{array}$ \\
\hline & $\begin{array}{l}2.35-000-160 \\
2.35-000-160 \\
2.35-000-165 \\
2.35-000-165 \\
2.35-000-165\end{array}$ & $\begin{array}{l}2-1-1 \\
2-1-2 \\
2-1-3 \\
2-1-4 \\
2-1-5\end{array}$ & $\begin{array}{l}<0.25 \\
<0.25 \\
<0.25 \\
<0.25 \\
<0.25\end{array}$ & $\begin{array}{l}<0.05 \\
<0.05 \\
<0.05 \\
<0.05 \\
<0.05\end{array}$ & $\begin{array}{r}0.5 \\
1.5 \\
2.7 \\
1.5 \\
6.0\end{array}$ & $\begin{array}{c}<0.03 \\
18.2 \\
0.04 \\
11.2 \\
14.2\end{array}$ & $\begin{array}{l}<0.03 \\
<0.03 \\
<0.03 \\
<0.03 \\
0.03\end{array}$ & $\begin{aligned} & \therefore 0.25 \\
& 1.9 \\
&< 0.25 \\
& 1.6 \\
& 1.4\end{aligned}$ & $\begin{array}{l}0.03 \\
1.4 \\
0.86 \\
1.4 \\
2.4\end{array}$ & $\begin{array}{r}<0.5 \\
2.4 \\
0.6 \\
2.9 \\
1.9\end{array}$ & $\begin{array}{r}<0.1 \\
0.3 \\
<0.1 \\
0.1 \\
0.3\end{array}$ & $\begin{array}{l}<0.2 \\
<0.2 \\
<1.5 \\
<0.2 \\
<0.2\end{array}$ & $\begin{array}{l}0.4 \\
0.6 \\
6.1 \\
0.5 \\
0.9\end{array}$ & $\begin{array}{l}<0.01 \\
<0.01 \\
<0.01 \\
<0.01 \\
<0.01\end{array}$ & $\begin{array}{c}0.03 \\
10.6 \\
0.14 \\
7.2 \\
6.1\end{array}$ \\
\hline & None b) & $3-2-1$ & $=0.25$ & $=0.05$ & 10.3 & $<0.03$ & 0.05 & $=0.25$ & 2.5 & $<0.5$ & $<0.1$ & 2.1 & 4.0 & $<0.01$ & $<0.03$ \\
\hline & $\begin{array}{l}4.3-002-196 \\
4.3-002-196 \\
4.3-002-196\end{array}$ & $\begin{array}{l}3-2-2 \\
3-2-3 \\
3-2-5\end{array}$ & $\begin{array}{l}<0.25 \\
=0.25 \\
<0.25\end{array}$ & $\begin{aligned}< & 0.05 \\
& 0.07 \\
< & 0.05\end{aligned}$ & $\begin{array}{r}3.9 \\
3.7 \\
11.4\end{array}$ & $\begin{array}{l}0.20 \\
0.18 \\
0.63\end{array}$ & $\begin{array}{l}0.06 \\
0.08 \\
0.06\end{array}$ & $\begin{array}{l}0.57 \\
0.75 \\
0.40\end{array}$ & $\begin{array}{l}3.5 \\
3.3 \\
3.7\end{array}$ & $\begin{array}{l}5.6 \\
7.9 \\
1.7\end{array}$ & $\begin{array}{r}0.1 \\
0.2 \\
<0.1\end{array}$ & $\begin{aligned}< & 0.2 \\
= & 0.2 \\
& 0.6\end{aligned}$ & $\begin{array}{l}4.6 \\
5.3 \\
2.7\end{array}$ & $\begin{array}{l}0.08 \\
0.11 \\
0.02\end{array}$ & $\begin{array}{l}0.26 \\
0.26 \\
0.18\end{array}$ \\
\hline & $\begin{array}{l}4.3-000-192 \\
4.3-000-192 \\
4.3-000-201 \\
4.3-000-202 \\
4.3-000-203 \\
4.3-000-204 \\
4.3-000-204 \\
4.3-000-204 \\
4.3-000-204 \\
4.3-000-204 \\
4.3-000-205 \\
4.3-000-206\end{array}$ & $\begin{array}{l}1-2-2 \\
1-2-3 \\
1-2-5 \\
1-2-5 \\
1-2-7 \\
1-2-8 \\
1-2-9 \\
1-2-10 \\
1-2-11 \\
1-2-12 \\
1-2-13 \\
1-2-14\end{array}$ & $\begin{array}{r}<0.25 \\
<0.25 \\
3.8 \\
5.0 \\
5.7 \\
7.3 \\
8.6 \\
8.3 \\
8.5 \\
10.0 \\
6.1 \\
6.4\end{array}$ & $\begin{aligned} &< 0.05 \\
&< 0.05 \\
&< 0.05 \\
&< 0.05 \\
&< 0.05 \\
& 0.06 \\
& 0.08 \\
& 0.09 \\
& 0.09 \\
& 0.13 \\
& 0.09 \\
& 0.08\end{aligned}$ & $\begin{array}{l}<0.05 \\
18.2 \\
19.2 \\
19.1 \\
18.8 \\
18.6 \\
18.8 \\
18.4 \\
18.2 \\
18.4 \\
18.5 \\
18.6\end{array}$ & $\begin{array}{r}0.03 \\
0.03 \\
0.05 \\
0.10 \\
0.22 \\
0.30 \\
0.34 \\
0.36 \\
0.40 \\
0.51 \\
0.35 \\
0.35\end{array}$ & $\begin{array}{l}<u .0 .3 \\
0.08 \\
0.08 \\
0.06 \\
0.05 \\
0.06 \\
0.07 \\
0.07 \\
0.07 \\
0.08 \\
0.07 \\
0.07\end{array}$ & $\begin{array}{l}<0.25 \\
-0.25 \\
1.0 \\
1.3 \\
1.7 \\
2.1 \\
2.4 \\
2.5 \\
2.6 \\
2.9 \\
2.1 \\
2.1\end{array}$ & $\begin{array}{l}0.04 \\
4.9 \\
5.5 \\
5.6 \\
5.5 \\
5.7 \\
5.9 \\
5.9 \\
5.8 \\
5.8 \\
5.5 \\
5.5\end{array}$ & $\begin{array}{r}0.5 \\
<0.5 \\
1.1 \\
3.5 \\
8.1 \\
10.7 \\
12.0 \\
12.0 \\
13.3 \\
17.8 \\
12.0 \\
12.2\end{array}$ & 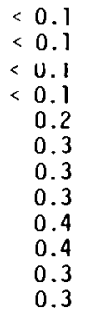 & $\begin{aligned} & 0.2 \\
& 3.1 \\
& 2.2 \\
&< 0.2 \\
&< 0.2 \\
&< 0.2 \\
&< 0.2 \\
&< 0.2 \\
&< 0.2 \\
&< 0.2 \\
&< 0.2 \\
&< 0.2\end{aligned}$ & $\begin{array}{l}0.5 \\
6.9 \\
4.4 \\
4.3 \\
4.1 \\
3.5 \\
3.5 \\
3.4 \\
3.3 \\
3.3 \\
3.3 \\
3.4\end{array}$ & $\begin{array}{l}<0.01 \\
0.01 \\
0.02 \\
0.05 \\
0.11 \\
0.15 \\
0.16 \\
0.17 \\
0.19 \\
0.25 \\
0.17 \\
0.17\end{array}$ & $\begin{array}{l}0.03 \\
0.05 \\
0.34 \\
0.43 \\
0.56 \\
0.65 \\
0.75 \\
0.75 \\
0.77 \\
0.81 \\
0.60 \\
0.61\end{array}$ \\
\hline & $\begin{array}{l}2.35-000-170 \\
2.35-000-170 \\
2.35-000-170\end{array}$ & $\begin{array}{l}2-2-1 \\
2-2-2 \\
2-2-3\end{array}$ & $\begin{array}{l}1.2 \\
3.8 \\
8.0\end{array}$ & $\therefore \begin{array}{r}0.05 \\
\therefore \\
0.05 \\
0.05\end{array}$ & $\begin{array}{l}2.7 \\
7.0 \\
9.0\end{array}$ & $\begin{array}{l}0.03 \\
0.03 \\
0.09\end{array}$ & $\begin{array}{r}0.03 \\
0.03 \\
0.04\end{array}$ & $\begin{array}{l}0.4 \\
10.3 \\
0.0\end{array}$ & $\begin{array}{l}0.8 \\
2.2 \\
3.3\end{array}$ & $\begin{aligned}< & 0.5 \\
\therefore & 0.5 \\
& 1.2\end{aligned}$ & $\begin{array}{l}<0.1 \\
<0.1 \\
<0.1\end{array}$ & $\begin{array}{l}2.1 \\
2.2 \\
1.3\end{array}$ & $\begin{array}{l}1.6 \\
1.7 \\
1.4\end{array}$ & $\begin{array}{l}0.01 \\
0.01 \\
0.03\end{array}$ & $\begin{array}{l}0.74 \\
1.2 \\
2.0\end{array}$ \\
\hline & $\begin{array}{l}4.3-002-207 \\
4.3-002-208 \\
4.3-002-209 \\
4.3-002-209 \\
4.3-002-209 \\
4.3-002-209\end{array}$ & $\begin{array}{l}3-2 M-1 \\
3-\hat{i} M-\bar{C} \\
3-2 M-3 \\
3-2 M-4 \\
3-2 M-5 \\
3-2 M-6\end{array}$ & $\begin{array}{l}2.5 \\
3.1 \\
5.4 \\
6.5 \\
6.5 \\
7.6\end{array}$ & $\begin{aligned}< & 0.05 \\
< & 0.05 \\
< & 0.05 \\
< & 0.05 \\
& 0.09 \\
& 0.12\end{aligned}$ & $\begin{array}{l}18.0 \\
13.0 \\
13.0 \\
13.0 \\
18.0 \\
18.0\end{array}$ & $\begin{array}{l}0.13 \\
0.08 \\
0.10 \\
0.11 \\
0.31 \\
0.50\end{array}$ & $\begin{array}{l}0.07 \\
0.013 \\
0.03 \\
0.013 \\
0.06 \\
0.03\end{array}$ & $\begin{array}{l}0.8 \\
0.7 \\
0.8 \\
0.8 \\
1.5 \\
1.9\end{array}$ & $\begin{array}{l}5.0 \\
3.7 \\
4.0 \\
4.0 \\
5.5 \\
5.4\end{array}$ & $\begin{array}{l}2.0 \\
1.1 \\
2.0 \\
2.2 \\
6.0 \\
8.3\end{array}$ & $\begin{array}{l}0.1 \\
0.1 \\
0.1 \\
0.1 \\
0.1 \\
0.3 \\
0.5\end{array}$ & 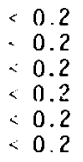 & $\begin{array}{l}3.3 \\
2.1 \\
1.6 \\
2.2 \\
3.3 \\
3.0\end{array}$ & $\begin{array}{l}0.06 \\
0.05 \\
0.06 \\
0.06 \\
0.16 \\
0.26\end{array}$ & $\begin{array}{l}0.49 \\
0.26 \\
0.38 \\
0.18 \\
0.89 \\
0.93\end{array}$ \\
\hline
\end{tabular}

a) Includes experiment 165 .

b) Control sample. 
APPENDIX D

Trace Impurities Measured

In Lattice Plate Material 


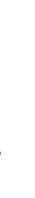 \\ $-$
}

14

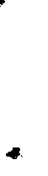




\section{Trace Impurities Measured \\ In Lattice Plate Material}

Trace impurity levels are presented in this Appendix for the polypropylene material used in fabricating the lattice plates for these experiments. The analytical results are from a spark source mass spectrographic analysis of a sample taken from, and considered representative of, the polypropylene during fabrication of the lattice plates. The spectrographic analysis were performed by the Hanford Engineering Development Laboratory, Richland, Washington, on June 14, 1982. 
Trace Impurities Present in Lattice Plates

$\underline{\text { El ement }}$

B

$F$

$\mathrm{Na}$

$\mathrm{Mg}$

Al

Si

$P$

Cl

K

$\mathrm{Ca}$

$\mathrm{Ti}$

V

$\mathrm{Cr}$

$\mathrm{Mn}$

$\mathrm{Fe}$

Cu

$\mathrm{Zn}$

$\mathrm{Ge}$

As

$\mathrm{Rb}$

Y

Zr

Mo

$\mathrm{Sn}$

$\mathrm{Br}$
Parts Per Million by Weight

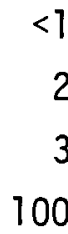

90

80

2

3

2

20

200

20

40

0.3

$<20$

40

40

10

20

8

10

200

15

4

10 


\section{APPENDIX E}

Center-to-Center Spacing Between Fuel Rods 


\title{
Center-to-Center Spacing Between Fuel Rods
}

\begin{abstract}
Measurements to determine the center-to-center spacing between the fuel rods in each experimental assembly are covered in this Appendix. Each experimental assembly was provided with three plates of polypropylene into which equally spaced holes, having diameters $0.013 \mathrm{~cm}$ larger than the fuel rods, had been milled on specified center-to-center spacings within $\pm 0.013 \mathrm{~cm}$. These plates were positioned approximately equal distance apart in the experimental assembly to maintain a constant distance between the fuel rods over their entire length. Corresponding center-to-center spacings between holes were measured along two diameters, $60^{\circ}$ apart, of each lattice plate to obtain an average lattice spacing for each experimental assembly and to determine if the holes were uniformly spaced as specified.
\end{abstract}




\section{Lattice 11 Genter-to-Center Spacings}

\begin{tabular}{ccc}
$\begin{array}{c}\text { Top Plate } \\
\text { (inch) }\end{array}$ & $\begin{array}{c}\text { Middle Plate } \\
\text { (inch) }\end{array}$ & $\begin{array}{c}\text { Bottom Plate } \\
\text { (inch) }\end{array}$ \\
\cline { 2 - 2 } 0.945 & & \\
0.944 & 0.946 & 0.945 \\
0.946 & 0.944 & 0.945 \\
0.943 & 0.944 & 0.946 \\
0.944 & 0.944 & 0.944 \\
0.945 & 0.945 & 0.944 \\
0.946 & 0.945 & 0.946 \\
0.944 & 0.946 & 0.946 \\
0.943 & 0.943 & 0.944 \\
0.943 & 0.943 & 0.944 \\
0.944 & 0.942 & 0.943 \\
0.944 & 0.943 & 0.944
\end{tabular}

Average: $0.944 \pm 0.001 \quad 0.944 \pm 0.001 \quad 0.945 \pm 0.001$

Overall Average Center-to-Center Spacing: $0.944 \pm 0.002$ inch $(2.398 \mathrm{~cm})$ 


\section{Lattice 12 Center-To-Center Spacings}

\begin{tabular}{lll}
$\begin{array}{c}\text { Top Plate } \\
\text { (inch) }\end{array}$ & $\begin{array}{c}\text { Middle Plate } \\
\text { (inch) }\end{array}$ & $\begin{array}{c}\text { Bottom Plate } \\
\text { (inch) }\end{array}$ \\
\cline { 2 - 3 } 0.710 & 0.714 & 0.713 \\
0.712 & 0.712 & 0.712 \\
0.712 & 0.712 & 0.710 \\
0.712 & 0.713 & 0.713 \\
0.712 & 0.712 & 0.712 \\
0.714 & 0.713 & 0.712 \\
0.711 & 0.714 & 0.713 \\
0.713 & 0.712 & 0.712 \\
0.712 & 0.712 & 0.712 \\
0.711 & 0.712 & 0.712 \\
0.712 & 0.713 & 0.711 \\
0.711 & 0.712 & 0.713 \\
0.713 & 0.712 & 0.712 \\
0.709 & 0.711 & 0.708 \\
0.711 & 0.712 & 0.712 \\
0.712 & 0.713 & 0.712 \\
0.712 & 0.711 & 0.712 \\
0.712 & 0.712 & 0.712
\end{tabular}

Average: $0.709 \pm 0.002 \quad 0.709 \pm 0.001 \quad 0.709 \pm 0.001$

Overall Average Center-To-Center Spacing: $0.709 \pm 0.002$ inch $(1.801 \mathrm{~cm})$ 
Lattice $13^{(a)}$ Center-To-Center Spacings

\begin{tabular}{|c|c|c|}
\hline $\begin{array}{l}\text { Top P1ate } \\
\text { (inch) } \\
\end{array}$ & $\begin{array}{l}\text { Middle Plate } \\
\text { (inch) }\end{array}$ & $\begin{array}{l}\text { Bottom Plate } \\
\text { (inch) }\end{array}$ \\
\hline $\begin{array}{l}0.629 \\
0.629 \\
0.629 \\
0.629 \\
0.629 \\
0.630 \\
0.628 \\
0.629 \\
0.628 \\
0.631 \\
0.628 \\
0.630 \\
0.630 \\
0.629 \\
0.628 \\
0.631 \\
0.630 \\
0.630 \\
0.629 \\
0.630 \\
0.632 \\
0.626 \\
0.629 \\
0.628 \\
0.630 \\
0.629 \\
0.631 \\
0.629 \\
0.630 \\
0.630\end{array}$ & $\begin{array}{l}0.630 \\
0.632 \\
0.630 \\
0.629 \\
0.630 \\
0.629 \\
0.631 \\
0.630 \\
0.627 \\
0.631 \\
0.629 \\
0.628 \\
0.630 \\
0.631 \\
0.627 \\
0.630 \\
0.625 \\
0.633 \\
0.625 \\
0.629 \\
0.637 \\
0.624 \\
0.626 \\
0.628 \\
0.626 \\
0.626 \\
0.632 \\
0.627 \\
0.633 \\
0.624\end{array}$ & $\begin{array}{l}0.635 \\
0.624 \\
0.633 \\
0.627 \\
0.634 \\
0.628 \\
0.626 \\
0.624 \\
0.637 \\
0.631 \\
0.627 \\
0.635 \\
0.628 \\
0.632 \\
0.627 \\
0.637 \\
0.629 \\
0.637 \\
0.630 \\
0.628 \\
0.637 \\
0.633 \\
0.627 \\
0.629 \\
0.629 \\
0.630 \\
0.629 \\
0.637 \\
0.630 \\
0.629\end{array}$ \\
\hline $0.629 \pm 0.001$ & $0.629 \pm 0.004$ & $0.629 \pm 0.005$ \\
\hline
\end{tabular}

(a) Lattice plates also used in experiments identified by Lattice Identification Number: 32 and 32M. 


\section{Lattice 21 Center-To-Center Spacings}

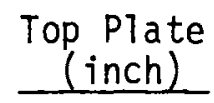

0.746

0.746

0.746

0.746

0.746

0.746

0.745

0.745

0.747

0.746

0.746

0.745

0.747

0.746

0.745

0.747

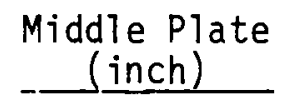

0.745

0.746

0.746

0.746

0.746

0.745

0.746

0.746

0.747

0.747

0.747

0.748

0.746

0.748

0.746

0.747
Bottom Plate
(inch)

0.746

0.746

0.746

0.746

0.746

0.746

0.746

0.746

0.746

0.747

0.746

0.745

0.747

0.746

0.746

0.747

Average: $0.746 \pm 0.001 \quad 0.746 \pm 0.001 \quad 0.746 \pm 0.001$

Overall Average Center-To-Center Spacing: $0.746 \pm 0.002$ inch $(1.895 \mathrm{~cm})$ 


\section{Lattice 22 Center-To-Center Spacings}

$\begin{array}{ccc}\begin{array}{c}\text { Top Plate } \\ \text { (inch) }\end{array} & \begin{array}{c}\text { Middle Plate } \\ \text { (inch) }\end{array} & \begin{array}{c}\text { Bottom Plate } \\ \text { (inch) }\end{array} \\ 0.628 & & 0.632 \\ 0.630 & 0.629 & 0.628 \\ 0.629 & 0.629 & 0.632 \\ 0.631 & 0.629 & 0.629 \\ 0.628 & 0.629 & 0.630 \\ 0.629 & 0.629 & 0.631 \\ 0.630 & 0.630 & 0.629 \\ 0.628 & 0.629 & 0.629 \\ 0.630 & 0.629 & 0.630 \\ 0.630 & 0.629 & 0.630 \\ 0.629 & 0.630 & 0.629 \\ 0.629 & 0.629 & 0.629 \\ 0.630 & 0.630 & 0.629 \\ 0.630 & 0.630 & 0.630 \\ 0.630 & 0.630 & 0.630 \\ 0.630 & 0.630 & 0.630\end{array}$

Average: $0.629 \pm 0.001 \quad 0.629 \pm 0.001 \quad 0.630 \pm 0.001$

Overall Average Center-To-Center Spacing: $0.62 .9 \pm 0.002$ inch $(1.598 \mathrm{~cm})$ 


\section{APPENDIX $F$}

Loading Diagrams for Critical and Subcritical Assemblies 


\section{Loading Diagrams for Critical and Subcritical Assemblies}

A loading diagram for each critical and subcritical assembly is presented in this Appendix. Each diagram identifies the type or types of fuel involved, the amount of fuel required for criticality and the location of the fuel in the assembly. Each diagram also identifies any irregular features present in the experimental assemblies. The location of control and safety rod guide sleeves and the location of reaction rate devices are shown when present. Lattice and experiment identification numbers are provided in each diagram for cross reference with tables presented in the text.

In an attempt to minimize computational input errors, lattice spacings, gadolinium concentrations and, when applicable, subcritical $k_{\text {eff }}$ values are also given on each diagram. 


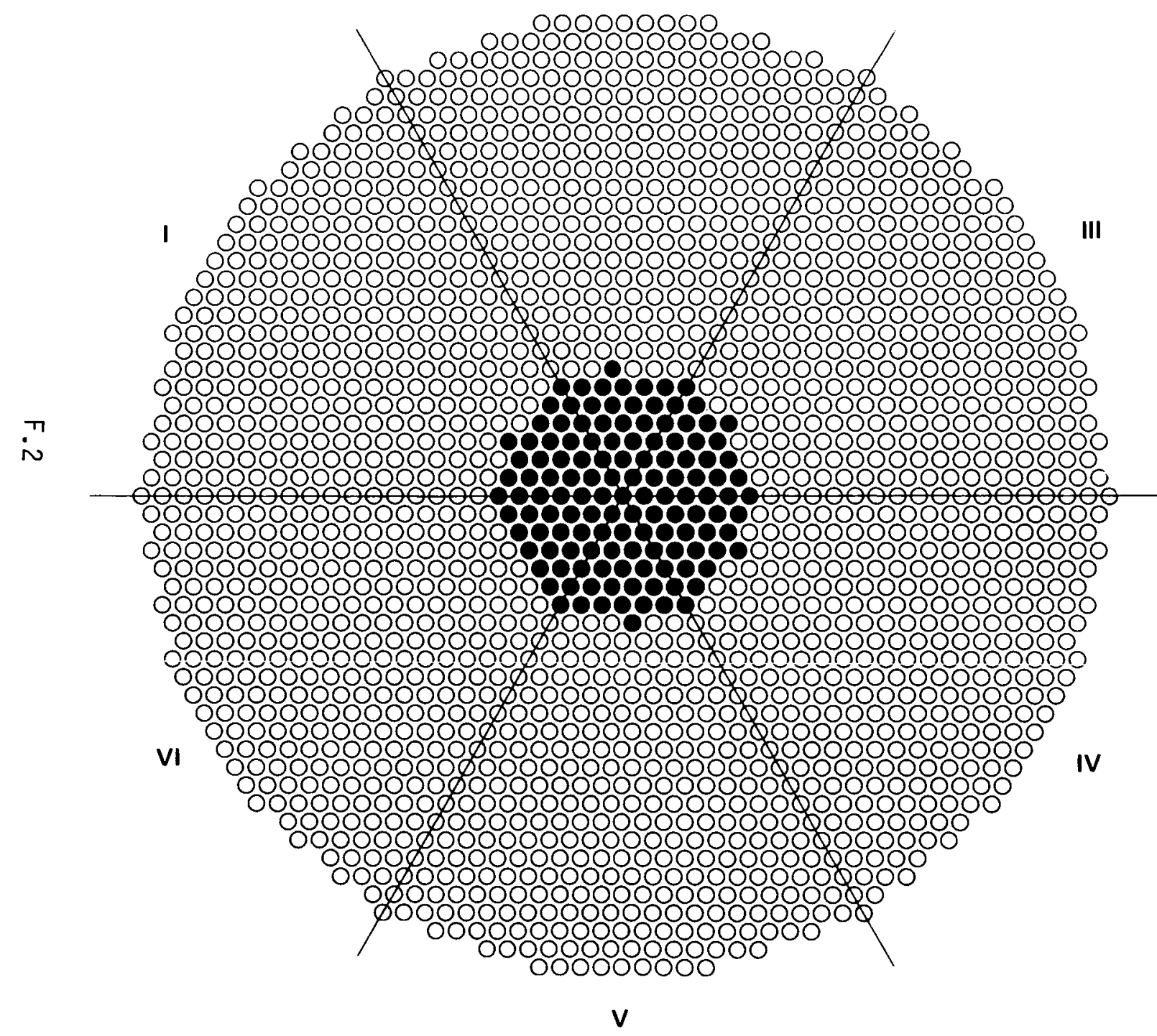

FUEL: $4.31 \mathrm{wt} \%{ }^{235} \mathrm{U}$ ENRICHED $\mathrm{UO}_{2}$

EXPERIMENT: 4.3-000-182

LATTICE: 11

PITCH: $2.398+0.005$

GADOLINIUM: SEE COMMENTS

CONTROL ROD: NONE

SAFETY ROD: NONE

REACTION RATES: NONE

hữus: $1 \overline{3} 2 \mathrm{UUO}_{2}$ RŨús AT •

keff: SEE COMMENTS

COMMENTS :

Keff $=1.0$ AT ZERO g Gd/liter

$k_{\text {eff }}=0.985$ AT $0.068 \pm 0.001 \mathrm{~g} \mathrm{Gd} /$ liter 


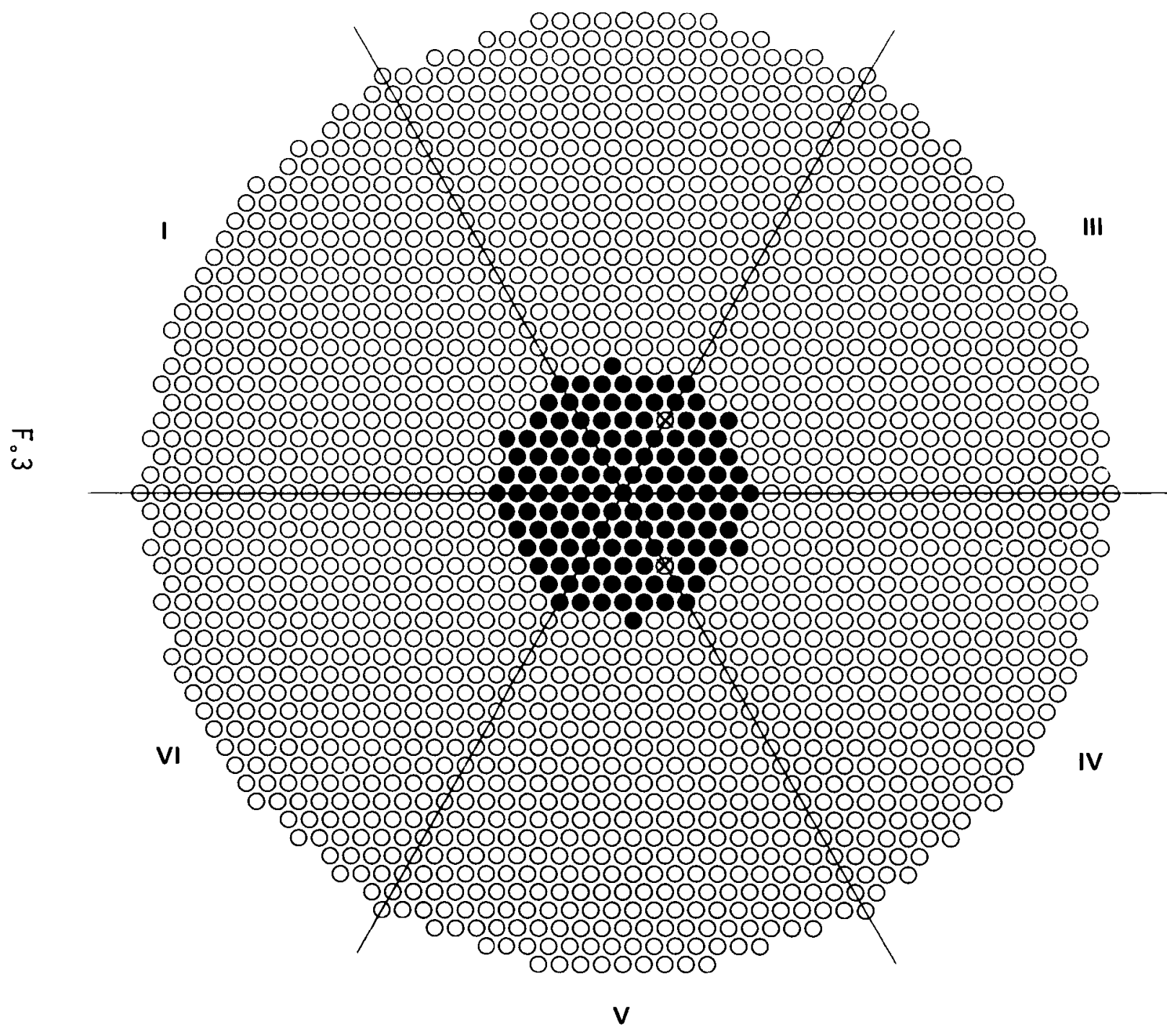

FUEL: $4.31 \mathrm{wt} \%{ }^{235} \mathrm{U}$ ENRICHED $\mathrm{UO}_{2}$

EXPERIMENT: $4.3-000-182 \mathrm{~A}$

LATTICE: 11

PITCH: $2.398+0.005 \mathrm{~cm}$

GADOLINIUM: 0

CONTROL ROD: OUT

SAFETY ROD: OUT

REACTION RATES: NONE

RODS: $130 \mathrm{UO}_{2}$ RODS AT $\bullet$

keff: 1.0

COMMENTS: WATER FILLED ALUMINUM SLEEVES AT 
II

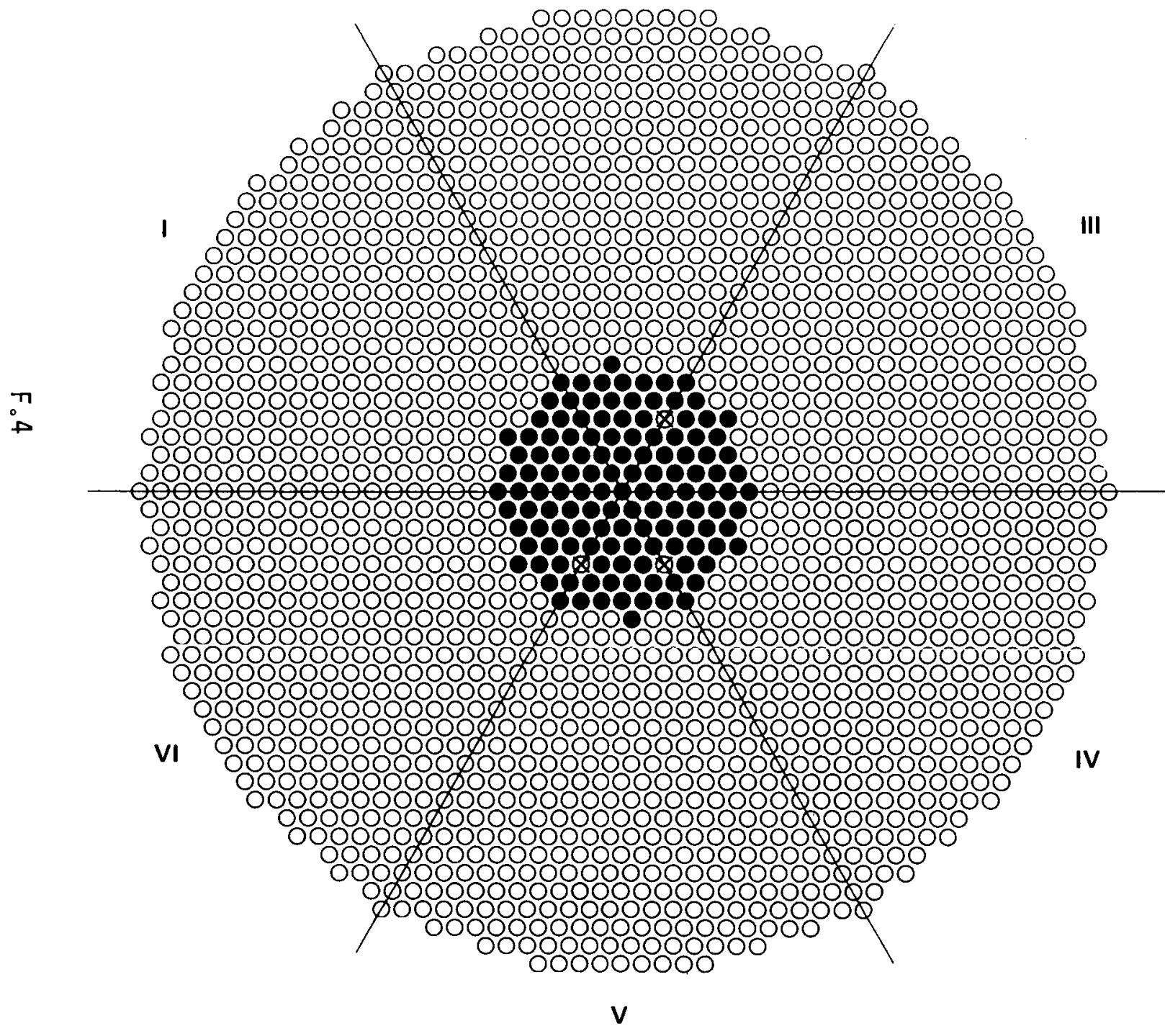

FUEL: $4.31 \mathrm{wt} \%{ }^{235} \mathrm{U}$ ENRICHED $\mathrm{UO}_{2}$

EXPERIMENT: $4.3-000-182 \mathrm{~B}$

LATTICE: 11

PITCH: $2.398 \pm 0.005$

GADOLINIUM: 0

CONTROL ROD: OUT

SAFETY ROD: OUT

REACTION RATES: NONE

RODS: $130 \mathrm{UO}_{2}$ RODS AT

Keff: 1.0

COMMENTS: WATER FILLED ALUMINUM SLEEVES AT 


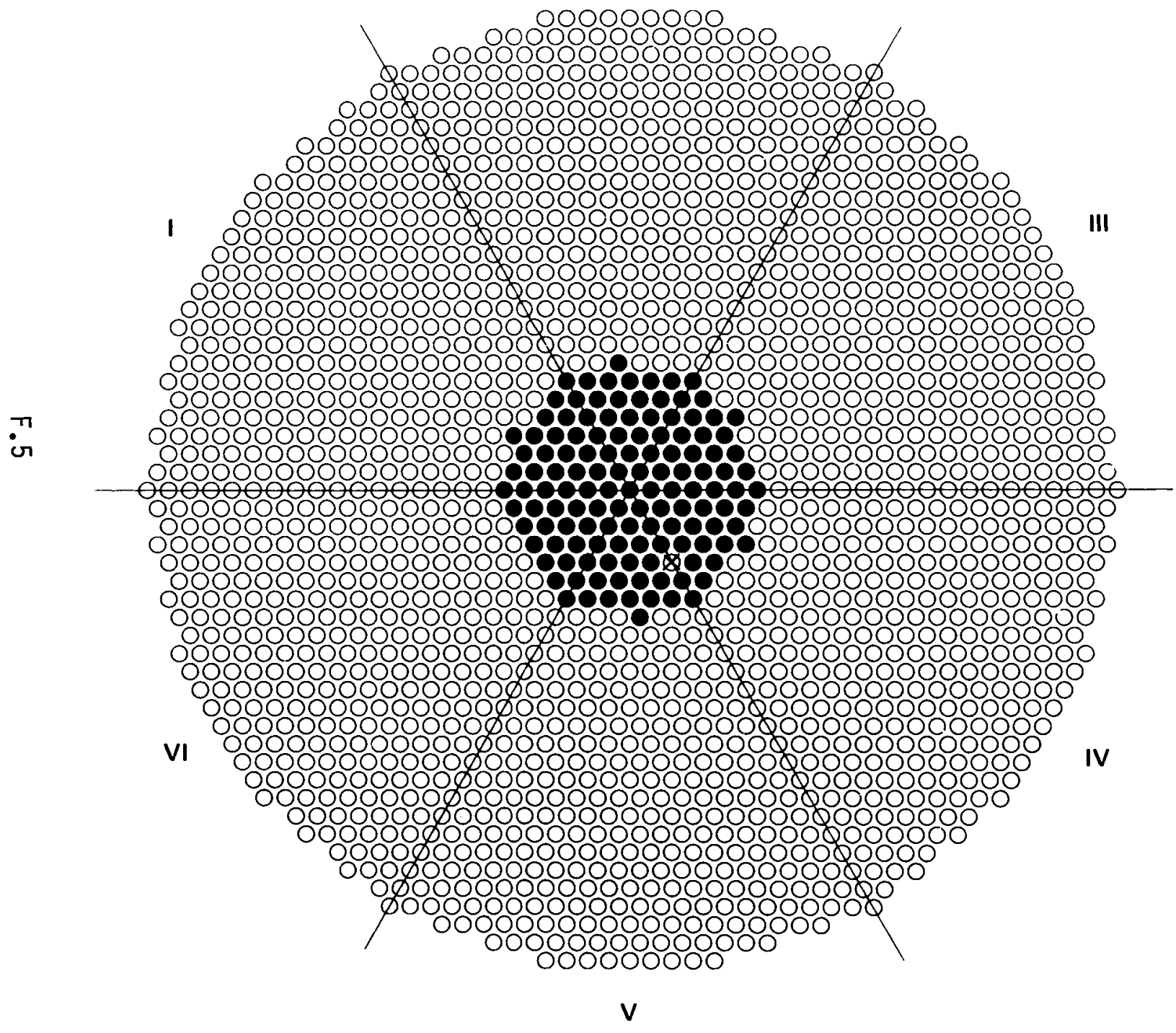

FUEL: 4.31 wt $\%$ 235U ENRICHED $\mathrm{UO}_{2}$ EXPERIMENT: $4.3-000-182 \mathrm{C}$

LATTICE: 11

PITCH: $2.398 \pm 0.005 \mathrm{~cm}$

GADOLINIUM: 0

CONTROL ROD: OUT

SAFETY ROD: NONE

REACTION RATES: NONE

RODS: $131 \mathrm{UO}_{2}$ RODS AT

keff: 1.0

COMMENTS: WATER FILLED ALUMINUM SLEEVES AT 
II

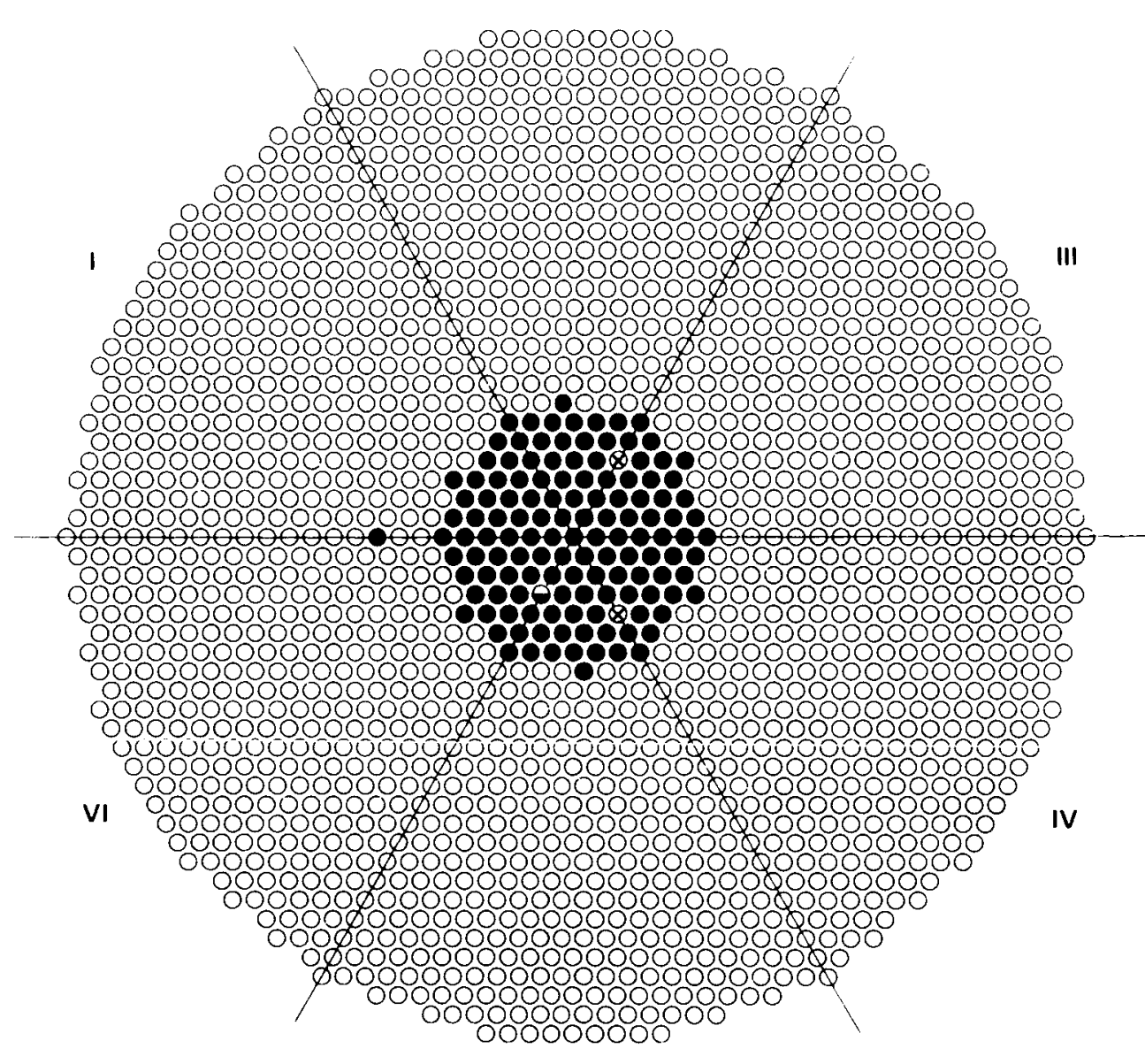

FUEL: $4.31 \mathrm{wt} \%{ }^{235} \mathrm{U}$ ENRICHED $\mathrm{UO}_{2}$

EXPERIMENT: 4.3-000-182D

LATTICE: 11

PITCH: $2.398 \pm 0.005 \mathrm{~cm}$

GADOLINIUM: NONE

CONTROL ROD: OUT $52.4+0.3 \mathrm{~cm}$ FROM BOTTOM OF FUEL (LOCATION $V \otimes$ )

SAFETY ROD: OUT

REACTION RATES: SOLID STATE ${ }^{235}$ U TRACK RECORDER IN

RODS: $132 \mathrm{UO}_{2}$ RODS AT

keff: 1.0

COMMENTS: CONTROL AND SAFETY ROD ALUMINUM GUIDE SLEEVES AT $\otimes$ 


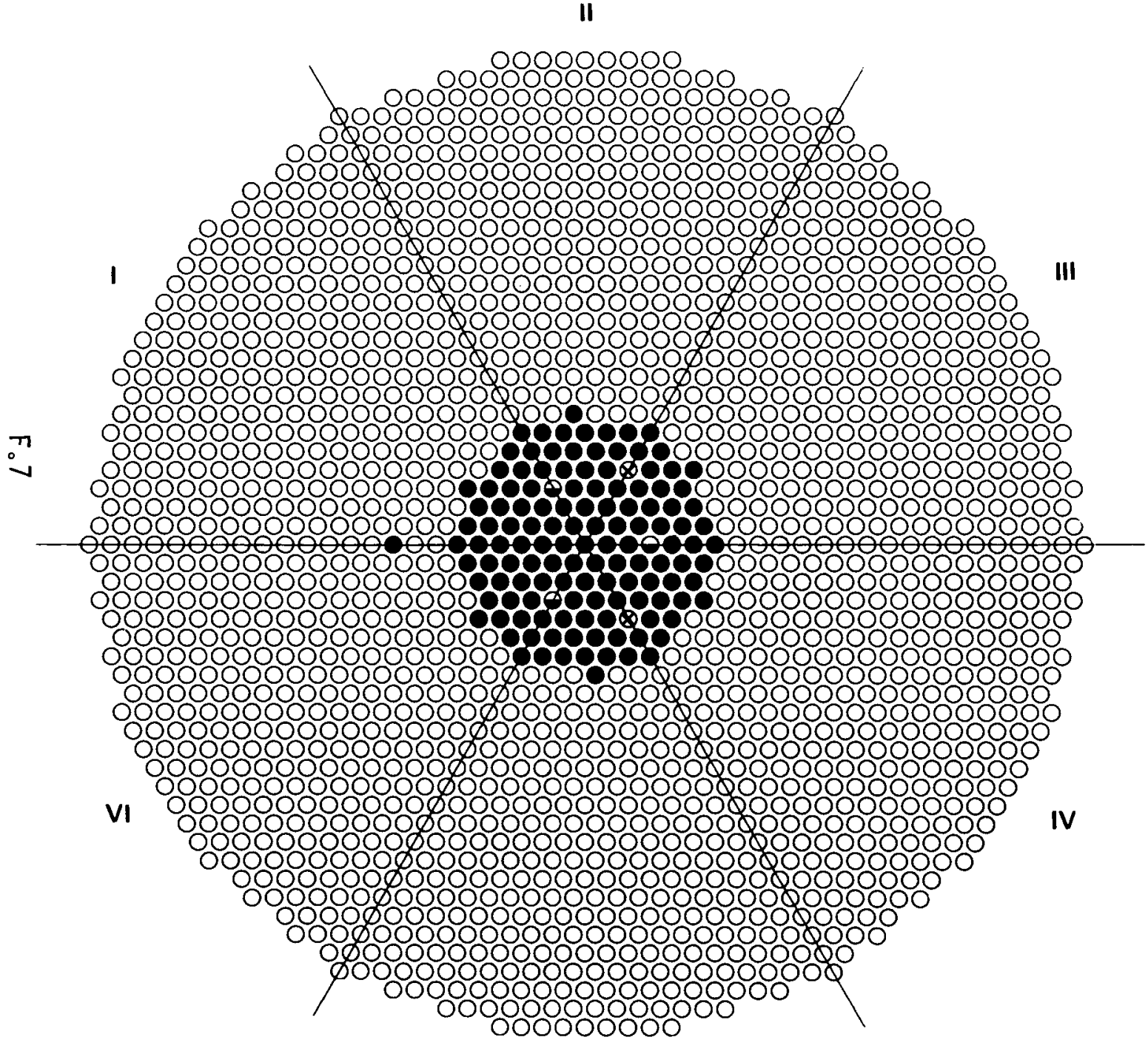

V
FUEL: $4.31 \mathrm{wt} \%{ }^{235} \mathrm{U}$ ENRICHED $\mathrm{UO}_{2}$

EXPERIMENT: 4.3-000-182E

LATTICE: 11

PITCH: $2.398 \pm 0.005$

GADOLINIUM: NONE

CONTROL ROD: OUT $58.4 \pm 0.3 \mathrm{~cm}$ FROM BOTTOM

OF FUEL (LOCATION $V \otimes$ )

SAFETY ROD: OUT

REACTION RATES: ${ }^{238} \mathrm{U}$ AND ${ }^{235} \mathrm{U}$ FOILS IN $\odot$ (SEE COMMENTS)

RODS: $132 \mathrm{UO}_{2}$ RODS AT $\bullet$

$k_{\text {eff: }} \mathbf{1 . 0}$

COMMENTS: CONTROL AND SAFETY ROD ALUMINUM GUIDE SLEEVES AT $\otimes$

AEEW 3 FOIL PACKET IN II $\odot$ AEEW 4 FOIL PACKET IN IV $\theta$ AEEW 11 FOIL PACKET IN VI $\theta$ 


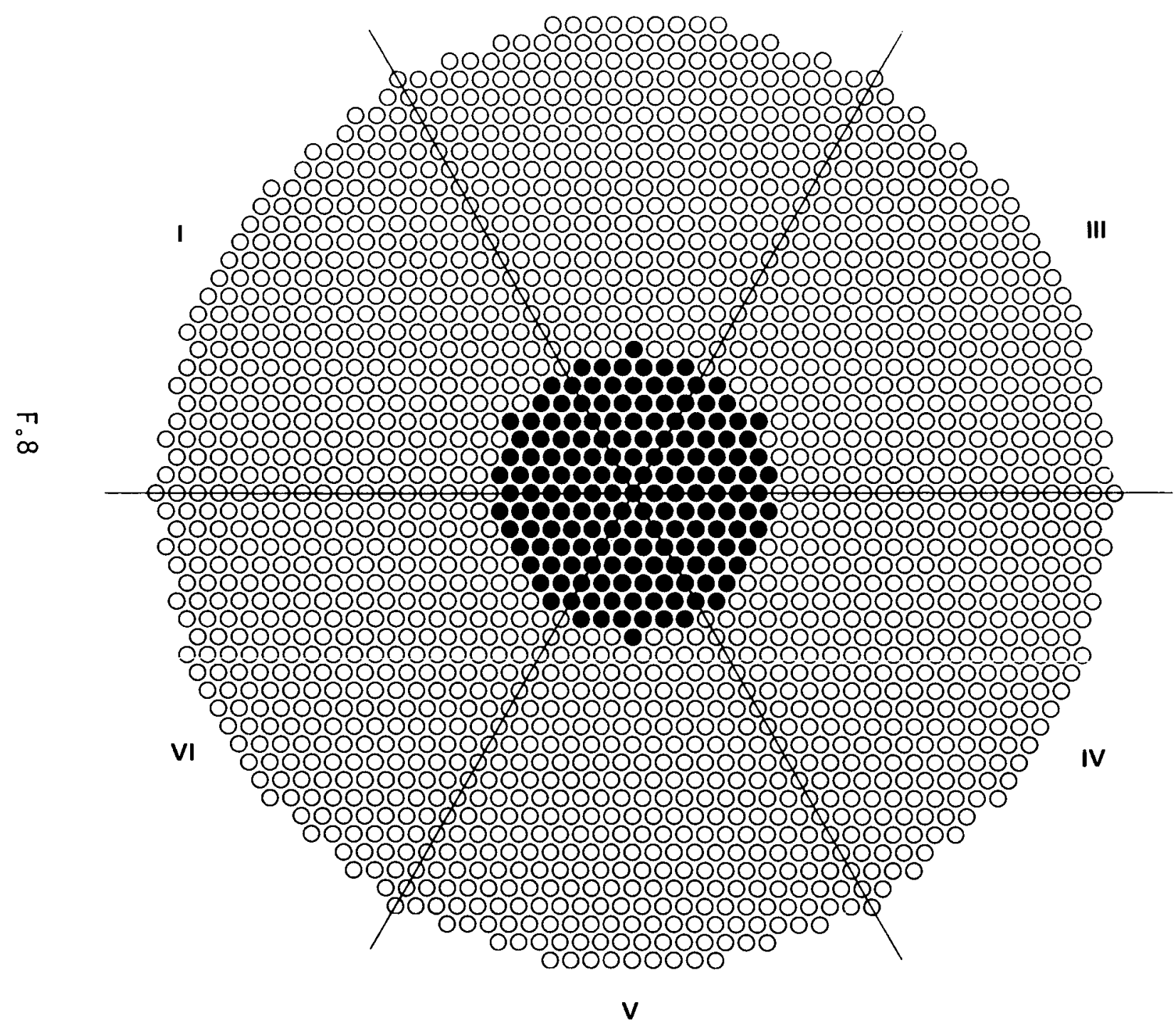

FUEL: $4.31 \mathrm{wt} \%{ }^{235} \mathrm{U}$ ENRICHED $\mathrm{UO}_{2}$ EXPERIMENT: $4.3-000-185$

LATTICE: 11

PITCH: $2.398 \pm 0.005$

GADOLINIUM: $0.068 \pm 0.001 \mathrm{~g} \mathrm{Gd} / \mathrm{liter}$ CONTROL ROD: NONE

SAFETY ROD: NONE

REACTION RATES: NONE

RODS: $167 \mathrm{UO}_{2}$ RODS AT *

keff: 1.0

COMMENTS: 
II

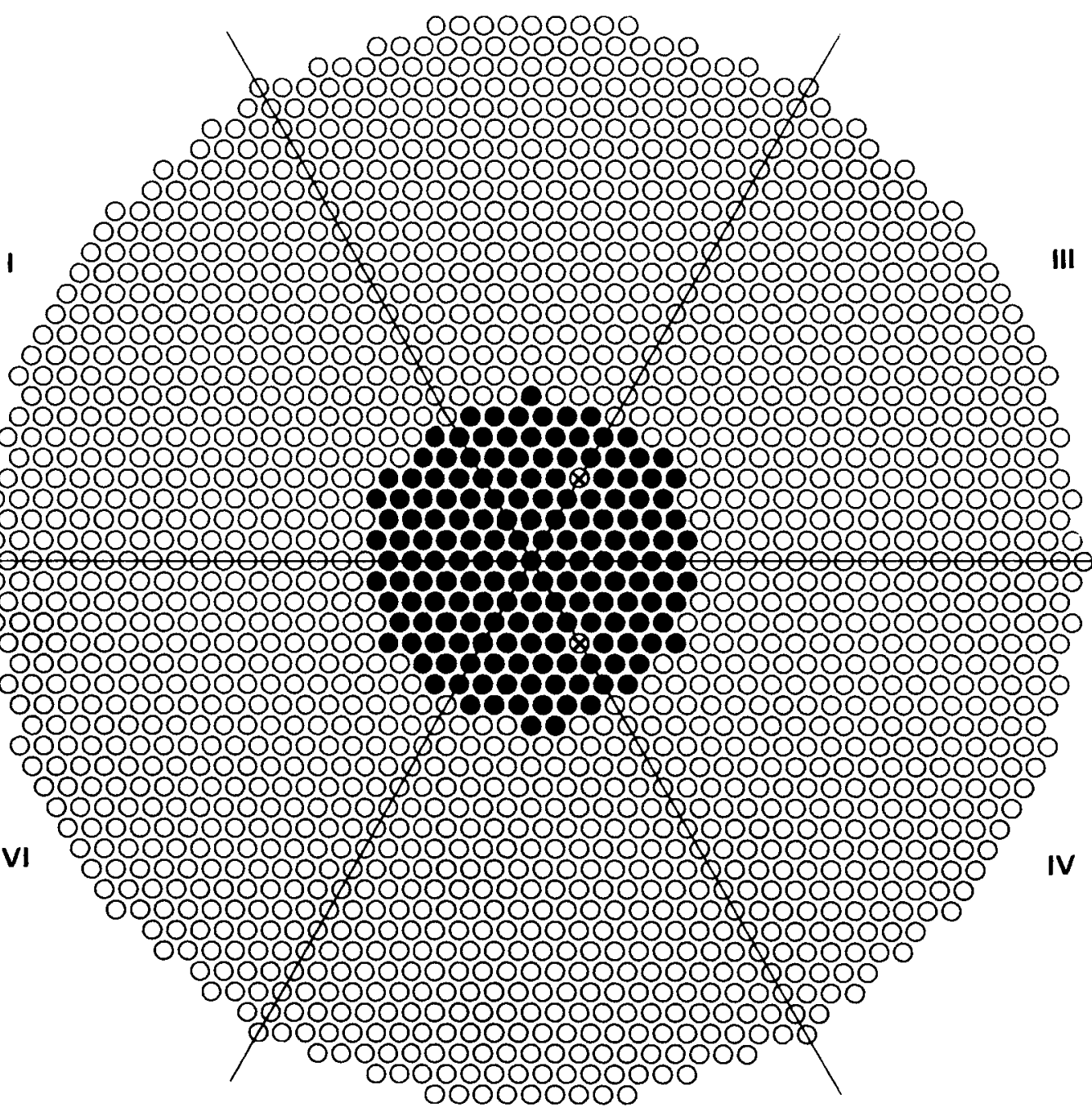

000000000

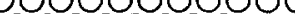

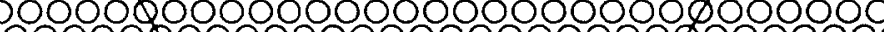

年

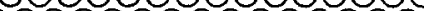
年

o000000000000000

年 1
0

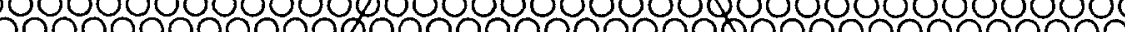

V
FUEL: $4.31 \mathrm{wt} \%{ }^{235} \mathrm{U}$ ENRICHED $\mathrm{UO}_{2}$ EXPERIMENT: $4.3-000-185 \mathrm{~A}$

LATTICE: 11

PITCH: $2.398 \pm 0.005$

GADOLINIUM: $0.068 \pm 0.001 \mathrm{~g} \mathrm{Gd} /$ liter

CONTROL ROD: OUT

SAFETY ROD: OUT

REACTION RATES: NONE

RODS: $170 \mathrm{UO}_{2}$ RODS AT •

keff: 1.0

COMMENTS: WATER FILLED ALUMINUM SLEEVES AT $\otimes$ 


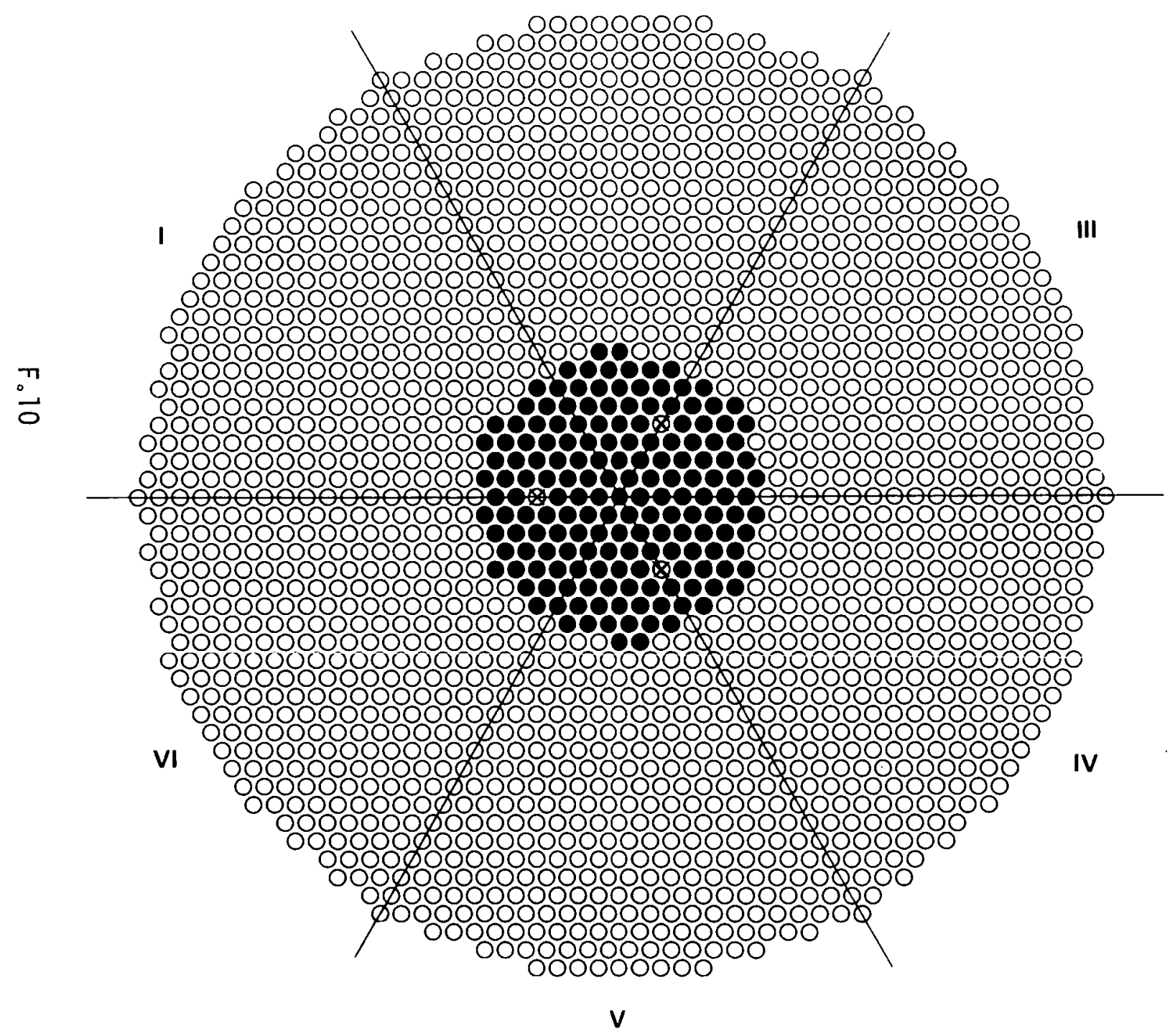

FUEL: $4.31 \mathrm{wt} \%{ }^{235} \mathrm{U}$ ENRICHED $\mathrm{UO}_{2}$ EXPERIMENT: $4.3-000-185 \mathrm{~B}$

LATTICE: 11

PITCH: $2.398 \pm 0.005$

GADOLINIUM: $0.068 \pm 0.001 \mathrm{~g} \mathrm{Gd} /$ liter CONTROL ROD: OUT

SAFETY ROD: OUT

REACTION RATES: NONE

RODS: 171 UO $_{2}$ ROONS ÁT •

Keff: 1.0

COMMENTS: WATER FILLED ALUMINUM

\author{
SLEEVES AT
}




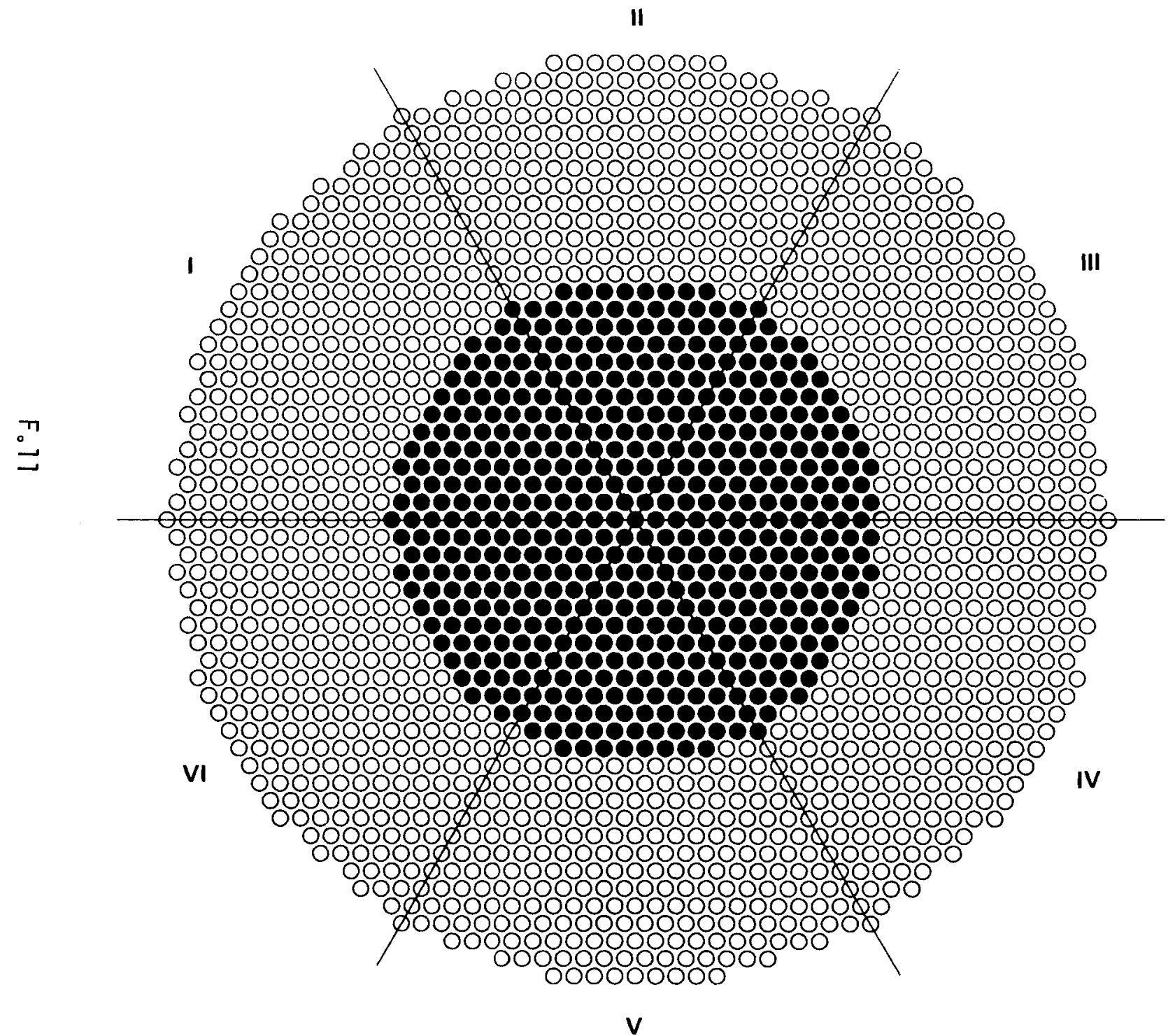

FUEL: $4.31 \mathrm{wt} \%{ }^{235} \mathrm{U}$ ENRICHED $\mathrm{UO}_{2}$

EXPERIMENT: 4.3-000-186

LATTICE: 11

PITCH: $2.398 \pm 0.005$

GADOLINIUM: $0.438 \pm 0.004 \mathrm{~g} \mathrm{Gd} /$ liter

CONTROL ROD: NONE

SAFETY ROD: NONE

REACTION RATES: NONE

RODS: $515 \mathrm{UO}_{2}$ RODS AT •

keff: 1.0

COMMENTS: 
II

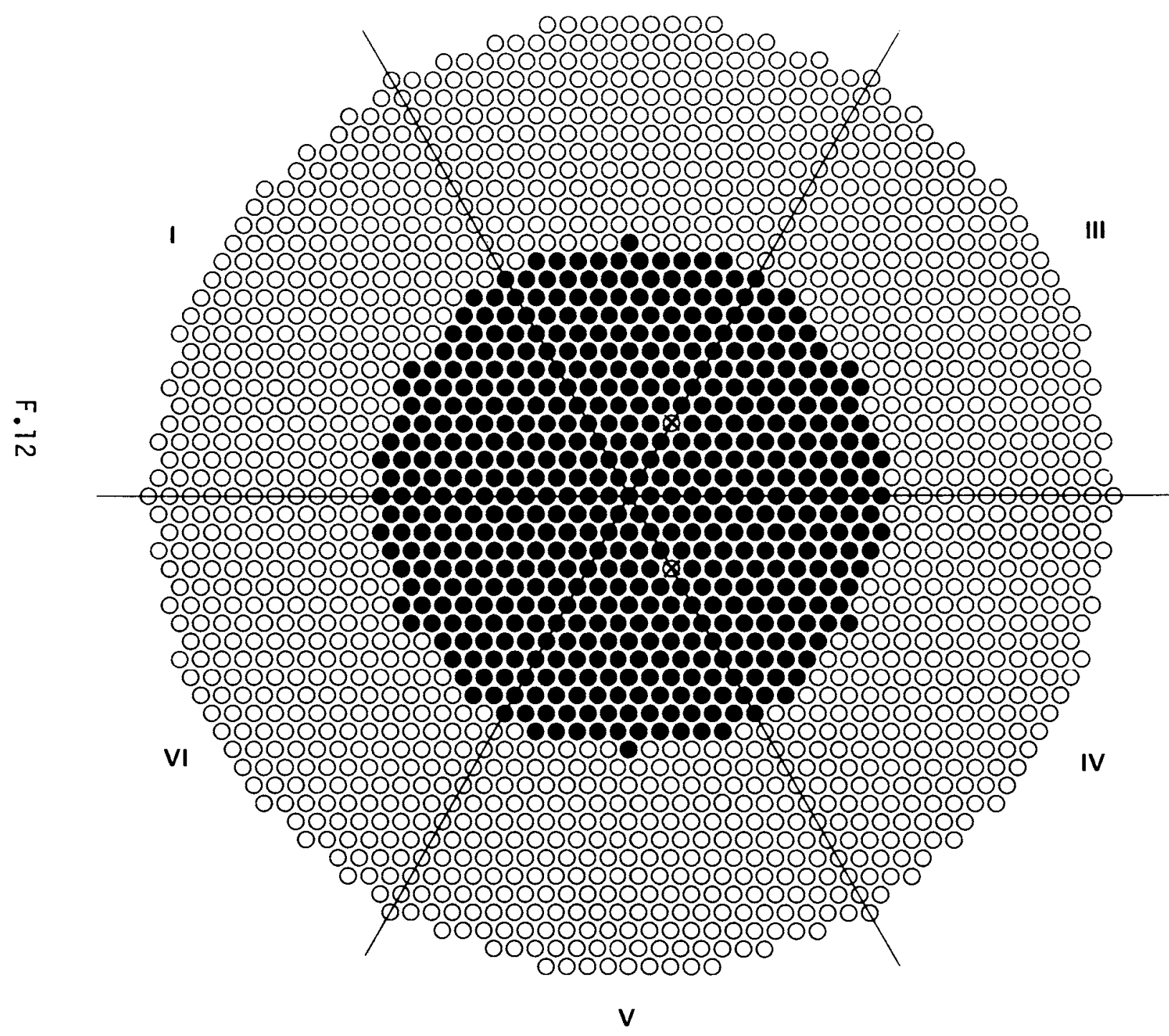

FUEL: $4.31 w t \%{ }^{235} \mathrm{U}$ ENRICHED $\mathrm{UO}_{2}$ EXPERIMENT: $4.3-000-186 \mathrm{~A}$

LATTICE: 11

PITCH: $2.398 \pm 0.005$

GADOLINIUM: $0.438 \pm 0.004 \mathrm{~g} \mathrm{Gd} /$ liter CONTROL ROD: OUT

SAFETY ROD: OUT

REACTION RATES: NONE

RODS: $536 \mathrm{UO}_{2}$ RODS AT

$k_{\text {eff: }} 1.0$

COMMENTS: WATER FILLED ALUMINUM SLEEVES AT 


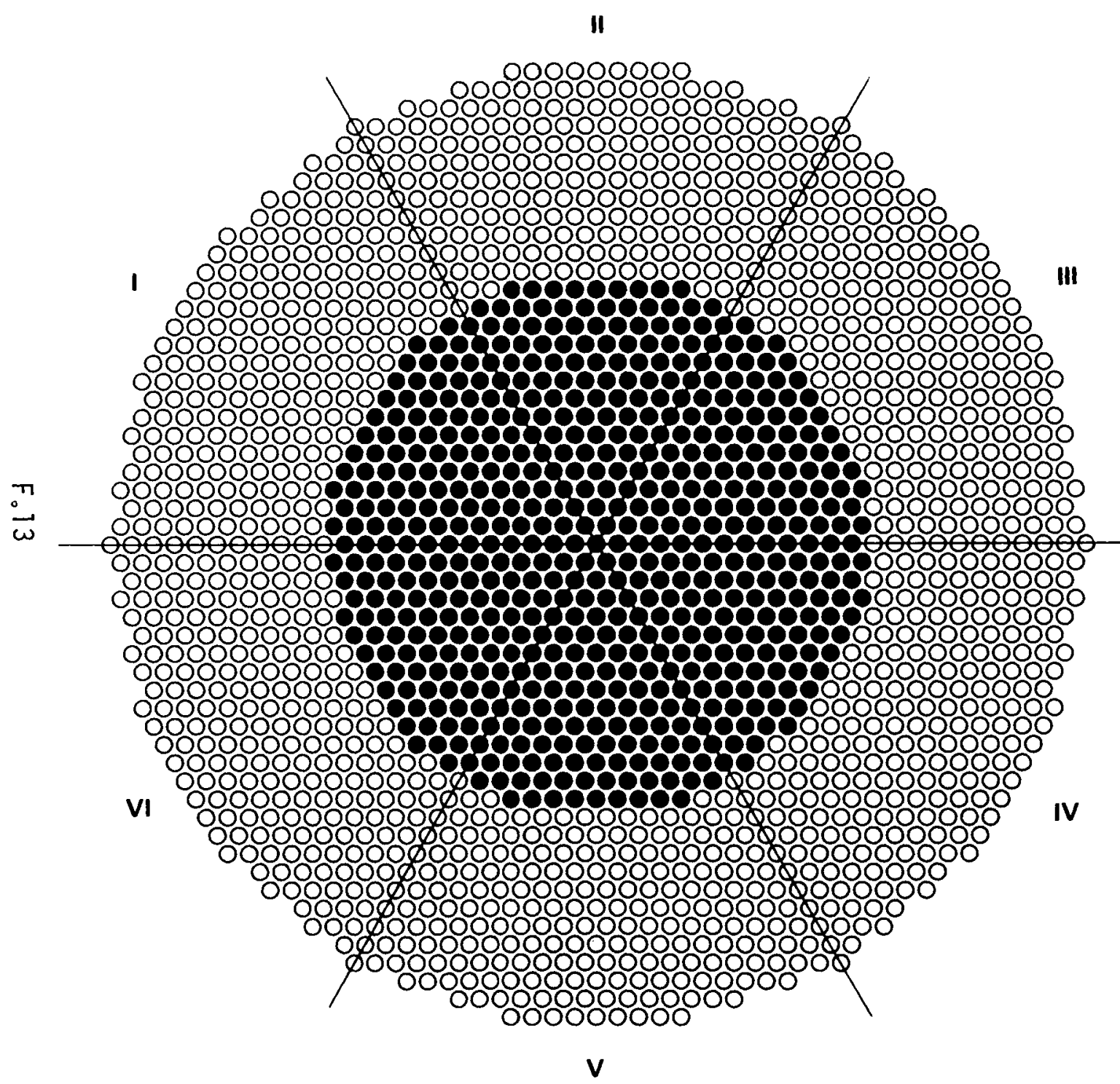

FUEL: $4.31 \mathrm{wt} \%{ }^{235} \mathrm{U}$ ENRICHED $\mathrm{UO}_{2}$

EXPERIMENT: $4.3-000-188$

LATTICE: 11

PITCH: $2.398 \pm 0.005$

GADOLINIUM: SEE COMMENTS

CONTROL ROD: NONE

SAFETY ROD: NONE

REACTION RATES: NONE

RODS: $593 \mathrm{UO}_{2}$ RODS AT •

keff: SEE COMMENTS

COMMENTS:

$k_{\text {eff }}=1.00$ AT $0.482 \pm 0.001 \mathrm{~g} \mathrm{Gd} /$ liter

$k_{\text {eff }}=0.975$ AT $0.549 \pm 0.008 \mathrm{~g} \mathrm{Gd} /$ liter

$k_{\text {eff }}=0.944$ AT $0.639+0.017 \mathrm{~g} \mathrm{Gd} /$ liter

$k_{\text {eff }}=0.861$ AT $0.788 \pm 0.011 \mathrm{~g} \mathrm{Gd} /$ liter 
II

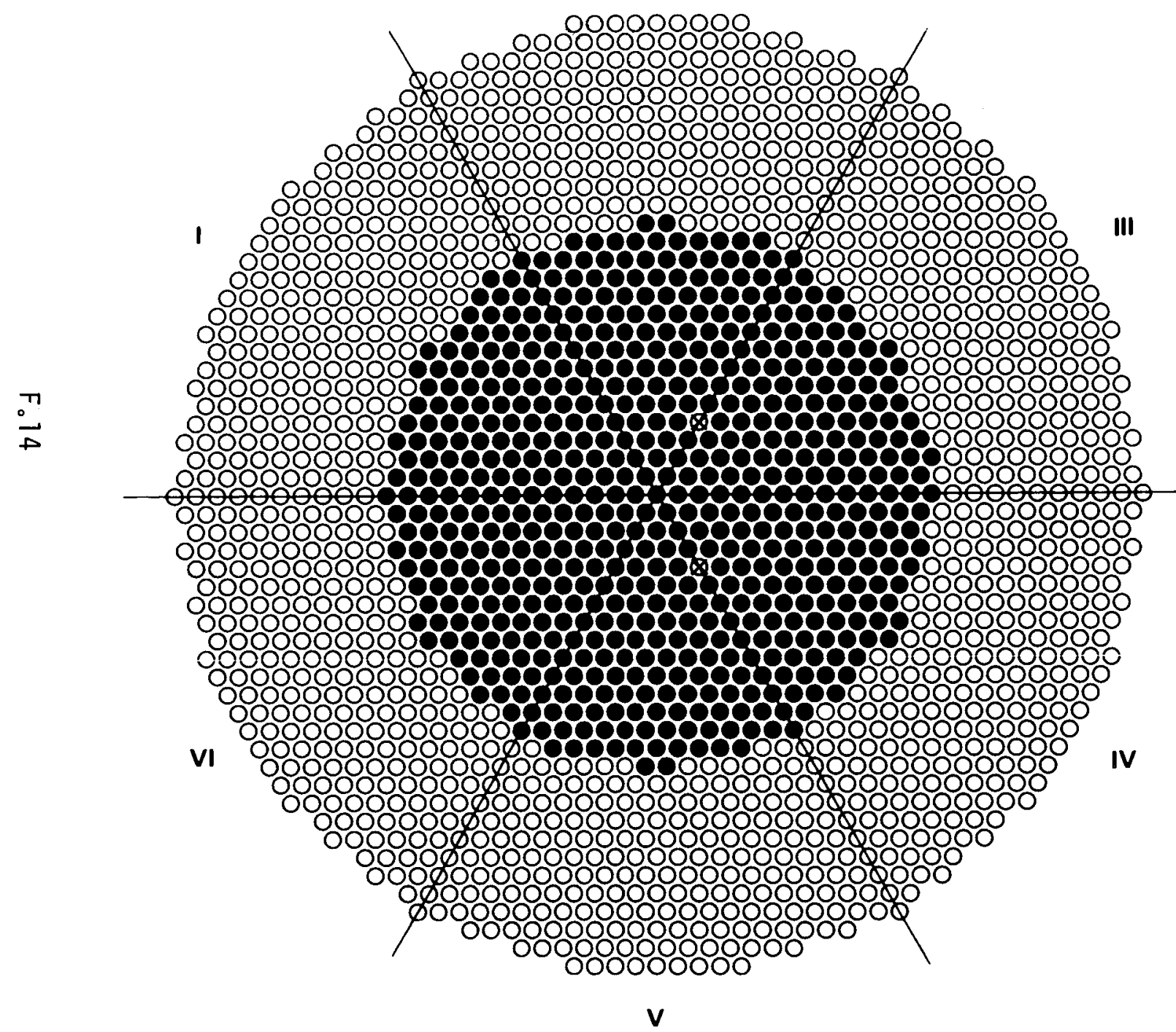

V
FUEL: $4.31 \mathrm{wt} \%{ }^{235} \mathrm{U}$ ENRICHED $\mathrm{UO}_{2}$ EXPERIMENT: $4 \cdot 3-000-188 \mathrm{~A}$

LATTICE: 11

PITCH: $2.398 \pm 0.005$

GADOLINIUM: $0.482 \pm 0.001 \mathrm{~g} \mathrm{Gd} /$ liter CONTROL ROD: OUT

SAFETY ROD: OUT

REACTION RATES: NONE

RODS: $615 \mathrm{UO}_{2}$ RODS AT •

keff: 1.0

COMMENTS: WATER FILLED ALUMINUM SLEEVES AT $\otimes$ 


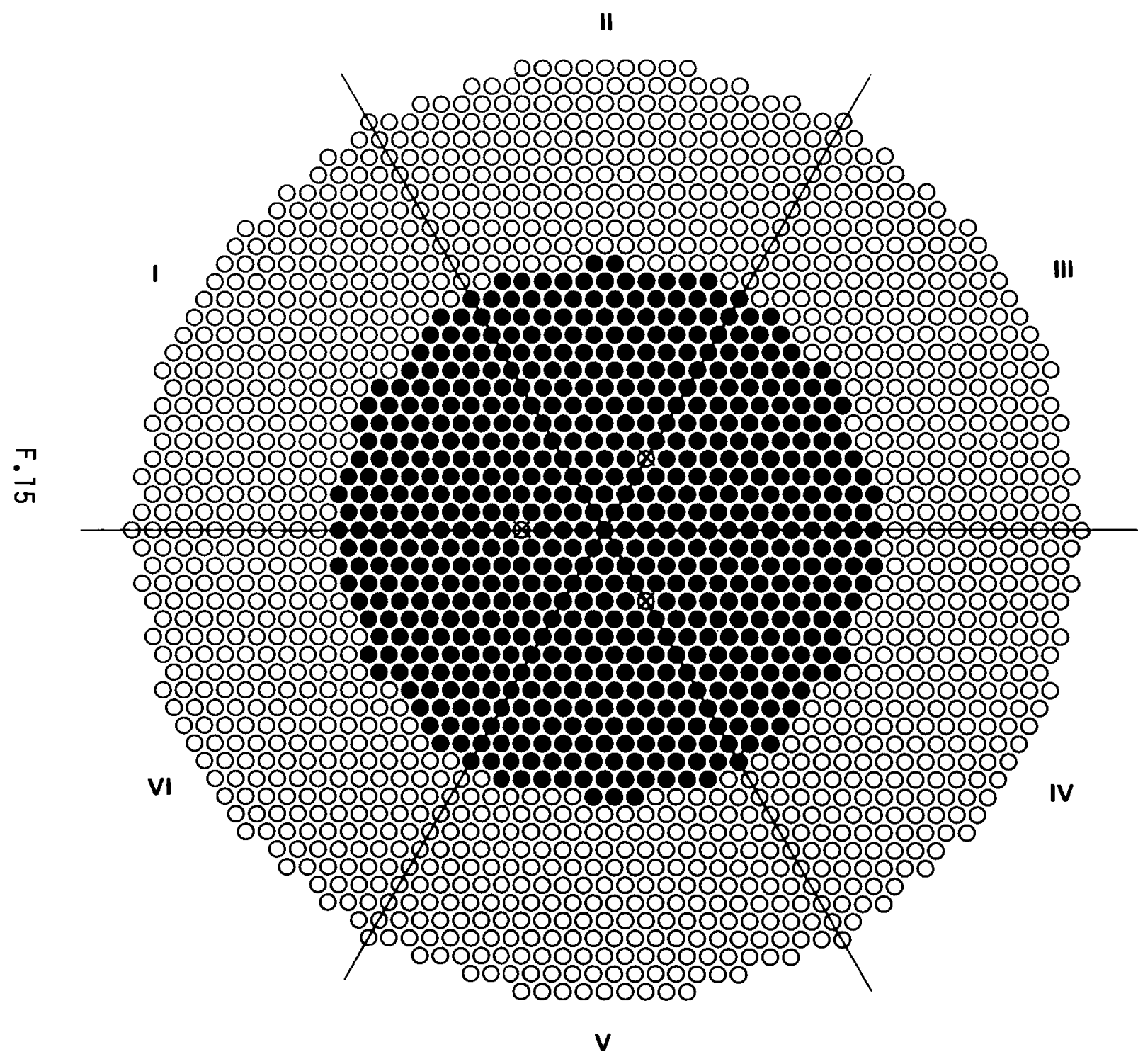

FUEL: $4.31 \mathrm{wt} \%{ }^{235} \mathrm{U}$ ENRICHED $\mathrm{UO}_{2}$

EXPERIMENT: 4.3-000-188B

LATTICE: 11

PITCH: $2.398 \pm 0.005$

GADOLINIUM: $0.482 \pm 0.001 \mathrm{~g} \mathrm{Gd} /$ liter

CONTROL ROD: OUT

SAFETY ROD: OUT

REACTION RATES: NONE

RODS: $625 \mathrm{UO}_{2}$ RODS AT $\bullet$

keff: 1.0

COMMENTS: WATER FILLED ALUMINUM SLEEVES AT $\otimes$ 


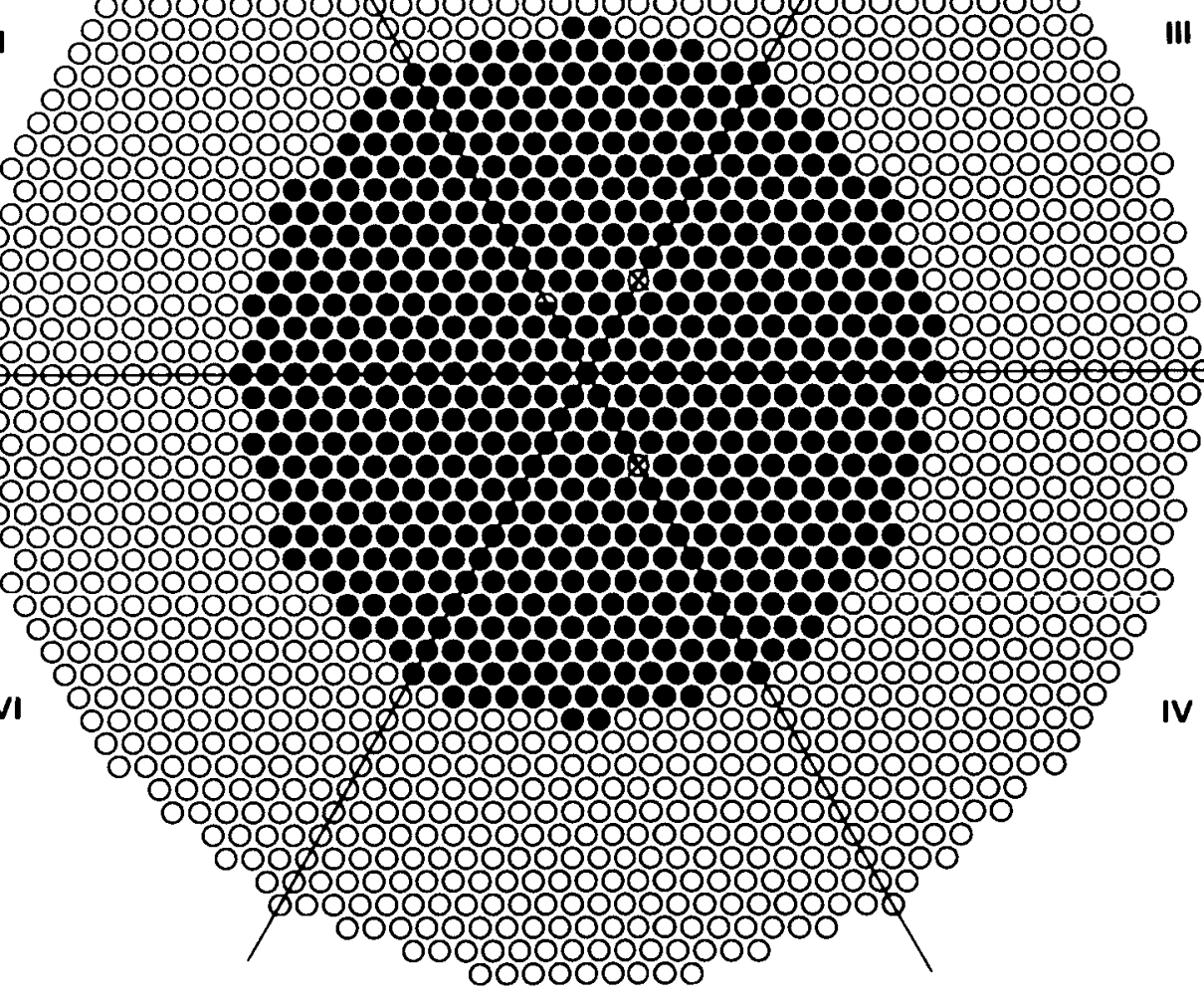

III (n) (n) (200000000 (1) (1) 等 O

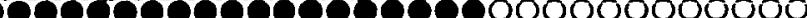

FUEL: $4.31 \mathrm{wt} \%{ }^{235} \mathrm{U}$ ENRICHED $\mathrm{UO}_{2}$ EXPERIMENT: $4.3-000-188 \mathrm{C}$

LATTICE: 11

PITCH: $2.398 \pm 0.005$

GADOLINIUM: $0.482 \pm 0.001 \mathrm{~g} \mathrm{Gd} / \mathrm{liter}$

CONTROL ROD: OUT $29.2 \pm 0.3 \mathrm{~cm}$ FROM BOTTOM OF FUEL (LOCATION $V \otimes$ )

SAFETY ROD: OUT

REACTION RATES: SOLID STATE 235 U TRACK RECORDER IN $\ominus$

RODS: $615 \mathrm{UO}_{2}$ RODS AT •

keff: 1.0

COMMENTS: CONTROL AND SAFETY ROD ALUMINUM GUIDE SLEEVES AT $\otimes$ 


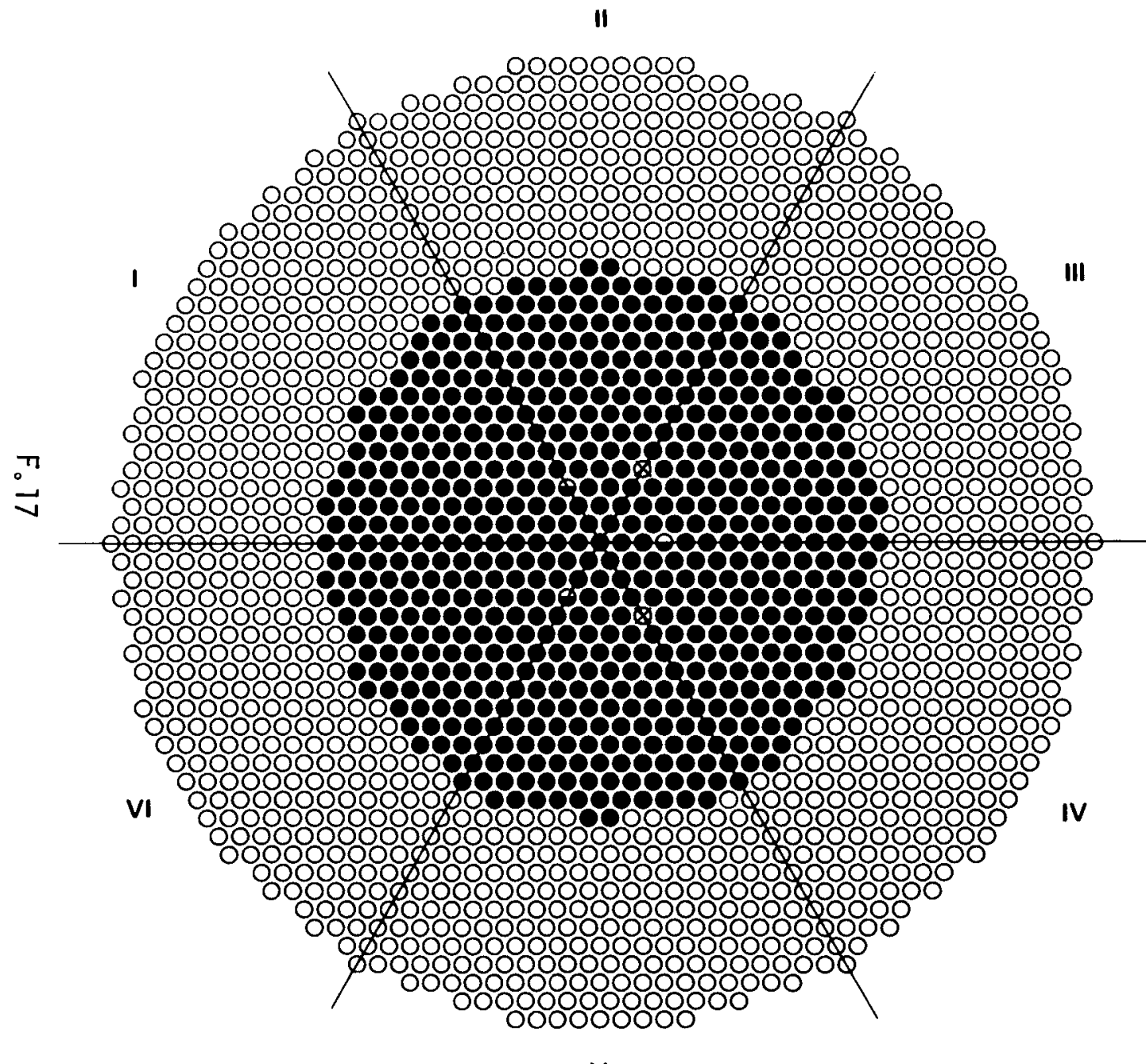

FUEL: $4.31 \mathrm{wt} \%{ }^{235} \mathrm{U}$ ENRICHED $\mathrm{UO}_{2}$

EXPERIMENT: 4.3-000-188D

LATTICE: 11

PITCH: $2.398 \pm 0.005$

GADOLINIUM: $0.482 \pm 0.001 \mathrm{~g} \mathrm{Gd} /$ liter

CONTROL ROD: OUT $26.0+0.3 \mathrm{~cm}$ FROM BOTTOM OF FUEL (LOCATION $\vee \otimes$ )

SAFETY ROD: OUT

REACTION RATES: ${ }^{238}$ U AND ${ }^{235}$ U FOILS IN $\odot$ (SEE COMMENTS)

RODS: $620 \mathrm{UO}_{2}$ RODS AT •

keff: 1.0

COMMENTS: CONTROL AND SAFETY ROD ALUMINUM GUIDE SLEEVES AT

AEEW 2 FOIL PACKET IN $\| \bullet$

AEEW 5 FOIL PACKET IN IV $\odot$ AEEW 1 FOIL PACKET IN VI $\ominus$ 


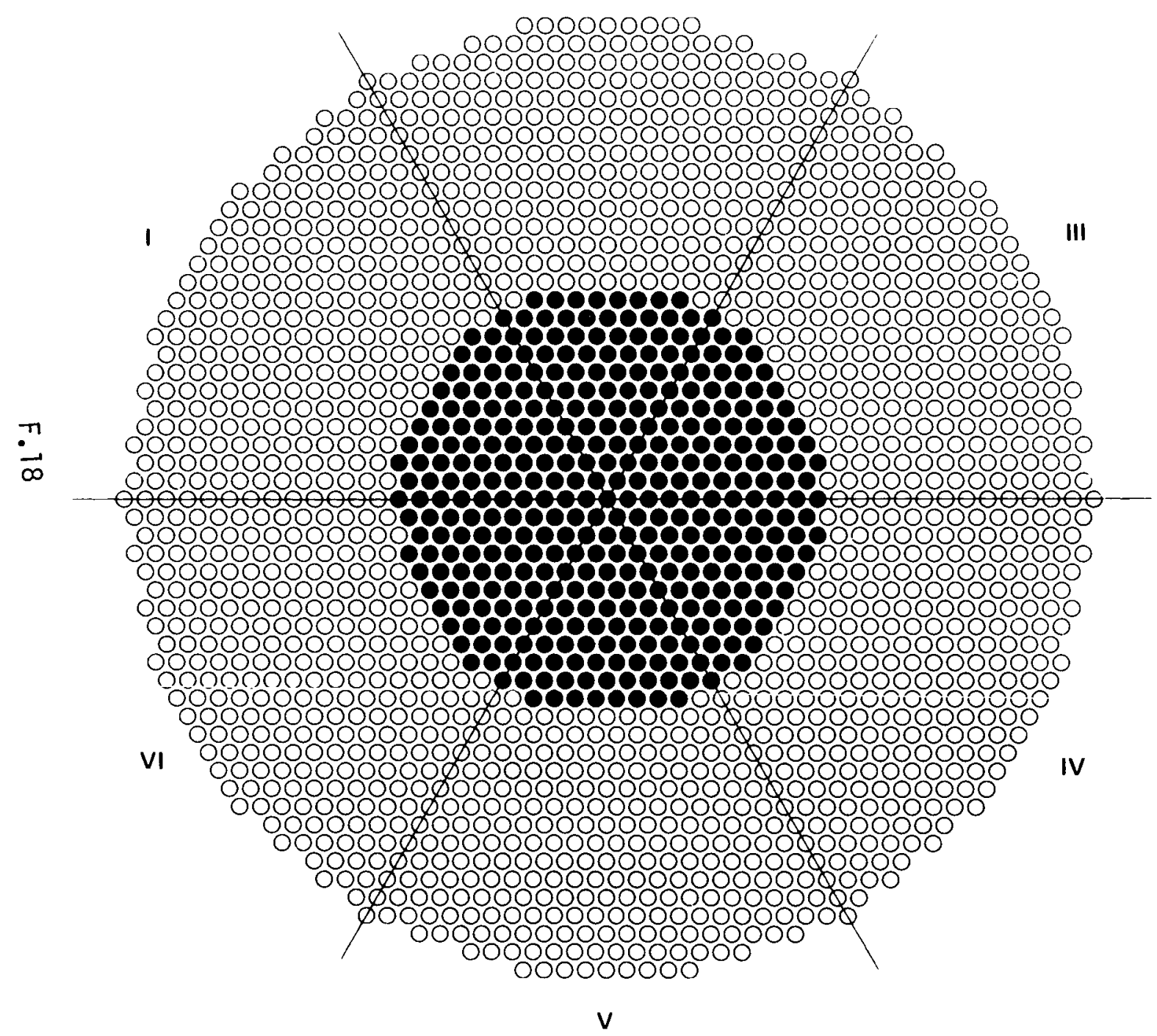

FUEL: $4.31 \mathrm{wt} \%{ }^{235} \mathrm{U}$ ENRICHED $\mathrm{UO}_{2}$

EXPERIMENT: 4.3-000-192

LATTICE: 12

PITCH: $1.801 \pm 0.005 \mathrm{~cm}$

GADOLINIUM: SEE COMMENTS

CONTROL ROD: NONE

SAFETY ROD: NONE

REACTION RATES: NONE

RODS: $378 \mathrm{UO}_{2}$ RODS AT •

Keff: SEE COMMENTS

COMMENTS: $k_{\text {eff }}=1.0 @$ ZERO g Gd/liter $k_{\text {eff }}=0.938 @ 0.122 \pm 0.001$ g Gd/liter 


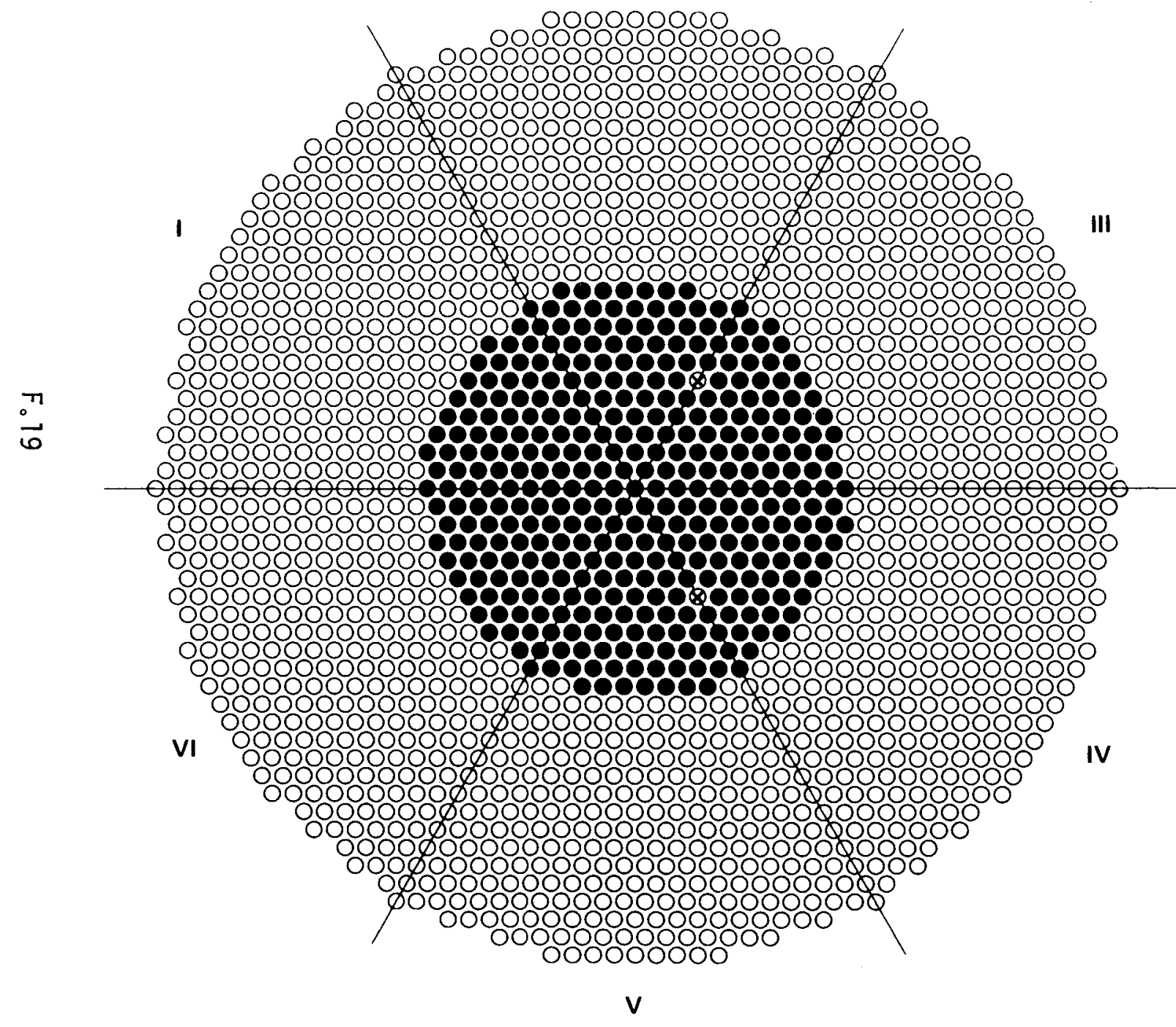

FUEL: 4.31 wt $\%{ }^{235} \mathrm{U}$ ENRICHED $\mathrm{UO}_{2}$ EXPERIMENT: 4.3-000-192A

LATTICE: 12

PITCH: $1.801 \pm 0.005 \mathrm{~cm}$

GADOLINIUM: NONE CONTROL ROD: OUT

SAFETY ROD: OUT

REACTION RATES: NONE

RODS: $370 \mathrm{UO}_{2}$ RODS AT

Keff: 1.0

COMMENTS: WATER FILLED ALUMINUM SLEEVES AT $\otimes$ 


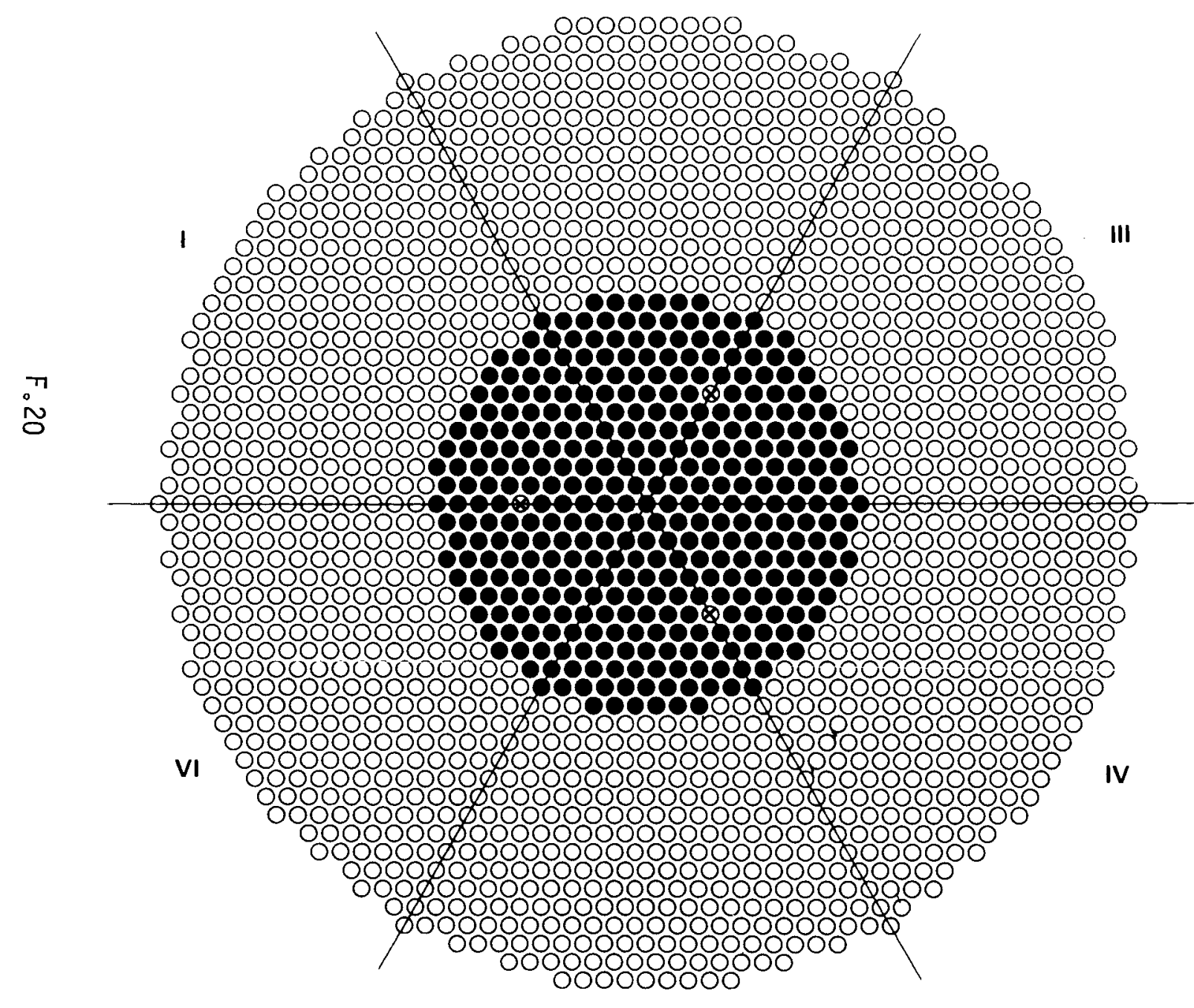

FUEL: $4.31 \mathrm{wt} \%{ }^{235} \mathrm{U}$ ENRICHED $\mathrm{UO}_{2}$ EXPERIMENT: 4.3-000-192B

LATTICE: 12

PITCH: $1.802 \pm 0.005 \mathrm{~cm}$

GADOLINIUM: NONE

CONTROL ROD: OUT

SAFETY ROD: OUT

REACTION RATES: NONE

RÕ̃S: $366 \mathrm{UUO}_{2}$ ROOUS ÂT *

$k_{\text {eff: }} \mathbf{1 . 0}$

COMMENTS: WATER FILLED ALUMINUM SLEEVES AT $\otimes$

V 
II

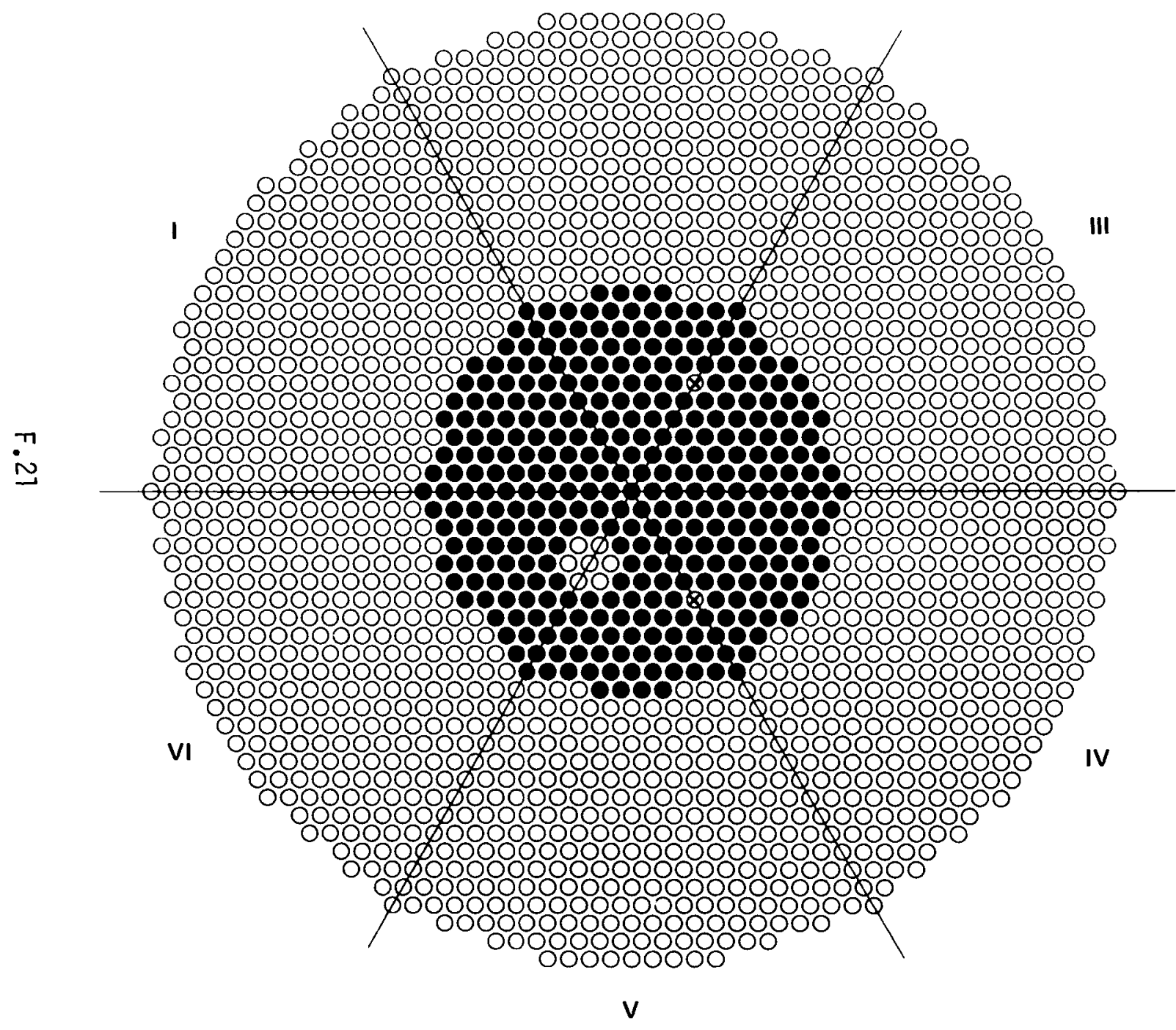

FUEL: $4.31 \mathrm{wt} \%{ }^{235} \mathrm{U}$ ENRICHED $\mathrm{UO}_{2}$

EXPERIMENT: 4.3-000-192C

LATTICE: 12

PITCH: $1.801 \pm 0.005 \mathrm{~cm}$

GADOLINIUM: NONE

CONTROL ROD: OUT

SAFETY ROD: OUT

REACTION RATES: NONE

RODS: $345 \mathrm{UO}_{2}$ RODS AT •

keff: 1.0

COMMENTS: WATER FILLED ALUMINUM SLEEVES AT $\otimes$ 
II

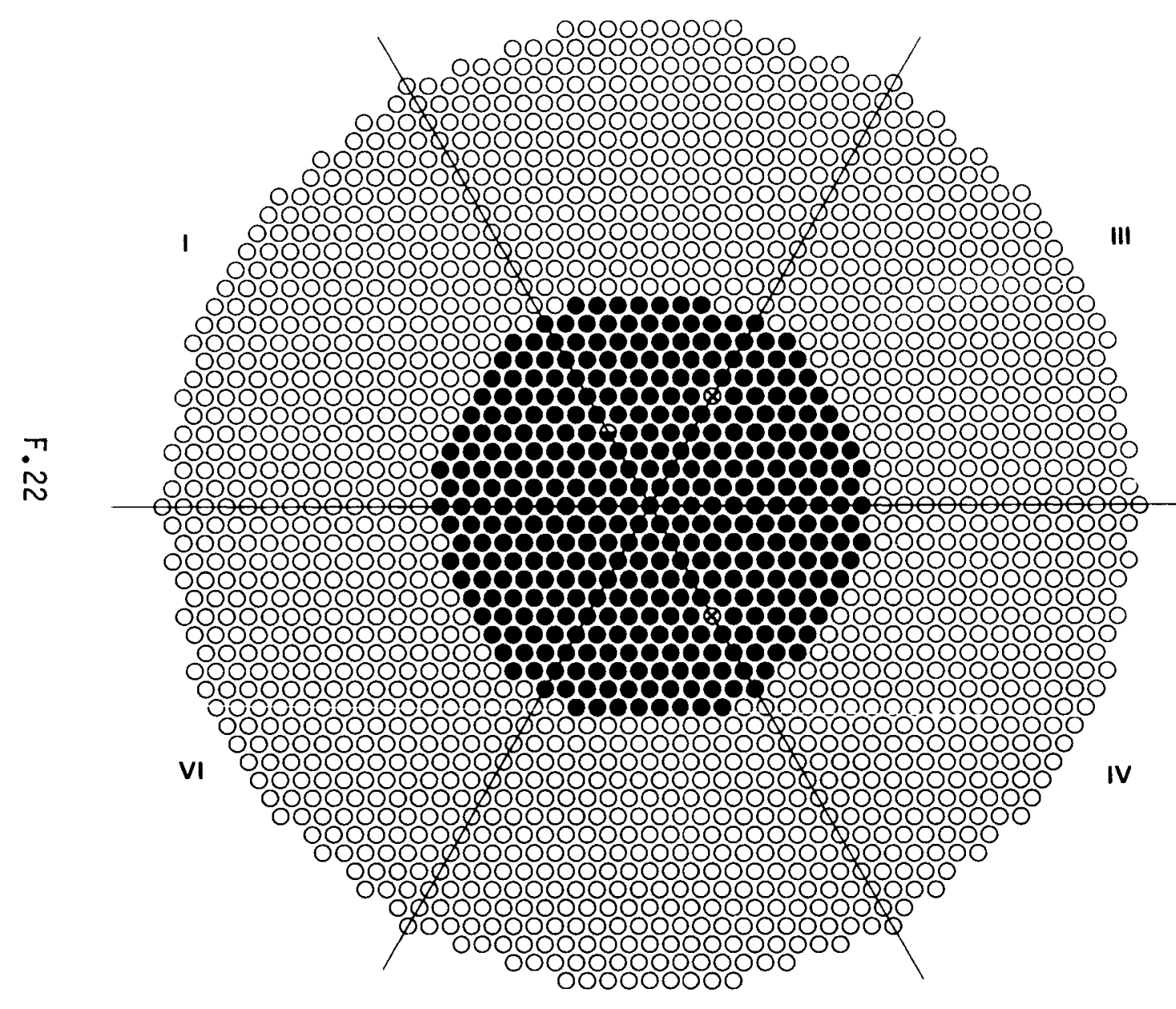
III (1) 0000989

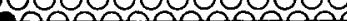
0000001010141010000000000000

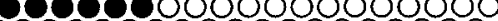

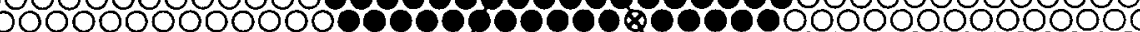
10001 每

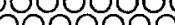

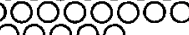
000000000
FUEL: $4.31 \mathrm{wt} \%{ }^{235} \mathrm{U}$ ENRICHED $\mathrm{UO}_{2}$ EXPERIMENT: 4.3-000-192D

LATTICE: 12

PITCH: $1.801 \pm 0.005 \mathrm{~cm}$

GADOLINIUM: NONE

CONTROL ROD: OUT $52.2 \pm 0.3 \mathrm{~cm}$ FROM BOTTOM OF FUEL (LOCATION V $\$$ )

SAFETY ROD: OUT

REACTION RATES: SOLID STATE ${ }^{235}$ U TRACK RECORDER AT $\odot$

RODS: $374 \mathrm{UO}_{2}$ RODS AT $\bullet$

keff: 1.0

COMMENTS: CONTROL AND SAFETY ROD ALUMINUM GUIDE SLEEVES AT $\otimes$ 


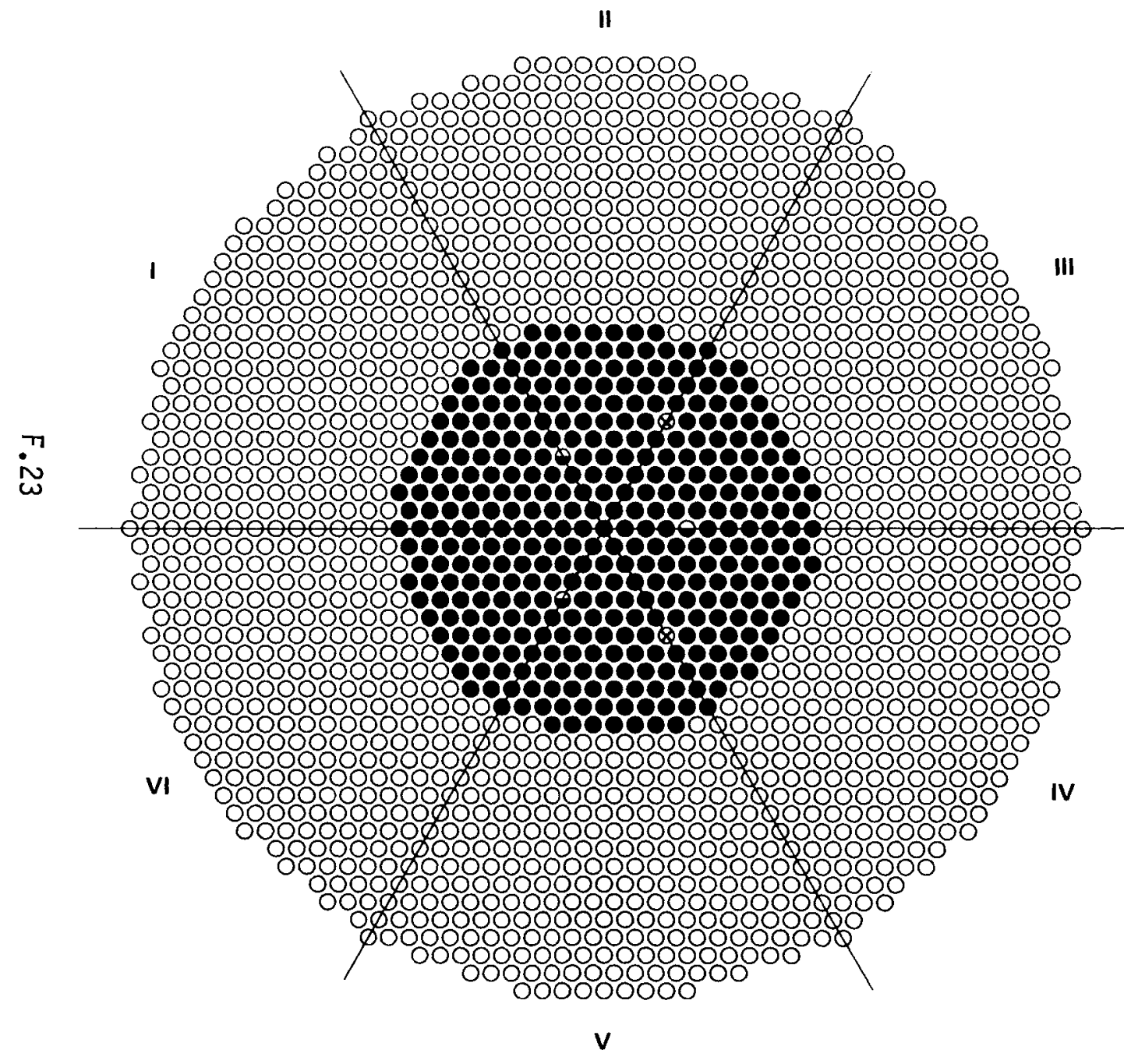

FUEL: $4.31 w t \%{ }^{235} U$ ENRICHED $\cup_{2}$ EXPERIMENT: $4.3-000-192 E$

LATTICE: 12

PITCH: $1.801 \pm 0.005 \mathrm{~cm}$

GADOLINIUM: NONE

CONTROL ROD: OUT $50.0 \pm 0.3 \mathrm{~cm}$ FROM BOTTOM OF FUEL (LOCATION $V \otimes)$

SAFETY ROD: OUT

REACTION RATES: ${ }^{238} U$ AND ${ }^{235} \mathrm{U}$ FOILS IN 0 (SEE COMMENTS)

RODS: $373 \mathrm{UO}_{2}$ RODS AT •

Keff: 1.0

COMMENTS: CONTROL AND SAFETY ROD ALUMINUM GUIDE SLEEVES AT $\otimes$

AEEW 8 FOIL PACKET IN II $\theta$ AEEW 6 FOIL PACKET IN IV $\odot$ AEEW 7 FOIL PACKET IN VI $\ominus$ 


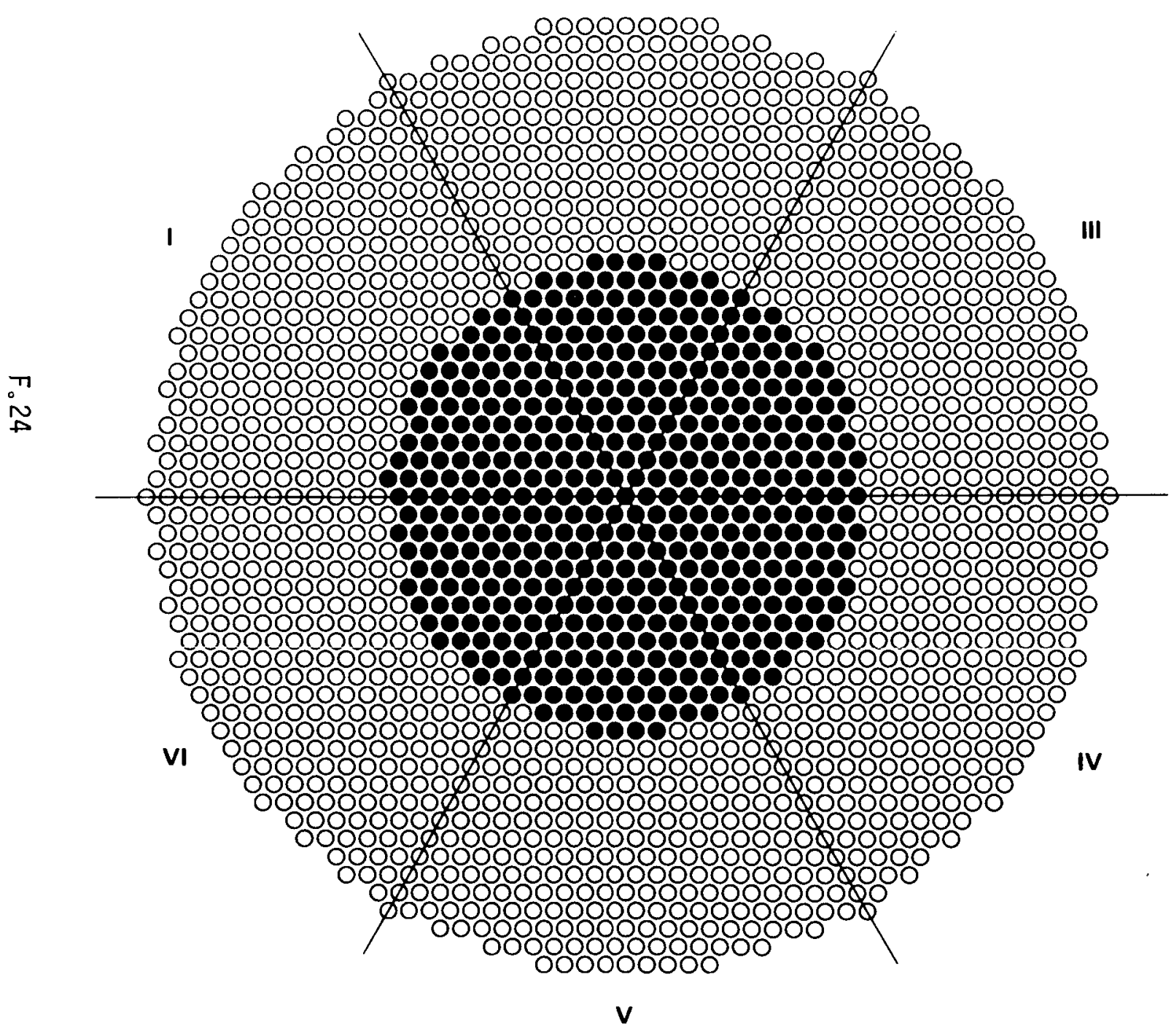

FUEL: $4.31 \mathrm{wt} \%{ }^{235} \mathrm{U}$ ENRICHED $\mathrm{UO}_{2}$ EXPERIMENT: 4.3-000-201

LATTICE: 12

PITCH: $1.801 \pm 0.005 \mathrm{~cm}$

GADOLINIUM: $0.122 \pm 0.001 \mathrm{~g} \mathrm{Gd} / \mathrm{liter}$ CONTROL ROD: NONE SAFETY ROD: NONE REACTION RATES: NONE RODS: $476 \mathrm{UO}_{2}$ RODS AT • keff: 1.0 COMMENTS: 
II

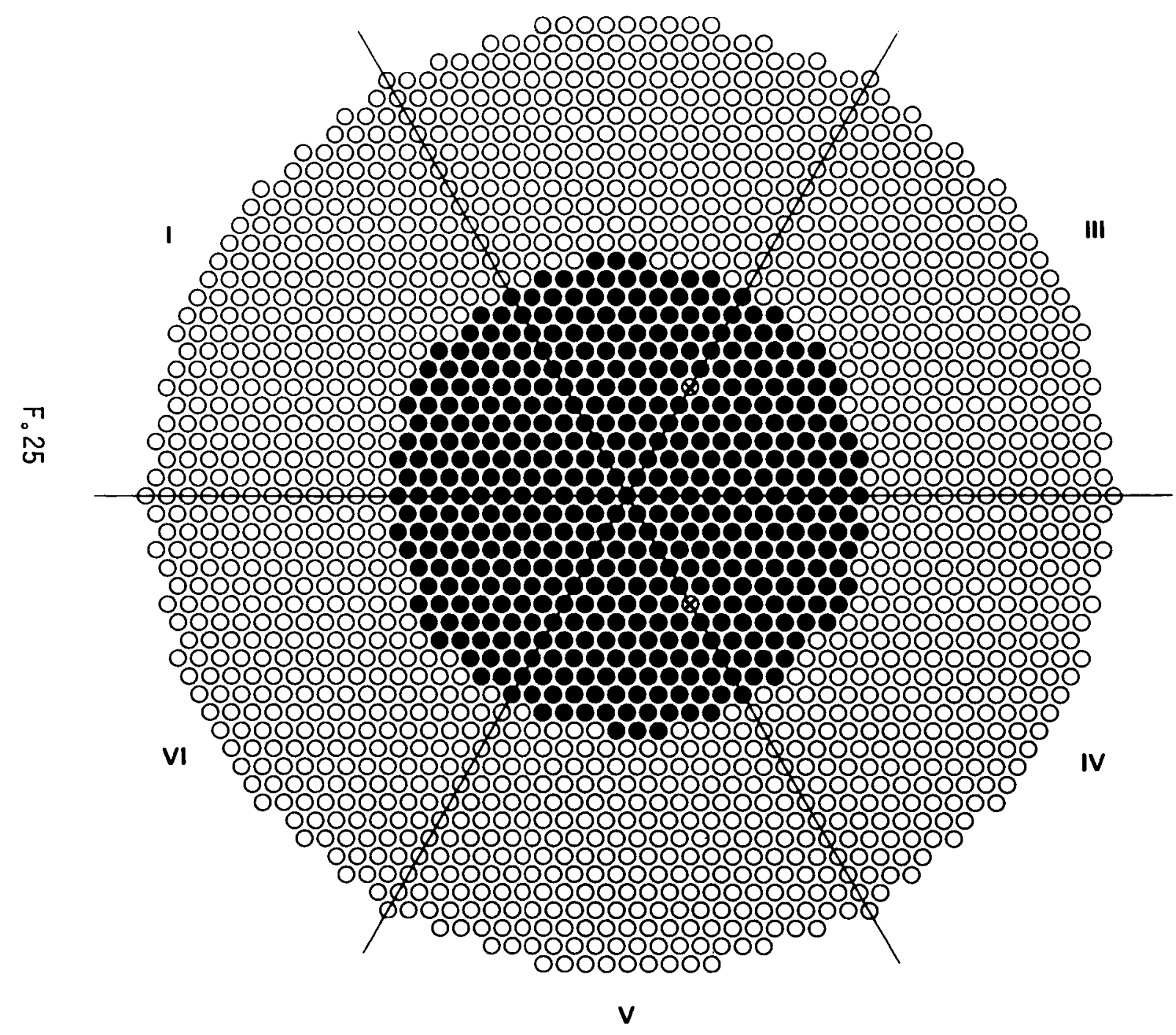

FUEL: $4.31 \mathrm{wt} \%{ }^{235} \mathrm{U}$ ENRICHED $\mathrm{UO}_{2}$ EXPERIMENT: 4.3-000-201A

LATTICE: 12

PITCH: $1.801 \pm 0.005 \mathrm{~cm}$

GADOLINIUM: $0.122 \pm 0.001 \mathrm{~g} \mathrm{Gd} / \mathrm{liter}$ CONTROL ROD: OUT

SAFETY ROD: OUT

REACTION RATES: NONE

RODS: $468 \mathrm{UO}_{2}$ RODS AT •

keff: 1.0

COMMENTS: WATER FILLED ALUMINUM SLEEVES AT $\otimes$ 
II

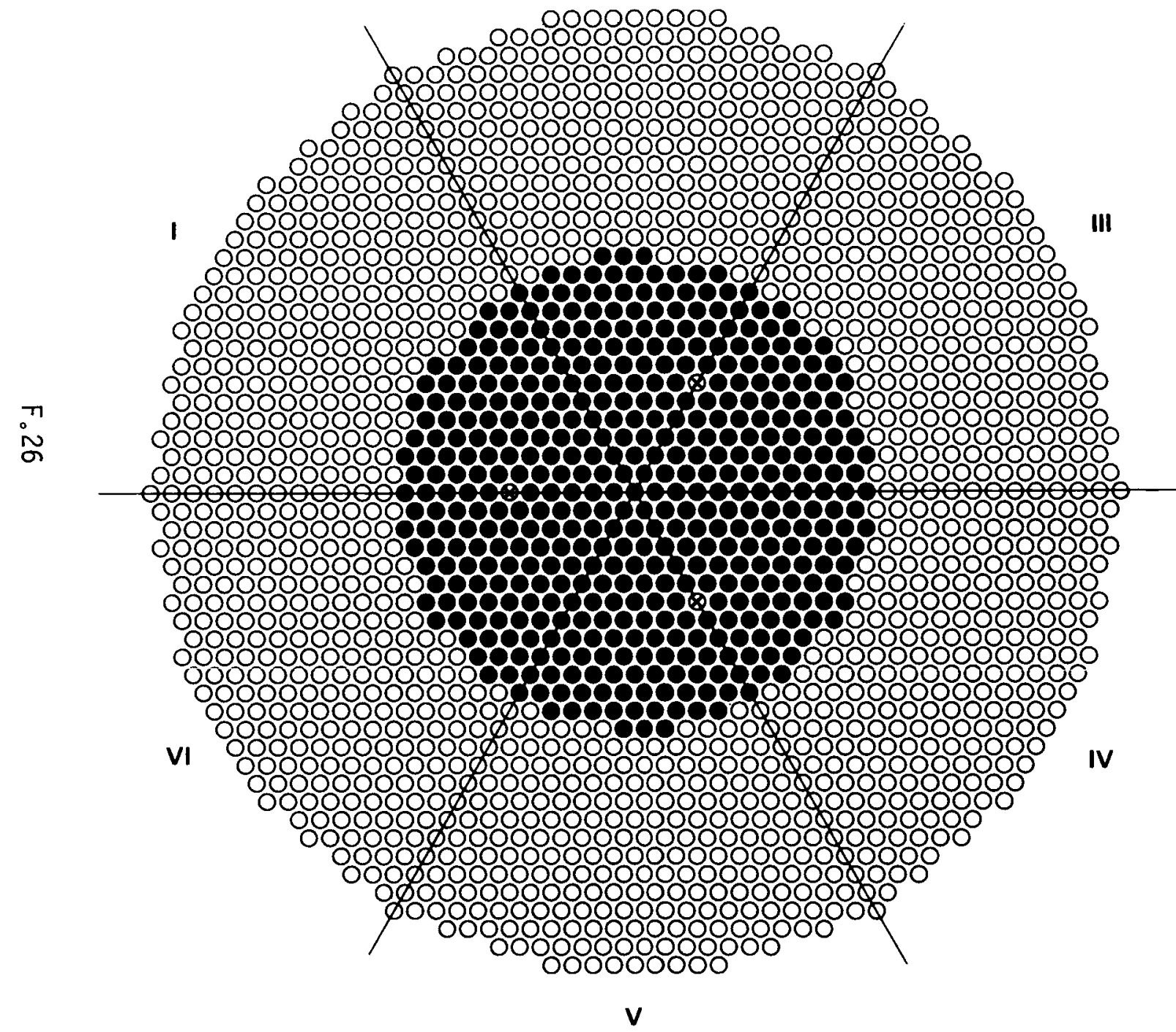

FUEL: $4.31 \mathrm{wt} \%{ }^{235} \mathrm{U}$ ENRICHED $\mathrm{UO}_{2}$ EXPERIMENT: 4.3-000-201B

LATTICE: 12

PITCH: $1.801 \pm 0.005 \mathrm{~cm}$

GADOLINIUM: $0.122 \pm 0.001 \mathrm{~g} \mathrm{Gd} /$ liter CONTROL ROD: OUT

SAFETY ROD: OUT

REACTION RATES: NONE

RODS: $464 \mathrm{UO}_{2}$ RODS AT

keff: 1.0

COMMENTS: WATER FILLED ALUMINUM SLEEVES AT $\otimes$ 


\section{II}

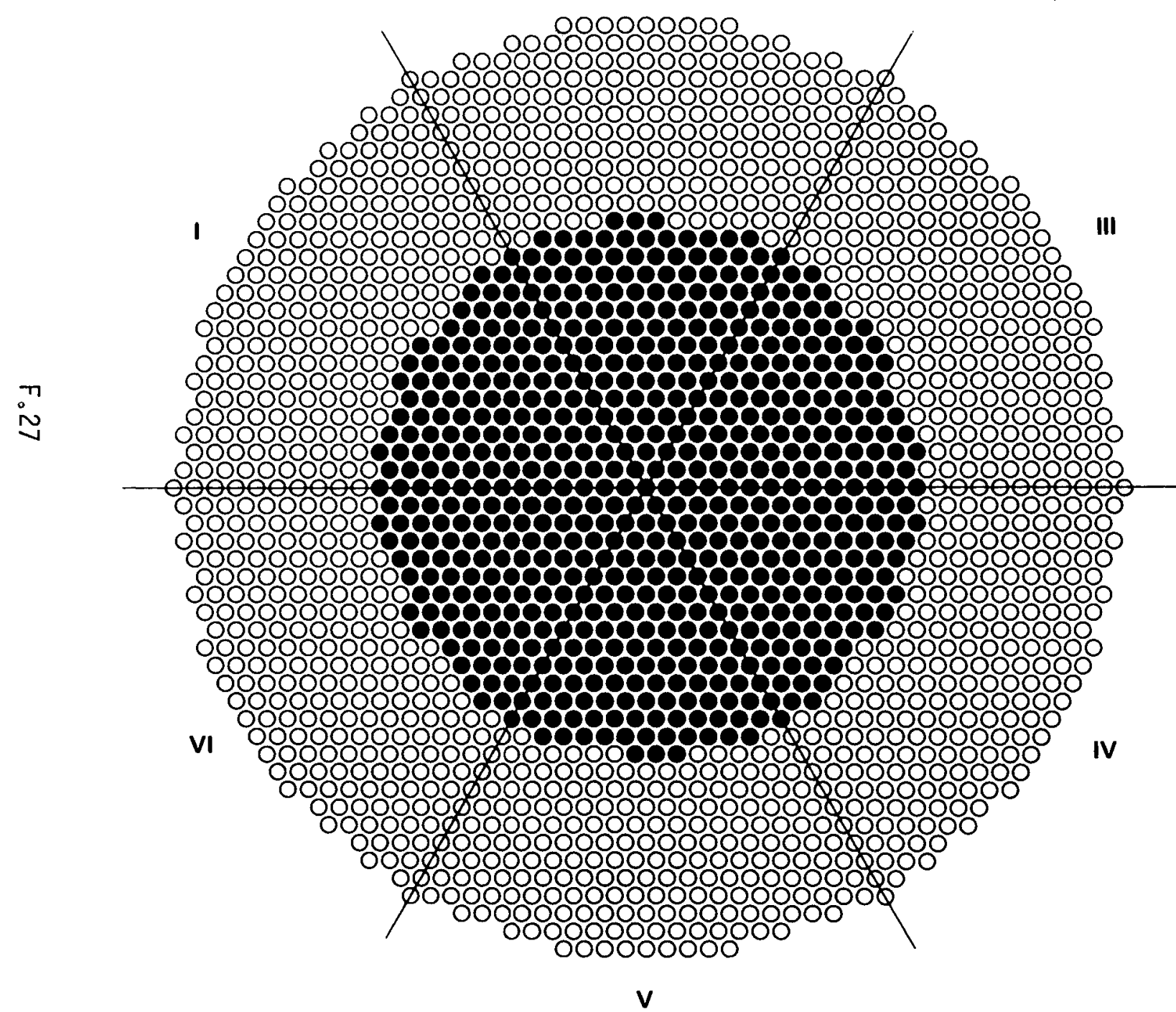

FUEL: $4.31 \mathrm{wt} \%{ }^{235} \mathrm{U}$ ENRICHED $\mathrm{UO}_{2}$ EXPERIMENT: 4.3-000-202

LATTICE: 12

PITCH: $1.801 \pm 0.005 \mathrm{~cm}$

GADOLINIUM: $0.400 \pm 0.021 \mathrm{~g} \mathrm{Gd} / \mathrm{liter}$ CONTROL ROD: NONE SAFETY ROD: NONE REACTION RATES: NONE RODS: $630 \mathrm{UO}_{2}$ RODS AT $\bullet$

keff: 1.0

COMMENTS: 


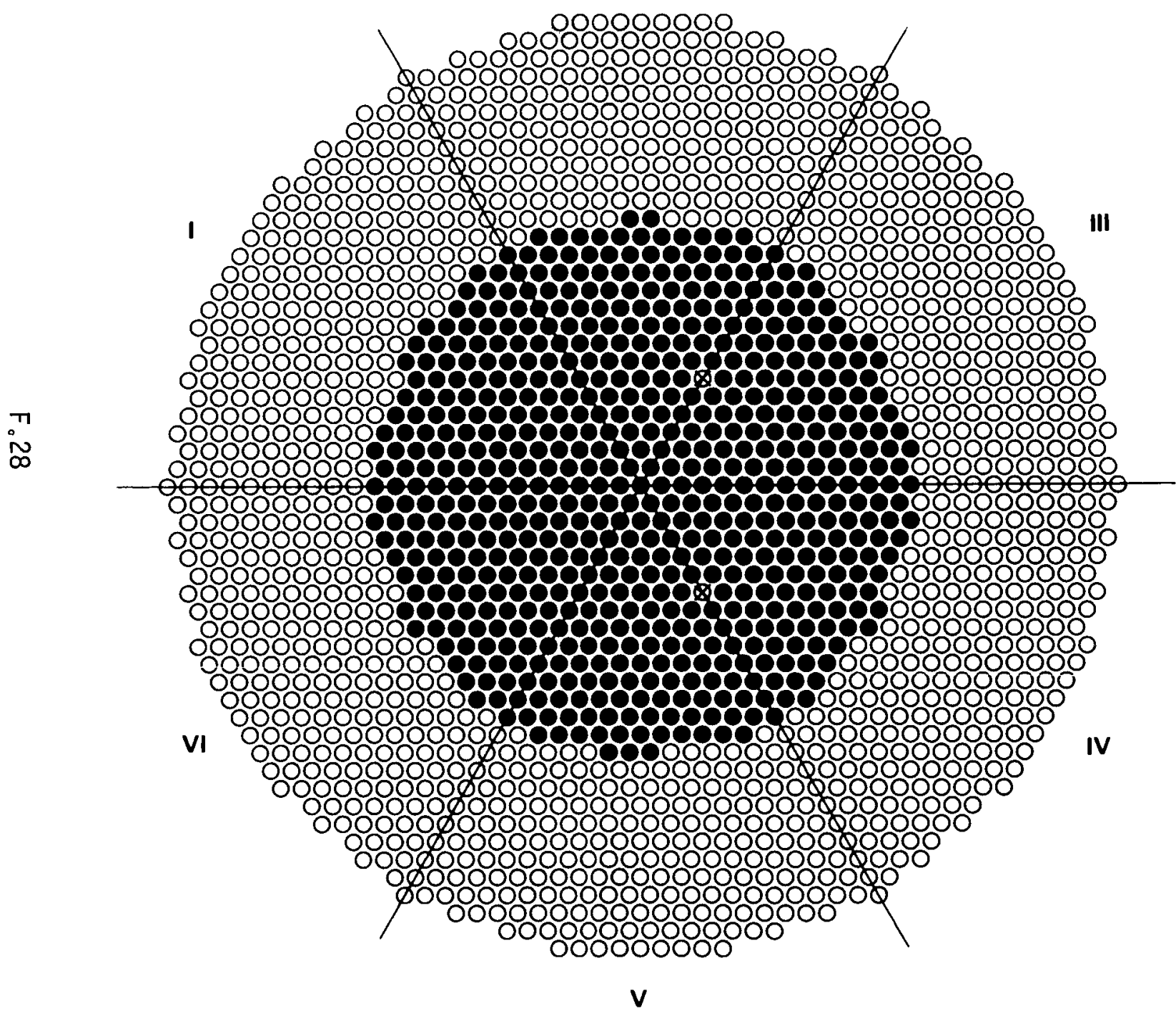

FUEL: $4.31 \mathrm{wt} \%{ }^{235} \mathrm{U}$ ENRICHED $\mathrm{UO}_{2}$ EXPERIMENT: 4.3-000-202A

LATTICE: 12

PITCH: $1.801 \pm 0.005 \mathrm{~cm}$

GADOLINIUM: $0.400 \pm 0.021 \mathrm{~g} \mathrm{Gd} /$ liter CONTROL ROD: OUT

SAFETY ROD: OUT

REACTION RATES: NONE

RODS: $625 \mathrm{UO}_{2}$ RODS AT $\bullet$

keff: 1.0

COMMENTS: WATER FILLED ALUMINUM SLEEVES AT $\otimes$ 


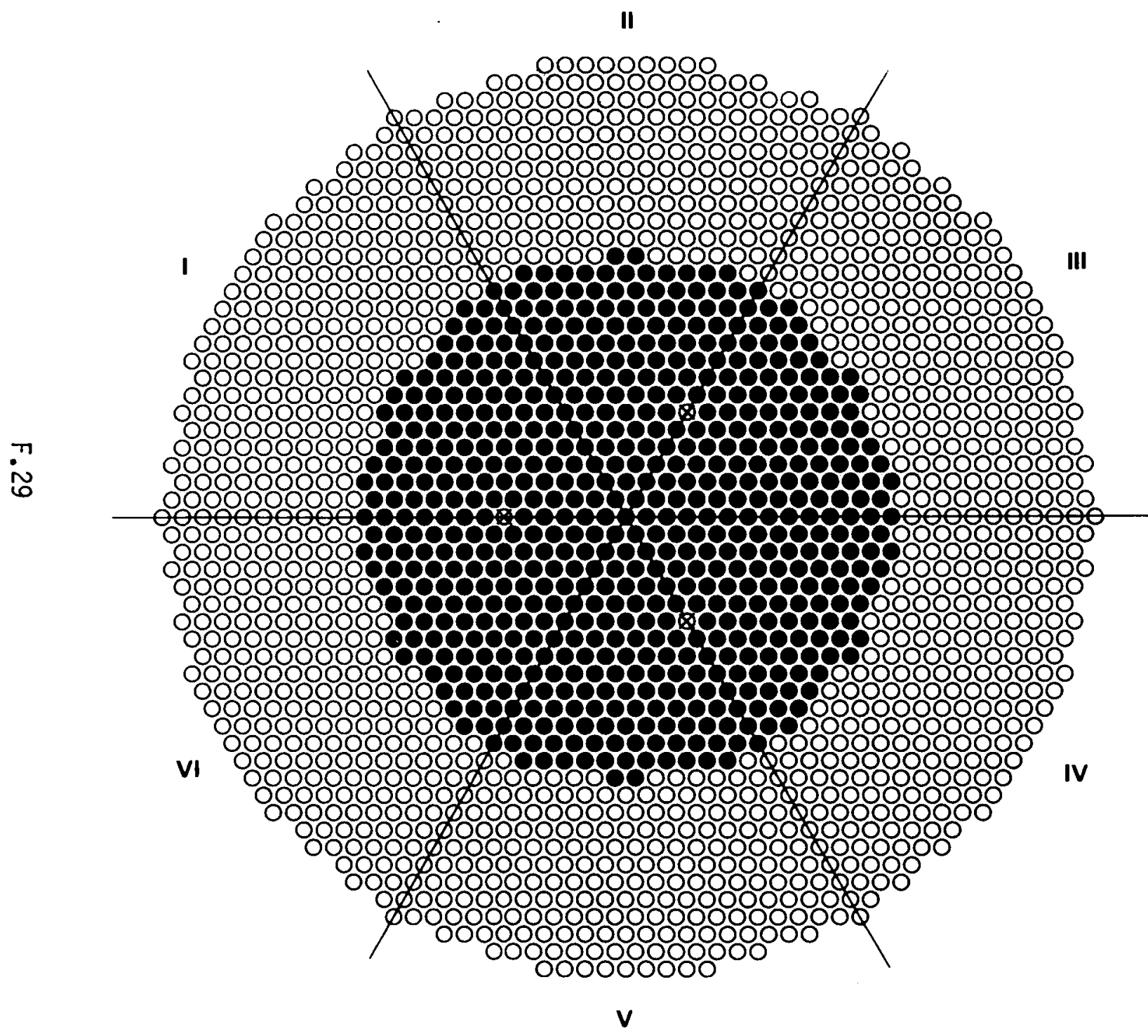

FUEL: 4.31 wt $\%{ }^{235} \mathrm{U}$ ENRICHED $\mathrm{UO}_{2}$ EXPERIMENT: 4.3-000-202B

LATTICE: 12

PITCH: $1.801 \pm 0.005 \mathrm{~cm}$

GADOLINIUM: $0.400 \pm 0.021 \mathrm{~g} \mathrm{Gd} /$ liter

CONTROL ROD: OUT

SAFETY ROD: OUT

REACTION RATES: NONE

RODS: $623 \mathrm{UO}_{2}$ RODS AT $\bullet$

keff: 1.0

COMMENTS: WATER FILLED ALUMINUM SLEEVES AT 


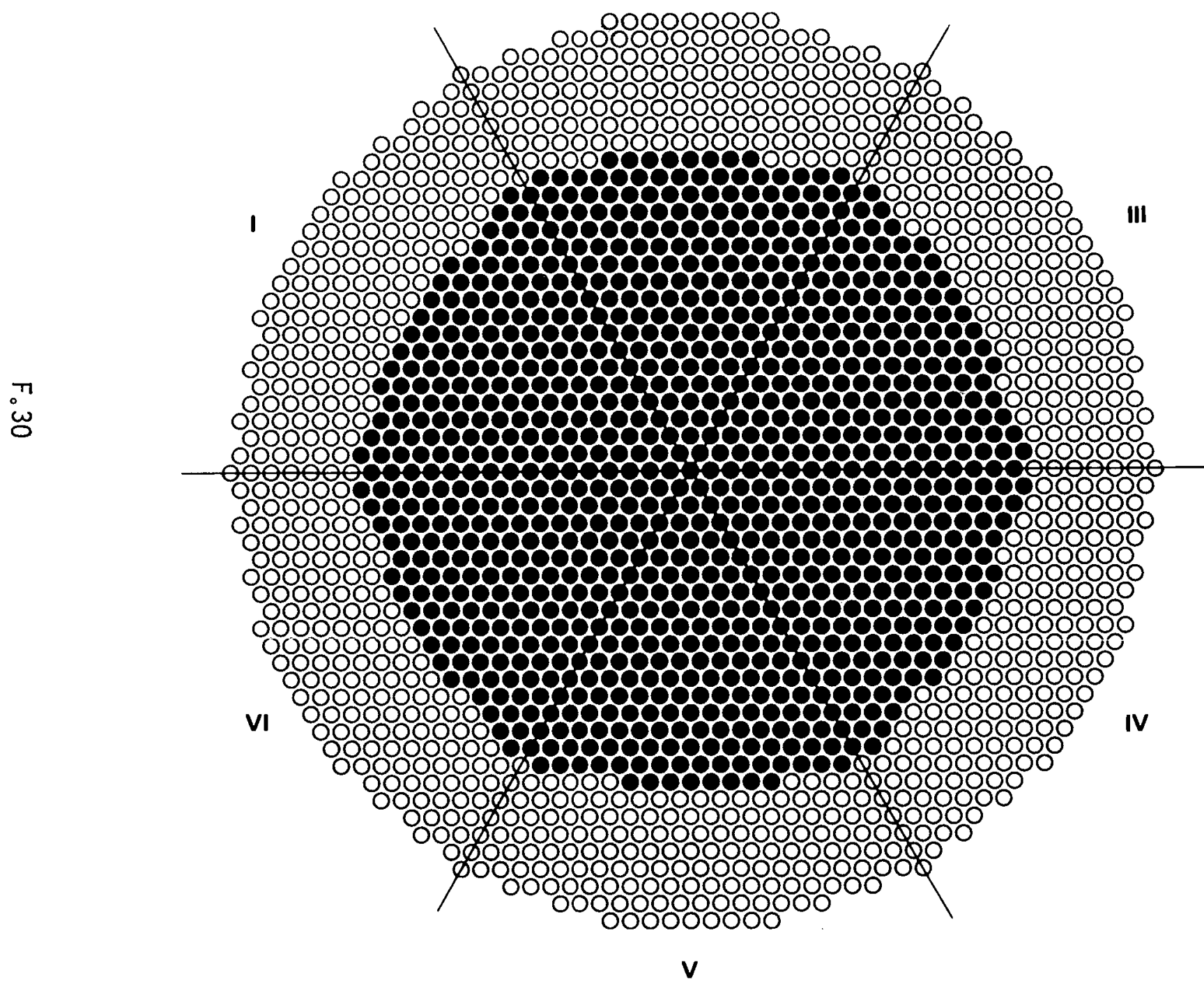

FUEL: $4.31 \mathrm{wt} \%{ }^{235} \mathrm{U}$ ENRICHED $\mathrm{UO}_{2}$ EXPERIMENT: $4.3-000-203$

LATTICE: 12

PITCH: $1.801 \pm 0.005 \mathrm{~cm}$

GADOLINIUM: $0.908 \pm 0.06 \mathrm{~g} \mathrm{Gd} /$ liter CONTROL ROD: NONE SAFETY ROD: NONE REACTION RATES: NONE RODS: $959 \mathrm{UO}_{2}$ RODS AT keff: 1.0 COMMENTS: 
II

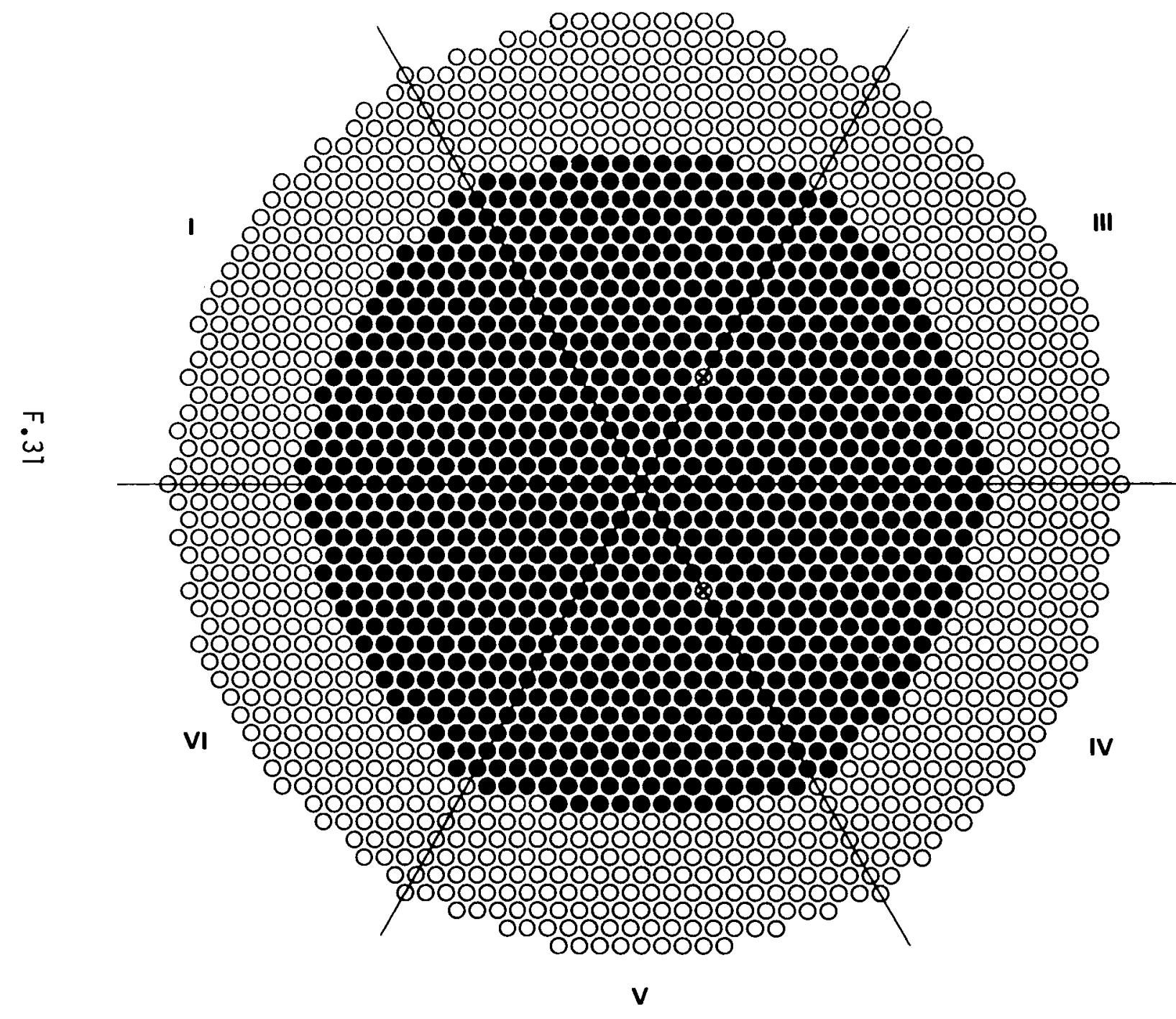

FUEL: $4.31 \mathrm{wt} \%{ }^{235} \mathrm{U}$ ENRICHED $\mathrm{UO}_{2}$

EXPERIMENT: $4.3-000-203 \mathrm{~A}$

LATTICE: 12

PITCH: $1.801 \pm 0.005 \mathrm{~cm}$

GADOLINIUM: $0.908 \pm 0.006 \mathrm{~g} \mathrm{Gd} /$ liter

CONTROL ROD: OUT

SAFETY ROD: OUT

REACTION RATES: NONE

RODS: $965 \mathrm{UO}_{2}$ RODS AT •

Keff: 1.0

COMMENTS: WATER FILLED ALUMINUM SLEEVES AT 8 
II

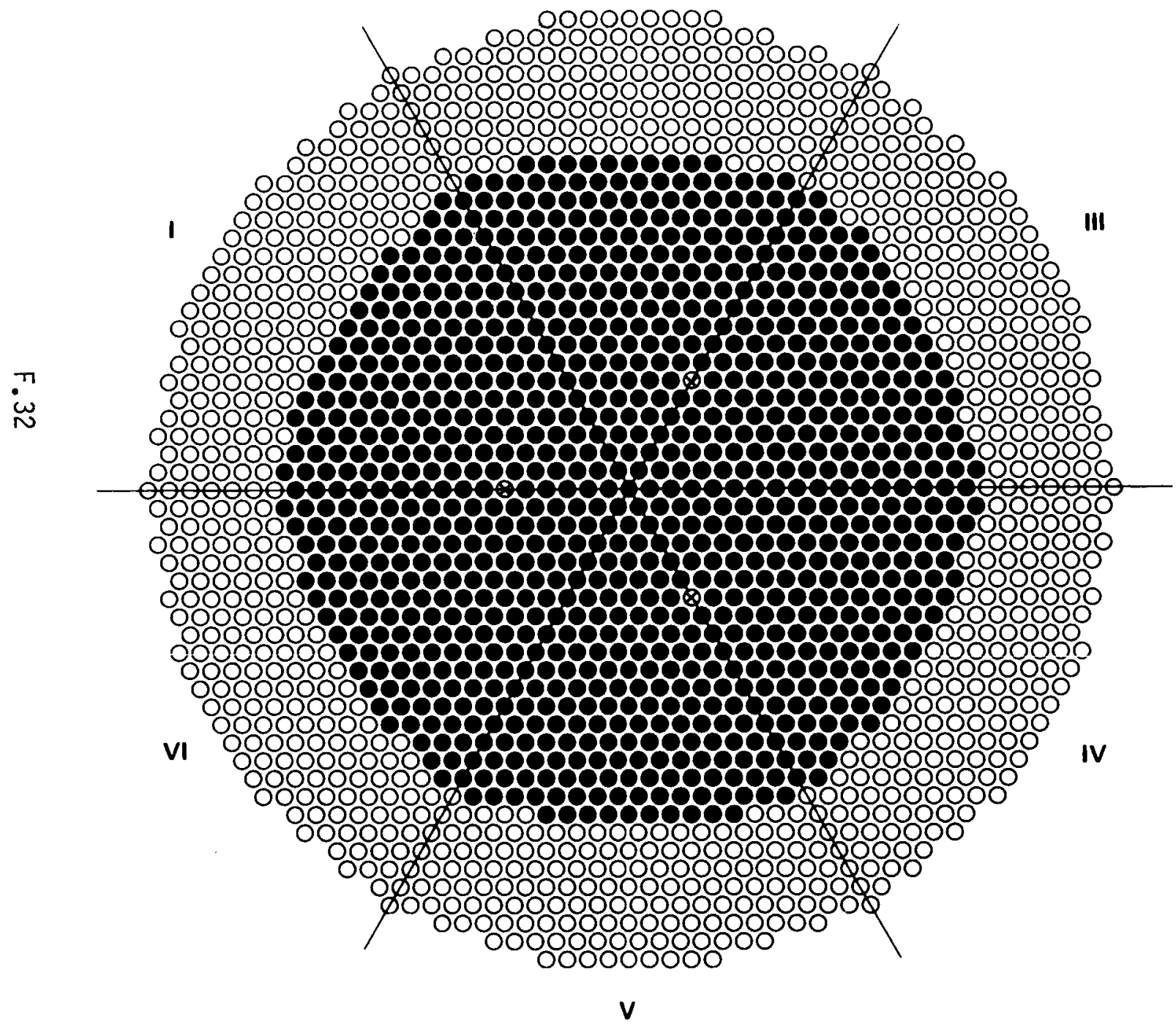

FUEL: $4.31 \mathrm{wt} \%{ }^{235} \mathrm{U}$ ENRICHED $\mathrm{UO}_{2}$

EXPERIMENT: 4.3-000-203B

LATTICE: 12

PITCH: $1.801 \pm 0.005 \mathrm{~cm}$

GADOLINIUM: $0.908 \pm 0.006 \mathrm{~g} \mathrm{Gd} / \mathrm{liter}$ CONTROL ROD: OUT

SAFETY ROD: OUT

REACTION RATES: NONE

RODS: $968 \mathrm{UO}_{2}$ ROODS ATT •

Keff: 1.0

COMMENTS: WATER FILLED ALUMINUM SLEEVES AT $\otimes$ 
II

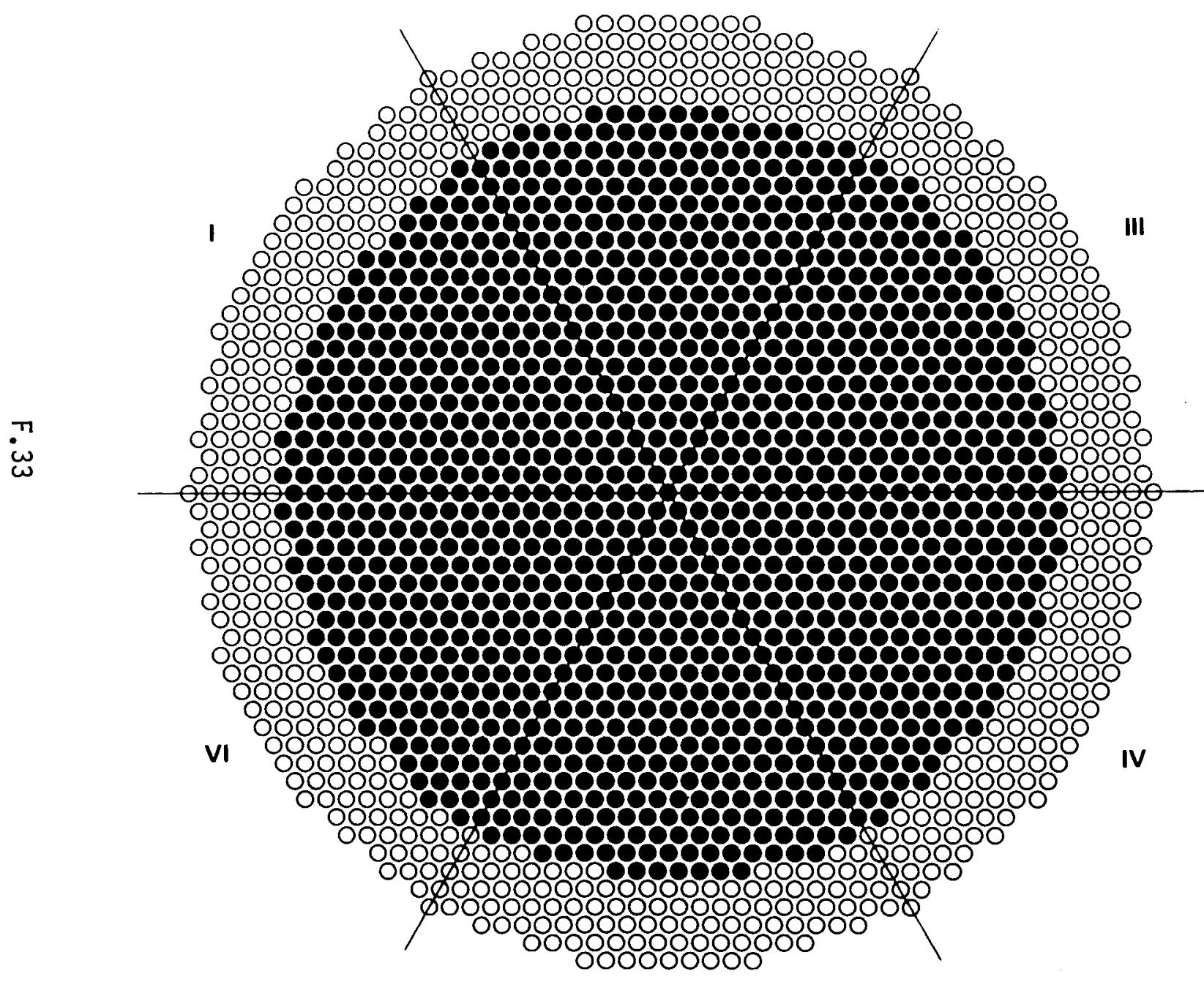

v
FUEL: $4.31 \mathrm{wt} \%{ }^{235} \mathrm{U}$ ENRICHED $\mathrm{UO}_{2}$

EXPERIMENT: 4.3-000-204

LATTICE: 12

PITCH: $1.801 \pm 0.005 \mathrm{~cm}$

GADOLINIUM: SEE COMMENTS

CONTROL ROD: OUT

SAFETY ROD: OUT

REACTION RATES: NONE

RODS: $1260 \mathrm{UO}_{2}$ RODS AT •

keff: SEE COMMENTS

COMMENTS:

$k_{\text {eff }}=1.0$ AT $1.247 \pm 0.038 \mathrm{~g} \mathrm{GD} /$ liter $k_{\text {eff }}=0.991$ AT $1.371 \pm 0.051 \mathrm{~g} \mathrm{GD} /$ liter $k_{\text {eff }}=0.980$ AT $1.456 \pm 0.051 \mathrm{~g} \mathrm{GD} /$ liter $k_{\text {eff }}=0.961$ AT $1.664 \pm 0.077 \mathrm{~g} \mathrm{GD} /$ liter $k_{\text {eff }}=0.909$ AT $2.195 \pm 0.035 \mathrm{~g} \mathrm{GD} /$ liter 
II

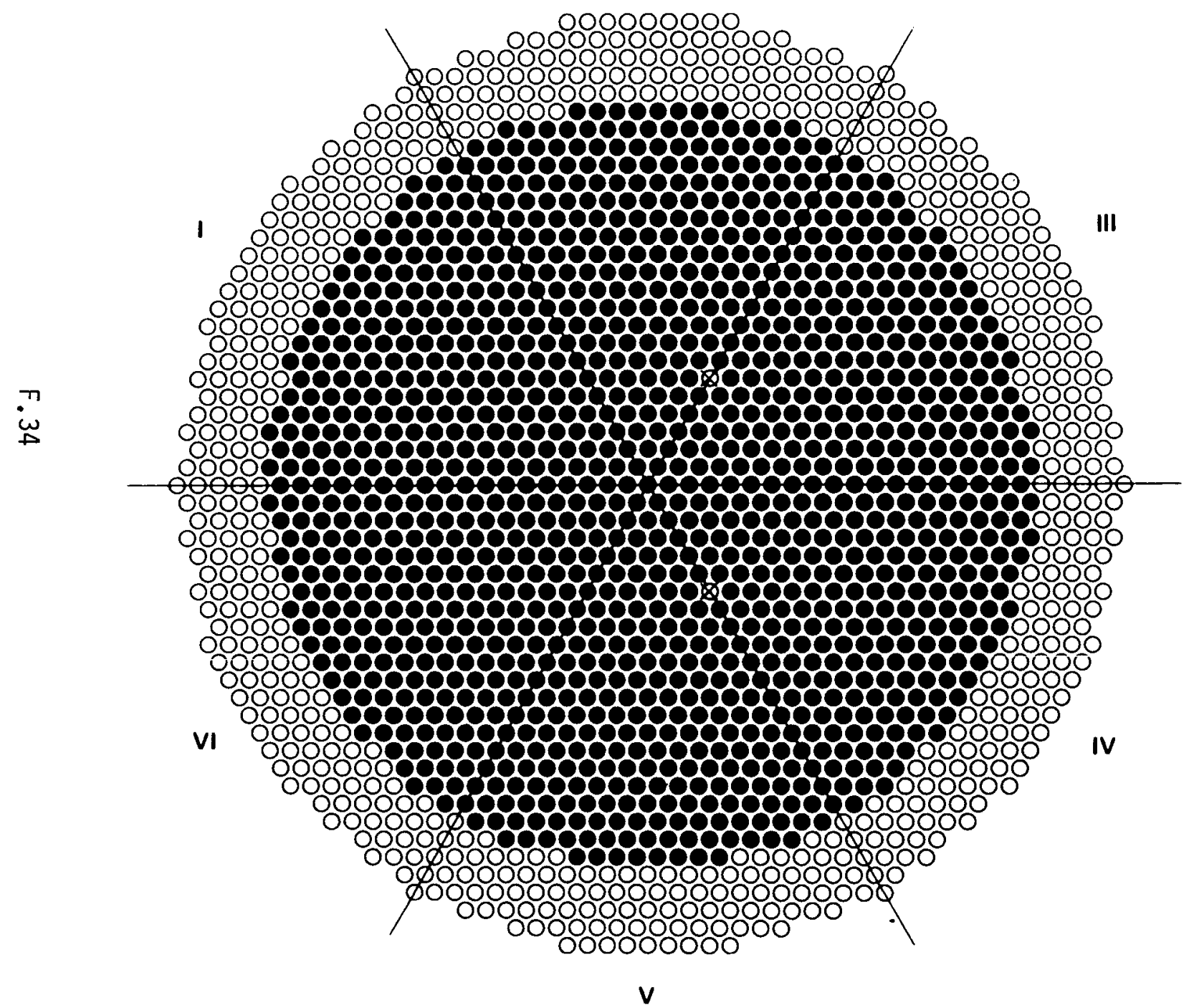

FUEL: $4.31 \mathrm{wt} \%{ }^{235} \mathrm{U}$ ENRICHED $\mathrm{UO}_{2}$ EXPERIMENT: 4.3-000-204A

LATTICE: 12

PITCH: $1.801 \pm 0.005 \mathrm{~cm}$

GADOLINIUM: $1.246 \pm 0.038 \mathrm{~g} \mathrm{Gd} /$ liter CONTROL ROD: OUT

SAFETY ROD: OUT

REACTION RATES: NONE

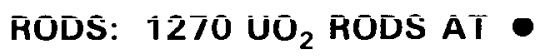

$k_{\text {eff: }} 1.0$

COMMENTS: WATER FILLED ALUMINUM SLEEVES AT $\bigotimes$ 
II

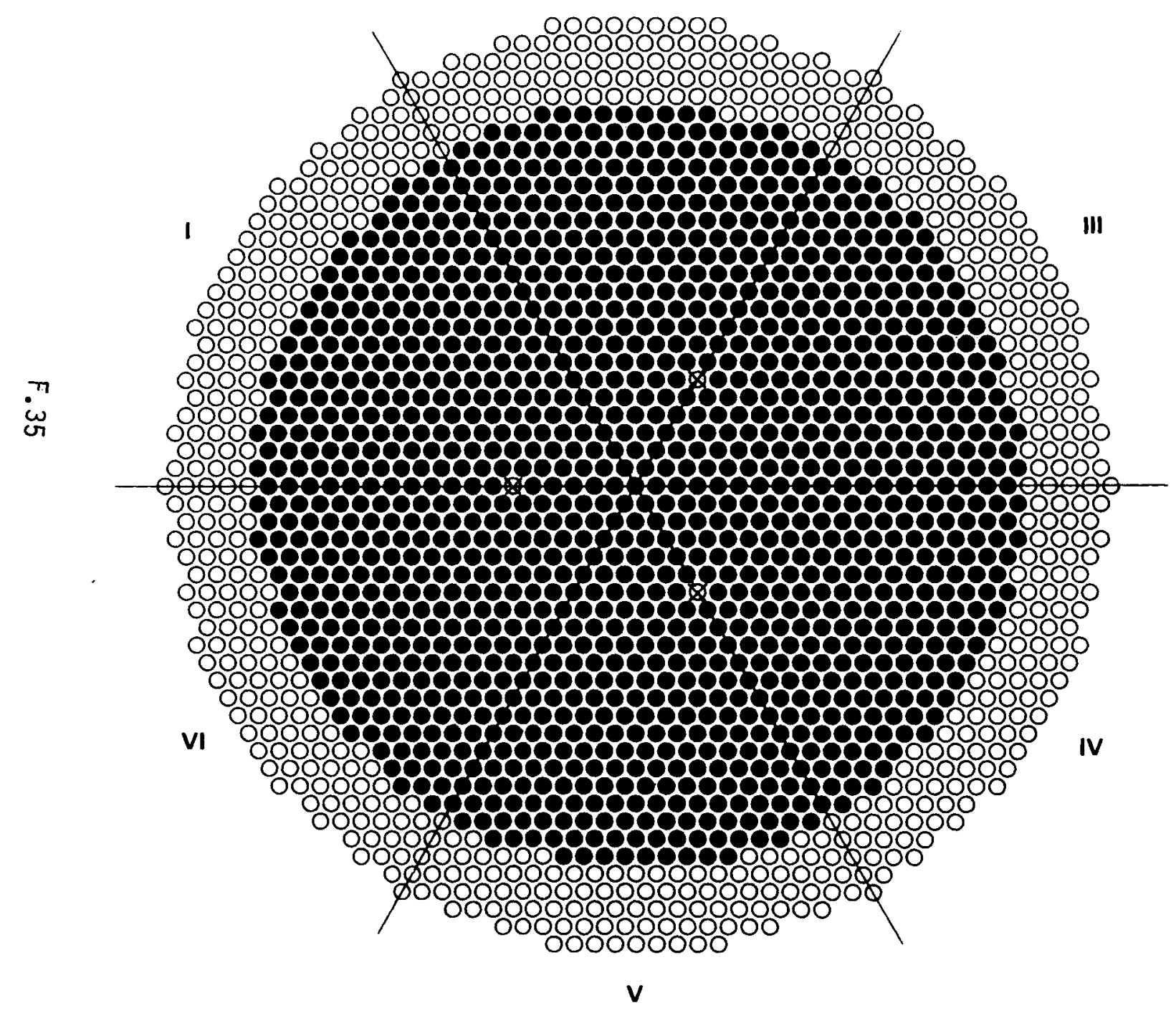

FUEL: $4.31 \mathrm{wt} \%{ }^{235} \mathrm{U}$ ENRICHED $\mathrm{UO}_{2}$ EXPERIMENT: 4.3-000-204B

LATTICE: 12

PITCH: $1.801 \pm 0.005 \mathrm{~cm}$

GADOLINIUM: $1.246 \pm 0.038 \mathrm{~g} \mathrm{Gd} /$ liter CONTROL ROD: OUT SAFETY ROD: OUT REACTION RATES: NONE RODS: $1275 \mathrm{UO}_{2}$ RODS AT • keff: 1.0

COMMENTS: WATER FILLED ALUMINUM SLEEVES AT 


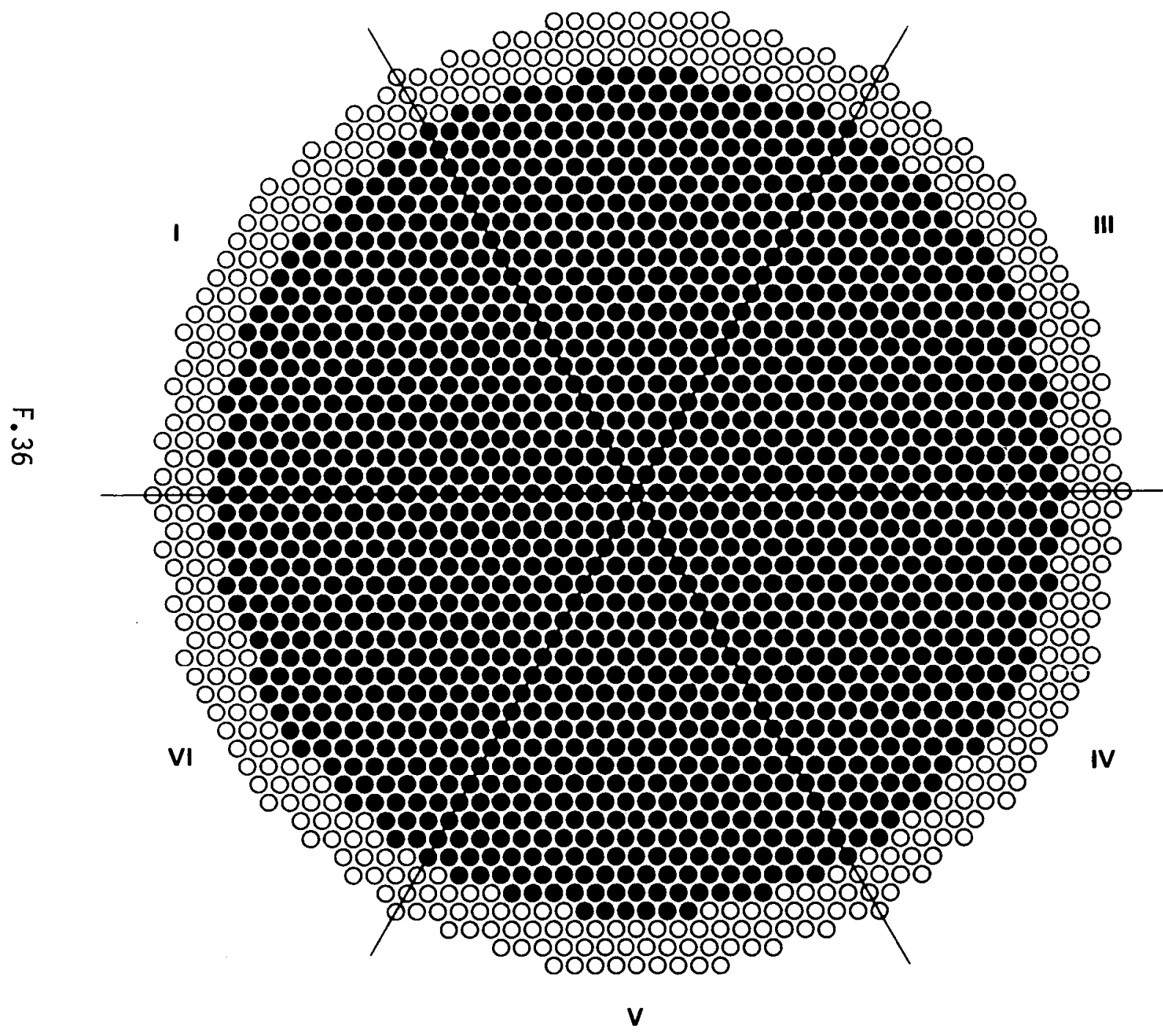

FUEL: $4.31 \mathrm{wt} \%{ }^{235} \mathrm{U}$ ENRICHED $\mathrm{UO}_{2}$ EXPERIMENT: 4.3-000-205

LATTICE: 12

PITCH: $1.801 \pm 0.005 \mathrm{~cm}$

GADOLINIUM: $1.448 \pm 0.025 \mathrm{~g} \mathrm{Gd} /$ liter CONTROL ROD: NONE SAFETY ROD: NONE REACTION RATES: NONE RODS: $1482 \mathrm{UO}_{2}$ RODS AT keff: 1.0 COMMENTS: 
II

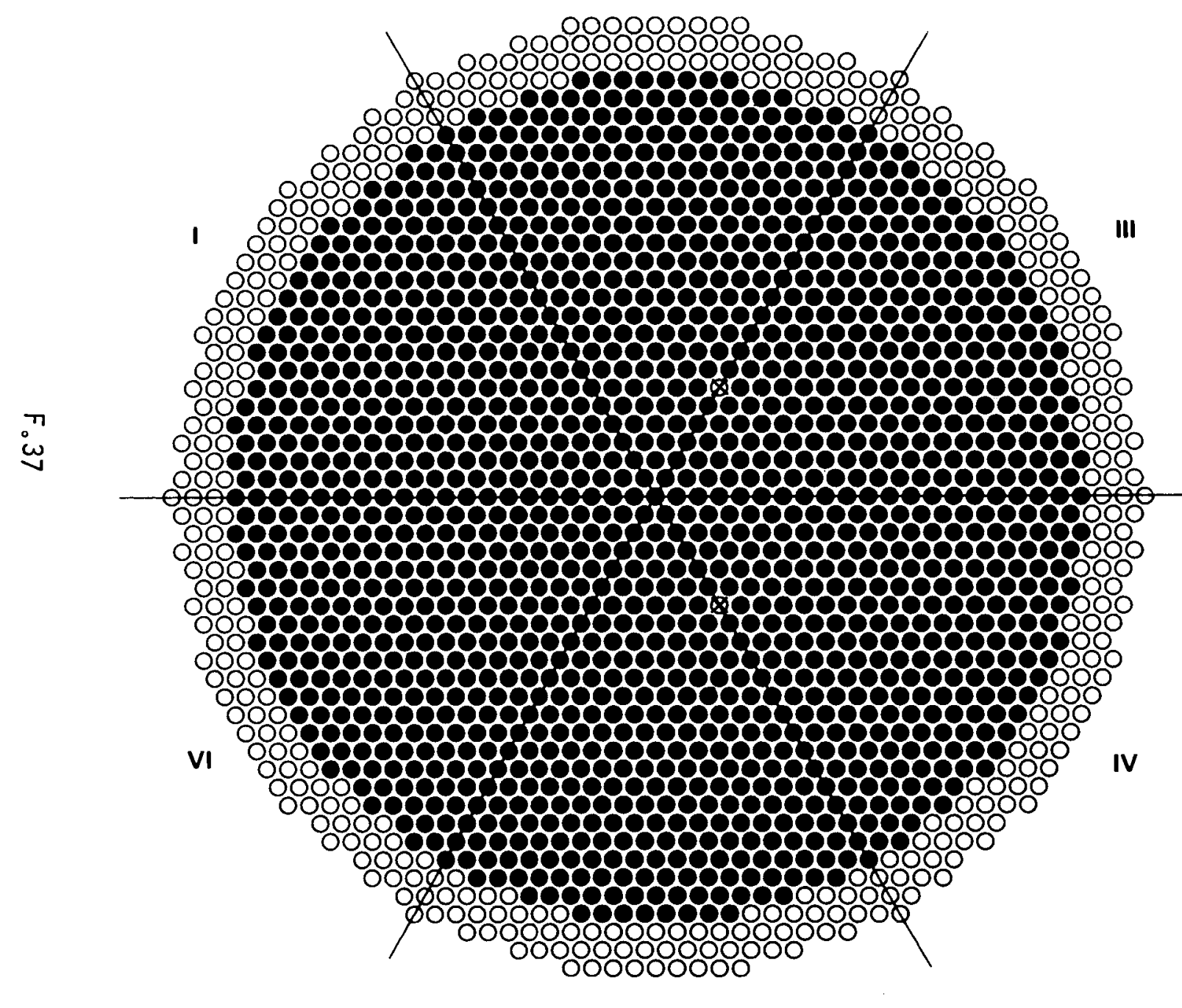

III EXPERIMENT: 4.3-000-205A

LATTICE: 12

PITCH: $1.801 \pm 0.005 \mathrm{~cm}$

GADOLINIUM: $1.448 \pm 0.025 \mathrm{~g} \mathrm{Gd} /$ liter CONTROL ROD: OUT

SAFETY ROD: OUT

REACTION RATES: NONE

RODS: $1494 \mathrm{UO}_{2}$ RODS AT $\bullet$

keff: 1.0

COMMENTS: WATER FILLED ALUMINUM SLEEVES AT $\otimes$ 


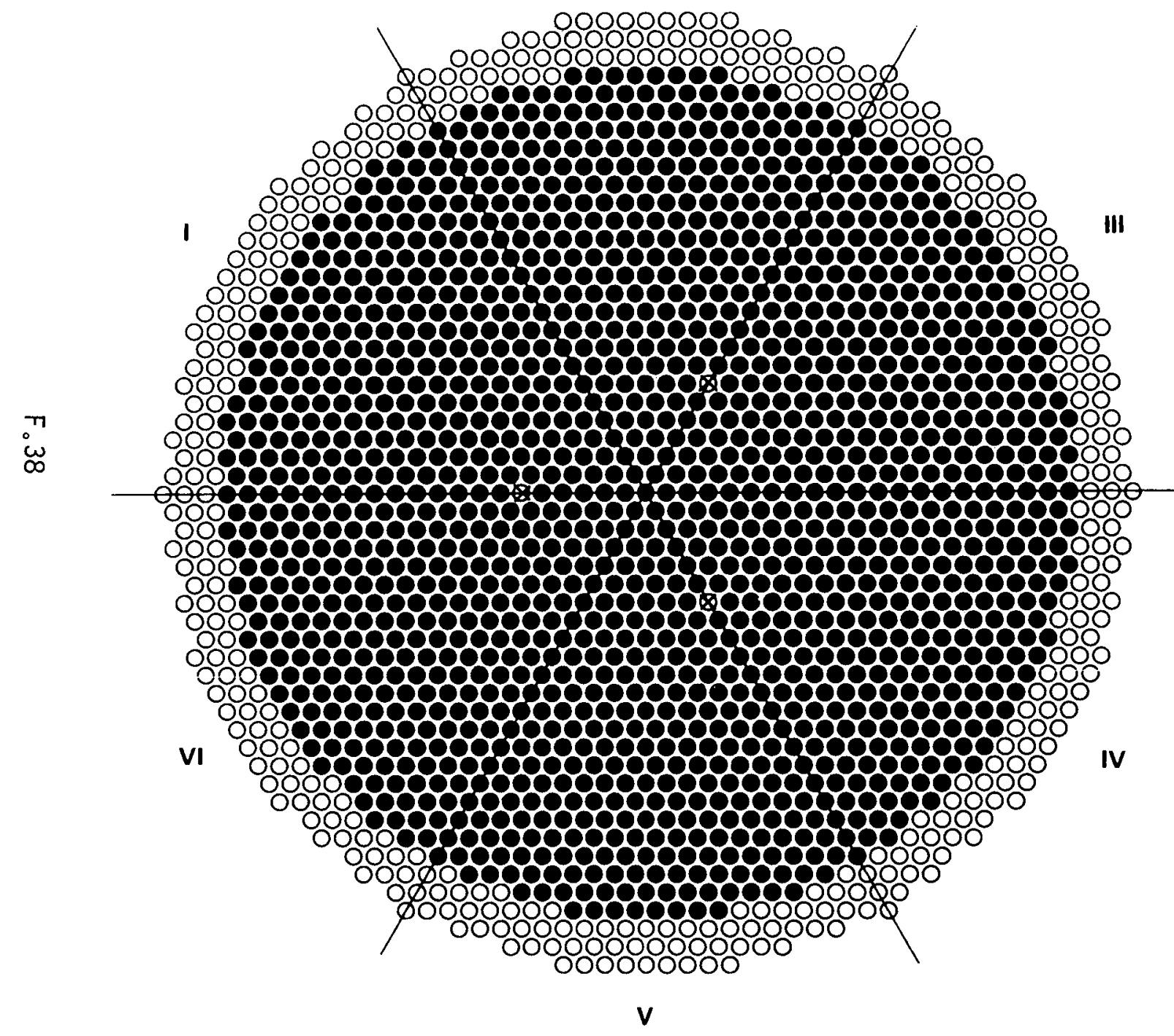

FUEL: $4.31 \mathrm{wt} \%{ }^{235} \mathrm{U}$ ENRICHED $\mathrm{UO}_{2}$

EXPERIMENT: 4.3-000-205B

LATTICE: 12

PITCH: $1.801 \pm 0.005 \mathrm{~cm}$

GADOLINIUM: $1.448 \pm 0.025 \mathrm{~g} \mathrm{Gd} /$ liter CONTROL ROD: OUT

SAFETY ROD: OUT

REACTION RATES: NONE

RODS: $1500 \mathrm{UO}_{2}$ RODS AT

$k_{\text {eff: }} 1.0$

COMMENTS: WATER FILLED ALUMINUM SLEEVES AT 
II

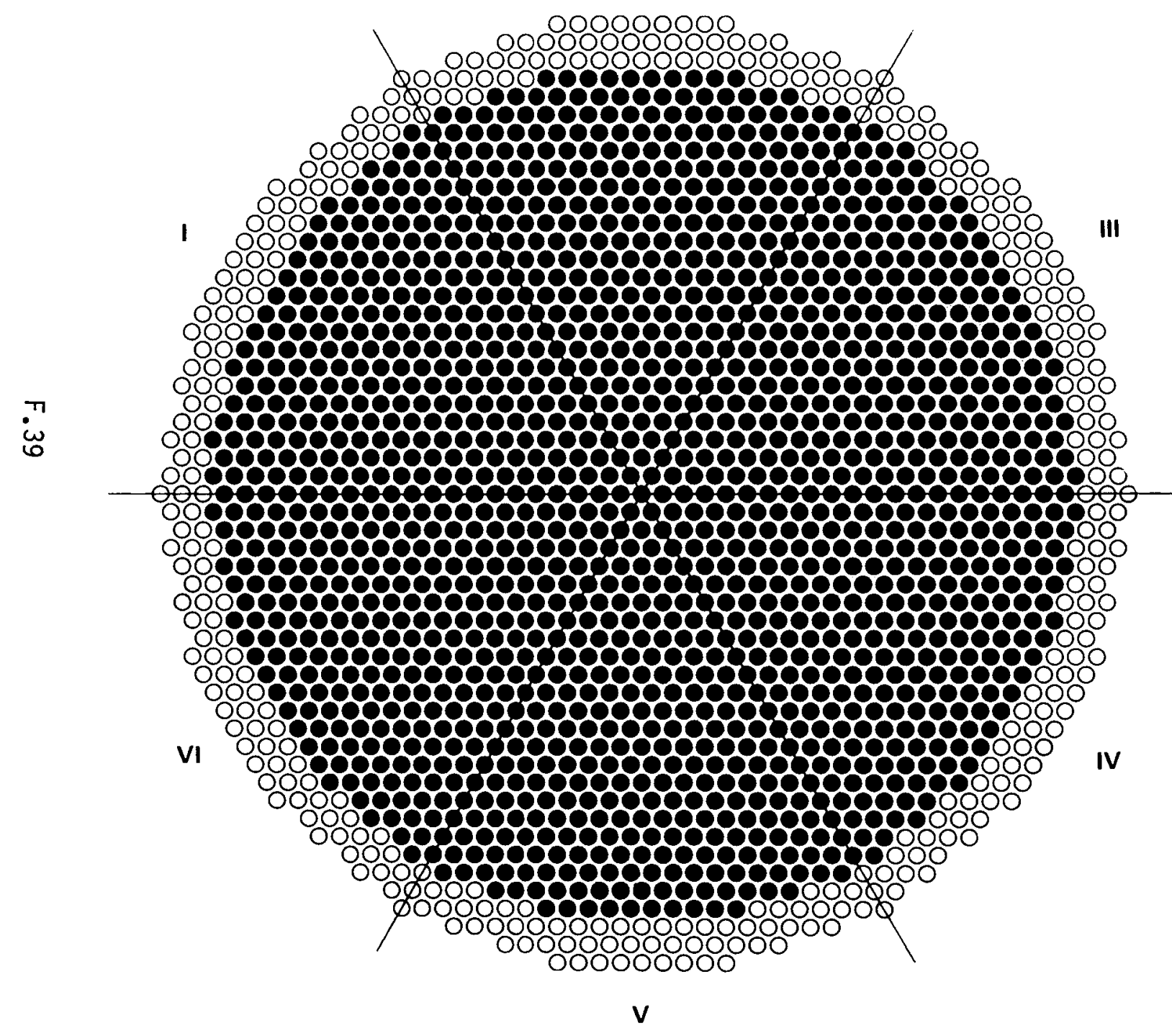

FUEL: $4.31 w t \%{ }^{235} \mathrm{U}$ ENRICHED $\mathrm{UO}_{2}$ EXPERIMENT: 4.3-000-206

LATTICE: 12

PITCH: $1.801 \pm 0.005 \mathrm{~cm}$

GADOLINIUM: $1.481 \pm 0.044 \mathrm{~g} \mathrm{Gd} /$ liter CONTROL ROD: NONE SAFETY ROD: NONE REACTION RATES: NONE RODS: $1533 \mathrm{UO}_{2}$ RODS AT • $k_{\text {eff: }} \mathbf{1 . 0}$ COMMENTS: 


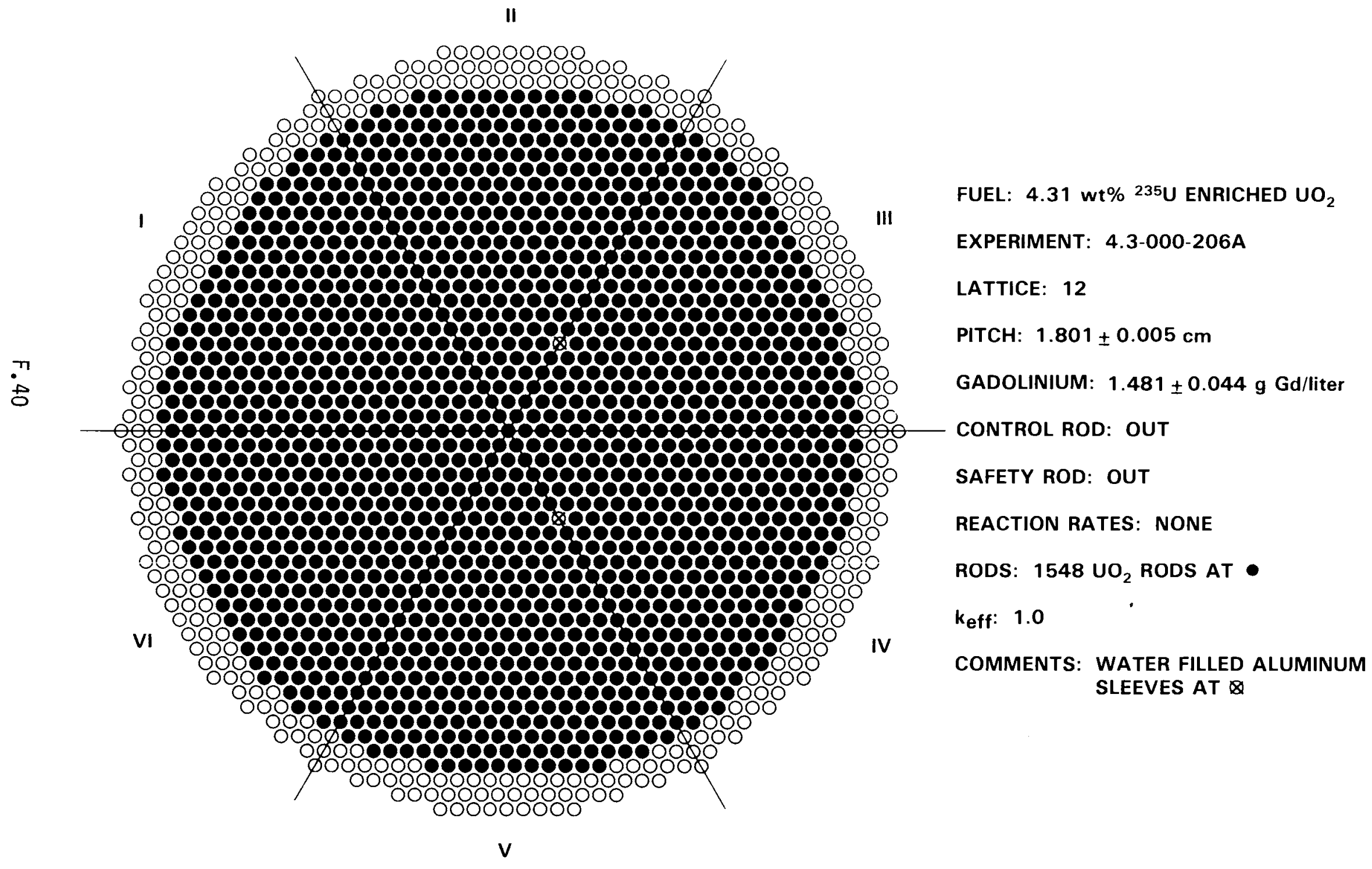




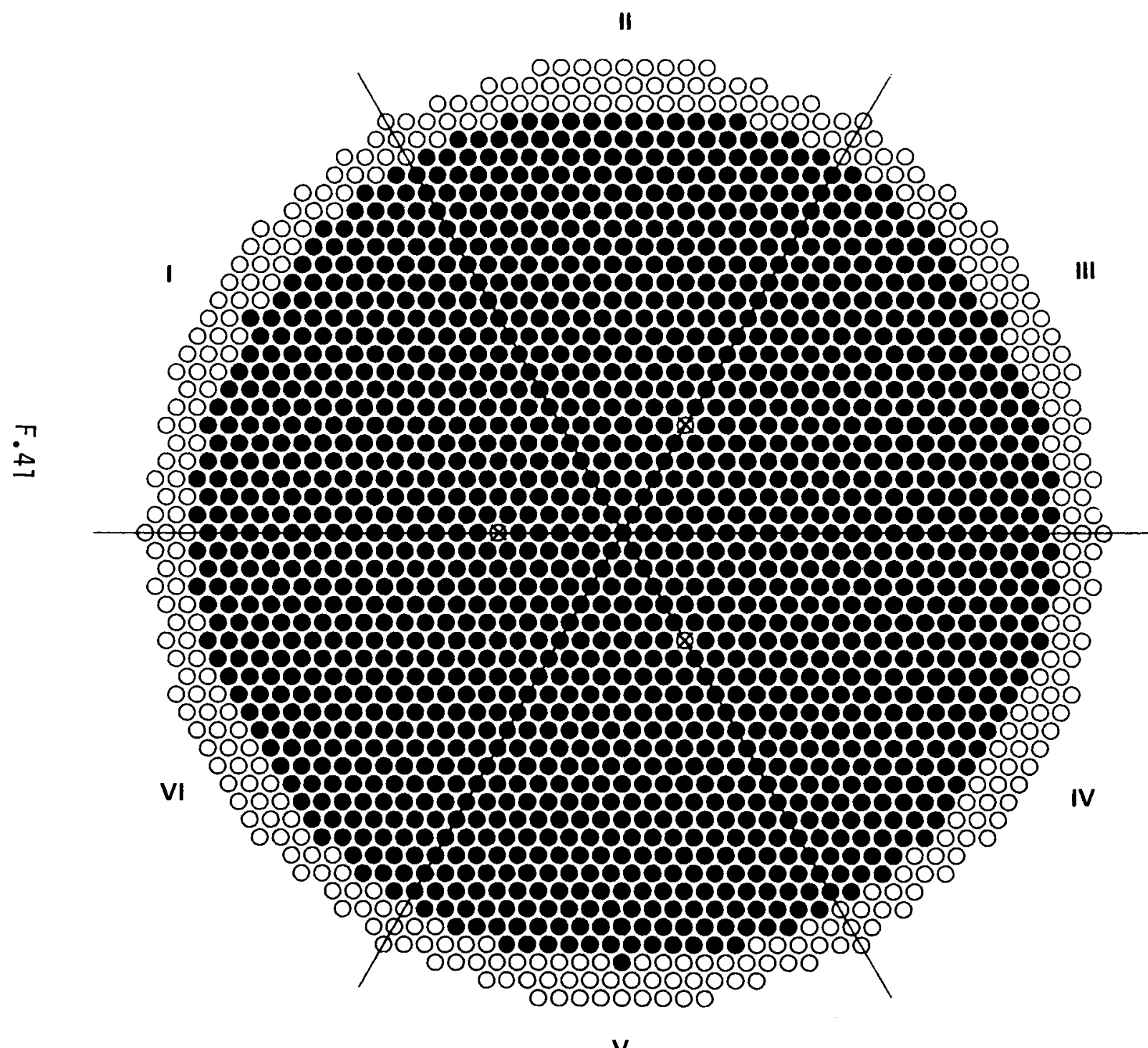

FUEL: $4.31 \mathrm{wt} \%{ }^{235} \mathrm{U}$ ENRICHED $\mathrm{UO}_{2}$ EXPERIMENT: 4.3-000-206B

LATTICE: 12

PITCH: $1.801 \pm 0.005 \mathrm{~cm}$

GADOLINIUM: $1.481 \pm 0.044 \mathrm{~g} \mathrm{Gd} /$ liter CONTROL ROD: OUT

SAFETY ROD: OUT

REACTION RATES: NONE

RODS: $1555 \mathrm{UO}_{2}$ RODS AT •

keff: 1.0

COMMENTS: WATER FILLED ALUMINUM SLEEVES AT $\otimes$ 
II

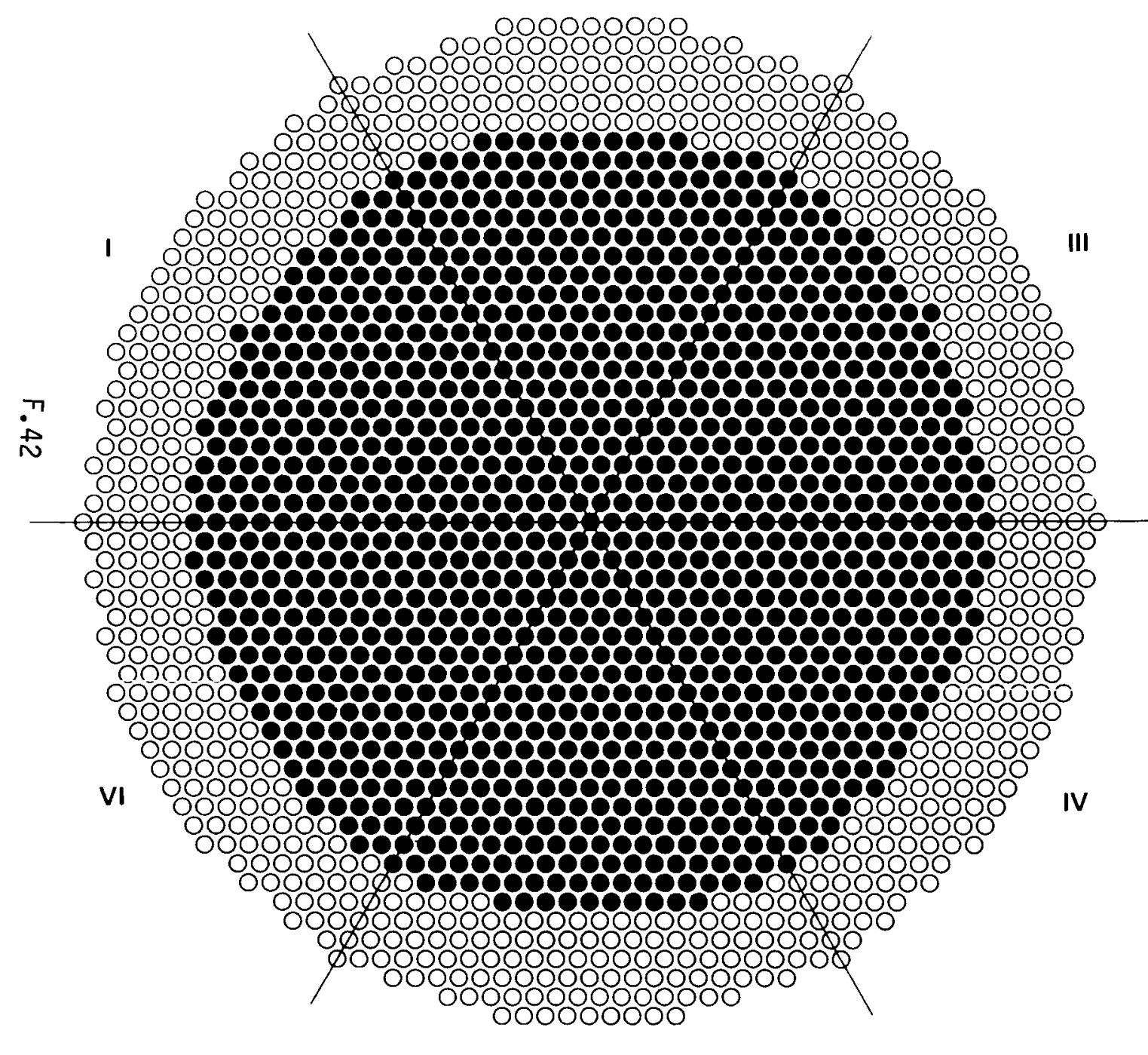

FUEL: $4.31 w t \%{ }^{235} \mathrm{U}$ ENRICHED $\mathrm{UO}_{2}$ EXPERIMENT: 4.3-000-194

LATTICE: 13

PITCH: $1.598 \pm 0.005 \mathrm{~cm}$

GADOLINIUM: SEE COMMENTS

CONTROL ROD: NONE

SAFETY ROD: NONE

REACTION RATES: NONE

RODS: $1185 \mathrm{UO}_{2}$ RODS AT $\bullet$

$k_{\text {eff: }}$ SEE COMMENTS

COMMENTS:

$k_{\text {eff }}=1.0 \quad$ AT ZERO $\mathrm{g} \mathrm{Gd} /$ liter

$k_{\text {eff }}=0.953$ AT $0.130 \pm 0.001 \mathrm{~g} \mathrm{Gd} /$ liter

$k_{\text {eff }}=0.923$ AT $0.456+0.001 \mathrm{~g} \mathrm{Gd} /$ liter

$k_{\text {eff }}=0.902$ AT $0.638 \pm 0.008 \mathrm{~g} \mathrm{Gd} / \mathrm{liter}$

$k_{\text {eff }}=0.901$ AT $0.750 \pm 0.008 \mathrm{~g} \mathrm{Gd} /$ liter 


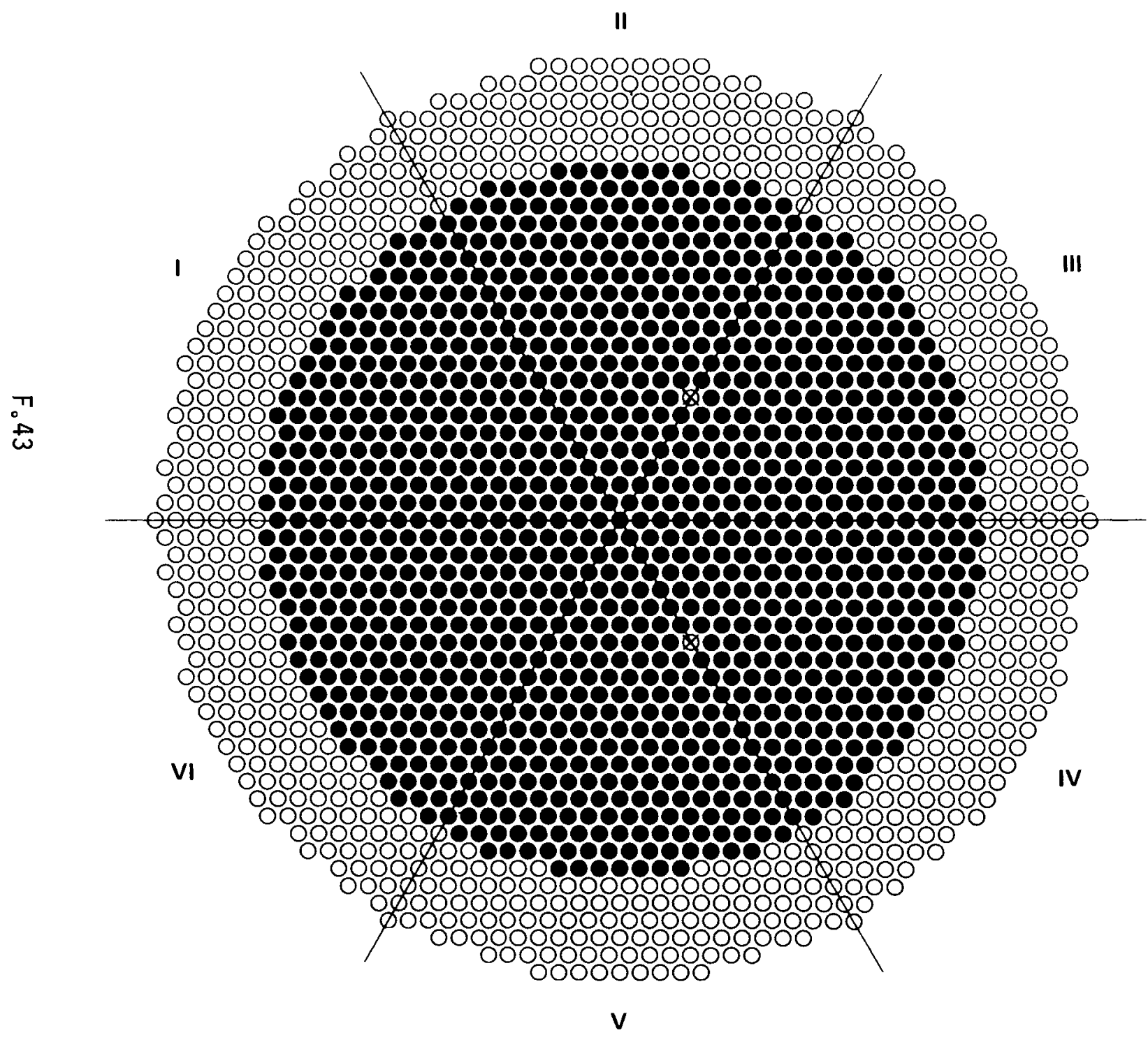

FUEL: $4.31 \mathrm{wt} \%{ }^{235} \mathrm{U}$ ENRICHED $\mathrm{UO}_{2}$ EXPERIMENT: 4.3-000-194A LATTICE: 13

PITCH: $1.598 \pm 0.005 \mathrm{~cm}$ GADOLINIUM: NONE CONTROL ROD: OUT SAFETY ROD: OUT REACTION RATES: NONE RODS: $1147 \mathrm{UO}_{2}$ RODS AT $\bullet$ keff: 1.0

COMMENTS: WATER FILLED ALUMINUM SLEEVES AT 


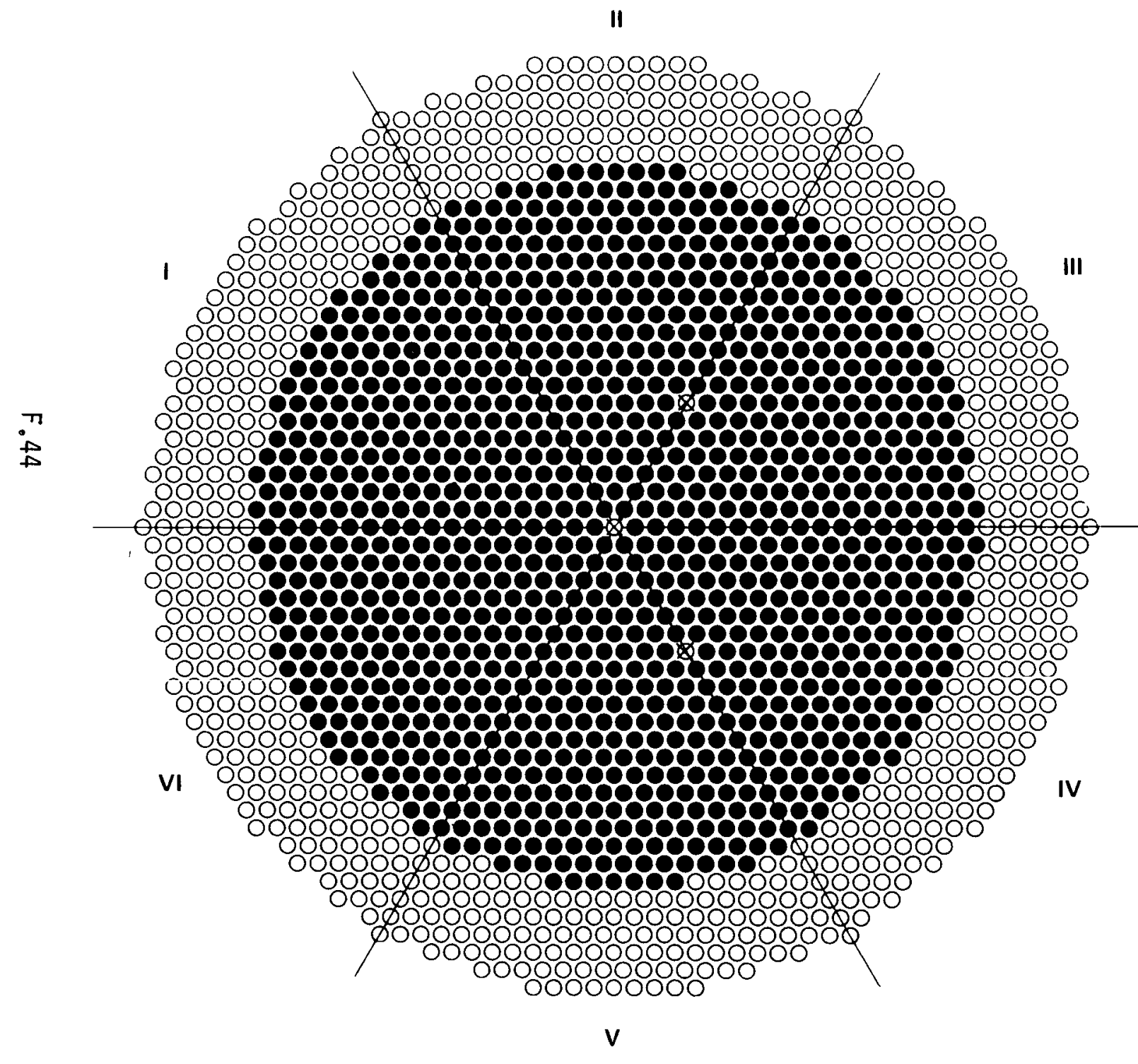

FUEL: $4.31 \mathrm{wt} \%{ }^{235} \mathrm{U}$ ENRICHED $\mathrm{UO}_{2}$ EXPERIMENT: $4.3-000-194 B$

LATTICE: 13

PITCH: $1.598 \pm 0.005 \mathrm{~cm}$

GADOLINIUM: NONE

CONTROL ROD: OUT

SAFETY ROD: OUT

REACTION RATES: NONE

RODS: $1135 \mathrm{UO}_{2}$ RODS AT $\bullet$

$k_{\text {eff: }} \mathbf{1 . 0}$

COMMENTS: WATER FILLED ALUMINUM SLEEVES AT $\bigotimes$ 


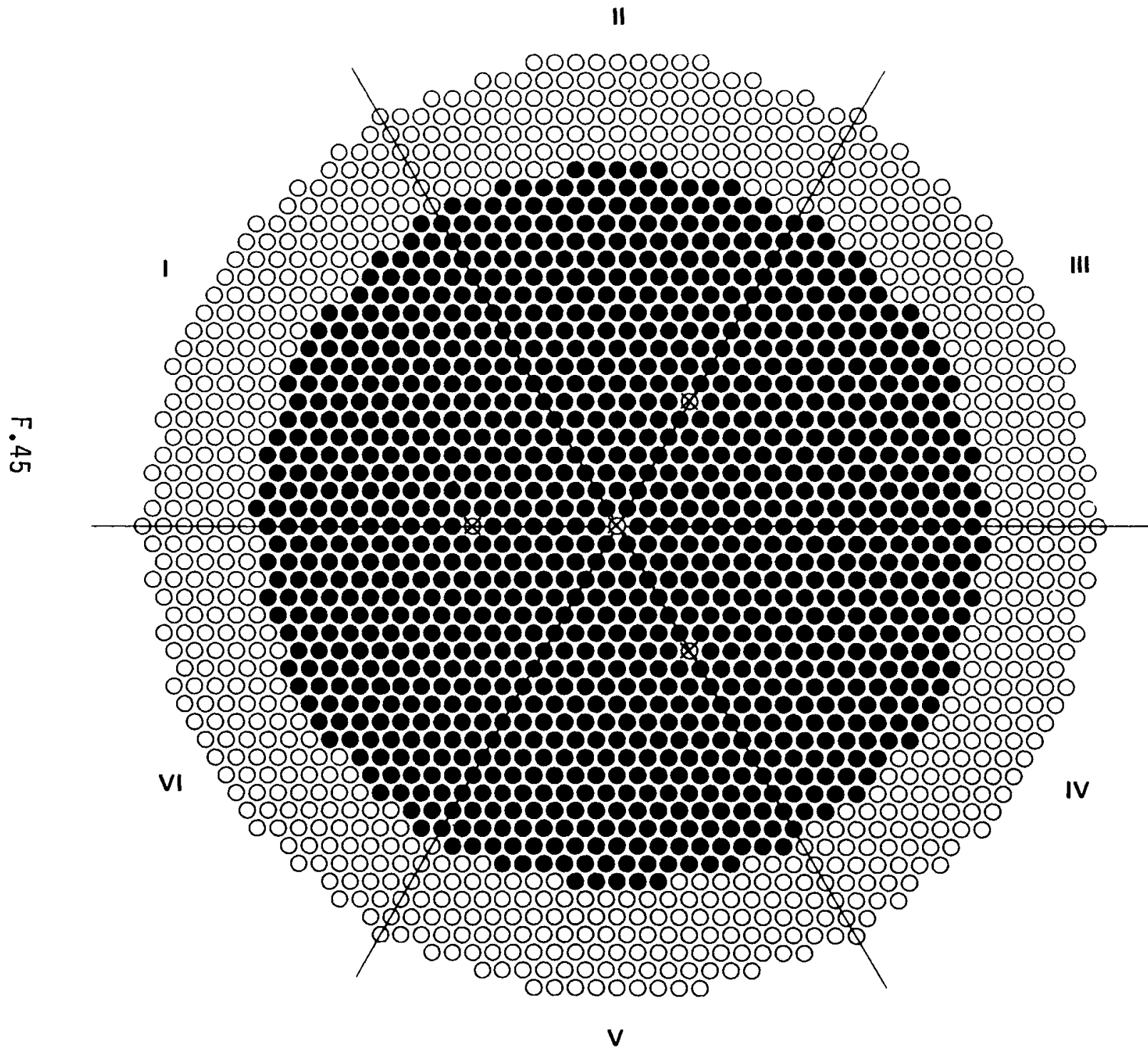

FUEL: $4.31 \mathrm{wt} \%{ }^{235} \mathrm{U}$ ENRICHED $\mathrm{UO}_{2}$

EXPERIMENT: $4.3-000-194 \mathrm{C}$

LATTICE: 13

PITCH: $1.598+0.005 \mathrm{~cm}$

GADOLINIUM: NONE

CONTROL ROD: OUT

SAFETY ROD: OUT

REACTION RATES: NONE

RODS: $1116 \mathrm{UO}_{2}$ RODS AT $\bullet$

keff: 1.0

COMMENTS: WATER FILLED ALUMINUM SLEEVES AT 


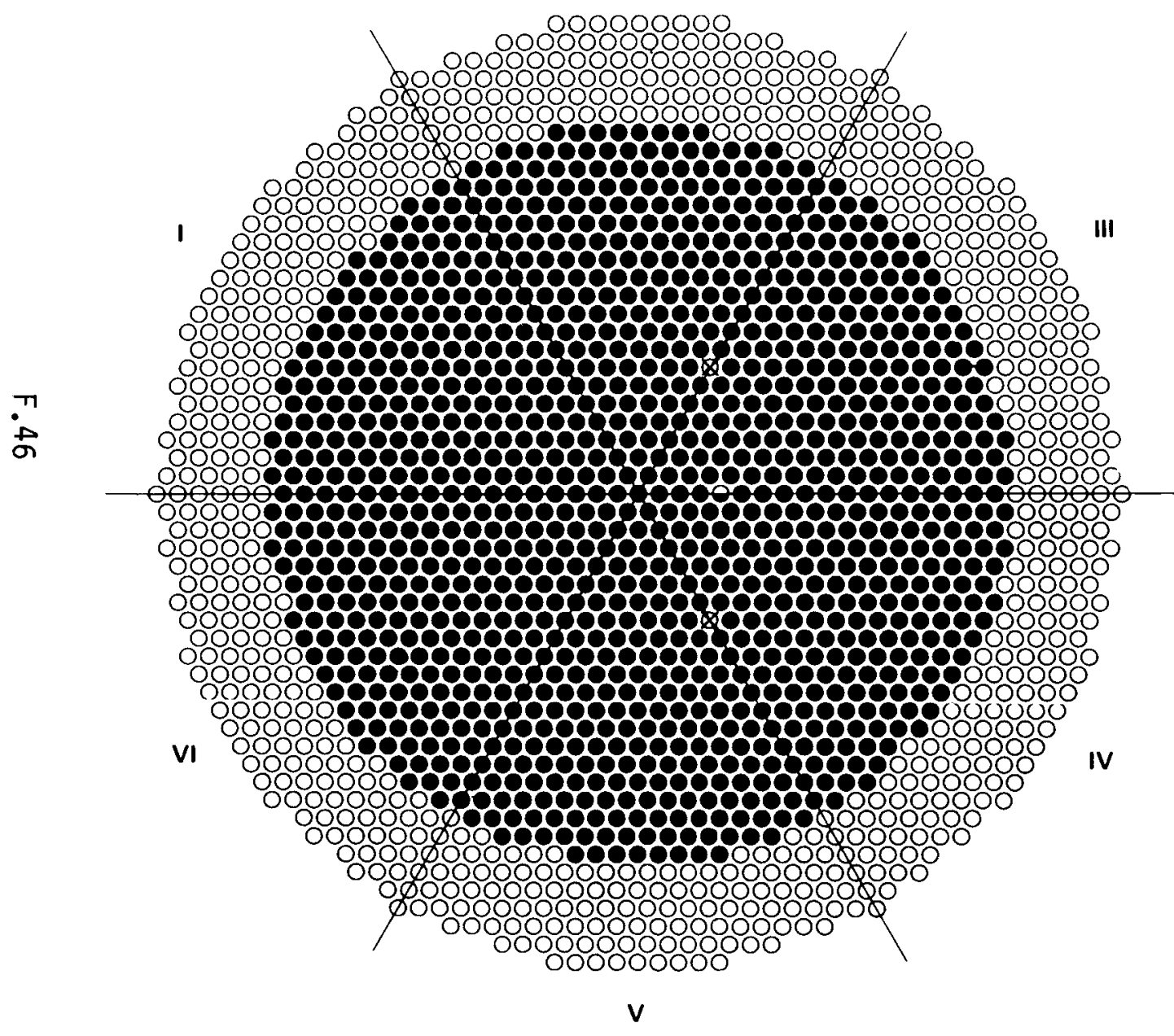

FUEL: 4.31 wt $\%{ }^{235} \mathrm{U}$ ENRICHED $\mathrm{UO}_{2}$

EXPERIMENT: 4.3-000-194D

LATTICE: 13

PITCH: $1.598 \pm 0.005 \mathrm{~cm}$

GADOLINIUM: NONE

CONTROL ROD: OUT $52.4 \pm 0.3 \mathrm{~cm}$ FROM BOTTOM OF FUEL (LOCATION $\vee ख$ )

SAFETY ROD: OUT

REACTION RATES: SOLID STATE ${ }^{235}$ U TRACK RECORDER AT $\odot$

RODS: $1151 \mathrm{UO}_{2}$ RODS AT •

keff: 1.0

COMMENTS: CONTROL AND SAFETY ROD ALUMINUM GUIDE SLEEVES AT 


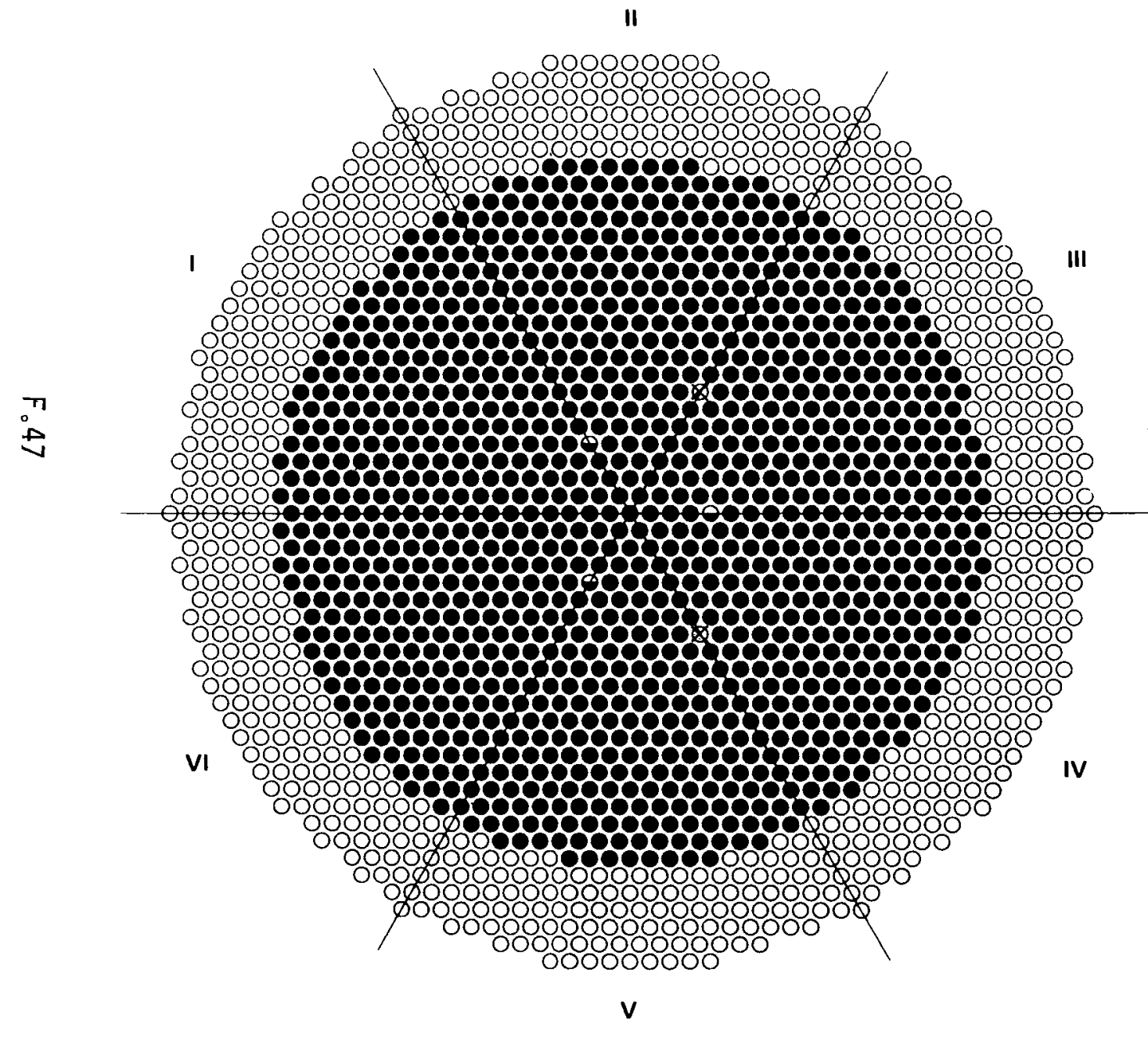

FUEL: $4.31 \mathrm{wt} \%{ }^{235} \mathrm{U}$ ENRICHED $\mathrm{UO}_{2}$

EXPERIMENT: 4.3-000-194E

LATTICE: 13

PITCH: $1.598 \pm 0.005 \mathrm{~cm}$

GADOLINIUM: NONE

CONTROL ROD: OUT $56.5 \pm 0.3 \mathrm{~cm}$ FROM BOTTOM

OF FUEL (LOCATION $\vee \otimes$ )

SAFETY ROD: OUT

REACTION RATES: ${ }^{238} \mathrm{U}$ AND ${ }^{235} \mathrm{U}$ FOILS IN 0 (SEE COMMENTS)

RODS: $1151 \mathrm{UO}_{2}$ RODS AT •

$k_{\text {eff: }} 1.0$

COMMENTS: CONTROL AND SAFETY ROD ALUMINUM GUIDE SLEEVES AT AEEW 9 FOIL PACKET IN II $\odot$ AEEW 10 FOIL PACKET IN IV $\odot$ AEEW 12 FOIL PACKET IN VI $\odot$ 
II

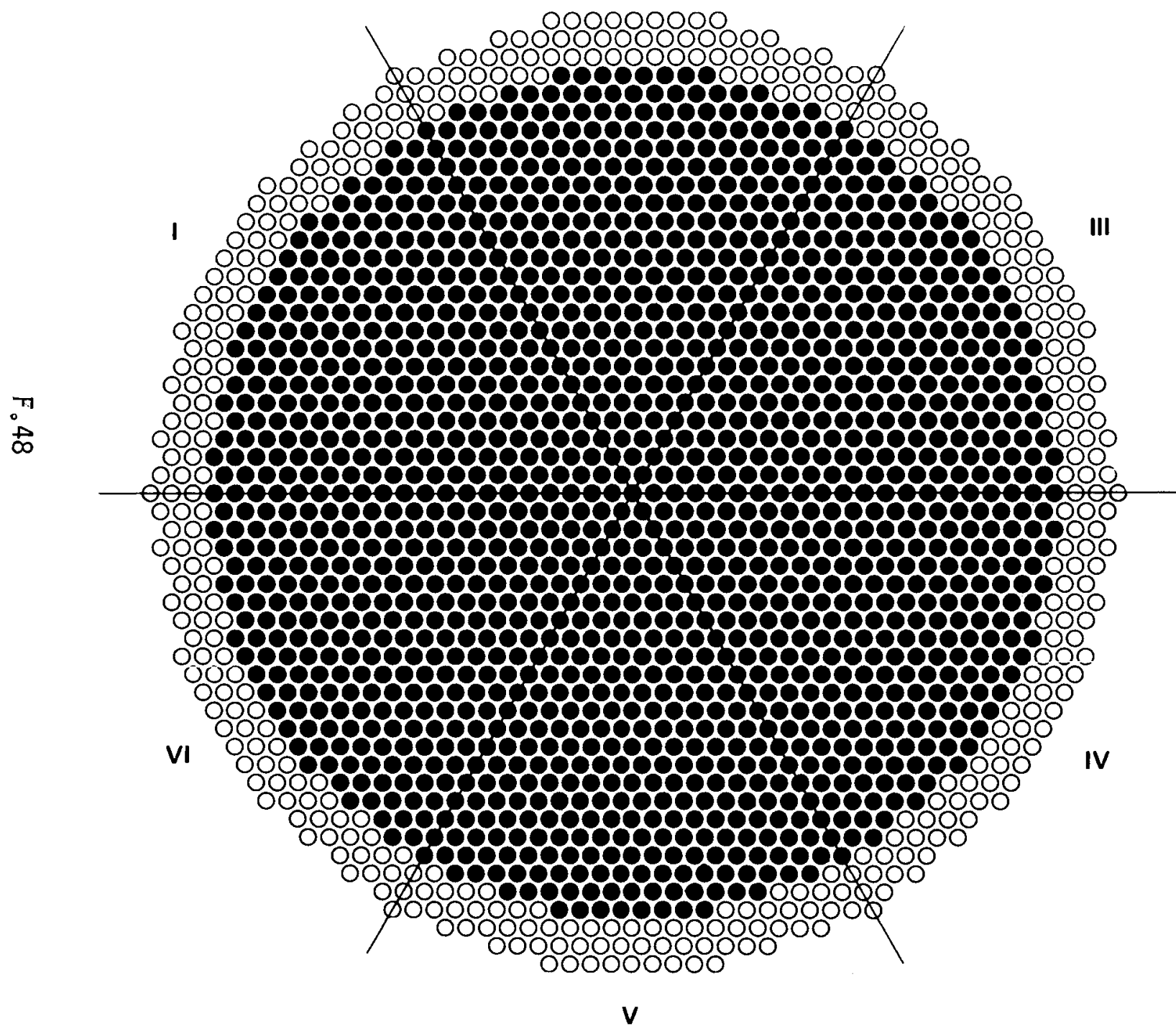

FUEL: $4.31 \mathrm{wt} \%{ }^{235} \mathrm{U}$ ENRICHED $\mathrm{UO}_{2}$ EXPERIMENT: $4.3-000-198$

LATTICE: 13

PITCH: $1.598 \pm 0.005 \mathrm{~cm}$

GADOLINIUM: $0.121 \pm 0.002 \mathrm{~g} \mathrm{Gd} / \mathrm{liter}$ CONTROL ROD: NONE SAFETY ROD: NONE REACTION RATES: NONE KROŨS: $14 \overline{9} \overline{\text { UUO }}{ }_{2}$ ROŨS ÁT • Keff: 1.0

COMMENTS: 


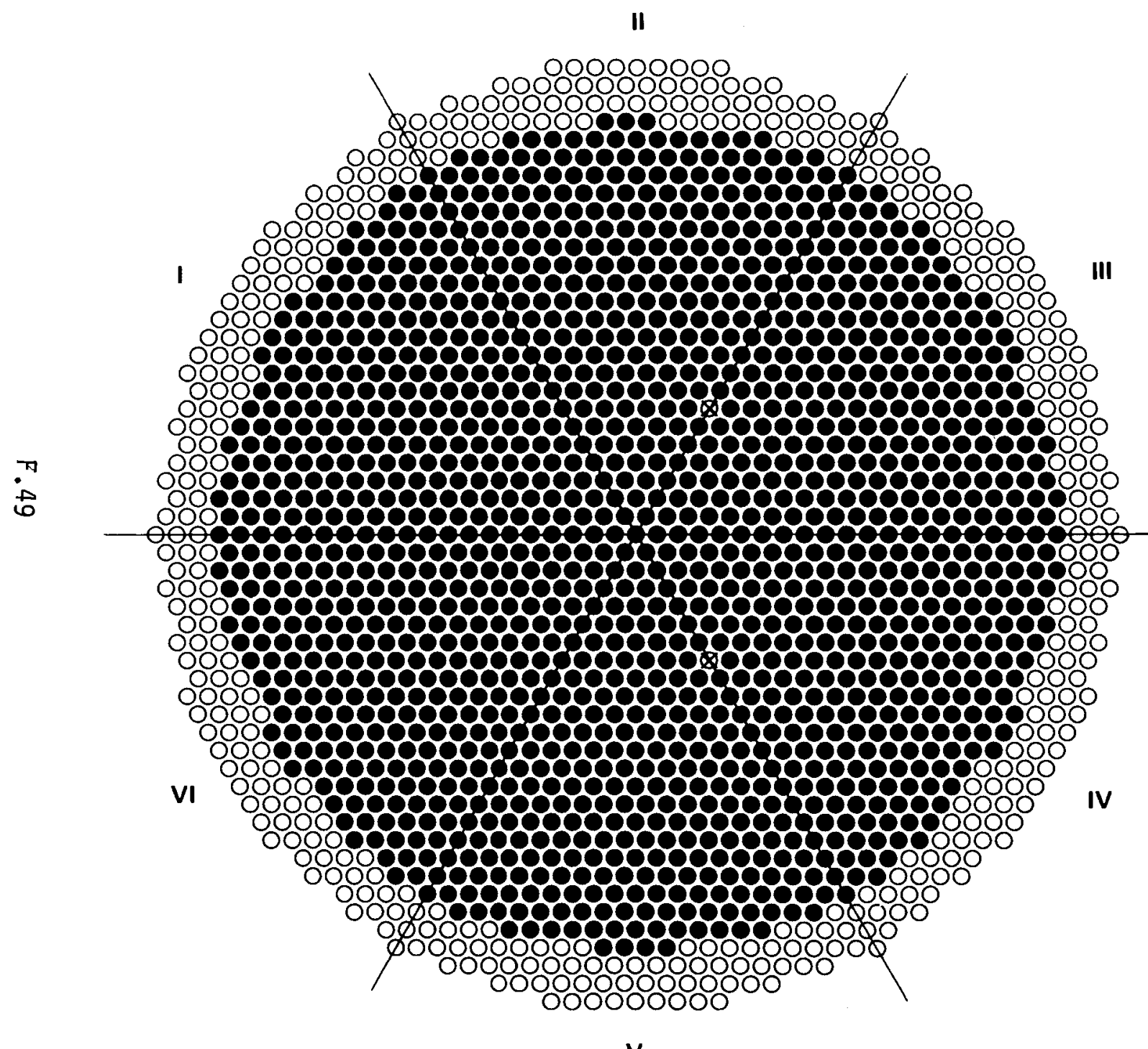

FUEL: $4.31 \mathrm{wt} \%{ }^{235} \mathrm{U}$ ENRICHED $\mathrm{UO}_{2}$

EXPERIMENT: 4.3-000-198A

LATTICE: 13

PITCH: $1.598 \pm 0.005 \mathrm{~cm}$

GADOLINIUM: $0.121 \pm 0.002 \mathrm{~g} \mathrm{Gd} /$ liter CONTROL ROD: OUT

SAFETY ROD: OUT

REACTION RATES: NONE

RODS: $1466 \mathrm{UO}_{2}$ RODS AT

Keff: 1.0

COMMENTS: WATER FILLED ALUMINUM SLEEVES AT $\otimes$ 
II

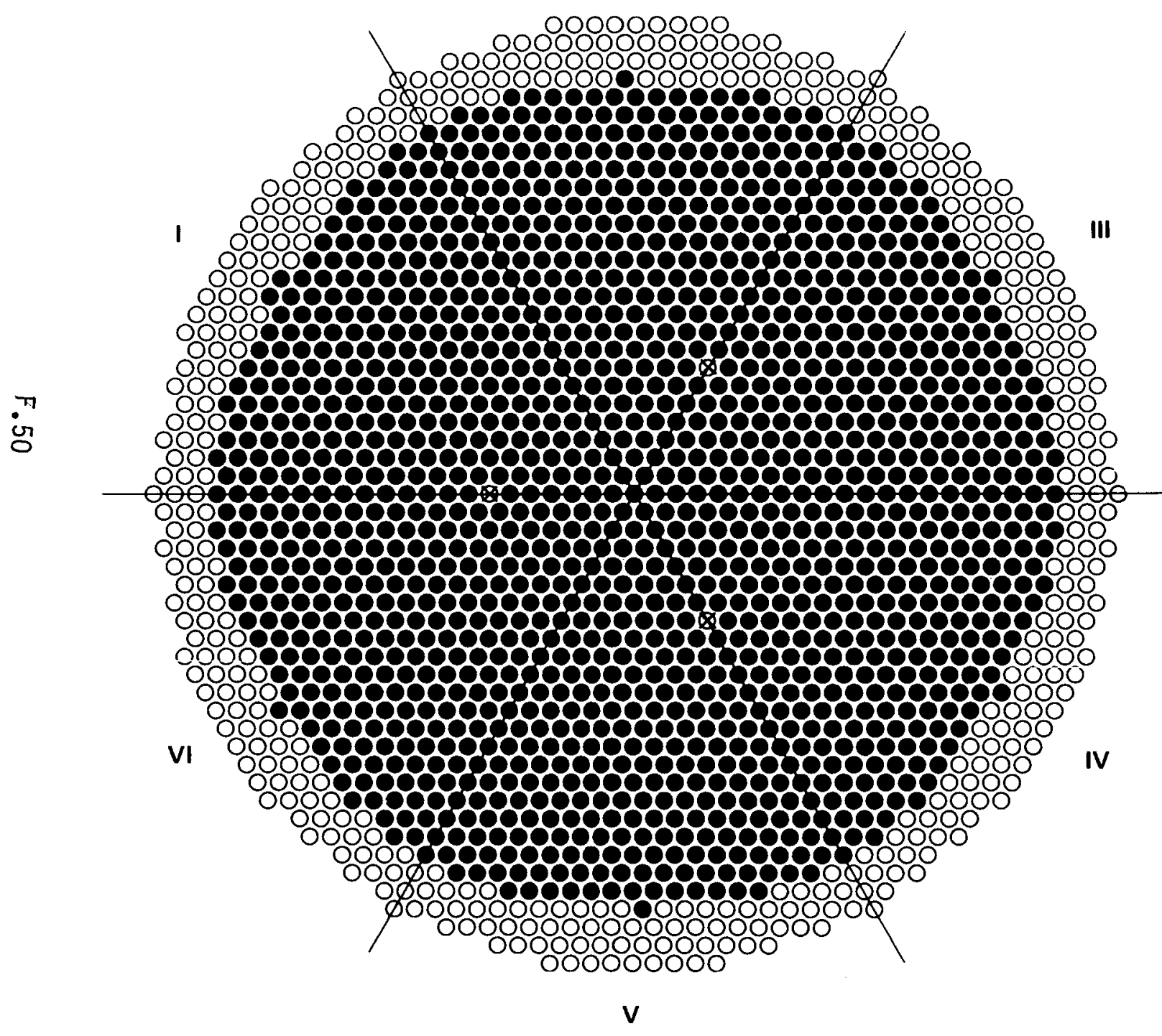

FUEL: 4.31 wt $\%{ }^{235} \mathrm{U}$ ENRICHED $\mathrm{UO}_{2}$ EXPERIMENT: 4.3-000-198B

LATTICE: 13

PITCH: $1.598 \pm 0.005 \mathrm{~cm}$

GADOLINIUM: $0.121 \pm 0.002 \mathrm{~g} \mathrm{Gd} / \mathrm{liter}$ CONTROL ROD: OUT SAFETY ROD: OUT REACTION RATES: NONE RODS: $1451 \mathrm{UO}_{2}$ RODS AT

$k_{\text {eff: }} \mathbf{1 . 0}$

COMMENTS: WATER FILLED ALUMINUM SLEEVES AT $\square$ 


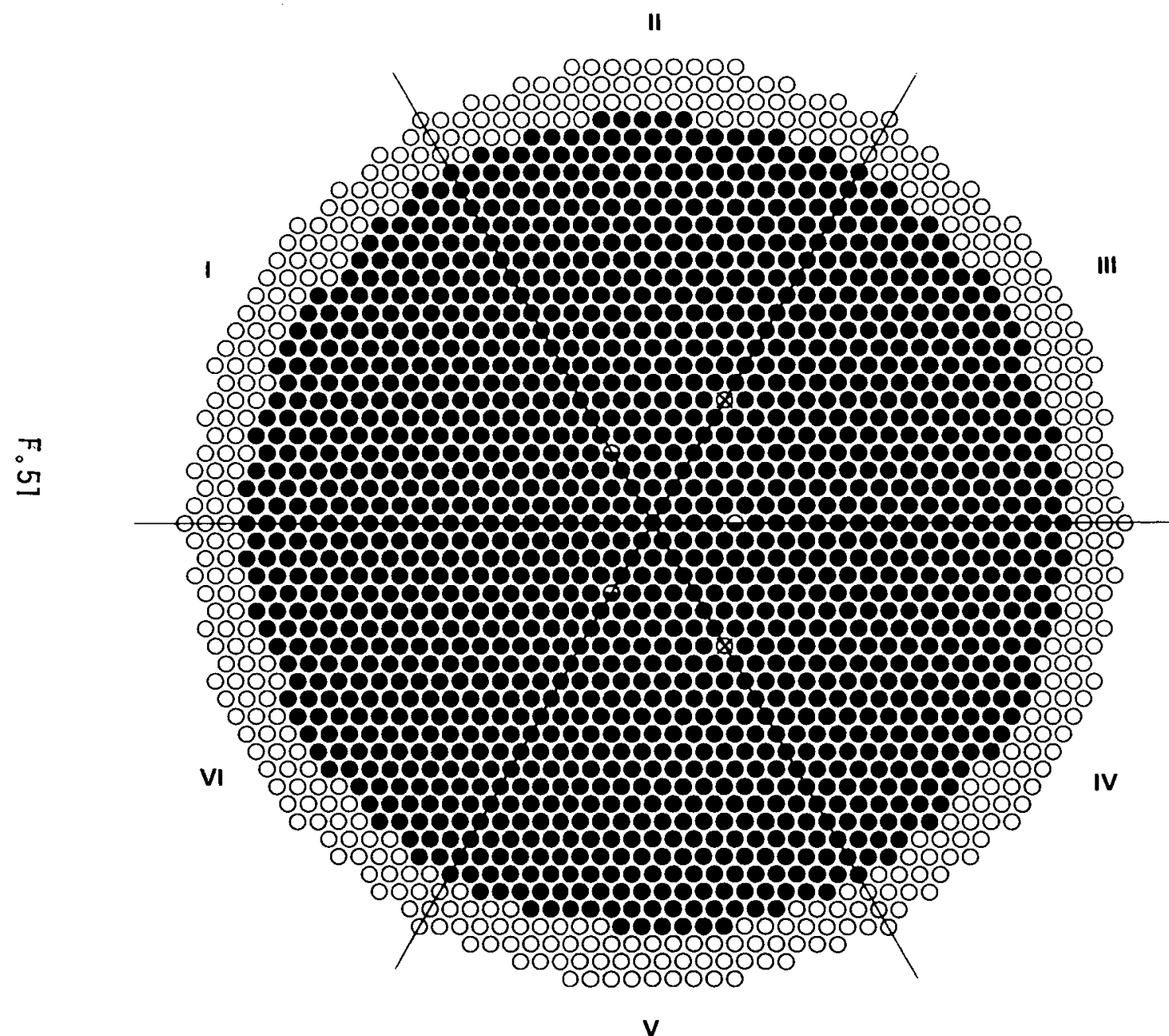

FUEL: 4.31 wt $\%{ }^{235} \mathrm{U}$ ENRICHED $\mathrm{UO}_{2}$

EXPERIMENT: $4.3-000-198 \mathrm{C}$

LATTICE: 13

PITCH: $1.598 \pm 0.005 \mathrm{~cm}$

GADOLINIUM: $0.121 \pm 0.002 \mathrm{~g} \mathrm{Gd} / \mathrm{liter}$

CONTROL ROD: OUT $50.6+0.3 \mathrm{~cm}$ FROM BOTTOM OF FUEL (LOCATION $\vee$ )

SAFETY ROD: OUT

REACTION RATES: ${ }^{238} \mathrm{U}$ AND ${ }^{235} \mathrm{U}$ FOILS IN $\odot$ (SEE COMMENTS)

RODS: $1475 \mathrm{UO}_{2}$ RODS AT •

keff: 1.0

COMMENTS: CONTROL AND SAFETY ROD ALUMINUM GUIDE SLEEVES AT

AEEW 15 FOIL PACKET IN II $\odot$

AEEW 14 FOIL PACKET IN IV $\odot$ AEEW 13 FOIL PACKET IN VI $\odot$ 


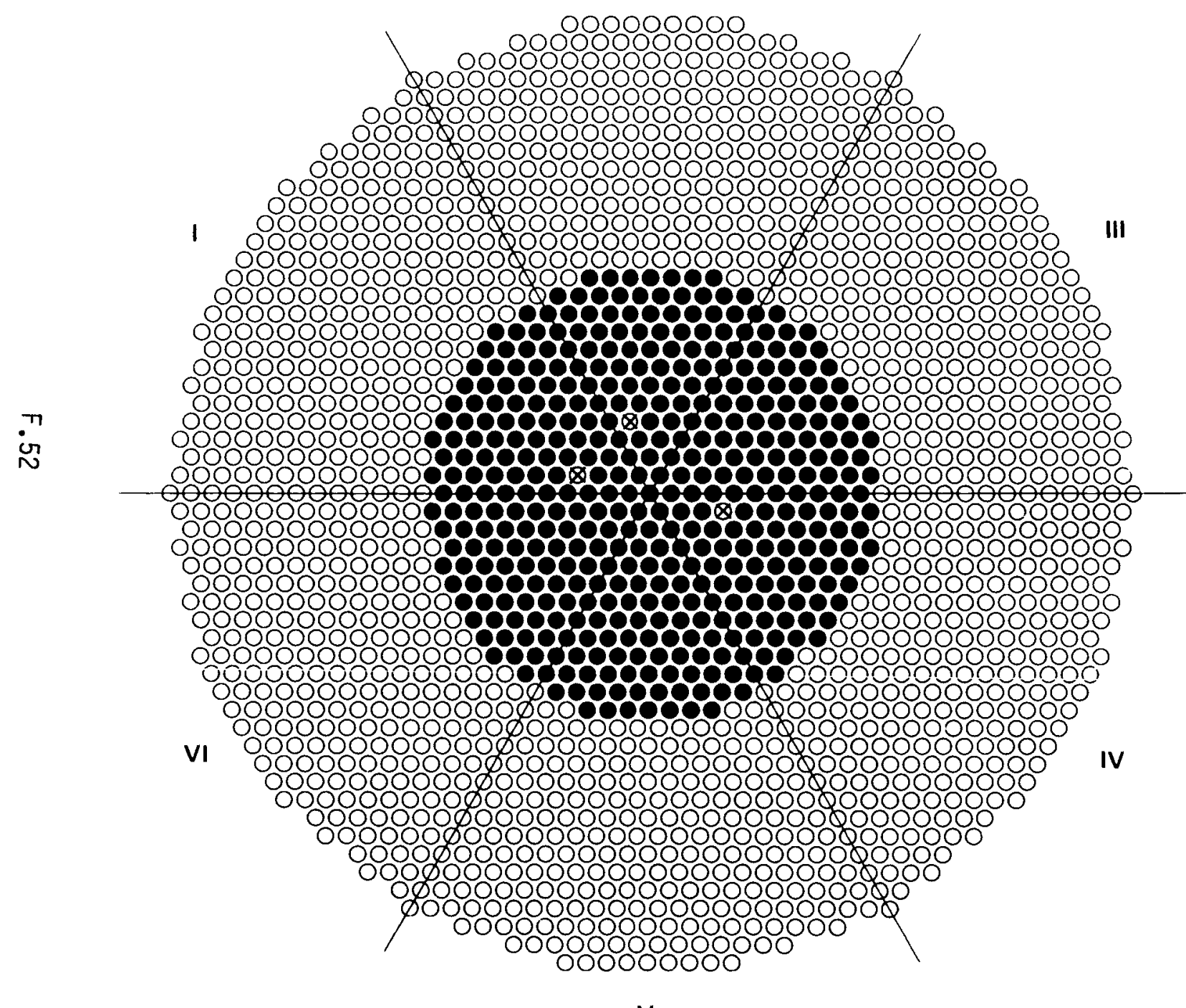

III

FUEL: $2.35 w t \%{ }^{235} \mathrm{U}$ ENRICHED $\mathrm{UO}_{2}$

EXPERIMENT: 2.35-000-159A

LATTICE: 21

PITCH: $1.895+0.005 \mathrm{~cm}$

GADOLINIUM: NONE

CONTROL ROD: OUT

SAFETY ROD: OUT

REACTION RATES: NONE

RODS: $428 \mathrm{UO}_{2}$ RODS AT $\bullet$

keff: 1.0

COMMENTS: WATER FILLED ALUMINUM SLEEVES AT $\otimes$

v 
II

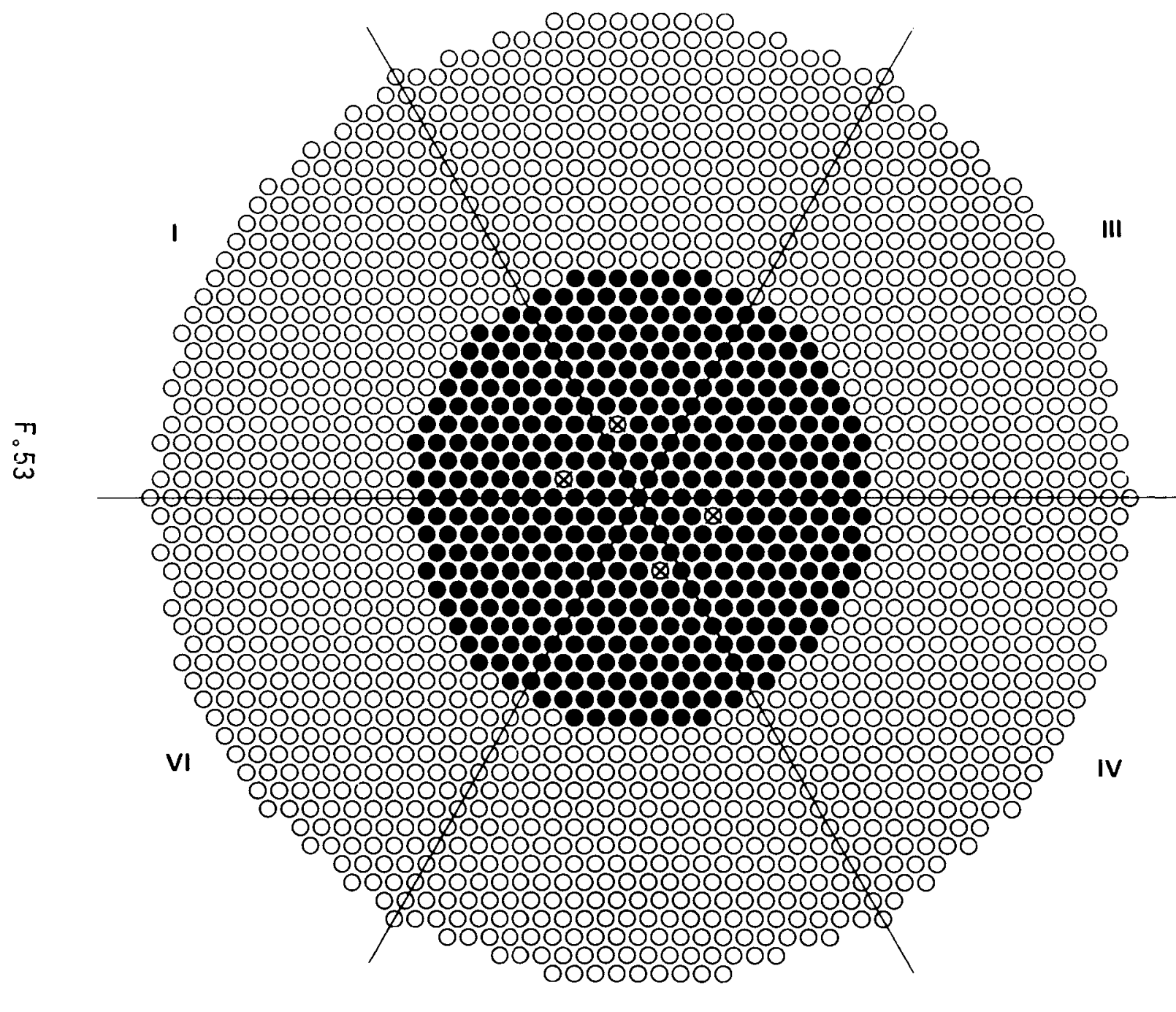

III torop

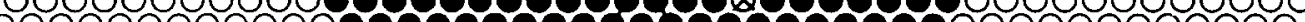
$\begin{array}{lll} & 0 \\ 0\end{array}$ (1) 年 0
0

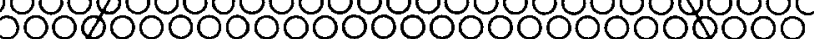

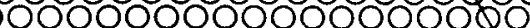
0000000000000000000 000000000

V
FUEL: $2.35 \mathrm{wt} \%{ }^{235} \mathrm{U}$ ENRICHED $\mathrm{UO}_{2}$

EXPERIMENT: $2.35-000-159 \mathrm{~B}$

LATTICE: 21

PITCH: $1.895 \pm 0.005 \mathrm{~cm}$

GADOLINIUM: NONE

CONTROL ROD: OUT

SAFETY ROD: OUT

REACTION RATES: NONE

RODS: $427 \mathrm{UO}_{2}$ RODS AT $\bullet$

keff: 1.0

COMMENTS: WATER FILLED ALUMINUM SLEEVES AT 
II

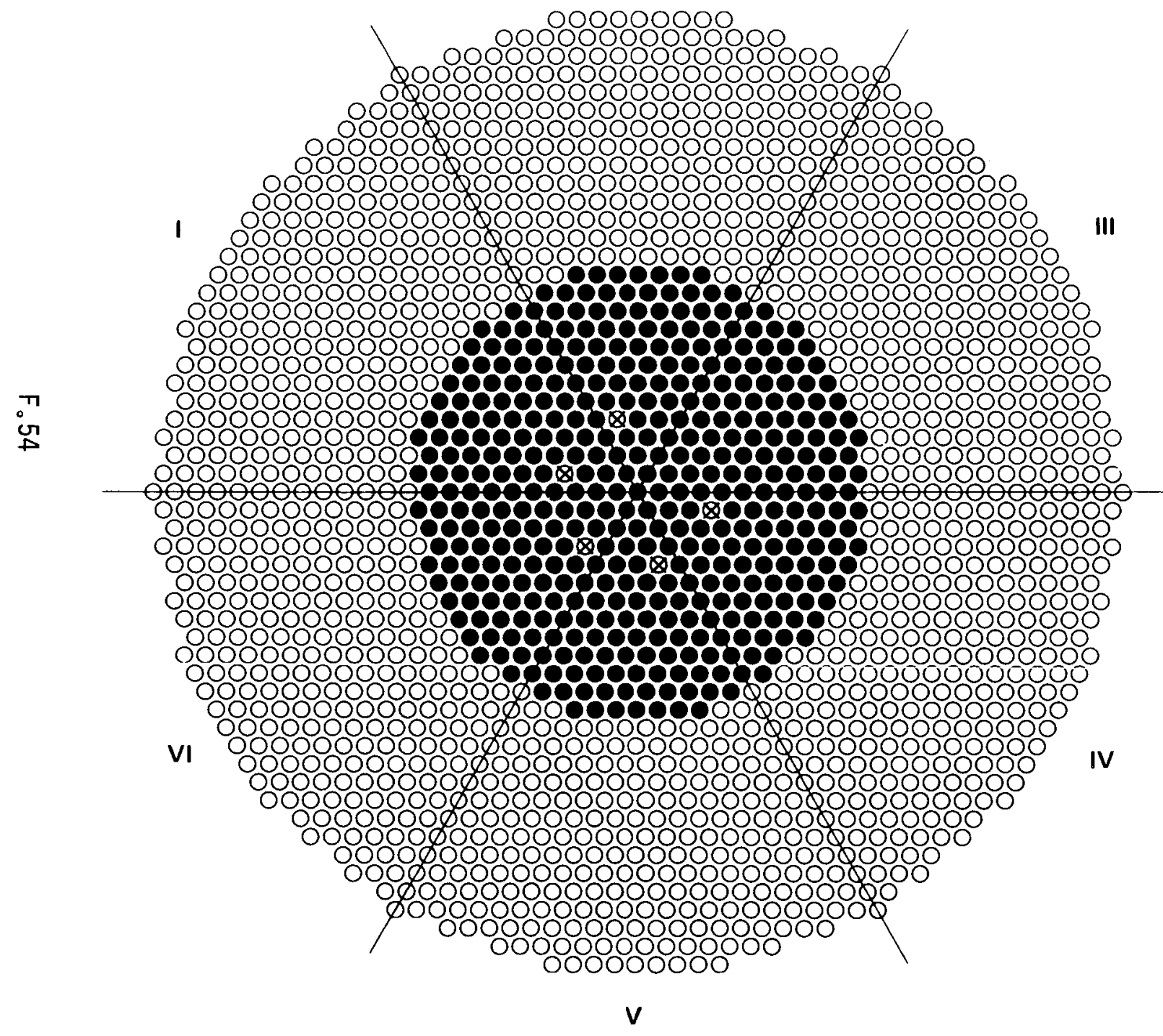

FUEL: $2.35 w t \%{ }^{235} \mathrm{U}$ ENRICHED $\mathrm{UO}_{2}$ EXPERIMENT: $2.35-000-159 \mathrm{C}$

LATTICE: 21

PITCH: $1.895 \pm 0.005 \mathrm{~cm}$

GADOLINIUM: NONE

CONTROL ROD: OUT

SAFETY ROD: OUT

REACTION RATES: NONE

RODS: 426 UO RODS AT •

keff: 1.0

COMMENTS: WATER FILLED ALUMINUM SLEEVES AT 
II

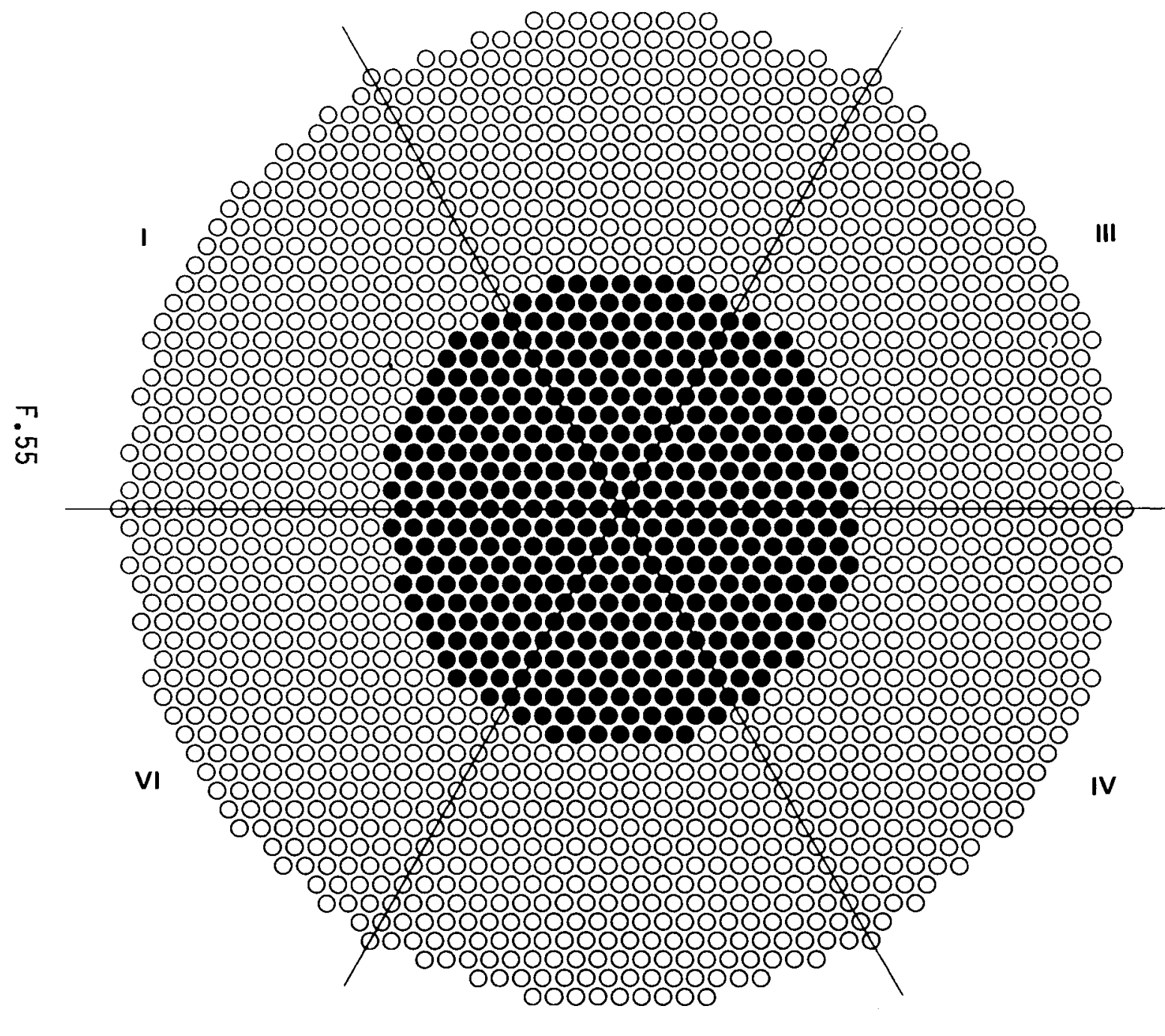

FUEL: $2.35 w t \%{ }^{235} \mathrm{U}$ ENRICHED $\mathrm{UO}_{2}$

EXPERIMENT: $2.35-000-160$

LATTICE: 12

PITCH: $1.895 \pm 0.005$

GADOLINIUM: SEE COMMENTS

CONTROL ROD: NONE

SAFETY ROD: NONE

REACTION RATES: NONE

RODS: $431 \mathrm{UO}_{2}$ RODS AT •

keff: SEE COMMENTS

COMMENTS:

$k_{\text {eff }}=1.0$ AT ZERO $\mathrm{g} \mathrm{Gd} /$ liter

$k_{\text {eff }}=0.960$ AT $0.120 \pm 0.001 \mathrm{~g} \mathrm{Gd} /$ Liter 


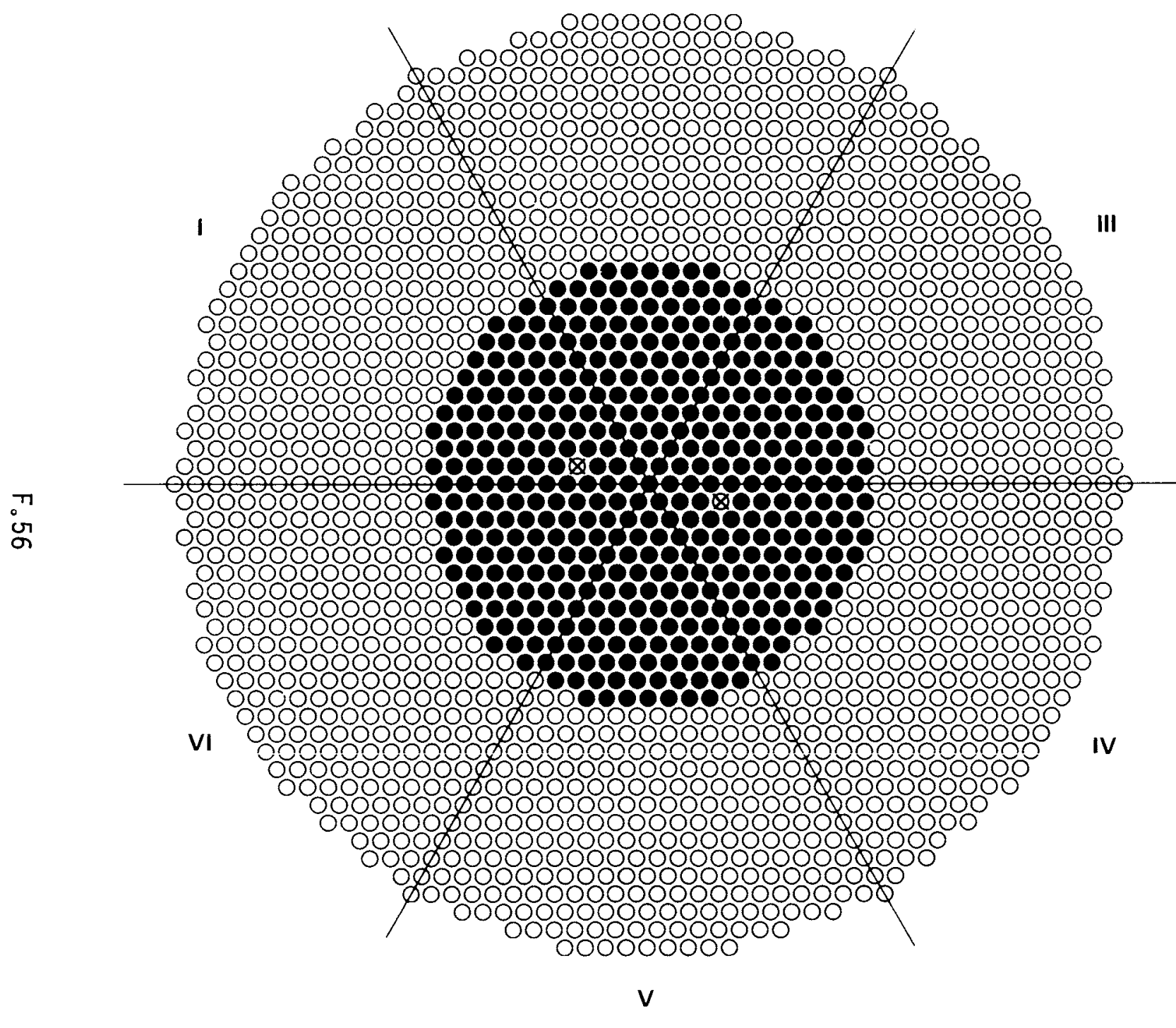

FUEL: $2.35 w t \%{ }^{235} \mathrm{U}$ ENRICHED $\mathrm{UO}_{2}$ EXPERIMENT: $2.35-000-160 \mathrm{~A}$

LATTICE: 21

PITCH: $1.895 \pm 0.005 \mathrm{~cm}$

GADOLINIUM: NONE

CONTROL ROD: OUT

SAFETY ROD: OUT

REACTION RATES: NONE

RODS: $429 \mathrm{UO}_{2}$ RODS AT •

$k_{\text {eff: }} 1.0$

COMMENTS: WATER FILLED ALUMINUM SLEEVES AT $\otimes$ 


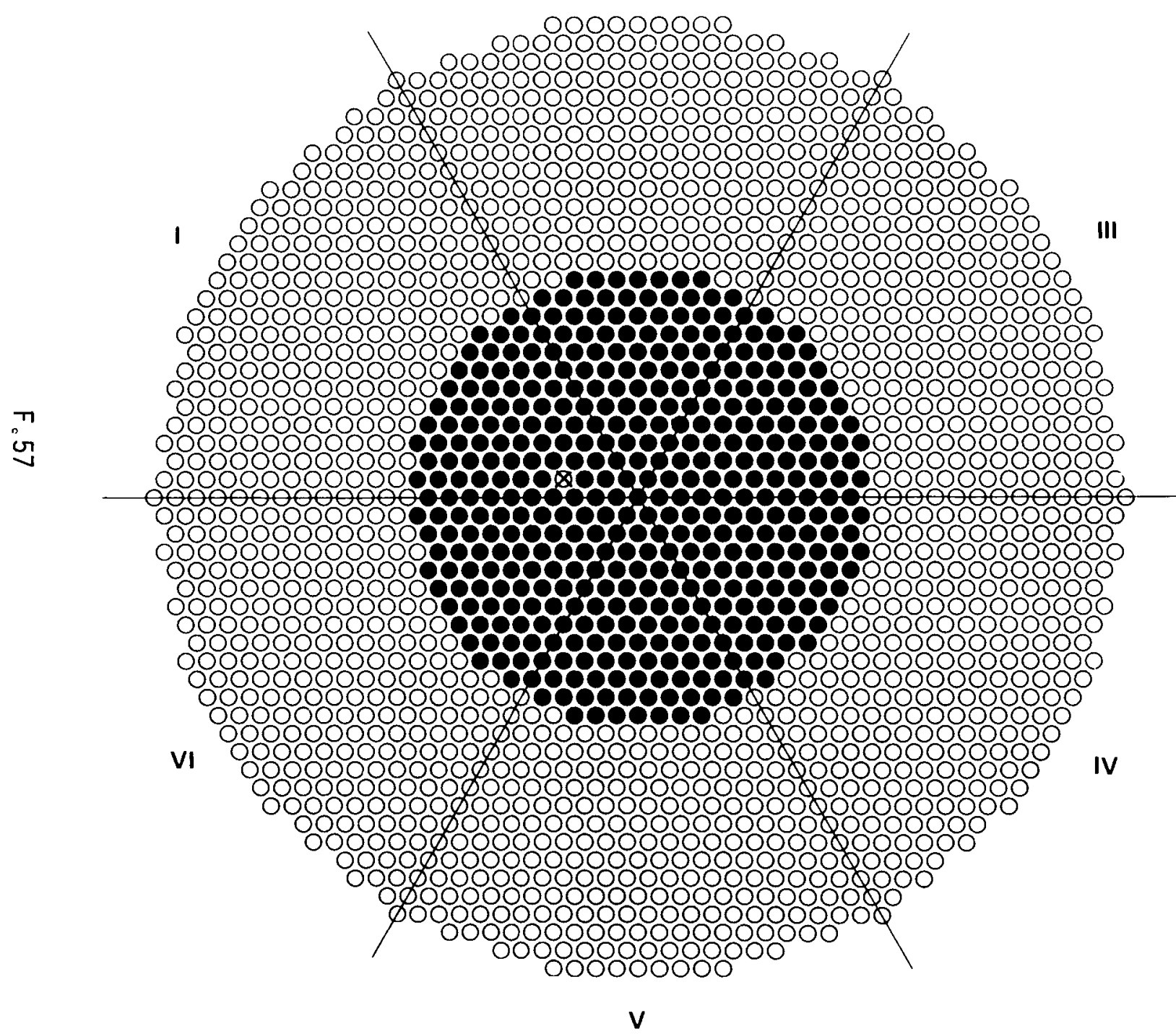

FUEL: $2.35 \mathrm{wt} \%{ }^{235} \mathrm{U}$ ENRICHED $\mathrm{UO}_{2}$

EXPERIMENT: $2.35-000-160 B$

LATTICE: 21

PITCH: $1.895 \pm 0.005 \mathrm{~cm}$

GADOLINIUM: NONE

CONTROL ROD: OUT

SAFETY ROD: OUT

REACTION RATES: NONE

RODS: $430 \mathrm{UO}_{2}$ RODS AT •

$k_{\text {eff: }} \mathbf{1 . 0}$

COMMENTS: WATER FILLED ALUMINUM SLEEVES AT 
II

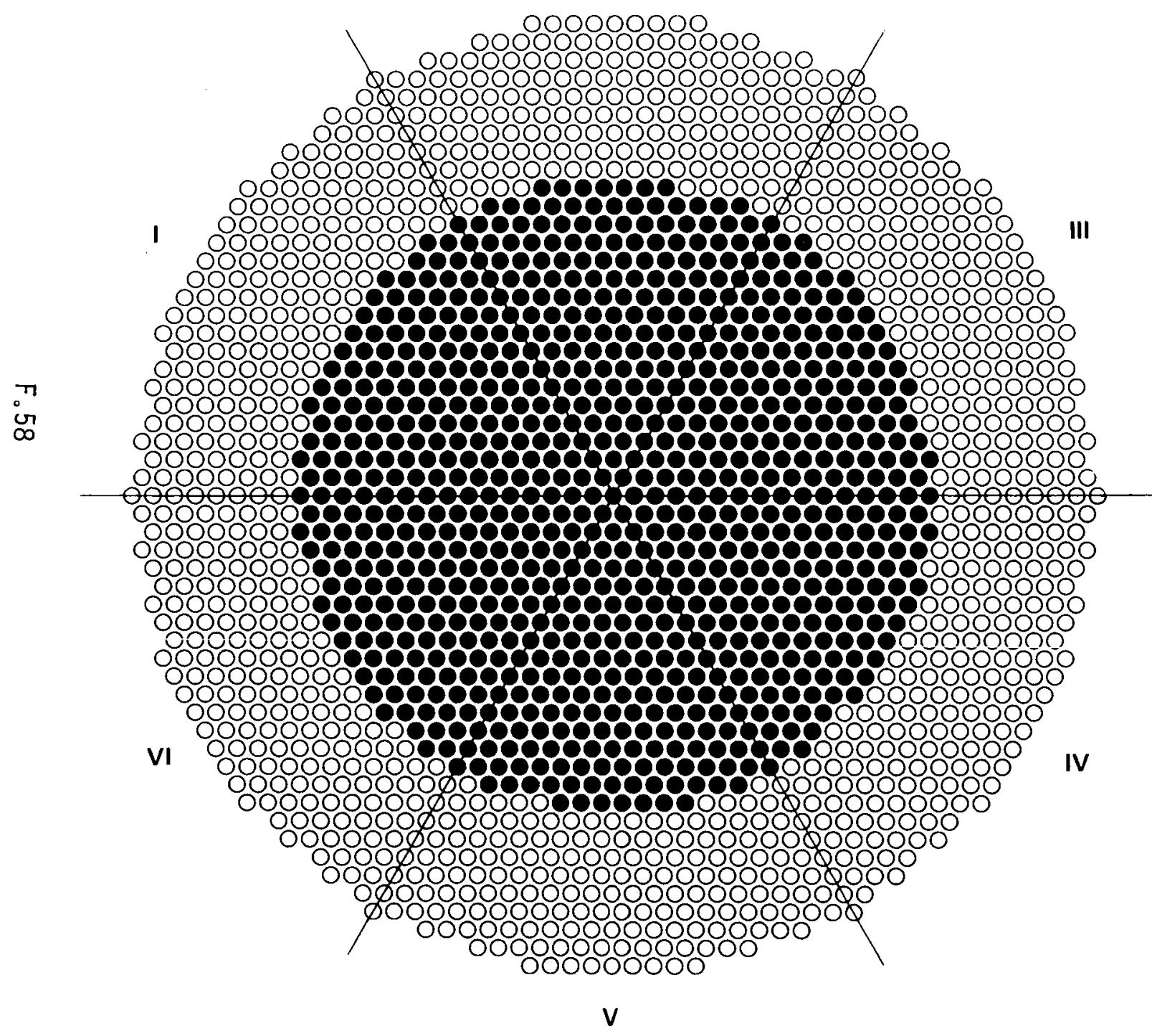

FUEL: $2.35 \mathrm{wt} \%{ }^{235} \mathrm{U}$ ENRICHED $\mathrm{UO}_{2}$ EXPERIMENT: $2.35-000-165$

LATTICE: 21

PITCH: $1.895 \pm 0.005$

GADOLINIUM: SEE COMMENTS

CONTROL ROD: NONE

SAFETY ROD: NONE

REACTION RATES: NONE

RODS: $842 \mathrm{UO}_{2}$ RODS AT $\bullet$

keff: SEE COMMENTS

COMMENTS:

$K_{\text {eff }}=1.0$ AT $0.120 \pm 0.001 \mathrm{~g} \mathrm{Gd} /$ liter

$k_{\text {eff }}=0.939$ AT $0.218 \pm 0.001 \mathrm{~g} \mathrm{Gd} /$ liter

$k_{\text {eff }}=0.918$ AT $0.262 \pm 0.003 \mathrm{~g} \mathrm{Gd} /$ liter

$k_{\text {eff }}=0.876$ AT $0.317 \pm 0.001 \mathrm{~g} \mathrm{Gd} /$ liter 
II

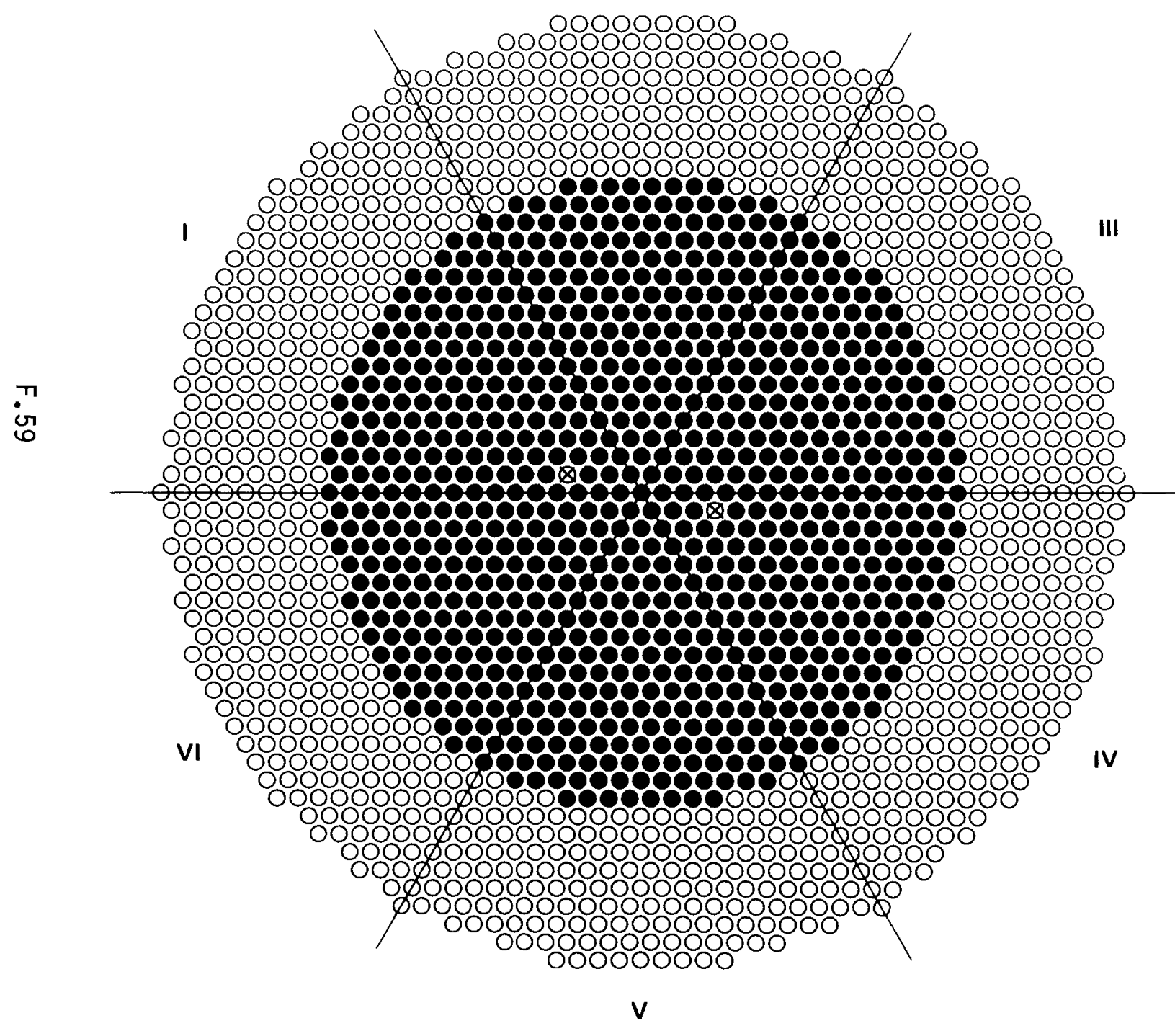

FUEL: $2.35 \mathrm{wt} \%{ }^{235} \mathrm{U}$ ENRICHED $\mathrm{UO}_{2}$ EXPERIMENT: 2.35-000-165A

LATTICE: 21

PITCH: $1.895+0.005$

GADOLINIUM: $0.120 \pm 0.001 \mathrm{~g} \mathrm{Gd} /$ liter CONTROL ROD: OUT SAFETY ROD: OUT REACTION RATES: NONE RODS: $842 \mathrm{UO}_{2}$ RODS AT $k_{\text {eff: }} \mathbf{1 . 0}$

COMMENTS: WATER FILLED ALUMINUM SLEEVES AT $\otimes$ 
II

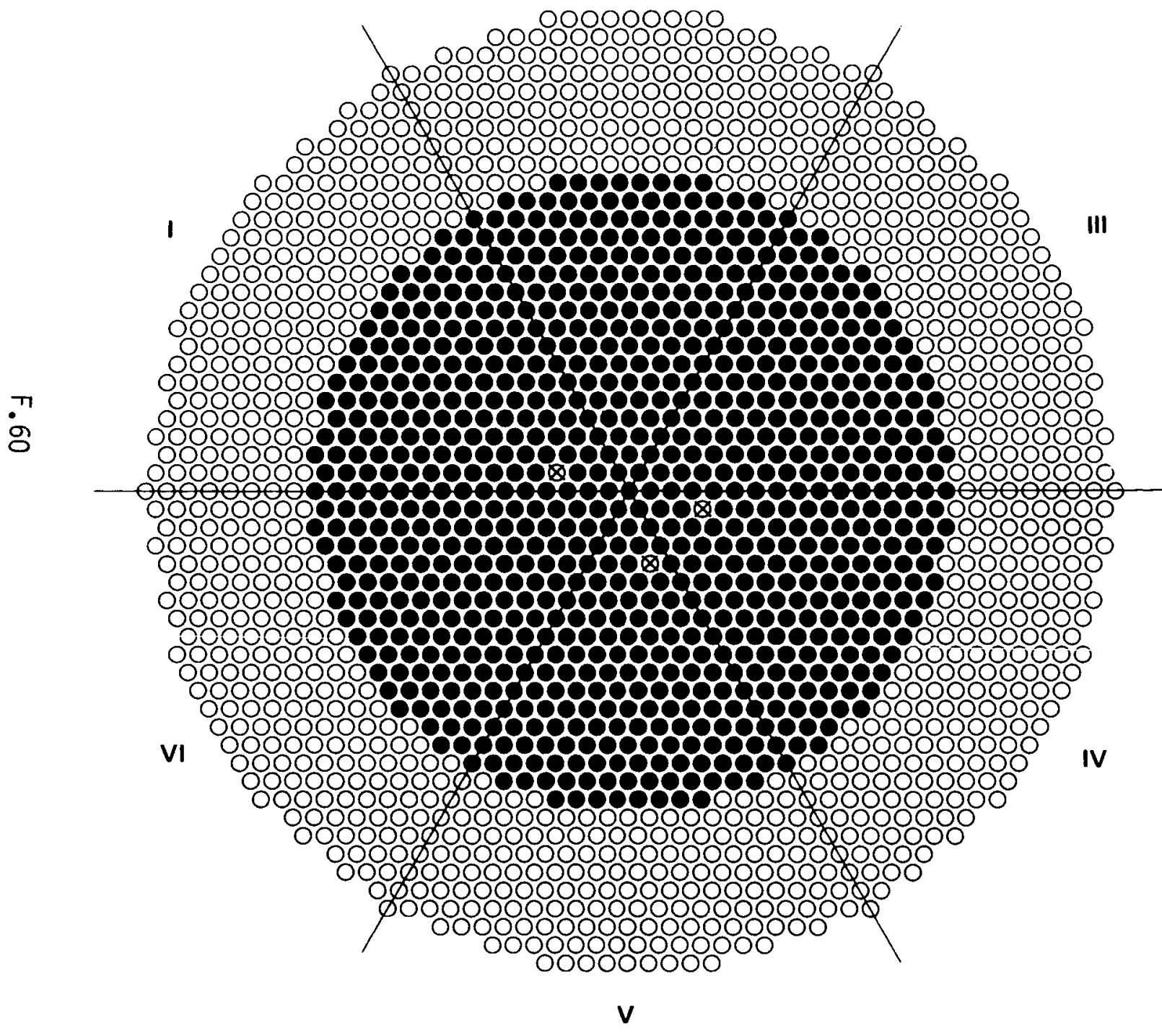

FUEL: 2.35 wt $\%{ }^{235} \mathrm{U}$ ENRICHED $\mathrm{UO}_{2}$ EXPERIMENT: $2.35-000-165 \mathrm{~B}$

LATTICE: 21

PITCH: $1.895 \pm 0.005$

GADOLINIUM: $0.120 \pm 0.001 \mathrm{~g} \mathrm{Gd} /$ liter CONTROL ROD: OUT

SAFETY ROD: OUT

REACTION RATES: NONE

RODS: $842 \mathrm{UO}_{2}$ RODS AT •

keff: 1.0

COMMENTS: WATER FILLED ALUMINUM SLEEVES AT $\otimes$ 
II

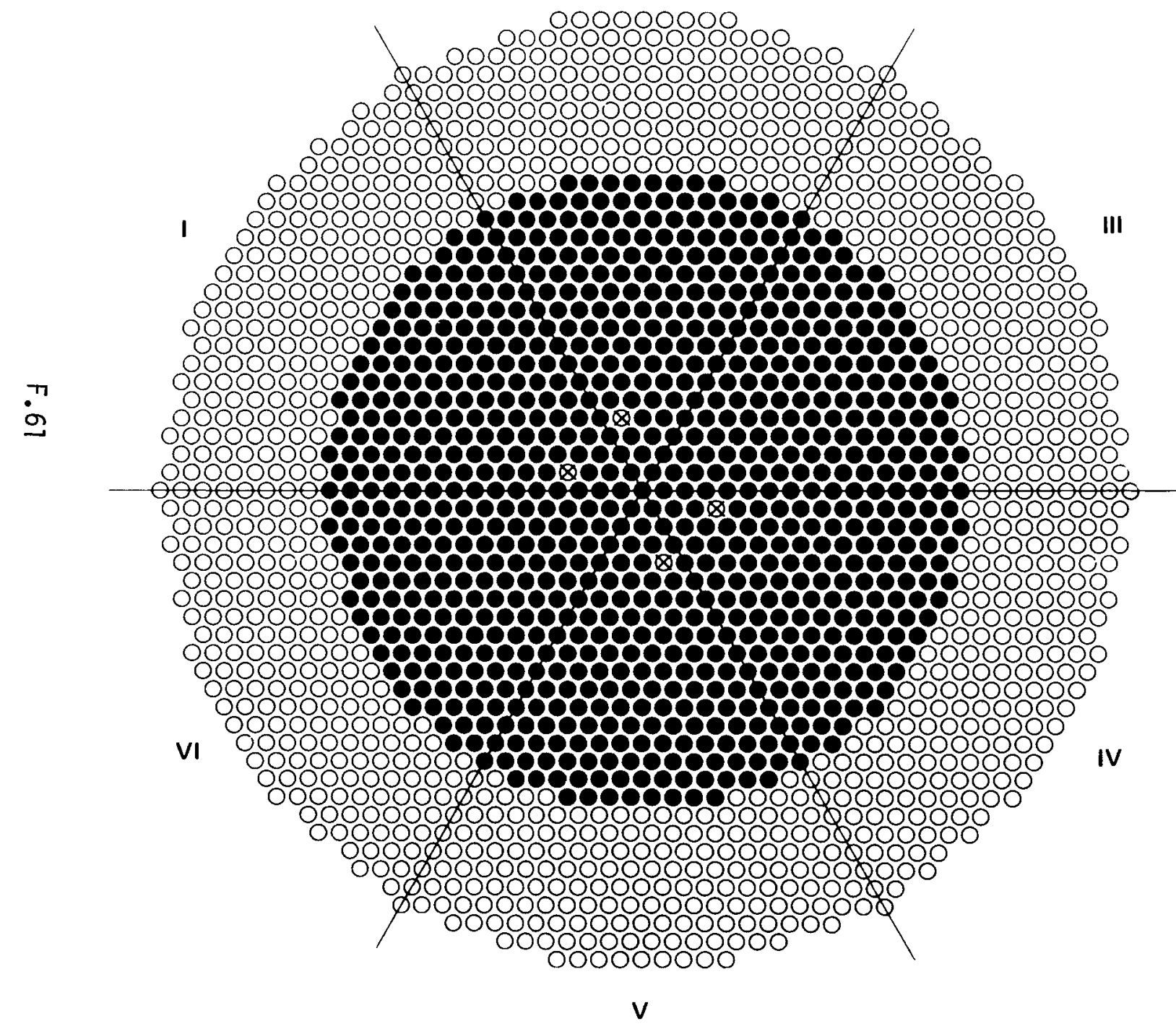

FUEL: $2.35 \mathrm{wt} \%{ }^{235} \mathrm{U}$ ENRICHED $\mathrm{UO}_{2}$

EXPERIMENT: $2.35-000-165 \mathrm{C}$

LATTICE: 21

PITCH: $1.895 \pm 0.005$

GADOLINIUM: $0.120 \pm 0.001 \mathrm{~g} \mathrm{Gd} /$ liter CONTROL ROD: OUT

SAFETY ROD: OUT

REACTION RATES: NONE

RODS: $842 \mathrm{UO}_{2}$ RODS AT $\bullet$

Keff: 1.0

COMMENTS: WATER FILLED ALUMINUM SLEEVES AT $\otimes$ 


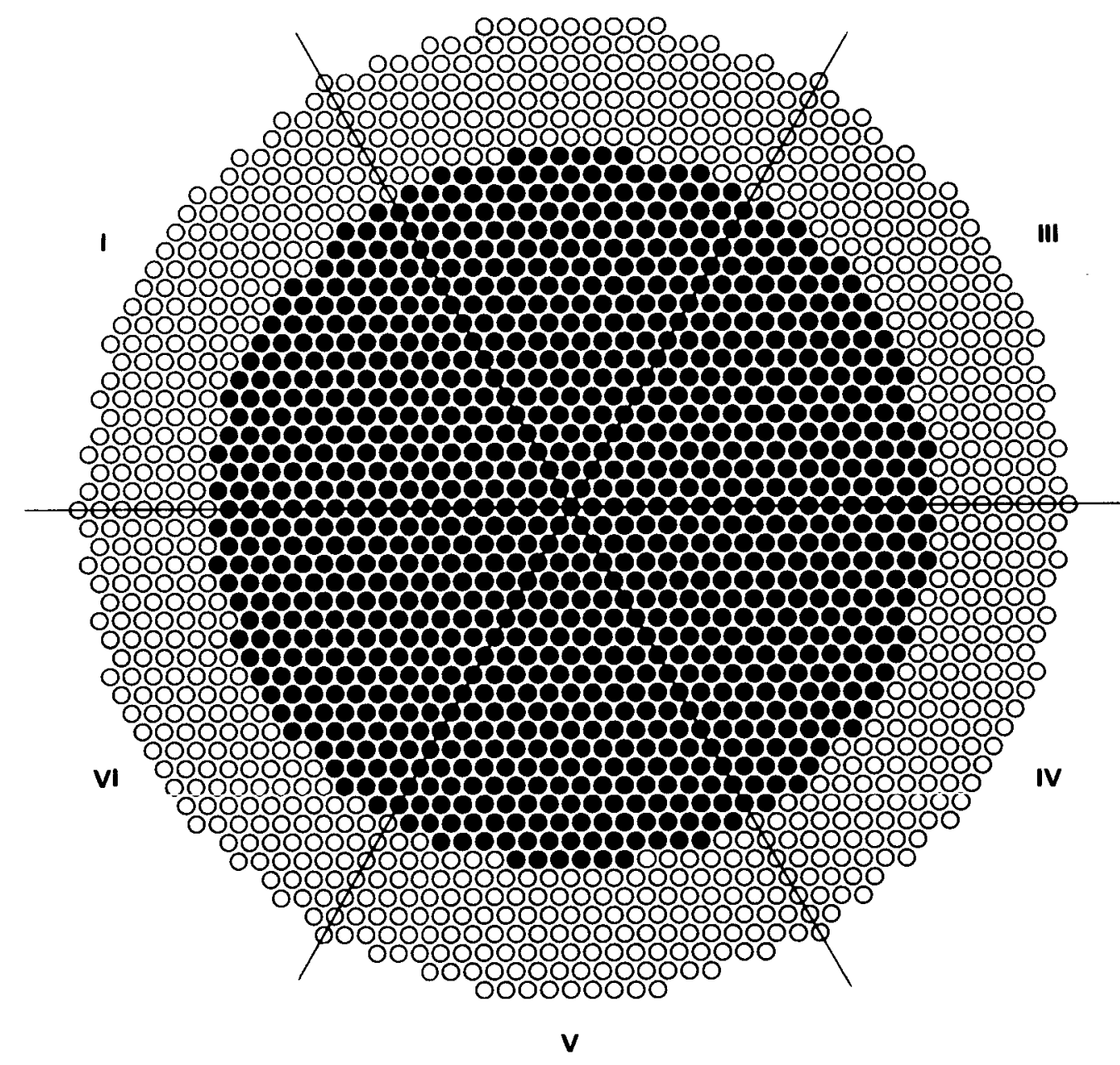

FUEL: $2.35 \mathrm{wt} \%{ }^{235} \mathrm{U}$ ENRICHED $\mathrm{UO}_{2}$ EXPERIMENT: $2.35-000-170$

LATTICE: 22

PITCH: $1.598 \pm 0.005 \mathrm{~cm}$

GADOLINIUM: SEE COMMENTS CONTROL ROD: NONE SAFETY ROD: NONE REACTION RATES: NONE RODS: $1029 \mathrm{UO}_{2}$ RODS AT • keff: SEE COMMENTS COMMENTS:

$k_{\text {eff }}=1.0$

AT ZERO $g$ Gd/liter $k_{\text {eff }}=0.987$ AT $0.055 \pm 0.001 \mathrm{~g} \mathrm{Gd} /$ liter $k_{\text {eff }}=0.963$ AT $0.078 \pm 0.001 \mathrm{~g} \mathrm{Gd} /$ liter $k_{\text {eff }}=0.890$ AT $0.257 \pm 0.001 \mathrm{~g} \mathrm{Gd} /$ liter 
II

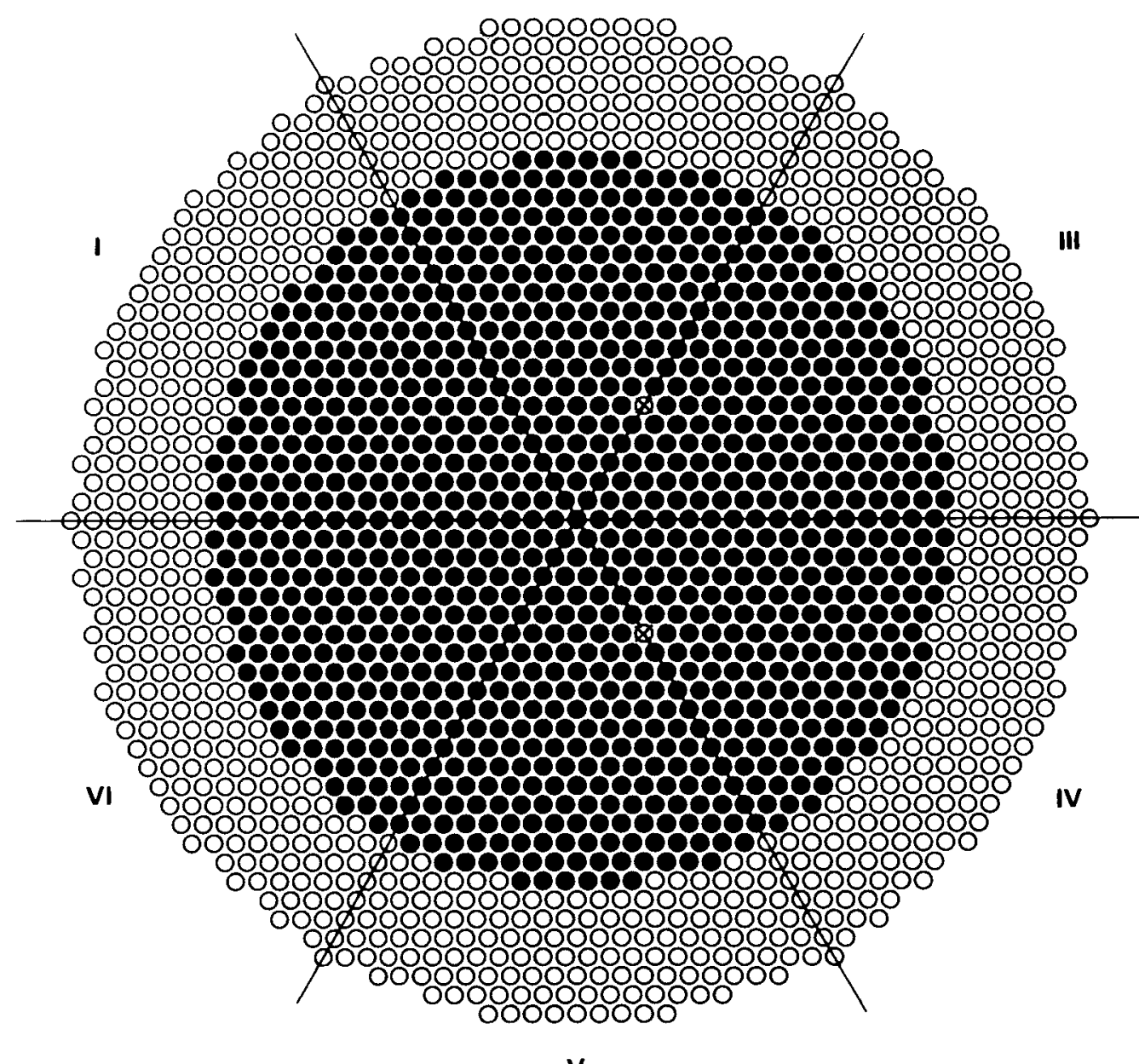

FUEL: $2.35 \mathrm{wt} \%{ }^{235} \mathrm{U}$ ENRICHED $\mathrm{UO}_{2}$

EXPERIMENT: $2.35-000-170 \mathrm{~A}$

LATTICE: 22

PITCH: $1.598 \pm 0.005 \mathrm{~cm}$

GADOLINIUM: NONE

CONTROL ROD: OUT

SAFETY ROD: OUT

REACTION RATES: NONE

RODS: $1025 \mathrm{UO}_{2}$ RODS AT •

keff: 1.0

COMMENTS: WATER FILLED ALUMINUM SLEEVES AT $\otimes$ 
II

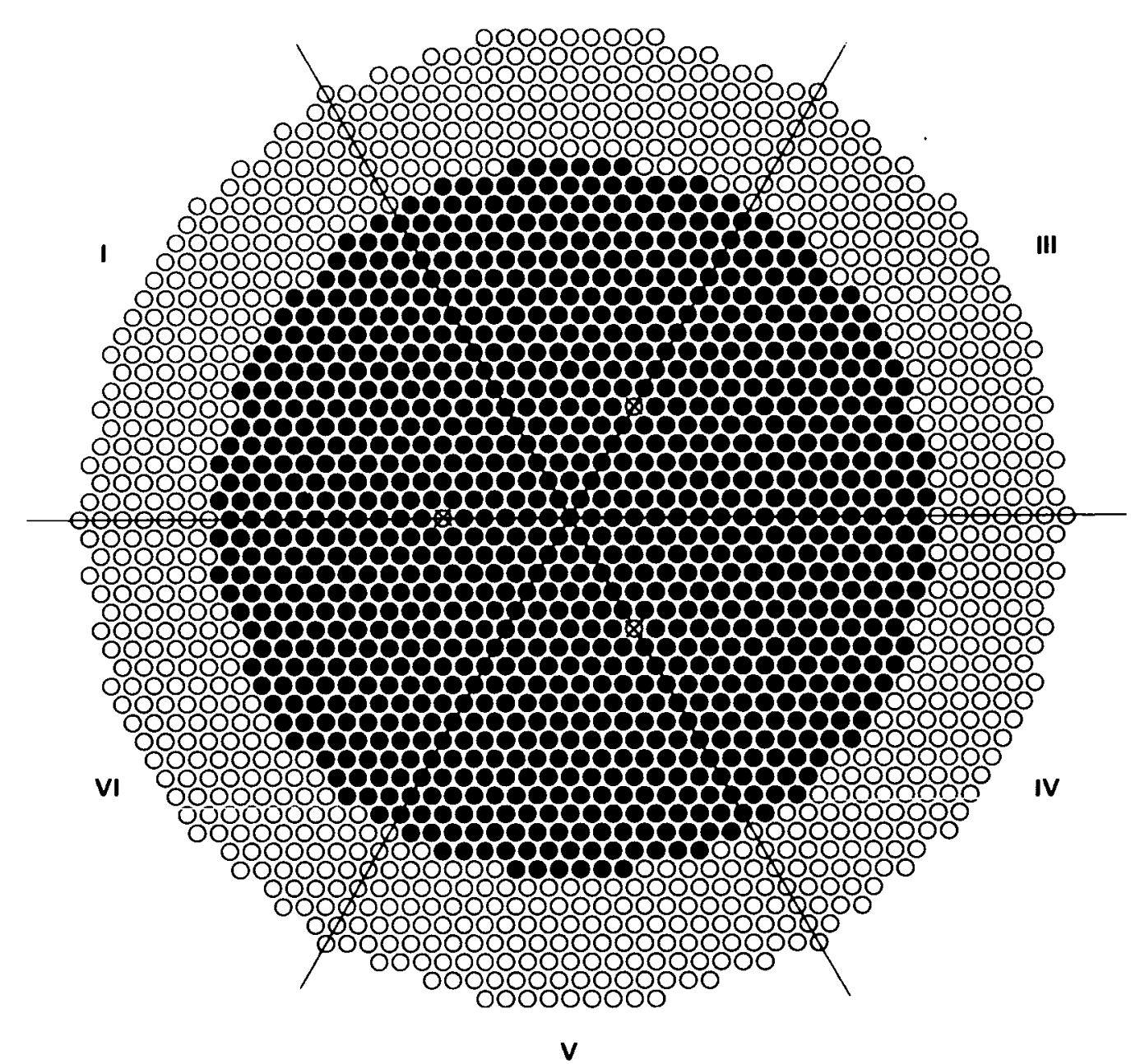

FUEL: 2.35 wt $\%{ }^{235} \mathrm{U}$ ENRICHED $\mathrm{UO}_{2}$ EXPERIMENT: $2.35-000-170 B$

LATTICE: 22

PITCH: $1.598 \pm 0.005 \mathrm{~cm}$

GADOLINIUM: NONE

CONTROL ROD: OUT

SAFETY ROD: OUT

REACTION RATES: NONE

RODS: $1023 \mathrm{UO}_{2}$ RODS AT

$k_{\text {eff }}: 1.0$

COMMENTS: WATER FILLED ALUMINUM SLEEVES AT 
$\ddot{\circ}$

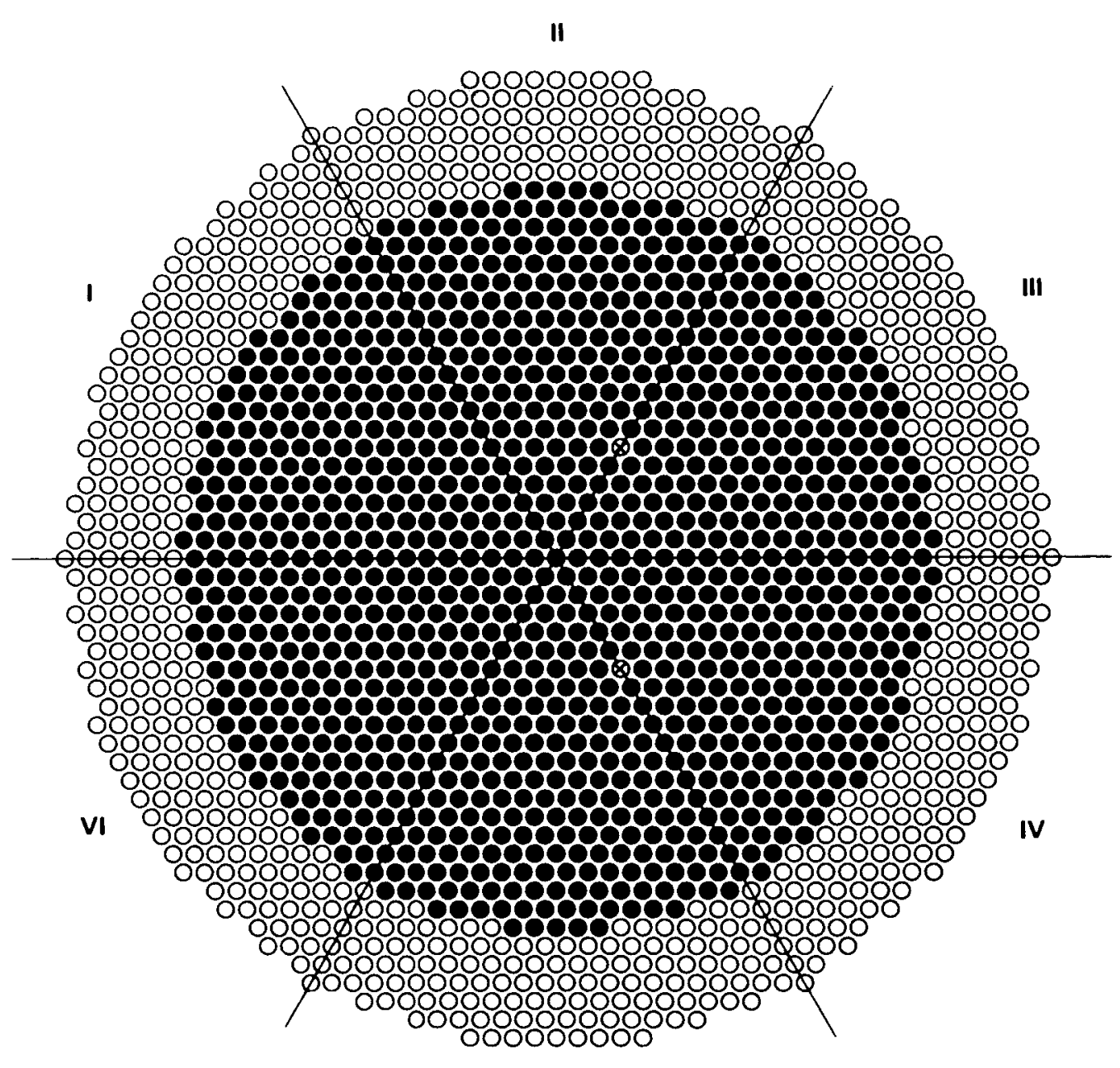

FUEL: $2.35 \mathrm{wt} \%{ }^{235} \mathrm{U}$ ENRICHED $\mathrm{UO}_{2}$ EXPERIMENT: $2.35-000-172$

LATTICE: 22

PITCH: $1.598 \pm 0.005 \mathrm{~cm}$

GADOLINIUM: $0.055 \pm 0.001 \mathrm{~g} \mathrm{Gd} /$ liter

CONTROL ROD: OUT

SAFETY ROD: OUT

REACTION RATES: NONE

RODS: $1122 \mathrm{UO}_{2}$ RODS AT •

keff: 1.0

COMMENTS: WATER FILLED ALUMINUM SLEEVES AT $\otimes$ 
II

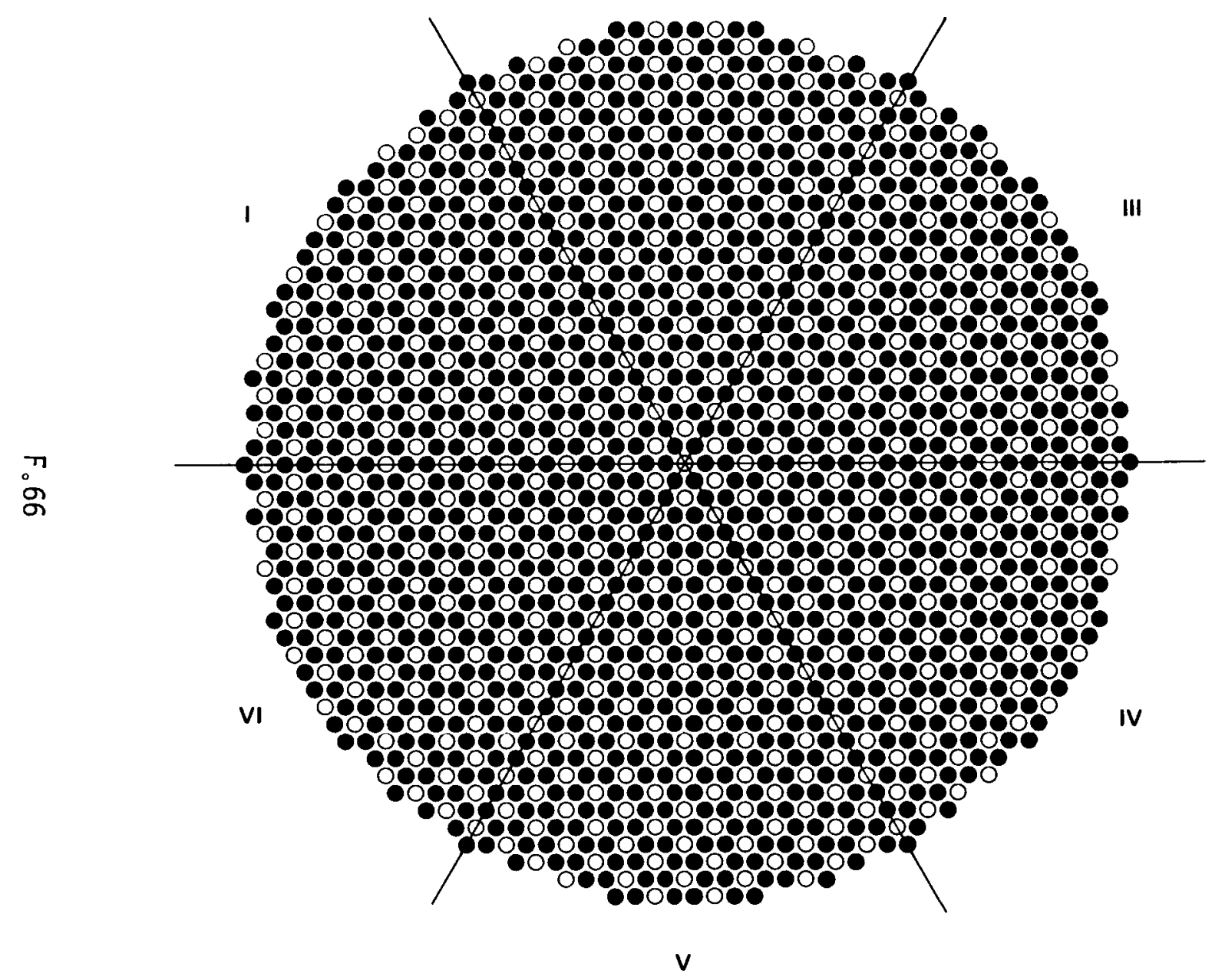

FUEL: $4.31 \mathrm{wt} \%{ }^{235} \mathrm{U}$ ENRICHED UO ${ }_{2}$ AND $\mathrm{PUO}_{2}-$ NATURAL $\mathrm{UO}_{2}$ CONTAINING $2.0 \mathrm{wt} \% \mathrm{PuO}_{2}$

EXPERIMENT: 4.3-002-196

LATTICE: 32

PITCH: $1.598 \pm 0.005 \mathrm{~cm}$

GADOLINIUM: SEE COMMENTS

CONTROL ROD: NONE

SAFETY ROD: NONE

REACTION RATES: NONE

RODS: $583 \mathrm{MO}_{2}$ RODS AT O PLUS $1174 \mathrm{UO}_{2}$ RODS AT •

keff: SEE COMMENTS

COMMENTS: PERIPHERIAL UNUSED LATTICE LOCATIONS NOT SHOWN

$k_{\text {eff }}=1.0 \quad$ AT ZERO $\mathrm{g} \mathrm{Gd} /$ liter $k_{\text {eff }}=0.957$ AT $0.194 \pm 0.001 \mathrm{~g} \mathrm{Gd} /$ liter $k_{\text {eff }}=0.931 \mathrm{AT} 0.408 \pm 0.006 \mathrm{~g} \mathrm{Gd} /$ liter $k_{\text {eff }}=0.914$ AT $0.626 \pm 0.008 \mathrm{~g} \mathrm{Gd} / \mathrm{liter}$ $k_{\text {eff }}=0.891 \mathrm{AT} 0.918 \pm 0.015 \mathrm{~g} \mathrm{Gd} / \mathrm{liter}$ 


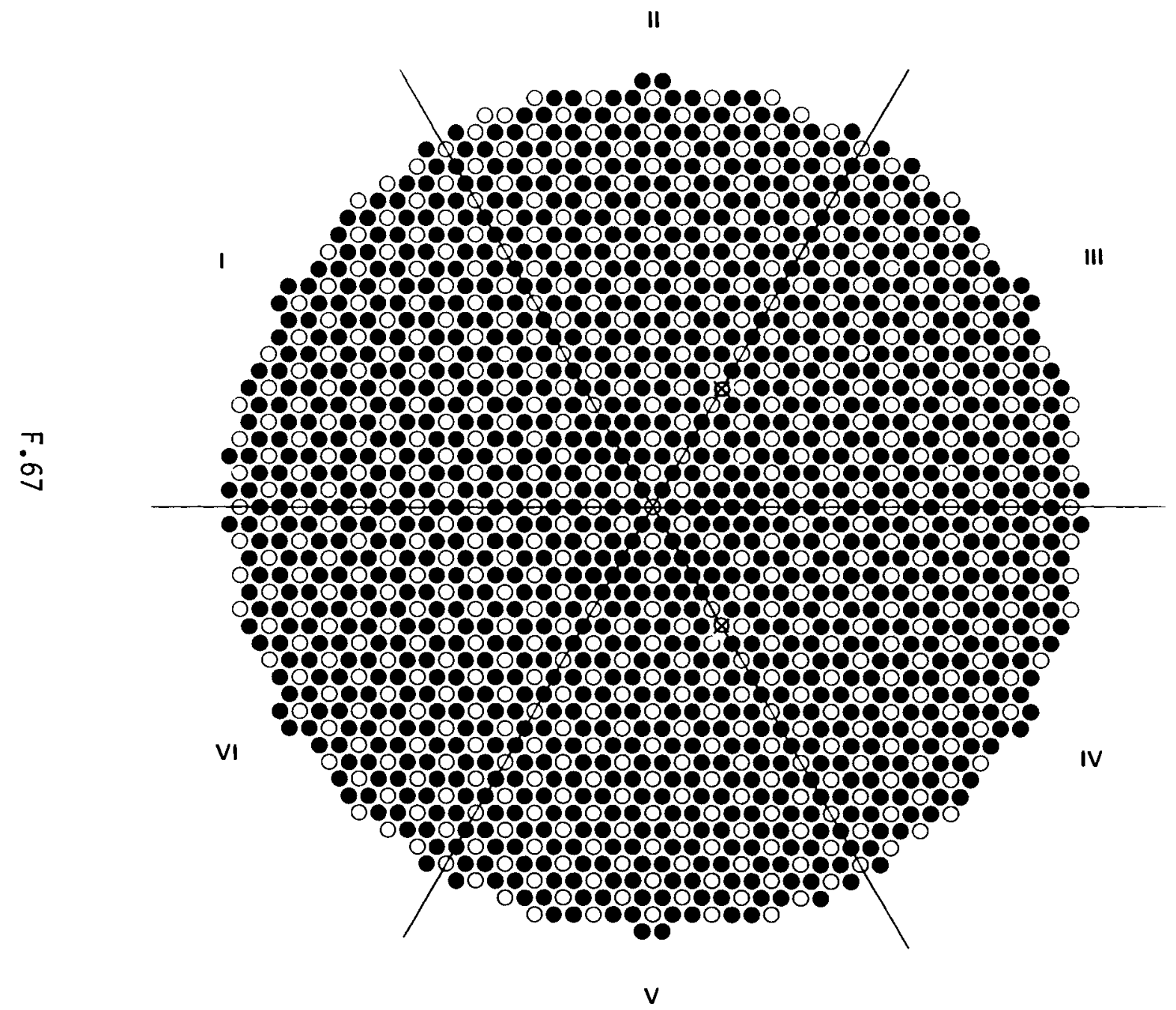

FUEL: $4.31 \mathrm{wt} \%{ }^{235} \mathrm{U}$ ENRICHED $\mathrm{UO}_{2}$ AND $\mathrm{PuO}_{2}$ NATURAL $\mathrm{UO}_{2}$ CONTAINING $2.0 \mathrm{wt} \% \mathrm{PuO}_{2}$

EXPERIMENT: 4.3-002-196A

LATTICE: 32

PITCH: $1.598 \pm 0.005 \mathrm{~cm}$

GADOLINIUM: NONE

CONTROL ROD: OUT

SAFETY ROD: OUT

REACTION RATES: NONE

RODS: $559 \mathrm{MO}_{2}$ RODS AT O PLUS

$1142 \mathrm{UO}_{2}$ RODS AT

keff: 1.0

COMMENTS: WATER FILLED ALUMINIUM SLEEVES AT

PERIPHERIAL UNUSED

LATTICE LOCATIONS NOT SHOWN 
II

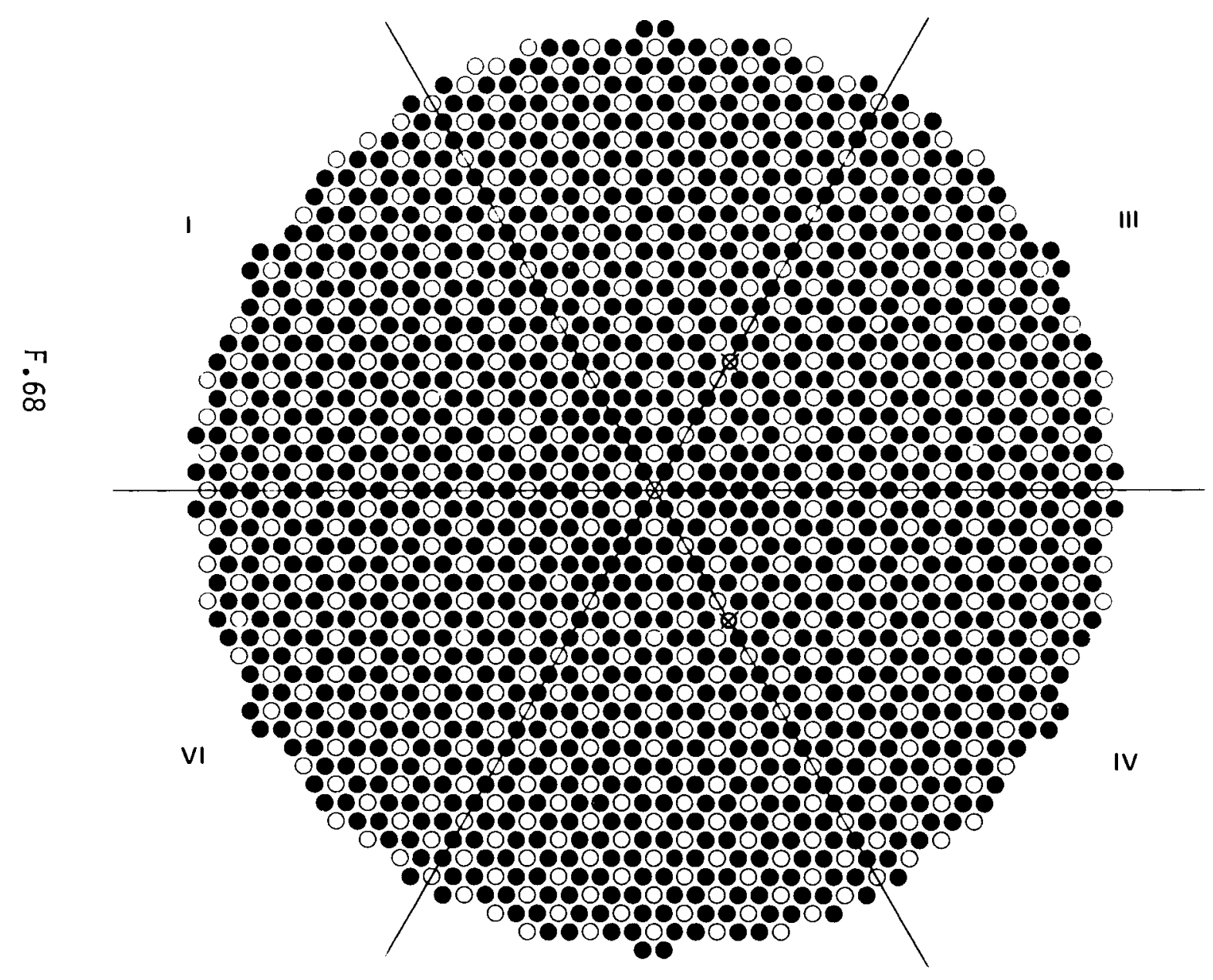

III

FUEL: $4.31 \mathrm{wt} \%$ 235U ENRICHED UO ${ }_{2}$ AND $\mathrm{PuO}_{2}$ NATURAL $\mathrm{UO}_{2}$ CONTAINING $2.0 \mathrm{wt} \% \mathrm{PuO}_{2}$

\section{EXPERIMENT: 4.3-002-196B}

LATTICE: 32

PITCH: $1.598 \pm 0.005 \mathrm{~cm}$

GADOLINIUM: NONE

CONTROL ROD: OUT

SAFETY ROD: OUT

REACTION RATES: NONE

RODS: $562 \mathrm{MO}_{2}$ RODS AT $\bigcirc$ PLUS

$1146 \mathrm{UO}_{2}$ RODS AT

$k_{\text {eff: }} \mathbf{1 . 0}$

COMMENTS: WATER FILLED ALUMINUM SLEEVES AT

PERIPHERIAL UNUSED LATTICE

LOCATIONS NOT SHOWN 


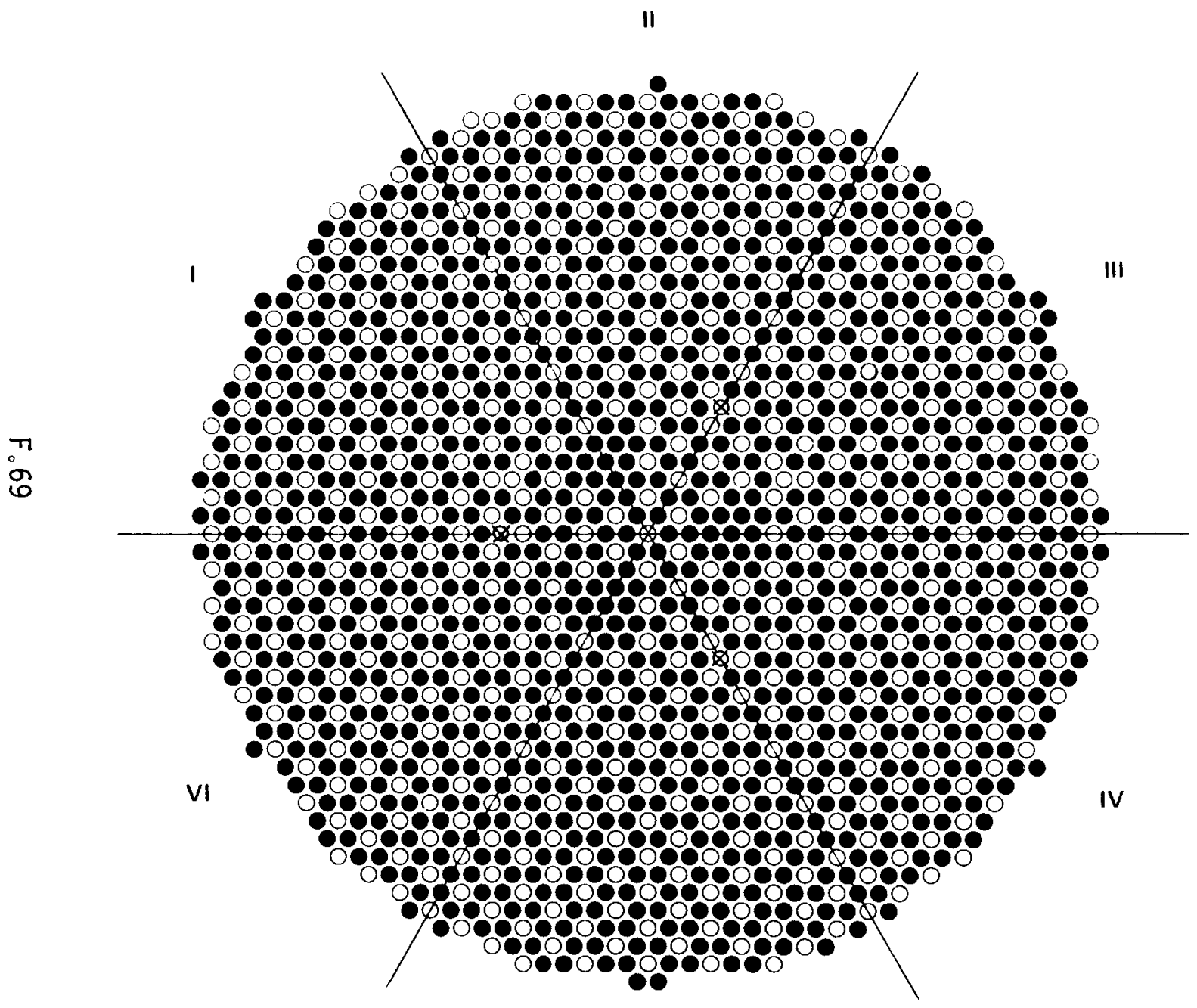

FUEL: 4.31 wt $\%$ 235Uं ENRICHED UO ${ }_{2}$ AND PUO $_{2}$ NATURAL $\mathrm{UO}_{2}$ CONTAINING $2.0 \mathrm{wt} \% \mathrm{PuO}_{2}$

EXPERIMENT: 4.3-002-196C

LATTICE: 32

PITCH: $1.598 \pm 0.005 \mathrm{~cm}$

GADOLINIUM: NONE

CONTROL ROD: OUT

SAFETY ROD: OUT

REACTION RATES: NONE

RODS: $562 \mathrm{PuO}_{2}-\mathrm{UO}_{2}$ RODS AT O PLUS $1131 \mathrm{UO}_{2}$ RODS AT $\bullet$

keff: 1.0

COMMENTS: WATER FILLED ALUMINUM

SLEEVES AT $\$$

PERIPHERIAL UNUSED LATTICE

LOCATIONS NOT SHOWN 
II

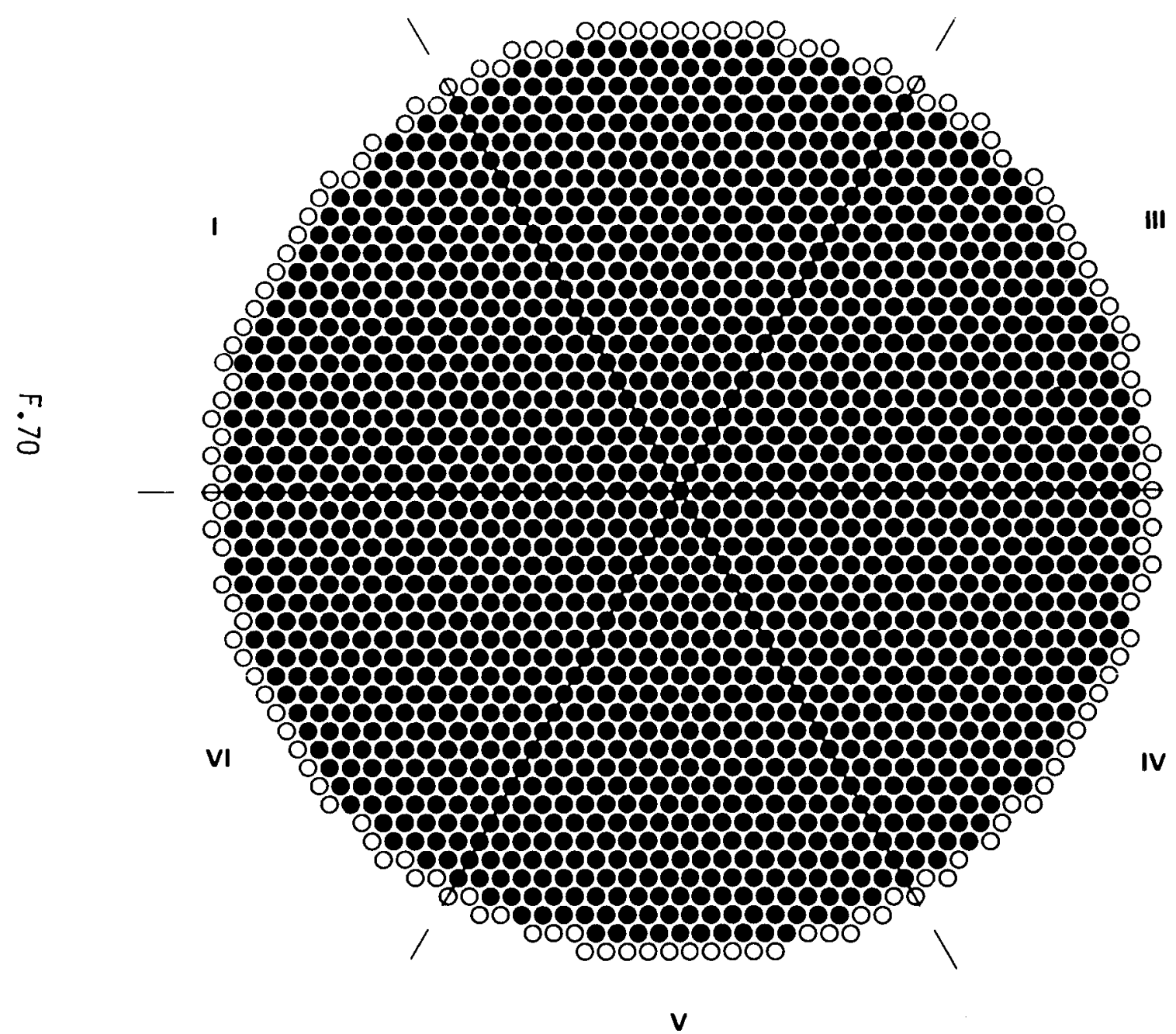

FUEL: $4.31 \mathrm{wt} \%{ }^{235} \mathrm{U}$ ENRICHED $\mathrm{UO}_{2}$ AND $\mathrm{PuO}_{2}-$ NATURAL $\mathrm{UO}_{2}$ CONTAINING 2.0 wt $\% \mathrm{PuO}_{2}$

EXPERIMENT: $4.3-000-207$

LATTICE: 32M

PITCH: $1.598+0.005 \mathrm{~cm}$

GADOLINIUM: $0.466 \pm 0.001 \mathrm{~g} \mathrm{Gd} /$ liter

- CONTROL ROD: OUT

SAFETY ROD: OUT

REACTION RATES: NONE

RODS: $139 \mathrm{MO}_{2}$ RODS AT O PLUS 1657 UO, RODS AT •

keff: 1.0

COMMENTS: . PERIPHERIAL UNUSED LATTICE LOCATIONS NOT SHOWN. 


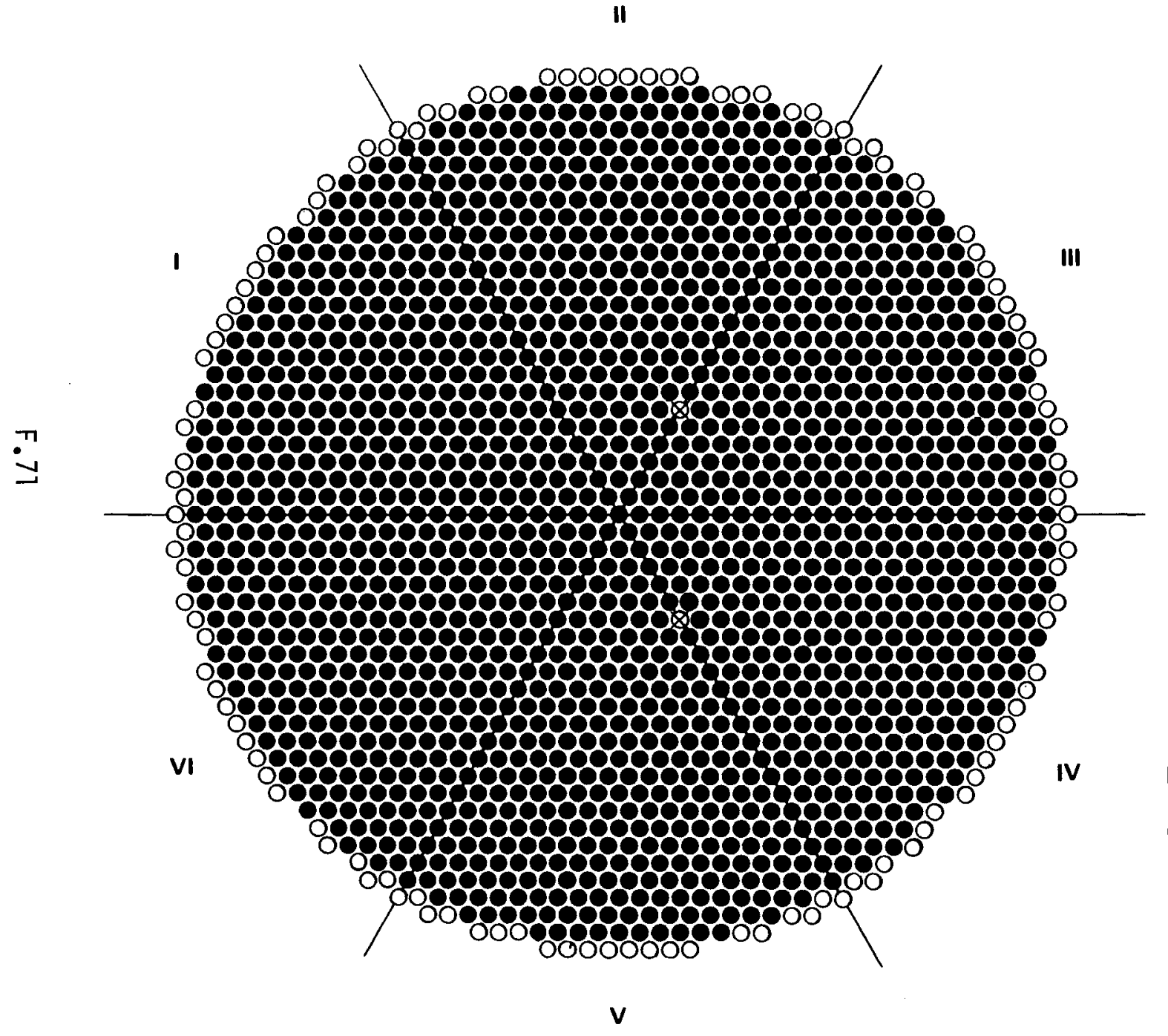

FUEL: $4.31 \mathrm{wt} \%{ }^{235} \mathrm{U}$ ENRICHED $\mathrm{UO}_{2}$ AND $\mathrm{PuO}_{2}$ NATURAL $\mathrm{UO}_{2}$ CONTAINING 2.0 wt $\% \mathrm{PuO}_{2}$

EXPERIMENT: 4.3-000-207A

LATTICE: $32 \mathrm{M}$

PITCH: $1.598 \pm 0.005 \mathrm{~cm}$

GADOLINIUM: $0.466 \pm 0.001 \mathrm{~g} \mathrm{Gd} /$ liter

CONTROL ROD: OUT

SAFETY ROD: OUT

REACTION RATES: NONE

RODS: $120 \mathrm{MO}_{2}$ RODS AT O PLUS $1655 \mathrm{UO}_{2}$ RODS AT

$k_{\text {eff: }} 1.0$

COMMENTS: WATER FILLED ALUMINUM SLEEVE AT . PERIPHERIAL UNUSED LATTICE LOCATIONS NOT SHOWN. 
II

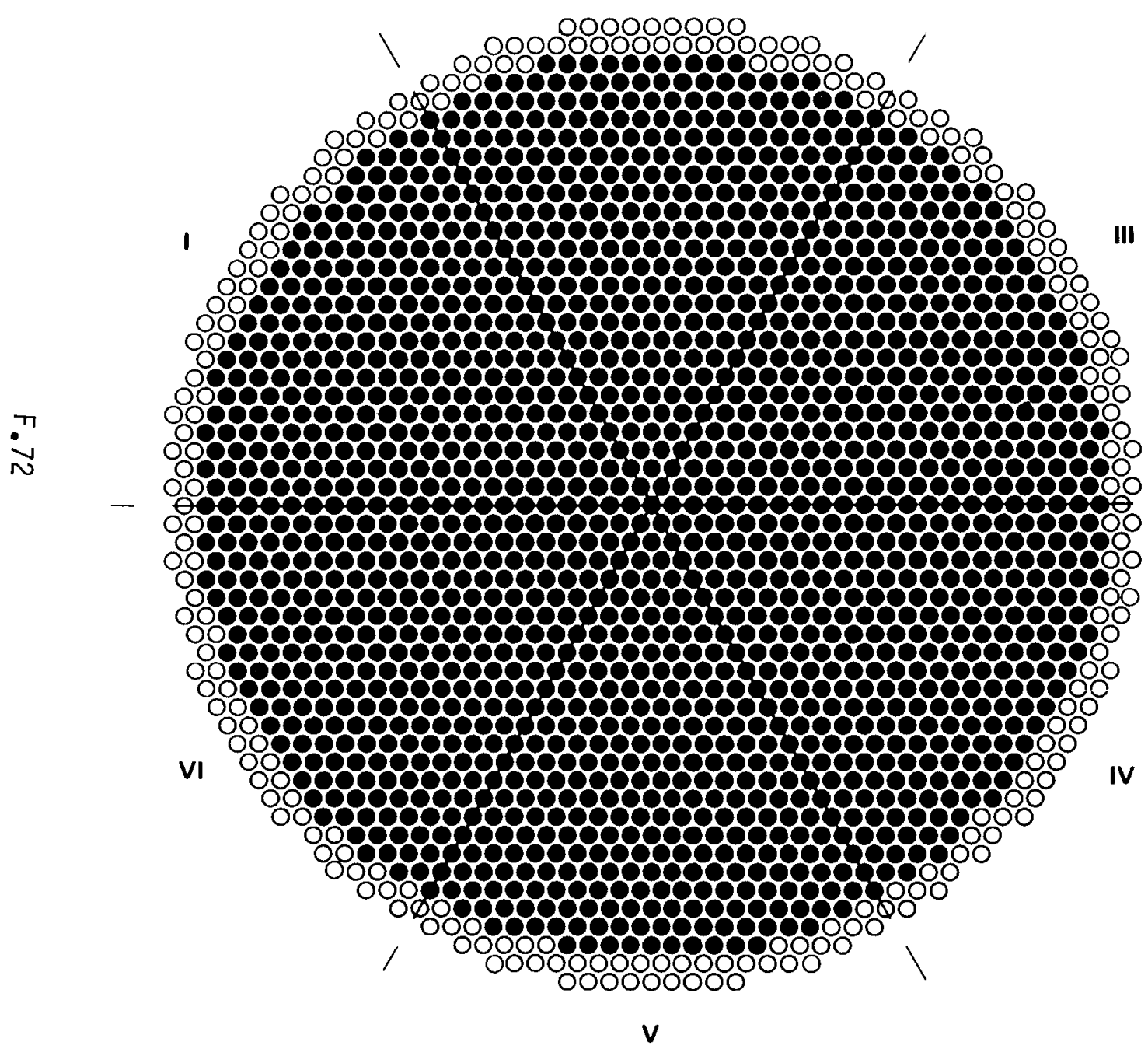

FUEL: $4.31 \mathrm{wt} \%$ $235 \mathrm{U}$ ENRICHED $\mathrm{UO}_{2}$ AND $\mathrm{PuO}_{2}-$ NATURAL $\mathrm{UO}_{2}$ CONTAINING $2.0 \mathrm{wt} \% \mathrm{PuO}_{2}$

EXPERIMENT: $4.3-000-208$

LATTICE: $32 \mathrm{M}$

PITCH: $1.598 \pm 0.005 \mathrm{~cm}$

GADOLINIUM: $0.566 \pm 0.010 \mathrm{~g} \mathrm{Gd} / \mathrm{liter}$

- CONTROL ROD: NONE

SAFETY ROD: NONE

REACTION RATES: NONE

RODS: $256 \mathrm{MO}_{2}$ RODS AT O PLUS $1657 \mathrm{UO}_{2}$ RODS AT

keff: 1.0

COMMENTS: PERIPHERAL UNUSED LATTICE LOCATIONS NOT SHOWN. 


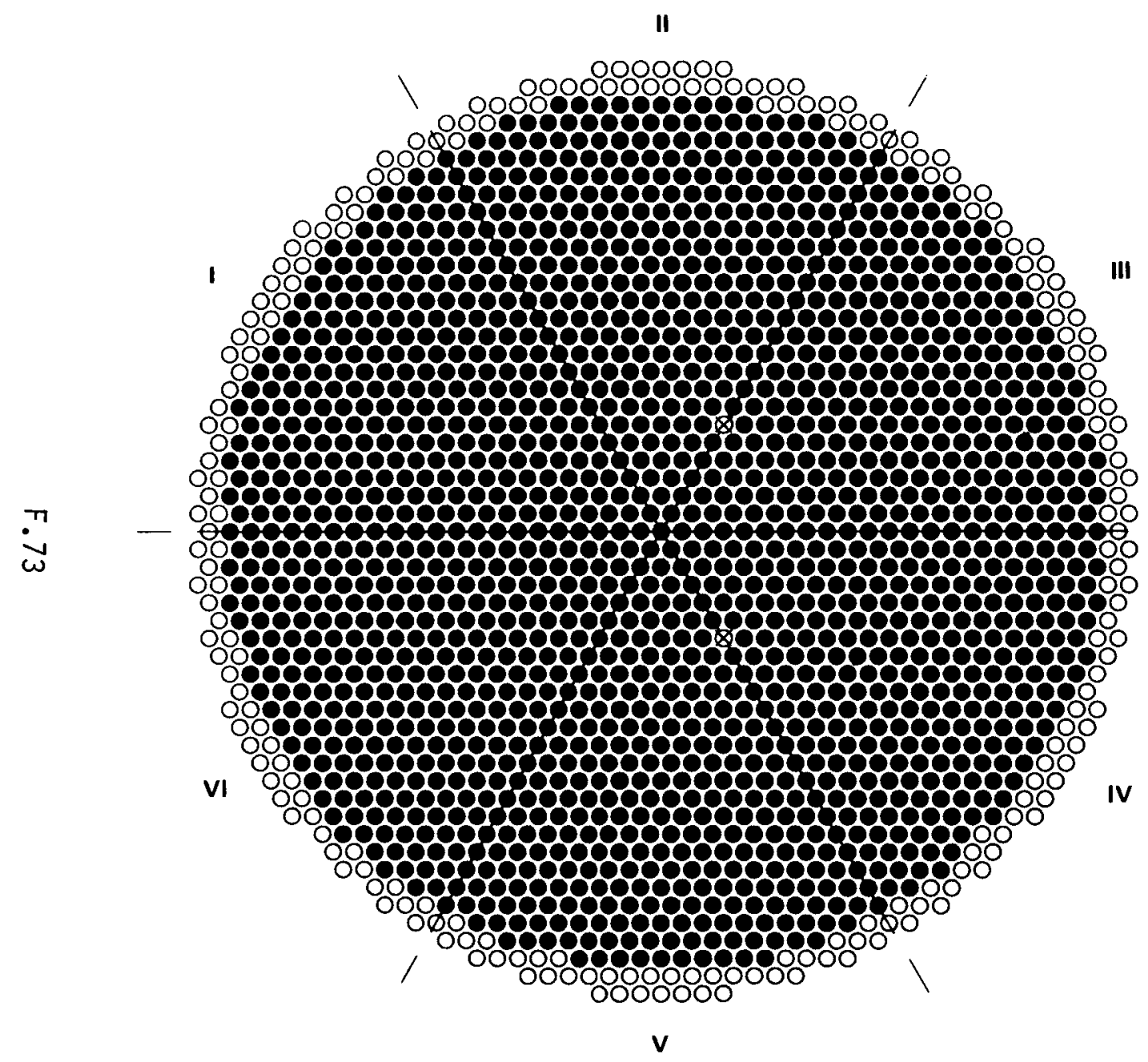

FUEL: $4.31 \mathrm{wt} \%{ }^{235} \mathrm{U}$ ENRICHED $\mathrm{OO}_{2}$ AND PUO $_{2}$ NATURAL $\mathrm{UO}_{2}$ CONTAINING $2.0 \mathrm{wt} \% \mathrm{PuO}_{2}$

EXPERIMENT: $4.3-000-208 \mathrm{~A}$

LATTICE: $32 \mathrm{M}$

PITCH: $1.598 \pm 0.005 \mathrm{~cm}$

GADOLINIUM: $0.566 \pm 0.010 \mathrm{~g} \mathrm{Gd} / \mathrm{liter}$

- CONTROL ROD: OUT

SAFETY ROD: OUT

REACTION RATES: NONE

RODS: $237 \mathrm{MO}_{2}$ RODS AT O PLUS $1655 \mathrm{UO}_{2}$ RODS AT

Keff: 1.0

COMMENTS: WATER FILLED ALLIMINUM SLEEVE AT PERIPHERIAL UNUSED LATTICE LOCATIONS NOT SHOWN. 


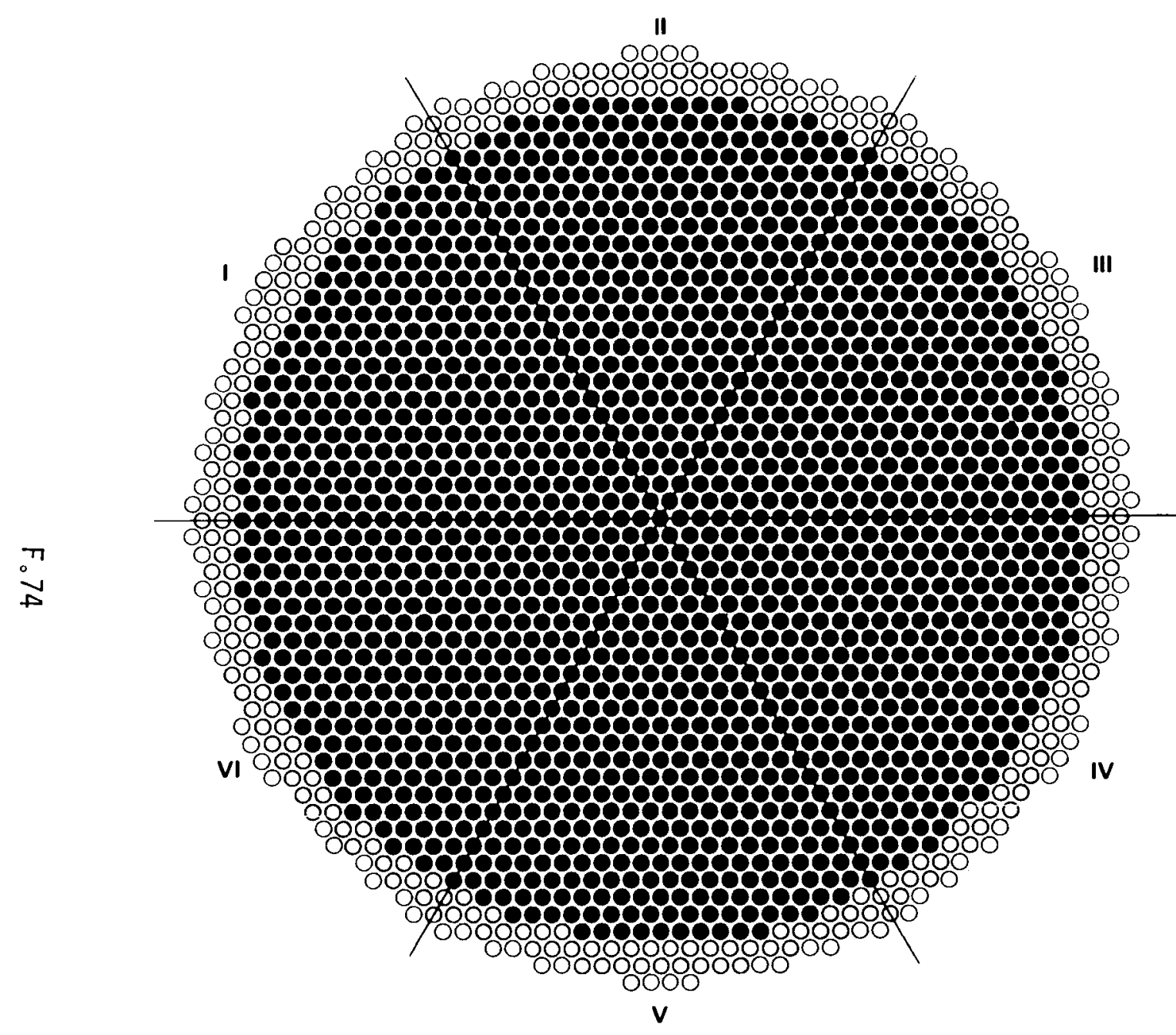

FUEL: 4.31 wt $\%$ 235U ENRICHED $\mathrm{UO}_{2}$ AND $\mathrm{PuO}_{2}$ NATURAL $\mathrm{UO}_{2}$ CONTAINING 2.0 wt $\% \mathrm{PuO}_{2}$

EXPERIMENT: 4.3-000-209

LATTICE: 32M

PITCH: $1.598 \pm 0.005 \mathrm{~cm}$

GADOLINIUM: SEE COMMENTS

CONTROL ROD: NONE

SAFETY ROD: NONE

REACTION RATES: NONE

RODS: $349 \mathrm{MO}_{2}$ RODS AT O PLUS $1657 \mathrm{UO}_{2}$ RODS AT

keff: SEE COMMENTS

COMMENTS

$k_{\text {eff }}=1.0 \quad$ AT $0.673+0.001$

$k_{\text {eff }}=0.996$ AT $0.760 \pm 0.001$

$k_{\text {eff }}=0.970$ AT $1.371 \pm 0.001$

$k_{\text {eff }}=0.937$ AT $2.362 \pm 0.002$

PERIPHERAL UNUSED LATTICE

LOCATIONS NOT SHOWN. 


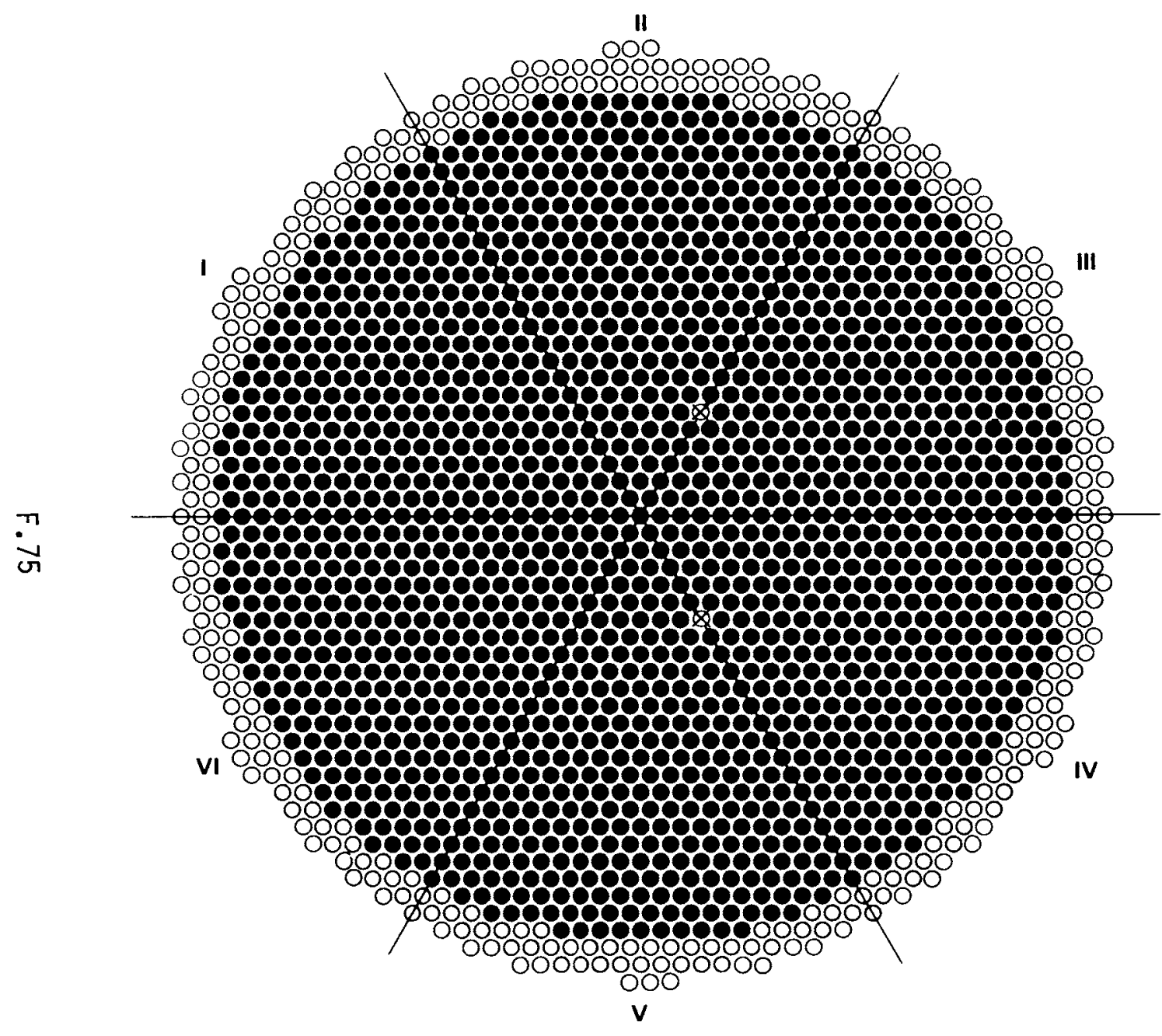

FUEL: $4.31 \mathrm{wt} \%{ }^{235} \mathrm{U}$ ENRICHED UO ${ }_{2}$ AND $\mathrm{PuO}_{2}$ NATURAL $\mathrm{UO}_{2}$ CONTAINING $2.0 \mathrm{wt} \% \mathrm{PuO}_{2}$

EXPERIMENT: 4.3-000-209A

LATTICE: $32 \mathrm{M}$

PITCH: $1.598 \pm 0.005 \mathrm{~cm}$

GADOLINIUM: $0.673 \pm 0.001 \mathrm{~g} \mathrm{Gd} / \mathrm{liter}$

CONTROL ROD: OUT

SAFETY ROD: OUT

REACTION RATES: NONE

RODS: $330 \mathrm{MO}_{2}$ RODS AT O PLUS $1655 \mathrm{UO}_{2}$ RODS AT

Keff: 1.0

COMMENTS: WATER FILLED ALLIMINUM SLEEVE AT . PERIPHERIAL UNUSED LATTICE LOCATIONS NOT SHOWN. 


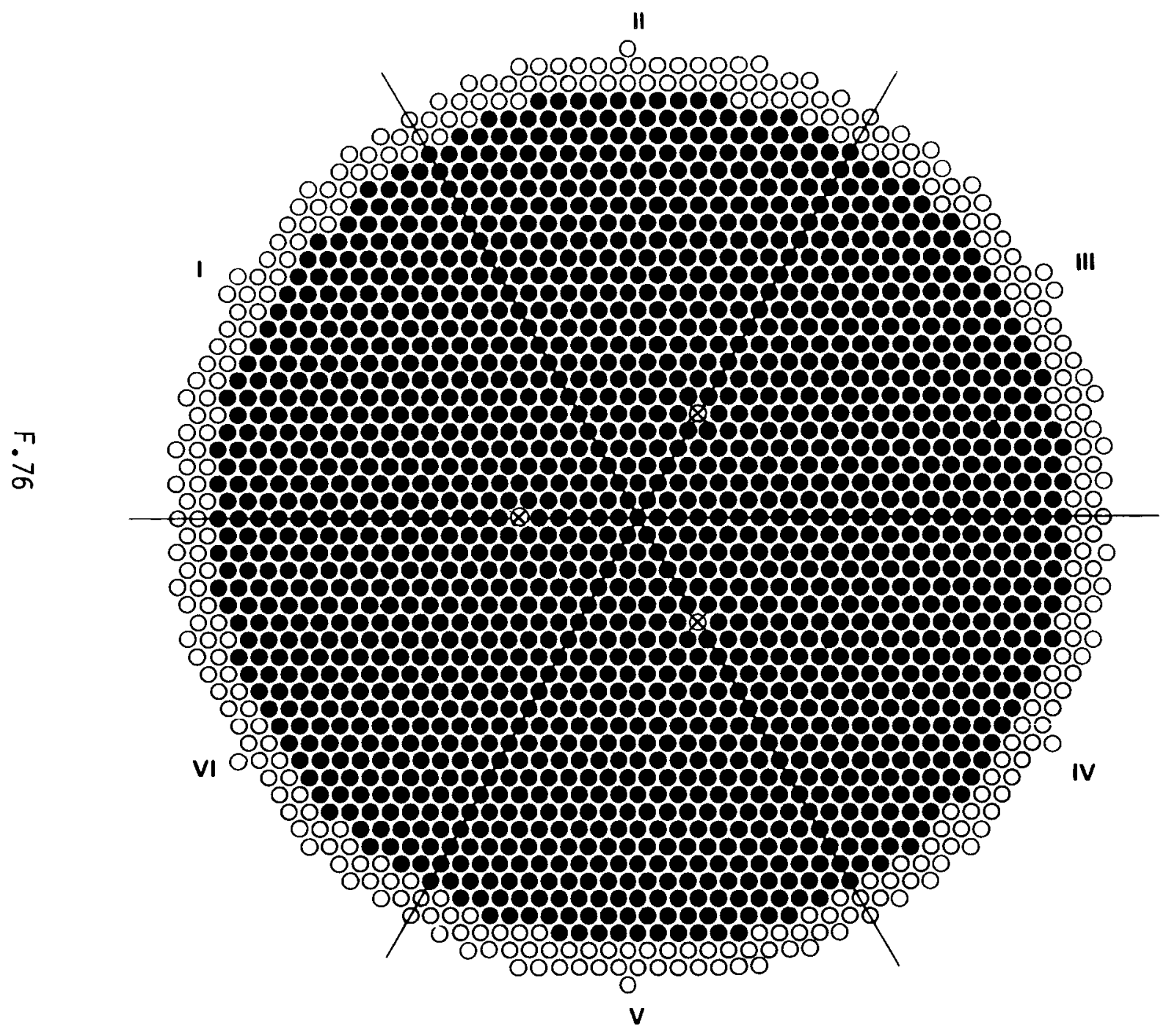

FUEL: $4.31 \mathrm{wt} \%{ }^{235} \mathrm{U}$ ENRICHED $\mathrm{UO}_{2}{\text { AND } \mathrm{PuO}_{2}}^{-}$
NATURAL UO ${ }_{2}$ CONTAINING $2.0 \mathrm{wt} \% \mathrm{PuO}_{2}$ EXPERIMENT: 4.3-000-209B

LATTICE: $32 \mathrm{M}$

PITCH: $1.598 \pm 0.005 \mathrm{~cm}$

GADOLINIUM: $0.673 \pm 0.001 \mathrm{~g} \mathrm{Gd/liter}$

CONTROL ROD: OUT

SAFETY ROD: OUT

REACTION RATES: NONE

RODS: $320 \mathrm{MO}_{2}$ RODS AT O PLUS $1655 \mathrm{UO}_{2}$ RODS AT •

keff: 1.0

COMMENTS: WATER FILLED ALUMINUM SLEEVE AT . PERIPHERIAL UNUSED LATTICE 'LOCATIONS NOT SHOWN. 


\section{APPENDIX G}

Computerized Plots of Pulse Neutron Source Measurement Data 
APPENDIX G

\section{Computerized Plots of Pulse Neutron Source Measurement Data}

The observed time behavior of the neutron flux in each of the pulsed neutron source measurements is presented in this Appendix as photo-reproductions of computer plots obtained following data reduction and analys is. In each of the measurements, 511 data channels were used in accumulating and analyzing the time dependent data. Because of limited computer storage capacity, a few of the plots do not reproduce all 511 data points. All of the data have been corrected for coincidence losses. The least-square calculated fit of the data is also shown in each of the plots. The data indicated by an " $X$ " were not considered in the least-squares fitting process; however, these data were included in the (Garel is and Russell 1963) reactivity determinations. The first data channel used in the least-squares fitting is identified as start channel in the legend.

The fundamental mode and the delayed neutron plus background level, as determined by the least-squares fitting of the data, are shown as solid lines in each figure. The slope of the fundamental mode curve is tabulated in the legend of each figure as alpha in $\mathrm{sec}^{-1}$ Also included in the legend of each figure are the (Garelis-Russell (GRRHO) and the Gozani (GOZRHO) determined reactivities in dollars, the neutron background level during each measurement, the delayed neutron level as determined by the least-squares fit, and the data accumulating channel widths in microseconds.

It should be noted that some irregularity exists in the data for measurement number BNFL 11-2. The cause of the irregularity is unknown. Because of its location and the methods of data analyses the presence of the irregularity should have a minimal effect on the results. With respect to reactivity, the value determined by the (Gozani 1965) method would probably be least affected by the irregularity. 
MEASUREMENT NUMBER BNFL 11-2

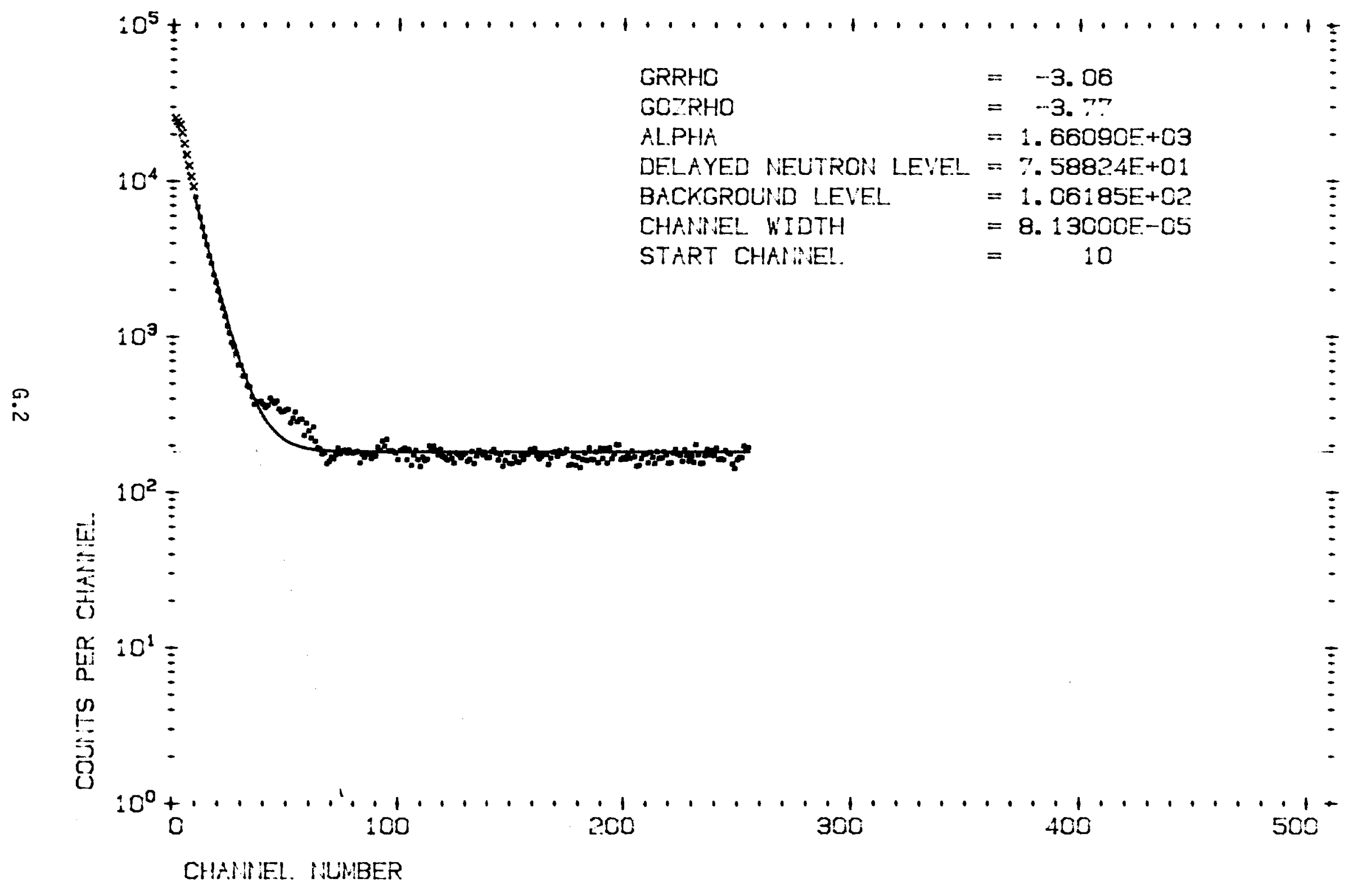


MEASUREMENT NUMBER BNFL 11-3

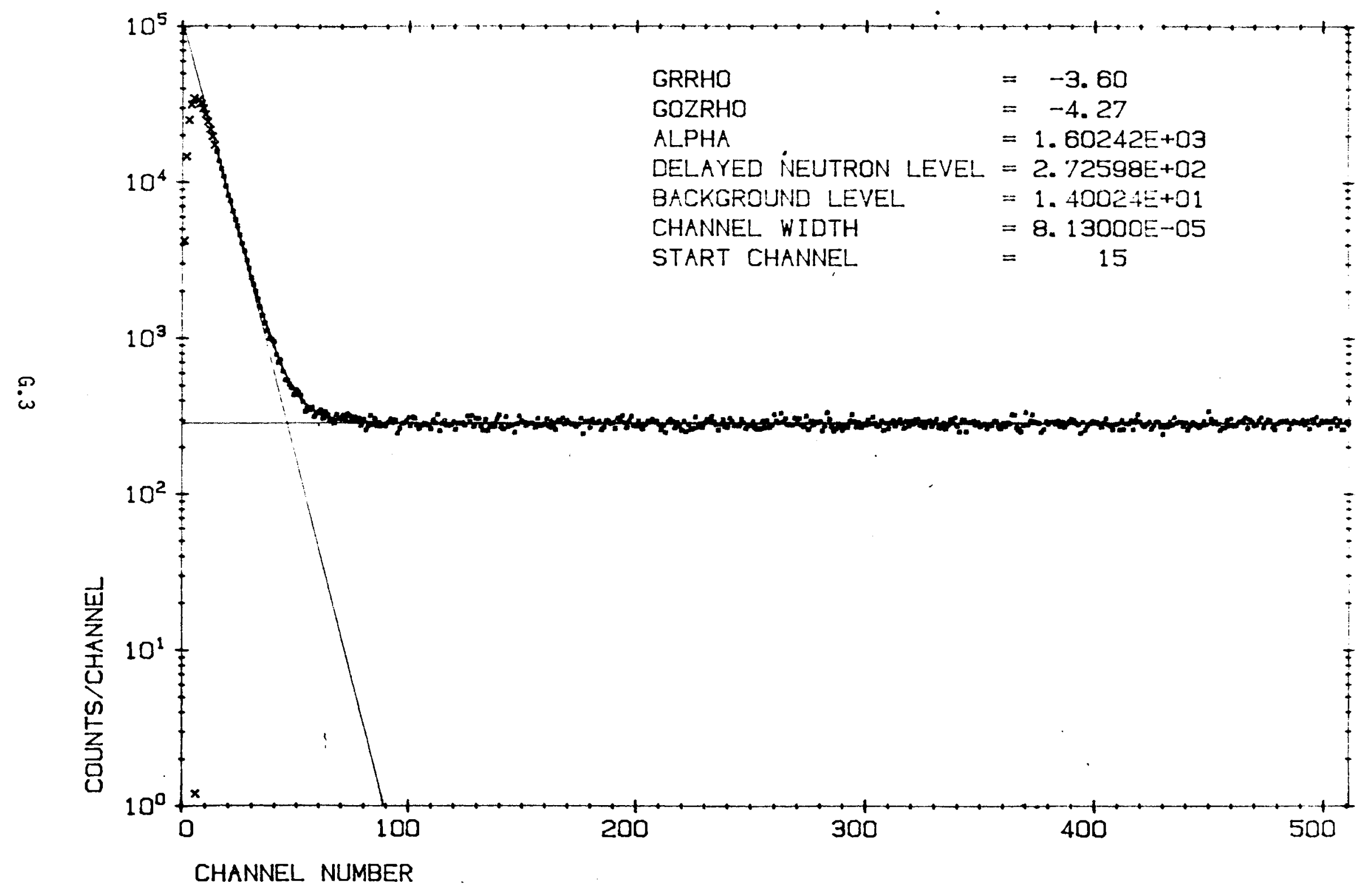


MEASUREMENT NUMBER BNFL 11-4

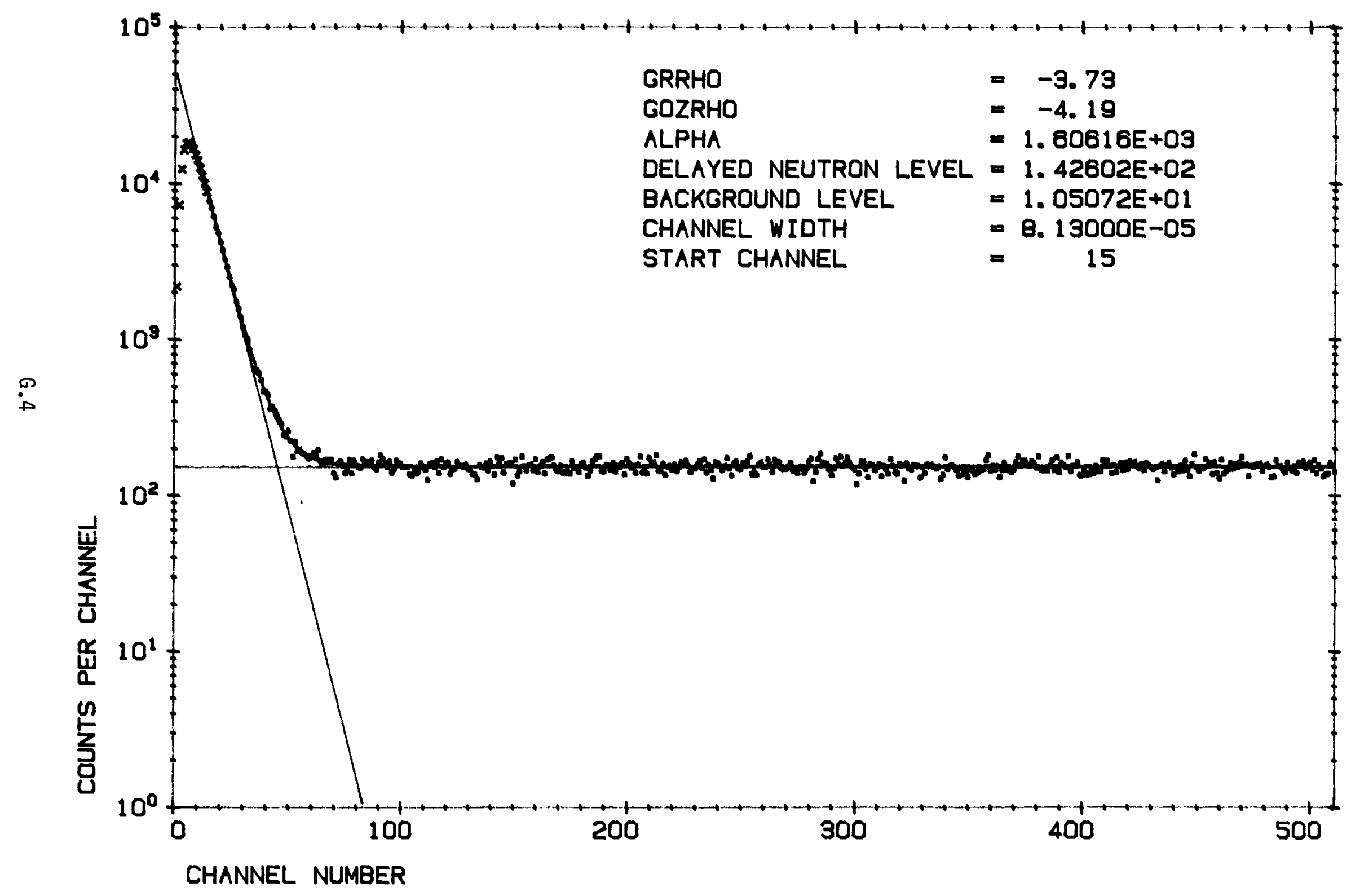


MEASUREMENT NUMBER BNFL 11-5

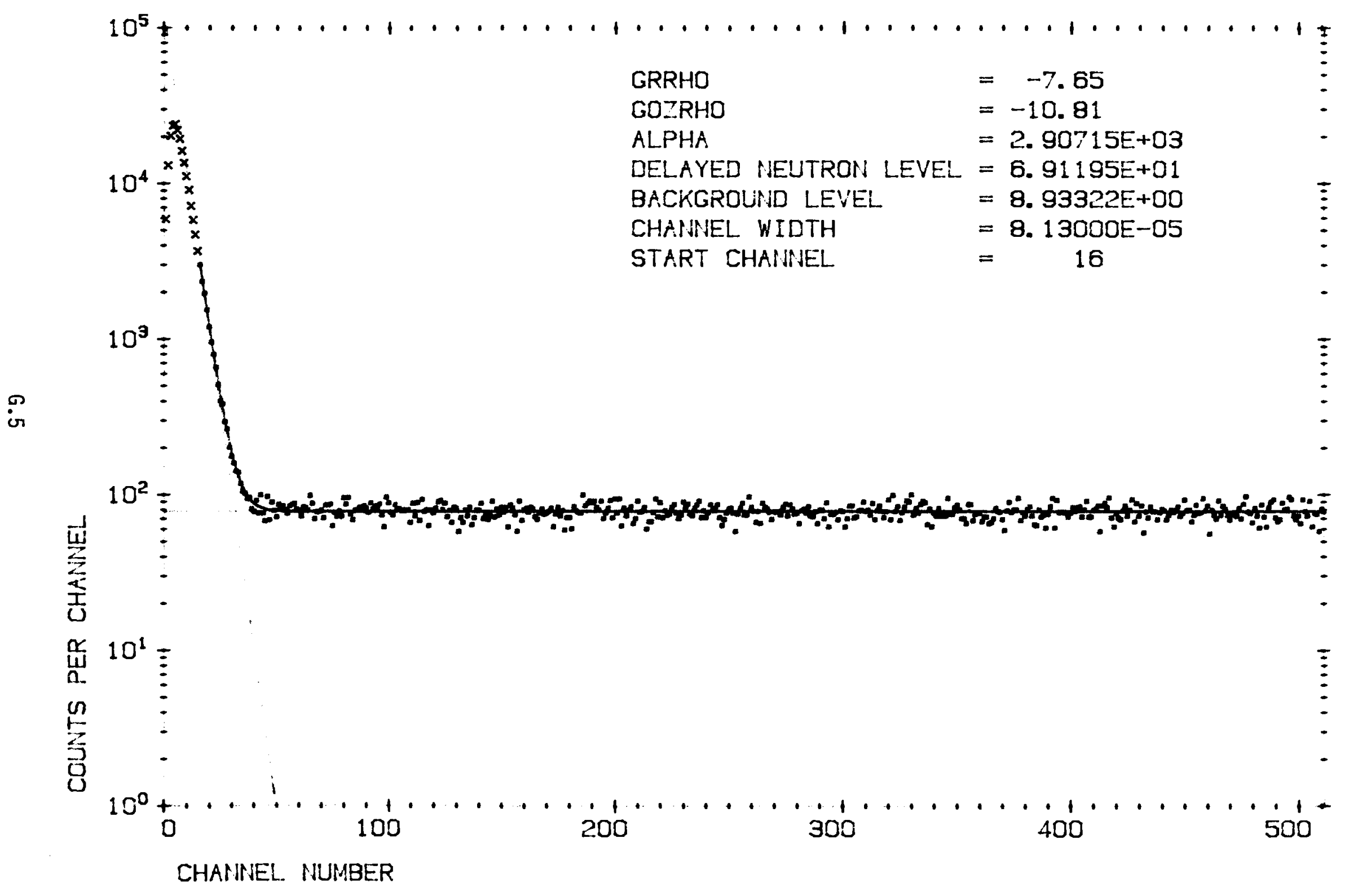


MEASUREMENT NUMBER BNFL 11-6

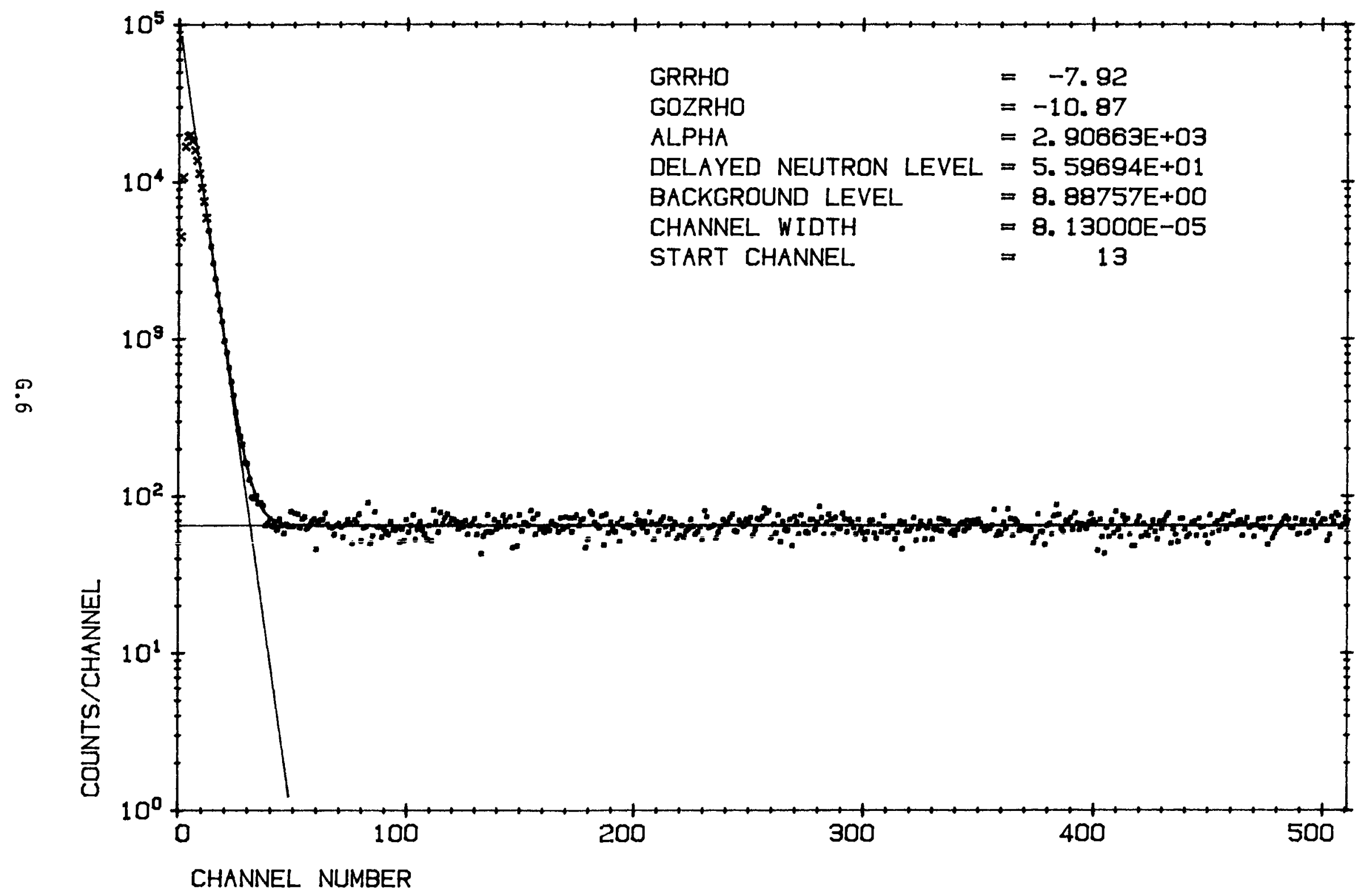


MEASUREMENT NUMBER BNFL 11-7

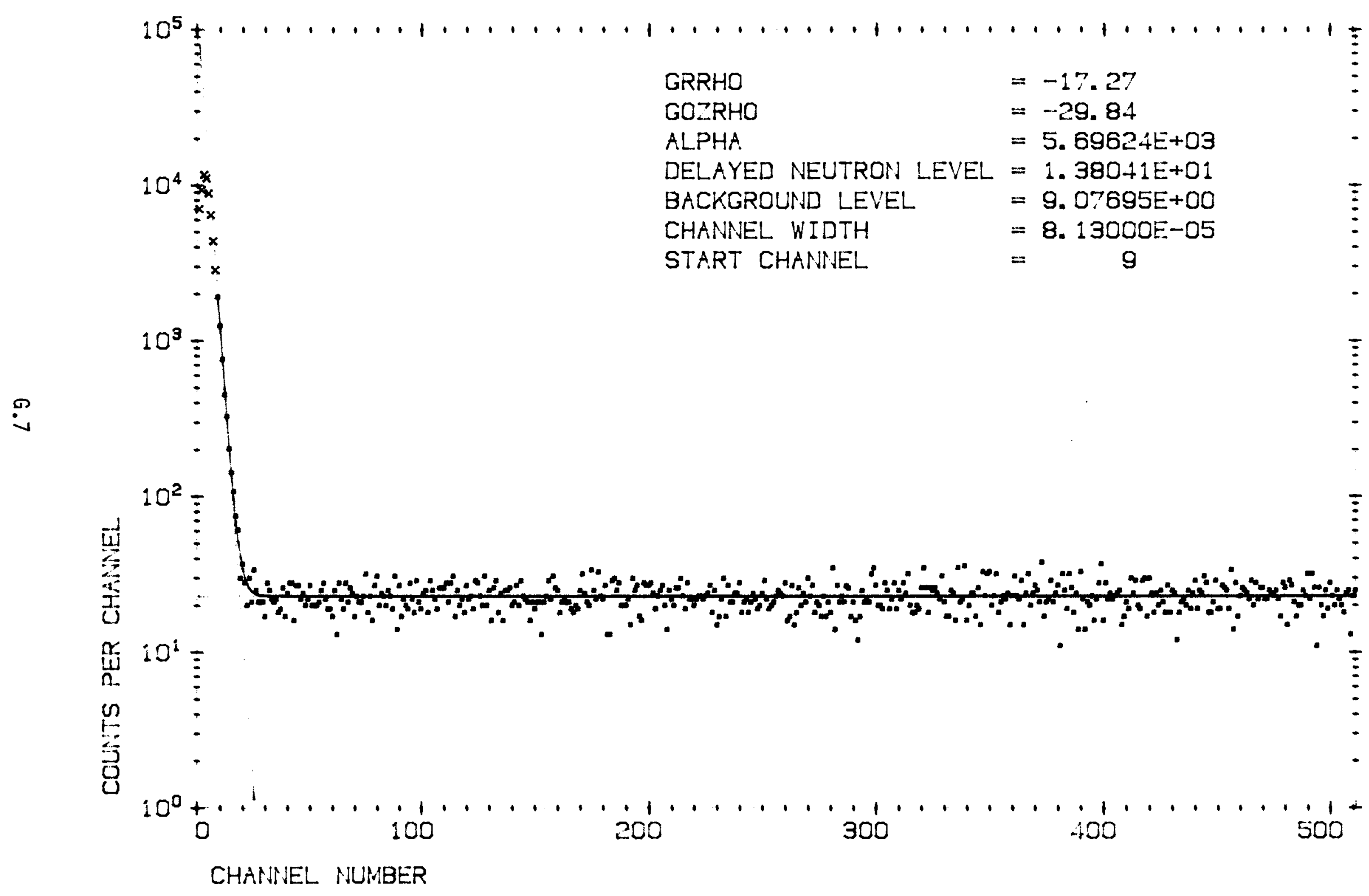


MEASUREMENT NUMBER BNFL 11-8

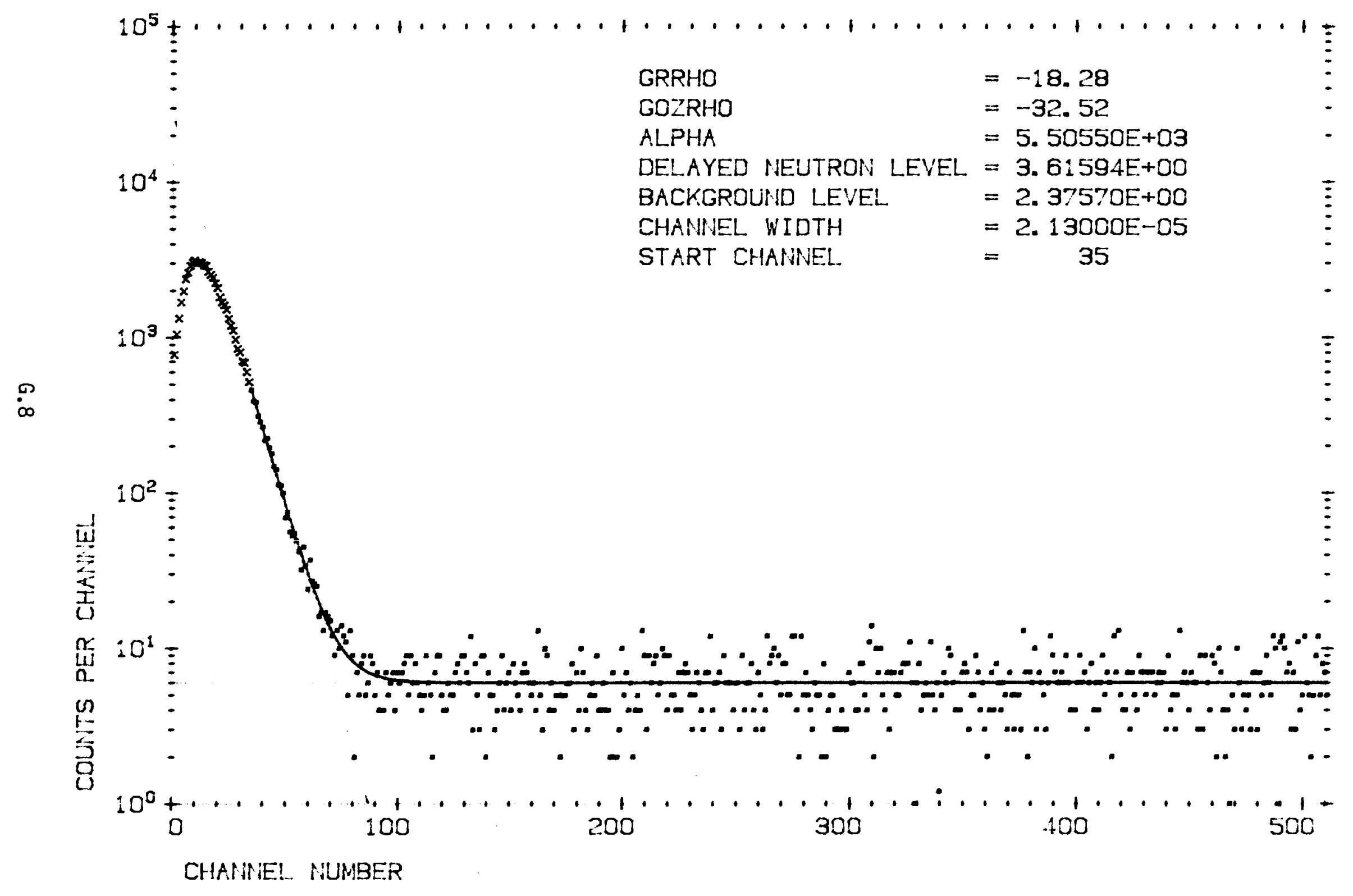


MEASUREMENT NUMBER BNFL 11-9

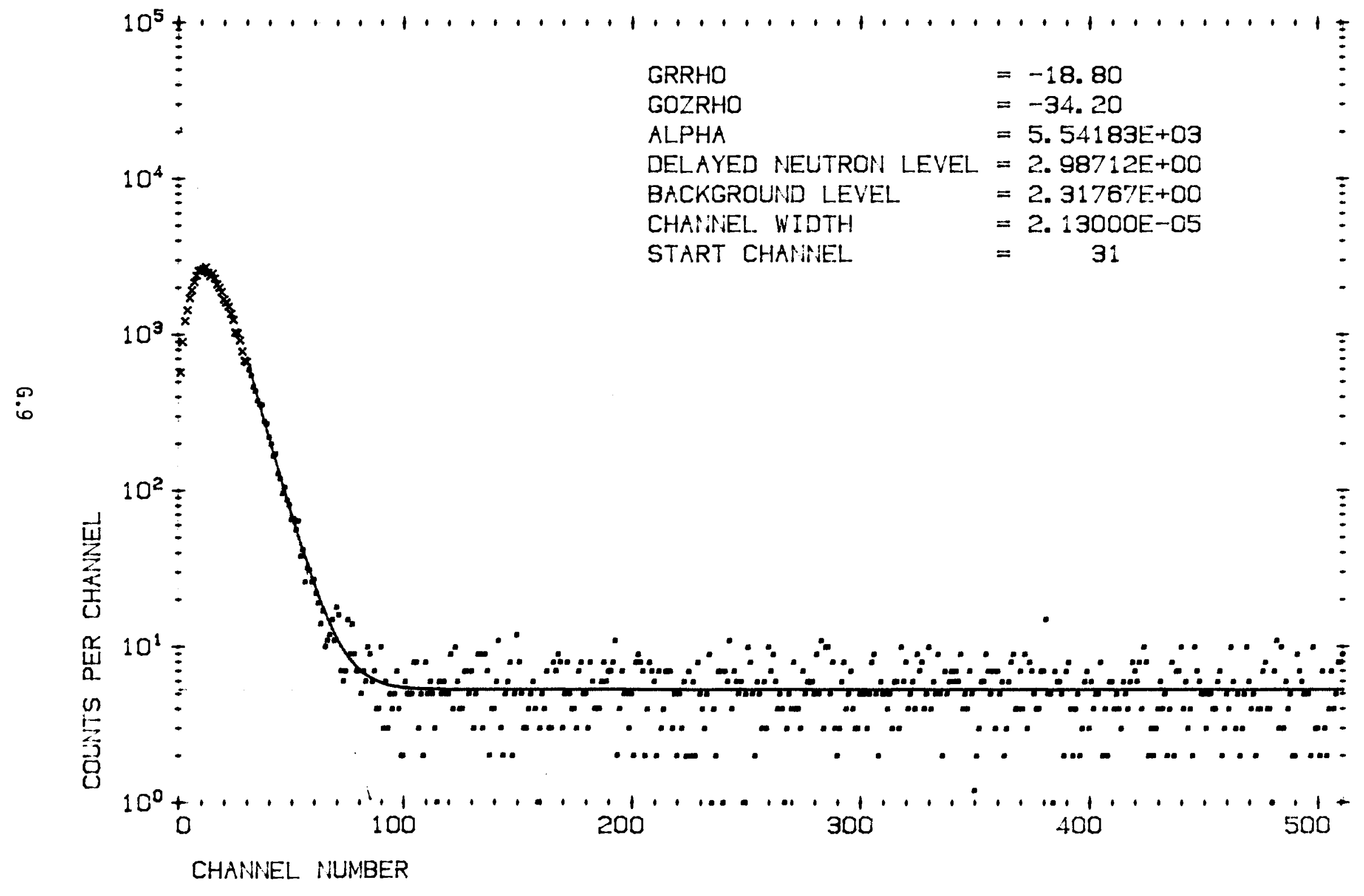


MEASUREMENT NUMBER BNFL 12-1

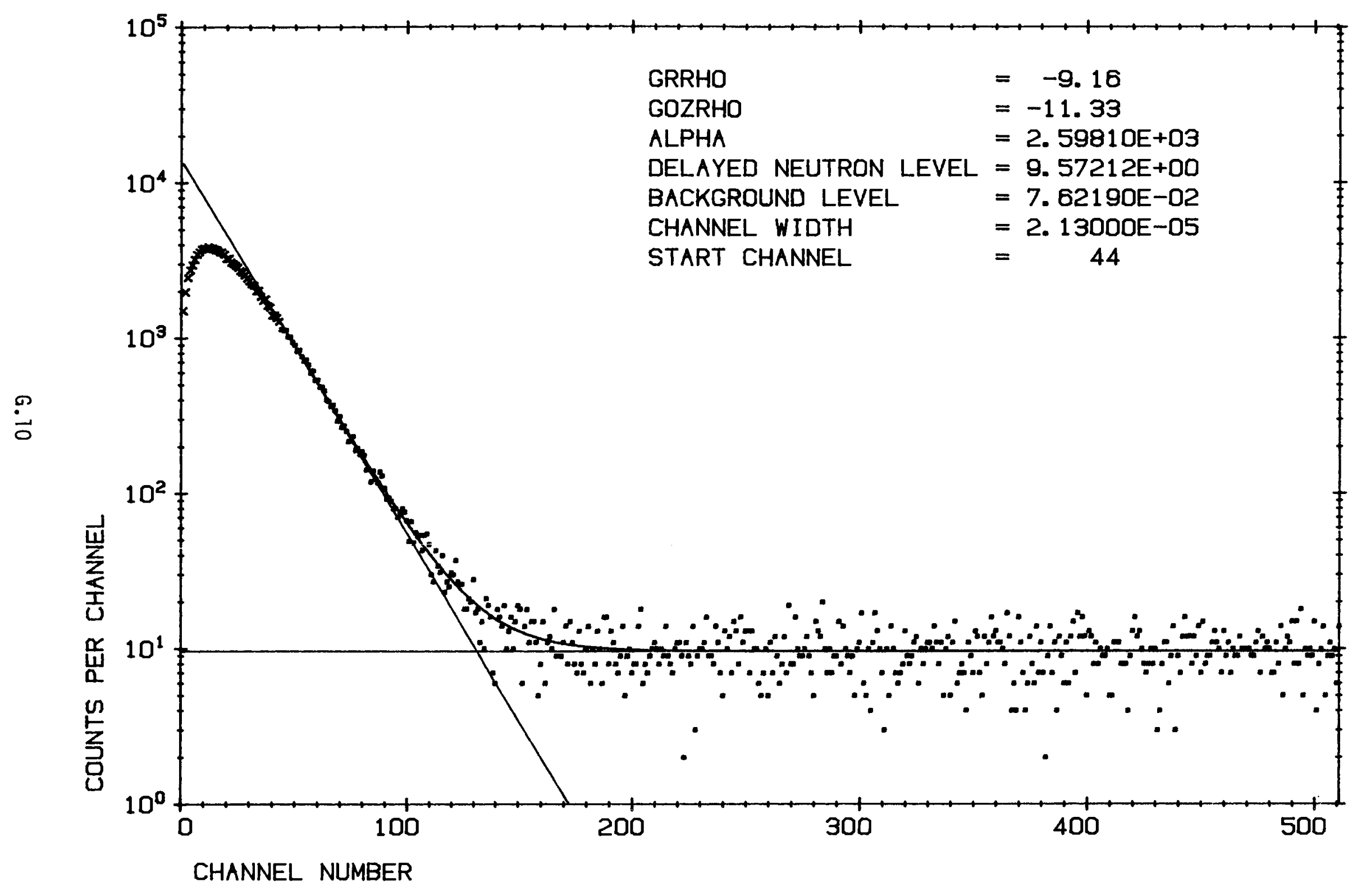


MEASUREMENT NUMBER BNFL 12-3

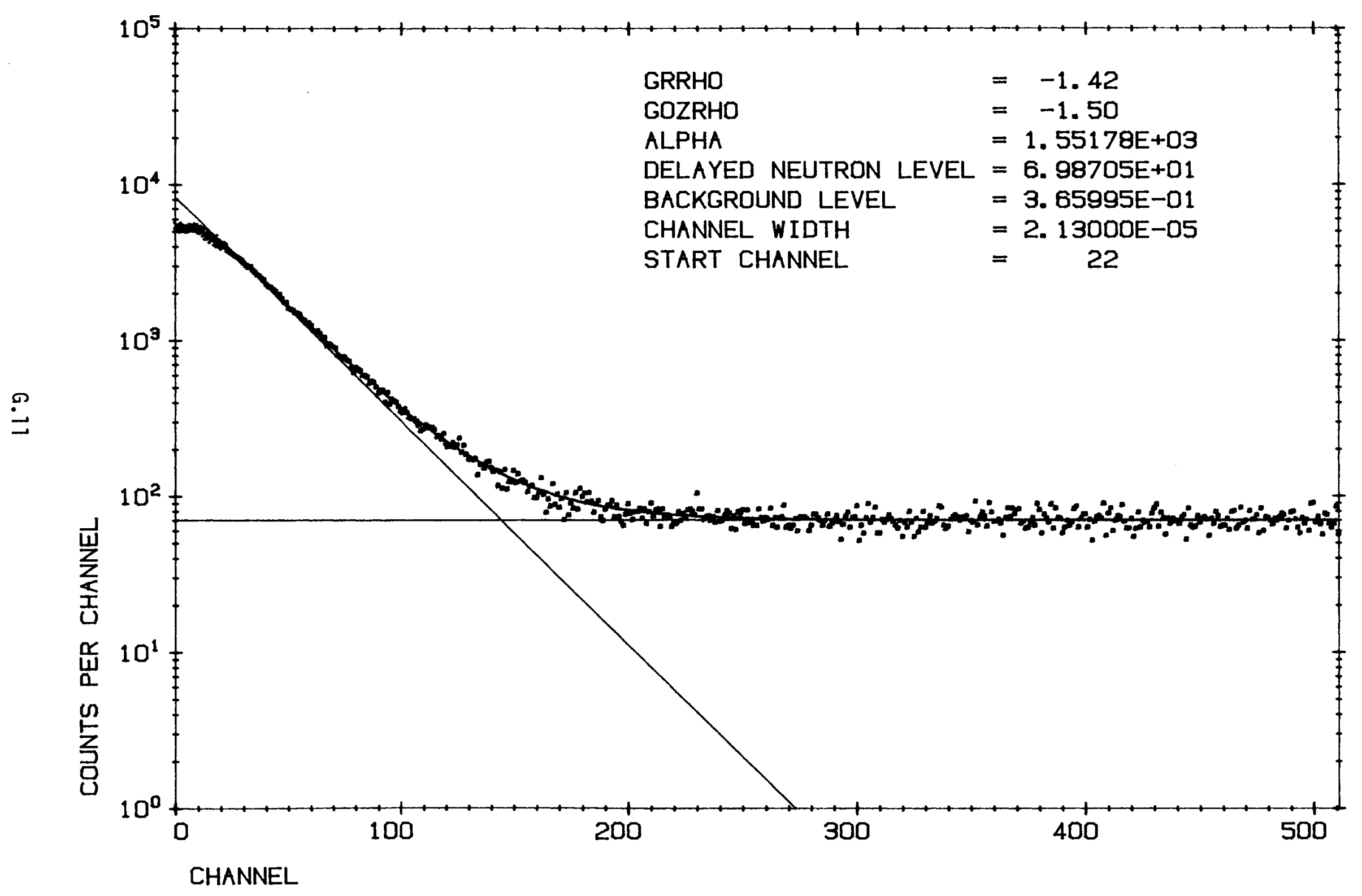


MEASUREMENT NUMBER BNFL 12-4

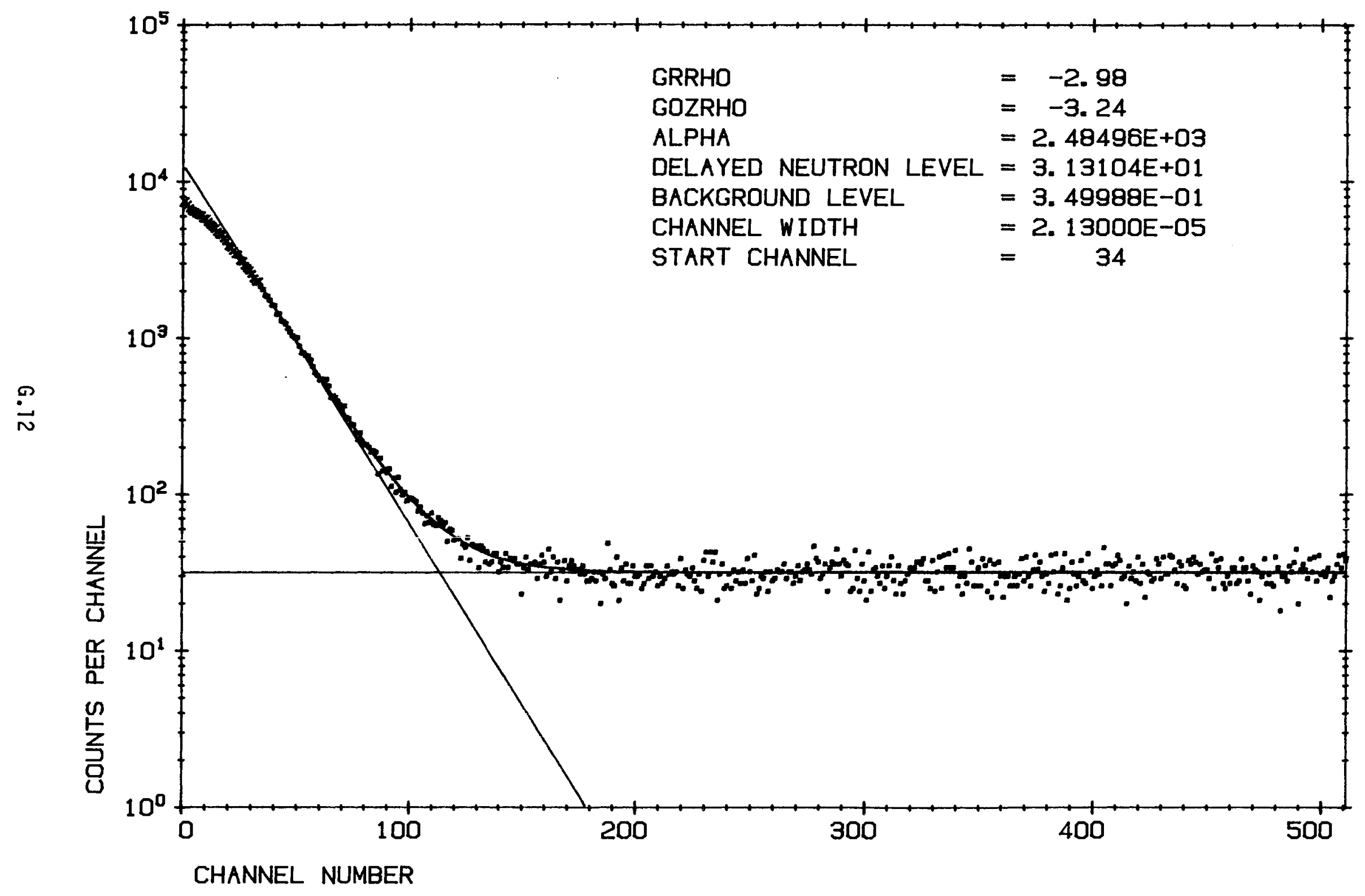


MEASUREMENT NUMBER BNFL $12-5$

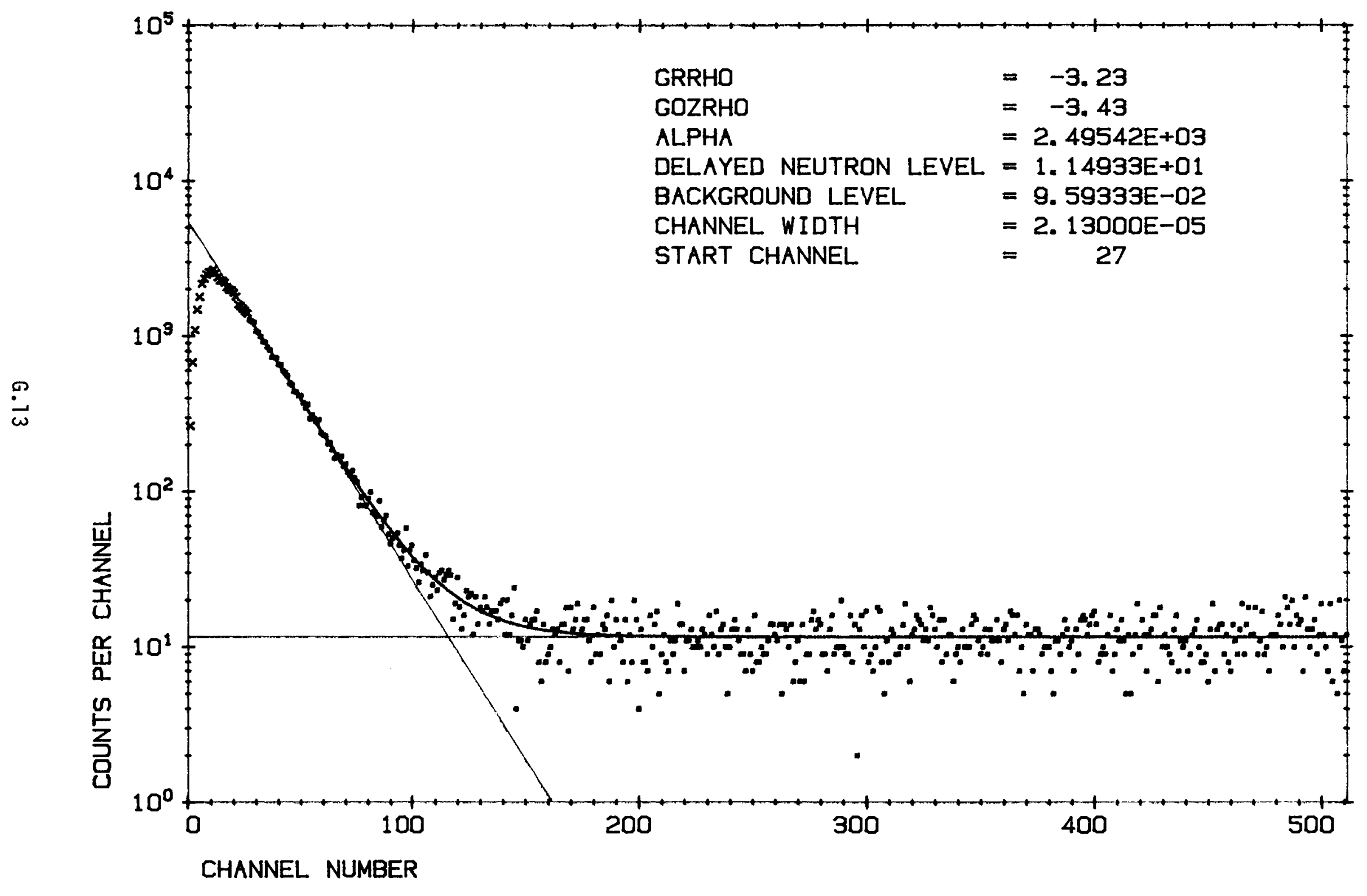


MEASUREMENT NUMBER BNFL 12-6

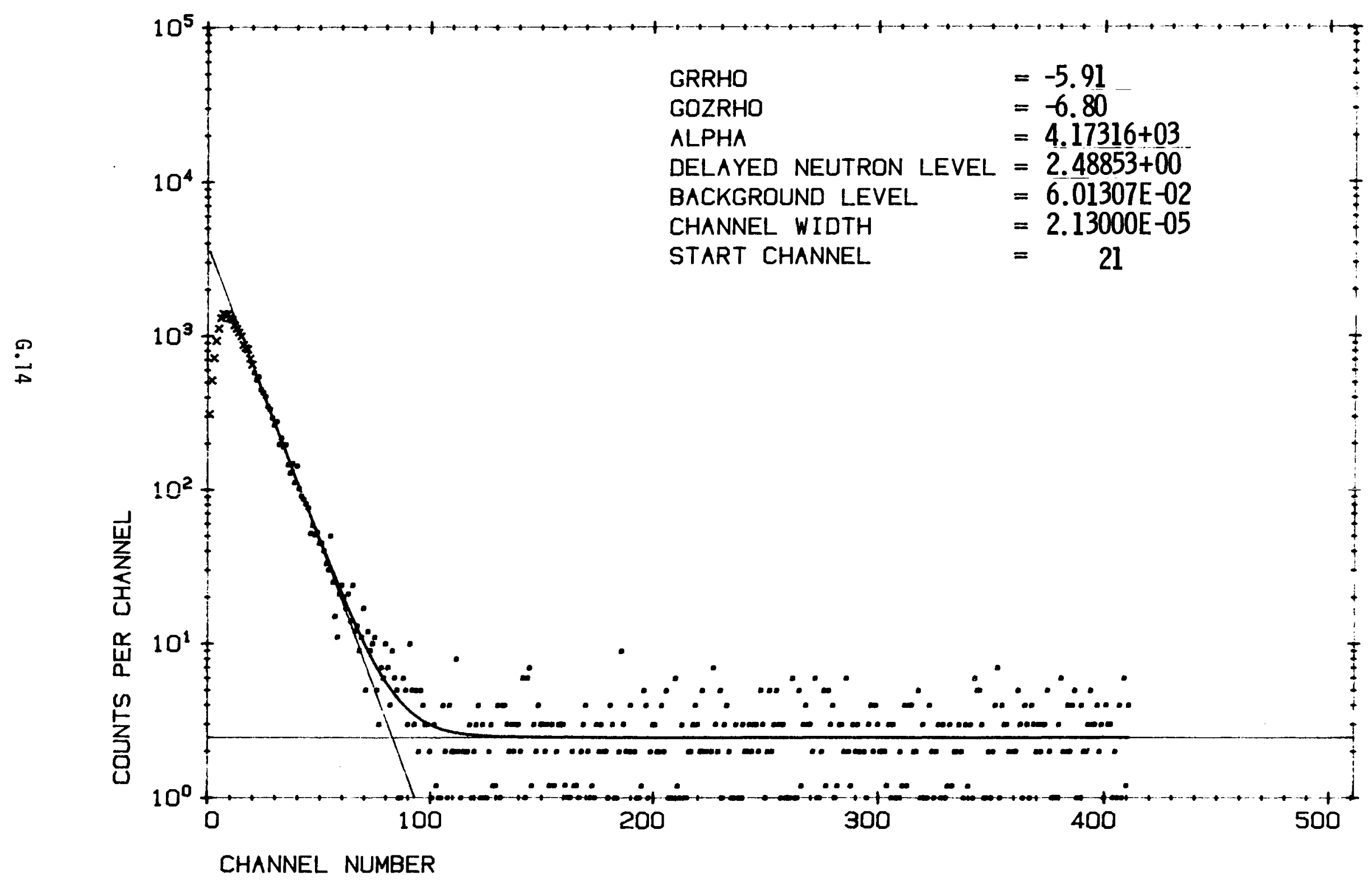


MEASUREMENT NUMBER BNFL 12-7

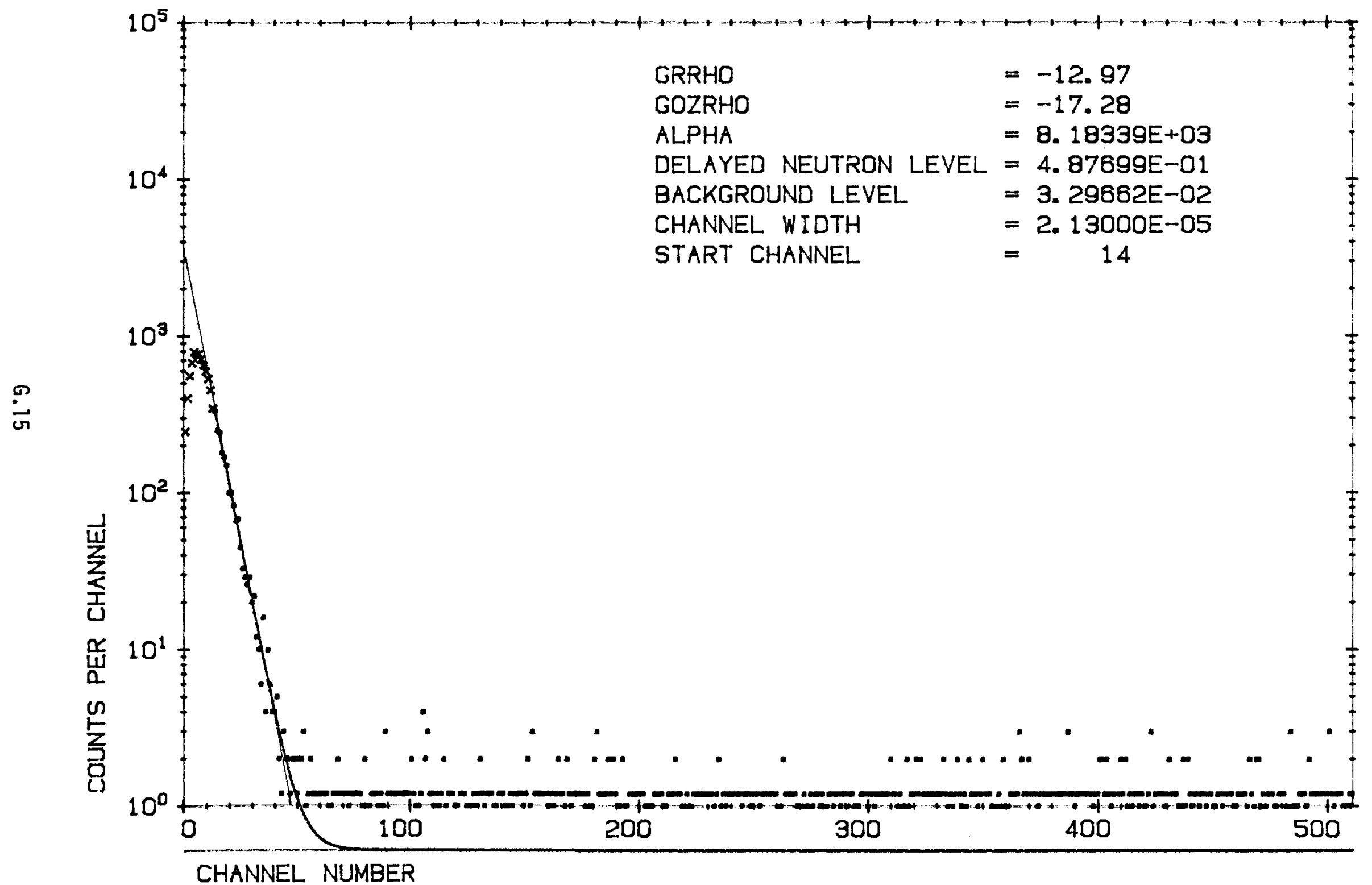


MEASUREMENT NUMBER BNFL $12-8$

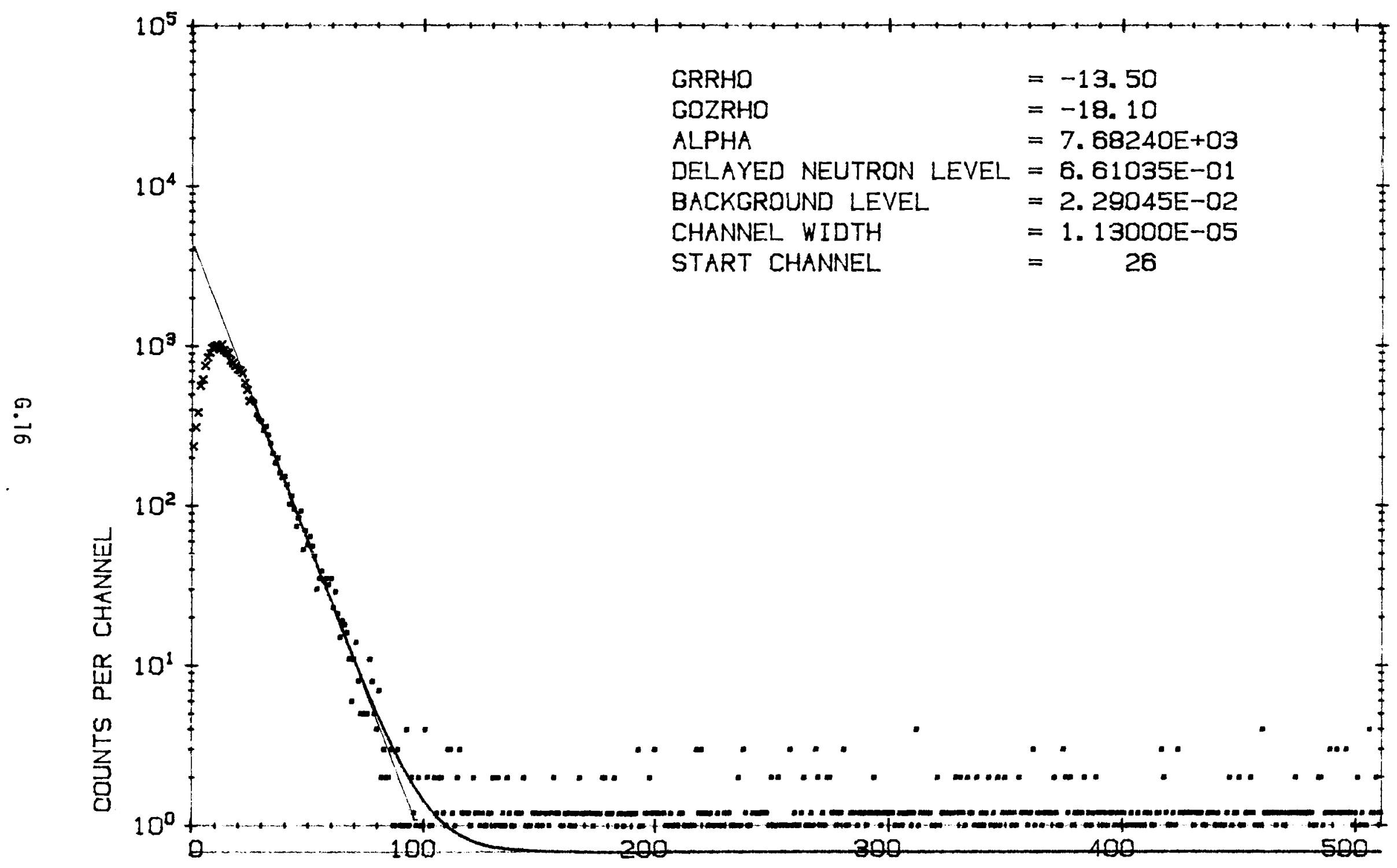

CHANNEL NUMBER 
MEASUREMENT NUMBER BNFL 13-6

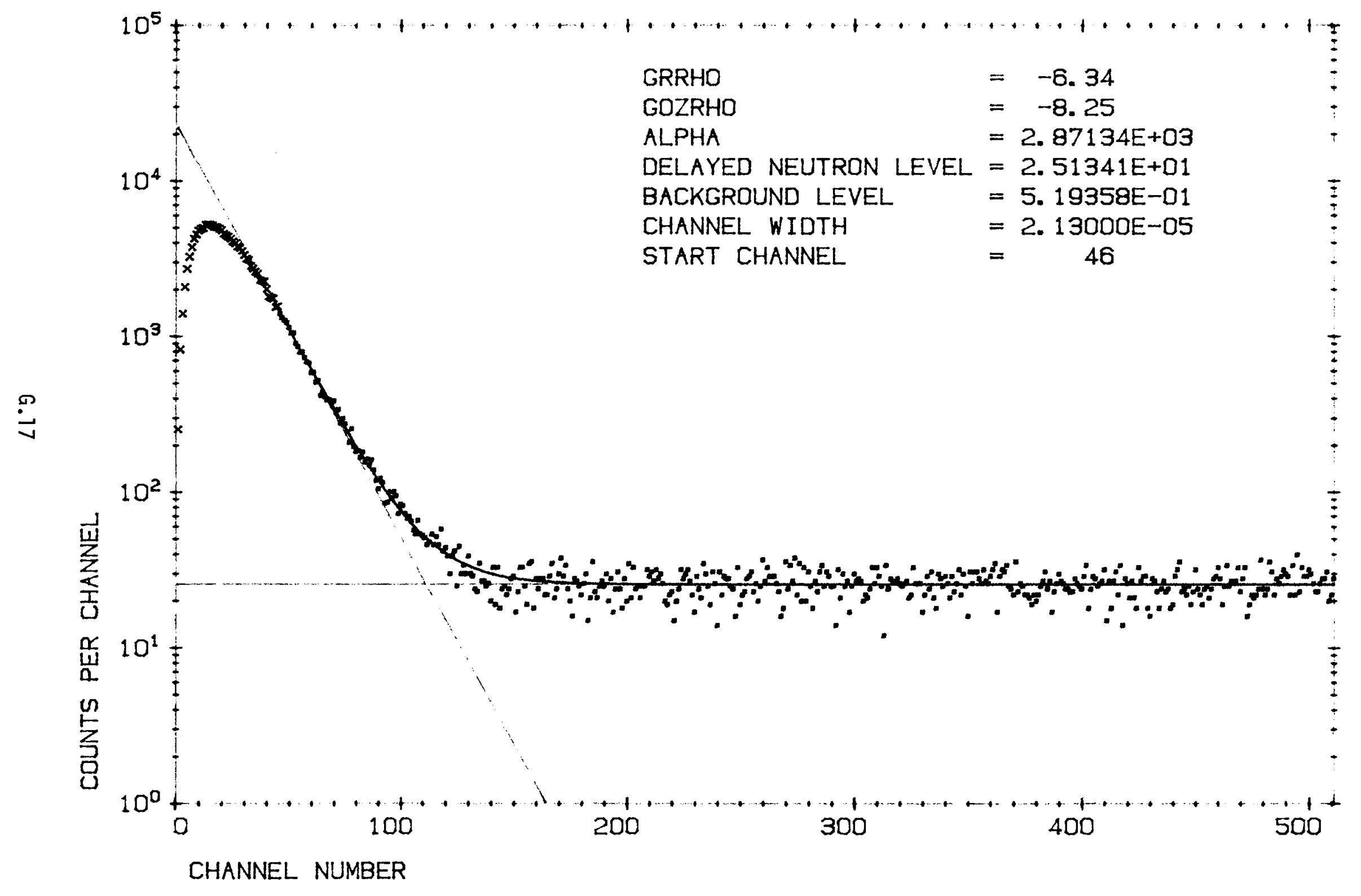


MEASUREMENT NUMBER BNFL 13-5

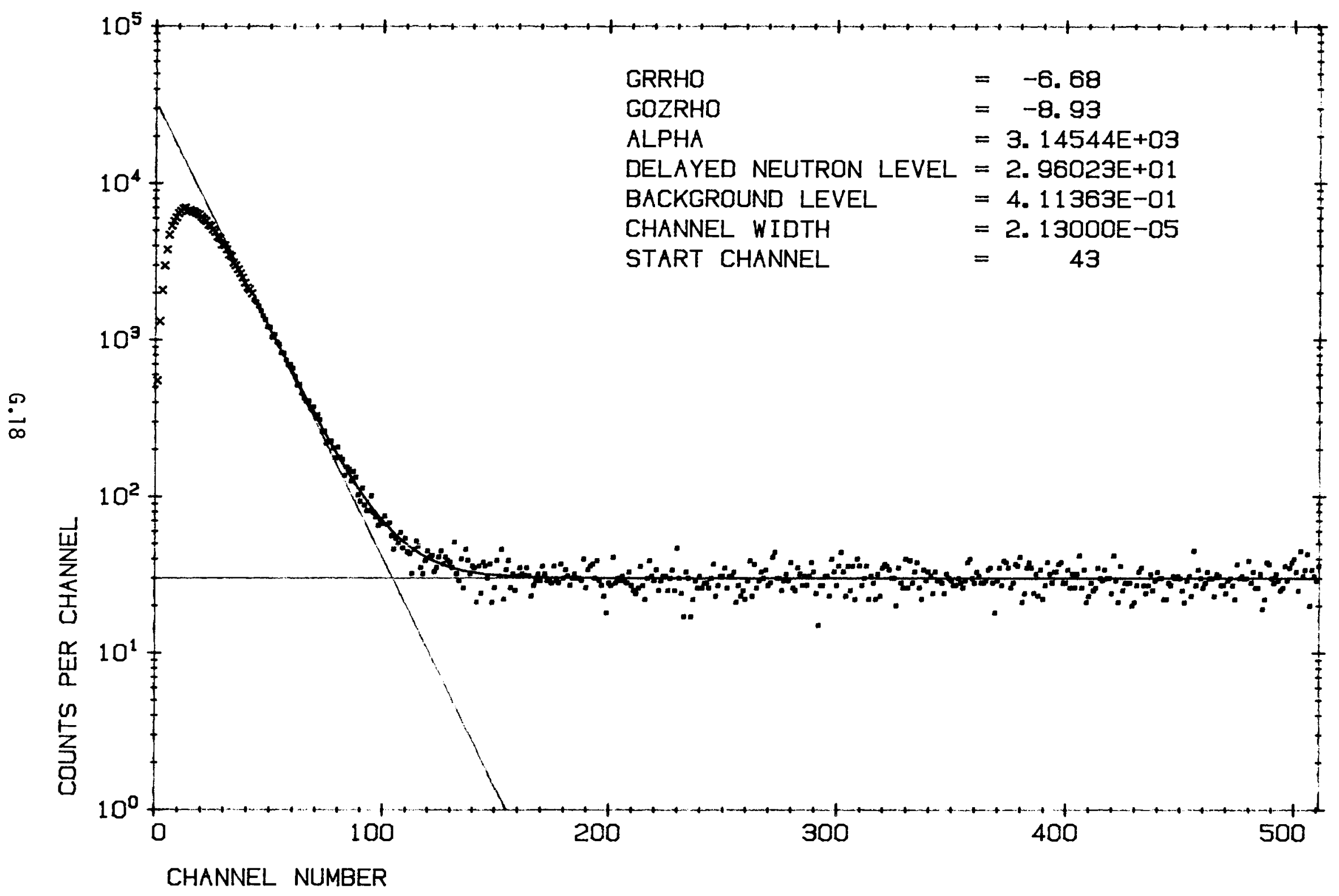


MEASUREMENT NUMBER BNFL 13-4

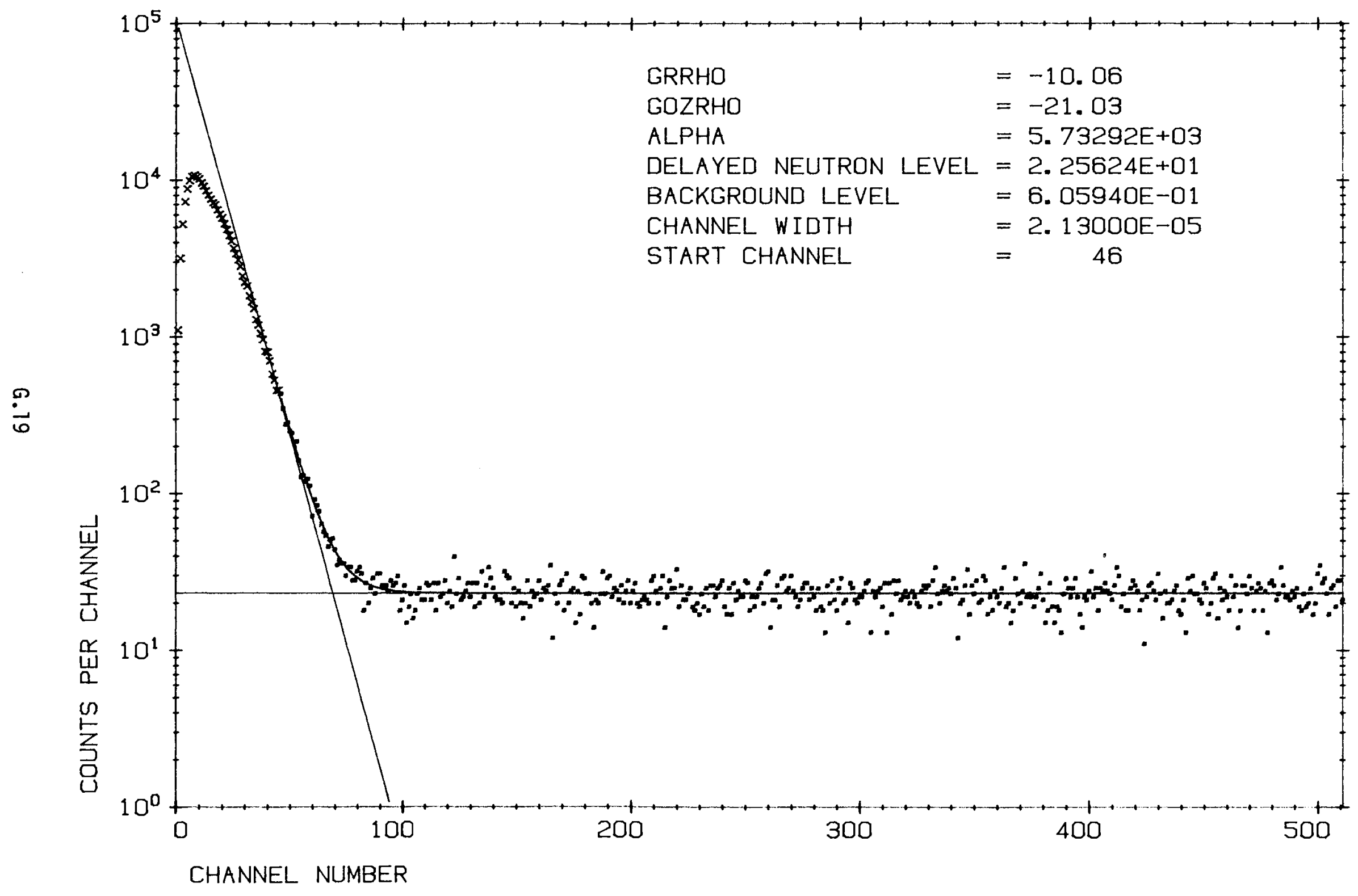


MEASUREMENT NUMBER BNFL 13-3

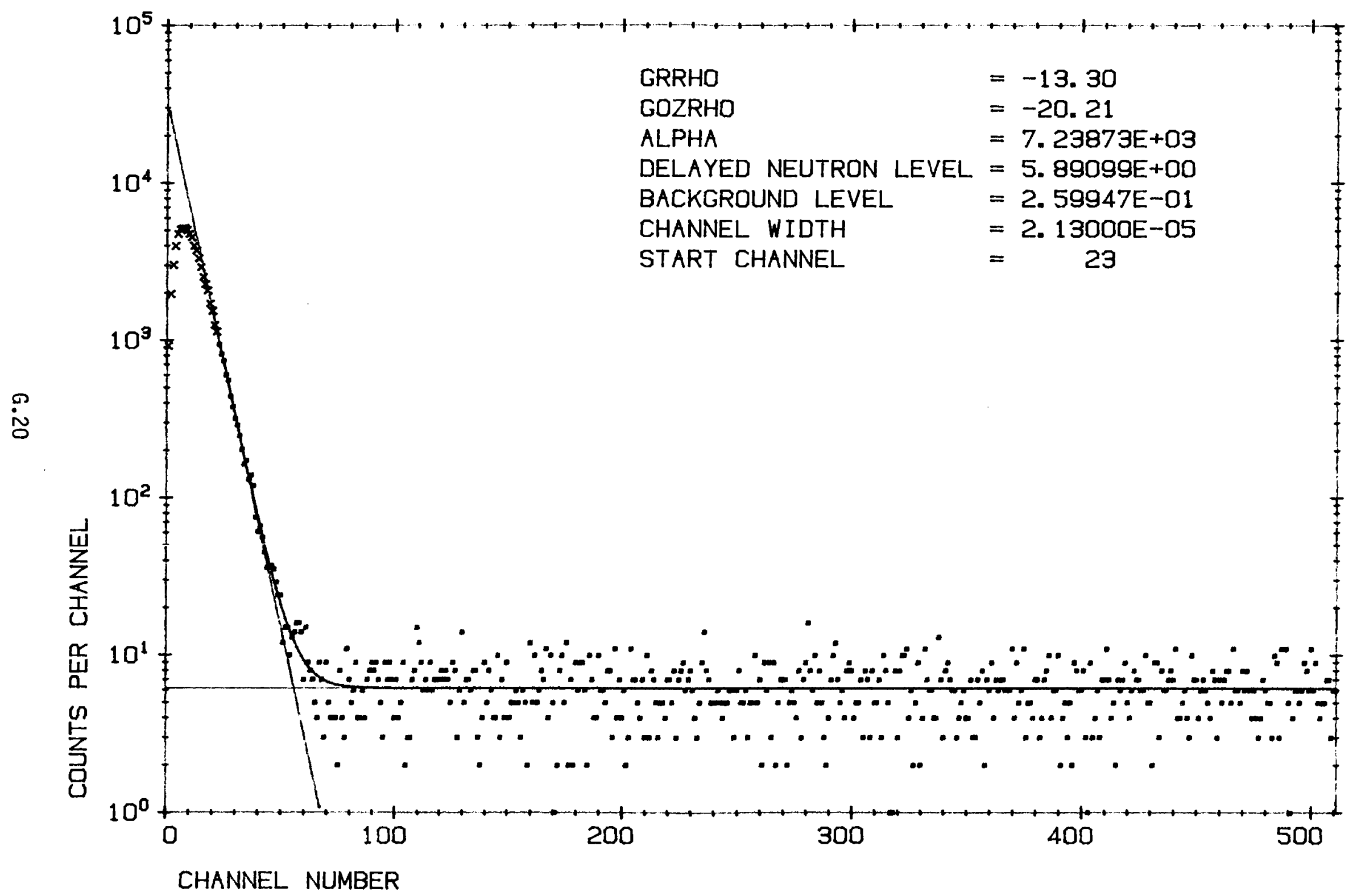


MEASUREMENT NUMBER BNFL 13-2

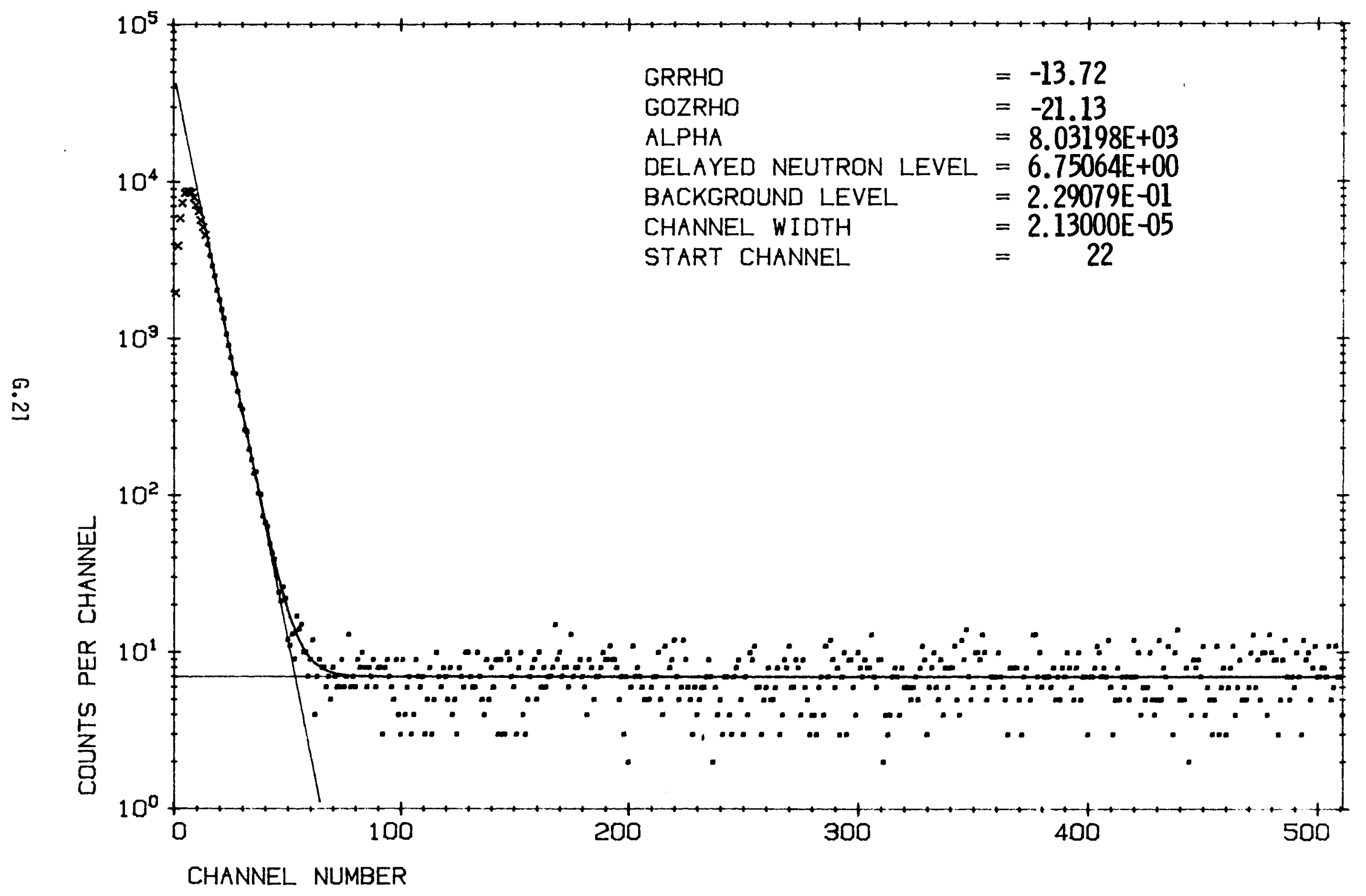


MEASUREMENT NUMBER BNFL 13-1

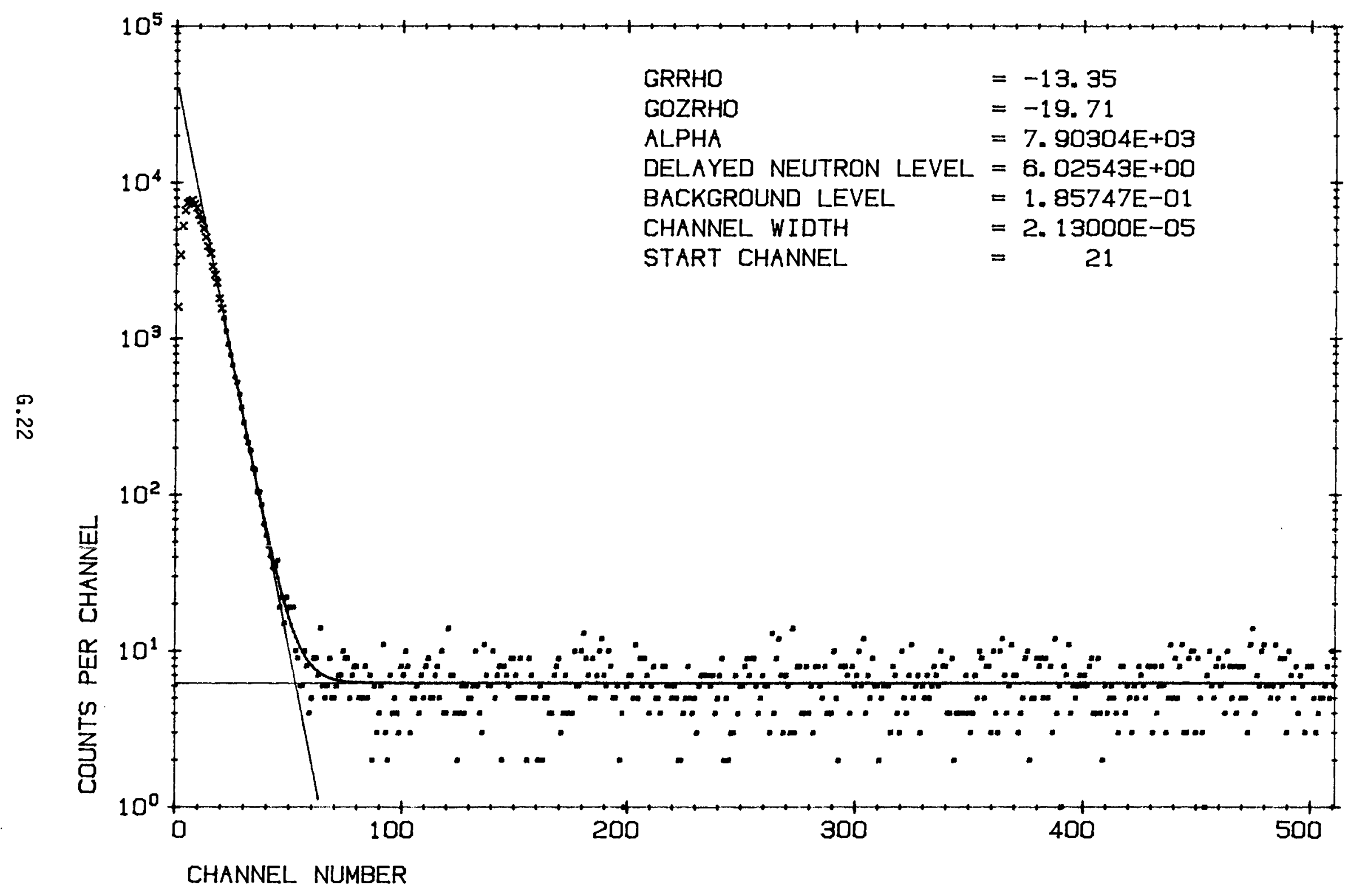


MEASUREMENT NUMBER BNFL 21-2

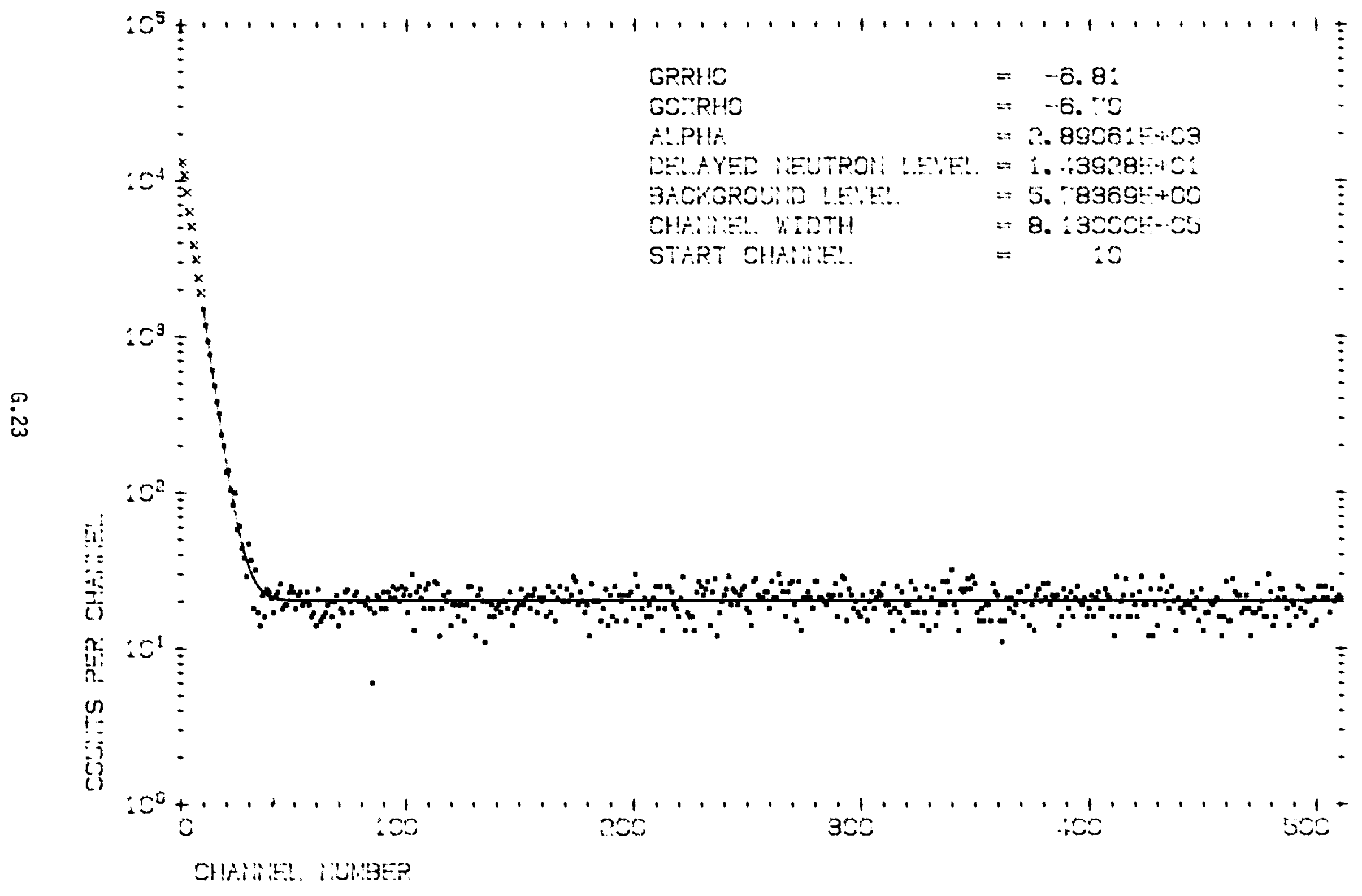


MEASUREMENT NUMBER BNFL 21-4

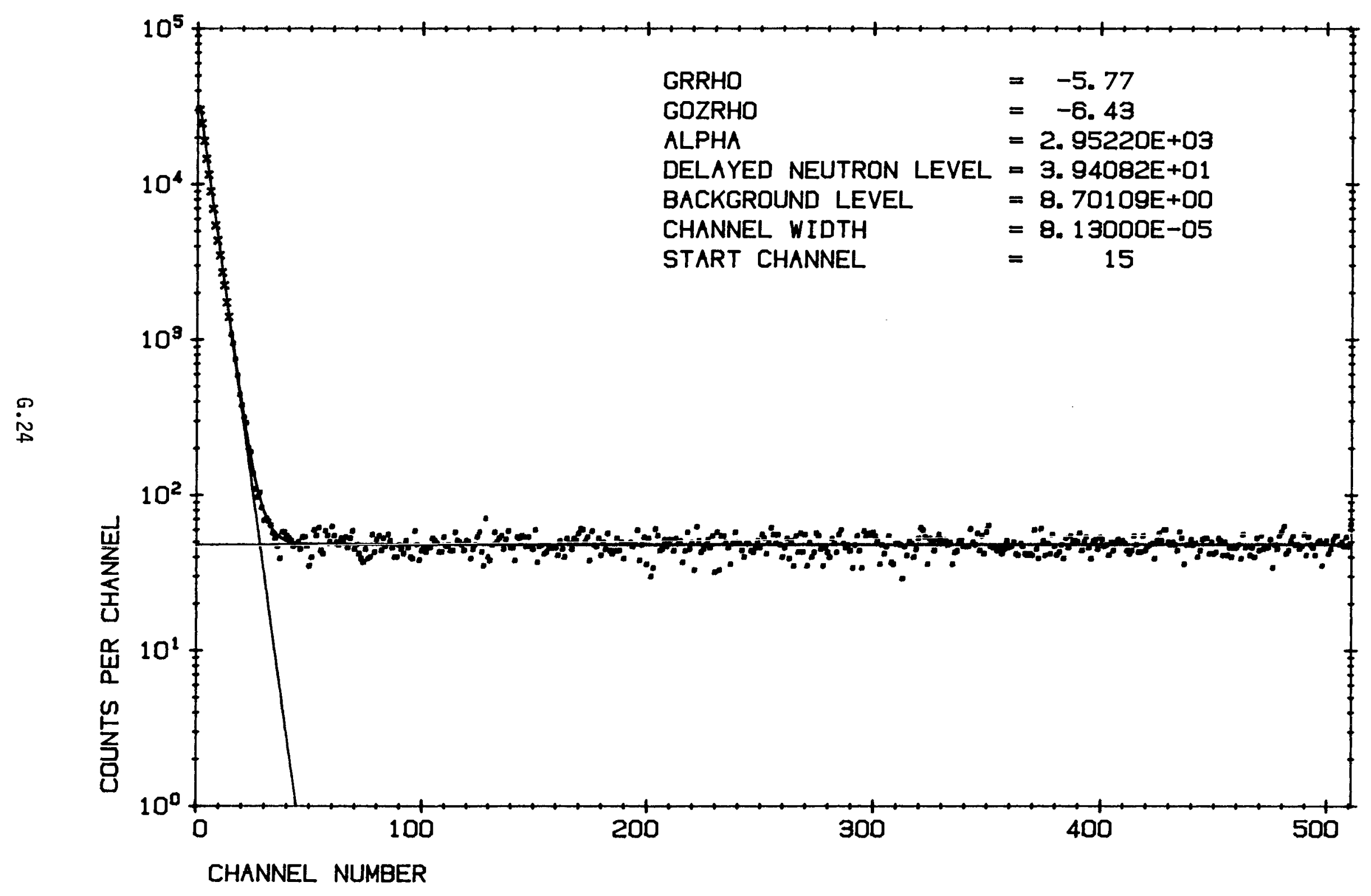


MEASUREMENT NUMBER BNFL 21-11

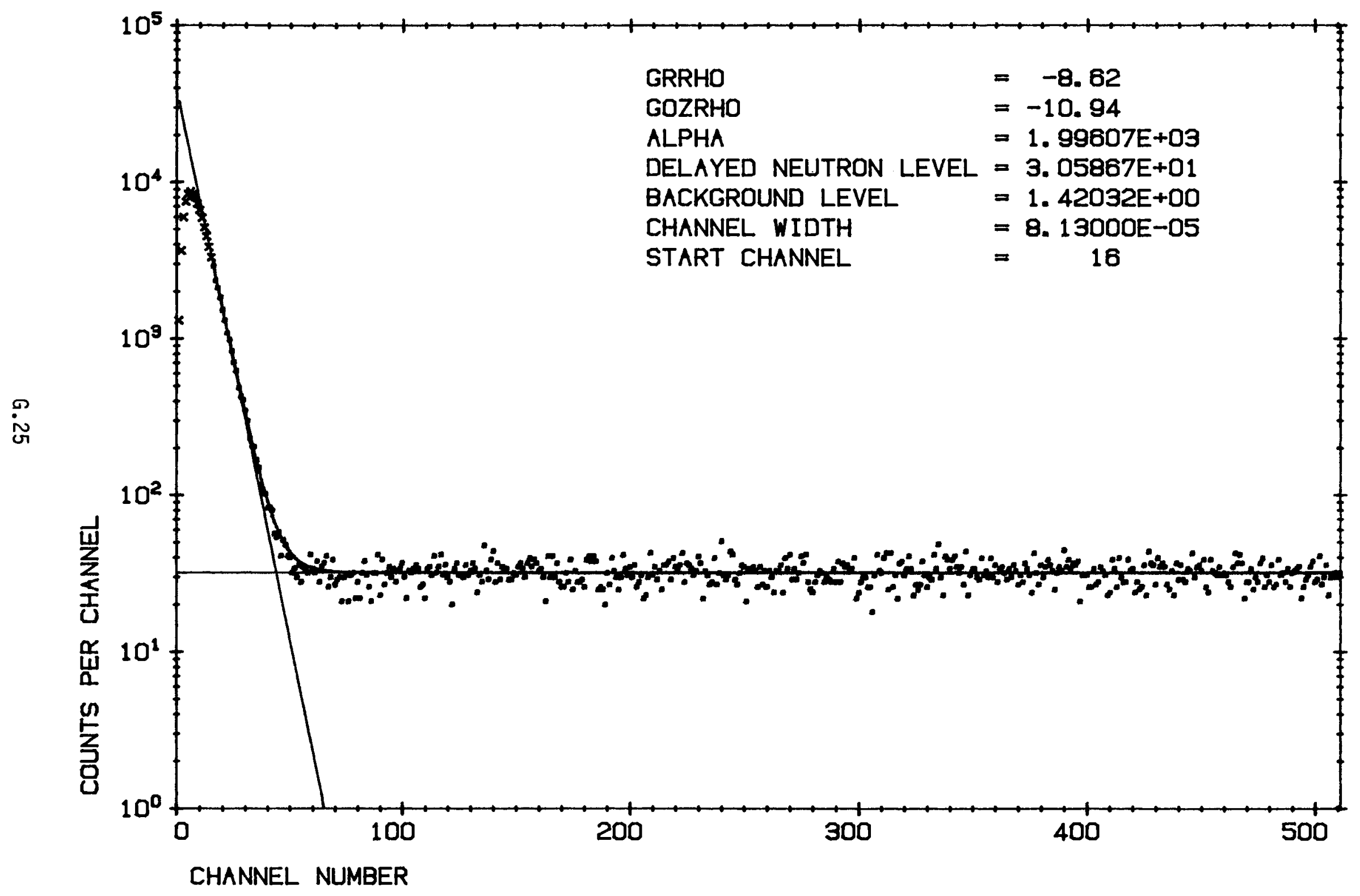


MEASUREMENT NUMBER BNFL 21-12

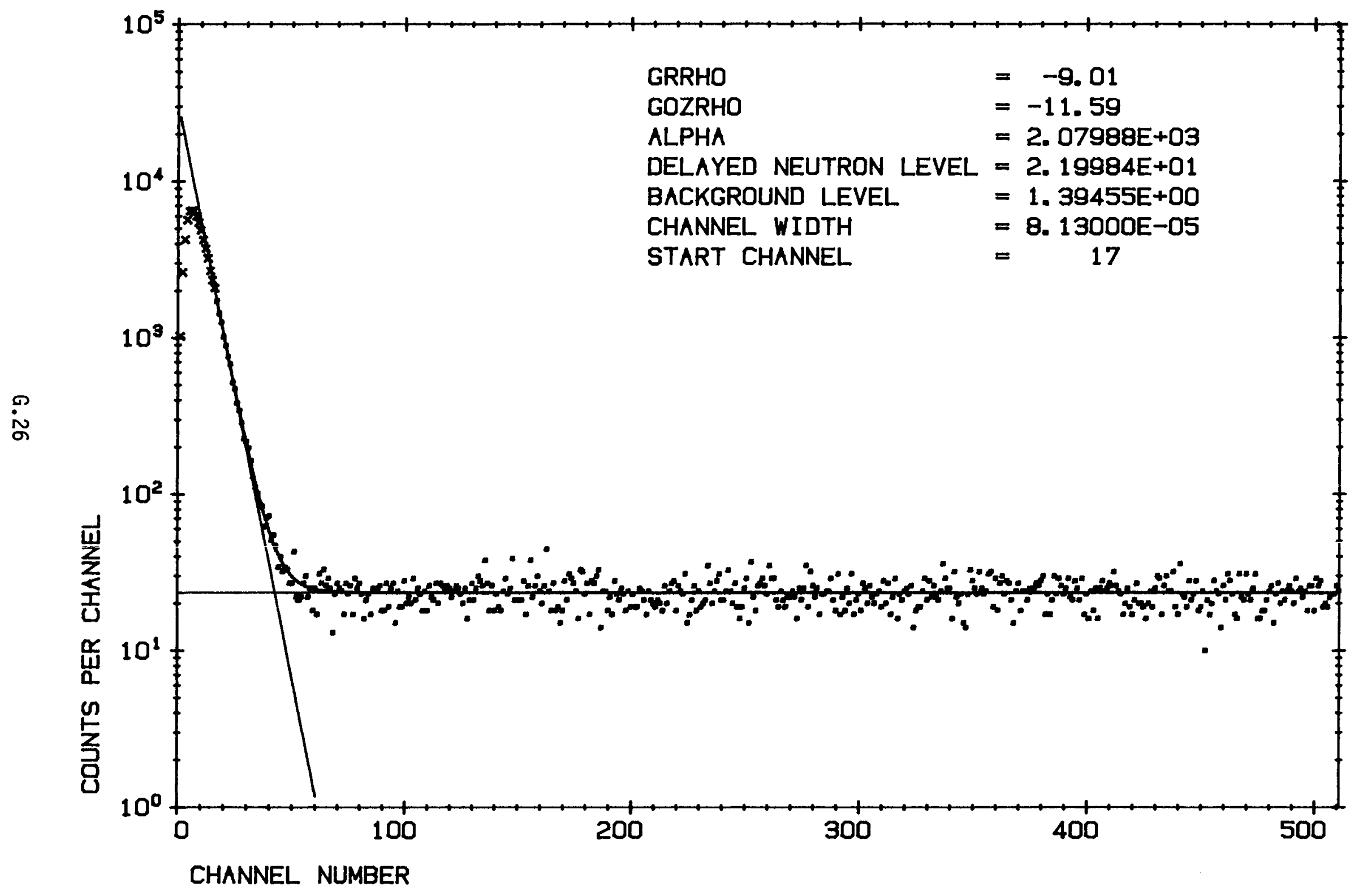


MEASUREMENT NUMBER BNFL 21-6

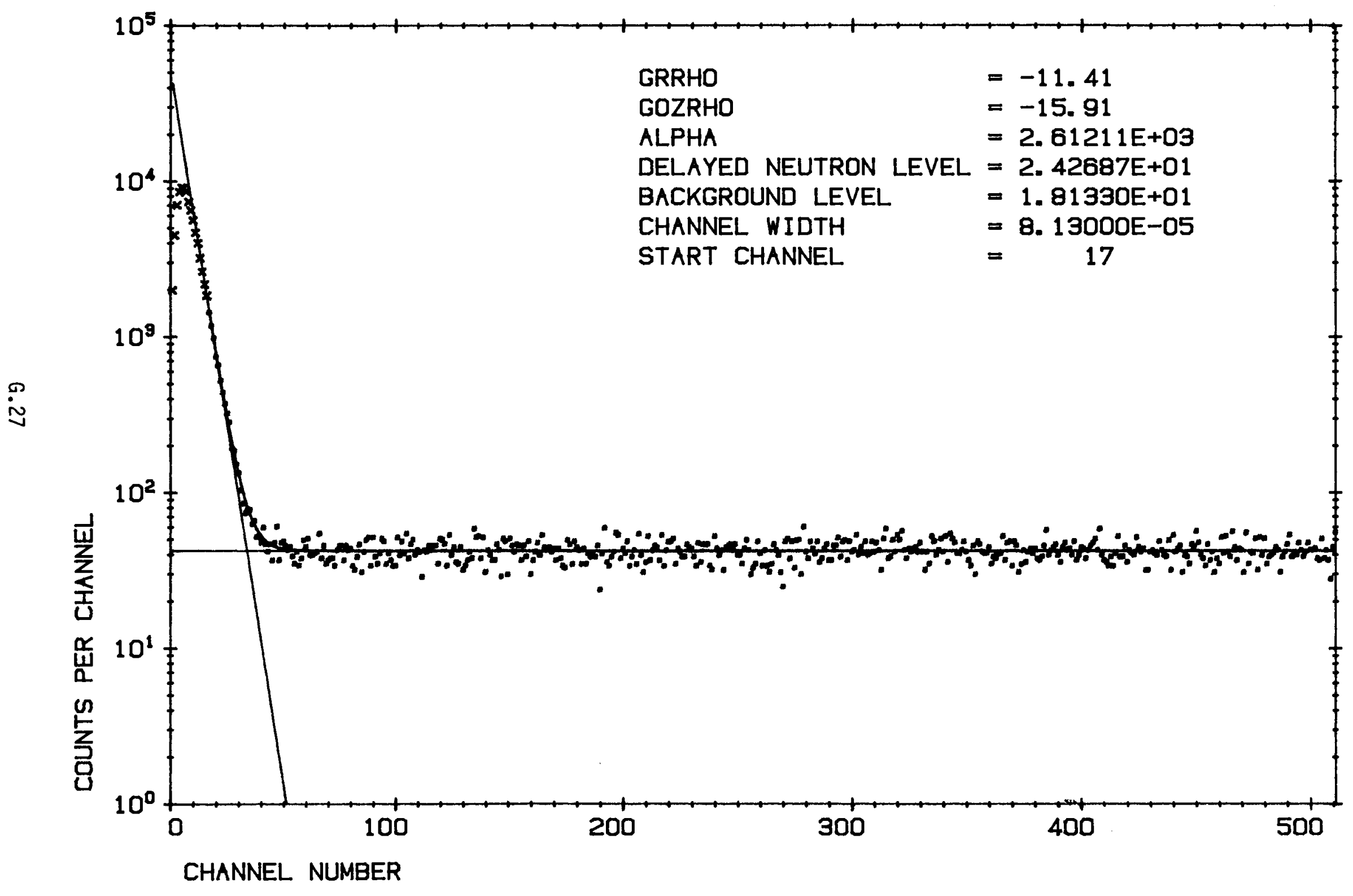


MEASUREMENT NUMBER BNFL 21-7

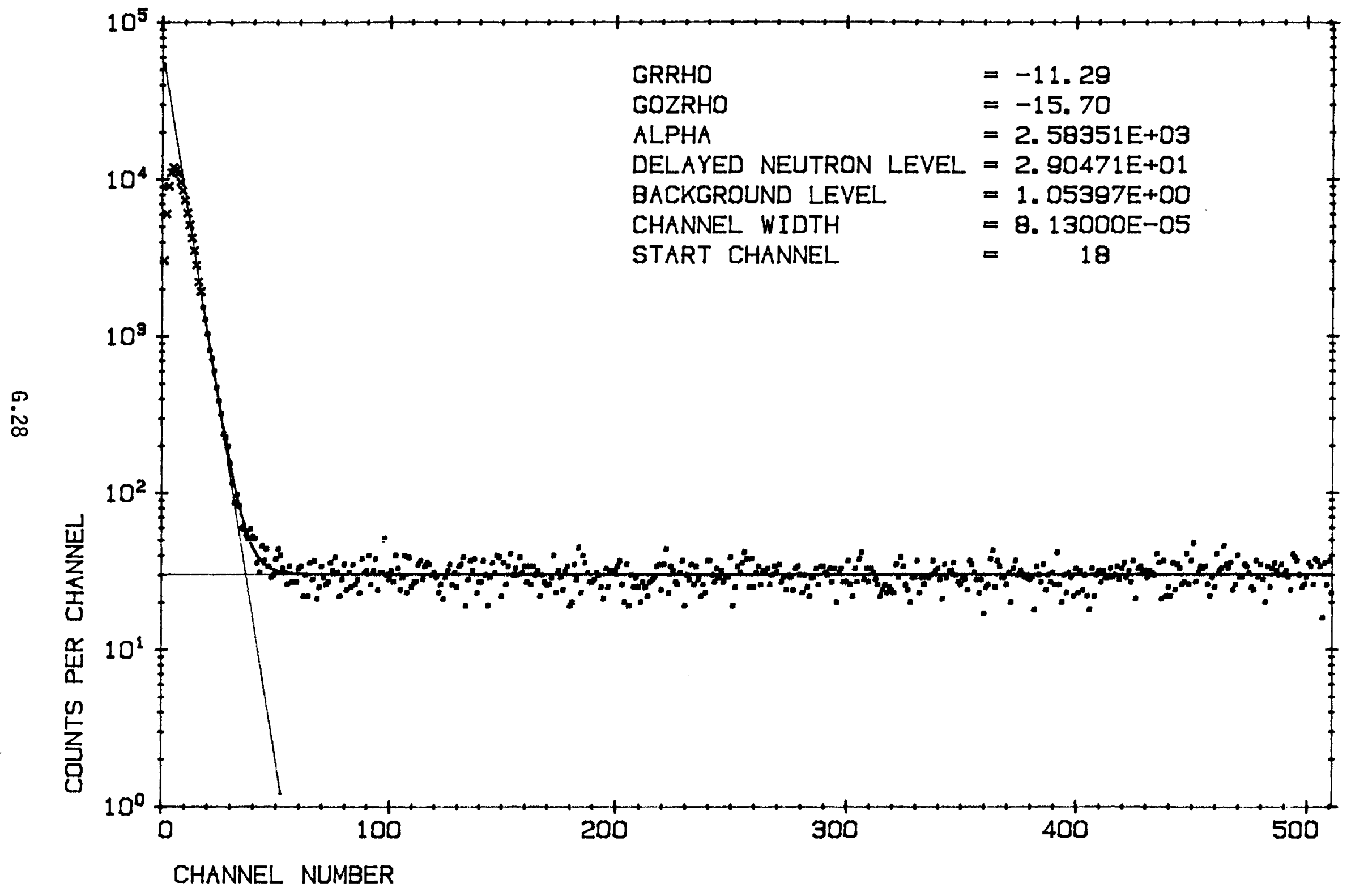


MEASUREMENT NUMBER BNFL 21-8

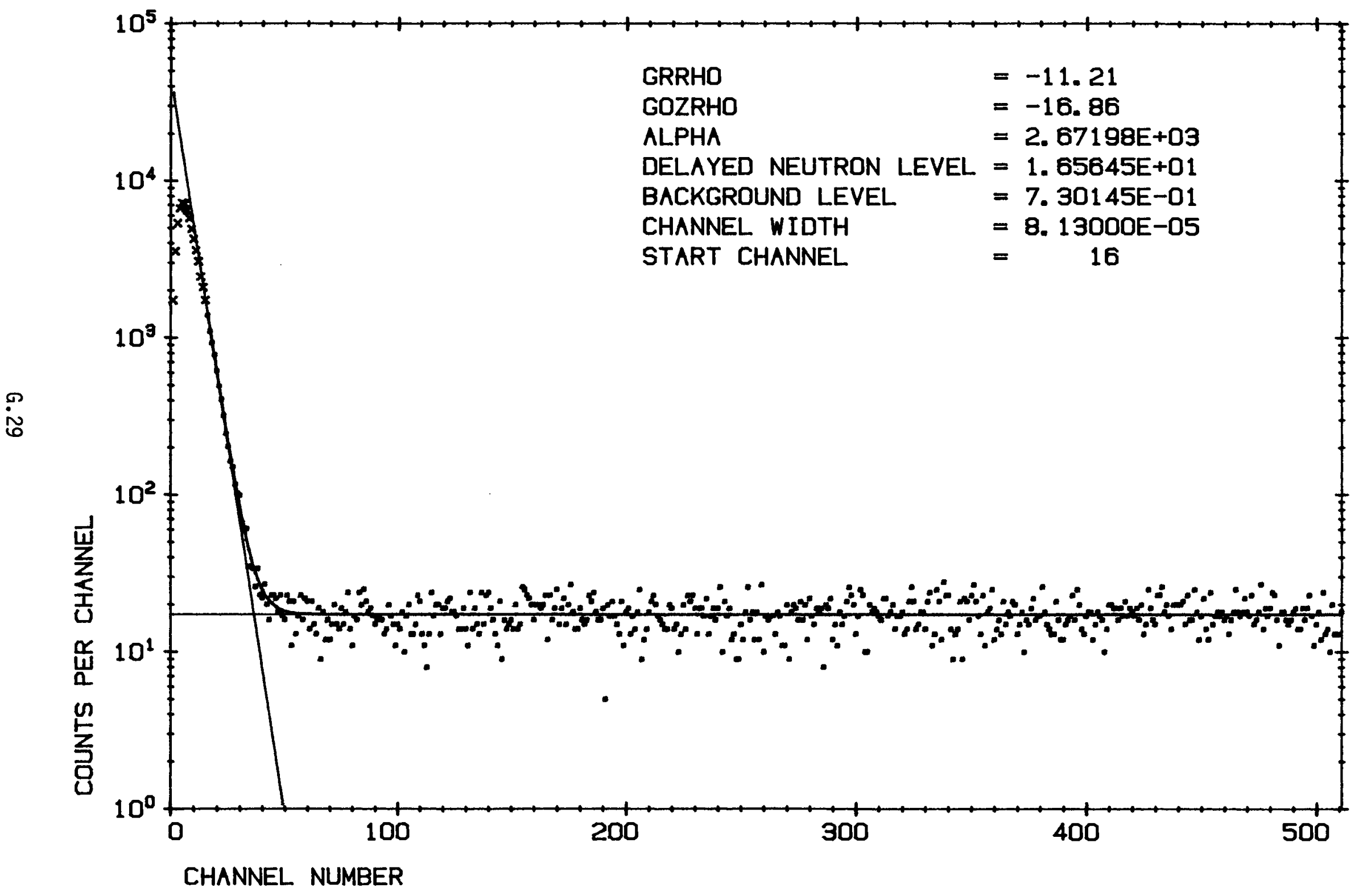


MEASUREMENT NUMBER BNFL 21-9

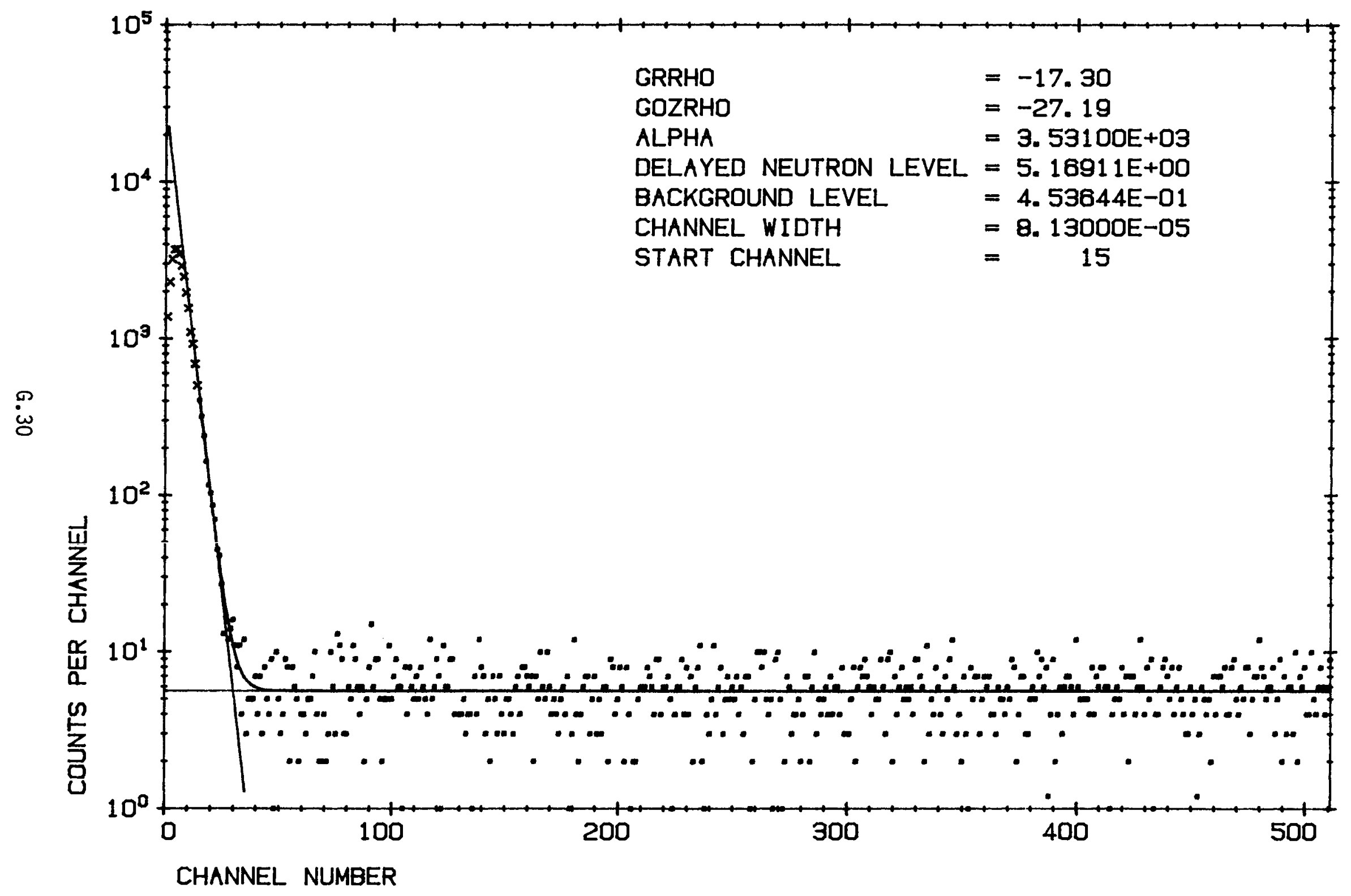


MEASUREMENT NUMBER BNFL 21-10

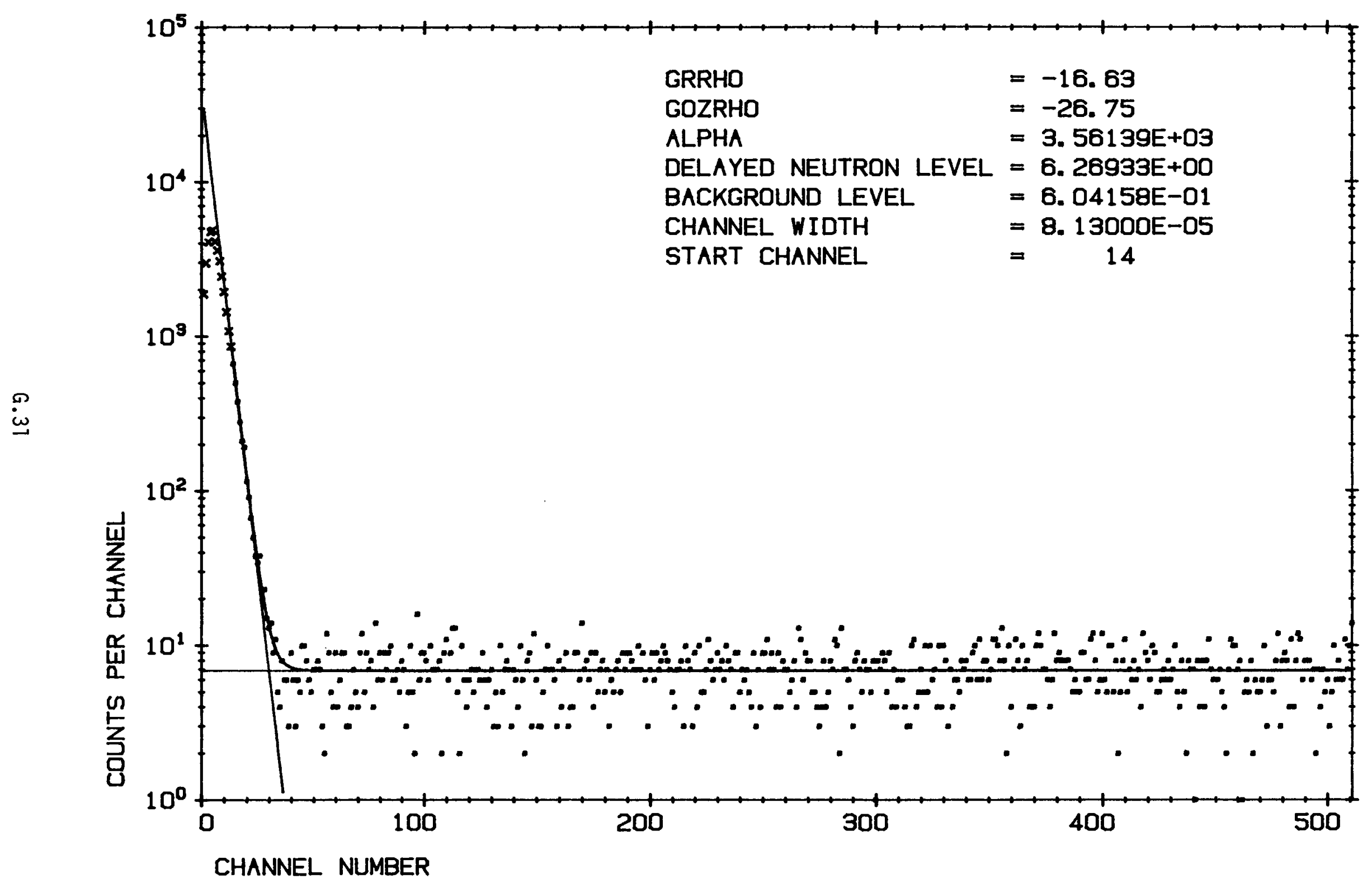


MEASUREMENT NUMBER BNFL 22-2

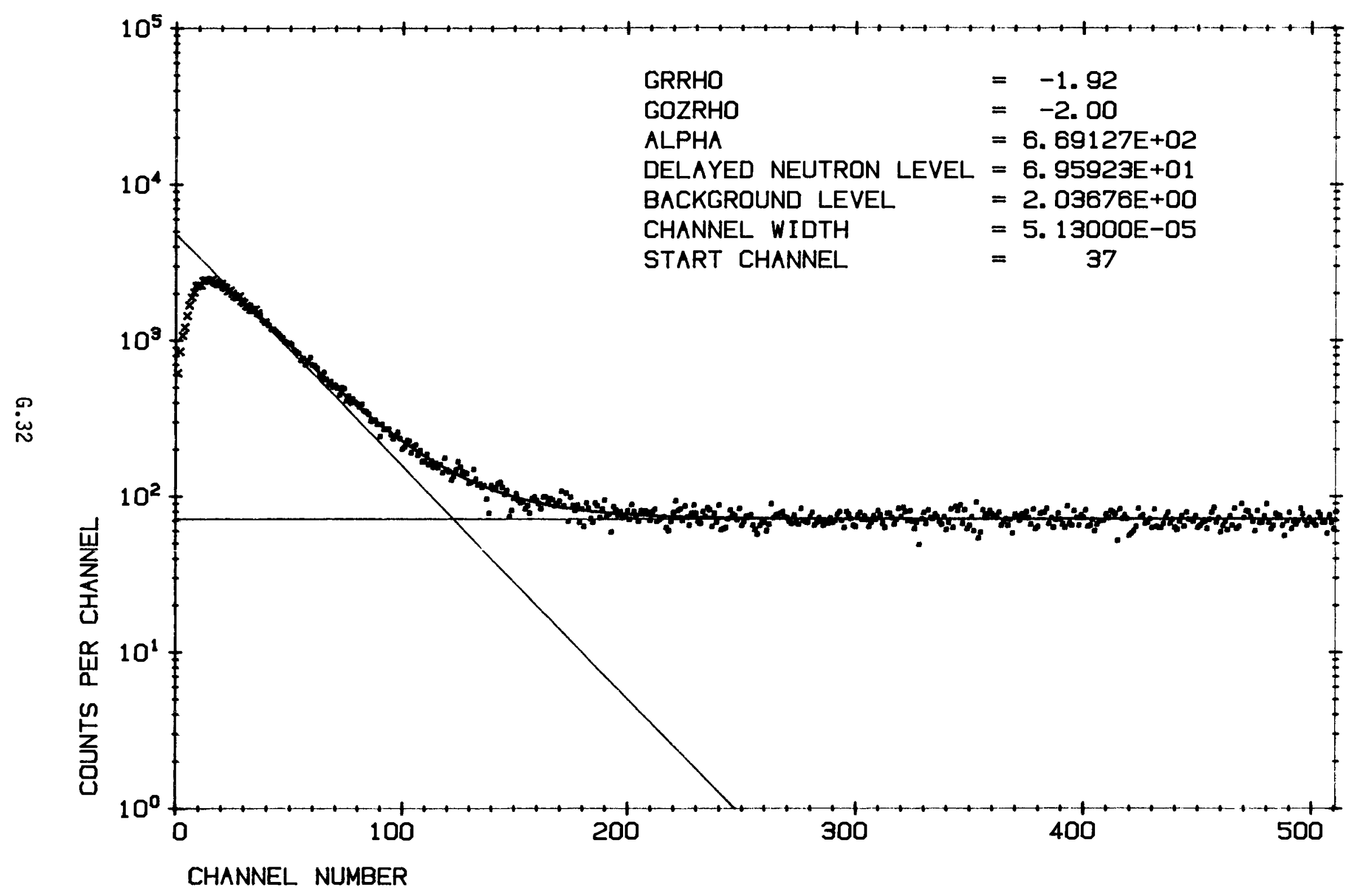


MEASUREMENT NUMBER BNFL 22-1

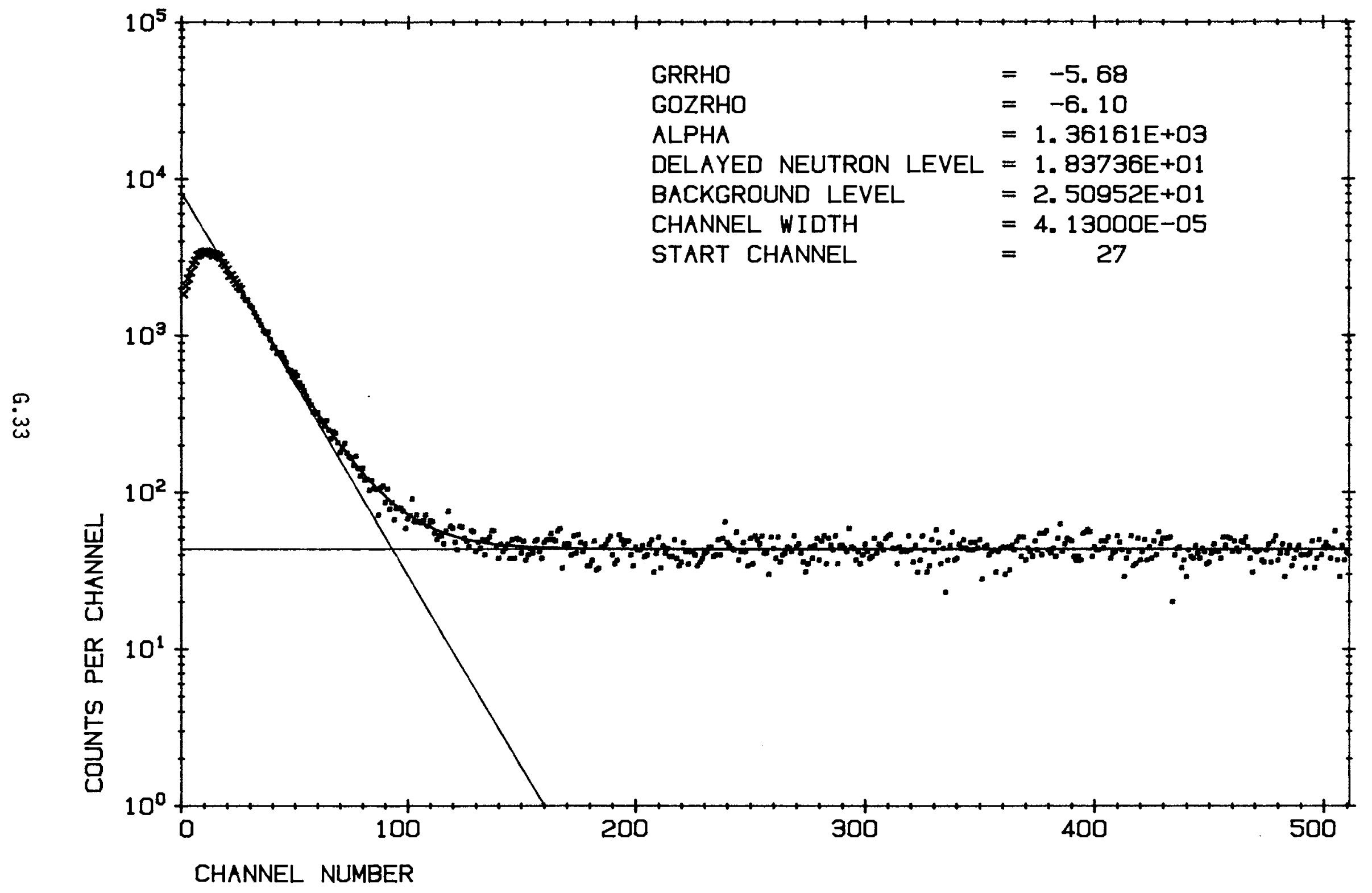


MEASUREMENT NUMBER BNFL 22-4

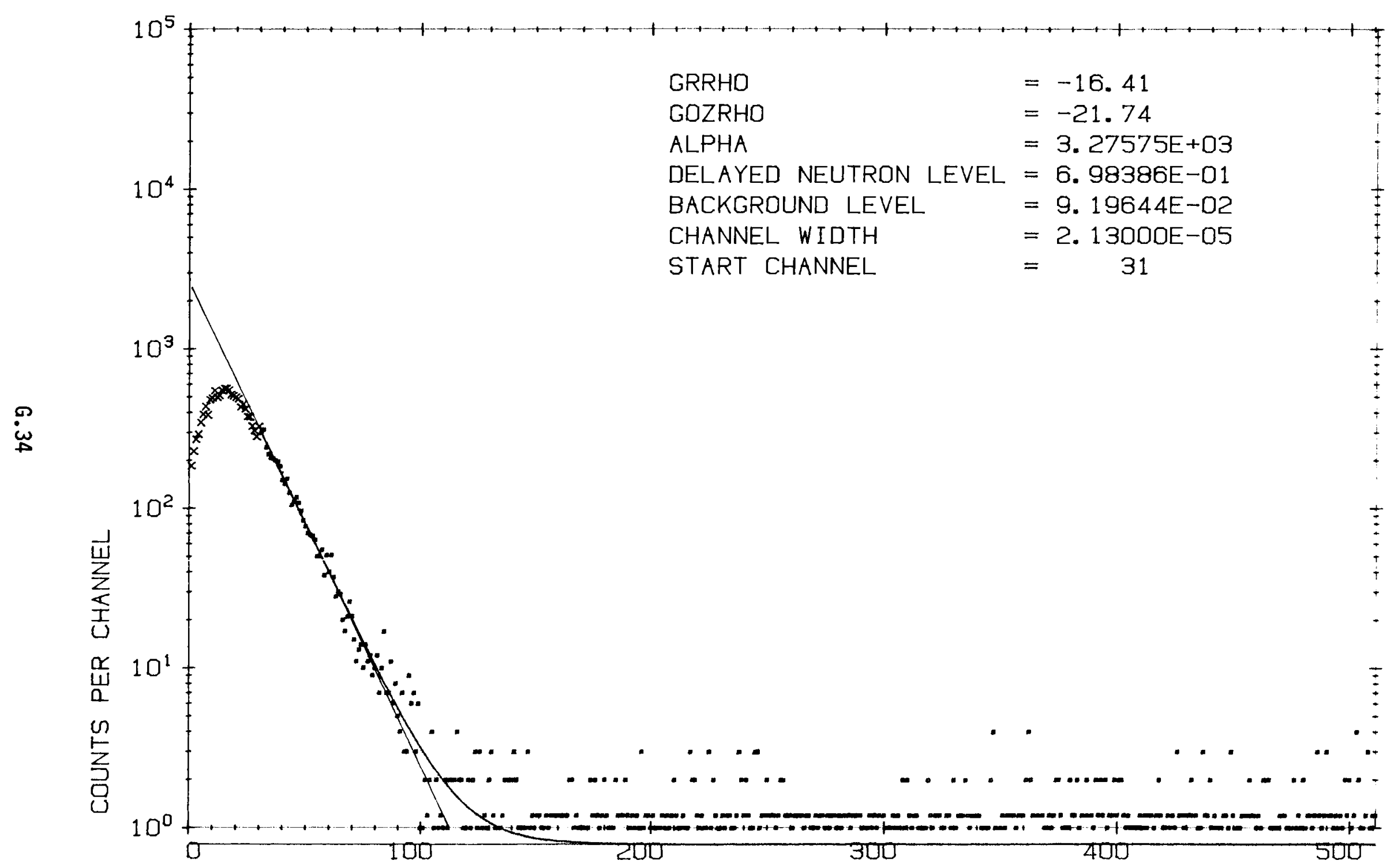

CHANNEL NUMBER 
MEASUREMENT NUMBER BNFL 32-5

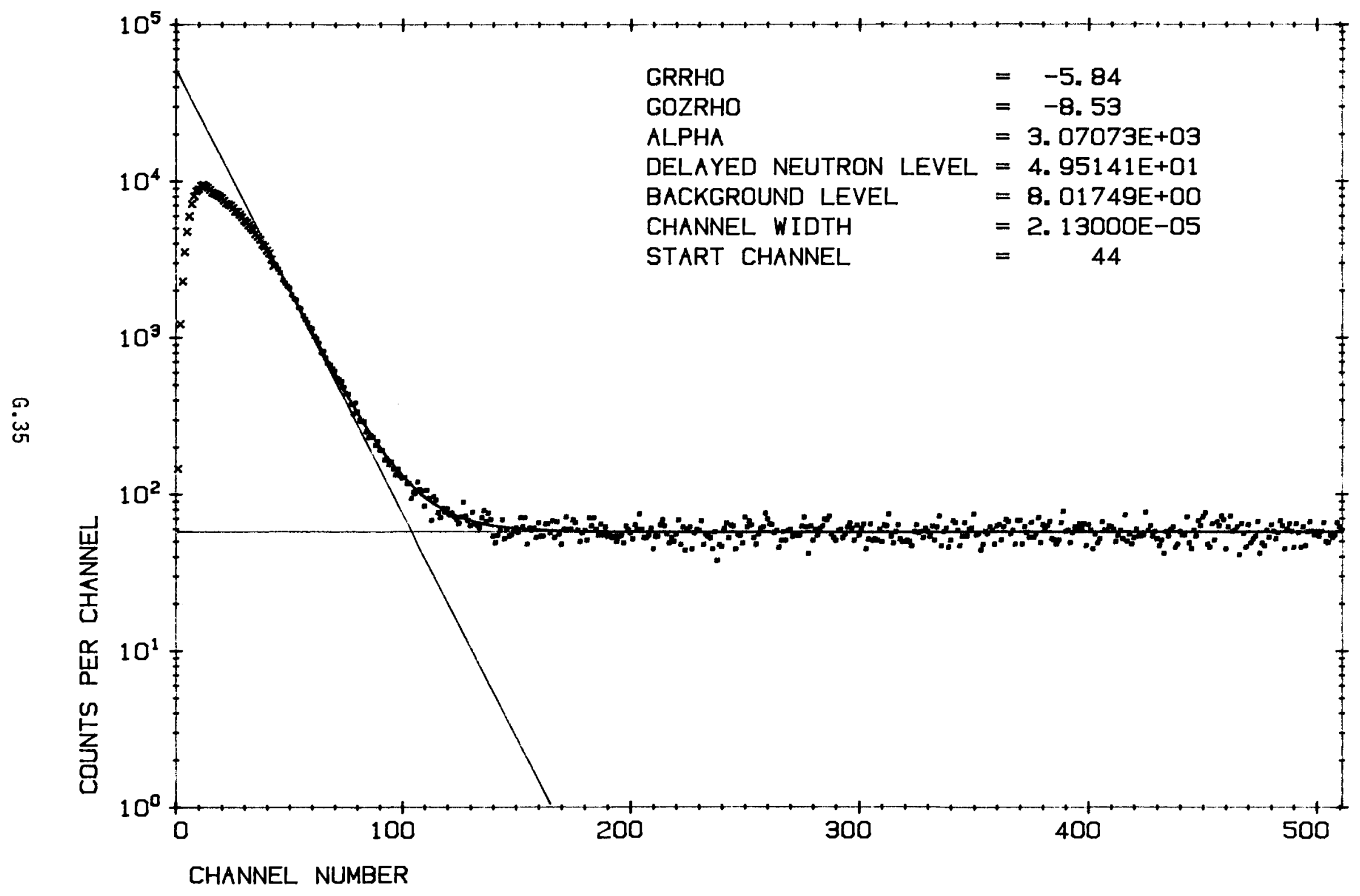


MEASUREMENT NUMBER BNFL 32-4

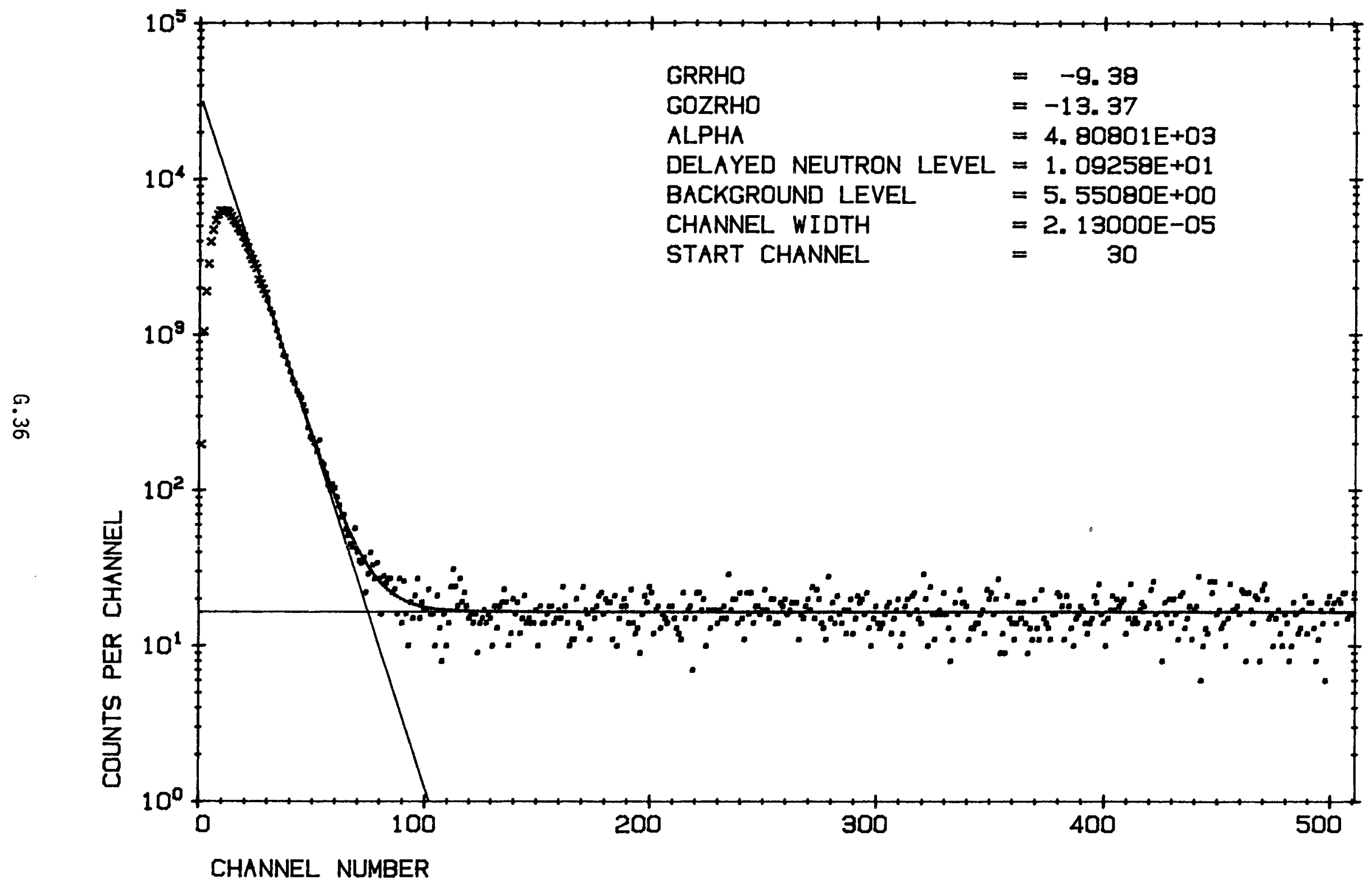


MEASUREMENT NUMBER BNFL 32-2

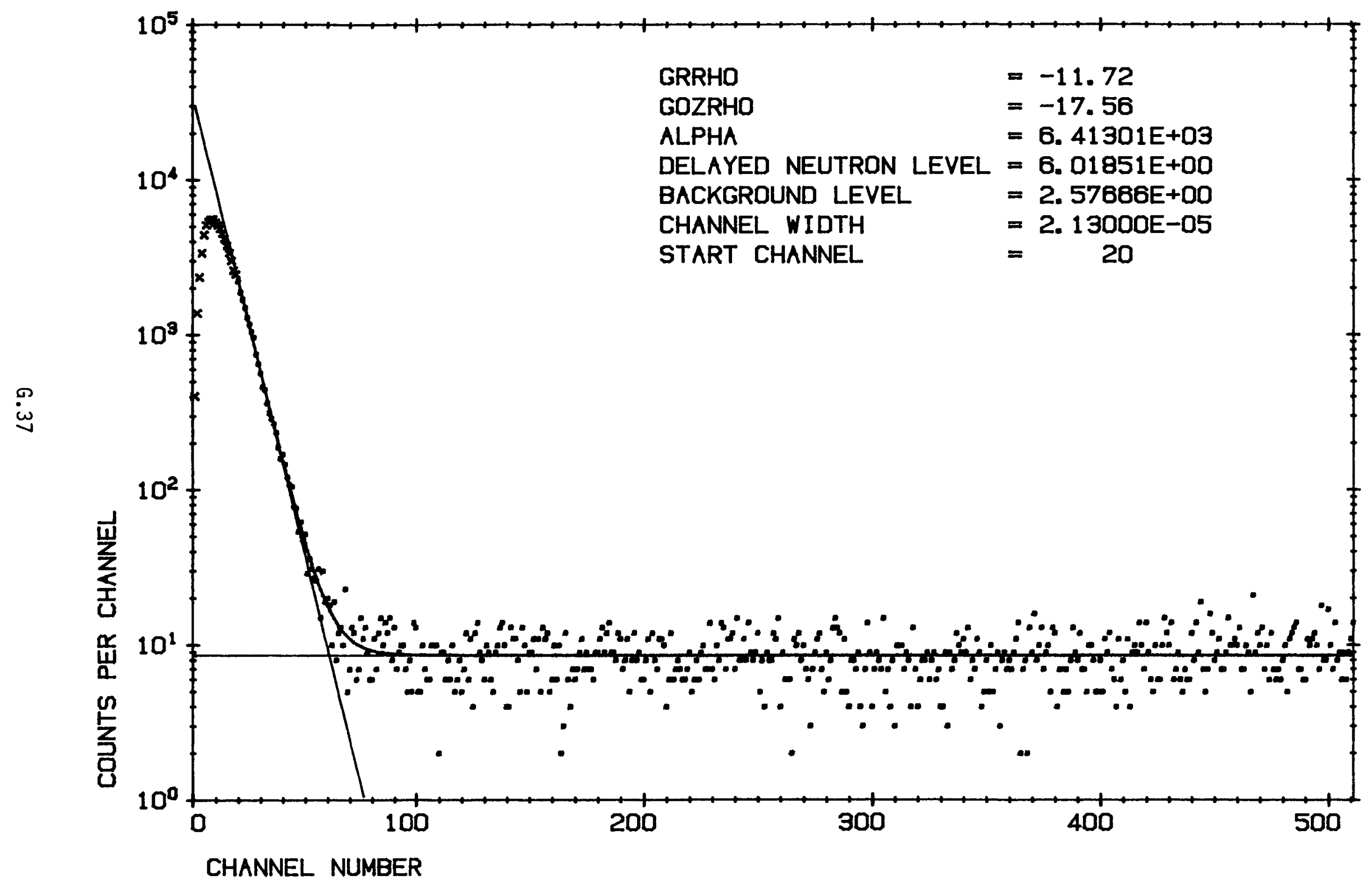


MEASUREMENT NUMBER BNFL 32-3

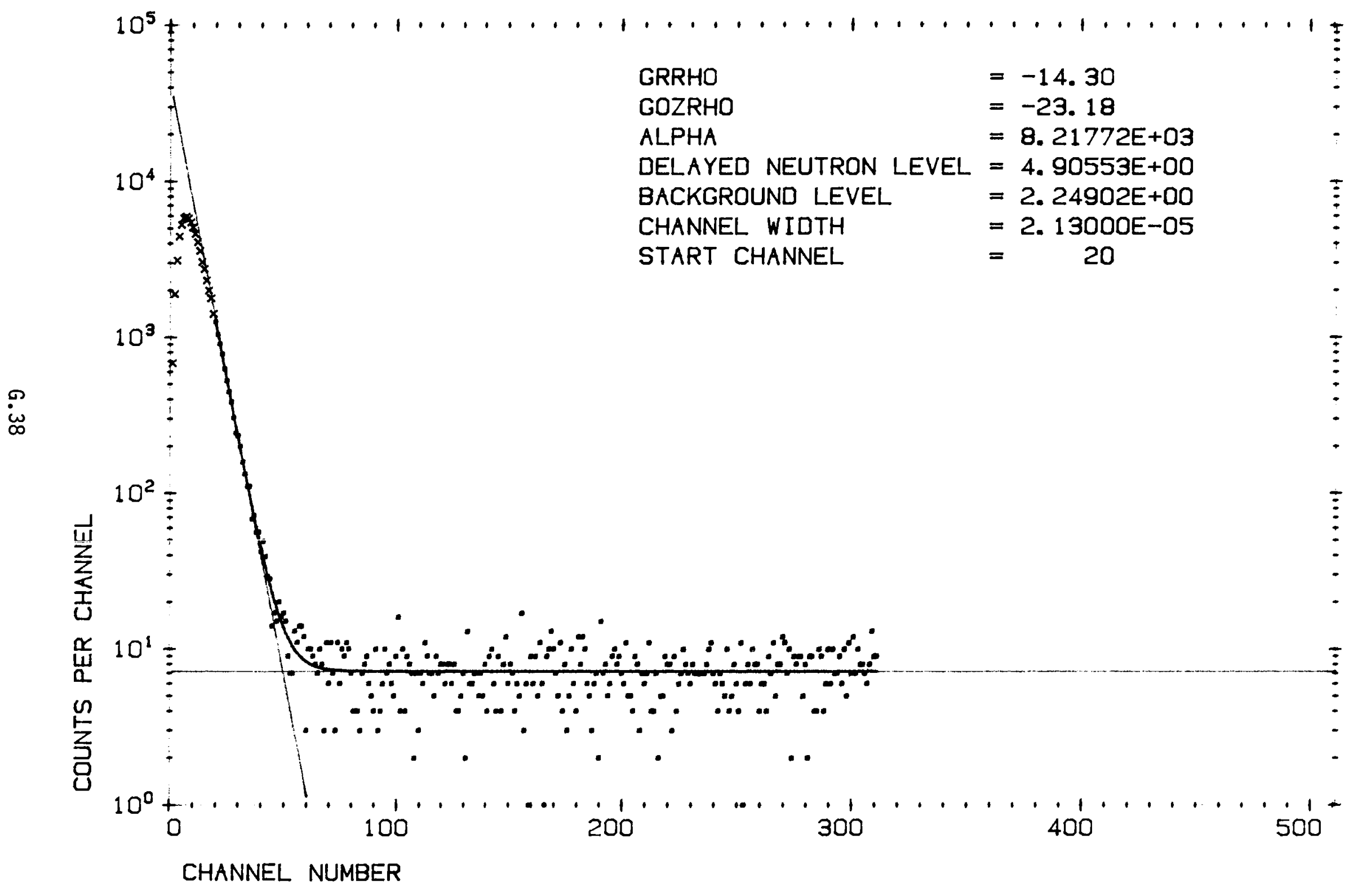


MEASUREMENT NUMBER BNFL 32M-1

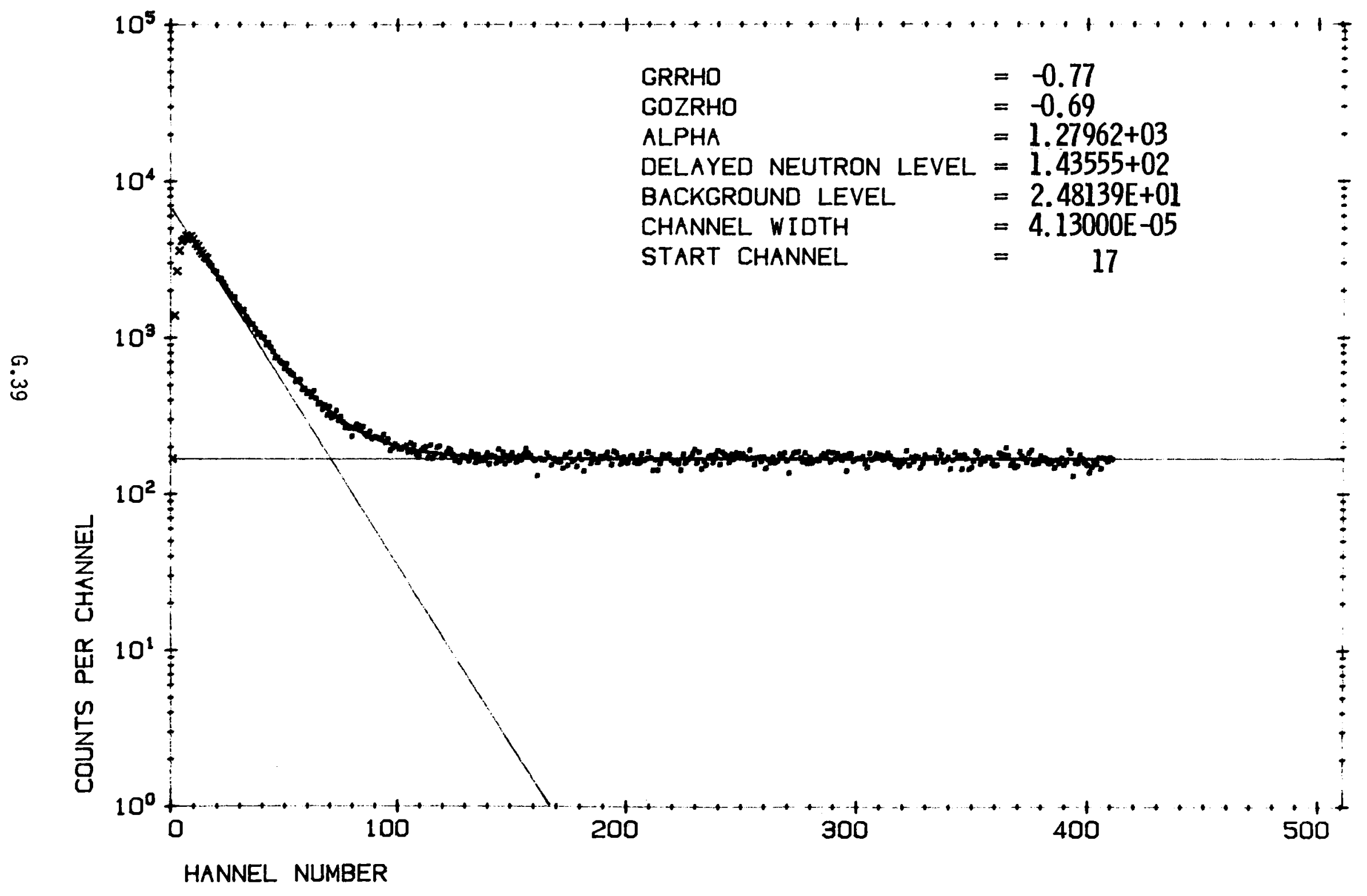


MEASUREMENT NUMBER BNFL 32M-3

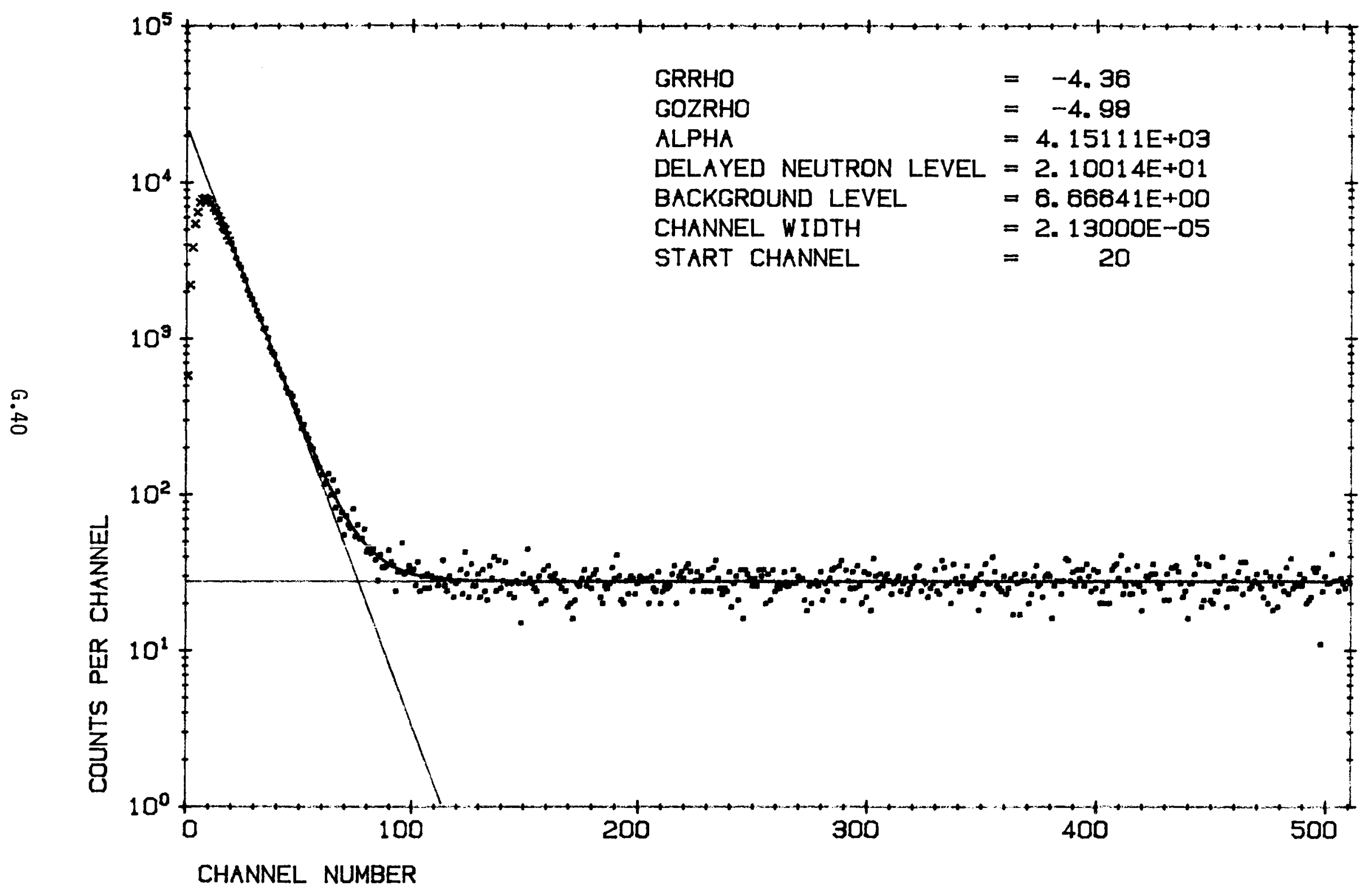


MEASUREMENT NUMBER BNFL 32M-4

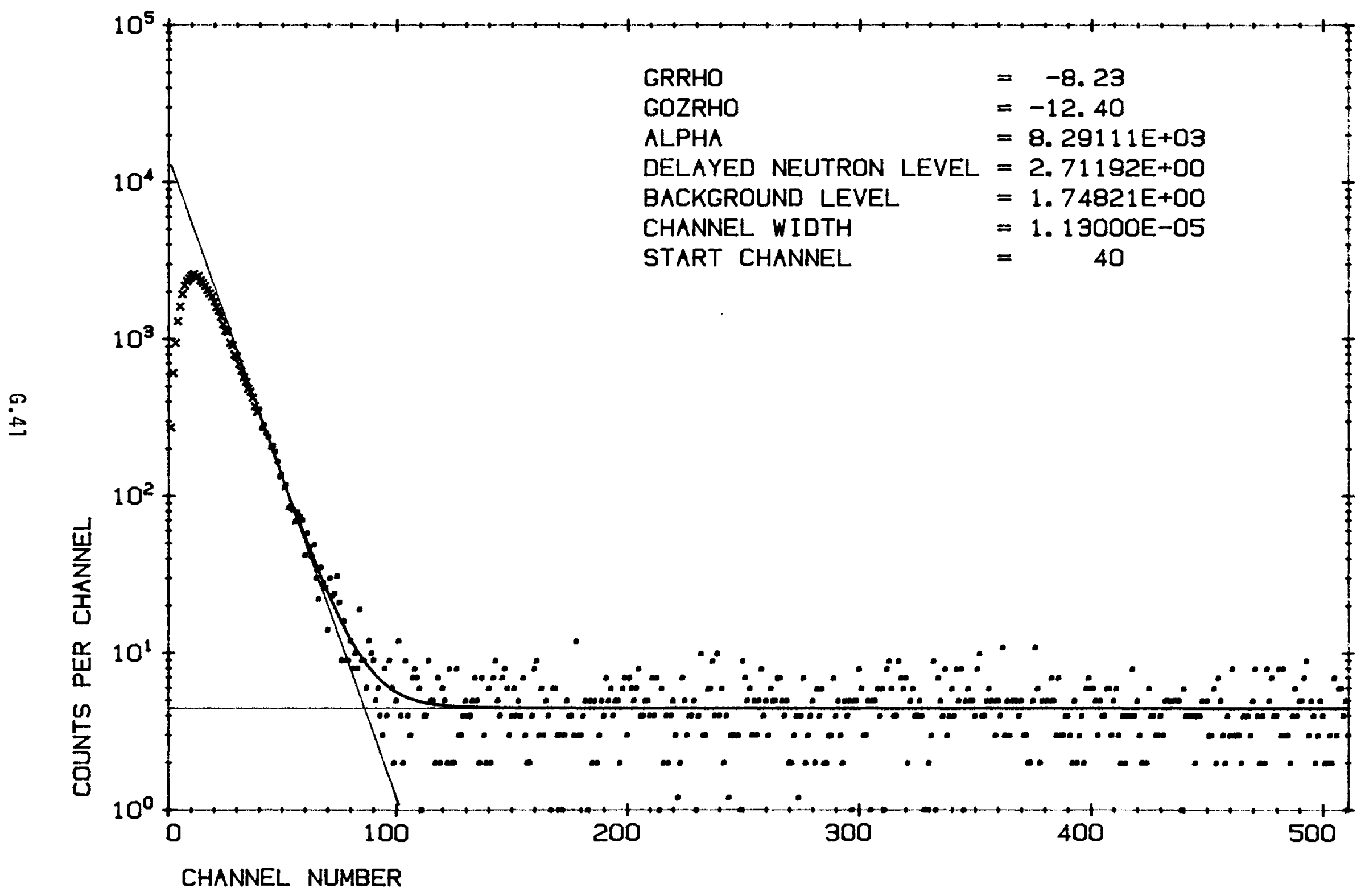





\section{APPENDIX $\mathrm{H}$}

\section{Fast Fission Ratio and Relative}

\section{Conversion Ratio Measurements}

The preparation, irradiation, data reduction, and analyses of foil packs to determine ${ }^{238} \mathrm{U} /{ }^{235} \mathrm{U}$ Fast Fission Ratios in the $4.31 \mathrm{wt} \%{ }^{235} \mathrm{U}$ enriched $\mathrm{UO}_{2}$ fueled lattices is presented in this Appendix along with the results obtained. Also similar details are presented in this Appendix for determining the ${ }^{238} \mathrm{U}$ capture to ${ }^{235} \mathrm{U}$ fission ratio in the $4.31 \mathrm{wt} \%$ ${ }^{235} \mathrm{U}$ enriched $\mathrm{UO}_{2}$ fuel relative to that in a known thermal flux (the Relative Conversion Ratio). 
$\mathrm{RPD} / \mathrm{MFM} / 830$

FAST FISSION RATIC AND

I

REIATIVE CONVERSION RATIO

MEASUREMENTS IN WATER INCDERATE

UO2 LATIICES

M F MURPHY

Reactor Physics Division

AEE Winfrith

21. JUIY 1983

H.2 
CONTENTS

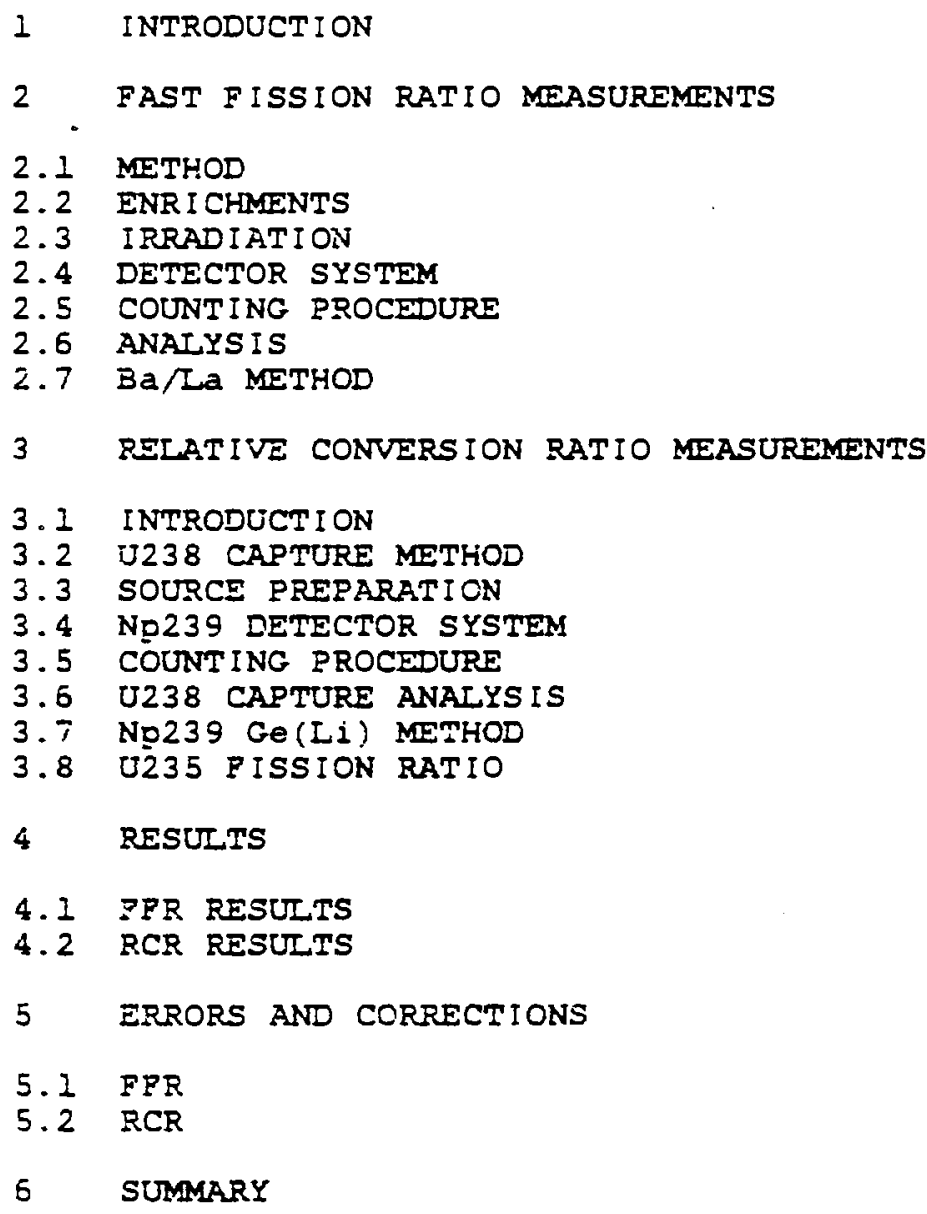




\section{$1 \quad$ INTRODUCTION}

As part of a programme of criticality experiments, reaction rate measurements have been mace in a series of water moderated lattices of $12.7 \mathrm{~mm}$ diameter $4.3 \%$ enriched $\mathrm{UO}_{2}$ fuel rods. This report deals with the measurements of Fast Fission Ratios and Relative Conversion Fatios in these lattices. The Fast Fission Ratio (FFR) is defined here as the ratio of; fission rate per atom of U238, to fission rate per atom of U235. The Relative Conversion Ratio (RCR) is aefined as the ratio of; capture rate per atom of U238, to fission rate per atom of U235, in the reactor fuei, relative to the same ratio in a well thermalised neutron spectrum.

A major aspect of these measurements was that the irradiations took place in the USA and the measurements were made at AEE Winfrith. This resulted in a considerable logistics problem but by good planning and the co-operation and diligence of all concerned this problem was overcome. However, the long distance involved inevitably meant that samples were not available for measurement until about 28 hours after the irradiation. It was therefore necessary to modify the techniques that are normally used in the Reactor Physias Division Counting Laboratory on samples that are available about two hours after shut-down. These modifications will be detailed later in this paper.

PPR and RCR measurements can be made separately. However, to economise on materials and reactor time it was convenient to use componants from. the same experimental sample pack (Figure i) to measure both ratios.

\section{MEASUREMENT OF PAST PISSION RATIO}

\subsection{NETHOD}

The basis of the method used for measuring FPR(i)(2) involves the simultaneous irraciation, in a fuel elemert, of two uranium samples of different enrichments. The fission product rray activity of each sample is then measured and hence, knowing the enrichments, the ratio of $U 238$ to 0235 fission product activities can be deduced. A calibration factor to relate fission product activities to true ission rates is determined in a separate experiment.

\subsection{ENRI CGNIRINS}

The choice of enrichments for the sample pair is a compronise between; minimising the flux perturbations in the measuring region, and obtaining a well conditioned simultaneous equation. In tirese measurements the sample pair comprised a $4.3 \%$ $0235 \mathrm{UO}_{2}$ disc and a 0.048 U235 uranium metal foil. The $\mathrm{UO}_{2} \mathrm{~d} 1 \mathrm{sc}$ is effectively a $0.2 \mathrm{~mm}$ thick slice of the fuel elenent and therefore has a nesligible perturbation effect, the $0.07 \mathrm{~mm}$ depleted foil with its $0.07 \mathrm{~mm}$ depleted metal guard foils causes a pertuziation of leas than $i \frac{1}{3}(2)$. 
For the lattices studier, the 4238 fission rate in the enriched disc was in the range $5 \%$ to $12 \%$ of the total isision rate, whilst in the depleted foil the 4235 fission rate was $10 \%$ to $20 \%$ of the total fission rate. Thus the simultaneous equations for deducing tihe FFRs were reasonably well conditioned.

\subsection{IRRADIATION}

The samples are positioned in the measuring pack as shown in Figure i. The depleted guard foils protect the depleted foil from fission products from the enriched $\mathrm{UO}_{2}$ material, and ersure that there is no net loss of ission products from the depleted foil. The $4.3 \% \mathrm{UO}_{2}$ disc is also used to measure the $\mathrm{U} 235$ lattice to thermal fission ratio, as part of the RCR measurement, in. conjunction with similar $\mathrm{UO}_{2}$ discs irradiated simultaneously in $a$ thermal spectrum. Also contained in the pack is the $\mathrm{UO}_{2}$ pellet to be used in the 0238 capture rate measurement.

Measurement packs were irraciated in sets of three in each of the lattice arrangements studied. A simultaneous irradiation was made, in each case, in the thermal colum of the winfrith source reactor Nestor. The thermal colum is a graphite cube of $1.8 \mathrm{~m}$ side. The $4.3 \% \mathrm{UO}_{2}$ discs used for the thermal irradiation were mounted in a special graphite holder which was positioned in the cclumn, $1.4 \mathrm{~m}$ from the face nearest the reactor. These $\mathrm{UO}_{2}$ discs were guarded on each side by identical discs, to provide the same interchange of fission producis as in the lattice packs. synchronisation of the ixradiations was achieved by maintaining a telephone link during the start-up phase. The neutron shutter to the thermal column has opened when the American reactor was at 37\% of fuli power, on a constant doubling time. The irradiations were for exactly two hours, at a constant neutron flux of about $2 \times 10^{8} \mathrm{ncm}^{-2} \mathrm{~s}^{-1}$, in both the experimental reactor and the Nestor thermal column.

Pollowing the irradiation the measuring packs were transported by road and air and arrived at AEE Winfrith about 28 hours after the irradiation had finished.

\subsection{DETECTOR SYSTEN}

The fission product $y$-ray activities were measured on a detector system having as its basis two NaI(TI) detectors $50 \mathrm{~mm}$ in ciameter by 5cmm thick. These are installed, in a vertically opposed configuration, in an automatic sample changer mechanism which is housed in a thermostatic enciosure, controlied to $\pm 0.1^{\circ} \mathrm{C}$. Tempezature stabilisation is necessary as the detertors have a gain coefficient with temperature of 1 o per $1^{\circ} \mathrm{C}$. Control of the detector system is erfected by a PDP computer via CAMAC and the activity data are collected by ths computer via caMac. scalers (3). 


\subsection{COUNTING PROCEDURE}

The detector system discriminators were set to accept puises from $\gamma$-rays greater than $0.64 \mathrm{MeV}$ in energy. Normally a discriminator level of $1.28 \mathrm{Mev}$ is used but the lower value was used in these measurements to compensate for the long delay, by including more of the $\gamma$-rays from longer lived fission products.

After irradiation and transport to AEE Winfrith the measuring packs were dismantled and the folis and discs were carefully cleaned with a solvent. This was particularly important for the depleted foils as it removed possibie contamination by small particles of enriched $\mathrm{UO}_{2}$. The depleted Eoils were then mounted in aluminium holders which were inserted into the plastic nolders of the automaic detector system. The depleted foils were measured by themselves on the system to avoid interference from the much higher activity $\mathrm{UO}_{2}$ discs $(\sim \times 25)$. After sufficent counts had been accumulatec from the depleted foils, they were removed and the $\mathrm{UO}_{2}$ discs from the measuring packs and from the thermal column were loacied on to the system. The measurement then continued until sufficilent counts had been accumulated from the $\mathrm{UO}_{2}$ discs. Another icientical detector system was also used but the samples were neasured in the reverse order; enriched first and then depleted. So effactively two separate measurements were made on each set: of samples.

\subsection{ANAIYSIS}

The data collected from the measuremerits were transmitted to the main computer at AES Winfrith (ICL 257G) at the end of the measurement.) Analysis of the data was then performed by the FREDA coce a). Which, after correcting for deadtime, background, mass, decay, etc, produces Past Pission Ratios and I 235 lattice to thermal ratios, with their theoretical and rms errors.

Consider: a depleted foil countod at time $t$, and an enriched foil counted at time $t^{\prime}$. Then one may writ:e:

$$
\begin{aligned}
& C^{D}(t)=N_{8}^{D} F{ }_{8}(t)+N_{5}^{D} F(t) \\
& C^{E}\left(t^{\prime}\right)=N_{8}^{E} F_{8} G_{8}\left(t^{\prime}\right)+N_{5} E_{5} G_{5}\left(t^{\prime}\right)
\end{aligned}
$$

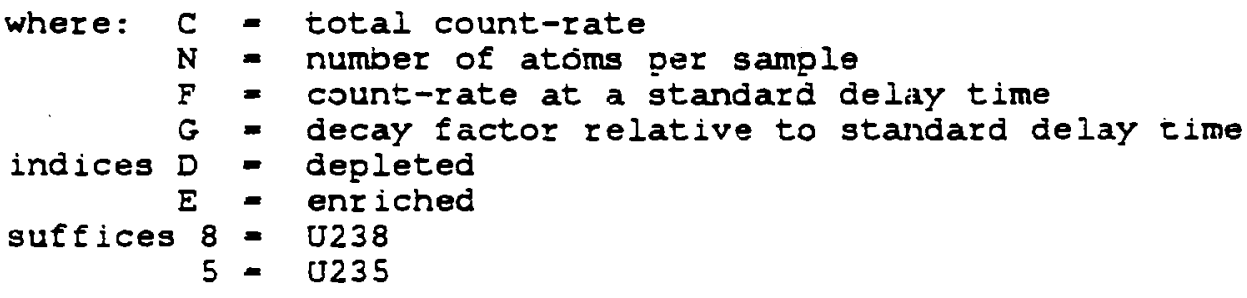

a) AEEW fission ratio computer programme 
Solving (I) and (2) for F8 and F5 one finds:

$$
\frac{F_{8}}{F_{5}}=\left[\frac{c^{D} E_{5} G_{5}\left(t^{\prime}\right)}{c^{E_{2} D_{8} G_{5}(t)}}-\frac{N_{5}^{D}}{N_{8}^{D}}\right] \cdot\left[1-\frac{c^{D} N_{8}^{E} G_{8}\left(t^{\prime}\right)}{c^{E} N_{8}^{D} G_{8}(t)}\right]^{-1}
$$

If the depleted foil is counted $n$ times and the enriched disc is counted m times, then PREDA solves $\mathrm{nm}$ equations of form ( 3 ) and produces a mean value of $88 / F 5$. This is the ratic of fission product $y-r a y$ activities, which must be converted by a calibration factor to the true fission ratio. The determination of this factor is described in section 5.1.9. The FFR zesults are presented in section 4.1 .

\subsection{Ba140/LEI40 METHCD}

As a check on possible systematic errors the FPR was also measured by another method. This involved using the same uranium sample pair as for the previous method but measuring only one particular fission product $y-r a y$. The relative abundances of the Bal40 fission product, produced in the two types of sample, were measured by observing the decay of its daughter Lal40. This method is largely independent of the previously described detection method but is somewhat less precise.

Bal40 decays by $\beta$-emission, with a i2.8 day half life, to Lal40 which decays by 8 -emission, with a 40.2 hour half life. to stable cel40. At short times after irradiation the Lal 40 activity is low, it builds up to a maximum at about 5 days after shut-down, and then decreases until at about 14 days after shutdown it is decaying with the Bai40 half life. The main $7-r a y$ emitted by Lal40 has an energy of $1.6 \mathrm{Mev;}$ at about 3 days after shut-down this can be cleariy resolved from other fission product $y$-rays by using a germanium $y$-ray detector.

The Lal40 activities were measured by placing the various samples in turn, in a zeproducible position, close to a Ge(Li) detector of $15 \%$ relative efficiency. The r-ray spectra were collected on a multi-channel analyser and were analysed by the GAMANAL code (3); a typical spectrum is shown in Figure 4 .

The peak areas obtained were corrected for Bal40 and Lal40 decay using the code coUNTLA (a), this corrects for the ingrowth of Lal40 and for decay during counting. An analysis, similar to that described in section 2.6 , was then carried out to give the ratio of Lal40 activity from $U 238$ relative to that from U235. This ratio was then converted to the true fision rate ratio by applying the Bal40 flssion yields for U238 and U235. The yields

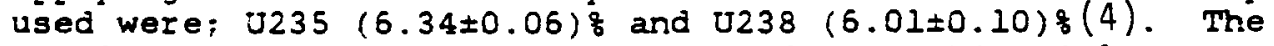
results for this method are presented in section 4.1 .

a) AEEW decay computer programme 


\subsection{INTRODUCTION}

The measurement of RCR can be conveniently considered in two parts; the U238 lattice to thermal capture ratio and the U235 lattice to thermal fission ratio.

\subsection{U238 CAPTURE METHOD}

The nuclear transformations involved in the $U 238$ capture measurement are as follows:

$$
0238+\Omega \rightarrow U 239 \frac{\beta^{-}}{23.5 \mathrm{~min}}>\operatorname{Np239} \frac{\beta^{-}}{2.35 \text { days }}>\text { Pu239 }
$$

The rate of 0238 capture is determined after irradiation by observing the decay of Np239. This decays by $\beta$-emission to excited states of Pu239 which reach the grcund state by $y-r a y$ emission, as shown in Figure 4. Some of the higher energy $y-r a y s$ are highly internally converted, giving $r$ ise to the emission of plutonium $x$-rays which are in coincidence with the $y$-rays. By observing the coincidences between the $104 \mathrm{kev} \mathrm{k} \mathrm{X}-\mathrm{rays}$ and the $106 \mathrm{kev} \gamma$-rays, good discrimination can be obtained against fission product $\gamma$-rays and natural activity.

The method used for the 0238 capture determinations was derived from a dissolution technique, developed inirially for measurements in particulate $\mathrm{UO}_{2}$ fuel $(5)$. It had been necessary, in chat case, to dissolve a large number of the particles to produce a solution containing the average activity of a test section. A small aliquot of this solution could then be taken for activity measurements. The same principle can be applied to rod type fuel where it is necessary to examine a representative section of the iuel.

The choice of this method for 0238 capture was governed by three factors:

(a) The original technique for rod type lattices(2) required thin $\mathrm{UO}_{2}$ discs, $0.12 \mathrm{~mm}$ thick, and matching $\mathrm{UO}_{2}$ peliets, to be made to tolerances of about $\pm 0.002 \mathrm{~mm}$. It was doubtful if these ccmponents could have been made on the time scale envisaged for these measurements.

(b) The fabrication of $\mathrm{UO}_{2}$ components to such fine tolerances is extremely costly.

(c) The dissolution method can use components with iarger tolerances, $\pm 0.05 \mathrm{~mm}$, and therefore lower cost and easier availability, and yet gives results which are comparable in accuracy $(6)$ to the original method.

To use the relaxed fabrication tolerances, bsaring in mind that resonance capture is effectively a surface effect, a $\mathrm{UC}_{2}$ 
peliet about $20 \mathrm{~mm}$ long must be used rather than a thin disc. This ensures that resonance activation of the end surfaces of the peliet, caused by neutron streaming, is small compared to the tojal activation. The derivation of the required tolerances is given in Section 5.2.3. Suitable measuring pellets were produced from standard fuel pellets by removing a thin silce of material from each end with a high speed diamond saw. Care was taken to ensure that the resulting flat end surfaces were perpendicular to the length of the peliet. The $0.25 \mathrm{~mm}$ thick $\mathrm{UO}_{2}$ discs for the thermal column measurements, and those for the fission measurements in the reactor, were prepared by cutting slices of $\mathrm{UO}_{2}$ of approximately the required thickness from standard pellets. The siices were then lapped with a planetary lapping machine to the specified thickness and flatness.

\subsection{SOURCE PRERARATION}

The irradiation procedure has been described in section 2 but it should be noted that about $40 \mathrm{mg}$ of $93 \%$ U235 $\mathrm{J}_{3} \mathrm{O}_{8}$ powder was also included in the thermal column irradiations to provide a fission product correction source. After irradiation and transportation to winfIith, the $\mathrm{UO}_{2}$ pellets for the 0238 capture rate measurement were weighed and then dissolved in nitric acid. Each solution was made up to a known volume ( $\sim 250 \mathrm{ml}$ ) and a scitable aliquot was taken to give the required activity in the final source. The $\mathrm{UO}_{2}$ discs and the $\mathrm{U}_{3} \mathrm{O}_{8}$ powder from the thermal irradiation were also dissolved in the same way. Solutions were also prepared of unirradiated natural uranium and $93 \%$ enriched uranium to act as natural activity standards. At this stage a portion of a solution containing a known mass of unirraciated natural urariun was added to each aliquot to give, as closely as possible, the same total mass of uranium in each alicuot. This was to ensure that the $y$-ray iransmission probabilities from each source were nearly identical, so that the resulting differential corrections from one source to another were very small. Each of the aliquots was reduced to dryness by heating; the resultani residucs wore then redissolved in nitric acid and made up to volumes of $5 \mathrm{ml}$. Portions of these solutions were transierzed to $2 \mathrm{ml}$ liquid source holders using hypodermic syringes. The quantities of solution transfersed were determined gravimetrically.

\subsection{NO239 DETECTION SYSTEM}

The Np239 activities were measured by a coincidence method using a detection system based on two pairs of NaI (Tl) detectors $75 \mathrm{~mm}$ in diameter and $25 \mathrm{~mm}$ thick. Each pair of detectors is vertically opposed and the liquid sources are located in turn between the detectors by means of a twelve position norizontal turntable. The two pairs of detectors are diametrically opposite relative to the turntable. Pulses from the detector amplifiers are passed to single channel analysers which select pulses equivalent to an energy range of $95 \mathrm{kev}$ to $115 \mathrm{kev}$. The selectea pulses from each pair of detectors are used to drive a coincidence unit which produces an output pulse if the pulses at the two inputs ocur within $400 \mathrm{~ns}$ of each other. Thus the system 
preferentially detects coincident Np239 radiaticns and discriminates against fission procuct $y$-rays and ratural activity. The system is housed in a thermostatic enclosure and the sample changer mechanism is computer controlled. Counts are collected, by the computer, from the coincidence units and the single channel analysers.

\subsection{NP239 COUNT ING PROCEDURE}

The liquid sources were loaded onto the twelve position turtable in the order shown below:

$\begin{array}{cl}\text { Position } & \text { Sample } \\ 1 & \text { Lattice position } 1 \\ 2 & \text { Lattice position } 1 \text { duplicate } \\ 3 & \text { Lattice position } 2 \\ 4 & \text { Lattice position } 2 \text { duplicate } \\ 5 & \text { Lattice position } 3 \\ 5 & \text { Lattice position } 3 \text { duplicate } \\ 7 & \text { Thermal disc } 1 \\ 8 & \text { Thermal disc } 2 \\ 9 & \text { Irradiated U235 } \\ 10 & \text { Unirradiated U235 } \\ 11 & \text { Unirradiated natural U } \\ 12 & \text { An243 standard source }\end{array}$

Each sourcecwas measured for ten minutes at, a time ano this procedure continued for about three days to accumulate sufficient counts to give the required precisions. The duplicate sources were additional aliquots taken from the same original solution. A comparison of the results from a source and its duplicate gave information on the reproducibility of the method itself, after the dissolution stage, eliminating effects due to variations in the lattice geometry, for example. The thermal sources were made from two separate $\mathrm{UO}_{2}$ discs.

It was necessary to measure the fissicn product activities of the sources, relative to the irradiated 0235 source, in order to make corrections for fission product interference. These measurements were made on the detection system, previously used to measure the fission ratios, which was described in section 2 . A discriminator level equiralent to $0.64 \mathrm{MeV}$ was used.

\subsection{U238 CAPTURE ANATYSIS}

After the collected data had been trarsferred to the main. computer, the analysis was carried out using the ANCORA code (a). This makes corrections for; deadtime, decay, mass, background, natural activities, Eission products, chance coincidences, $y-r a y$ transmission, etc, and produces lattice to thermal No239 activity ratios and errors.

Natural activity corrections were made on the basis of tine counts recorded from the unirradiatea samples of natural and enriched uranium. Knowing tine isotopic compositions and masses

a) AEEW coincidence counting analys is computer programme 
of these samples, the specific natural activity can be derived for $U 235$ and U238. Then, as the isotopic compositions and masses of all the other sources are known, the individual natural activity for each source may be derived.

Corrections for fission oroduct interference were made by using the coincidence counts from the fission products in the irradiated $\mathrm{U} 235$ source as a reference. The counts due to fission products in the other sources were derived via the previously determined ratios of fission product activities. Making corrections for natural activities and fission products as described aboveinas the advantage that the corrections are determined close to the time of counting, rather than in a previous calibration. Therefoze smali variations in anplifier gain or analyser threshold will have negligible effects on the derived Np239 activity ratios.

As stated previously, the total uranium contents of ail the sources were made as closely as possible the same by adding unirradiated uranium during preparation. Nevertheless, there were still corrections to be made for $y$-ray transmission from the sources. These corrections were made by first calculating the linear $\gamma$-ray absorption coefficient for a source from its chemical composition. The $y$-ray escape probability was then obtained, by interpolation, from a table of absorption coefficients versus escape probabilities. This table was groduced, using published tabulated functions (7), assuming that each detector crystal has 2 geometrical efficiency. This is not strictly the case but, as the detectors are $75 \mathrm{~mm}$ in diameter and the $15 \mathrm{~mm}$ sources are only $10 \mathrm{~mm}$ away from them, it is a reasonable approximation. The method has been checked by a Monte-Carlo code, using the specific detector geometry, and was found to be satisfactory.

The results of the 0238 capture measurements are given in Section 4.2 .

\subsection{No239 MEASUREMENT BY Ge(I.i) DETECTOR}

As a check on possible systematic errors in the NaI(TI) coincidence detection system, the Np239 measurement was repeated on selected liquid sources using a high resolution germanium detector. Discrimination against fission products was obtained solely by virtue of the detector's high resolution, as it was not operated in the coincidence mode. It was therefore necessary to measure the $278 \mathrm{kev}$ Np239 y-ray as this was the only significant Np239 peak clear of fission product $\gamma$-rays.

The measurements were made using a Ge(Li) detector installed in an autonatic sample changer system and the $y-r a y$ spectra were collected on a multi-channel analyser. These spectra were transmitted to the main computer where they were corrected for Np239 decay and for the sample masses. Lattice to thermal activity ratios were then calcuiated. The results obtained are given in section 4.2. 


\subsection{U235 LATTICE TO THERMAT EISSION RATICS}

The ratio of the $U 235$ fission rate in the reactor iattice relative to the $U 235$ fission rate in a thermal spectrum was determined, in conjunction with the Fast Fission Ratio measurement, using the two $0.25 \mathrm{~mm}$ thick $\mathrm{UO}_{2}$ discs from each lattice pack and similar discs from the thermal column. $\mathrm{UO}_{2}$ discs were positioned at each end of the $\mathrm{UO}_{2}$ pellet to be used for the U238 capture measurements, as shown in Figure i. A mean U235 fission rate for the pellet region could then be obtainea. Also a comparison of the rates measured by the two discs gives an indication of possible flux gradients ihrough the pack. The irradiation and counting procedures wás described in section 2; the analysis of the data was carried out ty the FraDA code.

Consider: a lattice disc counted at ime $t$ after shut-down, and a thermal disc counted at time $t$ ' after shut-down. Then one may write:

$$
\begin{aligned}
& C^{I}(t)=N_{5}^{I} F_{5}^{I} G_{5}(t)+N_{8}^{I} F_{8}^{I} G_{8}(t) \\
& C^{T}\left(t^{\prime}\right)=N_{5}^{T} F_{5}^{T} G_{5}\left(t^{\prime}\right)
\end{aligned}
$$

where: $C=$ total count-rate

$N$ - number of atoms per sample

$F=$ count-rate at a standard delay time

$G$ - decay factor relative to the standard delay time

indices $I=$ lattice (reactor)

$T=$ thermal colum

sufices $8=0238$

$5=0235$

Solving (4) and (5) for $F_{5}{ }^{I}$ and $F_{5}{ }^{T}$ one finds:

$$
F_{5}^{L}=\frac{c^{L}(t) N_{5}^{T} G_{5}\left(t^{\prime}\right)}{C^{T}\left(t^{\prime}\right) N_{5}^{I} G_{5}(t)} \quad\left[1+\frac{N_{8}^{L} F_{8}^{L} G_{8}(t)}{N_{5}^{I} F_{5}^{I} G_{5}(t)}\right]^{-1}
$$

where the term in brackets is effectively the correction to the lattice sample count for $U 238 \mathrm{fissions.} \mathrm{The} F g^{L / F}{ }_{5}$ ratio is, in fact, the FFR that was obtained fron the depleted and enriched samples, as described previously in section 2.

Lattice to thermal $U 235$ fission ratios were obtained for each pair of $\mathrm{UO}_{2}$ discs from each measurement pack. These ratios were then combined with the $U 238$ capture lattice to thermal ratios to give the Relative Conversion Ratios. The results obtained are given in section 4.2 . 


\section{RESULTS}

\subsection{RAST PISSION RATIO RESULTS}

The results for the FPR measurements are presented in Table i. Errors quoted on the individual values of FFRy are based on those produced by the FREDA code but also take account of any differences between the results from the two detector systems. The error quoted on each mean value is the standard error derived in the usual way from the deviations of the individual values from the mean. This error reflects all the random processes in the measurement, including any effects of the reactor environment, and is less than is for all five irradiations.

To convert PFRy to true FFR the FFRy values are multiplied by a calibration factor of $1.031 \pm 2 \%$. The error on the factor is the major systematic error in the measurement of FPR. Corrections and errors in the determination of FPR are aiscussed in section 5.1 and are summarised in Table 3. A comparison of the results from the gross $y$-ray method with those from the La140 method is given in Table 6. The mean ratio, for all the irradiations, of gross $\gamma-r$ ay to $\mathrm{La}-140$ is $1.025 \pm 1.2 \%$ random, \pm $2.5 \%$ systematic.

\subsection{RELATIVE CONVERSION RATIO RESULTS}

The results of the Relative Conversion Ratio measurements are presented in Table 2. The RCR is derived by dividing the lattice to thermal ratio of $\mathrm{U} 238$ capture by the lattice to thermal ratio of $U 235$ fission. Errors quoted on the U235 fission ratios and the U238 capture ratios are based on those produced by the FREDA and ANCORA codes respectively. A contribution from other causes is included as indicated in Tables 4 and 5 . The erzors on the mean RCR ralues are derived from the deviations of the values from the mean. As for FFR this error on the mean may include effects due to small variations in the reactor environment. The quoted errors on the mean $R C R$ are $0.5 \%$, or less, for every irradiation. A comparison between the coincidence counting method and the $G e(L i)$ detector method is given in Table 6. The mean ratio of coincidence to Ge(Li) is $0.996 \pm 0.8 \%$. Corrections and errors in the measurement of RCR are discussed in section 5.2 and are summarised in Tables 4 and 5 .

\section{CORRECTIONS AND ERRORS}

\subsection{CORRECTIONS AND_ERRORS FOR FAST FISSION RATIO}

\section{1 .1 Deaditime}

A correction was applied by FREDA assuming a deadtime of 1 usecond. For tire count-rates encountered in these experiments the maximum corection was about $0.15 \%$ and the ercor on the correction produced a negligible effect on the results. 


\section{1 .2 Detector Background}

A separate detector was used specifically to measure $y-r a y$ background activity. Prior to each measurement the ratio was decermined of the background activity from the measuring detectors to that from the background detector. This ratio was then applied to the counts collected from the background detector during the measurement to derive the background counts from the measuring detectors. The error on the final result due to background is estimated at $0.1 \%$.

\section{1 .3 Nątural Activity}

The natural activities of the samples were determined by measuring them on the automatic y-ray detection system prior to the preparation of the sample packs. The contribution of the natural activity was about $8 \%$ for the depleted foils and less than 18 for the $\mathrm{UO}_{2}$ discs. As the natural activties were determined to $\pm 2 \%$ this gave $a \neq 0.16 \%$ error on the FPR result.

\section{1 .4 Peedthrough}

Samples that are being measured on the automatic detector system are subject to interference or "feedthrough" from samples in the magazine. Approximately $0.1 \%$ of the activity from a sample in the magazine is detected at the measuring position. The depleted and $\mathrm{UO}_{2}$ samples are separated for measurement to minimise this problem but even so there is a correction of about $0.3 \%$ to be made. The effect on the result is an additional error of about $0.03 \%$.

\section{1 .5 Perturbation}

Putting a depleted uranium foil into the $4.31 \% \mathrm{UO}_{2}$ measuring pack inevitably causes a flux pezturbation. Previous measurements with varying thickeseses of depleted foils have shown that the perturbation is less than $1 \%$ but with ar uncertaincy of $\pm 1 \%$.

\section{$5.1 .6 \quad y-R a y$ Attenuation}

Small corrections were made for the effects of $y$-ray attenuation in the depleted and $\mathrm{UO}_{2}$ samples. Initial calculations were made using a Monte-Carlo code. Ihis showed that the attenuation in a typical depleted foil was 1.00 and ir. a typical $\mathrm{UO}_{2}$ disc was $1.7 \%$. Corrections to the individual foils were then made by FREDA using the algorithm $I+\left(C . M / D^{2}\right)$, where $M$ is the sample mass, $D$ is its diameter and $C$ is a constant derived by comparison with the Monte-Carlo result. The effect on FFR was estimated to be an additional error of less than 0.18 . 


\section{1 .7 Samole Holders}

As the depleted and $\mathrm{UO}_{2}$ samples are measured separateiy on the automatic detector system, the depleted and $\mathrm{UO}_{2}$ samples from a particular experimental pack are measured in the same sample holder. Any positioning or attenuation effects due to the sample holder therefore cancel out in the calculation of FFR.

\section{1 .8 Sample Enrichments}

It can be shown from a consideration of the equation for $P P R$ in section 2.7 that a variation in the $U 235$ content of the depleted foil gives $r$ ise to an effect many times smalier in FPR. The increased error varies from $0.3 \%$ for the first irradiation to 0. If for the last irradiation. Any variation in the enrichment of the enriched discs has an almost direct effect on FFR. The enrichments of both materials have been measured by comparison with natural uraniun samples. The $185 \mathrm{kev} \gamma$-ray from U235 was observed using a $\mathrm{Ge}(\mathrm{Li})$ detector. The depleted enrichment was measured to be $(0.0417 \pm 0.0006)$ and the $\mathrm{UO}_{2}$ enrichment was measured to be $(4.31 \pm 0.03)$, compared to the quoted value of $(4.31 \pm 0.01) \%$.

\section{1 .9 Conversion Pactor for $7 P$ ga to $F B B$}

As stated previously the measured FPR is derived in terms of $\gamma$-ray activities rather than true fission rates. The relationship is given by FFRy.P = FPR, where FPRy is the $\gamma$ activity ratio derived by FREDA, $P$ is the calibration factor and FPR is the true fission rate ratio. A brief description of the method used to ceauce the calibration factor is given below.

The true FFR was measured close to the perioheral reflector of the source reactor Nestor using zebra type (8; U235 and $\mathrm{U} 238$ absolute fission chambers (ZEB48 and ZEBS7) operated under cadmium shields. Then the PFR, was measured using depleted and natural uranium foils placed in demountable dummy fission chambers. The dummy chambers were positioned in the cadmium shields in the same location as real fission chanbers had been. An irradiation of exactly 2 hours was made, then about 24 hours later the foils were measured on the $r$-detector system in the same way as described in section 2. After the oross $\gamma$ - ray FPR had been determined the La-140 activities were aiso measured by the method described in sectior. 2.7 .

The True PFR measured by fission chambers was $0.00150 \pm 28$ and by the La-140 method was $0.00151 \pm 28$, the FPRy was $0.00145 \pm$ 18. This gives a calibration factor of $P=1.03 \pm 2.28$. Previous work in the Zebra reactor has yielded similar values of $P$ for experiments using a $y$-ray discrimination level of $0.65 \mathrm{MeV}$.

\subsubsection{Decay Correction}

Decay corrections were made by using a previously determined decay table incozporated in tine FREDA cods. The error due to this correction was estimated to be $0.5 \%$. 


\subsection{CORRECTIONS AND ERRORS FOR U238_CAPTURE}

\subsubsection{Deadtime and Chance Coinciaences}

Corrections were made by ANCORA for deadtine and for chance coincidences. The magnitudes of the corzections were about $0.2 \%$ in both cases and were of opposite sign. The effect of errors on the corrections on the final results was negligible.

\section{2 .2 Natural Activity}

The method of correction for natural activity was described in section 3.6. The magnitude of the correction was between 18 and $6 \%$, depending on the sample activity. Uncertainties on the corrections had the effect of an additional error of about $0.15 \%$ on the final result.

\section{2 .3 Calculation of Tojerances on Dimensions of Measuring Pellet in RCR Determinations}

Tolerance on Pellet Diameter

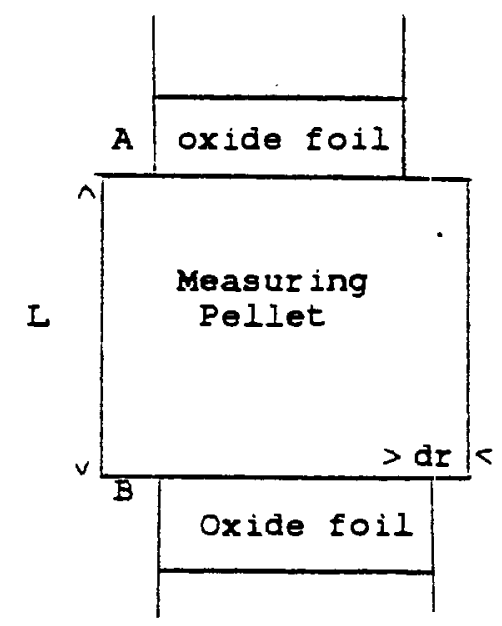

Consider measuring pellet with oversize diameter - r+dr exposing additional surface area of $4 \Pi r d r$. (The additional cylindrical surface would be accommodated in the calculations). This constitutes a fractional increase in surface area of

$$
\frac{4 \pi r d r}{2 \pi r L}=\frac{2 d r}{L}
$$


This wili cause a fractional increase in resonance activation of $d r / L$ since the solid angle for neutrons able to strike $A$ or $B$ is half that to strike the cylindrical surface. Since resonance activation accounts for $50 \%$ of the total $U 238$ capture rate in the rcd a limit of $0.1 \%$ on an increase in total capture rate requires a limit of an increase of $0.2 \%$ in resonance capture i.e. $d r / L=0.002$ since $L=15.49 \mathrm{~mm} d r=0.03 \mathrm{~mm}$. $0.002^{\circ}$

Thus the tolerance on the pellet diameter $=2 \mathrm{dr}=0.06 \mathrm{~mm}$ or Tolerance on surface Platness

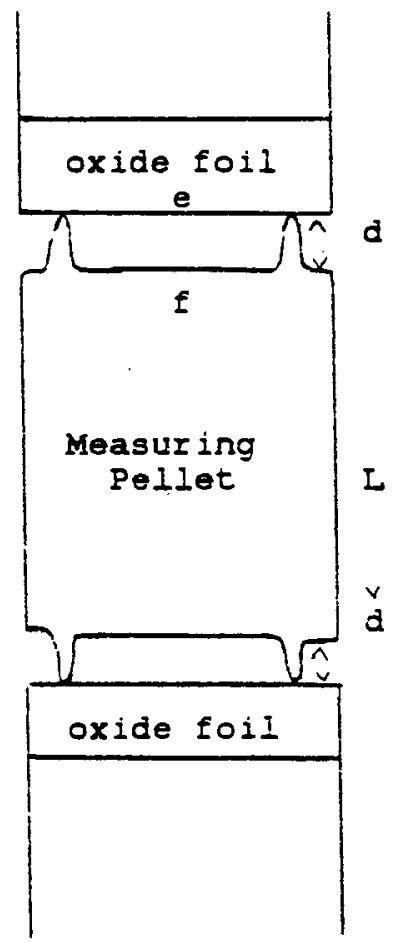

Assuming that neutrons entering the gap $d$ wili be absorbed (since the gap is very small compared with the diameter) and absorbed equaliy on surfaces $e$ and $f$, each gap is therefore equivalent to an extra slirface of $2 \pi r$ d.

This will be a fractional increase in area of

$\frac{2 \pi r d}{2 \pi r L}=\frac{d}{L}$ 
Since an increase in resonance capture must be limited to $0.2 \%$ (to limit increases in the total capture to $0.1 \%$ ).

$$
\frac{d}{L}=0.002 d=0.002 \times 15.5 \mathrm{~mm}=0.031 \mathrm{~mm} \text { or } 0.0012 \text { \% }
$$

Thus the ends of the measuring pellet and the oxide foil must be flat to within $0.031 \mathrm{~mm}$.

\section{2 .4 y-Ray Attenuation}

The method of correction for $\gamma$-ray attenuation in the liquid sources was described in section 3.6. Although there was about a $23 \%$ loss of $\gamma-r a y s$ due to absorption, the lifferential effects were very small. The effects of errors in the corrections were less than $0.1 \%$.

\section{2 .5 Holder Calibration}

The Iiquid source holders are made with as near the same dimensions as is practicable. Calibrations of the holders using standard solutions of $\mathrm{Np}-239$ have shown that the efficiencies of the holders do not vary beyond $\pm 0.2 \%$.

\section{2 .6 Rission Product Correction}

The method of correction for fission product interference was described in section 3.6. The correction varies from about 18 for the latice samples to about 78 for the thermal samples. The effect of errors in the fision product corrections resulted in an additional error of about 0.158 on the final result.

\section{2 .7 Decay Correction}

Due to the method of measurement and analysis it was only necessary to make corrections over a periol of about 2 hours. The size of the correction was about 2.58 and the error on the correction resulted in a negligible error on the final results.

\section{2 .8 Sample Dispensing}

Liquid sample preparation was carried out by an experienced Chemist and great care was taken to minimise errors by careful weighing during the various stages of preparation. An analysig(10)

of the method has indicated that an errol of $\pm 0.2 \%$ is possible in the quoted mass of a sample.

\section{2 .9 U235 Plssion Lattice to Thermal Ratio}

The corrections and errors in the determination of the U235 fission ratio are broadiy the same as has been discussed for the FFR measurement in section 5.1. The components are sumnarised in Table 5 . 


\section{SUMARY}

Measurements have been made of Fast Fission Ratios and Relative Conversion Ratios in five different water moderated $\mathrm{VO}_{2}$ lattices. The measurements were out of the ordinary in that the irradiations took palce in the USA and the activity determinations were made at AEE winfrith. In spite of the transportation problems involved, successful measurements have been achieved for all five experiments.

The Fast Fission Ratios have been measured with an accuracy of $2.3 \%$ and the Relative Conversion Ratios with an accuracy of $0.5 \%$ or better. The results have been checked for systematic errors by using alternative methods where possible and r.o significant errors have been found.

\section{ACRNOWLEDGENENTS}

I wish to record my thanks to Dr $W H$ Taylor for his help and advice in the initial planning of these experiments. I thank; Dr $S$ Bierman and his team at Battelle PNL in the USA for the care taken in providing carefully controlled irradiation conditions, and $M r$ March and $M r ~ R$ Stout and his team at AEEW for organising the Nestor irradiations. I thank; Mr W Cox for preparing the liquid sources, $M r$ A Gregory and $M r ~ R$ Keay for organising the transportation of the samples, and $M r F$ Eltham for running the analysis codes. 


\section{REFERENCES}

(1) W $\mathrm{A} \vee$ BROWN et a1. Measurements of Fast Fission Ratio. AEEW-R 341 .

(2) G A Barnett et al. Measurement of Relative Conversion Ratio and Fast Fission Ratio in Low Enrichment 0xide Lattices. AEEW - R 648.

(3) W H Taylor et al. Control of the Counting Laboratory at AEE Winfrith by a Smal1 Computer. AEEW - R 830 .

(4) J B Niday, R Gunnink. Computerised Quantitative Analysis by Gamma-Ray Spectrometry. UCRL-51061.

(5) J G Cunninghame. The Status of Fission Product Yield Data in 1977. AERE - R 8753.

(6) W H Taylor et al. Measurement of Fast Fission Ratio and Relative Conversion Ratio in Particulate Fuel. AEEW - R 712.

(7) M F Murphy et a 1. RCR Measurements in the Natural Uranium Metal/ $\mathrm{H}_{2} \mathrm{O}$ Cores in JUNO Using the Liquid Source Method. International Publication. ETM/P161.

(8) S Chandrasekav. Tabulated Functions. Astrophysics. Jul Vol 108, No. 1, P92 (1948).

(9) J M Stevenson, A M Broomfield. Measurements and Calculations of Ratios of Effective Fission Cross-Sections in the Zero-Power Fast Reactor Zebra. AEEW - R 526.

(10) J'Grattan. An Assessment of Errors in the Preparation of Liquid Sources of Natural $\mathrm{UO}_{2}$ Foils and Plates. AEEW-CSR(78)16. 
TABLE 1

FAST EISSION RATIO RESULTS

\begin{tabular}{|c|c|c|c|c|c|c|c|}
\hline Expt & Pack & FFR $_{\gamma}$ & $\begin{array}{c}\frac{9}{0} \\
\text { Random } \\
\text { Error }\end{array}$ & $\begin{array}{l}\text { Mean } \\
\text { FFR }_{\gamma}\end{array}$ & $\begin{array}{c}\frac{9}{0} \\
\text { Random } \\
\text { Error }\end{array}$ & FFR & Error \\
\hline $\begin{array}{l}1 \\
1 \\
1\end{array}$ & $\begin{array}{l}1 \\
2 \\
3\end{array}$ & $\begin{array}{l}0.001901 \\
0.001914 \\
0.001901\end{array}$ & $\begin{array}{l}0.6 \\
0.6 \\
0.6\end{array}$ & 0.00190 & 0.4 & 0.00195 & 2.3 \\
\hline $\begin{array}{l}2 \\
2 \\
2\end{array}$ & $\begin{array}{l}1 \\
2 \\
3\end{array}$ & $\begin{array}{l}0.002161 \\
0.002215 \\
0.002171\end{array}$ & $\begin{array}{l}0.6 \\
0.6 \\
0.6\end{array}$ & 0.00218 & 0.8 & 0.00225 & 2.4 \\
\hline $\begin{array}{l}3 \\
3 \\
3\end{array}$ & $\begin{array}{l}1 \\
2 \\
3\end{array}$ & $\begin{array}{l}0.003785 \\
0.003866 \\
0.003886\end{array}$ & $\begin{array}{l}0.8 \\
0.8 \\
0.8\end{array}$ & 0.00385 & 0.8 & 0.00396 & 2.4 \\
\hline $\begin{array}{l}4 \\
4 \\
4\end{array}$ & $\begin{array}{l}1 \\
2 \\
3\end{array}$ & $\begin{array}{l}0.00564 \\
0.00557 \\
0.00555\end{array}$ & $\begin{array}{l}0.9 \\
0.9 \\
0.9\end{array}$ & 0.00559 & 0.5 & 0.00571 & 2.3 \\
\hline $\begin{array}{l}5 \\
5 \\
5\end{array}$ & $\begin{array}{l}1 \\
2 \\
3\end{array}$ & $\begin{array}{l}0.00552 \\
0.00548 \\
0.00558\end{array}$ & $\begin{array}{l}0.8 \\
0.3 \\
0.8\end{array}$ & 0.00553 & 0.5 & 0.00568 & 3.3 \\
\hline
\end{tabular}


TARIE 2

RELATIVE CONVERSION RATIO RESULTS

\begin{tabular}{|c|c|c|c|c|c|c|c|c|c|}
\hline Expt & Pack & $\begin{array}{r}F 5 \\
L / T\end{array}$ & $\begin{array}{c}\% \\
\text { Random } \\
\text { Error }\end{array}$ & $\begin{array}{r}C 8 \\
L / T\end{array}$ & $\begin{array}{c}\delta \\
\text { Random } \\
\text { Error }\end{array}$ & $\mathrm{RCR}$ & $\begin{array}{c}\delta \\
\text { Random } \\
\text { Error }\end{array}$ & $\begin{array}{r}\text { Mean } \\
\text { RCR }\end{array}$ & $\begin{array}{c}\delta \\
\text { Random } \\
\text { Error }\end{array}$ \\
\hline $\begin{array}{l}1 \\
1 \\
1\end{array}$ & $\begin{array}{l}1 \\
2 \\
3\end{array}$ & $\begin{array}{l}6.43 \\
6.44 \\
6.46\end{array}$ & $\begin{array}{l}0.5 \\
0.5 \\
0.5\end{array}$ & $\begin{array}{l}17.47 \\
17.43 \\
17.38\end{array}$ & $\begin{array}{l}0.8 \\
0.8 \\
0.8\end{array}$ & $\begin{array}{l}2.72 \\
2.70 \\
2.69\end{array}$ & $\begin{array}{l}0.9 \\
0.9 \\
0.9\end{array}$ & 2.70 & 0.5 \\
\hline $\begin{array}{l}2 \\
2 \\
2\end{array}$ & $\begin{array}{l}1 \\
2 \\
3\end{array}$ & $\begin{array}{l}0.934 \\
0.940 \\
0.922\end{array}$ & $\begin{array}{l}0.25 \\
0.25 \\
0.25\end{array}$ & $\begin{array}{l}2.96 \\
3.01 \\
2.94\end{array}$ & $\begin{array}{l}0.5 \\
0.5 \\
0.5\end{array}$ & $\begin{array}{l}3.17 \\
3.20 \\
3.18\end{array}$ & $\begin{array}{l}0.6 \\
0.6 \\
0.68\end{array}$ & 3.18 & 0.3 \\
\hline $\begin{array}{l}3 \\
3 \\
3\end{array}$ & $\begin{array}{l}1 \\
2 \\
3\end{array}$ & $\begin{array}{l}0.877 \\
0.859 \\
0.855\end{array}$ & $\begin{array}{l}0.25 \\
0.25 \\
0.25\end{array}$ & $\begin{array}{l}4.42 \\
4.37 \\
4.37\end{array}$ & $\begin{array}{l}0.5 \\
0.5 \\
0.5\end{array}$ & $\begin{array}{l}5.04 \\
5.09 \\
5.11\end{array}$ & $\begin{array}{l}0.6 \\
0.6 \\
0.6\end{array}$ & 5.08 & 0.4 \\
\hline $\begin{array}{l}4 \\
4 \\
4\end{array}$ & $\begin{array}{l}1 \\
2 \\
3\end{array}$ & $\begin{array}{l}0.355 \\
0.359 \\
0.357\end{array}$ & $\begin{array}{l}0.25 \\
0.25 \\
0.25\end{array}$ & $\begin{array}{l}2.72 \\
2.74 \\
2.72\end{array}$ & $\begin{array}{l}0.5 \\
0.5 \\
0.5\end{array}$ & $\begin{array}{l}7.58 \\
7.62 \\
7.64\end{array}$ & $\begin{array}{l}0.6 \\
0.6 \\
0.6\end{array}$ & 7.64 & 0.3 \\
\hline $\begin{array}{r}5 \\
.5 \\
5\end{array}$ & $\begin{array}{l}1 \\
2 \\
3\end{array}$ & $\begin{array}{l}1.210 \\
1.223 \\
1.212\end{array}$ & $\begin{array}{l}0.25 \\
0.25 \\
0.25\end{array}$ & $\begin{array}{l}9.10 \\
9.16 \\
9.09\end{array}$ & $\begin{array}{l}0.5 \\
0.5 \\
0.5\end{array}$ & $\begin{array}{l}7.52 \\
7.49 \\
7.50\end{array}$ & $\begin{array}{l}0.6 \\
0.6 \\
0.6\end{array}$ & 7.50 & 0.3 \\
\hline
\end{tabular}




\section{TABLE 3}

CORRECTIONS TO EPR

\begin{tabular}{|c|c|c|c|}
\hline Correction & Size & $\begin{array}{c}\text { Error } \\
\text { on } \\
\text { Correction }\end{array}$ & Effect \\
\hline $\begin{array}{l}\text { Dead time } \\
\text { Background } \\
\text { Depleted natural activity } \\
\text { UO natural activity } \\
\text { Peedthrough } \\
\text { Perturbation } \\
\text { y-ray attenuation } \\
\text { Depleted enrichment } \\
\text { UO enrichment } \\
\text { Factor FFR to FFR } \\
\text { Decay } \\
\text { Detector stability }\end{array}$ & $\begin{array}{l}0.15 \% \\
5 \% \\
8 \% \\
1 \% \\
0.38 \\
1 \% \\
1.7 \% \\
0.00417 \% \\
4.31 \% \\
1.031 \\
\times 2\end{array}$ & $\begin{array}{r}108 \\
28 \\
28 \\
28 \\
108 \\
100 \% \\
108 \\
1.58 \\
0.258 \\
2.28 \\
0.58 \\
-\end{array}$ & $\begin{array}{l}0.015 \% \\
0.1 \% \\
0.168 \\
0.028 \\
0.038 \\
1 \% \\
0.078 \\
0.28 \\
0.258 \\
2.28 \\
0.58 \\
0.18\end{array}$ \\
\hline
\end{tabular}


TABIE 4

CORRECTIONS TO 0238 CARTURE RATIO

\begin{tabular}{|c|c|c|c|}
\hline Correction & Size & $\begin{array}{c}\text { Error on } \\
\text { Correction }\end{array}$ & Effect \\
\hline $\begin{array}{l}\text { Deadtime and chance coincidences } \\
\text { Natural Activity } \\
\text { Perturbation - pellet size mismatch } \\
\text { y-ray attenuation } \\
\text { Holder calioration } \\
\text { Fission product correction } \\
\text { Fission product corrections ratio } \\
\text { Decay correction } \\
\text { Sample dispensing } \\
\text { Detector stability }\end{array}$ & $\begin{array}{l}0.2 \% \\
1 \%-6 \% \\
0.15 \% \\
23 \% \\
0.2 \% \\
18-7 \% \\
\quad 1 \\
2.5 \% \\
\quad- \\
\quad-\end{array}$ & $\begin{array}{l}10 \% \\
2.5 \% \\
100 \% \\
10 \% \\
100 \% \\
2 \% \\
1 \% \\
0.5 \% \\
0.2 \% \\
-\end{array}$ & $\begin{array}{l}0.028 \\
0.15 \% \\
0.15 \% \\
0.18 \\
0.28 \\
0.15 \% \\
0.07 \% \\
0.01 \% \\
0.28 \\
=.2 \%\end{array}$ \\
\hline
\end{tabular}

\section{TABIE 5}

CORRECTIONS TO U235 RISSION RATIO

\begin{tabular}{|c|c|c|c|}
\hline Correction & Size & $\begin{array}{c}\text { Error on } \\
\text { Correction }\end{array}$ & Effect \\
\hline $\begin{array}{l}\text { Deadtime } \\
\text { Background } \\
\text { Natural activity } \\
\text { Peedthrough } \\
\text { y-ray attenuation } \\
\text { Holder calibration }\end{array}$ & $\begin{array}{l}0.15 \% \\
0.38 \\
1 \% \\
1 \% \\
1.7 \% \\
0.1 \%\end{array}$ & $\begin{array}{l}108 \\
28 \\
1.58 \\
108 \\
108 \\
1.08\end{array}$ & $\begin{array}{l}0.0158 \\
0.0068 \\
0.0158 \\
0.18 \\
0.018 \\
0.18\end{array}$ \\
\hline
\end{tabular}




\section{TABIE E}

CHECK MEASUREMENTS

\begin{tabular}{|c|c|c|c|c|c|c|}
\hline Expt & $\mathrm{Co} / \mathrm{Ge}(\mathrm{Li})$ & Error & $\mathrm{FFR}_{\gamma} / \mathrm{La}$ & Error & $\begin{array}{c}\text { U235 } \\
\text { FREDA/Ge (Li) }\end{array}$ & $\begin{array}{c}\% \\
\text { Error }\end{array}$ \\
\hline $\begin{array}{c}1 \\
2 \\
3 \\
4 \\
5 \\
\text { Mean }\end{array}$ & $\begin{array}{c}1 . \overline{0} \\
1.929 \\
0.990 \\
1.011 \\
0.986 \\
0.996\end{array}$ & $\begin{array}{l}- \\
3 \\
1.5 \\
1.2 \\
0.9 \\
0.8\end{array}$ & $\begin{array}{l}1.042 \\
1.027 \\
1.020 \\
1.027 \\
1.009 \\
1.025\end{array}$ & $\begin{array}{l}2.6 \\
2.7 \\
2.8 \\
2.9 \\
2.9 \\
2.5\end{array}$ & $\begin{array}{c}1.030 \\
- \\
1.015 \\
- \\
1.015 \\
1.020\end{array}$ & $\begin{array}{l}1.0 \\
0.8\end{array}$ \\
\hline
\end{tabular}

Notes: 1 Co/Ge(Li indicates coincidence counting for U238 capture compared to $\mathrm{Ge}(\mathrm{Li})$ counting for U238 capture

2 FPR $/$ La indicates the gross y-ray method for PFR compared to tine Lal40 method

3 U235 FREDA/Ge(Li) indicates the gross $y-z a y$ method for 0235 lattice to thermal ratio compared to the tal40 method

4 The error on FFR/La contains a large systematic component from the calibration factor $F$ and from the uncertainties on the Bal40 fission yielas 


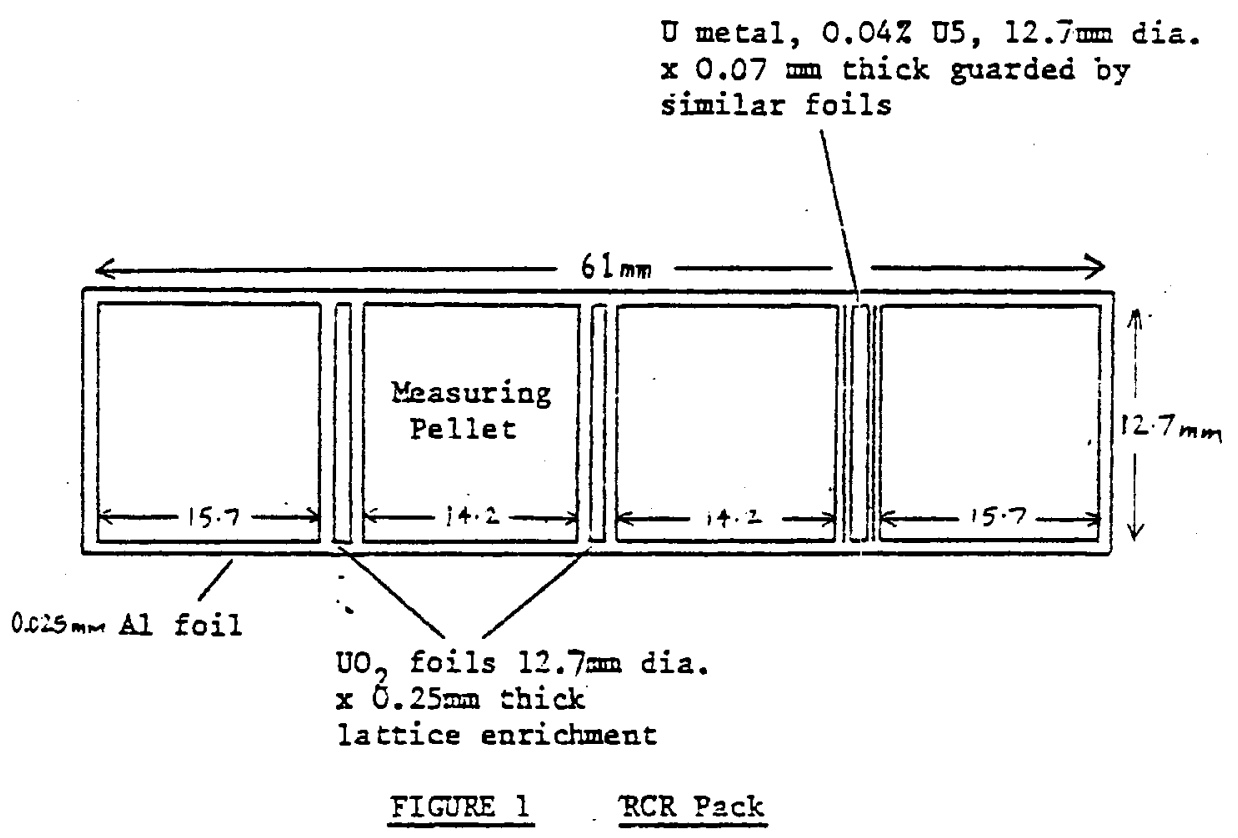

guard foils

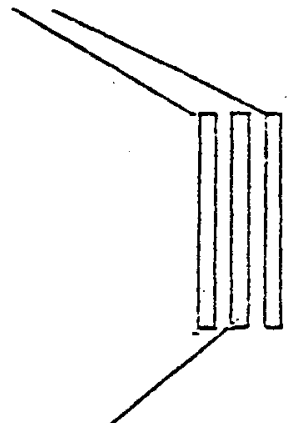

measuring foil; UO, 12.7 dia.

$x 0.25 \mathrm{~mm}$ thick, lattice enrichnen:

FIGURE 2 Thermel Foil Pack 


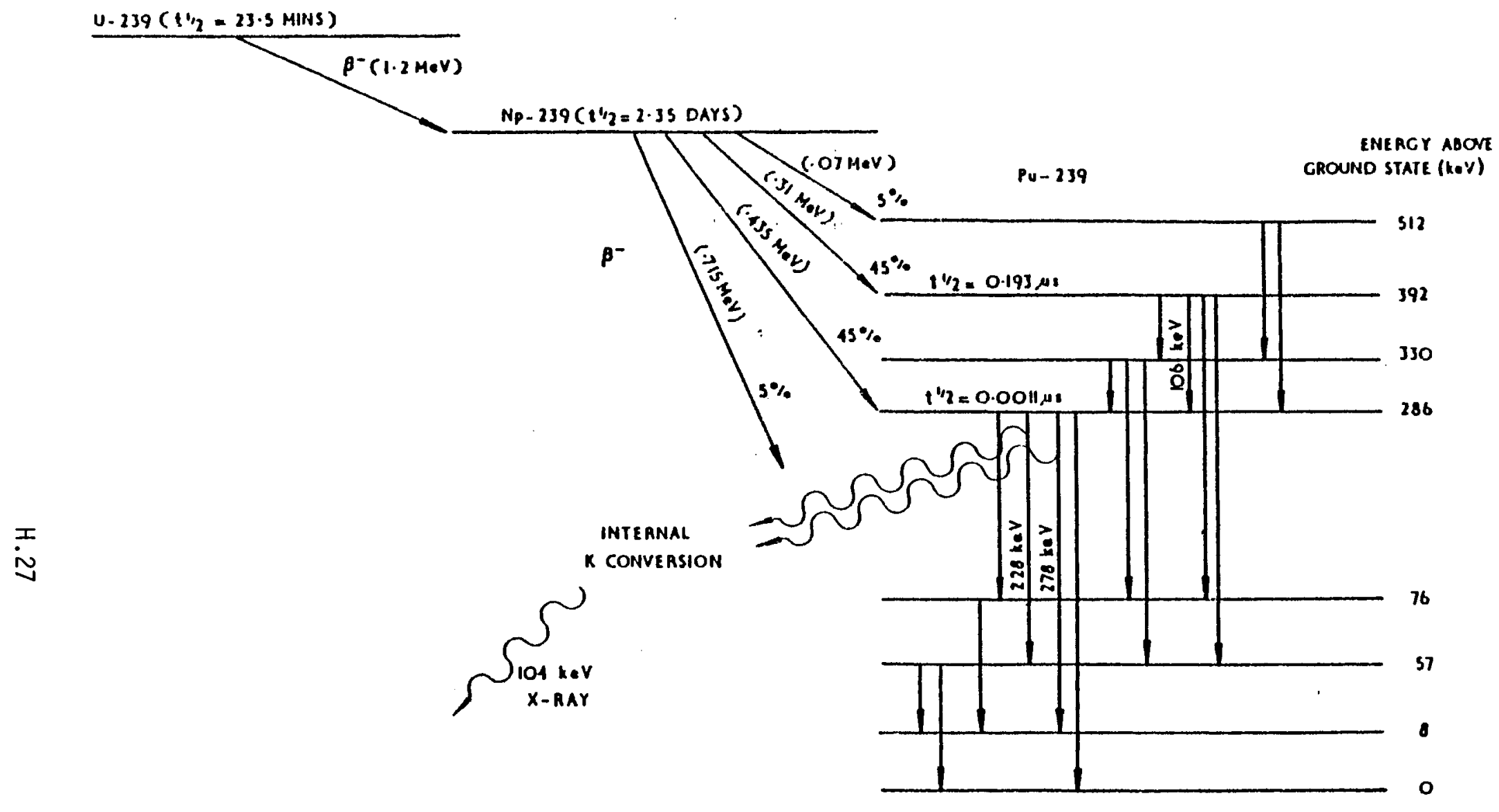

FIG.3. U-239 DECAY SCHEME 


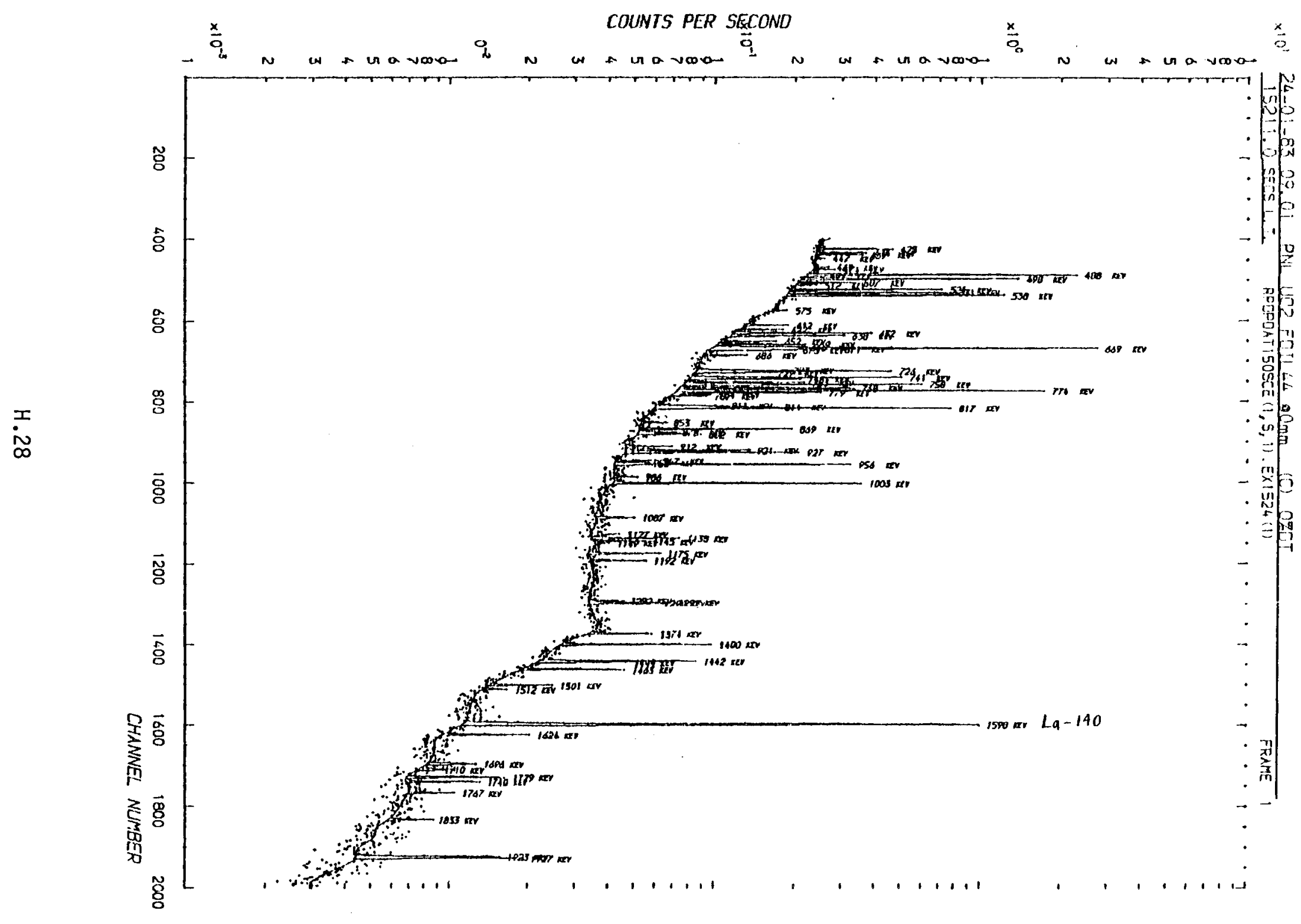




\section{APPENDIX I}

Photo Reductions of Control Channel 4 Recorder Charts During Reaction Rate Measurements 
1

$\downarrow$ 


\title{
APPENDIX I
}

\section{Photo Reductions of Control Channel 4 Recorder} Charts During Reaction Rate Measurements

\begin{abstract}
Copies of the recorder chart displaying the thermal neutron flux level immediately preceding and during each irradiation associated with the reaction rate measurements are presented in this Appendix for information only. No attempt has been made to define or modify the notations made on the chart recordings at the time of irradiations. The constancy of the flux level achieved during the irradiations can be noted.
\end{abstract}




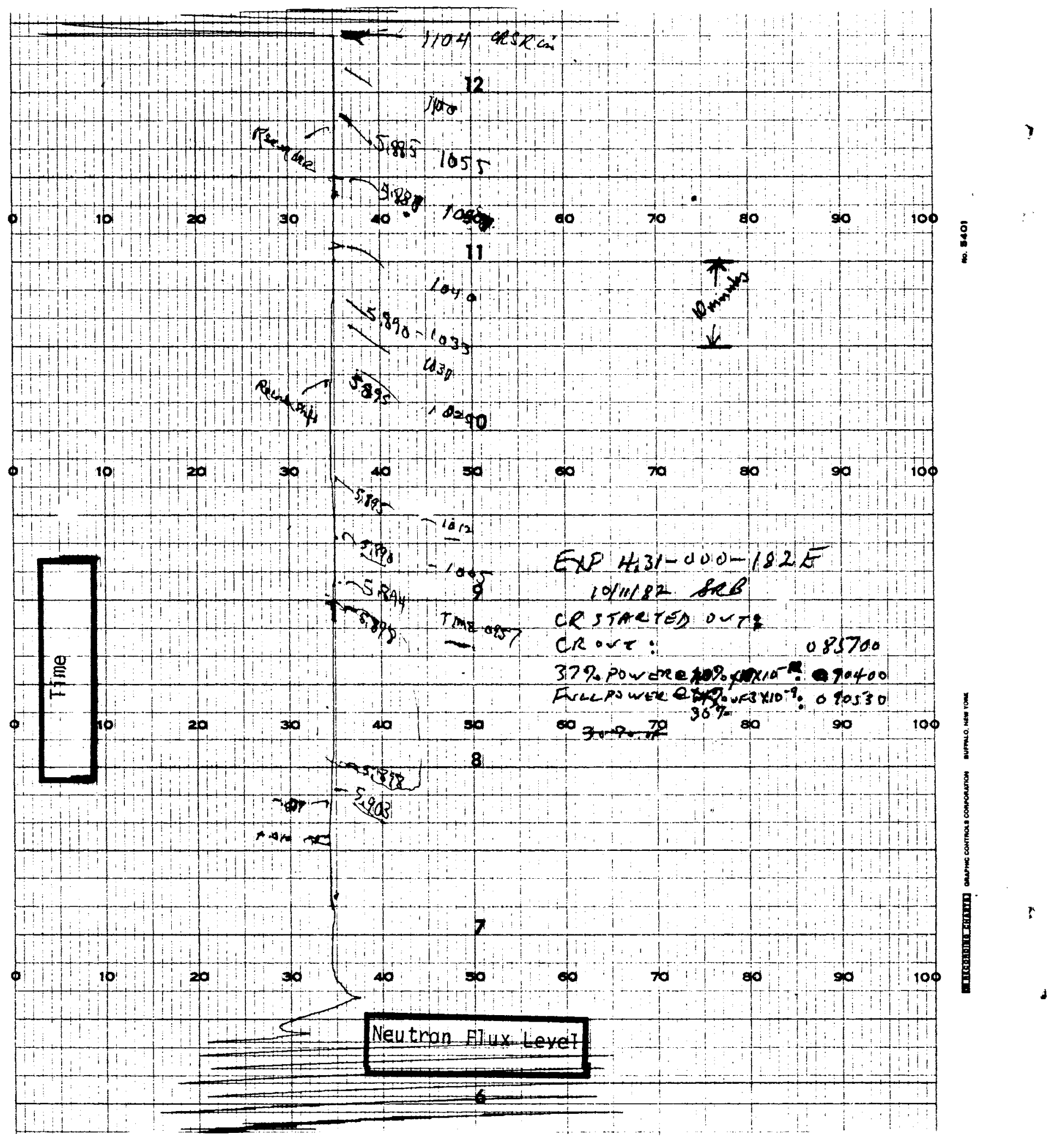




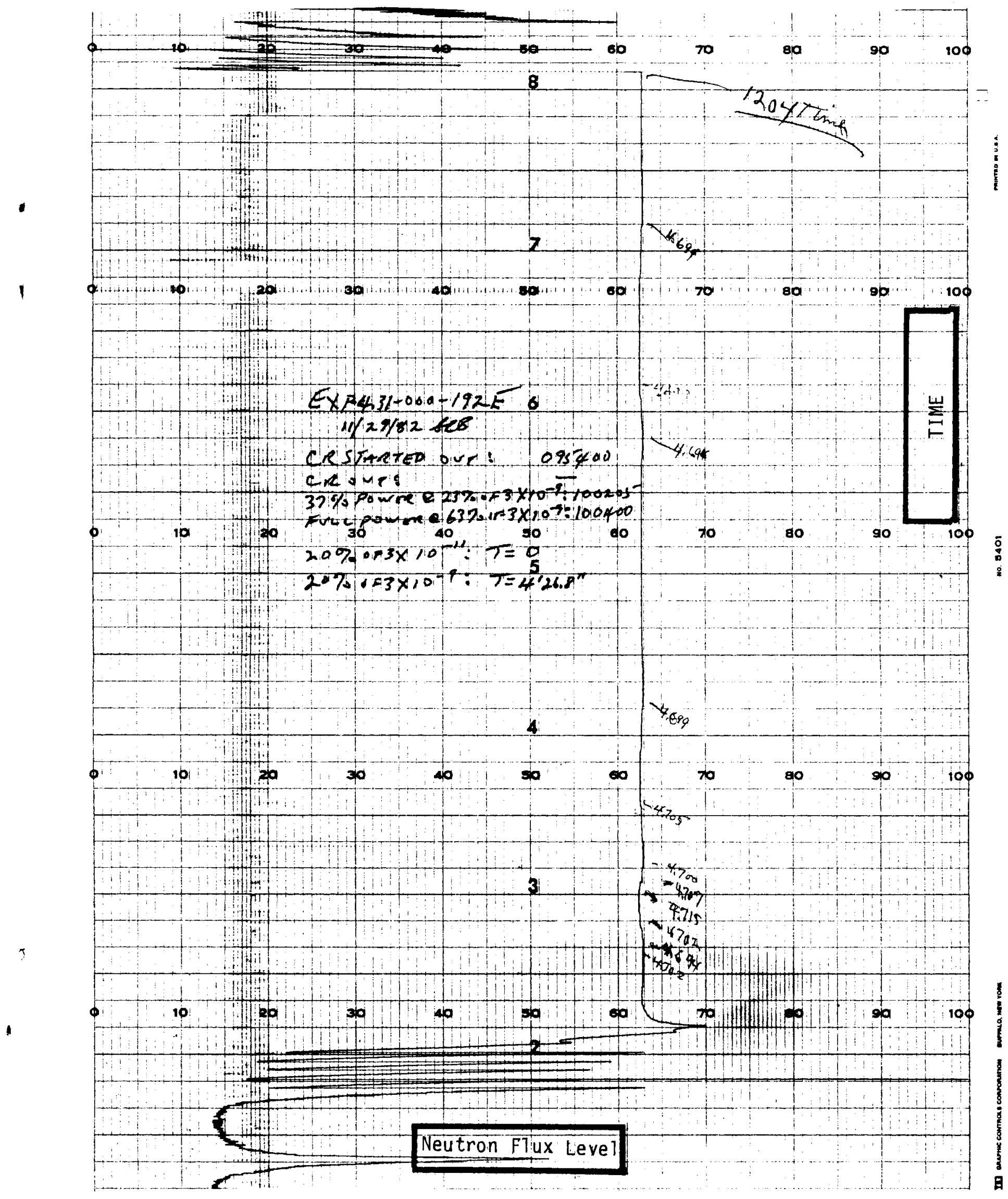




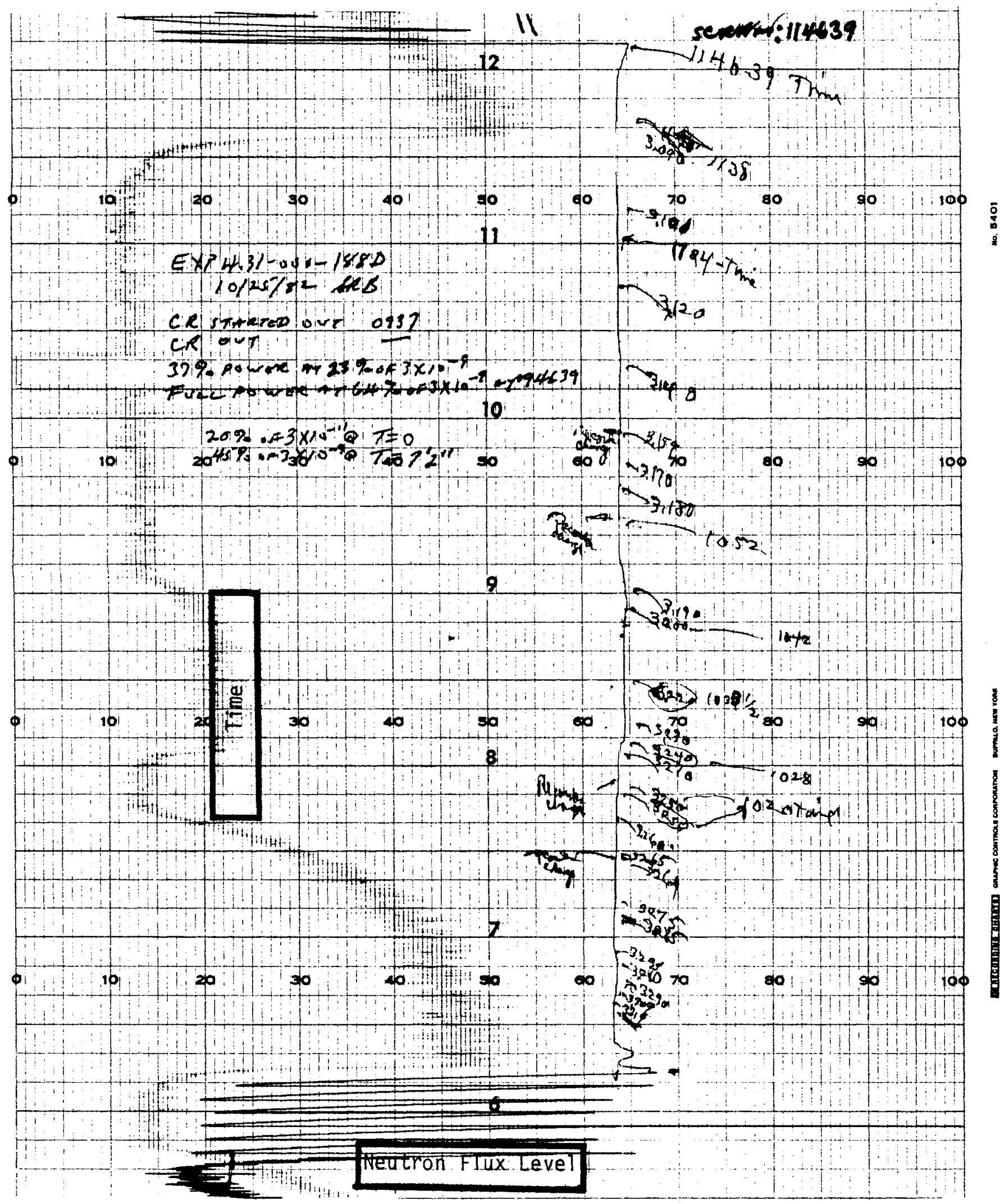




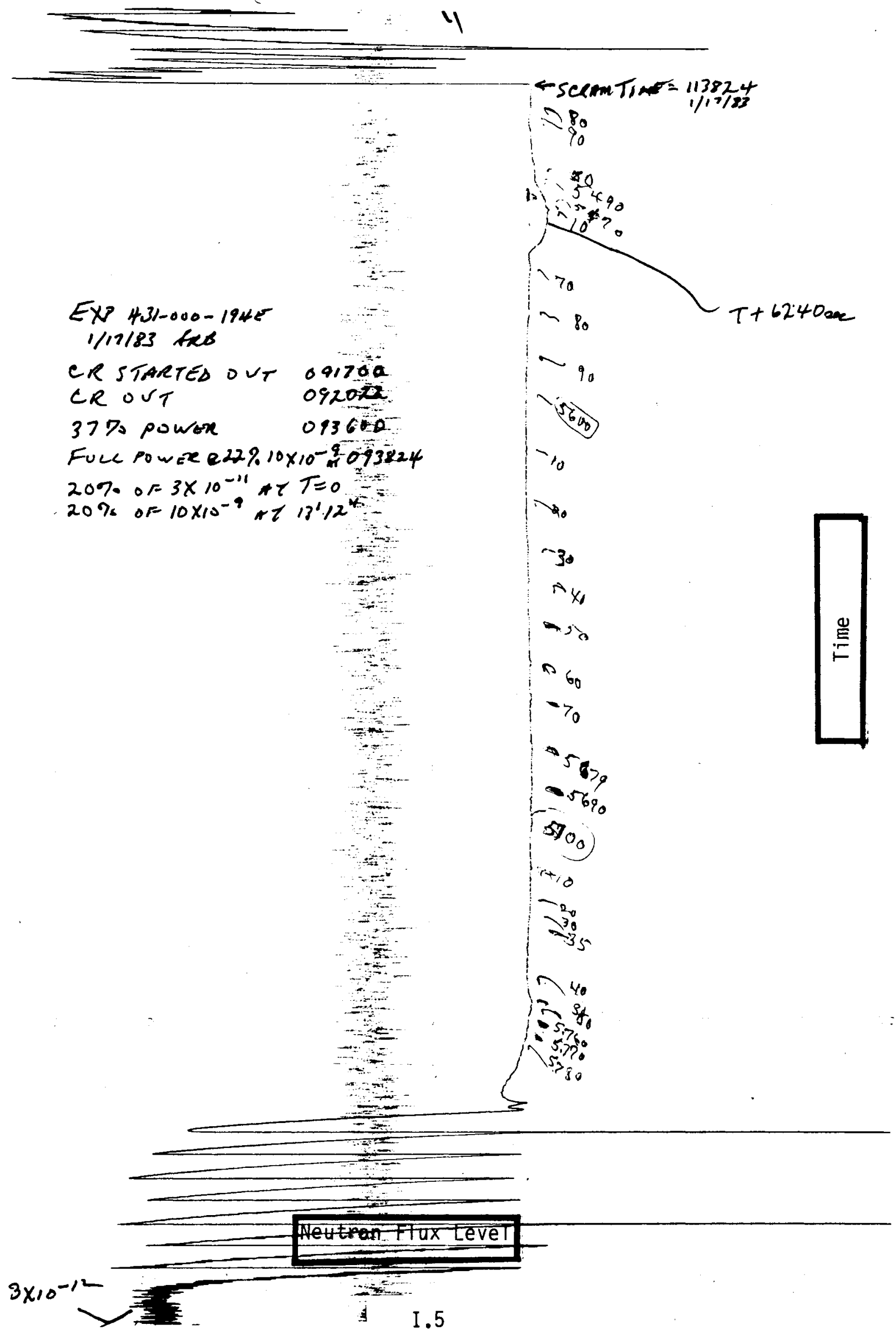




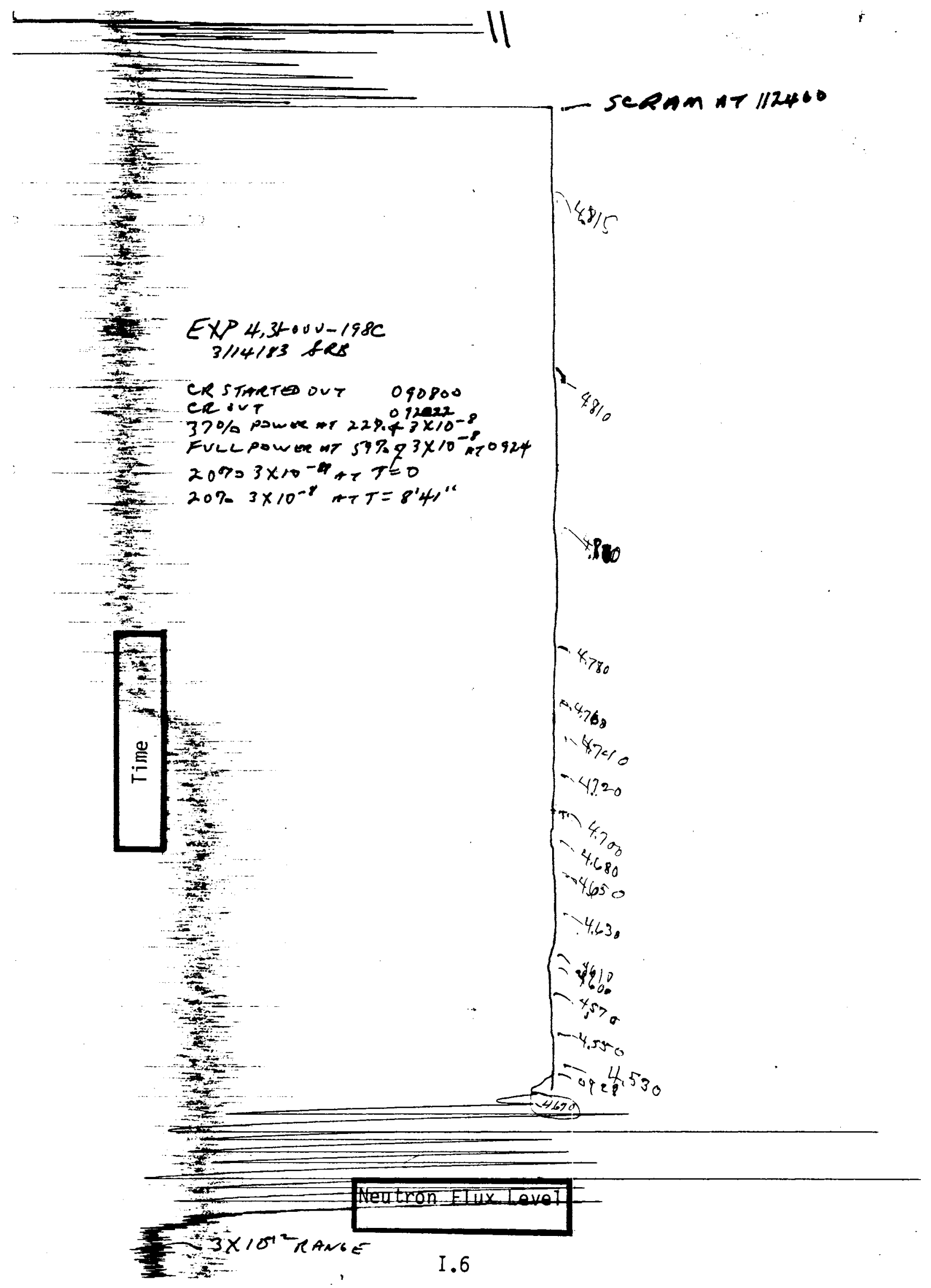


1085 .

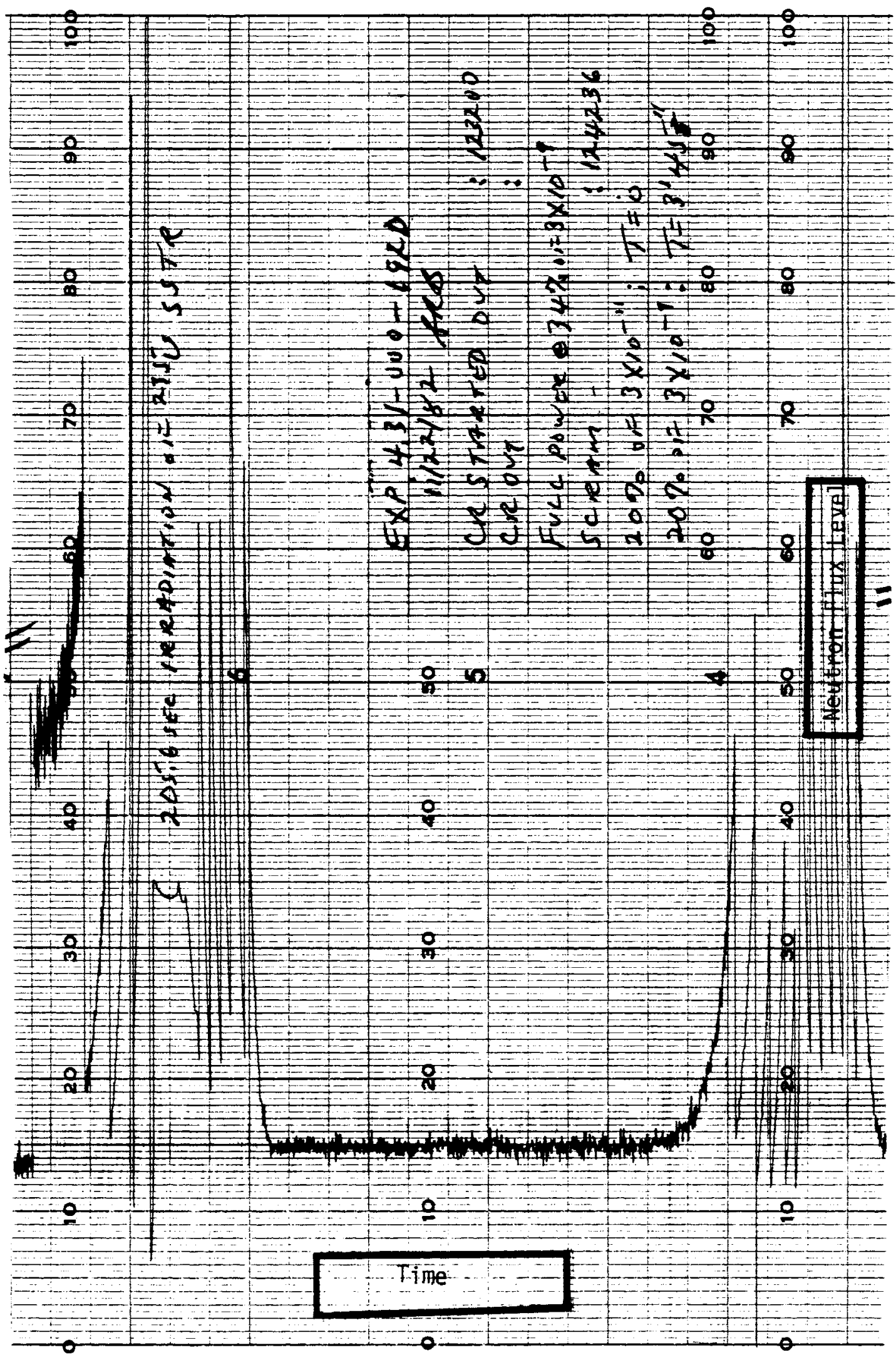




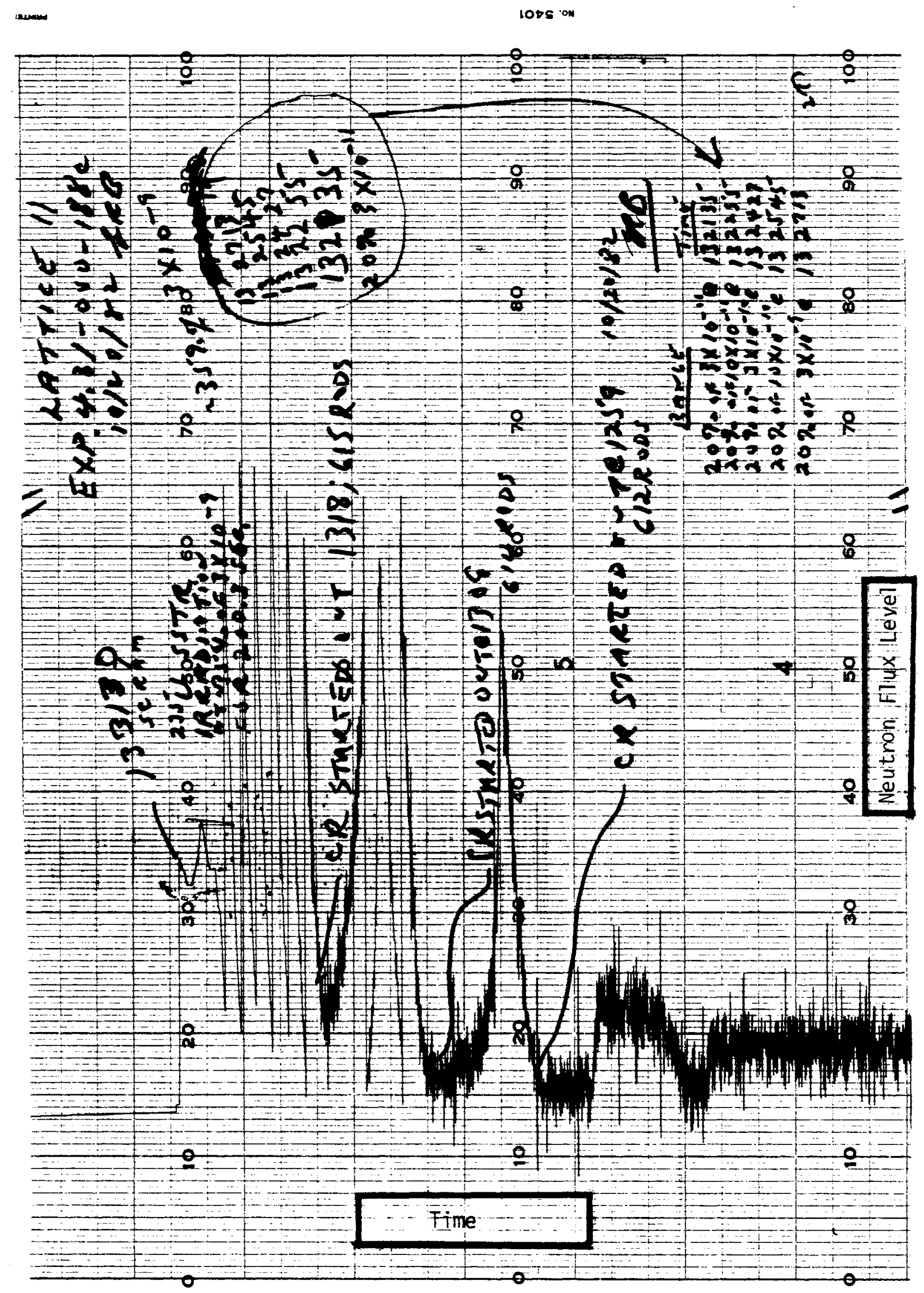




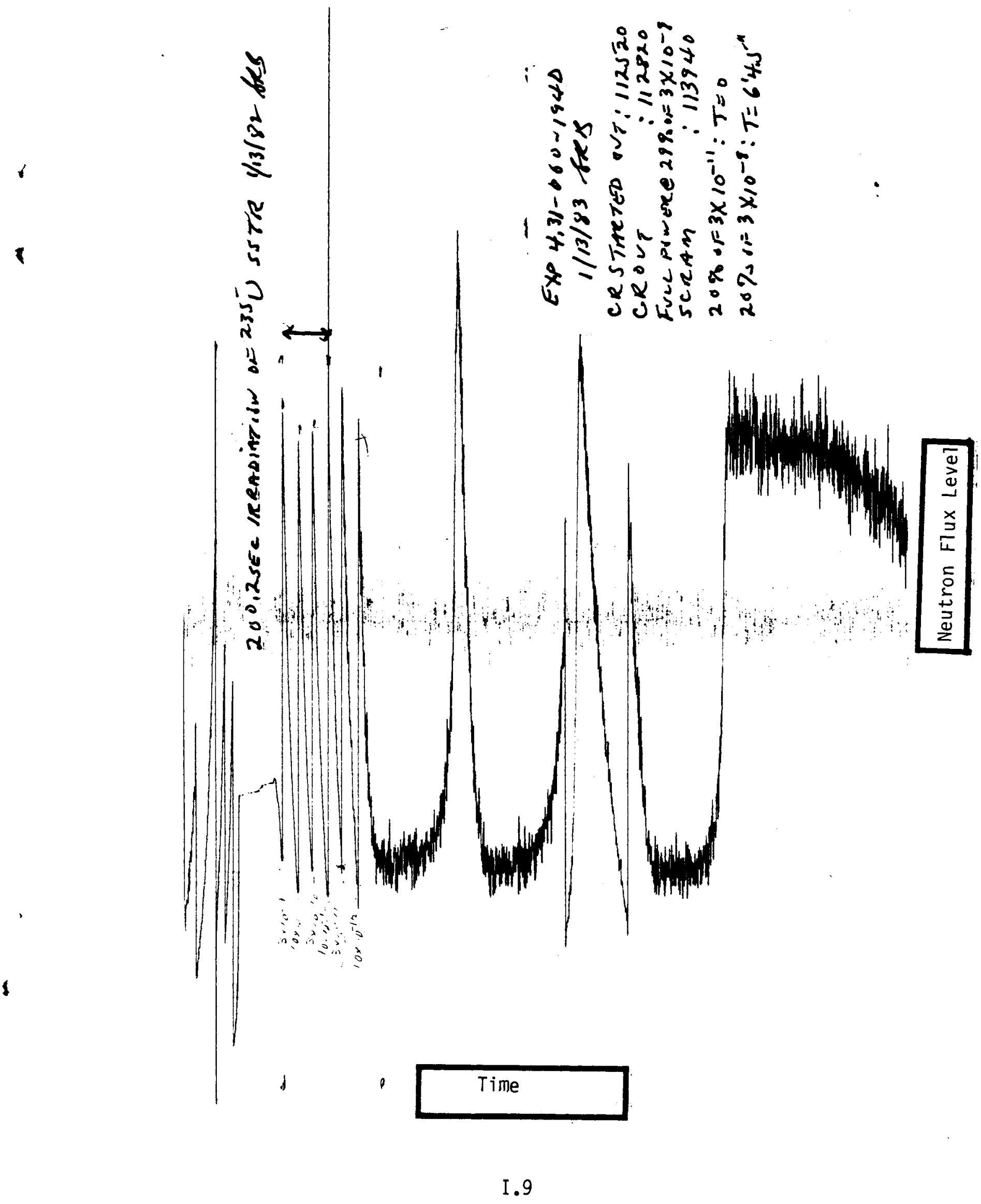




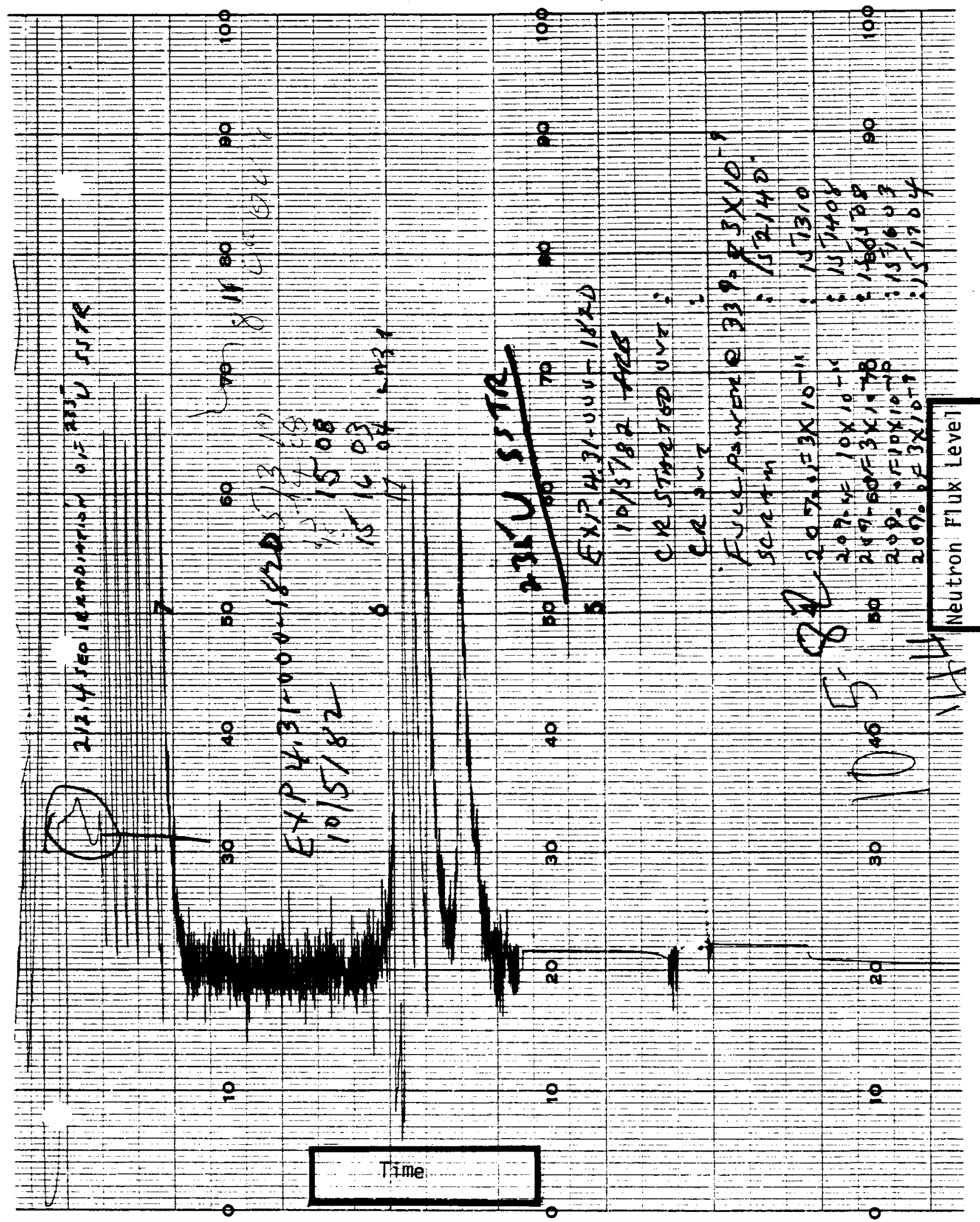


DISTRIBUTION

No. of

Copies

OFFSITE

Richard B. Chitwood

Office of Nuclear Fuel Cycle

$U$. S. Department of Energy

NE 340

Mai1 Stop B-107

Washington, DC 20545

Clint Bastin

Office of Nuclear Fuel Cycle

$U$. S. Department of Energy

NE 340

Mai 1 Stop B-107

Washington, DC 20545

10 Richard T. Keay

British Nuclear Fuels, Ltd.

Technical Services

R101 Rutherford House

Risley, Warrington, Cheshire

WA3 6AS

England

27 DOE Technical Information Center

ONSITE

DOE Richland Operations Office

H. E. Ransom

M. J. Plahuta

22 Pacific Northwest Laboratory

S. R. Bierman (10)

E. D. Clayton

D. A. Dingee

R. M. Fleischman

E. S. Murphy

L. D. Williams

Publishing Coordination (2)

Technical Information (5) 
